T.C.

MARMARA ÜNIVERSITESİ

KAMU HUKUKU ANABİLIM DALI

KAMU HUKUKU BİLIM DALI

\title{
HUMAN SECURITY AND INTERNATIONAL LAW
}

Doktora Tezi

EMERANT YVES OMGBA AKOUDOU

İSTANBUL, 2021 
T.C.

MARMARA ÜNIVERSITESI

KAMU HUKUKU ANABILIM DALI

KAMU HUKUKU BILIM DALI

\section{HUMAN SECURITY AND INTERNATIONAL LAW}

Doktora Tezi

EMERANT YVES OMGBA AKOUDOU

Tez Danışmanı

Doç. Dr. Hakkı Hakan ERKİNER

İSTANBUL, 2021 


\begin{abstract}
The concept of human security has been subject to an important attention in international affairs for more than two decades. This interest, in connection or not with related or shifted issues, within the academia and political worlds, is considerable and yet, fails to lead to a sustainable answer to human insecurity. The thesis on Human Security and International Law is a contribution to this reflection. It starts from the observation of the non-existence, within the literature, of a clear theoretical framework of human security, which can be the basis of consequent interventions for the benefit of the human person, member of the international community. Since such a statute inevitably involves international law, this absence of a theoretical framework of human security was clear evidence of the need for additional reflection on the real relationship between human security and international law. In this sense, we have advanced the hypothesis that such a relation is ontological, that is to say, human security stands as the (natural) law of international law, as a consequence of that it stands as the (natural) law of national law. The verification of this hypothesis enables us to give an account of the theoretical framework of human security and to confirm its application in the trajectories of national and international Law. This endeavor is part of an interdisciplinary approach centered on law, from its natural expression (essentialist philosophy, politics) to its implementation (history, sociology), passing by its rules (theory).
\end{abstract}

Keywords: human security, international law, national law, law of nature, political society, international society. 


\section{ÖZET}

İnsan güvenliği kavramı, uluslararası ilişkilerde yirmi yılı aşkın süredir önemli derecede ilgi görmektedir. Akademik ve siyasi dünya içerisindeki ilgili veya değişen konularla bağlantılı olsun veya olmasın, bu ilgi dikkate değerdir fakat henüz insani güvensizliğe sürdürülebilir bir yanıt vermekte başarısızdır. İnsan Güvenliği ve Uluslararası Hukuk tezi bu düşünceye yönelik bir katkıdır. Çalışma, literatürde insan güvenliğinin net bir teorik çerçevesinin bulunmadığının gözlemlenmesiyle başlar ki bu durum, uluslararası toplum üyesi olan insan için müteakip müdahalelerin temeli olabilecektir. Böyle bir durumun kaçınılmaz olarak uluslararası hukuku da ilgilendirecek olması; insan güvenliği hakkındaki teorik çerçevenin yokluğunun, insan güvenliği ile uluslararası hukuk arasındaki gerçek ilişki üzerine ilave düşünme ihtiyacı doğuracağının açık bir kanıtıdır. Bu anlamda, böyle bir ilişkinin ontolojik olduğu; yani insan güvenliğinin uluslararası hukukun (doğal) kanunu olduğu, dolayısıyla ulusal hukukun (doğal) kanunu olduğu hipotezini geliştirdik. Bu hipotezin doğrulanması, insan güvenliğinin teorik çerçevesini belirlememizi ayrıca ulusal ve uluslararası hukukun kapsamında uygulanmasını kabul görmesini sağlayacaktır. Bu çaba, kurallarına (teori) değinerek, doğal hukuk ifadesinden (özcü felsefe, siyaset) uygulanmasına (tarih, sosyoloji) kadar, hukuk merkezli disiplinler arası yaklaşımın bir parçasıdır.

Anahtar Kelimeler: insan güvenliği, uluslararası hukuk, ulusal hukuk, doğa hukuk, uluslararası toplum, siyasi toplum 


\section{CONTENT}

ÖZET

PART I: THE NECESSARY PRECONDITION OF HUMAN SECURITY AS FOUNDATION AND FINALITY OF INTERNATIONAL LAW: HUMAN SECURITY AS FOUNDATION

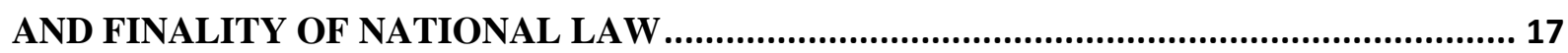

CHAPTER I: HUMAN SECURITY: THE LAW OF HUMAN NATURE ............................. 18

1. HUMAN SECURITY: THE NATURAL HUMAN ORDER .......................................... 19

1.1. Human Security within Essentialist Theory in Perspective ................................... 19

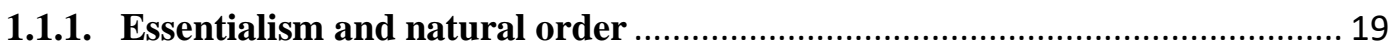

1.1.2. Prospects for an essentialist account of human nature ................................ 25

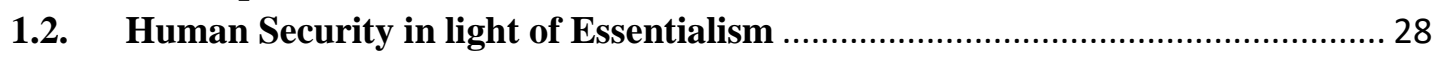

1.2.1. Human security as law of human nature: a finite order ……....................... 28

1.2.2. Human security as law of human nature: a final order ................................ 34

2. HUMAN SECURITY AS A LAW OF NATURE AND DISORDER................................... 39

2.1. Human security, as a law of nature and the illusion of disorder........................ 39

2.1.1. Unreality of disorder in light of the finite and final orders ........................... 39

2.1.2. Human security, order of means and disorder .............................................. 43

2.2. Human Security, Order of Means and Experience ......................................... 47

2.2.1. Human security, as a law of nature and the philosophy of history ................ 47

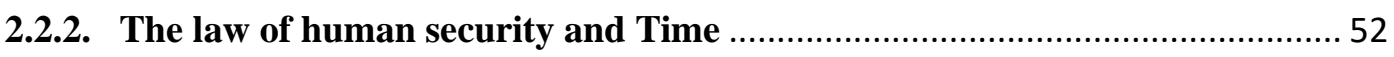

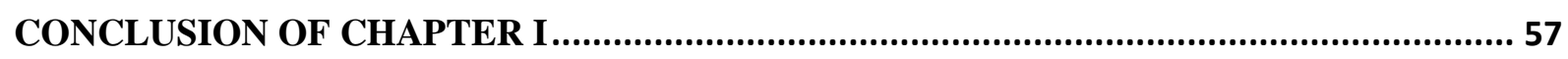

CHAPTER II: HUMAN SECURITY: LAW OF NATURE OF POLITICAL SOCIETY .......... 58

1. THE HUMAN POLITICAL ANIMALITY: A NATURAL NATURE ….........................58

1.1. Substance of Human Security as Law of nature of Political Society ….............. 59

1.1.1. Human security as law of nature of political society: a logical implication of

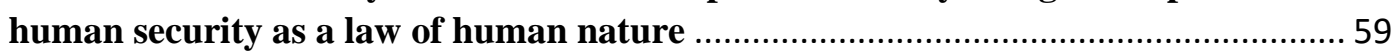

1.1.2. Family: the primordial embryonic political society .................................... 62

1.2. The Substance of the understanding of human security as law of nature of

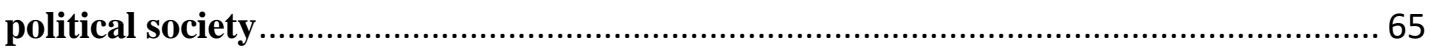

1.2.1. The human understanding of security as law of nature of political society ... 65

1.2.2. The possible misunderstanding of human security as law of nature of political society 68

2. THE HUMAN POLITICAL ANIMALITY: A CULTURAL NATURE........................... 73

2.1. The Community management of conservation ............................................... 73

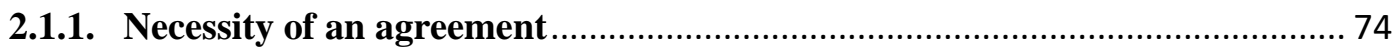


2.1.2. Resources as a condition exercise of human rationality

2.2. The philosophy of history, a progressive enterprise of conformation of man to his nature

2.2.1. Continuous search for the best formulation of political society .................... 83

2.2.2. The end of history: the discovery of the order of natural means of

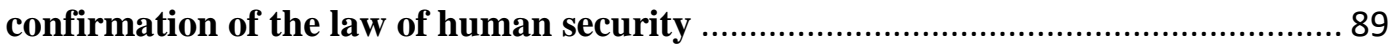

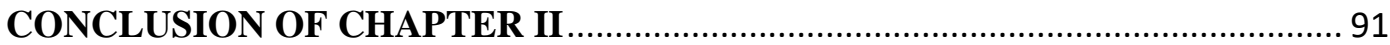

CHAPTER III: HUMAN SECURITY: FOUNDATION AND FINALITY OF NATIONAL

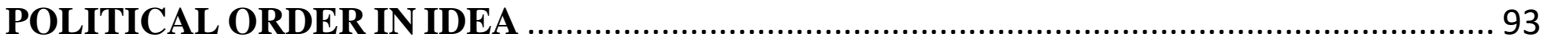

1. HUMAN SECURITY, AS A LAW OF NATURE AND LIBERALISM......................... 95

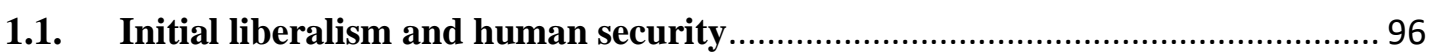

1.1.1. The World conception of liberalism.............................................................. 96

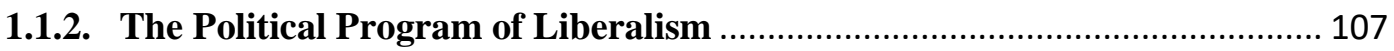

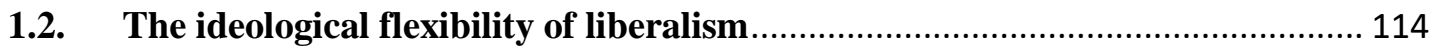

1.2.1 Social liberalism: Reassertion of the real meaning of liberalism ................. 114

1.2.2. The managerial State, configuration of the liberal political order ............... 118

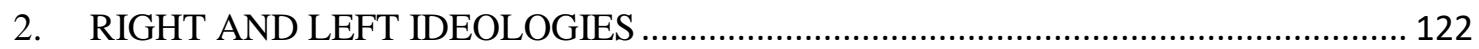

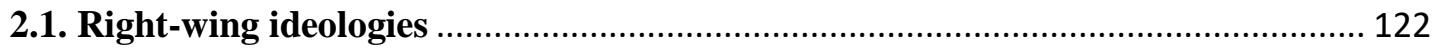

2.1.1. The Conception of the World proper to Rights-Wing ideologies................. 122

2.1.2. The Political Program of Right-wing political ideologies ............................ 127

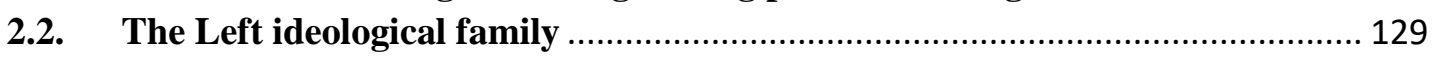

2.2.1. The conception of the world proper to left-wing political ideologies ............ 129

2.2.2. The Political Program proper to left-wing ideologies .................................. 131

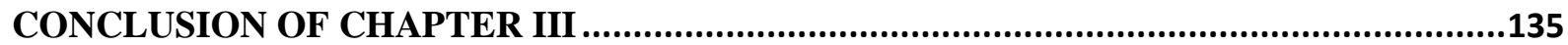

CHAPTER IV: HUMAN SECURITY AND THE NATIONAL POLITICAL ORDER IN

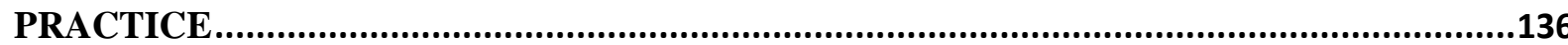

1. THE LAW OF HUMAN SECURITY AND THE ADVENT OF MODERN

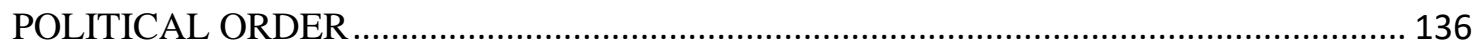

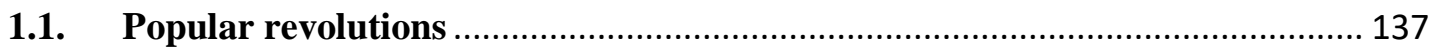

1.1.1. The situation prevailing in popular revolutions ....................................... 137

1.1.2. The response brought by popular political revolutions: the people at the

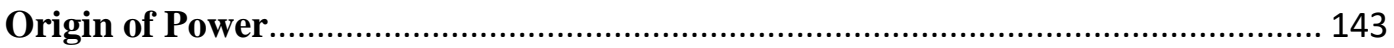

1.2. A later stammering confirmation of the People as an original constituent ...... 149

1.2.1. The preponderance of privileged groups in the definition of the national

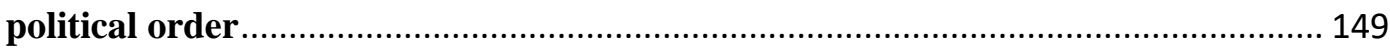

1.2.2. The preponderance of Strong Leaders in the definition of the modern

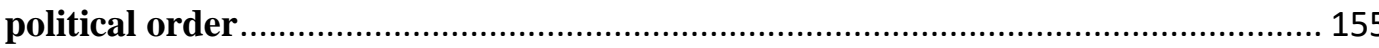

2. HUMAN SECURITY, AS A LAW OF NATURE AND NATIONAL DEMOCRATIC

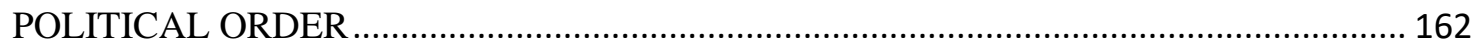

2.1. Democracy and modern political order in theory ......................................... 162

2.1.1. The affirmation of human rights in the modern political order ................... 162

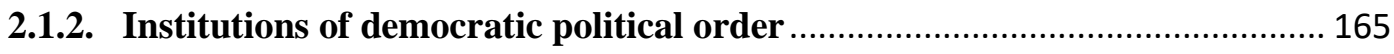

2.2.1. Human rights in modern political order in practice .................................. 170

2.2.2. The separation of powers and democratic constitutionalism in practice ..... 173

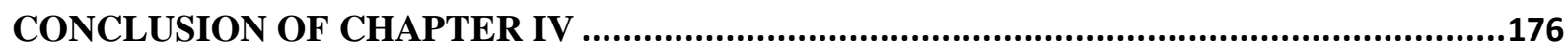

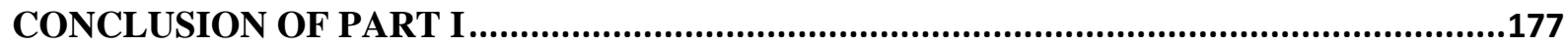


CHAPTER V: HUMAN SECURITY AND THE IDEOLOGY OF INTERNATIONAL LAW OR

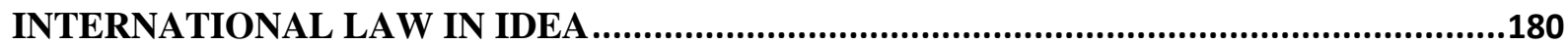

1. HUMAN SECURITY, AS A LAW OF NATURE AND RATIONALIST THEORIES OF

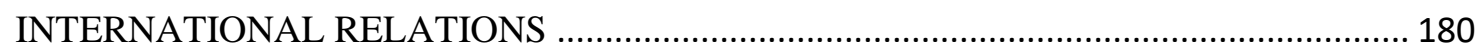

1.1. Human security and realism in international relations .................................... 181

1.1.1. Postulates of realism and law of human security ..................................... 181

1.1.2. The realist conception of security and human security ................................ 192

1.2. Liberalism and Human Security .............................................................. 197

1.2.1. Postulates of Liberalism and Human Security ............................................ 197

1.2.2. The liberal concept of security and human security ....................................... 204

2. HUMAN SECURITY AS A LAW OF NATURE AND REFLEXIVISM IN THEORY OF

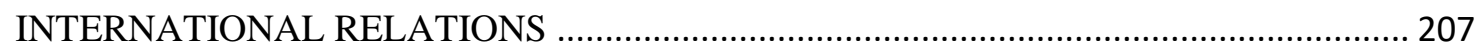

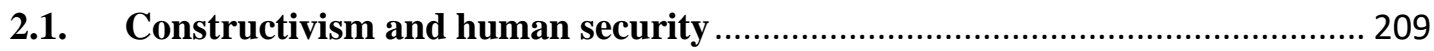

2.1.1. Constructivist postulates and human security ............................................... 209

2.1.2. The constructivist conception of security and law of human security ......... 215

2.2. The Critical School and human security .................................................... 219

2.2.1. The postulates of the Critical School and human security ........................... 219

2.2.2. Critical Security studies and law of Human Security ................................. 225

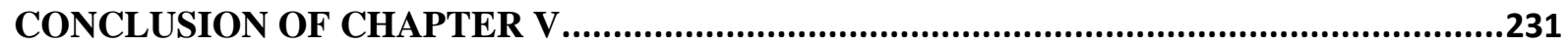

\section{CHAPTER VI: HUMAN SECURITY AS LAW OF NATURE OF INTERNATIONAL}

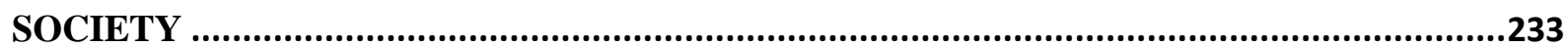

1. HUMAN SECURITY: FINITE ORDER OF INTERNATIONAL SOCIETY ................ 234

1.1. The individual: primary ontological unit of the International Society ............. 234

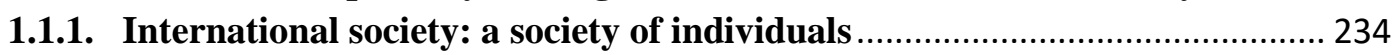

1.1.2. Law of human nature: Law of nature of international society: ................ 238

1.2. National Political Society as the secondary ontological unit of international society 241

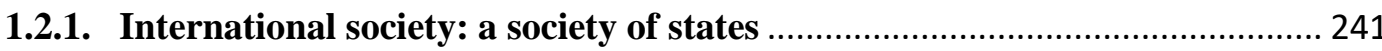

1.2.2. Law of international society: law of the national political society or State.. 243

2. HUMAN SECURITY: FINAL ORDER OF INTERNATIONAL SOCIETY ................. 246

2.1. Human security and instrumental necessity of international society .............. 246

2.1.1. Globalization: a characteristic phenomenon of international society with the

objective of human security ........................................................................... 247

2.1.2. Globalization: A phenomenon of acquisition of the resources necessary for

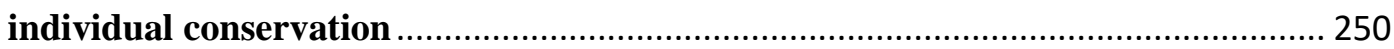

2.2. Human security and the formulation of international society ............................. 253

2.2.1. The formulation of international society and the principle of liberty ....... 253

2.2.2. The discovery of the adequate formulation of international society through

the historical process of experimentation ........................................................... 257

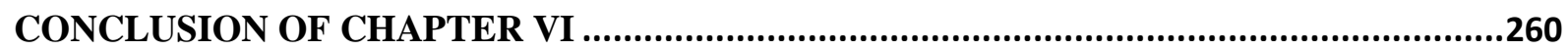

CHAPTER VII: HUMAN SECURITY AS FOUNDATION AND FINALITY OF

INTERNATIONAL CONSTITUTIONAL LAW .262 
1. HUMAN SECURITY AND THE REALITY OF AN INTERNATIONAL

CONSTITUTION

1.1. The international constitution from the theoretical framework of human security .

1.1.1. The international constitution from the perspective of the theoretical framework of human security

1.1.2. An International constitution from the point of view of the international constitutional theory

1.2. The United Nations Charter at the service of Human Security ............................ 272

1.2.1 The United Nations Charter indirectly at the service of human security..... 272

1.2.2. The United Nations Charter, at the direct service of Human Security ........ 278

2. INTERNATIONAL CONSTITUTIONAL LAW AND THE HISTORICAL PROCESS

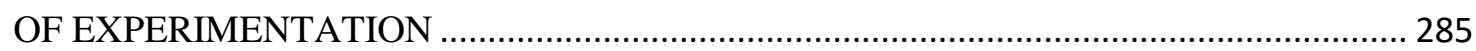

2.1. From the Covenant of the League of Nations to the United Nations Charter .... 285

2.1.1. The advent of the League of Nations ............................................................ 285

2.1.2. Advent of the Charter of the United Nations .............................................. 291

2.2. International Constitutional Law and the historical process of experimentation 295

2.2.1. The United Nations Reform Project

2.2.2. The essential purpose of international constitutional law: Resulting to the best formulation for the confirmation of human security ............................................ 299

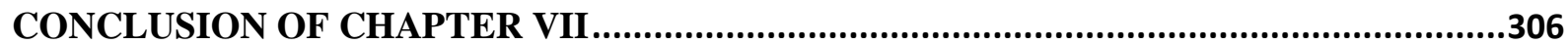

\section{CHAPTER VIII: HUMAN SECURITY: FOUNDTION AND FINALITY OF} INTERNATIONAL GOVERNMENTAL LAW

1.1. Human Security and the United Nations Resolving Practice at the Service of State Security ....

1.1.1. Human security and international peace and security in the service of the aggressed State

1.1.2. Human security and international peace and security at the service of the security of intervening States

1.2. Human Security and the United Nations resolutory practice at the service of the security of individuals

1.2.1. The resolutory practice of the United Nations and humanitarian intervention 319

1.2.2. The resolutory practice of the United Nations and the responsibility to protect 322

2. HUMAN SECURITY: FOUNDATION AND FINALITY OF THE UNITED NATIONS RESOLUTORY PRACTICE UNDER THE LABEL "HUMAN SECURITY".

2.1. The Substance of the label "human security" in the United Nations resolutory Practice.

2.1.1. The advent and debate of human security within the United Nations.......... 330

2.1.2 The United Nations Consensus on Human Security ................................... 334

2.2. The resolutory practice of the United Nations at the service of human security under the label "human security" in perspective.

2.2.1. The resolutory practice of the United Nations at the service of human security: A certain ambiguity

2.2.2. The ambiguous intervention under the responsibility to protect and human security 


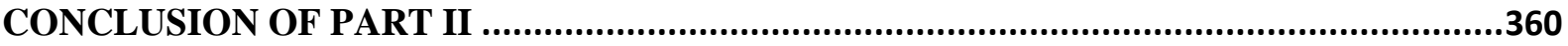

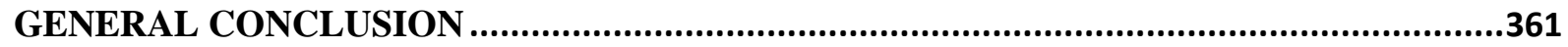

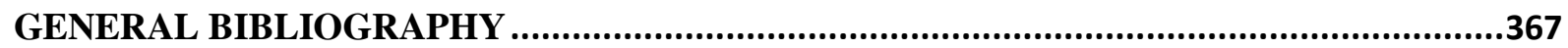




\section{INTRODUCTION}

\section{RESEARCH PROBLEM}

The problem raised by this research will emerge, after a review of literature and concrete facts of international life, and then we will be able to precise our research question.

\section{The problem raised by this research}

Identifying the problem raised by this research requires a review of scholarly production concerning its general theme. This will relate to three points: definition and scope of the concept of human security, human security in the context of the security debate into the theory of international relations, the impact of the concept of human security, the relationship between the concept of human security and international law

\section{Definition and scope of human security}

The debate around the definition of human security has grown at the instigation of the United Nations Development Program with its 1994 Development Report. This debate was subsequently the prerogative of United Nations and other international organizations, the Commission on Human Security and the Network for Human Security and academicians.

Generally, there are three approaches or conceptions of Human Security: broad, restricted and hybrid. According to the broad conception, human security includes all threats endangering the well-being of individuals. It emphasizes human vulnerability in all its dimensions and therefore encompasses threats of all kinds without taking into account the degree of severity. The broad view is about protecting the vital essentials of every human being and therefore guaranteeing them a life free from want and fear. This would tend to bring it closer to the concept of human development. ${ }^{1}$ The narrow view does not embrace all possible threats to

\footnotetext{
${ }^{1}$ United Nations Development Programme, Human Development Report 1994, Published for the United Nations, Oxford University Press, New York, Oxford, 1994, Chap. 2 : "New Dimensions of Human Security"; United Nations, General Assembly, Resolution adopted by the General Assembly on 10 September 2012 [without reference to a Main Committee (A/66/L.55/Rev.1 and Add.1)], Follow-up to paragraph 143 on human security of the 2005 World Summit Outcome, A/RES/66/290 66/290, 25 October 2012; Commission on Human Security, Human Security Now: Final Report, CHS, New York, 2003 ; S. FUKUDA-PARR, C. MESSINEO, Human Security: A critical review of the literature, Centre for Research on Peace and Development, Working Paper $n^{\circ}$ 11, KU Leuven, January 2012 ; J. NEF, "Human Security, Mutual Vulnerability and Sustainable Development: A Critical View", The Whitehead Journal of Diplomacy and International Relations, Vol. 7, $\mathrm{n}^{\circ} 1$ Winter-Spring 2006, pp. 55-73 ; J. LEANING, S. ARIE, Human Security: A Framework for Assessment in Conflict and Transition. Prepared for US AID, Tulane Complex Emergency Response and Transition Initiative (CERTI),
} 
human security, but focuses on the most violent threats, particularly organized political violence. ${ }^{2}$ Supporters of this conception of Human Security defend its immediate operational character in comparison to the broad conception which requires a very long-term strategic development plan. ${ }^{3}$ Finally, the hybrid conception of Human Security aims to reconcile the first two ones on the threshold of gravity. Thus, it would be a matter of giving priority to the most serious threats. Security would therefore aim to deal with threats of a high level of gravity, no matter what area they fall into. ${ }^{4}$ The hybrid view of human security has the advantage of finding a balance between the broad and the narrow ones by determining a criterion that makes human security initiatives more practical.

Regarding the scope of human security, it actually refers to the conceptual extent of it. This implies the analysis of a connection to other concepts like that of cosmopolitanism. Some authors believe that human security is aligned with ethical or moral cosmopolitanism. The latter considers that all human beings are members of a single moral community and that they have moral obligations towards all other human beings, regardless of their nationality, language, religion, customs, etc. This concept was developed by the Stoics that all human beings should be considered "fellow citizens and neighbors" (Plutarch) regardless of their national, ethnic, religious or other affiliations. From a cosmopolitan view, the idea of a human identity is certainly at the heart of the concept of human security. ${ }^{5}$ However, if such a human identity is postulated within cosmopolitanism, it is because it has a very obvious political ambition, that of building an international political structure, a kind of federalism, which would be responsible for ensuring the well-being to all men. But it should be noted that the link between human security and cosmopolitanism has not yet been explicitly established in related literature.

Tulane University, December 2000; A. ACHARYA, "Human Security: East versus West”, International Journal, Vol. 56, n³, 2001, pp. 442-460

${ }^{2}$ Human Security Network, http://www.humansecuritynetwork.org/network-f.php ; S. FUKUDA-PARR, C. MESSINEO, ibid. L. AXWORTHY, "Human Security and Global Governance: Putting People First", Global Governance, 2001, Vol. 7, n¹, pp.19-23

${ }^{3}$ P.H. LIOTTA, T. OWEN, "Why Human Security?" The Whitehead Journal of Diplomacy and International Relations. Vol 7, $\mathrm{n}^{\circ}$ 1, Winter-Spring 2006: 37-54

${ }^{4}$ T. OWEN, "Human security. Conflict and Consensus: Colloquium Remarks and Proposal for a Threshold-Based definition”, in Security Dialogue, , Vol. 35, n³, September 2004pp. 373-387; E. D. ESTRADA-TANCK, "Human Security and Human Rights under International Law: Crossroads and Possibilities", European University Institute, 2010, pp.1-31, available at http://www.operationspaix.net/DATA/DOCUMENT

5 K. HUTCHINGS, R. DANNREUTHER (Eds.), Cosmopolitan Citizenship, Basingstoke, Macmillan, : St Martin's, New York, 1999; DANNREUTHER, R. International Security: The Contemporary Agenda, Cambridge, Polity, 2007; Z. T. KAKA AMIN, "Human Security in Contemporary International Politics: Limitations and Challenges", in International Journal of Social Sciences and Educational Studies, Vol. 3, n ${ }^{\circ}$, September 2016; E. Newman, "Critical human security studies", Review of International Studies, Vol. 36, n¹, 2010, pp.77-94; P. KERR, "Human Security" in A. Collin and al. (Eds.), Contemporary Security Studies, Oxford University Press, Oxford, 2010, pp. 121-135 
Regarding the relationship between human security and the responsibility to protect, the report of the International Commission on Intervention and State Sovereignty which has developed this concept mentions that the purpose of the responsibility to protect is human security. One would therefore wonder whether the responsibility to protect is part of human security. ${ }^{6}$ However, a Report by the United Nations' Secretary General ${ }^{7}$ specifies that the concept of human security differs from the concept of responsibility to protect and its application. While human security refers to the multidimensional situations of insecurity experienced by individuals today, the responsibility to protect mainly consists in protecting populations in specific cases of genocide, war crimes, ethnic cleansing and crimes against humanity. This clarification itself is ambiguous, even if the United Nations is the driving force behind the concept of human security. Indeed, how can one think that human security, aimed at ensuring human beings free from fear and want would exclude protection against serious international crimes? The broad conception of human security within the United Nations includes the multidimensional threats to the human being, including those against which the responsibility to protect intervenes. In addition, both rely only on state capacities.

\section{The Security debate of human security into the theory of international relations}

Human security in the security debate within the theory of international relations is tackled in its relations with the dominant rationalist paradigm and its place within critical studies.

It is widely recognized that human security in the theory of international relations is a major challenge to the traditional concept of security developed by the realist school, namely state security or national security. Human security thus moves the referent of state security to the human person. ${ }^{8}$

Regarding the topic of human security belonging to the Critical Theory of Security Studies, two types of response are observed in the literature corresponding to two ways of approaching human security and each carrying different consequences.

On the one hand, human security would be understood as a concept integrating itself into the critical analyzes of security studies in the theory of international relations, through a deductive

\footnotetext{
${ }^{6}$ International Commission on Intervention and State Sovereignty (ICISS), The Responsibility To Protect, National Library of Canada cataloguing in publication data, Ottawa, December 2001

${ }^{7}$ United Nations, General Assembly, Follow-up to the outcome of the Millennium Summit, Follow-up to General Assembly resolution 64/291 on human security, Report of the Secretary-General, A/66/763, 5 April 2012

${ }^{8} \mathrm{H}$. VIAU, La (re) conceptualisation de la sécurité dans les théories réaliste et critique : quelques pistes de réflexion sur les concepts de sécurité humaine et de sécurité globale, Series Memoires 1 août 2000, S. FUKUDAPARR, C.MESSINEO, op. cit; E. NEWMAN, op. cit.
} 
interpretation, making either the human or the individual the referent of security without doing so under the label "human security". Indeed in the perspective of critical studies, in a normative and intersubjective posture, the reference object of security is not a philosophical abstraction such as the State, but, on the contrary, the human or the individual. It is in this absence of differentiation between "individual" and "human person" that it is considered that the postpositivist epistemology of interpretative methodology of the global ethics approach (defending the concept of emancipation) and the historical materialism epistemology of dialectical methodology of the neo-Gramscian approach (the transformation of international order by making the individual the center of all concerns) consecrate and defend human security. ${ }^{9}$

On another hand according to the scholarly production among critical theory that straight and explicitly address the concept of Human Security after its impulse by the 1994 UNDP Report, Human Security is generally apprehended as a guide for policies design and an advocacy tool. On this ground, although contesting the primacy of state security as the security's reference object and insisting on multidimensional responses to all threats to human insecurity, in the same way critical theory approaches do, Human Security is not critical yet. ${ }^{10}$ Indeed, studies on Human Security tend to be pragmatic in looking for solutions. Thus they defeat the primacy of State while being ready to agree to state power and work with State to find solutions. That cannot be allowed within the critical approach, which beforehand is suspicious towards State and the current interstate order, identified as the main causes of human insecurity. ${ }^{11}$ It is important to notice that this criticism to Human Security is also made by scholars belonging to critical theory, whose works are assessed as explicitly devoted to human security. ${ }^{12}$

In conclusion, there is inharmony in the overall understanding of the concept of human security, which, compared to national or state security, lacks a single coherent analytical framework and guidance for sound policy making. This is not a good start in terms of the impact of human security in practice.

\footnotetext{
${ }^{9}$ H. VIAU, ibid.

${ }^{10}$ S. FUKUDA-PARR, C.MESSINEO, op. cit; E. NEWMAN, ibid. Z. T. KAKA AMIN, op. cit.

${ }^{11}$ E. NEWMAN, ibid. Z. T. KAKA AMIN, ibid. K. BOOTH, Theory of World Security, Cambridge University Press, New York, 2007

${ }^{12}$ H. VIAU, op. cit. K. BOOTH, Ibid.
} 


\section{The impact of human security}

The literature on the impact of human security will be reviewed with regard to both conceptions of human security, as policy-oriented and as inferred from the work of critical studies.

With regard to human security in its policy-oriented sense, the literature is of the view that human security has been more negatively than positively impacted in international affairs. Indeed, it has borne valuable fruits with regard to its narrow conception, notably in the conclusion of treaties on anti-personal mines and on child soldiers, etc., and in the development of the international community as a whole. But the broad conception of human security is almost assessed as having no impact. Some analysts have argued that when humanitarian intervention is made in the light of human security, it has been transformed into another form, such as the classical realist perspective for the protection of State and national interests. ${ }^{13}$ Humanitarian intervention would even be another form of imperialism ${ }^{14}$ in that it increases the interventionist role of traditional security actors ${ }^{15}$ who therefore see in it, an opportunity to satisfy their interests, as in the case of the United States invasion of Iraq. ${ }^{16}$ Thus national security has found a way to adapt to the "outcry" of human security in order to continue to satisfy itself at the expense of the latter. ${ }^{17}$

With regard to human security as it relates to the concept of development, some scholars are of the view that it has not had a significant impact. Although human security is useful for development in terms of threats, it is perceived as inadequate for development policies. ${ }^{18} \mathrm{In}$ fact, it is pointed out that the major problem is the confusion between human security and human development within the United Nations. Therefore human security is posed in

\footnotetext{
${ }^{13}$ B. BUZAN, L. HANSEN, The Evolution Of International Security Studies, Cambridge University Press, New York, 2009; DANNREUTHER, 2007, op. cit.

${ }^{14}$ T. MCCORMACK, 2011: "Human security and the separation of security and development", Conflict, Security and Development, Vol. 11, n², pp. 235-260

${ }^{15}$ R. CHRISTIE, "Critical voices and human security: To endure, to engage or to critique?" Security Dialogue, Vol. 41, n², 2010, pp. 169-190

${ }^{16}$ P. KERR, op. cit.

${ }^{17}$ A. SUHRKE, "Human Security and the Interests of States”, Security Dialogue, Vol. 30, n³, 1999, pp. 265-276; S.TADJBAKHSH, A. CHENOY, Human Security: Concepts and Implications, Routledge, London, 2007 ; S. WOODWARD, "Post-Cold War Debates on International Security", Presentation to the New School GPIA Workshop: The Practices of Human Rights - Human Security, Mimeo, October 8, 2010; T. FARER, "Human Security: Defining the Elephant and Imagining its Tasks", Asian Journal of International Law, Vol. 1, n 1, 2011, pp. 43-55, D.CHANDLER, "Human Security: the dog that didn’t bark", Security Dialogue, Vol. 39, n4, 2008, pp. 427-438; T. JACOBY, "Hegemony, Modernisation and Post-War Reconstruction", Global Society, Vol. 21, n4, 2007, pp. 521-537; KALDOR, M., al. "Human Security: A New Strategic Narrative for Europe", in International Affairs, Vol. 83, 2, 2007, pp. 279-288; SHANI (G.), "From National to Human Security? Reflections on Post 3.11 Japan”, The Journal of Social Science, 76, 2013, pp. 5-24

${ }^{18}$ S.TADJBAKHSH, A. CHENOY, ibid.
} 
theoretical terms as an ethical concept. ${ }^{19}$ As a result, achieving this goal is difficult in the real world. For example, there are multiple cases of poverty, lack of education and social conflicts in the world. ${ }^{20}$ Scholars have therefore come to the conclusion that linking human security and development is damaging ${ }^{21}$ because human security would represent a vast and expansive program of control of developing countries by developed countries. ${ }^{22}$ This then makes the fulfilment of economic and social rights very uncertain. ${ }^{23}$

Concerning the impact of human security as it is understood in critical security studies, there is a difficulty in the literature in applying human security because of the ambition of transforming the representation of the international order that it requires. The various initiatives for this colossal project, some even attempting to use the structures and principles of the current international system organized around the State, remain without resonance within international society. ${ }^{24}$

It can be concluded that, as far as the practical assessment of human security in international society and of related literature is concerned, human security is trying to be implemented within or in place of the international inter-state system, dominated by national interest. This is of no significant consequence. The lack of analytical coherence and policy guidance on human security within this previously identified literature should only contribute to such a practical outcome.

\section{The link between human security and international law}

The scholarly production on the relation between human security and international law is generally of the opinion that it is not a link of identity but of complementarity.

In an approach that focuses on human rights and human security, the two concepts are close in meaning, because of their common human-centered approach. In particular, it is recognized that all human rights are central to human security and that the differentiating element, the one that

\footnotetext{
${ }^{19}$ Ibid.

${ }^{20}$ Z. T. KAKA AMIN, op. cit.

${ }^{21}$ K. KRAUSE, "Critical Perspectives on Human Security" in M. MARTIN, T. OWEN (Eds.), The Routledge handbook of human security, Routledge, London, 2010, pp.76-93; M. DUFFIELD, Development, Security and Unending War: Governing the World of Peoples, Polity, Cambridge, 2007

${ }^{22}$ T. MCCORMACK, op. cit.

${ }^{23}$ Z. T. KAKA AMIN, op. cit.

${ }^{24}$ H. VIAU, op. cit.
} 
unites the two concepts and thus makes it meaningful for both rights and security, is the risk or "vulnerability" element. ${ }^{25}$

For another very significant approach, ${ }^{26}$ noting the lack of a consensual definition of human security, a basic understanding of human security was proposed. The core idea of human security is to focus security on people. This idea is neither usually complex nor particularly vague. However, it may be difficult to put into practice. On this basis, it sets out three basic functions that human security could usefully serve in relation to international law: the agendasetting function, which helps to focus attention on issues and mobilize resources; the normative function (conceptual and normative approach), which includes a set of interrelated ideas that can be used as points of reference, a guide to interpretation, and a way of organizing discussion. This function makes the human being, the reference point, the primary objective of security. The critical function of human security is to constantly challenge traditional approaches to problem solving. Finally, by linking international law and these different approaches to human security, there is a fairly significant content of international law that is relevant to ensuring human security: Human rights law, the law of international peace and security, humanitarian law, in particular the common responsibility to protect, refugee law, environmental law, health law instigated by the World Health Organization.

It can therefore be noted that international law is guaranteeing human security in its various components. In this sense, it is recognized that any violation of human security is a violation of international law in some of its pre-established components. ${ }^{27}$ However, human security represents a challenge for international law because the latter primarily protects the interests of its main subjects, which are States. ${ }^{28}$ Thus oriented towards the satisfaction of national security, which can be considered as the main obstacle to a consistent guarantee of human security, international law has many limitations against which major recommendations are proposed. These ones refer almost to a reinterpretation, improvement or simply greater respect for international law at the benefit of human security. ${ }^{29}$

\footnotetext{
${ }^{25}$ E. D. ESTRADA-TANCK, op. cit.

${ }^{26}$ B. von TIGERSTROM, Human Security and International Law. Prospects and Problems, Hart Publishing, Oxford and Portland, Oregon, 2007

${ }^{27}$ Y. ROZNAI, "The Insecurity of Human Security”, Wisconsin International Law Journal, Vol. 32, n 1 , pp. 95141, G. OBERLEITNER, "Human Security: A Challenge to International Law"? Global Governance, Vol. 11, 2005, pp. 185-203

${ }^{28}$ G. OBERLEITNER, ibid. B. von TIGRESTROM, op. cit. Y. ROZNAI, ibid.

${ }^{29}$ B. von TIGRESTROM, ibid.
} 
The general opinion about the literature review regarding the link between human security and international law refers to the usefulness of international law to human security. This usefulness is found within international law, in its components that privilege individuals or govern the concerns of the individual. International law that has developed after the advent of human security is relatively limited, including the Statute of the International Criminal Court, the AntiPersonal Mine Ban Treaty, the Protocol to the International Convention on the Rights of the Child on the Involvement of Children in Armed Conflict, etc. Thus all the components of international law mentioned as guaranteeing human security (human rights, refugee rights, international humanitarian law), for the most part, were already present before the official advent on the international scene of the concept of human security. The simple question that this literature review would raise is therefore that of why human security still echoed itself in international affairs when a whole legal framework already existed for the benefit of the human person. Thus, taking into account this framework, some scholars would tend to conclude that human security is useless because it would complicate the conduct of international affairs and would propose instead of emphasizing greater respect for international law. ${ }^{30}$ This argument taken in another direction would, however, supports the idea that the notion of human security raised up, precisely in order to call out to the urgency to provide an effective response to the many threats faced by human beings, what international law as it was or continues to be enshrined in favour of the individual has not fully succeeded in doing. In this sense, it would no longer make much sense to evoke, in support of human security, an international law that existed before its advent and which was supposed to respond to problems that it has just tried, by this advent, to solve or for which it calls out to international society. As a result, the answer of the literature review on the link between human security and international law may well be out of step with the true meaning of its advent on the international political scene. Hence the need for a clear understanding of the meaning of the advent of human security. This need is well reflected in the background of the proposals made for a reinterpretation or improvement of the various components of international law guaranteeing human security. ${ }^{31}$

Indeed, following these very demanding proposals ${ }^{32}$, can it be ensured that international society, which is understood as including States as main component and international organizations, will take these proposals into account? In addition to what (international law at the benefit of

\footnotetext{
${ }^{30}$ Y. ROZNAI, ibid.

${ }^{31}$ B. von TIGRESTROM, op. cit.

32 Ibid
} 
human beings) is already conceived as enshrined, will these main subjects of international law evolve to serve human security in a unidirectional way?

Beyond these recommendations it is necessary to address a crucial question for the future of human security within international society in general: how could these important proposals be adopted? Or by what means can they be taken into account? These questions, in our view, would no longer be targeted to international law, but to those who make or create it, that is to say, to States and international organizations. As these proposals therefore do not refer directly to international law, they suggest that international law, as far as the human security debate is concerned, is a second order or second priority area. In order to be taken into account within international law, it is necessary that the actors who make and implement this law do so in that sense and this is only possible if they fully adhere to Human Security. But how will they fully adhere to a concept that is not subject to a coherent analytical framework commensurate with that of national security, even if its most basic understanding leaves no room for ambiguity? While taking into account international law favorable to human security, the literature emphasized that it is ultimately important to construct a coherent analytical framework for this concept of security because it is this one that should have a favorable impact on the improvement of the law for the benefit of human security. This would ultimately confirm that the link that human security would maintain with international law depends on the link that exists between it and international relations at whole.

\section{RESEARCH QUESTION}

As a general conclusion to our literature review, we can note that, despite the important and relevant scholarly production noted in its complementary variants, the concept of human security is not yet subject to a coherent analytical framework. This can be seen in the link that this concept maintains with international law and in its impact on the daily lives of its potential beneficiaries. So the question of the real relationship between human security and international law is still relevant. It would allow us to construct this analytical framework and to consider the kind of impact and results that could be expected in practice.

\section{HYPOTHESIS}

The interest arousing from human security in political and academic debate should inspire an analysis that can help to find the analytical framework that this notion postulates and whose claim it verifies. Thus, taking into account the above-mentioned literature and the context of its advent on the international scene through the impetus of the United Nations in its 1994 
Human Development Report, we believe that human security carries a clear message: Human security is at the heart of international affairs.

Supporting the logic that the human being is at the centre of international affairs, the concept of human security postulates to be a guide, a beacon that overlooks and guides the conduct of international affairs. The majority of scholars who have dealt with human security have in one way or another concluded that, either positively or negatively, as a concept with a broad, vague, all-encompassing and all-encompassing meaning. Such a concept can only be subject to an apprehension that refers to the logic it implies or the one behind it. Human security seeks to be, or to be seen to be, inscribed at the heart or foundation of international affairs. Thus it carries an idea that transcends the entire international political (and legal) system. And it is precisely at this level that it invites analysis.

In our view, this postulate is the core of an analytical framework of human security in relation to international law.

Thus, in response to the question of what is the real relationship between human security and international law, this research will then test the following hypothesis, which will present two complementary variations:

The real relationship between human security and international law is ontological in that

- human security postulates to be the foundation and finality of international law, as a consequence of

- Its postulate of being the foundation and finality of national law.

Since international law is understood as the law of inter-state or international relations, it goes without saying that if human security postulates to be the foundation and finality of international law it assumes to be the same for national law. This postulate is the starting point for an analytical framework of human security.

There are several variations on this assumption:

- Human security as foundation and finality of national law presupposes above all a fundamental relationship between human security and human nature. It is thus intended to account for the human nature, to explain it, in a word, to be its law of nature, understood as the state of affairs, of functioning or simply the reality of things.

- This, which should therefore apply to every human person, applies to any form of organization that is made up of human beings, such as political human groupings, generally appearing in the 
contemporary form of States. It should then be noted that state security or national security is reduced to human security. For if human security stands as the law of human nature, then it is the law of nature of political society and of national law that reflects and signifies it. The state "legal person" symbolizes a set of human beings who constitute themselves in this way in order to ensure, by means of a leading team or government, the security of each one.

- International society is then presented as a collection of people who constitute themselves into various political units or States through which they organize their relations with the aim of confirming their respective security.

- Therefore, when looking at States in order to really see individuals that make them or are their main components, we are led to consider international relations or relations between national political societies or States as being reduced to the common denominator of the human being who seeks to confirm the law of his nature that is security. Thus, international law, which is the instrument of these relations, has human security as its foundation and purpose.

\section{METHODOLOGICAL FRAMEWORK}

As we consider human security as the foundation and purpose of international law, this research therefore has a vocation of empirical theory. Although at first glance this would seem refutable and rather as "what should be", given the simple evidence of human insecurity that characterizes international society, the idea of human security as a law of nature postulates a set of irrefutable principles that govern international law. It will then be a question of verifying the coherence and the permanent force of this postulate beyond this (apparent) reality. Thus, verifying human security as foundation and finality of international law implies verifying that human security is in Reality at the centre of this law and that this does not seem to be the case because international society has not yet fully arrived at the understanding of this Reality. It is therefore a question of shedding light on this state of affairs or reality which, because it is the true foundation of international relations, is its inescapable finality.

With this precision made, which supports the general logic of verification of our hypotheses, it goes without saying that we will use the qualitative method and precisely a content analysis (documentary) which will be completed and confirmed by the historical method in its diachronic and synchronic variants. These two variants of the historical method were originally emphasized in the field of linguistics to characterize the study of the "evolutions" (diachrony) and the study of the "states" (synchrony) of the language system respectively. Diachrony makes it possible to approach social, economic and political facts from the point of view of their 
evolution over time. Synchrony, on the other hand, makes it possible to study the states of a social or political system over time. So in this understanding, a system, from one state to another (temporarily) stable (synchrony), is marked by an evolutionary process (diachrony). In our study, we will consider the international system as governed by human security, as a law of nature. The different states that this system has known in its history confirm this through an evolutionary process constantly made necessary by the consequences of initiatives that do not comply with this natural state of affairs or reality. Since these initiatives, which are more or less based on a false basis, can only have unfortunate consequences in return for international society, the latter is always confronted with the need to preserve the gains for the compliance with the human security requirements, and to readjust permanently until it puts in place the conditions that make it possible to confirm the harmonious state of human security. Thus, synchrony and diachrony will allow us to verify the progressive process of crystallization or in stages, of the Reality. Finally, it would be about a progressive awareness of human security, as the law of nature of international society, or its natural state of affairs, functioning, or simply, its foundation and its finality.

Based on that, the verification of our hypothesis requires us to have a broad conception of law, both national and international. This conception will go beyond the mere nature of positive rules to include all the ideas that underpin them. In such an understanding, our research will be interdisciplinary. We will then have recourse to philosophy/theory/history of law and politics in the following way.

To verify that human security is the foundation and finality of national law, we will use general philosophy, precisely essentialism, which will allow us to discover the theoretical framework of human security. Indeed, the epistemological approach of essentialism, that is to give an account of reality by focusing on its essence, can best enable us to investigate human security as the law of human nature. Based on the theoretical framework of human security that it would allow us to discover, political philosophy, especially that relating to the "reasons" of political society, will allow us to investigate the real relationship between human security and political society. This part of the analysis will be put to the account of national law in that it assumes, at its most fundamental level, an identity with political society, which, on the basis of its terms "society" and "politics", refers to ideas of "agreement" and "organization", the latter meaning "law" at its simplest expression. All these theoretical elements will then have to be verified in practice, particularly in the practice of national law. Thus we will investigate the permanent force of human security, as a law of nature, in the political and legal history of the political 
society or State. Since the abundance of this history cannot be recorded, we will limit ourselves to certain case studies. All these verifications should confirm that human security is the foundation and finality of national law. This will then make it possible to verify that, consequently, it is the foundation and finality of international law.

In order to do so, we will first situate ourselves in the theory of international relations, to examine, in the light of human security, as a law of nature, all the approaches proposing to account for the meaning of international relations. This undertaking is necessary because these theories are to account for the idea of international law or international law as idea, what necessarily has vocation to apply for standing as a positive rule of international law. Thus if human security postulates to be the foundation and finality of this rule, it cannot be so without first governing the idea of it. Human security should then make it possible to centralize these theories around a common understanding of international relations and international society for which it constitutes the law of nature or its foundation and purpose. Essentialist philosophy should reinforce this, by investigating the essence or ontological units of international society. It will be supported by political philosophy, which will familiarize us with the "reasons" of international political society. All of this will further account for international law, in its basic apprehension of agreement, organization. After studying human security as the foundation and finality of international law in idea, we will finally dwell on the verification of human security as the law of positive international law. We will limit ourselves to a single level of internationality, namely, the universal, which has the particularity of representing international society as a whole, and thus we will focus on international law as presented by the constitutive acts of universal international organizations. So far, international society has experimented with the Covenant of the League of Nations and the Charter of the United Nations. We will try to relate these instruments, as well as their subsequent normative production on security to human security, as a natural law. At that point we will be dealing with the theory, history and sociology of international law. We will resort to the theory International law for the interpretation of those legal instruments, history of international law for understanding their trajectory over time, sociology of international law for the impact of these instruments in the international life. Such an undertaking, which is meant to be suitable, should be sufficient to complete the verification of human security as foundation, and finality of international law.

\section{INTEREST AND ADDED VALUE OF THE RESEARCH}

We choose to deal with this subject because of the positive impact it can have on international affairs. Indeed, this topic allows us to situate ourselves in the debate to understanding the 
meaning of human security and its place in international society and thus in international law. Consequently, it should be given the full consideration it deserves in the light of that place. Before any in-depth development, there is clear unanimity about the concept of human security: its positivity. Indeed, human security, in a nutshell, is about the security of human beings and therefore aims at guaranteeing them a life free from fear and want. This noble goal of confirming human dignity in international society is laudable if it is recognized that life is the cardinal value, which is also confirmed by various prescriptions of international law (United Nations Charter, human rights). This research allows us to contribute to the understanding of human security and its implications, for the undoubted benefit of the large community of individuals that constitutes international society.

The added value of our research is that it should provide a new way of thinking about human security and security in general in international society. This research will propose the theoretical framework of human security, which, since its resonance within international society in 1994, had not yet been clarified. This should make it possible to conceive human security no longer at a micro level that is mired in the established international order, but at a macro level that becomes the compass of international affairs or international life. It is precisely no longer a question of conceiving it as a concept, a policy, a field of action, but as a law, the law of human nature and, consequently, the law of nature of political society (internal and international). This should thus make it possible to revitalize or consolidate the scholarly production hitherto in force in favour of human security, particularly as regards the role that international law is supposed to play for its effective implementation. Precisely Barbara von Tigerstrom's advocacy through the highly relevant proposals she formulates for this purpose should then be supported by elements of "full law" (essentialist and political philosophy on behalf of the philosophy of international law) that this research would allow us to mobilize, in the hope that they receive much more serious attention.

\section{PLAN AND JUSTIFICATION}

Our plan for testing our assumptions will be organized around its two main variants, which will constitute the two parts:

- The Necessary Precondition of Human Security as foundation and finality of International Law: Human Security as foundation and finality of national Law (part I)

- Human Security as foundation and finality of International Law (part II) 
The first Part is justified in that international law can only exist through States that maintain it, which are governed by a political order that is national law. Thus, without States or without national law, there would be no international society, which is governed by international law. Human security, as foundation and finality of international law, is then a consequence for it to stand as foundation and finality of national law. This Part would be structured around 4 chapters. In the two first, human security is analysed as a law of nature, by giving an account of its ontological and epistemological postulates. In the two last, human security is consequently analysed as the foundation and finality of national political order. The two first chapters are of extreme importance in that they will make it possible to account for the theoretical framework of human security, on which the rest of the subsequent verification undertaking is based. Thus, it is structured around Human security as the law of human nature (chapter I) and as the law of nature of political society (chapter II). Once these elements of human security, as a law of nature have been established, their application will be verified in the following chapters in the ideology of national political order or national law in idea (chapter III) and in national law in practice (chapter IV). National political order or national law in idea, generally preceding and founding its translation into a positive rule, it is necessary to carry out this verification for if human security stands as foundation and finality of this order, it is so above all because it governs its idea and whose coherence it restores. Thus this idea will be reflected in the trajectory of the practical national political order within the framework of the modern State that will be chosen as example.

The precondition of human security, as foundation and finality of international law emptied, we will start the Second Part by relating, in its two first chapters, human security to the ideology of international law or international law in idea. We will complete it by relating, in the two last chapters, human security to international positive law. Under the same conditions as national law, international law has two layers: the idea and the positive. Thus if human security postulates to stand as foundation and finality of the positive, then it postulates to stand the same for its idea. Thus, human security, as a law of nature is related to the theory of international relations (chapter V). These theories that are intended to account for the meaning of international relations, which are more or less translated into positive rules of international law, should all be known to varying degrees as having human security as their foundation and purpose. Secondly, the way in which human security constitutes the common denominator is investigated in its relationship with international society (chapter VI). Consequently, human 
security should be understood as foundation and finality of positive international law in its two constitutional (chapter VII) and governmental (chapter VIII) variants. 


\section{PART I: THE NECESSARY PRECONDITION OF HUMAN SECURITY AS FOUNDATION AND FINALITY OF INTERNATIONAL LAW: HUMAN SECURITY AS FOUNDATION AND FINALITY OF NATIONAL LAW}

International law can only exist as a result of a pre-existing national or domestic law. International law presupposes, given its "international" characterization, at least two national legal orders which it would unite or bring together on one or more specific objects. Human security can then only stand as foundation and finality of international law if it first constitutes the law of national or domestic law. The relationship of human security with national law will necessarily determine the relationship of human security with international law, since international law has a primary state source. It is then a question of accounting for human security as a genuine natural existing, independent of any human convention. Thus it will stand as a law of nature, that is to say, a state of affairs, a reality, a state of functioning or simply a state of things. That way, human security will be considered as the foundation and finality of national law. And only then would it be considered the same for international law.

On these considerations, in order to test human security as foundation and finality of national law, it is necessary first to deal in this framework with numerous preliminaries referring to the general aspects of human security as law of nature. Once clarified, these fundamentals aspects accounting for the theoretical framework of human security will be checked in the trajectory of domestic law could be read and understood.

Human security as a law of nature contains a certain ontological and epistemological substance that must be discovered before any further verification. This will involve bringing out the sense of the status of human security, as a law of nature This one refers only to human nature and political society. Human nature is indeed at the centre of all possible substance of human security. In reality, security can only be security of this nature. As far as political society is concerned, it denotes an organized communal living space in which human beings are called to coexist. Thus human security stands as the law of human nature (Chapter I), and therefore, stands as the law of nature of political society (Chapter II), which is generally the framework of human nature. 


\section{CHAPTER I: HUMAN SECURITY: THE LAW OF HUMAN NATURE}

Human security as the law of nature of politics or political society is in reality only a consequence of human security as the law of human nature. From the outset, a clarification is necessary. The law of human nature dealt with in this framework refers not to positive law in its legal understanding, but to natural law. It would then be a question of associating security as participating in, or better reflecting, or giving an account of human nature. Apprehending human security in this way makes it possible to better understand its meaning, somewhat better than the broad, narrow and hybrid conceptions it has been given. ${ }^{33}$ In contrast to the broad, narrow and hybrid understandings of human security, which tend to refer to a negative conception of human security by focusing on the threat or the risk of insecurity, the natural or naturalistic conception integrates all these understandings and goes beyond them by better signifying them and complementing them with a harmonious inclusion of the negative (state of absence of insecurity) and positive (state of security itself) meanings of human security.

What, then, does a naturalistic conception of human security mean, establishing it as a law of nature? Human nature is probably one of the topics that has most firmly anchored itself in the history of human knowledge, involving almost all scientific disciplines, whether hard (physical) or soft (social) sciences. Despite all the important contributions that have tried to account for this nature, this debate is still going on nowadays. With the aim of understanding human security, we will contribute to this debate by positing that security gives an account of or for human nature. In other words, it is only in the state of security that human nature has bears full significance. Human security is thus the consubstantial state of human nature and signifies it in its functioning and reality. Thus it constitutes the law of human nature. To postulate thus human security as the law of human nature is precisely to postulate it as the natural human order (1). The truthfulness and solidity of this postulate can finally be confirmed only by analyzing its relation to disorder (2). These various developments should serve as the basis for a theoretical framework for human security.

\footnotetext{
${ }^{33}$ S. FUKUDA-PARR, C. MESSINEO, op. cit.
} 


\section{HUMAN SECURITY: THE NATURAL HUMAN ORDER}

To approach human security as a natural human order is to conceive it as a matter of human essence. Thus it can only be understood in relation to the philosophical approach of essentialism. In this framework, we shall consider this perspective (1.1) before dwelling on its concrete application (1.2).

\subsection{Human Security within Essentialist Theory in Perspective}

As law of human nature, human security stands as a natural human order. This refers to a state of human nature that is established and needs to be known the way it is. In other words, this order is an essence that must no longer be realized or made but must be discovered. In order to properly define it, it is necessary first to understand the essentialist postulates (1.1.1) and then to consider its perspectives in order to give an account of human nature (1.1.2).

\subsubsection{Essentialism and natural order}

Essentialism in general may be characterized as the doctrine that (at least some) objects have (at least some) essential properties. ${ }^{34}$ Although this characterization can be broken down into several different and complex conceptions, this definition has the merit of being simple and straightforward. Indeed, we will not enter into a purely essentialist debate bringing out the different conceptions that it may have given rise to. ${ }^{35}$ We will limit ourselves more to some of its variants which will enable us to better account for security as the law of human nature. In a complementary way, we will then rely on the essentialist conceptions of St Thomas Aquinas and Brian Ellis, which will enable us to develop a significative approach to the essence of human nature about "security".

According to Ellis, things, in their basic constituents, contain dispositional properties that determine how things work. "Essentialist argue that things must behave in the sorts of ways they do not because the laws of nature require them to, but rather because this is how they are intrinsically disposed to behave. The causal powers, capacities and propensities of things, they say, are genuine properties, which they are bound to display in their various actions and

\footnotetext{
${ }^{34} \mathrm{Ph}$. ATKINS, "Essential vs. Accidental Properties", Stanford Encyclopedia of Philosophy, First published: Tuesday April 29, 2008; substantive revision: Monday April 18, 2016, https://plato.stanford.edu/entries/essentialaccidental

${ }^{35}$ For a brief historic of this notion, see F. BIRKIN, P. STAPLETON, C. LARRINAGA, "New Essentialism and the Foundations of Accounting Realism", Paper presented at the Administrative Sciences Association of Canada Conference, Halifax 2003 and at the Interdisciplinary Perspectives on Accounting conference, Madrid, 2003, See also J. BARNES, Early Greek Philosophy. Harmondsworth, Penguin Books, 1987
} 
interactions" 36 Basic properties thus account for the order of things. The reality of things does not depend on chance but on an essential informational content. Thus this order is no longer to be created, since it already exists from the beginning.

The precision between classical or Aristotelian essentialism and the modern essentialism advocated by Ellis is necessary in order to situate the naturalistic conception of human security.

\section{Classical or Aristotelian essentialism}

Aristotle's classical essentialism is an attempt to understand the intrinsic nature of the world. Aristotle believed that we can distinguish among the things that make up the world, those that are by nature, by art and by chance. According to Aristotle, things that exist by nature ${ }^{37}$ are distinguished from other things in that each of them has within itself various principles of change and resistance to change, principles that are intrinsic causes of its formal development (formal causes) and its role in nature (its final cause). Such principles are distinct from the various kinds of things that exist by nature and that are definitive to them: they constitute their essences. ${ }^{38}$ Aristotelian essentialism noted that material things of a given kind distinguish each other by ${ }^{39}$

- The substances they contain (their material causes);

- Their shapes, sizes, textures (their formal causes)

- What brings them into existence (their efficient causes)

- The purposes for which they exist (their ultimate causes).

According to Thomas Aquinas' commentary, this distinction would then make it possible to grasp the meaning of "natural kinds" as products of nature, rather than those of art or chance.

Moreover, this theory notes that things belonging to a given natural kind must be essentially similar. As a result of this nature, they are assumed to possess distinctive characteristics. These must necessarily include those that all must have as members of the kind or those that they would lose without ceasing to be members of the group. Thus, Aristotle's essentialism establishes the fundamental distinction between the notions of essence and accident. Essence in metaphysics can be defined as what is considered as the fundamental reality of a being [or

\footnotetext{
${ }^{36}$ B. ELLIS, The Philosophy of Nature, A Guide to the New Essentialism, Acumen Publishing Limited, Chesham, 2002, p.4

${ }^{37}$ In the Category of things existing by nature one finds animals and their parts, plants and elements from which all terrestrial and celestial bodies are ultimately are made.

${ }^{38}$ B. ELLIS, op. cit. p. 10

${ }^{39}$ Ibid.
} 
thing] as opposed to the secondary attributes and modifications that affect it only superficially or temporarily. ${ }^{40}$ According to Ellis, the essence of a thing refers to those characteristics that it has by nature and that it cannot lose without becoming denatured, that said, ceasing to be a thing of that nature. ${ }^{41}$ The accidental properties of a thing are those that it acquired accidentally or that depend on its particular circumstances and that it can lose without losing its identity. Such is the Aristotelian conception of the essence of a thing in reference to its nature, that is, "What the growing being grows from, that is, a source within the growing being. From this comes the idea of nature as the primary intrinsic source of movement or change belonging to something by virtue of what it is" ${ }^{\prime 4}$. In his Commentary, Thomas Aquinas notes the three fundamental aspects of this nature: "In the first place, nature recalls the idea of stability and formal specificity; secondly, it functions as both an active and a passive principle, so playing the role of an inner code capable of governing all the natural changes that a certain entity is subject to; thirdly, the concept of nature is associated with the idea of finality" 43

According to Ellis, Aristotelian essentialism focused primarily on explaining the existence and development of animals and plants. This explanation was possible if one could reasonably assume that each animal and plant carried within it a certain intrinsic property for its development that could pass through the process of reproduction to the second generation. The concepts of formal and final causality that are postulated to account for this property hold a central place in Aristotelian essentialism and it is no surprise to learn that the essence of an animal or plant kind consists in the final causal powers of its soul (human, animal or vegetative). Thus, Aristotle can be considered to have believed in the existence of intrinsic causal powers. ${ }^{44}$ According to Aristotle the final cause is that for which the thing is or exists. Thus everything has a purpose which grounds its nature. Things exist only for a purpose that accounts for their nature. Final causes essentially have a purpose and the explanations given in these terms are said to be teleological, that is, they account for the purpose for which the thing is what it is. ${ }^{45}$ For Ellis, teleological explanations have no role to play in science because they focus more on

\footnotetext{
40 “Ce qui est considéré comme la réalité fondamentale d'un être [ou d'une chose] par opposition aux attributs secondaires et aux modifications qui ne l'atteignent que superficiellement ou temporairement", in D. MARTIN, Dictionnaire des idées de Kant Vocabulaire de la Critique de la raison pure, des Prolégomènes, du cours Logique et de la Fondation de la métaphysique des mours, Update: 30 January 2018,

http://www.danielmartin.eu/Philo/Vocabulaire.pdf, p.482; See also Ph. ATKINS, op. cit.

${ }^{41}$ B. ELLIS, op. cit. p. 11.

${ }^{42}$ G. TANZELLA-NITTI "The Aristotelian-Thomistic Concept of Nature and the Contemporary Debate on the

Meaning of Natural Laws" in Acta Philosophica, n 6, 1997, p. 4

${ }^{43}$ Ibid. p. 5

${ }^{44}$ B. ELLIS, op. cit. p. 11

${ }^{45}$ B. ELLIS, ibid., G. TANZELLA-NITTI, op. cit. p. 8
} 
artefacts or artificial or original facts, whereas the hard sciences (physics, chemistry) deal rather with things that exist by nature. Such sciences ask how things work, not what is their purpose. The latter is generally regarded as a function for which the thing can be used. ${ }^{46} \mathrm{~A}$ thing can indeed accomplish a role different from the one for which it is brought into existence. Let us imagine, for example, that water fulfils a multitude of functions; it can be used for several functions and can fulfil an accidental function, depending on the point of view one takes or the appreciation one might have. Viewed so, the function of a thing cannot be of interest to science, whose standard of objectivity is intended to be the highest possible. ${ }^{47}$ However, a better understanding of Aristotle requires us to make a difference between his telos and the functional role of things, because the purpose of a thing that exists by nature is never accidental. Indeed, Aristotle assumes that everything that exists by nature has a telos that belongs to its essence: "Everything which happens either happens by chance or for the sake of an end. Now those things which happen outside the intention of an end are said to happen by chance. But it is impossible for those things which happen in every instance or in most instances to happen by chance. Therefore, those things which happen in every instance or in most instances happen for the sake of something Now whatever happens according to nature happen either in every instance or in most instances, as even they admitted. Therefore, whatever happens by nature happens for the sake of something. (...)Things which happen naturally are done so that they lead to an end. Therefore they are disposed to be done in such a way that they are for the sake of an end. And thus nature seeks an end, i.e. nature has a natural disposition for an end."48

Therefore the telos of everything that exists by nature exists independently of everything else. He further postulates that the ultimate goal of all philosophical research is to know the telos of things: the reasons for their existence. In this sense, the final cause is the highest of all causes. ${ }^{49}$

\section{New essentialism or modern essentialism}

The new essentialism or modern essentialism developed by Ellis can be seen as a version of Aristotelian essentialism "purified" of all elements whose scientific character seems doubtful. This scientific essentialism retains some elements and rejects others of the Aristotelian version.

First, new essentialism retains the idea that there are natural kinds of substance conceived as kinds of things of a material nature but rejects Aristotelian essentialism on species of animals

\footnotetext{
${ }^{46}$ B. ELLIS, ibid.

${ }^{47}$ Ibid. p. 12

${ }^{48}$ G. TANZELLA-NITTI, op. cit. pp. 9-10

${ }^{49}$ B. ELLIS, op. cit. p. 12
} 
and plants. According to Ellis, true natural kinds of substance exist only at a slightly deeper level than that of living species. They include basic kinds of chemical and physical substances such as various species of atoms, molecules and subatomic particles but not biological kinds. Concepts of biological species are really "group concepts" that have similarities with natural kind concepts, but biological species are not natural kinds. ${ }^{50}$

Second, new essentialism retains Aristotelian ideas about essential properties, but distinguishes more clearly between individual essences and kind essences. The individual essence of a thing refers to the set of characteristics by virtue of which the individual is what it is. However, this essence is problematic if, for example, issues of personal identity are to be addressed. One might then ask whether an individual in adulthood today is the same as in adolescence or childhood. The kind essence of a thing is the set of properties by which it is the kind of thing it is. And of these two conceptions of essence, the most important from the scientific point of view is the kind essence since science is much more concerned with kind than with individuals. ${ }^{51}$

Third, new essentialism does not share the idea of a final cause as enshrined by Aristotle. Indeed, for example, the parts of an animal do not exist for the animal from which they were made, as Aristotle believed, nor do organisms exist for the ecological systems in which they would be found. Scientific essentialism does not conceive the world as a large teleological system in which parts exist for the purpose of the whole. However, modern essentialists believe that things may have developmental potential or have behavioral dispositions of one kind or another. Indeed, modern essentialists believe that everything belonging to a natural kind has at least such dispositional properties. Thus the world of modern essentialism is not organic like the Aristotelian world, and it cannot be true to say that a part exists for the purpose of great wholes. However it is an integrated world in which things interact with each other in many ways, depending on their essential natures. ${ }^{52}$

Modern essentialists believe that things interact with each other on the basis of the intrinsic causal powers of their most basic constituents. These causal powers are among the essential properties of things of these kinds in such a way that they could not cease to have them without continuing to be things of these kinds. It is precisely at this level that the link between Aristotelian essentialism and scientific essentialism emerges, namely that both believe the

\footnotetext{
${ }^{50}$ Ibid. p. 12

51 B. ELLIS, Ibid. p.13, S. Mills, Gilbert Simondon, Causality, Ontogenesis and Technology, PhD Thesis, University of the West of England, Bristol, February 2014, p. 97

${ }^{52}$ B. ELLIS, ibid. p.13; F. BIRKIN, P. STAPLETON, C. LARRINAGA, op. cit.
} 
properties of things can include their potentialities, which are their dispositions to act or react in several ways according to circumstances. ${ }^{53}$

Modern essentialism conceives natural kinds in a stricter way than Aristotle did. Indeed, Aristotle believed that there are things by nature, which undoubtedly means that individuals can have the same nature, because most of the essences he studied are kind essences of things, rather than individuals. This shows that Aristotle was clearly committed to the idea that kind has distinct essences, as modern essentialists maintain. However, in Aristotle's sense, it is possible that a member of a natural kind may lose this quality and that properties that are essential to a kind may be absent. This is the example of a man who can lose his mind even though rationality is said to be essential to mankind. In the understanding of modern essentialism, it is not possible to conceive such a loss of essential properties without the thing continuing to belong to the natural kind. Moreover, the similarity between the members of a kind is perfect in all essential points. ${ }^{54}$

One of the fundamental characteristics of essentialism is metaphysical necessity. It refers to the value of a proposition that is true by virtue of the essence of the thing. ${ }^{55}$ To better understand this concept, Ellis distinguishes between "real essences" and "nominal essences". The real essence of a thing of a given kind is the set of properties or structures by virtue of which it is a thing of that kind. The nominal essence of a thing of a particular kind is the set of properties or structures by virtue of which it is described as a thing of that kind. ${ }^{56}$ The difference between these essences is clear. The nominal essence related to "name" refers to the way in which Man views the world, particularly in the classification and naming of things. Whereas the real essence linked to the thing (re) refers to the intrinsic nature of a thing, which exists independently of any human convention of classification or naming. The thing exists in what it is, even before it is subject to these conventions and thus it is only revealed as a result of scientific investigation. ${ }^{57}$ The example of water is taken to signify this difference. Water is water only in its constituent molecule $\mathrm{H} 2 \mathrm{O}$ and no matter what name is given to it and even before it was discovered, it existed as such so that if a substance were to be called "water" even though it was of a different molecular constituency, it would never be the thing that is $\mathrm{H} 2 \mathrm{O}$.

\footnotetext{
${ }^{53}$ B. ELLIS, ibid. p. 14; F. BIRKIN, P. STAPLETON, C. LARRINAGA, ibid.; S. Mills, op. cit. p. 98

${ }^{54}$ B. ELLIS, Ibid. p. 14

55 Ibid. p. 14

${ }^{56}$ Ibid. p. 16

${ }^{57}$ Ibid. p. 16
} 
The concept of metaphysical necessity ${ }^{58}$ is of fundamental importance to essentialists for two main reasons. First, metaphysical necessity is an authentic necessity. If something is metaphysically necessary then it must be so and there is no possible state of affairs where it would not be so. Necessity is generally opposed to contingency, which refers to the possibility that something may be this or that way. In the case of necessity, however, such a possibility is excluded. The thing is in what it is without the possibility that it could be otherwise, and this in all worlds and in all situations in which it would be involved. ${ }^{59}$ Second, metaphysical necessities are discovered through scientific investigation. They cannot be discovered by the conventions of language or classification because they depend on what the world is or what is in the world and how it is structured. Thus metaphysical necessities are a posteriori, that is, they are discovered through experience, which is different from the a priori conventions of language and classification that can be known without investigation. Thus a proposition expresses a metaphysical necessity if it does not reflect a convention of language but if it is shown to be so by virtue of its essential properties. ${ }^{60}$

\section{After this concise presentation of classical and modern essentialisms, what is our position within this doctrine in order to explain human security as a law of human nature?}

\subsubsection{Prospects for an essentialist account of human nature}

Essentialism in its Aristotelian and Ellisian version is the appropriate theoretical framework for accounting for human security as the law of human nature. Indeed, undertaking to give an account of things and their functioning by explaining the intrinsic properties of their most basic constituents is a realistic and scientifically sound approach. Essential properties are unquestionable realities that are the foundation of all things. Therefore it is not a creative work that would depend on the author's subjectivity, but on an objective existing. We consider human nature as existent, being so an objective reality that can be accounted for also objectively. To the question what is this essence that can account for human nature, we will advance that it is identifiable in the state of security. How can we know that on the basis of traditional and modern essentialisms?

\footnotetext{
${ }^{58}$ On this notion, see A. BIRD, Nature's Metaphysics, Laws and Properties. Oxford University, Press, Oxford, 2007; S. SHOEMAKER, "Causal and Metaphysical Necessity", in Pacific Philosophical Quarterly, n79, Blackwell Publishers 1998, pp. 59-77; J. COLLIER, On the Necessity of Natural Kinds, in P. RIGGS, (Ed.) Natural Kinds, Laws of Nature and Scientific Reasoning, Kluwer, Dordrecht, 1996

${ }^{59}$ B. ELLIS, "Causal Laws and Singular Causation", in Philosophy and Phenomenological Research, Vol. 41, n², September 2000, p. 335; B. ELLIS, The Philosophy of Nature, A Guide to the New Essentialism, op. cit. p. 18 ${ }^{60}$ B. ELLIS, "Causal Laws and Singular Causation", ibid. p. 334, B. ELLIS, The Philosophy of Nature, ibid. p. 18
} 
At first glance this thesis seems, already contradictory with New Essentialism as developed by Ellis. Indeed, New Essentialism is qualified as scientific and that is why it has undertaken to refrain from including elements likely to taint the quality of its scientific requirement. It therefore does not focus on animate but inanimate things, it rejects any final cause to things, for example the final cause of water may seem superfluous compared to its molecular constitution $\mathrm{H} 2 \mathrm{O}$ which adequately accounts for it. It is important to note that New Essentialism tackles the human being issue only at the level of its implications and under the general theme of social theory. ${ }^{61}$ Thus, scientific essentialism, unsurprisingly, could only do so by referring to the essential physical properties of the human being in order to try to explain the social behavioural tendency. In this sense, the focus is on genes or the genetic constitution of individuals: "Essentialists cannot dismiss psycho- or sociobiology altogether, as many theorists who see themselves as morally and socially progressive have wanted to do, for this would be to deny the relevance of natural selection to human thinking, reasoning, language abilities, conceptualization, socialization and so on, which would indeed be a very implausible position to take. People are certainly members of a biological kind, and biological kinds are sufficiently like natural kinds to make it likely that some patterns of linguistic, social or mental development are inbuilt, and common to all, or nearly all, members of the species. Indeed, it would be surprising if there were no psychological or sociological traits that human beings have, qua members of the genetic cluster to which they belong. Other animals undoubtedly have some specific behavioural traits, and naturally interact with each other in certain specific ways. Why shouldn't we?"62 This approach to human nature is an obvious consequence of scientific essentialism. By approaching the question of human nature as an implication of its theory, essentialism rather humbly proposes its elements as being able to account, by extension, for human nature. Thus, if new essentialism retains as object of exploration the intrinsic properties of the most basic constituents of things, it is difficult for it to include among them, even as an extension to its social theory, a (security) "state". How, then, can we use this scientific essentialism, which originally accounts for things, to account for a state, in this case the state of human security as the essence of human nature?

Focusing on genes to account for the human behavioural logic can certainly be of interest in understanding human nature, but this approach is also fundamentally limited and reductive. Indeed, human nature in both its material (physical) and immaterial (rational) aspects is

\footnotetext{
${ }^{61}$ B. ELLIS, The Philosophy of Nature, ibid. Chap. VIII: "Wider implications", "Essentialism and Social Theory", p. 157

${ }^{62}$ Ibid. pp. $157-158$
} 
fundamentally cognizant of the predominance of the immaterial, so that whatever the various genetic constitutions that individuals may present, they may deviate from such genetic determinism and freely adopt other behavioural patterns. The value of metaphysical necessity, which is of paramount importance for Essentialism, is very quickly relativized. Now we believe that, regarding human nature, the postulates of New Essentialism can be useful, not in the way in which they have been extended to social theory, but in the main way in which they have been formulated for inanimate things, that is, through the state of (human) security. By no longer relying on the fundamental genetic unit but on the human security "state" that would objectively be above the former, human nature can be resolved in such a way that it is also apprehended as an intrinsic property, thus satisfying the requirements of scientific character and metaphysical necessity.

Afterward, what can be the contribution of Aristotelian essentialism to account for human security as the law of human nature? This essentialism distinguished among the different causes of a thing or the final cause. This is of paramount importance for the animate nature of Man, because it accounts for the logic of his behavior. Man as an animate and rational being necessarily acts for a finality which is the basis of his actions. We will advance that the intrinsic state of security of human nature is the final cause of this nature. However, we will not understand it in the same way as in Aristotelian essentialism according to which the final cause is generally apprehended as unrealized until it occurs, that is, the final cause is only known as the purpose becomes concrete. Let us take as example the case of acorn and oak. Oak happens to be the final cause of acorn, that is, the intrinsic tendency of acorn is to become oak. Thus oak gives an account of the behavioural logic of acorn. In our understanding, however, with reference to this previous example, although we can easily assume that oak exists in potential in the intrinsic properties of acorn, we will assume that oak actually exists in acorn. What does this mean? The state of security as an intrinsic property reflecting human nature will already be apprehended as being real, so it should no longer be realized but, due to the animate nature of man, should rather be confirmed. It is not a matter of potentiality but of a real state which imposes to Man to remain in it through a perpetual confirmation. So it is the ground and the purpose of human nature, thus giving a perfect account of the logic of human behaviour.

Finally, this way of approaching the final cause establishes the link between Aristotelian or traditional essentialism and scientific or new essentialism. The latter castigates any possibility of final cause, which is undoubtedly true for inanimate things. Water, for example, exists only in its molecular constitution $\mathrm{H} 2 \mathrm{O}$ and no other purpose is imaginable in this understanding, if 
we refer, moreover, to the distinction between the teleological essence and the functionality of a thing in the sense of Aristotle. Thus $\mathrm{H} 2 \mathrm{O}$ is in itself part of a finite order. Likewise, as far as human nature is concerned, the state of security that accounts for its essence will be considered as an intrinsic property. A little like the water molecule $\mathrm{H} 2 \mathrm{O}$, which is no longer to be realized, this state of human security is no longer to be realized, since it is already real, but due to the human rational animate nature, it dictates a behavioral logic to Man, which is summed up in a perpetual confirmation. In this way it constitutes the final cause, that is to say, the ground and purpose of all human action.

Having considered human security in perspective in the essentialist theory, we will now turn to its actual detailing in the light of this approach.

\subsection{Human Security in light of Essentialism}

Human security, as the law of human nature, is understood in light of Essentialism as a finite order (1.2.1) and a final order (1.2.2).

\subsubsection{Human security as law of human nature: a finite order}

Human security, as law of human nature, is a finite order, that is, an order that from the outset exists in that it is without needing to be realized or created again. The most adequate similarity that could be made to characterize human security as a finite order of human nature is that of the atomic constitution of water or of the electron. Indeed water is water only by and in the $\mathrm{H} 2 \mathrm{O}$ formula. This atomic constitution is no longer to be realized, it is just so, just as the constitution of the electron is no longer to be realized because it exists only in the disposition of a negative and positive charge. Since it is no longer a question of either realizing or becoming, it is a question of a finite order, that is, of a definitive constitutive state. So is the consistence of the intrinsic state of security of human nature accounted for by human security.

New Essentialism or scientific essentialism cares to dwell on the most fundamental properties of things or intrinsic properties. These are authentic existing things, without their instances being the things themselves. The example is taken from the horse. If there is a property of being a horse, then its instances are the things that are supposed to have this property called "horse". This example is an obvious justification why animals and plants are excluded from this approach, which instead gives privilege to the most basic constituents of the physical world. According to Ellis, "With few, if any, exceptions, the fundamental properties of physical theory are all dispositional properties of the things that have them. They are either causal powers in 
the sense just defined, or else intrinsic capacities or propensities" ${ }^{\prime \prime 3}$. Intrinsic properties of the physical world are therefore dispositions inherent to things that are characterized either as causal powers, or else intrinsic capacities or propensities. For the purposes of this study, it is necessary to decline the meaning of these elements.

According to the Dictionary ${ }^{64}$, the word "property" refers among others, to the quality, the particular function (of a thing or a person). It is a distinctive character that belongs to a being, a species (...). For example it is named "essential property" or "fundamental property". In science in general and specifically in chemistry, property refers to a phenomenon or set of phenomena, attributes specific to a particular body that can determine its way of acting or reacting under specific conditions. It also refers to the particular virtue of a body, a substance. The idea of an intrinsic reality emerges from these definitions. Kant's Vocabulary apprehends intrinsic property as an absolute property because a thing disposes of it when this property exists due to the meaning of the thing in itself, intrinsically. ${ }^{65}$ It is then a property of the thing itself. As for it, the thing in itself as a real object is a set of information that represents it in its own nature, independently of any possibility of experience, therefore for any objective condition of existence, it is an absolute and eternal reality. ${ }^{66}$

"Disposition" is the term used to characterize the property of a thing. According to Ellis, dispositions, which are not immediately perceivable, include all the sources of all power and order in the world and therefore are at the centre of their account of reality. ${ }^{67}$ Dispositions include first of all the causal powers. "According to essentialists, a causal power is a disposition to engage in a certain kind of process: a causal process. A causal process is one of a kind that relates two kinds of events. The first of these kinds of events, which we may call the "causal kind", includes all of the events that have the role of causes in these causal processes, and the second of these kinds, the "effectual kind", includes all of those events that have the role of effects in these processes. In every kind of causal process, there is a specific functional relationship between the causes and the effects, so that a given cause in the causal range

\footnotetext{
${ }^{63}$ B. ELLIS, The Philosophy of Nature, op. cit. p. 47

${ }^{64}$ Dictionnaire sur PC Ortolang du CNRTL (Centre National de la Recherche Scientifique), comprenant les dictionnaires de l'Académie française jusqu'à la 9ème édition. http://www.cnrtl.fr/definition/PROPRIETE; See also the Definition of the Collins Online English Dictionary: https://www.collinsdictionary.com/dictionary/english/property

65 “(...) lorsque cette propriété existe du fait de la définition de la chose elle-même, de façon intrinsèque ", in $\mathrm{D}$. MARTIN, Dictionnaire des Idées de Kant, op. cit. p. 26

66 "La chose en soi d'un objet réel est un ensemble d'informations qui le représente dans sa nature propre, indépendamment de toute possibilité d'expérience, donc de toute condition d'existence, donc objectivement : c'est une réalité absolue et éternelle", Ibid. p. 173

${ }^{67}$ B. ELLIS, The Philosophy of Nature, op. cit. p. 46
} 
produces a given effect (or probability distribution over a range of possible effects) in the effectual range" 68 Thus the causal powers of things are their dispositions to produce specific changes in the world. They occur and have the characteristics they have independently of human subjective judgments or of any other causes external to things. ${ }^{69}$

Dispositions also come in propensities. "Generally, the propensities of things describe the ways in which they are disposed to act, independently of causal influences" ${ }^{70}$ According to the Dictionary, propensities refer to a natural innate inner force that spontaneously or voluntarily directs one's behavior. According to the Dictionary, propensity refers to an innate natural inner force that spontaneously or voluntarily orients towards a behaviour. Its synonyms include disposition, inclination and penchant. Thus propensity refers to a natural tendency. ${ }^{71}$ So by intrinsic propensity it is meant a natural disposition or tendency to be or behave in a certain way or to do something.

Finally, dispositions are intrinsic capacities. Ellis does not really define what "intrinsic capacity" should mean. One can then simply refer to the dictionary, which sees it simply as an ability to do something. ${ }^{72}$ One can therefore apprehend intrinsic capacity as a natural disposition of a thing to accomplish a certain type of action.

To summarize, dispositional properties of things include everything they are disposed to be and do. In examining these dispositions can we include a "state" in the sense of intrinsic dispositions?

Indeed, we can note that the concept of "disposition" has two meanings: static and dynamic. The static meaning refers to the intrinsic constitution of a thing and the dynamic meaning refers to an intrinsic tendency of a thing. Although New Essentialism is supposed to focus on things in the physical world, especially particles and sub-particles, it is clear that causal powers, propensities and capacities cannot be observed in the same way as the things that carry them. In a word, dispositional properties cannot constitute things in themselves. Instead, they are matched or associated with things that dispose of them. Thus, causal powers, propensities and capacities are properties of an informational nature that are consubstantial to things. That said, we understand that they can only be accounted for as a result of scientific observation. If,

\footnotetext{
${ }^{68}$ Ibid. p.48

${ }^{69}$ Ibid. p. 49

${ }^{70}$ Ibid. p. 47

${ }^{71}$ Dictionnaire sur PC Ortolang CNRTL : http://www.cnrtl.fr/definition/PROPENSION ; See also the Definition of the Collins Online English Dictionary: https://www.collinsdictionary.com/dictionary/english/propensity

${ }^{72}$ Dictionnaire sur PC Ortolang CNRTL : http://www.cnrtl.fr/definition/CAPACITE ; See also the Definition of the Collins Online English Dictionary: https://www.collinsdictionary.com/dictionary/english/capacity
} 
therefore, dispositional properties are informational properties, which by nature cannot be material but immaterial while remaining real, a state can just as easily be included as intrinsic dispositional property and be real, as we postulate for the state of human security consubstantial to the physical and rational nature of Man. How does this come about?

Human security as law of human nature is a finite order in that it is a consubstantial state with the physical and rational nature of Man. This state is an intrinsic disposition of human nature. Let us characterize it first.

Human security has been the subject of a very important debate on its apprehension, the result of which has been the ongoing need of a theoretical framework. If our approach to give an account of such a theoretical framework is based on that human security can be defined only if it refers to the message it conveys, namely that the human person is at the centre of international affairs, we cannot omit to characterize the state of security that justifies such a centrality. In our view, reference to the etymological sense should suffice. Indeed, the word "security" comes from the Latin "securitas" which means, among others, "carefree". Thus security refers to a state of absence of suffering or absence of pain. This apprehension of security is negative in that it emphasizes something that is not. On the contrary, in a positive way, it refers to a state of well-being. This basic definition of security, applied to human nature, captures human security as a finite order of that nature.

Human nature is a physical and rational nature. This dual dimension of Man is naturally ordered and functions in its own way and the state of security is the indicator of its order, that is to say, when body and mind are in order and function as they essentially should, Man is in security. Human security thus embodies human nature in its real state. Man is Man only in a state of human security. Thus, in any situation where this nature would be opposed to an order or a system that is contrary to what it intrinsically requires, the resulting state is simply an intolerable insecurity, by the very fact of this nature.

In accordance with New Essentialism, we postulate that the state of security is a genuine existent. It is a real state, like the atomic constitution of water. Since human nature is only in the order that intrinsically befits it, this order cannot be denied and this nature persists in being what it is. Since it is only in this order that this nature is real, the state of security which is its indicator is just as or equally real. In fact, its reality is the most fundamental if we take into account that it can be opposed to human nature, an order or system that does not correspond to that which it naturally requires and the result of which is malaise, ill-being, distress or simply insecurity. We must then ask ourselves how a state that postulates to be real can find itself not 
being real at certain times? This would contradict the postulates of New Essentialism because it cannot be possible for an authentic existing state not to be real. For example, the water molecule is $\mathrm{H} 2 \mathrm{O}$ whatever the situation.

In order to solve this problem, we need to point out, in two ideas, a very relevant example that corresponds to human nature: breathing. First, the human being is a breathing being. Breathing is a component of his being, so that one could not envisage a human being who does not breathe. Breathing therefore well corresponds to the example of the water molecule. However, the animate nature of man implies that breathing, although real, is constant. It is not a static state, that is to say, one has breathed once and for all, a little like the water molecule which is $\mathrm{H} 2 \mathrm{O}$ once and for all. It is rather that breathing is a real component, once and for all, of human nature, which unlike inanimate things, however, is perpetually or permanently confirmed. Can it then be said that in situations where human breathing is not confirmed, breathing is not a reality of human nature? We cannot. Second, any situation where Man's breathing is not confirmed can be conceived as a deprivation or a lack. But in relation to human nature, which is a state of breathing, the lack or deprivation of it cannot in fact be a state. A state is a reality, an existent. In the opposite, a lack implies nullity and therefore "nothing". A state cannot therefore be signified by "nothing". In other words, if the definitive consequence of the absence of breathing for a human being is extinction, which refers to nullity, or the reduction of his being to zero or nothing, then it is a case of non-being. Now, non-being cannot mean being. If security is the essential and therefore real disposition of the natural human order, insecurity cannot be a state but "nothing". For a being whose animate nature implies a constant confirmation, opposing it to "nothing" when it is "something" is opposing it to a nullity that cannot be it in reality. This is why the natural reaction or tendency for someone who is deprived of security is to quickly regain the state of security, just like a person who finds him/herself deprived of breathing seeks to regain the state of breathing. Since security, as the dispositional property essential to human nature is and therefore can never be what it is not, what is not real or is unreal, called insecurity, it can only be what it is, what is real and therefore confirms its reality. This is exactly what happens with water. Water can no longer be water under a molecular constitution other than $\mathrm{H} 2 \mathrm{O}$. Since water is and therefore can never be in what it is not, what is not real or is unreal, it can only be in what it is, what is real and therefore confirms its reality.

Unlike the most basic constituents of human nature, understood as genes on which New Essentialism focuses by implication, the state of consubstantial security with human nature accounts more for the human kind. Indeed, according to New Essentialism, if things that are 
members of a given natural kind must be essentially the same, that is, have the same internal dynamics, then one should expect these things to have certain distinctive characteristics that are the straight consequences of their similarity. ${ }^{73}$ Thus, for this theory, natural kind is summed up to the similarity of the intrinsic properties of the most basic constituents of the kind members. It is thus clear that genes cannot contain identical dispositions for all men. That is why, on this same basis, they are different. Thus, based on the postulate of New Essentialism, genes cannot represent the elements on which the natural human race is grounded. Yet the state of security essential to human nature is the very one that fulfils this function. Indeed, whatever the genetic characteristics or constituents of human beings, the age categories (childhood, adolescence, adulthood, old age), the different human races, the times, the places, human security is an essential disposition of human nature. It is an objective state that embodies the natural human order whatever its particularity. In that it is objective because it is the same for every human being. And because of this identity, security is the most basic and therefore most essential property that embodies the natural human kind. It is the common denominator of all human beings. It is in it that human nature is human nature.

\section{In this framework, one question remains to be answered: how do we know the state of human security as an intrinsic disposition of human nature?}

This epistemological question is necessary in the construction of a theoretical framework of human security. The way to access knowledge for Scientific Essentialism is through scientific observation. It is in fact only possible to account for dispositional properties by observing the constitution and functioning of things. The judgements of New Essentialism are therefore $a$ posteriori conclusions, that is, conclusions that arise from experience. As far as human nature is concerned, the best way to account for the state of security that is intrinsic to it is through experience. However, unlike the causal factors, propensities and capacities of New Essentialism, which require very demanding scientific means, the state of human security is a sensitive experience. This state is known by feeling, and one does not need to be a scientist to know it or to feel the need to confirm it. With the example of breathing, we can ask ourselves how we come to know it; quite simply by experience. For example, whether or not we are conscious of breathing, the fact is that breathing is an essential component of human nature and the very moment we are deprived of it, we understand that it is urgent to regain the real state. A new born cannot be conscious of its physiology but if it happens that it is not confirmed, there is an instantaneous reaction and it stops when the state of order is back. This applies to the state

\footnotetext{
${ }^{73}$ B. ELLIS, The Philosophy of Nature, op. cit. p. 100
} 
of security. Being the disposition that embodies the natural human order, it is felt in the wellbeing that one experiences. And when one is deprived, one feels a lack that stops when one has regained it.

This first paragraph has been an opportunity for us to present human security as a law of human nature, in its first variant of the finite order of that nature. This was possible in the light of New Essentialism whose requirements have been met by human security as an intrinsic disposition of human nature. Human security as a law of human nature by constituting a final order.

\subsubsection{Human security as law of human nature: a final order}

According to Aristotelian Essentialism "Everything which happens either happens by chance or for the sake of an end. Now those things which happen outside the intention of an end are said to happen by chance. But it is impossible for those things which happen in every instance or in most instances to happen by chance. Therefore, those things which happen in every instance or in most instances happen for the sake of something... Now whatever happens according to nature happens either in every instance or in most instances, as even they admitted. Therefore, whatever happens by nature happens for the sake of something" "74. Final cause is also understood as the reason why something is or functions in a certain way and without which it cannot be or function thus. The clear difference between teleology and the functionality of nature evokes the principle of necessity. The state of security as a final order complements its finite order nature in that it implies that the teleology of human nature be itself. This is what we call the necessary perpetual confirmation.

The animate nature of man requires that the intrinsic order that characterizes him be constant. It is not a question of the state of security being real once and for all, it is necessary that it be constantly lived and experienced in the way it is by the human being. If it happens that at certain times this be not the case, the feeling that is imposed on the human being is an intolerable nullity. He must then regain the state of reality which is security.

The principle of necessity is generally opposed to contingency. In philosophy, contingency refers to the state of what may or may not be, may or may not occur, may or may not have occurred. It is the way of being, the state of existence of an object, real or abstract, which may or may not exist. It is the way of being of a situation or an evolution that may or may not occur, may or may not have occurred. ${ }^{75}$ Necessity, on the other hand, refers to the state of what is

\footnotetext{
${ }^{74}$ Aristotle in II Liber Physicorum quoted by G. TANZELLA-NITTI, op. cit. pp. 10-11

${ }^{75}$ D. Martin, op. cit. p. 267
} 
imposed, rigorously determined by the nature of things or by a state of fact. It also refers to the state of what is inevitable, which cannot fail to occur, which escapes human will, to the state of what the opposite is impossible. ${ }^{76}$ The state of security indicative of the natural human order cannot be contingent in that it cannot be otherwise than what it is. And it cannot be otherwise without ceasing to be what it is. This is the very necessity that corresponds to the principle of identity, which is expressed in "what it is, is; what it is not, is not" A thing (object, situation, event) is (exists, takes place or has taken place), or is not (does not exist, does not take place or has not taken place). ${ }^{77}$ New Essentialism emphasizes metaphysical necessity, which corresponds to the situation according to which a thing is as it is, whatever the situation in which it finds itself. It is as it is in all possible worlds. We can still take the simple example of breathing. The natural human order includes that the human being is a being that breathes no matter what situation he finds himself in. If this were contingent, it would imply that Man is capable of being and continuing to be what he is without breathing. That is impossible. We see this reality in space exploration missions, for example. Wherever such a mission is conducted, Man continues to be a breathing being. When the planet in question where such a mission takes place does not have favorable conditions for breathing, all measures are taken to ensure that the explorer equipment is made up of a device that allows him to continue breathing in such environments. If breathing were a contingency, it is clear that humans would be able to survive in oxygen-deficient environments. The state of security is considered to be that dispositional property that reflects the order that is intrinsic to human nature. In this way, it is a reality in all situations in which the human being would find himself. Thus, a natural phenomenon cannot be contingent. Since a natural law has no exceptions, a natural phenomenon cannot be contingent. In the case where conditions to confirming the state of human security are met, then it is confirmed (whether or not an observer observes it), where they are not met, then it is not confirmed. ${ }^{78}$

Given the animate nature of the human being, the state of human security requires a perpetual confirmation. What do we mean by this? Actually since a thing is already real, its situation is not to be realized any longer. One does not realize reality, that is, one no longer makes it, nor does one create it. For example, water, with its real molecular constitution already H2O, can no longer be realized or created. In that case, what is the attitude one can have towards something that is already real? It is to confirm it in the way it is, that is to say, to respect what it is, to live

\footnotetext{
${ }^{76}$ Ibid. p. 870

${ }^{77}$ Ibid. p. 1341

${ }^{78}$ Ibid. p. 867
} 
in adequacy with its nature. Likewise, the state of security which is already the constitutive reality of the natural human order is no longer to be realized but requires that the human being continue to be in this disposition permanently. In the same manner, water could not cease to be $\mathrm{H} 2 \mathrm{O}$ without ceasing to be water, human nature could not cease to be (in) the state of security without ceasing to be itself. This is precisely what is called conservation.

The state of security has proven to meet the criterion of metaphysical necessity. It is a state inherent in human nature, so it has been considered the common denominator of all human beings. All human beings are bound to it. Whatever age category, from childhood to old age, race, social context, the state of security is a uniform state with which all identify and with which they aspire to constantly identify. Thus, it is clear that it is an invariant and permanent state. This is confirmed by Kant when he uses the terms "identical" and "identity" to refer to the character of what remains unchanged over time. Identity is an invariance, a permanence. ${ }^{79}$

The notion of permanence of substance as developed by Kant is very significant for us. In a first sense, all phenomena contain something permanent (substance), constituting the object, and something changing, corresponding to a simple determination of this object, that is, a mode of its existence. ${ }^{80}$ In the case of human nature, the state of security, as a dispositional property of human nature, ensures this permanence. Change, according to this nature, consists of states of age corresponding to different bodily states. In a second sense, in any change faced by phenomena, the substance persists, and its quantum is neither increased nor decreased in nature. ${ }^{81}$ The state of human security that validly represents this substance persists regardless of changes both in the rational and physical nature of man. The permanence and invariance of the state of human security therefore necessarily calls for a confirmation or conservation that better reflects the final order it constitutes.

According to the Dictionary, conservation is the action of maintaining the same state without any alteration. It is the action of keeping intact, the action of keeping, defending, opposing any change of state. ${ }^{82}$ Since the state of security is an essential invariant state, the essential logic for Man, who intrinsically identifies himself with it, is to continue or to remain permanently in

\footnotetext{
${ }^{79}$ Ibid. p. 691

80 "Tous les phénomènes contiennent quelque chose de permanent (substance), constituant l'objet même, et quelque chose de changeant, correspondant à une simple détermination de cet objet, c'est-à-dire à un mode de son existence". Ibid. p. 963

81 "Dans tout changement connu par les phénomènes, la substance persiste, et son quantum ne se trouve dans la nature ni augmenté ni diminué", Ibid. p. 963

${ }^{82}$ Dictionnaire sur PC Ortolang du CNRTL, op. cit. http://www.cnrtl.fr/definition/CONSERATION ; See also, the Definition of the Collins Online English Dictionary: https://www.collinsdictionary.com/dictionary/english/conservation
} 
this state. This is a confirmation of his nature. Any attitude contrary to conservation could mean only one thing; ruin, which gradually leads to nullity. This attitude has been elevated to the rank of instinct. If man's rationality is generally perceived as a rationalization of instinct, it is necessary to understand it.

According to the Dictionary, instinct refers to an innate, hereditary and specific behaviour, accomplished without prior learning and in all perfection; an innate tendency, at the origin of certain automatic elementary activities of Man: instinct of conservation, copulation, nutrition, sucking; an inner impulse independent of reflection which determines a person's feelings, judgements, acts; the faculty, in certain people, of feeling, of guessing, which determines a way of thinking, a behaviour. ${ }^{83}$ All these different definitions refer to an attitude linked to a primary nature. The inherence which emerges from them is compatible with the dispositional properties intrinsic to the most basic constituents of things. We have seen that disposition refers to an intrinsic state or intrinsic tendency. The state of security, as we have seen, is a real state and thus constitutes a finite order. Now this implies for the animate nature of man a continuity in this state because it is a tendency to maintain himself in it. It is in this meaning that the state of security is a final order. The instinct of conservation or confirmation thus apprehended belongs to the essential order of human nature in its twofold dimension of physical and rational. This instinct can only espouse the rationality of Man to be a rational instinct, what implies that any attitude of Man has the sole purpose of perpetuating himself (in) the state of security which embodies his order or, in other words, of confirming that it is so and only in the state of security that he is what he is.

In terms of human security as a final order that implies a permanent confirmation of Man, it is possible that he submits to it only on the basis of an obvious attribute of his rationality which is no other than freedom. Indeed, man is naturally a free being and the confirmation of the state of security which is intrinsic to his nature necessarily depends on it. The diversity of human composition is an undeniable reality. Human societies have always had different civilizations and cultures and ways of life have always been different. Human freedom makes the confirmation of human security a non-uniform affair. Everyone, according to his or her way of life, is dedicated to it. Human freedom focuses attention on the means used by Man to confirm himself. For example, men do not feed the same way, nor do they maintain their health in the

\footnotetext{
${ }^{83}$ Dictionnaire sur PC Ortolang du CNRTL, Ibid. http://www.cnrtl.fr/definition/INSTINCT ; See also the Definition of the Collins Online English Dictionary: https://www.collinsdictionary.com/dictionary/english/instinct
} 
same way not to talk of social morals are that vary from one society to another, just to name a couple. Even if they are reduced to the common denominator of the intrinsic security state proper to their natural order, Men define themselves in their own way and confirm themselves in this objective state. Human security thus constitutes both an objective order in its essence and its purpose and a subjective order in the means it implies for its confirmation.

Any theory that intends to deal with human nature cannot avoid this ontological attribute of human freedom. It is very important to mention it here because there is no uniform way of living and therefore no way to confirm the ontological state of human security. It is even an impossibility if one takes into account age categories. Newborns, prepubescent children, adolescents, adults, the elderly who do not necessarily have the same way of life, depending on cultures, times, conditions of the physical world. Even if they are identical in terms of the state of security that is intrinsically characteristic of their nature, their ways of life still differ. To illustrate this, let us imagine individuals each owning an identical telephone. This device is the same for everyone, but its use depends on the freedom of each individual. Each will use the phone in his own way even though it has the same features (call, message, camera, etc.) and maintenance requirements (charging, pouch, etc.) as the others. Claiming that all those individuals have the same way of enjoying the same phone is simply unthinkable.

Now let's suppose an attempt to impose on all owners of this identical phone an identical way of using it (calling, messaging, using the camera, etc.) or even an encroachment. Is this possible? No one will be able to accept it. This is still simply impossible because life is not set to the same mode. Let's just imagine that whoever tries to impose an identical way of using this identical phone, also owns it. Would he or she want to be forced to use the same phone in the same way, or would he or she want the same encroachment? This is unlikely simply because it is impossible for him/her to have his/her life set up in the same way as the others and any intrusion into the enjoyment of his phone would cause him inconvenience. This example is a good illustration of how the freedom confirming human security is to be understood. It is an attribute of ontological necessity. No one can wish to have his or her freedom violated, which would create insecurity for him or her, and no one, because of this and on this basis, would actually undertake to violate freedom of others. The same is true of the state of security intrinsic to human nature and the way in which it is confirmed. The latter is a matter of freedom, and each person bears the consequences of using it for his or her own benefit, without interfering with that of others. 
Considerations relating to freedom, basis on which confirmation of human security as the law of human nature, are not merely pure logical implications but are also a matter of metaphysical necessity. Since the state of human security is necessary a finite order in essence, it is equally a necessary finite order in the basic means of the freedom it implies for its confirmation, in accordance with Man's animate nature.

In this first section, drawing on both New Essentialism as carried by Ellis and Traditional Essentialism as carried by Aristotle, we have been able to recognize that human security, as a law of human nature, constitutes a finite order and a final order. The soundness of a theoretical framework for human security as a law of human nature has to be tested again by a confrontation with the concept of disorder.

\section{HUMAN SECURITY AS A LAW OF NATURE AND DISORDER}

To better test the resistance of human security as the law of human nature, it is imperative to analyze it in relation to the concept of disorder. In fact, it is a matter of dwelling on the question of whether it is possible for human security, as a law of nature to be flouted, whether it is possible for the order it embodies to be contradicted by disorder. This analysis, with reference to the two inclusive orders implied by human security, namely the finite and final orders, carries with it the assertion of illusion of disorder (2.1) which is being understood with time (2.2).

\subsection{Human security, as a law of nature and the illusion of disorder}

The intrinsic order of human security is a law of nature in that it embodies or is indicative of the order inherent in human nature. As the foundation and finality of this nature, it represents a finite order that no disorder can flout. If this is observed at varying degrees from the point of view of the finite and final order that includes human security, disorder remains an unreality (2.1.1). Conversely, in the order of means, the latter implies the confirmation of the state of human security. Therefore, it includes a relationship to the notion of disorder (2.1.2).

\subsubsection{Unreality of disorder in light of the finite and final orders}

The harmonious foundation of the theoretical framework of human security on Modern Essentialism and Traditional Essentialism confirms that it meets the requirements of a natural law. Disorder in this sense can only be reduced to unreality.

For New Essentialism, the concept of law of nature is of fundamental importance because this status is evidence of scientific character. Thus, for a law to have the status of a law of nature, it must satisfy four kinds of requirements: necessity, idealization, ontology and structure. 
The first requirement for a law of nature is that it must satisfy necessity. Natural necessity is not a kind of greatness, the laws of nature do not accede to necessity, but they are just of that nature. ${ }^{84}$ "If being an A necessitates being a $B$ in this world, then it does so in every world. Consequently, the laws of nature must themselves be necessary. There can be no question of a law of nature holding in one world, but not in another. If it is a law of nature, then it relates universals, and does so without reference to any particular worlds in which they might be instantiated". 85

The second requirement is idealization. Indeed, authentic laws of nature seem only to describe the behaviour of ideal kinds of things, or things in their ideal circumstances. New Essentialism makes such propositions possible. Indeed, "it enables us to give a good account of the abstractness, or ideality, of many laws of nature, because the essential properties of things are necessarily to be found among their intrinsic properties, and the intrinsic properties of things are just those of its properties that it has independently of its causal relations to other things. Therefore, in order to describe the essential properties of anything, it is necessary to abstract from any external forces that may be acting upon it to say how it would be or behave in the absence of such forces" $" 86$

The third requirement is ontological. Any true and solid theory of laws of nature has to account for their objectivity, which means that laws of nature should be discovered and therefore be or describe a reality that exists in an independent way. "The essentialist theory provides a clear answer to the question: in virtue of what is a law of nature true? The essentialist's reply is that laws of nature refer to the essential properties of the natural kinds, and that these are their truthmaker"87

The fourth requirement relates to structure. A theory of laws of nature should be able to explain the different categories of laws of nature and the hierarchy within each category. "[Essentialism] explains the varieties and hierarchies of laws of nature in a simple and straightforward way. The hierarchies of natural kinds naturally give rise to corresponding hierarchies of laws, with global laws at their summits". ${ }^{88}$

Grounding a theoretical framework of human security on Essentialism means that it fulfils the requirements of a law of nature. With regard to the first condition of necessity, the state of

\footnotetext{
${ }^{84}$ B. ELLIS, The Philosophy of Nature, op. cit. p. 90

${ }^{85}$ Ibid. pp.100-101

${ }^{86}$ Ibid. p. 101

${ }^{87}$ Ibid. p. 101

${ }^{88}$ Ibid. p. 100
} 
human security, as an essential disposition of human nature, undoubtedly fulfils it. The state of human security is valid in all possible situations in which human beings of all possible particularities would find themselves. Moreover, it is an invariant state, and confirms the marriage of immutability and necessity: "All that is immutable is necessary" and "All that is necessary is immutable". 89

With regard to the requirement of idealization, the state of human security represents the ideal state of human nature. It is the ultimate indicator of the natural human order.

With regard to the ontological requirement, the state of human security stands as the essential property of natural human kind. It gives an account of the animate nature of human kind. This state exists independently. It embodies human nature to the highest degree, so that without it, human nature is not itself. The state of security is the real intrinsic disposition of human nature. A human being can have perfect physical health but still face mental problems. Everyday human being, regardless of their physical-psychic state, always seeks to keep themselves secure. Since it is therefore not enough to be a human being, but to be secure, the state of human security is one that defines human nature. In that, it is an objective disposition, one that signifies human identity. Thus, it exists independently of any human capacity to account for it or not.

Regarding the last requirement relating to structure, the state of security accounts for human nature at the highest level. Scientific Essentialism, as part of its theoretical implications, has proposed itself to contribute to social theory. It has focused on genes. Since genes are natural kind, they are par excellence target of any theory that seeks to explain human behaviour. However, it has been observed that genes, as "things", are observable but not the informational quotient they carry, which are in fact the dispositional properties on which Scientific Essentialism focuses. Being immaterial things, the state of security, which has the same nature, finds itself at a higher level since it gives an account of the human kind, not of particular individuals as genes do. It is therefore at the highest rank in the hierarchy of intrinsic dispositions of human nature.

The state of human security thus fulfils the characteristics of a perfect law of human nature. Therefore, disorder cannot really concern it.

According to the Dictionary, disorder is defined as a lack of order, a defect of tidiness, a lack of functional or aesthetic arrangement; a lack of regularity in tidiness, in the order entailing that

\footnotetext{
89 "Tout ce qui est immuable est nécessaire" et : "Tout ce qui est nécessaire est immuable”, D. Martin, op. cit. p.
} 1136 
one does not or no longer find way around it. The two meanings evoked in this definition refer agreeably to the finite and final orders of human security.

Indeed, disorder is first apprehended as a lack of order. Lack refers to an insufficiency or absence. Both of these terms refer to a situation of nullity or unreality. In fact everything is, in itself, a substance, a quintessence, a reality. So it is not a question of all substances, all quintessences, all realities, but of "that" substance, "that" quintessence, "that" reality. It is therefore inscribed or stamped in the nature of a thing its own "law", which is nothing other than the intrinsic order that accounts for the real nature of that thing and without which, obviously, that thing would not be what it is. In this way it must be said that a thing is "that law". The absence of it means ipso facto either that it is "nothing" or that it is something else. Thus a thing cannot be changed in its intrinsic order and remain the same. Let's take the example of water, dear to new essentialists. Water exists only in the molecular constitution $\mathrm{H} 2 \mathrm{O}$, so that we can only speak of water in reference to $\mathrm{H} 2 \mathrm{O}$. If it were to be another intrinsic disposition, for example HXY, we would no longer speak of water, unless we do no longer agree on language conventions where it is possible to designate something that refers to another reality by name.

Disorder, in reference to order, therefore refers to what order is not. The order of a thing being the thing itself, disorder, since "nothing" is therefore not that thing. The state of security that essentially characterizes the natural human order falls within the scope of these considerations. One cannot really speak of human nature without human security. The well-being that signifies the state of human security easily translates the idea of a normal functioning of the rationalphysical nature of the human person. Its opposite, which is ill-being, can only refer to a situation of disorder, that is, a lack of the essential order that is intrinsically fitting to this nature. And the ultimate consequence of this lack is nothing else than progressive or definitive extinction. It is then simply impossible for Man to feel well in a situation of human insecurity. How can we understand this? Continuous lack is equivalent to progressive extinction and the point of saturation is complete extinction. This means that disorder is a nullity and the ideas of progression here can still only be apprehended with reference to the order that continues to be what it is until it is no longer. Helmut Kuhn confirms that when he conceives disorder as, " $a$ 
simple negation to which, in reality, nothing corresponds". ${ }^{90}$ This logic corresponds well to the final order of human security, which implies a permanent confirmation.

Human security in the finite and final inclusive orders is therefore perfectly a state, not "nothing". Disorder is then an impossibility that cannot concern it. However, the same cannot be said of the confirming attitude of Man that human security necessarily calls for. This implies, in conjunction with the ontological attribute of freedom, that there must be an adequate attitude that confirms the state of intrinsic security. But the principle of freedom itself undoubtedly makes an attitude that would not confirm the state of human security possible. The confirmation of human security therefore necessarily calls for an order of means which cannot be tackled exclusively without possible reference to the notion of disorder.

\subsubsection{Human security, order of means and disorder}

The reality of an order of means intended to confirm the intrinsic state of human security is a logical implication of the animate nature of the human kind. We have seen that this is the natural state of Man in which it is necessary for him to find himself permanently. Since the state of security is an intrinsic and therefore permanent disposition of human nature, as long as human nature "is", the confirmation of this state is an equally permanent tendency of the human being. Once again, let us take the example of breathing. Breathing is a component of human nature but needs to be permanently confirmed. We do not breathe once and for all, we breathe permanently. This does not make breathing any less a real component of human nature. And it is because it is real that it needs to be confirmed all the time. Let us imagine a situation of absence of breathing due, for example, to atmospheric conditions that do not correspond to the normal breathing conditions of Man, such as on the moon. The possibility of Man being there implies that he continues to breathe there under normal conditions with oxygen. If he is on the lunar ground without adequate equipment supplying him with oxygen, what is certain is that he would find himself in a situation of lack, and therefore in insecurity, what would in fact mean opposing him "nothing" while he is precisely that "thing" breathing oxygen. In other words, by opposing him this "nothing" that represents insecurity when he is this "thing" that represents the state of security, he can only be confronted with a progressive extinction up to the point of saturation which is death. Now if during this progressive extinction situation, he would find himself supplied with oxygen, he would confirm his normal state of breathing and therefore his

\footnotetext{
90 “une simple négation à laquelle, dans la réalité, ne correspond rien ", H. KUHN, "Le concept de l'ordre", in Gregorianum, Vol. 43, $\mathrm{n}^{\circ}$ 2, Pub. GB Press- Gregorian Biblical Press, 1962, p. 5, available on http://www.jstor.org/stable/23572398
} 
state of security. It would not make the respiratory component of its nature real, since it is already real, but would rather confirm it.

From the example above, the meaning of the notion of disorder clearly emerges. From the point of view of the order of ends, it represents a lack. From the point of view of the order of means, it represents the inadequacy of the means used to confirm the real state of human security. It means, therefore, the use of means whose purpose is not to confirm human security as a real permanent state of human nature, but rather to deny it. In our example, man breathes only with oxygen. This is the order of his nature. If he were to be in conditions where there is only sulfur, he would be opposed to something else than what is compatible with his order. Breathing sulfur and not oxygen is a disorder, not that the latter one is something, but a situation where there is no oxygen. That means opposing "nothing" to him when he is something called "oxygen". This example also applies to Man's psychic nature. When it is not confirmed by means that correspond with the well-being that intrinsically befits him, there is disorder. Thus in all situations where the foundation is not the finality, there is disorder. And this immediately calls the means of confirmation used into question.

Our example also allows us to understand what the normal reaction to insecurity is: that of regaining a state of security very quickly. Thus when the means used lead to a non-"sameness" 91 of the foundation and the finality, there is immediate intelligence of inadequacy of the means used. Since Man must necessarily confirm himself, he is obliged to change means and find the adequate ones. A concrete example helps to illustrate this situation. Let us imagine a human being in several environments $E$ close to each other, each with a different atomic composition of the breathing air. Let's name E1: sulphur; E2: nitrogen; E3: carbon dioxide; E3: helium; E4: oxygen. Held to breathe, he would stop only on E4. He doesn't even need to know the different atoms that constitute the different environments, he just feels the compatibility or incompatibility with his organism, he knows it by experience. He would be obliged to test all the environments until he reaches the right one, E4. The other environments that he would test, $\mathrm{E} 1, \mathrm{E} 2, \mathrm{E} 3$, would prove to be inadequate means whose natural consequence would be to move away from them, until he finds the right one and stays there. In the same way, any human being who finds himself confronted with insecurity after the means used to confirm his state of intrinsic security always finds himself confronted with the need to change means, until he finds good ones. Since every means necessarily has a consequence, it is clear that inadequate means

\footnotetext{
${ }^{91}$ To mean the character of being the same
} 
cannot lead to a precisely desired finality. And it is ultimately the confirmed state of security that provides information about the appropriate means.

So we see that if disorder were a reality, it would imply that an individual could delight himself in it and, for example, breathe under atomic conditions of oxygen deficiency. So is the case of human insecurity. If this were real, it would be possible for man to delight himself in it as in the state of human security. That would simply be saying that a thing is what it is not. But such a proposition is necessarily false, since it implies that order is disorder at the same time. There is one that is necessarily null or unreal and the other real. Order is therefore real and disorder unreal.

The order of means, under another glance, however, gives us to see the usefulness of disorder by its contribution to reality. Indeed, we have seen, with regard to the animate nature of the human being, that the order of ends necessarily implies an order of means to confirm it. Disorder then becomes an important indicator of the need for the necessary adequacy of the foundation and finality. That is to say, the nullity that disorder entails, itself signifying the inadequacy of the means used to satisfy the finality, makes it necessary to seek adequate means. Disorder then has a pedagogical function, because the more its means oppose nullity to the reality that essentially requires confirmation or conservation, the more the good means are researched for that purpose, what brings us closer to it. It is clear, therefore, that in the long run, disorder makes it possible to be educated on the true order of means confirming the reality of human security.

Disorder also makes it possible to understand the notion of punishment. The consequence of disorder from the point of view of the "thing" is nullity. This nullity can be considered as a sanction in that it is interpreted as a punishment resulting from the inadequacy of the means used to confirm reality. Since a law of nature is of immutable necessity, it cannot be flouted. The penalty that would result from a null flout can only be null and void. For an animate being, who is to be confirmed by the permanence of his intrinsic natural state, opposing him such nullity is precisely what constitutes a sanction. This amounts to an intolerable non-being. That emerges from the way St. Thomas Acquinas understands the notion of order. Indeed, "Every moral doctrine, which aspires to an objective and universal worth, must include some sanction. In the principle of order, [Thomas Aquinas] finds the basis for a natural sanction".92 "Order is considered here as "reciprocal convenience". From this moral and social order of reciprocal

\footnotetext{
92 "Toute doctrine morale, qui aspire à une valeur objective et universelle, doit disposer de quelque sanction. Dans le principe d'ordre, saint Thomas trouve le fondement d'une sanction naturelle ", A. SILVA TAROUCA, "L'idée d'ordre dans la philosophie de saint Thomas d'Aquin", in Revue néo-scolastique de philosophie, 40" année, Deuxième série, ${ }^{\circ} 55,1937$, p. 378
} 
convenience, in which Man is constituted by nature, he excludes himself if he flouts the order (...). The natural consequences of this exclusion constitute the natural sanction of natural moral." 93 The idea of reciprocal convenience emphasized here refers to the necessary adequacy of the order of endings to the order of means used to confirm of reality. And flouting the order ultimately means that Man has opposed himself to a nullity which he is not, since exclusion means that he is outside himself, outside that state which is intrinsic to him: security.

The order of means necessary to confirm the intrinsic order of human nature is certainly consistent with this nature. Indeed, "Man is a unity of body and soul. He is, in essence, rational. Now the natural operation must respond to the natural form. The corporeal aspect of his nature is revealed in his intentional becoming by a triple necessity, typically human: his knowledge must begin with the senses; it must be obtained through abstraction which dematerializes the sensible "species"; and it must be perfected through discourse: "componendo and dividend". So, this discourse itself must, to be true, proceed in order and by order to reach the intellection of order, which constitutes Man's natural wisdom. It is therefore in conformity with the essence of the real order, with the being of the creature and the nature of Man that Man acquires his science by distinguishing modal orders". ${ }^{94}$ So, "we thus find in the intentional domain the natural sanction of the flouted order. He who neglects the distinction of orders, distances himself from reality and destroys, in so far as it is in him, the most beautiful thing in the universe, his order. By virtue of the very principle of order it is therefore inevitable that the cognitive process that flouts this order (either by disobedience to sensitive data or by confusion of modal orders) finds its natural sanction in itself, it lacks the science that is perfection. In the intentional order this natural sanction is called error. That one falls into the error he who neglects experience or despises the distinction of orders" "95. The unhappiness or ill-being that

\footnotetext{
93 “L'ordre est considéré ici comme la "convenance réciproque”. De cet ordre de convenance réciproque, morale et sociale, dans lequel l'homme est constitué par nature, il s'exclut lui-même s'il viole l'ordre (...). Les conséquences naturelles de cette exclusion constituent la sanction naturelle de la morale naturelle ", Ibid. p. 379 94 "L'homme est unité de corps et d'âme. Il est, par essence, rationnel. Or, l'opération naturelle doit répondre à la forme naturelle. L'aspect corporel de sa nature se révèle dans son devenir intentionnel par une triple nécessité, typiquement humaine : sa connaissance doit commencer par les sens; elle doit être obtenue par l'abstraction qui dématérialise la species sensible et elle doit se perfectionner par le discours : « componendo et dividendo». Donc, ce discours même doit, pour être vrai, procéder dans l'ordre et par l'ordre pour arriver à l'intellection de l'ordre, qui constitue la sagesse naturelle de l'homme. Il est donc conforme à l'essence de l'ordre réel, à l'être de la créature et à la nature de l'homme que l'homme acquière sa science en distinguant les ordres modaux", Ibid. p. 381

95 “nous retrouvons donc dans le domaine intentionnel la sanction naturelle de l'ordre violé. Qui néglige la distinction des ordres, s'éloigne du réel et détruit, pour autant qu'il est en lui, ce qu'il y a de plus beau dans l'univers, son ordre. En vertu du principe même de l'ordre il est donc inévitable que le procédé cognitif qui viole cet ordre (soit par la désobéissance aux données sensibles, soit par la confusion des ordres modaux) trouve sa sanction naturelle en lui-même, il manque la science qui est perfection. Dans l'ordre intentionnel cette sanction naturelle se nomme erreur. Celui-là tombe dans l'erreur qui néglige l'expérience ou méprise la distinction des ordres", Ibid.
} 
result from this error of appreciating true means that confirm the intrinsic natural order for Man is the very one that is called insecurity.

By going against his intrinsic order, the human being goes against himself. Now an order that turns against itself is progressively cancelled out until its final extinction. Thus the ultimate sanction for something that is not confirmed in what it is, is to be reduced to "nothing"; from state to nullity; from real to unreal, from security to insecurity. This is straight observed for inanimate things. For an animate being such as human being, it is observed progressively if the necessary order of means is not used.

The order of means that confirms the intrinsic state of human security is therefore also a necessary order that can be discovered through experience. It is experience that ultimately clarifies it.

\subsection{Human Security, Order of Means and Experience}

Human security, as a law of nature, implies, by virtue of its permanence, that it should be just as permanently confirmed. It therefore includes an order of adequate means. Yet it is clear that human beings are more or less ignorant of this order. They can then only learn it by experience. To understand it well is to situate ourselves on the perspective of the philosophy of history (2.2.1) which gives us another understanding of the relationship between a natural law and time (2.2.2).

\subsubsection{Human security, as a law of nature and the philosophy of history}

History is perhaps the phenomenon that best captures the process of order of means that adequately confirms the intrinsic state of human security. History is inescapable, through the phenomenon of experimentation that it frames or manages or enables. According to the Glossary of Psychotherapy, the "principle of experimentation consists in physically experiencing for oneself the truthfulness of a proposition, always established in relation to the current situation". To experience means to test, to try out, to feel. It is about having experience, that is to say, having personally gone through situations and having drawn from these singular, strictly individual events or personal wisdom. This falls within the realm of subjectivity and the process of subjectivation. Becoming oneself then means deducing oneself from one's own experience which has finally been integrated. ${ }^{96}$

\footnotetext{
${ }^{96}$ Glossaire de la Psychothérapie, Centre Interdisciplinaire de formation à la Psychothérapie Relationnelle, CIFPR Paris/Aix Marseille, http://cifpr.fr/expérentiel
} 
The phenomenon of experimentation is a good reflection of the phenomenon taking place as confirmation of human security, as a law. Since it is necessary for every human being that this state be permanent, the best way to confirm it becomes clear through the results of the lived experience of confirmation or non-confirmation, which is ultimately only a consequence of the use of Man's ontological freedom. Generally, it is a test and its results that are felt as the consequences of the means used to confirm oneself in the intrinsic state of human security. Then, if the state of security is confirmed, the means used can be evaluated as good, otherwise they are evaluated as bad and therefore null because a null consequence can only have a null cause from the point of view of an irrefutable law. In reality, things are not so simple.

Let us consider breathing once more, especially the individual who finds himself in environments where the breathing air is differently constituted on the atomic level. Let's assume, in addition to the above-mentioned environments, another environment that is interposed on the chain and that is constituted of an atomic composition that includes oxygen and a substance that is harmful to human organism, but is not immediately detectable, so that the environment appears to be constituted only of oxygen. However, this compound is a mixture that has lethal consequences in the short or long term. For this individual who would be subjected to the experience of being in these different environments in turn, it is clear that in contact with the environments E1: sulfur, E2: nitrogen, E3: helium, this individual feels the immediate need to get out because the consequence on his organism is immediate. At the exit of E3 for E4: oxygen + subtle harmful substance, it is highly probable, given the orderly situation of the environments, that this experimenter believes that this environment is conducive to his natural breathing conditions and therefore that it is necessary for him to stay there. Even if he would not have been in contact with the E5: Oxygen environment, it is unlikely that he would immediately go there. Given that deprived of oxygen in the three previous environments, his need for oxygen would be stronger and stronger, and, that finding himself in E4, which would be felt to be favorable, since it would first be a question of survival, it would first be necessary for him to stay there and recover. He could only embark on the experience of E5 having recovered and on the basis of a curiosity of experimentation, quite rare moreover in survival situations and with regard to the apparently pleasant situation in which he would find himself, and if he was not convinced that E5 would surely be harmful like E1, E2, and E3. But what would be sure is that the environment is harmful for him and the consequences are inevitably felt. When these consequences would occur, at that moment, the experimenter would know that the environment was bad for his breathing. He would then have unknowingly 
opposed himself to a progressive nullity, and because of the duration of this exposure (depending on the effect of the atomic composition), it gradually goes extinct until it is complete. Thus the atomic conditions of respiration would apparently have confirmed the real breathing nature of this experimenter. In the end, through consequence and from the very beginning, through the law of breathing of the human being, it was nothing. The experimenter would therefore not have confirmed himself in his nature.

This example allows us to understand the human experience of confirmation implied by human security as a law of nature. This one necessarily requires a proper order of means. The confirmation of the intrinsic state is pleasant if this order is known by Man, who, otherwise, learns it from experience. This can be summed up in the set of consequences on his intrinsic natural state. Human security has been understood as a state of well-being that embodies the natural physical-rational human order. This state characterizes the real human order and Man cannot be in another state without continuing to be himself. This is the situation to which he tends when he is not confirmed in what he is. Such a situation faced as nullity, what is called insecurity is inadmissible for the animate being who he is. It is urgent that he comes out of it, and it is generally through a permanent test on himself to know the order of adequate means. When these means are known, he makes effort to maintain them. If he has been confronted with the illusion of adequacy of the means used, he uses them, until the deception becomes obvious. If he does not capitalize sufficiently on his experience, it is possible that he will oppose himself to a nullity that he is not for real.

This is the substance of the philosophy of history of Immanuel Kant. Indeed, history has a very important value in Immanuel Kant's philosophy. It is indeed through it that Man achieves his natural end. "Thus philosophy of history plays a decisive role in the elaboration of the system of critical philosophy. It gives meaning to the contingent development of human affairs and demonstrates the practical effectiveness of freedom, that is, its ability as a "causa noumenon" to produce effects in the empirical world. Viewed from the angle of progress, history is charged with providing signs of Man's moral improvement. From this point of view, the intelligibility of history is revealed in its teleological sequence, that is, in the necessary linkage of actions that make it up with the advent of the final goal they make possible. In this case, the aim of a coherent reading of history is the systematic unity of the totality of human actions. However, historical development can only appear as a whole if we adopt an impartial and disinterested point of 
view: that of the spectator." 97 Thus the philosophy of history presupposes that Man inevitably moves towards the achievement of the end (moral freedom), understood as the moral perfection that nature has assigned to him. Man's moral fulfillment is thus the final cause of human nature. Since all that exists in nature exists only for a specific purpose, history then proves to be the revelator of the progression towards its finality. "Halfway between nature and morality, history has the mandate to present, in the manner of a diagram, the "signs" of a moral progress of the human species and thus to testify inscription of freedom within nature". 98

In the Kantian logic, the philosophy of history, "seeks how empirical and natural teleology fits with practical teleology, that is, how the idea of good and nature fit together". ${ }^{99}$ History is therefore an indicator that provides information on the (state of) adequacy of nature or the world to the final cause, the supreme good. The supreme goal of morality is then to be realized in nature. From this point of view, it must be said that the idea of supreme good, which in the Kantian sense refers to an a priori, has not yet been realized. Since, however, everything exists for an end, this a priori ends up being realized in an inescapable way: "there are pure practical principles by which reason is a priori determined, and which therefore a priori give it its end, and the whole teleology, empiricism included, finds a foundation in the idea of supreme good. It is so founded on moral and consists in thinking the agreement of nature and freedom"100.

History in Kantian philosophy can be likened to a process that informs Man on the level of progress he has reached in the ultimate goal of realizing his nature. This could be understood as a mirror. Indeed, the function of a mirror is to reflect or send back the reality to he who uses it. It allows him to know how he looks and thus ultimately to be aware of his appearance. It is

97 "Ainsi la philosophie de l'histoire joue-t-elle un role déterminant dans l'élaboration du système de la philosophie critique. Elle permet de donner un sens au développement contingent des affaires humaines et démontre l'efficacité pratique de la liberté, c'est-à-dire son aptitude en tant que causa noumenon à produire des effets dans le monde empirique. Envisagée sous l'angle du progrès, l'histoire est chargée de fournir les signes d'une amélioration morale de l'homme. Dans cette optique, l'intelligibilité de l'histoire se révèle dans son enchainement téléologique c'est-à-dire dans la liaison nécessaire des actions qui la composent avec l'avènement du but final qu'elles rendent possibles. Dans ce cas, ce que vise, une lecture cohérente de l'histoire, c'est l'unité systématique de la totalité des actions humaines. Cependant le développement historique ne peut apparaitre comme un tout que si l'on adopte à son égard un point de vue impartial désintéressé : celui du spectateur", M. MORAIS, "La vocation pédagogique de l'histoire chez Kant et son horizon cosmopolitique", Archives de Philosophie, Tome 66, n4, 2003, p. 630

98 Ibid.

99 "cherche comment la téléologie empirique et naturelle s'accorde avec la téléologie pratique, c'est-à-dire comment l'idée du bien et la nature s'accordent (...)", J.-M MUGLIONI, "Le principe téléologique de la philosophie kantienne de l'histoire", Revuegermanique internationale [En ligne], n61, 1996, URL : http://rgi.revues.org/585, p. 8

100 "Il y a des principes purs pratiques par lesquels la raison est déterminée a priori, et qui donc lui donnent a priori sa fin, et toute la téléologie, l'empirique comprise, trouve dans l'idée de bien suprême un fondement. Elle est ainsi fondée sur la morale et consiste à penser l'accord de la nature et de la liberté”, Ibid. p. 7 
generally after looking at oneself that one sees the defects which are present or not and that one undertakes or not to correct them. Nature, which represents this scene or the ground on which Man acts, then informs him about his current moral state. And history represents both this constant work of improving reality and the stages of the journey that human beings reach in accordance with the final cause which refers to the Supreme Good. It is easy to understand why the latter is not just a vain a priori. It is only possible for the latter to pose itself as the Man's ultimate reference point in this process because it refers to the intrinsic natural order of human nature. Natural order is already a reality, the one which, known or unknown, is the meaning of all human action. Thus it is presumed that Man does not stop in this process until nature is a concretization of this supreme good. This would then mean that it will reflect the true moral state of Man, which is his real nature, that which is his natural law. This idea emerges from critical philosophy. We take the liberty here of transcribing at length J. M. Muglioni: "The whole of critical philosophy consists in this movement which goes from pure interiority to the world; and through this very movement it understands that whenever men have believed that they have found meaning in the world, it is from themselves that the light has shown it to them; Auguste Comte is therefore a worthy successor of Kant. But let us make it clear: philosophers believed they saw the brilliance of nature shining from it, which nevertheless only reflected the moral light coming from their hearts. (...) That experience shows us organized beings and an ordered nature irreducible to the mechanism, is a necessary condition for the exercise of reason, which otherwise would not discover in itself its teleological principles. But the supreme teleological principle is not empirically conditioned, it is reason itself. The empirical nature, as it is given, is a school without which reason, as the faculty of ends, would not discover itself: the natural end revealed by experience is our obligatory starting point. But the discovery of the ending is from this beginning ordered by a teleological and practical principle a priori, that is to say, by freedom. (...) The obligation of moral law remains even if we do not know how the nature of things agrees or disagrees with it. Moral certainty does not derive from teleological considerations about the world and its course; on the contrary, these considerations derive from our practical conviction, which extends itself, so to speak, into it, strengthen itself in it, and thus finds by reflecting itself in nature and even in history, its own confirmation" ${ }^{101}$.

\footnotetext{
101 "Toute la philosophie critique consiste dans ce mouvement qui va de l'intériorité pure au monde ; et par ce mouvement même elle comprend que chaque fois que les hommes ont cru trouver le sens dans le monde, c'est d'eux-mêmes que venait la lumière qui le leur a montré ; Auguste Comte est donc un digne successeur de Kant. Mais précisons : les philosophes croyaient voir l'éclat dont brille la nature venir d'elle qui ne faisait pourtant que réfléchir la lumière morale venue de leur cour. (...) Que l'expérience nous montre des êtres organisés et une nature ordonnée irréductibles au mécanisme, c'est une condition nécessaire de l'exercice de la raison qui sans cela ne découvrirait pas en elle-même ses principes téléologiques. Mais le principe téléologique suprême n'est pas
} 
With regard to human security, as a law of nature, the philosophy of history makes some definite points. The a priori which represents the Supreme Good that is the final cause of rational human nature is what we understand to be the state of human security, the essential principle of the intrinsic human order. If for Kant it is not yet realized and is the ultimate unavoidable end, it constitutes, in our view, a state that is very real, so that it is no longer to be realized but confirmed. We share the Kantian sense of history in that it focuses on the historical experimentation in which Man involves himself in his natural necessity to confirm the intrinsic state that befits his nature. The order of adequate means necessarily implied by this confirmation is either known or unveiled as a result of the means used, which either confirms him in this essential state or opposes him a nullity that he is not, what is intolerable and what obliges him to find means that confirm him in this state which is ultimately his reality. What we can be certain of is that false means, that is to say, those whose result is not the confirmation of the state of intrinsic security, whether their effects are immediate or mediate, will end up knowing themselves to be null and void. Thus until he becomes full educated to this order of means, the human being will probably oppose to himself, not what he is (state of security) but a nullity that represents what he is not (insecurity) and that he would never be without continuing to be what he is. In this natural process grounded on his ontological freedom, the means that confirm him will be known as the order of means and those that do not will be known as null and void. On the other hand, other means will be tested and that will progressively reveal the order of means that the natural law of human security necessarily implies. Thus history will confirm its immutability, which will allow another understanding of time.

\subsubsection{The law of human security and Time}

When considering human security as a law of nature from a purely essentialist perspective, we are prompted to highlight the notion of time it its new dimension. Indeed, we have noted that it includes both a finite order and a final order. For an animate nature such as human nature, this no longer implies realization but confirmation or conservation. It is then a question of confirming a reality in its permanence. The order of necessary means implied by the adequacy of the foundation and the end constituted by the law of security is known, for its part, through

conditionné empiriquement, il est la raison même. La nature empirique, telle qu'elle est donnée, est une école sans laquelle la raison, faculté des fins, ne se découvrirait pas elle-même : la finalité naturelle révélée par l'expérience est notre point de départ obligé. Mais la découverte de la finalité est dès ce commencement commandée par un principe téléologique et pratique a priori, c'est-à-dire par la liberté. (...) L'obligation de la loi morale demeure même si nous ignorons la manière dont la nature des choses s'accorde ou non avec elle. La certitude morale ne découle pas de considérations téléologiques sur le monde et son cours, au contraire ces considérations procèdent de notre conviction pratique qui s'y prolonge pour ainsi dire elle-même, s'y renforce et trouve ainsi en se réfléchissant dans la nature et même dans l'histoire, sa propre confirmation ", Ibid. p. 9 
experience. History has been evoked as the best account of this experiential process. Yet the concept of time is inscribed at the heart of the notion of history. Time is past, present and future. The question that then arises in this context is what is the relationship that an immutable law, which no longer implies realization because already real, but rather perpetual confirmation of this permanence, would sustain with time?

The historical process of discovering the order of means to confirm the permanence of the intrinsic order of human nature has the purpose of establishing the inexistence of time with regard to a law of nature. If, in fact, a law of nature never changes, then we cannot say of it that "it was" because it continues to be, and we cannot say of it that "it will be" because it is already. Thus this law is real in the past, in the present and in the future, and therefore from its point of view, time is only the present. There is only an eternal present as far as it is concerned. Let us consider the example of water in the light of New Essentialism. Water is real only in the atomic constitution $\mathrm{H} 2 \mathrm{O}$. This was true before it was discovered by human beings. It continues to be true after it is discovered by Man. So water is water in this essential constitution yesterday (in the past), today (in the present) and tomorrow (in the future). So a law of nature is an eternal law, as far as it is concerned, time does not exist, at least there is only an eternal present. This is what justifies the principle of necessity and identity: a thing being only what it is, it cannot be otherwise without continuing to be what it is. In a word, it is eternal in what it is. Now for a thing that is eternally the same, time does not exist.

This is precisely the postulate implied by Human Security. From an essentialist point of view, it is a law of nature. It is at the same time the foundation and finality of human nature. This is equivalent to saying that it is an eternal law or that it is of an eternal present. So since this is the case, how else can we understand the historical process of knowing the order of means that human security, as a law of nature necessarily implies? The problem of "atemporality" concerns mainly, if not exclusively, things that are the object of study. We speak of "atemporality" for the atomic constitution of water, we speak of atemporality for the state of human security. These are the most essential properties of the things we are focusing on, that is, water, human nature. Agreeing with Essentialism that only dispositional properties account for the real nature of things, for their identity, we have discovered that just as water is water only in $\mathrm{H} 2 \mathrm{O}$, human nature is human nature only in the state of security that is consubstantial with it. And this state is an eternal present. At first glance, this seems to be an incantation based on the changing nature of man, according to the different age categories from childhood to old age. How could he be unchanging by changing? We have noted that the state of human security is a state whose 
need for confirmation imposes itself on human nature, whatever its actual particularity. The child, the adult, the old, whatever their genetic quotient, their race, their cultural background, they all summed up in this state of security intrinsic to their physical-rational nature. Their seemingly particular and different natural states, however, demand this objective natural state in the same way. None of them is happy to face nullity (insecurity), but all of them are happy to confirm the security that corresponds to the reality of their nature. And all of them demand it constantly and perpetually.

If disorder whose consequence is the inadequacy of the foundation and finality intends to oppose a nullity to a state which intends to be permanent, then extinction means that the appropriate means have not been used to confirm that state in its permanent present. Let us observe this carefully. The extinction of man by death is always the saturation point of a nullity that is opposed to the state he is. As such, the more one opposes a nullity to a thing, instead of confirming it in its real state, the sooner it progressively gets extinct. We have seen that the adequate means of confirming the state can inform us about their reality, either immediately or mediately. A practical example would be that of an experimenter who breathes air composed of oxygen mixed with an atom that is toxic for breathing but whose effect is subtle enough to be detected. The consequence of this means, which is a progressive extinction, makes us realize in the end that it is null in relation to the breathing nature of the human being who therefore needs to confirm itself just with a certain thing; in this case only oxygen. Thus, if the consequence of a means confirming the intrinsic state of human security is the mediate or immediate extinction of the human being, it is clear that it does not fall within the order of necessary means to confirming the intrinsic state of human security. This presupposes that, given the timelessness of human security, as a law of nature, if the order of ends is confirmed by the order of adequate means, there would be no extinction, and therefore death that represents this extinction, would become an avoidable accident. As a matter of fact, since nothing can continue to be what it is by being otherwise, human nature cannot continue to be when it is no longer definitively confirmed in what it is. When it becomes something other than in a state of intrinsic security, it simply no longer is, just like water is no longer $\mathrm{H} 2 \mathrm{O}$ when it becomes something else, for example HXY. In fact, it does not even become otherwise. Just as it cannot be said that water becomes HXY, because HXY is not $\mathrm{H} 2 \mathrm{O}$, human nature cannot be otherwise than in a state of intrinsic security. Since it is not possible for it to become something else, it is simply no longer. This is well exemplified by the principle of necessity. 
Human nature is thus involved in an apparent temporality. Temporality is only signified by the experimentation in which Man is constantly involving himself for the knowledge of the order of necessary means to confirm the state of security which represents the essential order of his nature. Thus we have to agree with the Bernard Piettre's observation that, "Universe becomes what it is". From that, we can deduce that human nature becomes what it is. This is the conclusion Helmut Kuhn comes to when he considers things on a macro level, however: "Let us think of a multiplicity of substantial beings whose being consists in their efficiency or actuality and which are ordered together and interwoven into each other in a totality structurally composed of degrees. Without harming the diversity of structure of these beings, according to the level of order in which they find themselves at present, they have among themselves this in common: they are all moved in their way of living by the imperative: suum esse conservare. And, for each of them, the instinct of conservation is at the same time a principle of evolution. The ontological imperative that we have just named is inseparable from a second, evolutionary imperative: Become what you are! Now the all-encompassing totality of beings, that we call "world", is also the supreme example of an order as intense as it is rich, so that the activity that underlies the imperatives "become yourself" "conserve yourself" is at the same time the basis for harmonious cooperation within the great community of the world's beings. There is harmony between the conservation and actualization of the world and the "becoming yourself" of the beings who make it up. The being who becomes completely himself accomplishes precisely in this way the function that the order has assigned to him in the whole. To the authenticity of the being, inseparably corresponds the rank he occupies within the order. Of course, this scheme of order will only be valid as a scheme of the world if it takes into account the imperfection of the world. There can and must be room both for disorder and for the destruction of the beings of the world. But these negative moments, and the suffering they cause, must become intelligible within this scheme as the tribute that must be paid for the actualization of the whole". ${ }^{102}$

Human nature thus becomes what it is through the experiential process (historical or temporal) of education to the order of means by which he confirms his intrinsic permanent state. The ideas of imperfection of the world, disorder, suffering, refer to the results of this process marking the inadequacy of the order of necessary means for the confirmation of the order of ends. The consequent nullity becomes intelligible in that it unveils progressively, in one way or another, the order of adequate means. The inevitable result is the adequacy of the order of means to the

${ }^{102}$ H. KUHN, op. cit. p. 259 
order of ends. This should equally lead to a timeless confirmation of the state of intrinsic security. Let us look at this again!

The logic "becomes what you are" can be understood as follows: Before embarking on the process of becoming, there is one inescapable prerequisite: to already be. A nullity or "nothing" cannot start any process. But he who is already is precisely what makes him what he is. And that is what he is at present and above all. It is the present (time). Then the process characterized by "becoming", referring here to experience (history) translates a future in the sense of what is coming or what will come and then the future (time). Finally, "what you are" which is the purpose or the finality of the process is still the being, as he is from the beginning. If the purpose or finality had been another being, then the rule would be "Become another being". Which is obviously not anymore the same. So if we schematize we have:

Being (present) $\Longrightarrow$ Becoming (future) $\Longrightarrow$ Being (present).

What allows us to reformulate: "the Being becomes what he is". The future or what is to come, finding itself in the enclosure of the present, it can only be a false future which is rather reduced to the present. From that, the present having the present as its end or finality, we are led to the reformulation: "you are what you are". For Man "who is what he is" (principle of necessity), based on his nature of animate being, necessarily governed by the principle of confirmation, the imperative "become what you are" addressed to him ultimately results in "be what you are". But since he is already what he is (Finite order) how else can this be envisaged, if not by "confirm (that you are (in)) what you are"? (Final order). Finally, it is to the witnessing or conservation of himself, in his intrinsic identity (state of human security) to which Man is called.

The temporality of the historical process of knowledge of the order of means is therefore conceivable only within the framework of the characteristic timelessness intrinsic order of the thing. Therefore and ultimately, time is only in the present, history is only in the present. It is therefore an eternal present. This is well confirmed by the immutability characteristic displayed by human security, as a law of nature.

Finally, considerations of time in relation to the law of human security harmonize the ontological order of ends and the epistemological order of means, so as to testify human security, as being worth a law of nature. 


\section{CONCLUSION OF CHAPTER I}

As conclusion to this chapter, human security as a law of human nature has been tested through the essentialism approach, in a harmonious manner, in its traditional and modern variants. Modern or Scientific Essentialism, as developed by B. Ellis, has made it possible to verify human security as an intrinsic state or dispositional property of human nature. The law of human security was then detailed into a finite or finite order that was no longer to be realized, since it was already real. Thus, it satisfied the requirements of a law of nature, including metaphysical necessity, ideality, structuring and scientific objectivity. Standing as a finite order, human security include also a final order, starting from the final cause developed by traditional or Aristotelian essentialism. The final order gives a good account of the animate nature of man, which demands confirmation of what he is. It is the teleology of human nature, confirming the permanent state of human security which is its intrinsic order. This is done on the basis of freedom, which is an ontological attribute of human nature. Through this ontological requirement of confirmation, Human security, as a law of nature, necessarily implies an order of means. Therefore, the use of adequate means should confirm the sameness of the foundation and finality (state of human security). The use of bad means must necessarily oppose intolerable nullity to man; which also requires the use of adequate means of confirmation. Knowledge of the order of means is thus the object of an experiential (historical) process of progressive keeping of acquired knowledge. At the end of this process, it is envisaged that Man become what he is. By establishing the timelessness of human security, as a law of nature, and so attesting its immutability, this consequence confirms the ontological and epistemological harmony within it. It is therefore an authentic law of nature. Consequently, human security asserts itself as the law of politics. 


\section{CHAPTER II: HUMAN SECURITY: LAW OF NATURE OF POLITICAL SOCIETY}

Human security, as law of human nature, accounts for the natural human order. Thus, as we have seen in the previous chapter, it is the foundation and finality of Man's action, since this one is only justified in order to maintain itself in this state. It is in this logic that political society works. Relying on human security as the general law of political society requires that the link between human security and political society be made clear. In our view, this link is only established on the basis of three kinds of inclusive natural realities: the individual necessity of conservation, the multitude of individuals, and the need for nature's resources for conservation. Thus, humans are obliged to conserve themselves in the presence of a multitude of fellow human beings through the use of nature's resources. Based on these three natural requirements, human security as the law of human nature automatically implies that human security is the law of nature of political society, that is to say, its foundation and finality. They allow to postulate, in the sense of Aristotle, that man is naturally a political animal. We will explain the meaning of this postulate by referring to Aristotle's conception, but by considering it in the sense of a logical implication of human security as a law of nature, as elaborated in the previous chapter. In other words, we will conceive the political animality of man according to the requirements of human security, as a law of nature, which will sometimes imply a demarcation from the Aristotelian position and the recourse, when necessary, to reasoning by hypothesis to enable us to better grasp this reality. Thus, human security as the law of politics implies conceiving Man's political animality progressively from a natural nature (1.1) to a cultural nature (1.2). We will clarify the meaning of these concepts.

\section{THE HUMAN POLITICAL ANIMALITY: A NATURAL NATURE}

The political animality of man as a natural nature is an implication of human security as a law of human nature. The concept of "natural nature" means that the natural human order as human security accounts for it, is a reality or a state of affairs that is no longer to be realized but confirmed in view of its vocation to permanence. In this logic, the natural order and the human experience are more or less in phase. We shall bring this out by dwelling on two substances: the substance of the law of nature in itself (1.1) and the substance of Man's understanding of that law of nature (1.2). 


\subsection{Substance of Human Security as Law of nature of Political Society}

Testing human security as law of nature of political society by accounting for man's political animality as a natural nature, is undertaken as a logical implication of human security as a law of human nature (1.1) and by the fact of the embryonic society that constitutes the family (1.2).

\subsubsection{Human security as law of nature of political society: a logical implication of human security as a law of human nature}

Human security, as we have seen, is the state that is consubstantial with human nature. It is the essential disposition of human nature, accounting for the natural human order. This state of well-being, since it is already real, does no longer need to be realized, but confirmed or conserved because of its vocation to permanence. Human security, as a law of human nature, constitutes the foundation and purpose or end of all human action.

Human security, as a finite order of human nature, is confirmed only based on an order of means that the being discovers through the historical process of experimentation, which reveals the worth of confirming initiatives through their positive or negative consequences. This process is supposed to lead to the knowledge of the order of adequate means. Thus, according to Johann Gustav Droysen, "Undoubtedly we only understand completely that which is, when we recognize and make clear to ourselves how it came to be. But how it came to be, we recognize only if we investigate and understand, as exactly as possible, how it is. Our grasping that which came to be and comprehending its becoming is only one form and expression of our understanding of the present and existing can be derived only by temporally conceiving and analysing the existing in order to understand it"103

It is therefore legitimate to think that nature is a real order whose confirmation is possible through means just as real as it conceals, but up to the understanding or discovery of which human nature gradually comes. In this way Cicero asserted: "True law is right reason conformable to nature, universal, unchangeable, eternal, whose commands urge us to duty, and whose prohibitions restrain us from evil. Whether it enjoins or forbids, the good respect its injunctions, and the wicked treat them with indifference. This law cannot be contradicted by any other law, and is not liable either to derogation or abrogation. Neither the senate nor the people can give us any dispensation for not obeying this universal law of justice. It needs no

${ }^{103}$ H. BARTH, The Idea of Order, Contributions to a Philosophy of Politics, D. Reidel Publishing Company, Dordrecht-Holland, 1960, p. 1 
other expositor and interpreter than our own conscience. It is not one thing in Rome and another at Athens, one thing today and another tomorrow, but in all times and nations this universal law must forever reign, eternal and imperishable. It is the sovereign master and emperor of all beings. God himself is its author, its promulgator, its enforcer. And he who does not obey it flies from himself and does violence to the very nature of man. And by so doing he will endure the severest penalties even if he avoids the other evils which are usually accounted punishment."

Then, what is the relationship with political society?

The link between human security and political society is raised in consideration of two other equally natural requirements which conservation is undertaken with: conservation is made, among other things, through resources of nature and in the presence of a multitude of human beings. These two realities make the law of human security the law of political society.

Human security is the essential disposition of human nature, which happens to be twodimensional in its unity: a rational dimension and a physical dimension. Immanuel Kant expresses it in both the animal and the rational side. ${ }^{105}$ "The animal nature is the mechanical, impulse oriented side of human nature. It seeks the preservation of the self with the goal of maximizing personal pleasure and minimizing pain. In other words, the animal nature is based on sensuous impulses"106 The physical nature of the human being is conserved based on the resources of the physical nature surrounding him. He is taking everything he needs from it for food, health, shelter and clothing.

The human being is also called to share his life with a multitude of other human beings. Indeed, it is a fact of nature that the human being is not alone. The very conditions of his birth show that he is the fruit of a man and a woman who have been endowed by nature with dispositions enabling them to reproduce or to be perennial or simply to multiply. So whatever the real or hypothetical nature of the origin, including the spatial configuration, of the multitude of human beings populating earth, the multitude itself is an undeniable reality. The individual confirmation of the intrinsic state of human security for many individuals through resources of nature has therefore been provided for by nature itself. Since nature is an order and therefore

\footnotetext{
${ }^{104}$ C. F. ALFORD, Narrative, Nature, and the Natural Law. From Aquinas to International Human Rights, Palgrave Macmillan, New York, 2010, p. 22

105 C. J. FRIEDRICH (Ed.), The Philosophy of Kant: Moral and Political Writings, The Modem Library, New York: 1949 , p. 373

${ }^{106}$ I. KANT, The Doctrine of Virtue, trans. M. J. GREGOR, Harper Torchbooks, New York: 1964, p.10
} 
does nothing in vain, ${ }^{107}$ it must be thought that it contains the code of means by which the multitude of cohabiting human beings can, through resources of physical nature, each confirm individually the intrinsic state to which they are subject to by nature. This code of means is precisely the one that can be known under the generic term "society". So, since human security stands as the law of human nature, then it becomes the law of nature of political society, understood as the means by which nature allows a set of cohabiting human beings to individually confirm the law to which it has reduced them and which is simply themselves. This code or order of means is therefore real in that without it, the confirmation of the law of human security for each individual cohabiting with others cannot be adequate.

According to its etymology, society comes from the Roman "societas" referring to association, community, company, meeting, political union, alliance. According to a simple definition, society is a structured and organized grouping of individuals, a group of people brought together by common interests or for a common activity or action. It is a group of people living in an organized and structured way through institutions and conventions. ${ }^{108}$ From this simple apprehension of society, an idea of understanding, agreement, organization or simply order clearly emerges. Hence it emerges that if human security represents the order of human nature, which is no longer to be realized but confirmed, it means the order of the human kind and therefore of all human beings who are part of the kind. Nature has thus united human beings around the same condition and the sum of their individual conservation interests makes a common interest of confirmation. So how can we think that nature could have subjected them to and governed them under a condition other than agreement? If nature is already an order in itself, the disorder that would result from misunderstanding or conflict cannot be imputed to it. Thus, society must be thought of or apprehended as essentially natural. It refers more to an understanding, an agreement, an order that governs human beings in the individual purpose of confirmation. And it is this order which is generally understood as "politics". It is generally agreed that the concept of politics comes from the Greek polis meaning "city", the latter being considered the basic unit of political organization in the Greco-Roman world. ${ }^{109}$ Thus, politics

\footnotetext{
107 J. B.-SAINT-HILAIRE, La Politique d'Aristote, Traduite en Français d'après le Texte Collationné sur Les Manuscrits et les Éditions Principales, Troisième Édition, Revue et Corrigée, Paris, Librairie Philosophique de Ladrange, 1874

${ }^{108}$ Dictionnaire Encarta, Microsoft ${ }^{\circledR}$ Encarta ${ }^{\circledR} 2009$. (C) 1993-2008 Microsoft Corporation

${ }^{109}$ D. ROBERTSON, The Routledge Dictionary of Politics, 3rd Ed. Taylor \& Francis Group, Routledge New Fetter Lane, London, New York, 2004, p. 382
} 
meant the art of governing the city or the State. ${ }^{110}$ More precisely, "Politics can be simply defined as the activity by which differing interests within a given unit of rule are conciliated by giving them a share in power in proportion to their importance to the welfare and survival of the whole community" 111.

It can therefore be concluded that since human security is the law of human nature, that is, the foundation and finality of all human action, it is therefore the law of nature political society, since the latter presupposes only a community of human beings united or consenting to an order or organization of their relations for the purpose of conservation of each one. This conclusion is logical for the reason that, nature being in itself an order, cannot foresee a multitude of human beings who cohabit and whom it subjects to confirmation of their essence without an order that governs them. Thus society which in itself signifies an understanding, an agreement between individuals for the purpose of conservation, embodies precisely the order of natural means that governs them and that constitutes politics. However, the exact content of this order should be clarified by experience.

Thus based on the substance of a law of nature or the natural state of affairs, the political animality of Man is first of all a natural nature, for, it does no longer require realization and is in force, whether or not the human being has reached this understanding, as opposed, as we shall see later, to its cultural nature, which, in turn, highlights this cognitive process of appropriation of the order of natural means. This natural nature can already be recognized in the reality of the family, which represents the primordial embryonic society.

\subsubsection{Family: the primordial embryonic political society}

Human security as law of nature of political society is still verified in the sense of the political animality of Man in the natural reality of the family. In fact, the family situates the beginning of Man's political animality and, because of its original character, accounts for it as a natural nature. Before knowing this a little more, let us begin by evoking certain apprehensions of the family.

According to Sébastien Bauer and Laurent Gerbier, in order to think about family, we must distinguish two elements that can alternatively found it: parentage and the community of

\footnotetext{
${ }^{110}$ E. RIMBOUX, "Politique", Grand Dictionnaire de la Philosophie, Edition numérique, Larousse, Bibliothèque Nationale de France, pour la bibliothèque numérique Gallica, 2003, p. 239 ; R. SCRUTON, "Politics", The Palgrave Macmillan Dictionary of Political Thought, 3rd Ed., Palgrave Macmillan, New York, 2007

111 R. SCRUTON, "Politics", The Palgrave Macmillan Dictionary of Political Thought, 3rd Ed., Palgrave Macmillan, New York, 2007, p. 550
} 
residence. Parentage emphasizes the dual phenomenon of sexual completeness and inheritance (the family ensures permanence over time); the community emphasizes rather the original cell of together living, oriented towards work (Latin people include slaves and seasonal workers), or towards the existence of a non-biological affinity between individuals (the humanistic familia will then designate the circle of familiar: friends). ${ }^{112}$ Based on these distinctions, moral and political thought has made family a constant paradigm of its thinking: family thus represents the origin of the political community. ${ }^{113}$ Finally, family is an indissolubly ethical and legal concept: ${ }^{114}$ the natural (biological) model and the conventional model (affinity or social necessity) of living together are articulated within it. These models suggest that family is the place where the transition from nature to culture takes place ${ }^{115}$ or as a social machine for managing desires. ${ }^{116}$

According to the first sense of parentage, family is presented as concomitant with the birth of Man. Every human being is born from a Man and a Woman and together they constitute a family. Family is therefore made up of at least three persons: the father, the mother and the child. Thus according to Aristotle, "First of all, there is necessity in the coming together of two beings who cannot anything without each other: I am referring to the union of the sexes for reproduction. And there is nothing arbitrary about this; for, in Man, as in other animals and plants, it is a natural desire to want to leave behind a being made in one's own image". ${ }^{117}$ Thus naturally man and woman are made to be together. They are naturally endowed with dispositions that enable them to reproduce their species and in so doing they constitute family. Thus family is the most natural association there is, for it is not even necessary for Man to discover it through a knowledge process. Man does not come to the conclusion, as a result of a process of experimentation, that he must belong to a family; the family is concomitant with his birth. "Thus, the natural association of every moment is family". ${ }^{118}$

In order for it to be the embryonic political society for the purposes of our present verification, there must be an order. Indeed, if women and men are inclined to unite naturally and form a family with children, it is clear that the purpose of this association is the conservation of all its members. It is only in this way that all can confirm the intrinsic state to which nature has

\footnotetext{
112 S. BAUER, L. GERBIER, "Famille”, in CNRS (Ed.), Grand Dictionnaire de la Philosophie, Larousse, Paris, 2003, pp. 1236-1237

113 Ibid.

${ }^{114}$ P. OURLIAC, J.-L. GAZZANIGA, Histoire du droit privé français, II, 4, Albin Michel, Paris, 1985

${ }^{115}$ Cl. Lévi-Strauss, Les structures élémentaires de la parenté, PUF, Paris, 1949

116 G. DELEUZE, F. GUATTARI, L'anti-CEdipe, Minuit, Paris, 1972

${ }^{117}$ J. B.-SAINT-HILAIRE, La Politique d'Aristote, op. cit. Book I, I. 4

${ }^{118}$ Ibid. Book I, I. 6
} 
subjected them to. How could it do so without consent, without agreement and finally without order? It must therefore be agreed that whatever the nature of relations between the members of a family, they are not governed by disorder, whose consequence is self-destruction of members, what is not natural, but they are governed by an order whose purpose is their conservation, what is natural. Thus the family natural association confirms that it is, according to nature, an order. In this natural institution, which must be described as an embryonic political society, members are in fact pursuing the confirmation of the law of their nature, which is security. And this is precisely the vocation of the larger forms of political society. For family, it is then said that Man's political animality is a natural nature to mean that the law of his nature and his life experience are perfectly match.

Having made these clarifications, it is necessary to return to certain elements of the definition of family which seem debatable. The family is perceived as articulating the natural or biological models and the conventional model (affinity or social necessity) of living together, these models suggesting that family is the place where the transition from nature to culture takes place or as a social machine for managing desires. Starting from the fact that human nature is in itself a state of affairs or an order that does not need to be realized any longer but confirmed, it is clear that the order of means to this purpose is already a reality of nature. Consequently, this order of means is also no longer to be created but to be discovered. Under this understanding, everything that concerns the human being is part of a logic of conformation to his nature. Thus, whatever the biological or conventional dimension of family, it remains within the natural framework. It is therefore not a question of the passage from nature to culture, but of a permanent nature whose quintessence is discovered through the cultural process.

Based on these considerations, human security as the law of human nature, is, therefore, the law of nature of political society which begins with and in the family. At this level it should be pointed out that although it is real in itself and at the primordial level of family, the order of means that embodies political society in its broad dimension may be more or less known to all human beings who are naturally subject to cohabitation. And this has consequences for confirmation. 


\subsection{The Substance of the understanding of human security as law of nature of political society}

Human nature is also rational and this implies that it is called to understand the natural order of means for confirming the law of its nature both individually and in cohabitation with a multitude of fellow human beings. The necessity of nature's resources for the conservation of human beings has a great influence on the economy of human understanding of this law. Indeed, it must be postulated that the availability or deficiency of these resources for a multitude of individuals necessarily determines how the situation is managed. Thus, the natural order of means which presupposes the best mode of confirmation of the law of human security for each individual of the multitude in such a situation can more or less be understood.

\subsubsection{The human understanding of security as law of nature of political society}

The understanding of human security as law of nature of political society by human beings can be achieved in close or distant family relationships. According to Aristotle, "The primary association of many families, but made up for the purpose of relationships that are no longer daily, is the village, which might well be called a natural colony of family; for individuals who make up the village have, as other writers have put it, "sucked the milk of the family"; they are its children and "children of its children's". If the first states were subject to kings and if the great nations are still subject to kings today, it is because these states were made up by elements accustomed to royal authority, since in the family the oldest is a true king; and the family's colonies filially followed the example given to them. Homer was therefore able to say: "Each one of them governs his own wives and sons." At the beginning, in fact, all isolated families governed themselves in this way. Hence again the common opinion subjecting gods to a king; for all peoples once recognized or still recognize the royal authority and men have never failed to give their customs to gods, just as they represent them in their own image". ${ }^{119}$

The fact of postulating the final political society - which is currently the state from its family oriented village - implies the existence of an affective or family relationship between members of the state. Indeed, as we have seen, family members are inclined to a natural bond of solidarity, wherein affection is certainly the foundation. How can we think otherwise? Let us imagine that the bond between members of a family is hatred or simply indifference. In the hypothesis of

119 J. B.-SAINT-HILAIRE, La Politique d'Aristote, op. cit. Book I, I. 7 
hatred, the relationship between family members would certainly be one of hostility, the consequence of which would certainly be their self-destruction. In the hypothesis of indifference between family members, the relationship would be individualistic, since each would be turned towards managing his or her own affairs, which would certainly be evidence of a lack of union, agreement and therefore disorder leading to the separation of family members. These hypotheses cannot therefore be proven by the fact that their results would lead to denying family in its natural essence. Knowing that family is a natural reality and that the individual is inclined to conserve himself for the sake of the permanence of his nature, it is necessary to postulate that an affective solidarity between members of family is part of this logic, because it works towards this purpose or this end.

Thus, according to Aristotle's understanding, the finite political society that is the State is logically based on affective solidarity, because in fact it would constitute family on a somewhat larger scale. What is certain is that this affection would have its source in filiation that naturally unites the members of family. Viewed that way, we could believe that the understanding of the order of means that should confirm human security for everyone is proven.

How can we therefore consider the issue of the resources of nature? Indeed, in the hypothesis that these resources are available to all members of the group, one must ask oneself what would be the usefulness for a family group to organize itself. Individuals gather around a political society to solve or organize the management of a situation of general interest. There can only be politics if individuals find themselves confronted with a problem that needs to be solved by mutual agreement. Aristotle acknowledges this himself when he states that political society is established for the satisfaction of needs: "Association of several villages constitutes a complete state, reached, one can say, at this point of being absolutely self-sufficient, born first of all from the needs of life, and subsisting because it satisfies them all" ${ }^{120}$ So, in a situation of sufficient resources for all families, there would be no additional need to organize because all would be sufficient. In this hypothesis and in the Aristotelian logic, political society could not be the object of a decree but of something natural, a simple sum of villages united by filiation. Even the title of king or any other denomination of chief would have no political value, that is, the authority responsible for ordering relations between members of the extended family. This title would then be rather honorary. But it should also be considered that if resources of nature are sufficient for all families and although they would maintain emotional ties, the need for

\footnotetext{
${ }^{120}$ Ibid. Book I, I. 8
} 
reproduction should be considered, which would force the members of various families to look for partners outside their family or at least the nuclear one. This must be noted because it is a situation that would certainly require agreement between families and an authority responsible for managing disputes. This case implies an organisation between families that is much more demanding than the simple emotional solidarity unifying them. Thus a head would be responsible for ensuring order within this extended family. It is only in such a configuration, in the absence of a deficiency of nature's resources, that a group of villages would be a political society in a strict sense, since it would embody the order that should govern relations between the members, necessarily for the purpose of confirming the intrinsic state of human security as the order of their nature.

In the hypothesis of difficulties to enjoy resources of nature, due to their deficiency or the impossibility of their acquisition by a single family, families or villages should necessarily organize themselves. If resources are deficient for all, each one wishing to appropriate them for its own conservation, the management of this situation would be based on the choice between two alternatives: conflict or agreement. Being members of the same family, it should be borne in mind that the family link between them is likely to influence the option for an agreement. This order would be political in that it would consist in the manifestation of an organization for the general conservation interest of all members. In the hypothesis of difficulty in the acquisition of resources by a single family, all can agree to overcome the difficulty together. The resulting order would then govern a situation of general interest, which would certainly include guarantees that the agreement would be respected. Thus Aristotle thought that "Every state is obviously an association and every association is made up for the sole purpose of any good, since men, whoever they may be, never do anything but what seems good to them. Obviously all associations are concerned with a good of a certain kind, and the most important of all goods must be the object of the most important of associations, the one that contains all the others; and this one is precisely called State and political association". ${ }^{121}$

All these developments allow us to know that the understanding of human security as law of nature of political society can be proven if it is derived from family relationships underpinned by affectionate solidarity. Affection between members strongly influences and facilitates the understanding that the order of means confirming the intrinsic state of human security is based on understanding or agreement between members when they face natural challenges. Even without having a proper declination of this order, we, at least, know that we are in the sense of

\footnotetext{
${ }^{121}$ Ibid. Book I, I. 1
} 
a conformation to nature that cannot foresee cohabitation of a multitude of human beings and subject them to an imperative of confirming the law of their nature based on disorder. If this understanding can be facilitated in Aristotle's hypothesis, demonstrating Man's political animality in the hypotheses of other scholars is not the case.

\subsubsection{The possible misunderstanding of human security as law of nature of political society}

The understanding of human security as law of nature of political society may not be understood by human beings under certain circumstances that need to be addressed. The obvious consequence of that is the risk that human security may not be confirmed at the individual level. Although we have noted that family constitutes the embryonic political society, it is possible to envisage situations in which filiation between families or village members is, if not nonexistent, so remote or distant or indirect as to become insignificant in the daily lives of individuals. It is opportune to note this situation in view of the configuration of present-day societies which, even if they were based on filiation, their current heterogeneous and composite nature raises the question of politics in a more objective way. Thus it is necessary to formulate hypothesis adapted to this situation in order to give a better account of man's political animality, but in the sense of a natural nature misunderstood by human beings.

Political society certainly began with family. Let us take the hypothesis of several families or several villages which, in the sense of Aristotle, would constitute society, but which would not be united by a parentage bond and which would be subject to the imperative of cohabitation and confronted with difficulties in acquiring resources of nature. In such a hypothesis, the different families or villages would have the choice between the two alternatives, which are conflict and agreement. Since the different protagonists are not united by a bond of parentage or identity that would automatically lead to managing the situation on an affective basis, it is doubtful that they would come to an agreement all the way. If they do have this idea, it would still be necessary to know what reasons would lead them to such a decision. At the very least, it must be assumed that they would realize the negative consequences of conflict or the unsuccessful consequences of individualism. All these postulates correspond well to the myths of the state of nature as developed by Thomas Hobbes ${ }^{122}$ and John Locke. ${ }^{123}$

\footnotetext{
122 Th. HOBBES, Leviathan, 1651, R. TUCK (Ed.), Cambridge University Press, Cambridge, 1991

${ }^{123}$ J. LOCKE, Two Treatises of Government, from the Works of John Locke. A New Edition, Corrected, in Ten Volumes, Vol. 5, London: Printed for Thomas Tegg; W. Sharpe and Son; G. Offor; G. and J. Robinson; J. Evans and Co.: Also R. Griffin and Co. Glasgow; and J. Gumming, Dublin. Prepared by Rod Hay for the McMaster University Archive of the History of Economic Thought. 1823
} 
Thomas Hobbes asserted that to understand political society, it is first necessary to understand its members, that is, individuals. We must then understand the agreements that make up society and from these agreements we will understand the form and status of political society. The myth of the state of nature is then used to simply understand what human beings are. Self-preservation is the most fundamental desire and if there is no law or authority to influence our action regarding this desire, as viewed by Hobbes, no one has the power to dictate to others how to stay alive. According to Hobbes, the state of nature is a state of war. This conclusion stems from the consideration men have for one another. Indeed, men are naturally equal in body and mind, regardless of their abilities. Thus, no one can avail himself of his great strength or quickwittedness of mind against others, for a man can overcome a stronger opponent either by using his wits or by joining with others who are similarly in danger to overcome the threat. ${ }^{124}$ Hobbes wrote again that men generally tend to covet power and fight to death for it. ${ }^{125}$ Thus in the state of nature, there is no way for anyone to be totally safe since every kind of force shows limits. Since all men are basically equal, there is no common power to watch over them. That is why a state of war would exist among them. Thus, according to Hobbes, distrust to each other characterizes the state of nature and since no one can trust anyone, everyone has to fear everyone. It is this fear that grounds the state of war, which renders man incapable of enjoying life and its properties. The state of war means "every man against every man. Where there is no common Power, there is no Law: where no Law, no Injustice. Force, and Fraud, are in war the two Cardinall vertues, ..., It is consequent also to the same condition, that there be no Propriety, no Dominion, no Mine and Thine distinct; but onely that to be every mans that he can get; and for so long, as he can keep it... ${ }^{126}$. Such a state lets few possibilities for cooperation : «there is no place for Industry ... no commodious Building ... no account of Time; no Arts; no Letters; no Society; and which is worst of all, continually fear, and danger of violent death; And the life of man, solitary, poor, nasty, brutish, and short $\gg^{127}$.

Following Hobbes, Locke made a state of nature account. Locke asserted that it is unlikely to find traces of the state of nature because the traces only begin with civil societies which are political societies. However, Locke tried to show, from his point of view, what could be the most likely origin of civil society. In his Second Treatise on Civil Government, John Locke agrees with Hobbes that the state of nature is a state of perfect freedom and equality. But he

\footnotetext{
124 Th. HOBBES, Leviathan, op. cit. p. 183

${ }^{125}$ Ibid. p. 184

${ }^{126}$ Ibid. p. 188

${ }^{127}$ Ibid. p. 186
} 
meant the two terms differently. According to Hobbes, equality refers to the ability to gain power and satisfy one's desires, while freedom just means that everyone has the natural right to do whatever he or she thinks is necessary to secure self-preservation. Locke, on the other hand, supports a moral interpretation of each term. Equality means that no one has the right to have power over anyone. And while everyone has the right to self-preservation, Locke argues that there are limits to what can be done for this purpose, according to the law of nature. The law of nature prescribes that no one may subordinate another person or harm his life, health or property (except in self-defense), and furthermore that men must help one another when it does not cause them harm. Thus, according to Locke, the state of nature is the state of liberty and not of license, because it is governed by the law of nature. It appears, however, that there may be individuals in the state of nature who do not live according to the laws of nature, and in this case, too, the law of nature prescribes the extent of action in reaction against such criminals. In the state of nature men have the right to defend themselves and their property. However, it is possible that the reaction to the criminal act may be disproportionate as for example, murder in reaction to theft. The greatest objection to the state of nature according to Locke is therefore the possibility that natural freedom is abused both in the non-consensual interference in another individual sphere and in the reaction to it. ${ }^{128}$

Thus the myths of the state of nature developed by Hobbes and Locke confirm Man's natural tendency to conservation. However, the fundamental point of divergence is the way it is assumed.

Indeed, according to Hobbes, in the state of nature Man is a wolf to Man as they are all in search a natural egalitarian basis. To protect themselves, competition and rivalry therefore become their day to day way of life. Since men cannot trust one another to respect the natural law for each and for all, mistrust is the most widespread feeling. Thus in the Hobbesian state of nature, the conservation of the being is done in short by means of violence. ${ }^{129}$ It is the war of all against all. According to Locke, men being naturally equal in freedom and naturally inclined to rationality, conservation of being is naturally done or is called to be done peacefully because any idea of subordination of one man by another is inadmissible. ${ }^{130}$

\footnotetext{
${ }^{128}$ B. RUSSELL, A History of Western Philosophy and its Connection with Political and Social Circumstances from the Earliest Times to the Present Day, SIMON AND SCHUSTER, New York, 1945, p. 626 ${ }^{129}$ J. LOCKE, op. cit. p. 145.

130 "The natural state of men, before they had formed societies, was a perpetual war, and not only that, but a war of all against all'.; Th. HOBBES, ibid. p. 99
} 
Finally, Hobbes and Locke converge in the fact that they perceive the human being as an individualistic being. ${ }^{131}$ It is therefore at the level of the orientation of this individualism that they separate. According to Hobbes, human individualism refers to natural selfishness, whereas for Locke, this individualism is naturally altruistic. However, Locke acknowledges that there is still insecurity in the state of nature: through the possibility for individuals not to behave as rational beings as they really are and thus the possibility for them to encroach on the freedom of others. ${ }^{132}$ According to Locke, in the state of nature, Man's rationally altruistic natural individualism is the principle and man's irrationally selfish natural individualism is the exception. Conversely, for Hobbes, in the state of nature the principle without exception is the rationally selfish natural individualism. The solution to this exceptional and principle-based problem leads the two authors, each in his own way, to consider the constitution of a state of society. It goes without saying that since the problem is perceived differently, the solution in turn could not be identical.

The myths of the state of nature are therefore hypotheses that correspond to the case of a group of individuals who naturally find themselves subject to the imperative of individual confirmation of the law of human security without sustaining a link of filiation and on the basis of the resources of nature. The state of nature as characterized by the two authors would be a state of insecurity that naturally leads to the non-conservation of all, what emphasizes the importance attached to the solution of this problem, that is, the forthcoming political society. This one would be presented only as an agreement between individuals, having understood the consequences of conflict, of licentious behaviour or simply of the state of nature's ambient disorder.

Although this situation allows us to understand that the human nature political animality, as a natural nature cannot be so understood, we must take this opportunity to evaluate hypotheses of the state of nature in the sense of human security, as a law of nature. It is quite clear that these states of nature are not traceable historical realities, but abstract constructions which make it possible to grasp the foundation and the purpose of political society. If it is already necessary to recognize that human security certainly constitutes the foundation and finality of this one, one must still examine its nature. The myths of the state of nature focus on the behavior of people in their natural tendency for conservation. These myths therefore only deal with human

\footnotetext{
${ }^{131}$ F. TRICAUD, “Hobbes et Locke : convergences et divergences”, in: XVII-XVIII, Bulletin de la société d'études angloaméricaines, des XVIIe et XVIIIe siècles, $\mathrm{n}^{\circ}$ 25, 1987. p. 77, http://www.persee.fr/doc/xvii_02913798_1987_num 25_1_1120

132 J. LOCKE, op. cit. p. 156
} 
security. However, they seem to contradict the human nature political animality, since Man would only be a political animal outside the state of nature. This is undoubtedly contradictory to Aristotle's postulates. In the understanding of human security, as a law of nature, it is a question of knowing that nature in itself is already an order which is no longer to be realized, since it is already real, but is to be confirmed in the way it is. In this logic, since nature has subjected multitude of human beings to coexist, depending on its resources, it is clear that it has foreseen an order of means under and by which their conservation is ensured. Although the human being may not understand this order in a state of nature - as developed by these mythsand therefore may not know his political animality as a natural nature outside the family framework, this does not prevent this nature be real, because it dictates a necessity of confirmation. Thus, although the relevance of the myths of the state of nature is proven, their value is surely limited if they do not take somehow all the relevant elements or logics of reality into consideration .Since human being is always part of nature, he is therefore in that same nature a political animal and that is why we must agree with Aristotle that the State which is a form of political society is just as natural. But if it is no longer a natural nature with regard to the hypothesis that makes it possible to envisage political society without any bond of filiation, the best way to understand the myths of the state of nature of Hobbes and Locke is that of informing on the incomprehension or the ignorance by the human being of the natural order of means intended to confirm its essential state of human security as this implies. The various solutions of agreement, contract or order to which they lead to are not sufficient to see in political society, a fact outside nature. In this case the State, according to the particular formulation consequential to each myth, is not an artifice distinct from the nature, but it has its sense only in translating the beginning of the understanding or awareness by human beings of the natural order of means according to which they can confirm human security, as the law of their nature. Thus they come to learn that the preservation or conservation of each member is only possible based on a regulation or normalization of their relationships. This allows to know political society as included into the human nature's political animality, but as a cultural nature. In one level or another, human security is verified as the law of nature of political society, that is to say, its foundation and finality. 


\section{THE HUMAN POLITICAL ANIMALITY: A CULTURAL NATURE}

In the first section, we undertook to verify human security as the law of nature of political society by dwelling on the human political animality as a natural nature. By this concept we meant an adequacy of human security, as a law of nature, with the understanding and the experience of the human being. By the concept of cultural nature in this framework, we mean that the natural order of means for the confirmation of the intrinsic state of human security in a context of coexistence is not always known by human beings who learn it as a result of experience. ${ }^{133}$ Culture generally refers to the body of knowledge acquired. Culture is often distinguished from nature, the latter apprehended as referring to the innate while the former refers to the acquired. In light of human security, as a law of nature, we will understand "culture" as the human process of learning on the order of natural means which should enable him to conserve himself in coexistence with several other entities. When the human political animality fully remains in the natural framework as complimentary to his family aspect, it is revealed or gradually clarified to him as a result of the consequences of his initiatives for the purpose of confirming his intrinsic natural state of security. Thus it will be clear that the human understanding and experience are not always in compliance or become so by step or as the result of experience. The human political animality as a cultural nature will mean a nature which is known through education or quite simply which is discovered through experience. The cultural nature of human political animality to account for human security as law of nature of political society will be verified in the community management of conservation (2.1) which unveils a human enterprise of conformation with its natural order (2.2).

\subsection{The Community management of conservation}

As evidence of the cultural nature of the human political animality, the community management of conservation is implemented when human beings understand that consent or agreement is preferable to conflict and that collectivism is preferable to individualism. Thus, in the logic of conservation in the state of human security, political society is known as necessary (2.1.1) and thus follows knowledge of the order of natural means which can lead to that finality. Even if its form is not circumstantially accomplished, Man's rationality at work allows him to get closer to it (2.1.2).

133 A. CHARRAK, “Culture”, Grand Dictionnaire de la Philosophie, op. cit. p. 691 


\subsubsection{Necessity of an agreement}

The necessity of an agreement is the understanding to which comes a group of individuals subject to coexistence by nature and who find themselves around something of common interest necessary for conservation. So agreement is the determinant of political society. Let's try to understand its logic.

Agreement is a manifestation of the will to behave in a certain way. It is an expression of freedom that has been understood as one of the ontological attributes, emerging both from the finite order and from the final order which constitutes human security. Freedom therefore comes under natural law and is rightly at the centre of the myths of the state of nature. Given that each human is a freedom, it is therefore unnatural for anyone to be subjected to others because that would imply opposing him/her an intolerable lack of self-determination. Since freedom is part of the natural order, it cannot be harmful because it is only in this order that it participates in human security. Thus, it must be differentiated from license. By license we mean the possibility for a person to act in all directions, according to his whims, without his actions being subject to control. In fact, licentious behaviour involves chaos, since its actor can behave without restrictions, so he is able to harm others or himself. However, causing harm to others or to himself possibly implies a painful consequence for the actor because it is probable that, because of the pain abusively caused to others, the latter takes revenge, or because of the pain he inflicts on himself, he necessarily feels pain or even faces extinction or death. Freedom, on the contrary, implies a law of behavior which is measured, thought, rational, reasonable in the sense that the actor behaves with a view to the positive consequences of his action for himself. Free behavior can therefore never, in itself, have harmful consequences for its perpetrator, because he/she would respect, as the case may be, him/herself and/or others. Licentious behavior is therefore in itself evidence of an absence of order.

The myths of the state of nature emphasize that human beings would sustain a false understanding of freedom when they would believe that they are allowed everything in the necessity of his conservation. But instead of benefiting from that, they rather loose, and consequently, they gradually come to be aware that freedom means a way of behavior that does not harm self or others. This way consists in agreeing with fellows on a union aiming at the conservation of each one. This agreement is understood precisely in terms of "social contract". The formulation of this one corresponds to the concept of freedom in the state of nature.

According to Hobbes, the state of society consists in this political form where all individuals concede their full powers in the hands of a single person or an assembly, ensuring security for 
all. Now with the whole force and monopoly of its exercise, this individual or this assembly has all guarantees to be feared and to establish order and therefore a climate where everyone can pursue his own conservation safely. ${ }^{134}$ According to Locke, however, the individual, being naturally free, the social configuration he envisions is one that confirms this nature of Man. Thus, transition to society involves a contract among all individuals to create this entity which will ensure the security of everyone in his natural freedom to preserve himself. And the authority in charge of the power conferred by the social contract is responsible for its government before all individuals who can thus revoke him because they would have kept their freedom to do so. ${ }^{135}$ This is what fundamentally makes the difference with Hobbes because individuals, by fully conceding their freedoms to one, it is clear that they do no longer have the possibility of removing him/her unless he/she becomes logically irresponsible towards his/her fellow counterparts. He/she is accountable only to hims/herself. ${ }^{136}$ This way of conceiving political society would ultimately suggest that freedom is the most harmful element for all parties and therefore the solution is only found in renunciation. The conservation of the being thus require, according to Hobbes, renouncing to freedom that founds the State. Now according to Locke, freedom is the most characteristic good of Man and it is only because he can be threatened in an irrational way in the logic of confirmation of his being in the state of nature that political society is agreed. The conservation of the being cannot then be possible through the renunciation of freedom but through its conservation because it remains the only bulwark against the governors who would decide not to respect the social contract.

It is also relevant to mention the social contract as understood by Rousseau. Before elaborating it, he begins by assuming that "men to have reached the point at which the obstacles in the way of their preservation in the state of nature show their power of resistance to be greater than the resources at the disposal of each individual for his maintenance in that state. That primitive condition can then subsist no longer; and the human race would perish unless it changed its manner of existence" 137 Then he continues by saying "but, as men cannot engender new forces, but only unite and direct existing ones, they have no other means of preserving themselves than the formation, by aggregation, of a sum of forces great enough to overcome the resistance. These they have to bring into play by means of a single motive power, and cause to act in

\footnotetext{
${ }^{134}$ Th. Hobbes, op. cit. p. 144. B. RUSSELL, op. cit. pp. 555

135 Th. Hobbes, ibid. p. 253. B. RUSSELL, ibid. pp. 629-633

136 Th. Hobbes, ibid. p. 159

137 J-J. ROUSSEAU, The Social Contract, "6. The Social Compact", eBooks@Adelaide, The University of Adelaide Library, 2012, http://ebooks.adelaide.edu.au/r/rousseau/jean_jacques/r864s/index.html
} 
concert. This sum of forces can arise only where several persons come together: but, as the force and liberty of each man are the chief instruments of his self-preservation, how can he pledge them without harming his own interests, and neglecting the care he owes to himself? This difficulty, in its bearing on my present subject, may be stated in the following terms: "The problem is to find a form of association which will defend and protect with the whole common force the person and goods of each associate, and in which each, while uniting himself with all, may still obey himself alone, and remain as free as before." This is the fundamental problem of which the Social Contract provides the solution. The clauses of this contract are so determined by the nature of the act that the slightest modification would make them vain and ineffective; so that, although they have perhaps never been formally set forth, they are everywhere the same and everywhere tacitly admitted and recognised, until, on the violation of the social compact, each regains his original rights and resumes his natural liberty, while losing the conventional liberty in favour of which he renounced it. These clauses, properly understood, may be reduced to one - the total alienation of each associate, together with all his rights, to the whole community; for, in the first place, as each gives himself absolutely, the conditions are the same for all; and, this being so, no one has any interest in making them burdensome to others. Moreover, the alienation being without reserve, the union is as perfect as it can be, and no associate has anything more to demand: for, if the individuals retained certain rights, as there would be no common superior to decide between them and the public, each, being on one point his own judge, would ask to be so on all; the state of nature would thus continue, and the association would necessarily become inoperative or tyrannical. Finally, each man, in giving himself to all, gives himself to nobody; and as there is no associate over whom he does not acquire the same right as he yields others over himself, he gains an equivalent for everything he loses, and an increase of force for the preservation of what he has. If then we discard from the social compact what is not of its essence, we shall find that it reduces itself to the following terms: "Each of us puts his person and all his power in common under the supreme direction of the general will, and, in our corporate capacity, we receive each member as an indivisible part of the whole." At once, in place of the individual personality of each contracting party, this act of association creates a moral and collective body, composed of as many members as the assembly contains votes, and receiving from this act its unity, its common identity, its life and its will. This public person, so formed by the union of all other persons formerly took the name of city, and now takes that of Republic or body politic; it is called by its members State when passive. Sovereign when active, and Power when compared with others like itself. Those who are associated in it take collectively the name of people, and severally are called citizens, as 
sharing in the sovereign power, and subjects, as being under the laws of the State. But these terms are often confused and taken one for another: it is enough to know how to distinguish them when they are being used with precision". ${ }^{138}$

We have chosen to quote the whole "social contract" of Rousseau because it is a very edifying idea on how to organize relationships between free individuals naturally while confirming this natural attribute.

Although our three authors conceive the form of agreement differently, representing the social contract or political society, they all recognize nevertheless that it is a necessity. It is only in this way that a set of individuals who must preserve themselves in compliance to their nature can achieve this end. However, in our view, this necessity is related to the natural order which is already real and which has only to be discovered and known by Man. Thus, the best formulation of political society can only be discovered or known as a result of its consequences in the confirmation of human security. So the human political animality is a cultural nature. "Hence this obvious conclusion, that State is a fact of nature, that naturally Man is a sociable being"139. Aristotle further justifies this in these terms: "If man is infinitely more sociable than bees and all the other animals which live in a herd, it is obviously, as I have often said, that nature does nothing in vain. However, it gives voice to man exclusively. Voice can express joy and pain; also it is not lacking in other animals, because their organization goes so far as to feel these two affections and to communicate them. But speech is made to express good and evil, and therefore also the just and the unjust; and Man has this special thing, among all animals, that he alone sees good and evil, the just and the unjust, and all feelings of the same order, which by being associated constitute precisely family and State". ${ }^{140}$

It is then impossible for Man to confirm himself outside the natural order of means that political society embodies because in himself alone he can exercise the rational component of his nature to discover it through exchange with other citizens on the just and the unjust. That said, resources of nature are very much involved in this exercise of human rationality.

\subsubsection{Resources as a condition exercise of human rationality}

It is necessary to recall the immense participation of resources in the exercise of the rational component of human nature in the discovery of the natural order of means necessary for the confirmation of the law of his nature, in coexistence with a multitude of other human beings.

\footnotetext{
138 Ibid

139 J. B.-SAINT-HILAIRE, La Politique d'Aristote, op. cit. Book I, I. 8

${ }^{140}$ Ibid. Book I, I. 9
} 
Indeed, these resources as we have seen, are useful to conserving the physical nature of Man and we postulate that they condition the cultural nature of the human political animality.

Reading the myths of the state of nature developed by Hobbes and Locke, one must note the central place that take resources of nature in the undertaking of individual conservation, although they do not say it clearly. However if Hobbes does not make enough mention of goods necessary for conservation as noticed from the logic of his developments, Locke on his part makes clear mention of them as invaluable for conservation.

According to Hobbes "From this equality of ability arises equality of hope in the attaining of our ends. And therefore if any two men desire the same thing, which nevertheless they cannot both enjoy, they become enemies; and in the way to their end (which is principally their own conservation, and sometimes their delectation only) endeavour to destroy or subdue one another. And from hence it comes to pass that where an invader has no more to fear than another man's single power, if one plant, sow, build, or possess a convenient seat, others may probably be expected to come prepared with forces united to dispossess and deprive him, not only of the fruit of his labour, but also of his life or liberty. And the invader again is in the like danger of another" ${ }^{\prime 14}$. For his part, Locke extensively discusses ownership of things whose origin he immediately clarifies: "Whether we consider natural reason, which tells us that men, being once born, have a right to their preservation, and consequently to meat and drink and such other things as Nature affords for their subsistence (...) The earth and all that is therein is given to men for the support and comfort of their being. And though all the fruits it naturally produces, and beasts it feeds, belong to mankind in common, as they are produced by the spontaneous hand of Nature, and nobody has originally a private dominion exclusive of the rest of mankind in any of them, as they are thus in their natural state, yet being given for the use of men, there must of necessity be a means to appropriate them some way or other before they can be of any use, or at all beneficial, to any particular men. The fruit or venison which nourishes the wild Indian, who knows no enclosure, and is still a tenant in common, must be his, and so his i.e., a part of him, that another can no longer have any right to it before it can do him any good for the support of his life". ${ }^{142}$

Hobbes and Locke make the conservation of man the primary objective of human nature and resources or assets are the necessary elements for this purpose. With regard to the state of

\footnotetext{
${ }^{141}$ Th. HOBBES, Leviathan or the Matter, Form, and Power of a Common-wealth Ecclesiastical and Civil, printed for Andrew Crooke, at the Green Dragon in St. Pauls Church-yard, London, 1651, p. 76

142 J. LOCKE, Two Treatises of Government, op. cit, pp. 115-116
} 
Hobbesian nature, it is not very illogical to assume that it is these goods for conservation which are the real stake that leads to the state of war, each seeking to secure an advantage. If these goods are enough or sufficient for all, what could well be the source of conflict if all are inclined to conserve themselves? That importance of goods in the Hobbesian myth justifies the fact that "In such condition there is no place for industry, because the fruit thereof is uncertain: and consequently no culture of the earth; no navigation, nor use of the commodities that may be imported by sea; no commodious building; no instruments of moving and removing such things as require much force (...."143. As a means of conservation, goods would therefore be so coveted that in the end their production becomes almost impossible, since the owner is not certain to enjoy them. As far as the Lockean state of nature is concerned, the equitable use of natural resources for the just need of conservation and the peaceful personal enjoyment of property are not always guaranteed, although human beings are rational. "If man in the state of Nature be so free as has been said, if he be absolute lord of his own person and possessions, equal to the greatest and subject to nobody, why will he part with his freedom, this empire, and subject himself to the dominion and control of any other power? To which it is obvious to answer, that though in the state of Nature he hath such a right, yet the enjoyment of it is very uncertain and constantly exposed to the invasion of others; for all being kings as much as he, every man his equal, and the greater part no strict observers of equity and justice, the enjoyment of the property he has in this state is very unsafe, very insecure. This makes him willing to quit this condition which, however free, is full of fears and continual dangers; and it is not without reason that he seeks out and is willing to join in society with others who are already united, or have a mind to unite for the mutual preservation of their lives, liberties and estates, which I call by the general name-property". ${ }^{144}$

If goods for conservation take in the state of nature, a less obvious place in the theory of Hobbes and more flagrant in the theory of Locke, the fate which they receive inside the model of political society proposed in solution to the state of nature is much less problematic in Hobbes than in Locke. Indeed, Hobbes asserts that "The nutrition of a Commonwealth consists in the plenty and distribution of materials conducing to life (...) For the matter of this nutriment consisting in animals, vegetables, and minerals, God hath freely laid them before us, in or near to the face of the earth, so as there needs no more but the labour and industry of receiving them (...)The distribution of the materials of this nourishment is the constitution of mine, and thine,

\footnotetext{
143 Th. HOBBES, Leviathan or the Matter, Form, op. cit. p. 78
}

${ }^{144}$ J. LOCKE, Two Treatises of Government, op. cit. p. 159 
and his; that is to say, in one word, propriety; and belonged in all kinds of Commonwealth to the sovereign power. For where there is no Commonwealth, there is, as hath been already shown, a perpetual war of every man against his neighbour; and therefore everything is his that gets it and keeps it by force; which is neither propriety nor community, but uncertainty. (...)Seeing therefore the introduction of propriety is an effect of Commonwealth, which can do nothing but by the person that represents it, it is the act only of the sovereign; and consists in the laws, which none can make that have not the sovereign power. And this they well knew of old, who called that Nomos (that is to say, distribution), which we call law; and defined justice by distributing to every man his own. In this distribution, the first law is for division of the land itself: wherein the sovereign assigns to every man a portion, according as he, and not according as any subject, or any number of them, shall judge agreeable to equity and the common good." 145

Thus, it is in the political society that Hobbes comes to clearly recognize the inescapable nature of goods in the conservation of individuals and fix the issue of their availability as depending on the discretion of the sovereign. Although this solution is questionable in view of its implications for the confirmation of human security, it is already important to recognize that this question is crucial to this end.

Locke, for his part, proposes a model of political society which essentially deals with protecting the property of individuals whose enjoyment is threatened in the state of nature: "The great and chief end, therefore, of men uniting into commonwealths, and putting themselves under government, is the preservation of their property; to which in the state of Nature there are many things wanting" ${ }^{146}$. Locke made of the protection of property a major goal of political society to such an extent that he anticipated and fixed the hypothesis of any arbitrary interference of the sovereign in the enjoyment of property, no doubt in reaction to Hobbes. He sees this situation as unacceptable. However, it should rather be noted, in relation to the inescapability of goods for the conservation of individuals, a set of elements which can be considered as missing in this theory.

Indeed, the question of availability of goods necessary for conservation in political society does not really come up in Locke's political solution. In the state of nature, he deals with the appropriation of goods from nature. Not only should the rationality of principle of human beings lead them to an equitable use of the resources of nature and to respect the appropriation of each

\footnotetext{
145 Th. HOBBES, Leviathan or the Matter, Form, op. cit. pp. 151-152

${ }^{146}$ J. LOCKE, Two Treatises of Government, op. cit. p. 159
} 
one. Because it is possible for some to appropriate these resources more than what they need for their conservation, thereby harming others, or because there is a possibility of abusive interference in the property of everyone, an agreement is then necessary between all individuals, for the purpose of a better protection. This situation would either imply that everyone consents to political society by already owning a property which he would continue to enjoy in that frame, or that some do not own anything and nevertheless decide to consent to a political society, or that some have been dispossessed in the state of nature and could not have recovered their rights because the infringer was stronger and nevertheless would still consent to political society, or that some having unjustly appropriated more than what was necessary for their own conservation would consent to an agreement with others under such a title of property. In all these different hypotheses, consent to a political society would start on an unequal and surely unjust basis, because it is possible either that it protects those who have behaved badly in the state of nature, or that it offers, for those who do not appropriate anything in the state of nature, no alternative of property acquisition necessary for their conservation within political society whose purpose is to allow the enjoyment of property in safety and in rest. Consequently, one would have to think either that such a political society would have little chance of surviving, since the non-owners of goods would have to find some if political society does not provide them with anything. It is then possible that within the political society, they bring back behaviours of the state of nature, or that such an agreement of political society is impossible. Now, how would an individual who rationally used the resources of nature in an equitable way by recognizing the rights of others on the same resources without appropriating it beyond the simple requirements of conservation, consent to transfer his freedom to a society which would not provide him with the goods necessary for its conservation when irrational people have appropriated everything in the state of nature? Political society would then be contradictory to natural rationalism.

From the explanations above, the point raised is that political societies should guarantee the availability of goods for the benefits of all given that Nature already includes goods necessary for human conservation. And it is based on these ones that the cultural nature of the human political animality is confirmed because he gradually learn that he is, due to the unity of nature, in an order that includes him with all men and the whole nature, for, according to Hobbes, "This matter, commonly called commodities, is partly native and partly foreign: native, that which is to be had within the territory of the Commonwealth; foreign, that which is imported from without. And because there is no territory under the dominion of one Commonwealth, except it 
be of very vast extent, that produceth all things needful for the maintenance and motion of the whole body; and few that produce not something more than necessary; the superfluous commodities to be had within become no more superfluous, but supply these wants at home, by importation of that which may be had abroad, either by exchange, or by just war, or by labour: for a man's labour also is a commodity exchangeable for benefit, as well as any other thing: and there have been Commonwealths that, having no more territory than hath served them for habitation, have nevertheless not only maintained, but also increased their power, partly by the labour of trading from one place to another, and partly by selling the manufactures, whereof the materials were brought in from other places". ${ }^{147}$

Though insisting on property, Locke also recognizes that "God, who has given the world to men in common, hath also given them reason to make use of it to the best advantage of life and convenience. The earth and all that is therein is given to men for the support and comfort of their being". 148

These developments lead us to the conclusion that what both authors have called "state of nature" actually refers to a set of irrational behaviours that human beings would adopt in their natural tendency for conservation. Now seeking only to ultimately conserve their nature, under equally natural conditions (multitude of similar human beings, resources of nature) how would the state of nature in itself be a problem to itself? This contradiction is impossible because nature is already an order, but it is attributable to Man who has not yet understood the order of natural means provided so as to confirm himself under the conditions that this nature has subjected him to; which also proves some of the irrational behaviours that can persist within the agreed political society. Since Man is called upon to preserve goods, they drives human rationality in search of this order of natural means. Once again, we understand that human security is the foundation and finality of political society. This is further verified by the philosophy of history.

\footnotetext{
147 Th. HOBBES, Leviathan or the Matter, Form, op. cit. pp. 151

148 J. LOCKE, Two Treatises of Government, op. cit. p. 115
} 


\subsection{The philosophy of history, a progressive enterprise of conformation of man to his nature}

The cultural nature of the human political animality is accounted through the historical process of experimentation through which Man progressively discovers the order of natural means that confirms his human security, as the law of its nature within a multitude, using the resources of nature. So he is constantly looking for the best configuration of political society (2.2.1), until the order of means conforms to the order of ends (2.2.2).

\subsubsection{Continuous search for the best formulation of political society}

After learning that conflict is unnatural through its effect of non-confirmation of human security, Men realize that the consent and the agreement for a normalization of their relationships or what we call "political society" is pro nature because it allows this confirmation. If this is a good starting point, it is not generally sufficient for the discovery of the order of natural means by which human security is confirmed. Thus men are carried to a perpetual search for the best formulation of political society they can conserve well. How does it work so that human security accounts for the law of nature of political society?

Starting from the fact that a law of nature is a state of affairs, a state of things, a state of functioning, a reality, then it does not need to be created or realized, since it is already real. For human nature, this reality is reduced to an intrinsic dispositional state which is "security". Security or state of well-being therefore accounts for the natural human order so that it is not only a question of being a human, but necessarily of being in security. Thus, this state, due to the rational animate human nature has the vocation to confirm itself, that is to say, to be as it is naturally permanently. This is what is called conservation because, succeeding in this natural trend, permanence is ensured.

Since nature has prepared or subjected Man to confirm the law of his nature with a multitude of fellows also constrained to the same tendency based on its resources, human security logically becomes the law of relationships that they can sustain between them. If licentious behaviour or war or chaos or disorder results in the destruction and not the preservation of any of them, it is therefore unnatural and cannot in reality be considered as part of the order of means which confirms the natural law, which rather includes liberty, consent, agreement, organization embodied or signified in political society. Human security is therefore the law of nature of political society, in that it constitutes its foundation and its finality. 
Human security as the sense of the existence of a group of individuals subjected to the same condition by nature, it is obvious that political society is part of the order of means that this nature necessarily foresees and whose exact formulation is progressively to be discovered by them. History to which we refer in this context refers to the process by which Man, for the purposes of its conservation, formulates organizational initiatives and face the resulting consequences. Reason then commands him to be aware of the order of natural means which is unveiled through initiatives resulting to positive consequences on conservation and which knows itself to be null in those leading to negative consequences. Initiatives with positive consequences should then be capitalized and those with negative consequences should be either rejected or improved.

It is still necessary to ask ourselves what criterion is supposed to inform that a certain organization is a component of the order of natural means necessary to confirm human security. Political society is essentially made up of all the individuals who have consented to be part of it. It is essentially the product or the sum of the agreements of individuals who constituted themselves so for the purposes of their conservation. They therefore all expect the same consequence: security. It is therefore clear that a political society which does not succeed, based on its form or the way it is organized, in meeting the need of natural conservation of all the individuals who make it up would be failing. It is not even a question of confining oneself to the satisfaction of the majority because it is by individual agreement that individuals recognize themselves as members of a political society and therefore, if some of them do not obtain satisfaction of the expected result for which they have consented, it is clear that society is failing. Confirmation of human security is a collective affair because it concerns all individuals in the same way. It is because each individual human security is the finality that collective human security has a sense. Political society exists in the expectation of the satisfaction of everyone's security. If it does not succeed, then it would present itself as not having fulfilled its purpose. This is the meaning of the contractualist philosophy. All are equal contracting partners on a natural tendency to be confirmed. If only one is not, there is a failure of political society, and the main reason can only be diagnosed in the way it is organized to serve that purpose.

What could we expect from the lack of conservation of some? The dissatisfaction of some individuals due to a lack of conservation would be an obvious consequence and one must think that they would have the choice between two alternatives: either to resign in front of the majority, or to defend their rights to be satisfied like everyone else. Resignation in such a situation would appear to be unnatural because it would result in accepting an insecurity which 
is naturally unacceptable. Only the defense of the right to conservation would be natural. It is therefore clear that individuals would hold the political society accountable and if necessary they would question the usefulness of continuing to respect their agreement. They may then seek to satisfy themselves outside of the order that political society constitutes. If the latter, in its current state of configuration, aims to embody order within a territory, it is therefore exclusive of any other order within its sphere of sovereignty. Thus, dissatisfied individuals should either continue to obey the order they would have consented without however receiving the conservation expected result, or leave. However, they can only settle in another place if that one is either without a master or not subject to an agreement under a political society. But if that is the case, they should be welcomed and authorized to stay by the members of such a society, therefore allowing them to conserve themselves with them even though they would not have from origin consented to that society. This would be a benevolence with a precarious status because it is possible that this benevolence is not or no longer granted and that dissatisfied individuals in their society are pushed to leave. So in situations where benevolence is refused and there are no more territories without masters, it is clear that the only option that would remain for individuals whose conservation is not satisfied in their societies is to return or simply stay and defend their rights to be satisfied like all other contracting parties.

So a question is important: Is the situation of the dissatisfied individuals just a matter for themselves alone or is their situation a matter for all individual members of the political society? Political society is the sum of individual agreements, it represents an inter-individual agreement for a precise purpose which is the conservation of each. And because it is a matter of conservation of each individual that conservation of all matters. Political society therefore has an obligation of result because of its foundation and its finality: human security of each individual human nature that makes it up. It is therefore clear that if this order does not lead to confirmation of this natural intrinsic state, even of one, it is flawed in its formulation and must be reviewed. The satisfaction of the majority is therefore not the criterion of the viability of a political order, because that way, it testifies to its failure, in its current formulation, because it has not yet succeeded in reaching the level it can satisfy the agreement's expected counterpart of each member and therefore of all. The dissatisfied members must therefore draw other members' attention on this failure and require that the current formulation of the political society agreement be reviewed in the hope that each one can effectively see the counterpart of his consent satisfied. If the other consenters refuse due to their satisfaction in the present state of order and to the detriment of some, it is clear that they would enjoy the implementation of 
the unfair agreement. They would therefore forget that the political society based on which they are satisfied is the sum of inter-individual agreements and therefore that this in fact is a synallagmatic meta-contract since each individual would have consented to each other for his own conservation and the conservation of each other. If only one then fails to be satisfied, each of the contracting parties is defaulting towards him/her. Then it must be concluded that it is everyone's problem if only one of them is not satisfied in its conservation. And since it is the matter of each one, so it is the matter of all. For those who would have been satisfied, they would have to be considered as having benefited from the execution by each of the members of its obligation towards him/her including by the dissatisfied one, without him in return benefiting from the same counterpart of the execution by other members of theirs obliglations. Thus in a political society, all are responsible for the conservation of all, which means that each member is responsible for the conservation of each member. The dissatisfaction of one means that each member has not fulfilled his obligation. Could each of them do it? If everyone can be considered as satisfied as a result of the performance of the dissatisfied member's obligation, this means that everyone could also fulfill its obligation towards him/her. Thus it would appear that it is rather each of them who failed. But since it is not a question of the political society in itself but that of its current formulation or organization which results in negative consequences for some, it must be revised for this reason. It is that current formulation of the agreement which accounts for the failure of each member. Therefore it is necessary to change that formulation or that form, or organization in the hope that by the new one or in the correction of the old one, the satisfied members be no longer considered to be defaulting towards the dissatisfied one(s).

In the hypothesis that the current form of the failing organization is not reviewed by all, each of the beneficiaries reluctant in revising it, they would take pleasure in benefiting from the execution of the dissatisfied member's obligation without doing the same to him/her. It would be a flagrant injustice and the dissatisfied member can decide to withdraw his agreement which binds him/her to others and take care of his own conservation. If s/he remembers the foundation of political society and is aware that the licentious behaviour for the purpose of confirmation leads to negative consequences, s/he would have no other alternatives than withdrawing his agreement from such an organization. So this withdrawal of agreement would imply that s/he is no longer linked to anyone and that $\mathrm{s} / \mathrm{he}$ vows to his own conservation through the means at his/her disposal. To this end, if the dissatisfied member behaves as a rational being by not to using violence to acquire the means necessary to his conservation, s/he would withdraw also his/her properties from the framework of the agreement, in case he would have saved any, 
according to the Lockean hypothesis of contractualism, to deal only with his/her own situation. But if s/he did not save anything, in both the Hobbesian and Lockean hypotheses, then even the withdrawal of his/her agreement would undoubtedly harm him/her, because that withdrawal would not imply an alternative for his conservation. Thus withdrawing or not, his/her agreement will be worth the same thing because none of the alternatives would ipso facto assure him/her the means of conservation. But withdrawing his/her agreement would be more advantageous in that it would mean the return to an ultimate alternative of conservation: the licentious behavior. If s/he decides not to use it, s/he condemns himself to insecurity which would lead him to extinction. But as we have seen, insecurity, extinction being unnatural, the licentious behavior involving the use of all means in his/her possession, including force, cunning means, becomes a necessity for him/her. The question that arises in this hypothesis relates to the legitimacy of such a behavior.

It must be assumed that such a behaviour would be an unwanted consequence from the dissatisfied member. All s/he is looking for objectively is his/her conservation in the same way as the others. But each of them considered as not having fulfilled their obligation towards him/her, whereas he would have done it for each of them who delight themselves in such an unfortunate situation, it must be thought that the licentious behaviour in reaction to this injustice, although it is a behavior of the state of nature in the sense of Hobbes and Locke, would in fact be reinstated by each satisfied member of the political society when s/he would have defaulted in his/her obligation towards the conservation of the dissatisfied member while each of them would have benefited from the counterpart of the dissatisfied member. Since society is less an abstract entity than a sum of individuals acting in concert, non-compliance with the inter-individual agreement that it constitutes is in itself an indicator of a return to the state of nature in the sense of both authors. Thus the complacency in this state by each of the satisfied members without revising or correcting it in a sense that it brings positive consequences for each and therefore for all, that would be the sign of a licentious behavior to the detriment of the dissatisfied member whose own would be but a reaction. Such an attitude is necessary so that each of the satisfied members be aware of the consequences of their complacency. Due to the licentious behaviour of the dissatisfied member, it is thus possible that the property of each member of the political society be no longer guaranteed, for, the dissatisfied member not having means of preservation, s/he would target the means of the others. In this hypothesis everything is possible, because s/he can use force against any obstacle that would represent owners. 
In another hypothesis where the satisfied members, in synergy and based on their satisfaction with the current form of the agreement, would decide to eliminate the threat that would represent the dissatisfied member, in order to live peacefully within the framework of the agreement, their strength may be greater and they may reach their goal. But the question that would arise is whether the disappearance of the dissatisfied member would guarantee that no other member currently satisfied finds him/herself in the position of the dissatisfied one in the future. And if this is the case, would other members not react in the same way that they would have reacted towards the first dissatisfied member? In that hypothesis what would be left of the agreement that represent the political society? If the problems of such a society happen to disappear with the first dissatisfied member without any other member facing the same situation in the future, then this would be the ideal for each of the current satisfied members. But what happens to the first dissatisfied member is the indicator that this could have happened to everyone else on the basis of the origin equality between the contracting parties. Therefore it would be a mistake if they would not recognize themselves in the person of the dissatisfied party, considering in addition that, in an essentialist perspective, it is from them that the failure of the system would arise by not fulfilling their part of obligation towards him/her. It is therefore in a delusion that each member of the political agreement would find himself, if s/he does not come to recognize the state of nature he would have restored and within which he would think he would forever ensure its his/her conservation. Since the state of nature according to Hobbes and Locke is not a guarantee of security, it would be possible that in the future each satisfied member find him/herself in the position of the first dissatisfied party and experience the same fate as him/her. In the long run, how far would such a behaviour lead? Inevitably the disappearance of all and that would ultimately entail that to nobody achieve the permanence demanded by their natural state of affairs. Such a conclusion would be truly extreme in that if the ultimate consequence of the loss of all is not envisaged in the treatment of the case of the first dissatisfied member, it is possible that other members will become aware of it as other dissatisfied members would disappear and put themselves in the place of each of these ones, which would mean that they would see themselves as a satisfied today and a disappeared tomorrow. Then they would come to understand that the problem is not in the dissatisfied member but in the form of the organization. They would be educated that the current form of the organization is not the one that results in the conservation of each party-member and therefore the confirmation for all of the natural state of affairs accounted by human security, because, rather, it would gradually lead to insecurity for everyone. They would therefore decide to revise the organization so that each member experience a good outcome in terms of 
conservation satisfaction. Thus this would testify that they would not have yet understood that when political society fails to satisfy the confirmation of human security for one member, all are in danger from this fact and that the solution is not in the marginalization or the elimination of the dissatisfied member who could have been anybody else, but in the revision of the form of the organization or formulation which remains the vector of the licentious behavior they would have been part of. But in fact, the licentious behaviour is unnatural since it is the opposite of freedom, which involves behaving in a way that is not harmful to oneself and to others. Since it is possible that a licentious behaviour be surreptitious in the formulation of the agreement or its organization, the latter must therefore be considered as not corresponding to the natural order of means confirming human security, as the human natural state of affairs.

At this conclusion, members of the political society would testify that they are involved in a process of learning of the order of natural means that better confirm the law of their nature. By making use of their reason, they would be aware of the cultural nature of their political animality. What Hobbes and Locke have therefore called "state of nature" still only refers to the licentious and irrational behavior that is likely to surreptitiously interfere within the political society. This is verified in that this state, in the sense of Hobbes and Locke, was never a historical reality but rather took or takes in fact the form of a disorder alongside the state of real nature which is the real and constant natural order. Its force is known as well in the small substance that it can be the object in the family framework (nuclear or large) such as developed by Aristotle accounting for the natural nature of the human political animality, or in the large substance it can be the object or is called to be the object within the framework of the historical process of experimentation or learning accounting for the cultural nature of the human political animality in the sense of Hobbes and Locke. Men will not stop until they are fully educated on the whole substance of the real order of natural means through which they adequately confirm their intrinsic state, in coexistence with fellows, based on the resources of the nature.

\subsubsection{The end of history: the discovery of the order of natural means of confirmation of the law of human security}

The cultural nature of the human political animality is noticed through the historical experiential process of education for the discovery of the order of natural means aimed at confirming human security in a natural context of coexistence with fellow human beings and depending on the resources of nature. Nature, being an order in itself, is therefore a process of conformation to it. We have seen that human security, as law of nature of political society is a natural nature and thus education through history or experience leads to a conformation of the cultural nature to 
the natural nature, that is to say the situation in which the natural order and human experience are in phase. This situation is characterized by the understanding of the harmony within human security, as a law of nature, in its components of finite and final orders. This framework deals with the process of learning of the best formulation of political society that can guarantee conservation to each human being part of it. Such a situation is called "end of history" because it implies that the educational experience would be completed when men would discover the right formula. This process cannot be extended when it is grasped. Thus the historical process of experimentation would lead to a state of perpetual peace.

The cultural nature of the human political animality is therefore bound to manifest until it comes to discover the political order naturally provided for the conservation of each of its members. A question deserves to be asked in this context: is the achievement of such a result a certainty in the future?

Security being the intrinsic dispositional state of human nature, and since it is thus essential, it is a real state. Being the foundation and finality of all human action for the purposes of conservation or permanence, it constitutes the law of human nature. In this understanding, the confirmation of the intrinsic state of human security is only possible through the order of means already foreseen by nature which has subjected Men to coexist and to depend on its resources. Since this order exists and is to be discovered, it is therefore knowable. So it should be thought that this knowledge is a reality in the world of Men. In any case, it is a matter of knowing that as long as Men have not come to know this order, they would find themselves in a situation which is not very advantageous for the conservation of each of thm and therefore the process of experimentation is called to go on. One author thought that "History has been called, not without reason, an eternal restart. The accidental varies, the content (essence) - the substance, would say philosophers - escapes change. This content (essence) is first of all the human being, always similar to himself, through his faculties, his basic needs, his indestructible tendencies: the stable part of his nature, accentuated by heredity, education, the spirit of imitation and habit, is the principal one. All past generations have pursued happiness and pleasure and shunned suffering, worked and played, laughed and cried, loved and hated, invented and imitated, commanded and obeyed, as ours and future generations will be like the previous ones. The spirit of man, on the other hand, cannot shirk the immutable principles of metaphysics, logic, law and morals, the laws of nature"149. This excerpt confirms our remarks according to

149 “L'histoire a été appelée, non sans raison, un éternel recommencement. L'accidentel varie, le fond - la substance, diraient les philosophes - échappe au changement. Ce fond, c'est d'abord l'être humain, toujours 
which human nature is subject to a requirement of confirmation which is related to happiness or simply security. The idea of eternal restart marks the reality of necessary permanence of this state which must be so confirmed. Since the human being cannot escape the laws of nature, he is simply compelled to seek the best means by which he would confirm them. So it is clear that humans cannot stop in this process until they have discovered these means.

However, before it is discovered, knowledge of human security, as a law of nature can allow us to envisage the potential of a form or formulation of a political order to correspond to the order of natural means through a prospective analysis of its results. That said, this form should materialize to assess its real results.

\section{CONCLUSION OF CHAPTER II}

At the end of this chapter, let us recall that we undertook to check human security, as the law of nature of political society, that is to say, its foundation and finality. This was done through the premise of the human political animality. This has been legitimized by three natural realities: the need for individual conservation, the multitude of human beings, and the human dependence on natural resources. These natural demands mean that the human political animality is a natural nature and a cultural nature. The concept of "natural nature" refers to the adequacy between the substance of human security, as a law of nature, in itself and the human experience. The substance of human security, as a law of nature, in itself means that it is already a reality, a state of affairs, a state of functioning of human nature that must be confirmed the way it is and no longer to be realized. The human experience conforms to this nature through the institution of family, that is to say, man and woman, who, naturally inclined to get closer for the needs of reproduction, make children. Family is not the result of some kind of experiential process but is lived naturally. This institution gives an account of the unity of its members for the purpose of jointly pursuing their conservation or simply the confirmation of their natural law of human security. Thus through Family, the Aristotelian postulate of the human political animality is confirmed as a natural nature. But that is not enough because Men do not always master the order of natural means by which they are called to preserve themselves

semblable à lui-même, par ses facultés, ses besoins fondamentaux, ses tendances indestructibles : la partie stable de sa nature, accentuée par l'hérédité, l'éducation, l'esprit d'imitation et l'habitude, en est la principale. Toutes les générations passées ont poursuivi le bonheur et le plaisir et fui la souffrance, travaillé et joué, ri et pleuré, aimé et haï, inventé et imité, commandé et obéi, comme la nôtre et les générations futures ressembleront aux précédentes. L'esprit de l'homme, d'autre part, ne peut se dérober aux principes immuables de la métaphysique, de la logique, du droit et de la morale, aux lois de la nature ", E. VLIETINCK, "La philosophie de l'histoire", in Revue néo-scolastique de philosophie, $25^{\mathrm{e}}$ année, $\mathrm{n}^{\circ} 97,1923, \mathrm{p} .91$ 
according to the three natural requirements underlined. Thus, they discover it through learning, what stands as the cultural nature of the human political animality. Through this latter, men discover or learn, through a process of experimentation, the best natural form or formulation or organization by which each member part of it is assured conservation. Thus men progressively understand that their relationship are formalized in a framework larger than the natural family and in a way which necessarily includes each individual subject to the same natural tendency. Thus, political society stands as this agreement, this understanding, this organization, this order whose adequate substance is assessed through the practical consequences of its formulations. Thus, when only one of the contracting parties does not, benefit of the form of the agreement, in terms of conservation, it is evidence that that form must be improved or changed because so that each one is assured to see its security guaranteed. As long as Men have not reached it, they will remain subject to the historical process of experimentation. Ultimately, it will be a process of conformation of the cultural nature of the human political animality to the level of the natural nature of this political animality, in order to confirm the adequacy between human security, as a law of nature, and the human living experience.

That way we set out to give an account of the ontological and epistemological postulates necessary to recognize to human security, its status of a true law of nature. These account for the elements of a theoretical framework for human security. This one was a necessary prerequisite to check human security as the foundation and finality of national law, which again is a prerequisite to check it as the foundation and finality of international law. 


\section{CHAPTER III: HUMAN SECURITY: FOUNDATION AND FINALITY OF NATIONAL POLITICAL ORDER IN IDEA}

After studying the general aspects of human security, as a law of nature, in this framework, we will check its application in the human experience related to political organization. This is the generic meaning to be given to the concept of "political order". National political order, or simply national law, will be understood in the general sense of national public law understood as the set of rules which govern the management of public affairs or the common good for the general interest. Political order includes a double component: the constitution or constitutional order and the government or governmental order. Constitutional order is the foundation of politics. It represents the basis on which the management of public affairs lies. Governmental order can be considered as the actual management of public affairs, the concrete initiatives aiming at satisfying the public interest, so giving a concrete form to constitutional prescriptions. Government here has a more general meaning than that which it receives in constitutional law where it refers to the political body primarily responsible for conducting national policy and representing the state in international relations. It refers to the general governmental practice. The verification of aspects of human security, as a law of nature, into the national political order is made in this framework on an empirical basis. Thus, we will summon factual data referring to political history and political current affairs. Human security, postulating to be a law of nature, has therefore a vocation to apply in all human conditions, regardless of their temporality and thus to those relating to the first historical human political organizations. We will not include them all in this framework for two main reasons. The first is the lack of absolute certainty about the data of such organizations, which are rather the subject of hypotheses and theories from specialists such as archaeologists, historians and sociologists who try to give an account of them. ${ }^{150}$ The second reason, taking into account the first, is that a law of nature, having vocation for general application, checking the human security can then be conducted for recent and current historical facts. So we will take it to a specific context of history, that of the modern state. The State being the contemporary political society and which presents itself as the main actor of international relations, this delimitation makes much more consensual data available. By so doing, our verification undertaking will be topical and thus will further allow us to properly consider human security in relation to international law whose contours are shaped by States.

\footnotetext{
${ }^{150}$ M. MANN, The Sources of Social Power, A history of power from the beginning to A.D. 1760, Vol. I,
} Cambridge University Press, New York, 1986 
That said, national political order, before standing as a set of positive rules (constitutional and governmental) is, above all, a set of ideas which receive a social consensus to be the basis on which individual conservation is undertaken National law or national political order as we understand it here, cannot therefore be ex-nihilo, that is to say, having no origin or basis, or starting from nothing. Rather, it is a set of ideas that have been "positivized" that is to say, have come to receive a legal recognition, or simply, the rule of law, so that they become enforceable, they can govern a set of behavior and activities, in short, their respect becomes mandatory. So one can really understand positive law only by understanding the idea which so comes to receive such quality or recognition. Without this, the understanding of law would only be a blind formalism whose consequences could not be advantageous for the purpose that law pursues. Thus it is necessary to dwell first on and confront the elements of human security, as a law of nature, with national political order in idea (3.1) and then with positive national political order (3.2).

Human security as foundation and finality of national political order in idea means that human security governs, through its quality of a law of nature, the meaning of the set of ideas which are destined to be transformed into positive rule. This set of ideas is understood under the generic expression of political ideology.

The term ideology is generally attributed to the French Antoine-Louis-Claude Destutt de Tracy (1754-1836) who coined it in the 18th century on the roots "idea" and "logos" to mean the science of ideas, that is to say, a general theory of knowledge. Used in this sense, ideology embraces the ideas of disciplines of all kinds. Of political nature, ideologies have therefore as object, power, precisely its configuration within a society. Power must be understood here in its general sense, that is to say, as a capacity for initiative and action in its environment of a given actor in accordance with its interests. All that relates to the exercise of power constitutes the proper object of ideology, whether, for example, the manner in which its distribution is carried out, the principle of legitimacy that founds it, its ultimate purposes, its taking, its maintenance, or removal. In addition, to the extent that they are also deployed as a political program, ideologies always represent efforts to act on the configuration of power in society. Ideologies aim to produce effects on politics. This essential aim of any ideology, (...) is declined along two opposite axes: it is either at the Left to change the world, or at the Right to preserve the order of the world ${ }^{151}$. In addition, “Any systematic and all-embracing political

151 "De nature politique, les idéologies ont donc pour objet le pouvoir, précisément sa configuration à l'intérieur d'une société. Le pouvoir doit ici être entendu dans son sens général, soit en tant que capacité d'initiative et 
doctrine, which claims to give a complete and universally applicable theory of man and society, and to derive therefrom a programme of political action. An ideology in this sense seeks to embrace everything that is relevant to man's political condition, and to issue doctrine whenever doctrine would be influential in forming or changing that condition" ${ }^{252}$. Based on these definitions, political ideologies are the idea of Law in that they postulate to give or to account for the meaning of human existence and to confirm it within the framework of the collective or political action. Law is then the expression or the form of authority of these ideas when they receive the assent or the consent, or the acceptance of social members, directly or through their representants. Ideologies are concurrent with the modern state in which they receive or apply to receive a constitutional expression (constitutional law) or governmental expression (governmental law). Their confrontation with the elements of t human security, as a law of nature, is necessary in that it would enable to verify that whatever their respective formulations, they all aim at human security, what makes of it their foundation and finality. In this sense, political ideology, referring to a conception of the world and a political program ${ }^{153}$, we discuss liberal ideology, generally considered as the center (3.2) of the Right-Left suma divisio (3. 2) of all political ideologies.

\section{HUMAN SECURITY, AS A LAW OF NATURE AND LIBERALISM}

Liberalism is the political ideology which led the American and French revolutions and which resulted in the birth of the modern state. We will consider the conception of the world and the political program which it refers to (1.1). As time went by, this concept underwent adjustments (1.2). By these different articulations, we will check the strength of the postulates of human security, as a law of nature. ${ }^{154}$

d'action dans son milieu d'un acteur donné conformément à ses intérêts. Tout ce qui a trait à l'exercice du pouvoir constitue l'objet propre de l'idéologie, que ce soit, par exemple, la manière dont s'effectue sa répartition le principe de légitimation qui le fonde, ses finalités ultimes, sa prise, son maintien ou sa destitution. De plus, dans la mesure où elles se déploient également comme programme politique, les idéologies représentent toujours des efforts en vue d'agir sur la configuration du pouvoir dans la société. Les idéologies visent à produire des effets sur le politique. Cette visée essentielle de toute idéologie, comme nous le verrons au prochain chapitre, se décline suivant deux axes opposés : il s'agit ou bien à gauche de changer le monde, ou bien à droite de préserver l'ordre du monde", D. PARENTEAU, I. PARENTEAU, Les Idéologies Politiques, Le Clivage Gauche-Droite, Presses de l'Université du Québec, 2008, p. 10

${ }^{152}$ R. SCRUTON, The Palgrave Macmillan Dictionary of Political Thought, $3^{\text {rd }}$ Ed. 2007, New York, p. 317

153 Ibid. p. 13-14

154 A. HEYWOOD, Political ideologies. An Introduction, 3. Ed., Palgrave Macmillan, 2003 ; D. PARENTEAU, I. PARENTEAU, ibid. 


\subsection{Initial liberalism and human security}

We will highlight the conception of the world (1.1.1) and the political program of liberalism (1.1.2).

\subsubsection{The World conception of liberalism}

According to the Parenteaux, liberalism revolves around the premises of freedom or liberty, equality, atomic society, mistrust to political authority and property. ${ }^{155}$

Liberty, which is read at the root of liberalism, already translates that it constitutes its main postulate. ${ }^{156}$ Liberty represents for liberalism an ideal and the most important of its main ideas, insofar as it structures its conception of the world and the political program which is inspired by it. In addition, the major influence which liberalism has enjoyed and continues to enjoy in the Western world since the beginning of modernity is linked to this ideal of liberty. It can be said that this main idea carries with it all the modernity. Because to be free, as classic liberalism understands, means first and foremost, for human beings, to be aware of themselves capable of acting on reality. In other words, to be free is for a human being to be able to influence his own life, his own destiny and the course of the world; is to be autonomous. So, to be free is to refuse to believe that the reality in which we take place is something immutable or fixed for eternity, since we can act on it, so that the real can conform with the way we want it to be. However, it is precisely such a conception of reality which is at the foundation of modernity, a conception which starts from a refusal to see reality as something fixed and unchanging. Liberty and openness to a universe of possibilities, to an open reality since it is malleable, are very closely linked ${ }^{157}$. Thus on the basis of the principle of Liberty, liberals will work for the liberation of individuals from the Ancients' conception of the world. Thus embodying the Moderns, they

\footnotetext{
${ }^{155}$ D. PARENTEAU, I. PARENTEAU, ibid. p. 42

${ }^{156}$ M. CRANSTON, "Liberalism”, in P. EDWARDS (Ed.), The Encyclopedia of Philosophy, Macmillan and the Free Press, New York, 1967, p. 459

157 “La liberté représente pour le libéralisme un idéal et la plus importante de ses idées maîtresses, dans la mesure où elle structure sa conception du monde et le programme politique qui s'en inspire. De plus, l'influence majeure dont a pu jouir et continue de jouir le libéralisme en Occident depuis le début de la modernité est liée à cet idéal de la liberté. Sans trop exagérer, on peut dire que cette idée maîtresse porte en elle toute la modernité. Car être libre, ainsi que l'entend le libéralisme classique, signifie d'abord et avant tout, pour les êtres humains, se savoir capables d'agir sur le réel. Autrement dit, être libre, c'est le fait pour un être humain de pouvoir exercer une influence sur sa vie, sur sa destinée et sur le cours du monde; c'est être autonome. Du coup, être libre, c'est refuser de croire que la réalité dans laquelle nous prenons place est quelque chose d'immuable ou de fixe pour l'éternité, puisqu'il nous est possible d'agir sur elle, afin que le réel puisse s'accorder avec la manière dont on souhaite qu'il soit. Or, c'est précisément pareille conception de la réalité qui est au fondement de la modernité, conception qui part d'un refus de voir la réalité comme quelque chose de fixe et d'immuable. Liberté et ouverture sur un univers de possibles, sur une réalité ouverte puisque malléable, sont bien intimement liées", D. PARENTEAU, I. PARENTEAU, op. cit.
} 
have succeeded in overcoming the constraints that reality has come to be taken as something changeable.

First, Liberalism understand Liberty at the individual level. The individual, as the person taken individually, is the bearer or agent of this Liberty. ${ }^{158}$ According to Benjamin Constant, contrary to the ancient conception, freedom is not primarily the attribute of the city, the kingdom or the country, in short, of a community, but an attribute of each member of society, taken individually, by which he/she is able to exercise it for him/herself and in his/her own name. ${ }^{159}$

Second, if liberty is among the essential attributes of the individual, it is due to its natural origin; the individual is born free, $\mathrm{s} / \mathrm{he}$ does not become free ${ }^{160}$. Liberty is thus understood as a matter of privilege granted to individuals by others, for instance, those in power or some political organization. In this sense Liberty cannot be a creation of the human being, and therefore, similarly to natural sciences, it is somehow inscribed in the genetic code of humanity; the human being carries it within him/her from birth. Liberty can also be looked as the driving principle of the life; all actions of individuals and their ways of conceiving the world are conditioned by its research and its preservation. According to liberalism, this human attribute is so essential that, when it happens that individuals are dispossessed of it, it is then natural for the latter to strive to get it back. ${ }^{161}$ In that sense Etienne de la Boétie noted that "We were not only born with it (liberty), but also with the passion to defend it" ${ }^{\prime 162}$. So, the human being is free and wishes to remain so. To support liberty as an essential attribute of human nature, liberalism bases on a conceptual distinction opposing two systems of Law within which freedom is enshrined: natural Law and positive law. Positive law refers to the set of artificial laws, instituted as a legal system in all political societies of the world, a system created by human beings and which therefore based on a convention. In order to support liberty as written in human nature, the early liberals proclaimed that beyond positive law there is a more fundamental law, a kind of system of natural laws whose scope is universal and which therefore applies to any individual, regardless of the particular society to which s/he belongs and

\footnotetext{
${ }^{158}$ Ibid. p. 43

${ }^{159}$ B. CONSTANT, "De la liberté des anciens comparée à celle des modernes", Discours prononcé à l'Athénée royal de Paris en 1819, cité par A. LAQUIEZE, "Benjamin Constant et l'Acte Additionnel aux Constitutions de l'Empire du 22 Avril 1815”, op. cit. p. 217 Voir aussi, J. S. MILL, On Liberty, London, 1910, p. 73, cité par M. FREEDEN, Ideologies and Political Theory: A Conceptual, Approach, Clarendon Press, Oxford, p. $145 ; \mathrm{H}$. CERUTTI-GULDBERG, "Liberalism”, in E. CRAIG, (Ed.), The Shorter Routledge Encyclopedia of Philosophy, 2005 Routledge, New York, p. 572

${ }^{160}$ D. PARENTEAU, I. PARENTEAU, op. cit. p. 43

${ }^{161}$ D. PARENTEAU, I. PARENTEAU, Ibid. ; J. LOCKE, The Second Treatise of Government in Two Treatises of Government, 1689, P. LASLETT, (Ed.), Cambridge University Press, Cambridge, 1960, p. 287

${ }^{162}$ E. de la BOETIE, Discours de la servitude volontaire, 1548
} 
regardless of the era s/he lives. Natural law, in other words the law of nature, is thus conceived as being prior to positive law. This distinction serves to establish the fundamental character of liberty of individuals: if individuals are free, this is not the result of a decree supported by positive law, as if it were a privilege granted to individuals by political authorities, but of natural law, of this system of laws inscribed in the nature of the human being"163.

Third, classical liberalism apprehends liberty in negative terms. "Negative" liberty, according to Isaiah Berlin, as opposes to "positive" liberty, is defined as a state marked by absence of external constraints; anyone free is s/he who can act as s/he sees fit insofar no external limitation is exerted on him, whether these limitations emanate from the State, for example any prohibition law, from society, for example a traditional practice ruling precise behavior, or even from others, for example the weight of the group which can exert influence some behaviour. The second, which is said to be "positive", refers to a state in which a person or a community recognizes itself as being in control of itself and its destiny; in this sense, is free, s/he who has the capacity to exercise by and for him/herself his/her liberty. ${ }^{164}$

How then can liberalism be approached from the perspective of human security, as a law of nature?

Human security has been understood as the state consubstantial with human nature, thus accounting for the order of this nature. Human security is thus part of the very essence of human nature, so that it is itself only in security. Being a perfect existent and therefore a reality, it does

\footnotetext{
163 "Pour venir soutenir l'idée du caractère naturel de la liberté des individus, le libéralisme va s'appuyer sur une distinction conceptuelle qui met en opposition deux systèmes de droits distincts au sein desquels s'inscrit la liberté: le premier est dit «droit naturel» et le second «droit positif». Le droit positif désigne le système des lois artificielles, celles qui prévalent dans toutes les sociétés du monde en tant que système légal, système créé par les êtres humains et qui découle donc d'une convention. Afin de venir appuyer l'idée que la liberté est inscrite dans la nature de l'être humain, les premiers penseurs libéraux proclament qu'au-delà du droit positif il existe un droit plus fondamental, une sorte de système de lois naturelles dont la portée serait universelle - qui vaudrait donc pour tout individu, sans égard à la société particulière dans laquelle il s'inscrit et peu importe l'époque à laquelle il vit. Le droit naturel, autrement dit la loi de la nature, est ainsi conçu comme étant antérieure au droit positif. Aussi cette distinction sert-elle à consacrer le caractère fondamental de la liberté des individus: si les individus sont libres, cela ne tient pas d'un décret trouvant appui sur le droit positif, comme si cela était un privilège accordé aux individus par les pouvoirs politiques, mais bien du droit naturel, de ce système de lois inscrites dans la nature de l'être humain", in D. PARENTEAU, I. PARENTEAU, op. cit. p. 44

${ }^{164}$ I. BERLIN, "Two Concepts of Liberty", in his Four Essays on Liberty, Oxford University Press, Oxford, 1969, p. 122; See also Ch. TAYLOR, "What's Wrong with Negative Liberty", in The Idea of Freedom, A. Ryan (Ed.), Oxford: Oxford University Press, 1979; pp.175-93; Th. H. GREEN, Lectures on the Principles of Political Obligation and Other Essays, 1895, P. HARRIS and J. MORROW (Eds.), Cambridge University Press, Cambridge, 1986, pp. 228-229; B. BOSANQUET, Philosophical Theory of the State in Philosophical Theory of the State and Related Essays, 1923, G. F. GAUS, W. SWEET (Eds.), St. Augustine Press, Indianapolis, 2001; S. I. BENN, A Theory of Freedom, Cambridge University Press, Cambridge, 1988; G. DWORKIN, The Theory and Practice of Autonomy, Cambridge University Press, Cambridge, 1988; J. RAZ, The Morality of Freedom, Clarendon Press, Oxford, 1986, J. CHRISTMAN, J. ANDERSON, (Eds.) Autonomy and Challenges to Liberalism, Cambridge, University Press, Cambridge, 2005
} 
no longer have to be created or become real, but to be confirmed as it is. This is possible by the necessary human tendency to conservation. In this order of consideration, liberty has been noted as falling within this nature, both as an ontological attribute and as a means of general confirmation of the intrinsic state of security. Human beings are therefore essentially free; free as a natural way of being and free as a natural disposition to conserve themselves or to work for their conservation in their general way of being or as they think it suitable for themselves. Liberty has been distinguished from license in the sense that the latter refers to a disorderly behaviour which certainly leads to the non-conservation of its perpetrator or of other people. Therefore license cannot be part of the natural order of means necessary to confirm human security. Liberty therefore basically refers to an order since it results to human conservation. Thus it conforms to an order of natural means which allows the confirmation of human security. If this order is not understood by the individual, s/he is doomed to support the consequences of his/her free deeds. In this understanding, liberty in the substance of human security, as a law of nature corresponds to the way liberalism understands it. Not only is it a natural attribute specific to each individual, but also it is the means by which each one ensures its conservation in the own way s/he conceives it and for the consequences that this implies on and for him/herself. Liberty from both perspectives is therefore a matter of individual sovereignty. We can then say that liberal liberty can correspond to the liberty in the substance of human security.

Equality is the second premise of liberalism. All human beings are essentially equal; they all have the same intrinsic value. This equality is generally apprehended in its numerical sense in that it devotes the same intrinsic value for each individual, and this, compared to all others taken one by one. Etienne de La Boétie eloquently expresses this idea of numerical equality in these terms: "What is clear and obvious, that no one can ignore, is that the nature, minister of God, governess of men, created and in a way mould us all the same, to show us that we are all equal, or rather brothers" 165 .

This conception of society differs from the one that prevailed in the Western World, from Antiquity until the end of the Renaissance, and that rested on a natural hierarchy among human beings, whose unequal distribution of status and ranks within the population was at the heart of politics and enshrined in law. This is evidenced by the fact that there exists in all pre-modern societies a legal system in which there is always a dominant class, whose members enjoy a

165 We translate from : “Ce qu'il y a de clair et d'évident, que personne ne peut ignorer, c'est que la nature, ministre de Dieu, gouvernante des hommes, nous a tous créés et coulés en quelque sorte dans le même moule, pour nous montrer que nous sommes tous égaux, ou plutôt frères", in E. de la BOETIE, op. cit. 
superiority in status and privileges over the rest of population. We must, for example, identify the freemen in the Athenian city at the time of Plato and Aristotle, the patricians in ancient Rome, the aristocrats in the different kingdoms of medieval Europe. Liberalism cannot share this inequality as belonging to the nature of things, as it was understood in the Ancient western world, because, human beings are fundamentally equal; none is inherently superior to others. ${ }^{166}$ According to liberalism, the same as liberty, equality between human beings holds, as their natural constitution. All human beings are born equal; this equality is stamped in what they are naturally. It is not a privilege which would be granted to human beings by institutions or by political power; in this sense, equality is not a creation of these, but a fact of nature. ${ }^{167}$

In fact, this natural equality rests mainly on three basic natural conditions shared by the whole of mankind.

First, if human beings are naturally equal, it is because they share the same physical condition. In any society, there are (and always will be) differences in the physical capacities among individuals, some being stronger than others, more agile, more resistant, etc. However, although these differences which separate individuals are indisputable, they appear to be very relative altogether, when we compare what distinguishes the human race as a whole from other animal species. In other words, the resemblances which exist among human beings, in terms of physical capacities, are ultimately much greater than the differences which separate them. Also, the strongest of men is not strong enough to claim a status higher than that of others. ${ }^{168}$

Second, this equality is also based on the sharing of an equivalent intellectual condition among human beings. As with physical abilities, what differentiates individuals in terms of their thinking skills, that is, what makes some people more intelligent than others, more imaginative, than they demonstrate a better capacity for analysis, appears relatively incidental in comparison with what brings them all together, as being endowed with the faculty of reason. ${ }^{169}$

\footnotetext{
${ }^{166}$ D. PARENTEAU, I. PARENTEAU, op. cit. p. 44

167 “De plus, comme la liberté, cette égalité parmi les êtres humains tient selon le libéralisme de la constitution naturelle de ces derniers. Tous les êtres humains naissent égaux; cette égalité est inscrite dans ce qu'ils sont naturellement. Elle n'est point un privilège qui serait octroyé aux êtres humains par les institutions ou par le pouvoir politique ; en ce sens, l'égalité n'est pas une création de ces derniers, mais un fait de la nature.", D. PARENTEAU, I. PARENTEAU, Ibid. pp. 47-48 ; See also, R. BELLAMY, op. cit. M. FREEDEN, op. cit, pp. 160- 161; A. HEYWOOD, op. cit. pp. 28-29; E.S, ANDERSON, "What Is the Point of Equality?", in Ethics, n 109, 1999, pp. 287-337; A. Sen, Inequality Reexamined, Harvard University Press, 1992; I. M. YOUNG, Justice and the Politics of Difference, Princeton University Press, 1990; H. CERUTTI-GULDBERG, op. cit. p. 570 University Press, 1990; H. CERUTTI-GULDBERG, op. cit. p. 570

${ }^{168}$ D. PARENTEAU, I. PARENTEAU, Ibid.

${ }^{169}$ D. PARENTEAU, I. PARENTEAU, Ibid. p. 48; M. FREEDEN, op. cit. p. 160
} 
Third, this equality among individuals results from the fact that they form a "community of interests", that is to say, they all share, with few differences, similar interests. Almost all human beings aspire to similar ideals, and they all seek to satisfy the same basic needs. This, moreover, largely accounts for the almost inevitable nature of conflict among human beings. Everyone wants to get the same things, so human beings have an inevitable tendency to continually come into conflict with each other so that they can get their hands on those things that everyone covets. ${ }^{170}$

From the perspective of human security, as a law of nature, equality between individuals necessarily follows from the attribute of liberty. Since all human beings have an equal nature and are subject to it, to the same tendency of confirmation, individuals are essentially equal. We have seen that human nature is one in its essence, so it is impossible that individualities of this nature be not equal. There is no question here of doubting the peculiarities of these individuals or the different contexts or situations they may face. It is just a matter of knowing that human nature being itself only in the state of human security, this one being so the foundation and the finality of human life, all individuals are necessarily equal. It must therefore be recognized with liberalism that equality is a fact of nature. No one can therefore ever be legitimately justified in imposing him/herself on any other. Each one, with a view to its own conservation, is called to exercise his/her freedom and bear the consequences for himself, without infringing on the freedom of others, unless the latter consented to, which still implies freedom. Equality between individuals also presupposes an order, that of adequate means for confirming the intrinsic state of human security. All seeking to conserve themselves, human beings who need the resources of nature, have no other choice but to do so on an egalitarian basis of individual sovereignty. If they act based on an inequality basis, wanting for example to take advantage of false and abusive means of superiority, they all incur their loss because the state of nature this would translate, inescapably causes everyone's insecurity. The Ancient Western world was ruled as such, and because of the negative consequences of that, revolutions were held to abolish it. This is evidenced without the need for additional proof and accounts for the fact that inequality between individuals is essentially false and that it ends up being known as part of the historical process of learning implied by human security. Equality, in its liberal understanding, therefore falls within the substance of human security.

The third premise of liberalism is its way of apprehending society: atomistic. "According to liberalism, every human being is first and foremost an "individual", that is to say, he

${ }^{170}$ D. PARENTEAU, I. PARENTEAU, Ibid 
constitutes a sort of "atom"- human beings represent the smallest "indivisible entity"; they are "individuals". Naturally free, holder of inalienable rights, to the pursuit of his own interests which it is up to him, and him alone, to determine, the individual enjoys an almost perfect autonomy vis-à-vis individuals who surround it and, above all, the society in which it takes place. The individual somehow represents the "foundation of society", to the extent that it precedes it. Thus, in the liberal conception of society, it is conceived as being nothing more than a simple aggregate, that of individuals who are members of it. Deprived of its own essence, society appears as an external element which somehow comes to be grafted onto the individuals who compose it, as a simple "derivative originating from cohabitation, within the same territorial horizon and history, of a collection of individuals"171

The liberal conception of political society cannot be the same as the ancient one according to which society was a totality. Thus individuals were part of that collective person whose existence prevailed over others. It was then a holistic concept of society. According to liberals, society stands as the simple addition of the individuals who make it up. It has no greater value than the individuals who are members of it. However, western ancient societies conceived society as a whole, as a kind of collective being, having its own existence and enjoying a preponderance vis-à-vis the members who made them up, and who were subordinate to it. In this conception, the whole always represents more than the sum of its parts, because it has its own essence ${ }^{172}$. Based on the principles of liberty and equality, liberalism overturns this concept of equality.

"In the name of the ideal of individual liberty, liberalism is opposed to the strong social cohesion that is found in traditional societies. If holistic society derives its harmony from the attribution of distinct roles for each of the subgroups which compose it, it must still be said that this harmony always rests on a strong social cohesion, that the society exercises on all its members, both human beings taken individually and the sub-groups into which they belong, so

\footnotetext{
${ }^{171}$ We translate from: "Pour le libéralisme, tout être humain est d'abord et avant tout un « individu », c'est-à-dire qu'il constitue en quelque sorte un " atome » - les êtres humains représentent la plus petite entité "indivisible »; ils sont des «individus». Naturellement libre, détenteur de droits inaliénables, à la poursuite de ses propres intérêts qu'il revient à lui, et à lui seul, de déterminer, l'individu jouit d'une autonomie presque parfaite vis-à-vis des individus qui l'entourent et, par-dessus tout, de la société au sein de laquelle il prend place. L'individu représente en quelque sorte le «fondement de la société», dans la mesure où il la précède. Ainsi, dans la conception libérale de la société, celle-ci est conçue comme n'étant rien d'autre qu'un simple agrégat, celui des individus qui en sont membres. Privée d'essence propre, la société s'affiche comme un élément extérieur qui vient en quelque sorte se greffer aux individus qui la composent, comme un simple "dérivé » provenant de la cohabitation, à l'intérieur d'un même horizon territorial et historique, d'une collection d'individus", Ibid. p. 53

172 Ibid. p. 53
} 
that the latter remain where society wants them to be assigned. Holistic societies are indeed always based on diffuse mechanisms of authority and influence directed towards its members, mechanisms that are decisive for the latter in that they reinforce the idea that they all derive their identity of their relation to the whole (...) Now if the human being has been able to rise to the status of individual, to be autonomous and the new foundation of society, it is because he is fundamentally a being of liberty. Human beings are not dependent on anyone or anything to live their life: there are no constraints that can limit the way they intend to live their life. The individual knows what he wants and he covets what is good for him. Its existence does not have to be determined by society; the individual is the only master of his life"

"In the name of the ideal of equality, the liberal family refutes the principle of diversity on which holistic societies are founded. Any holistic society always draws its coherence and its harmony from the internal arrangement of the different parts which constitute it, that is to say, from the different sub-groups (states, orders, classes, castes, etc.) that it carries within it. (...) Now, the ideal of equality which is the foundation of liberalism is intended to overturn this principle, asserting rather the non-difference of all human beings on the basis of their natural equality. In this sense, from a traditional point of view, the ideal of equality defended by liberalism does indeed carry within it a certain "uniformizing" aim, a dynamic that is contrary to the spirit of distinction and social hierarchy on which rest holistic societies"174.

\footnotetext{
173 We translate from : “Au nom de l'idéal de liberté individuelle, le libéralisme s'oppose à la forte cohésion sociale que l'on trouve dans les sociétés traditionnelles. Si la société holistique tire son harmonie de l'attribution de rôles distincts pour chacun des sous-groupes qui la composent, encore faut-il dire que cette harmonie repose toujours sur une forte cohésion sociale, qu'exerce la société sur tous ses membres, tant les êtres humains pris individuellement que les sous-groupes dans lesquels ils s'insèrent, afin que ces derniers demeurent là où la société les veut assignés. Les sociétés holistiques reposent en effet toujours sur des mécanismes diffus d'autorité et d'influence dirigés à l'endroit de ses membres, mécanismes qui sont déterminants pour ces derniers en ce qu'ils viennent renforcer l'idée qu'ils tirent tous leur identité de leur relation au tout. Dans les sociétés holistiques, point d'existence propre pour les êtres humains en dehors de leur place à l'intérieur de la société. Concrètement, c'est ce dont témoigne le fait que, dans les sociétés anciennes, les êtres humains jouissent toujours de moins de libertés individuelles que dans les sociétés libérales, la société et son impératif de cohésion sociale ayant préséance sur les individus. Or, que le libéralisme soit parvenu à renverser cette conception de la société repose sur la grande confiance que celui-ci place dans les capacités des individus. En effet, si l'être humain a pu s'élever au statut d'individu, d'être autonome et de nouveau fondement de la société, c'est qu'il est fondamentalement un être de liberté. L'être humain n'est pas dépendant de quiconque ni de quoi que ce soit pour vivre sa vie : il n'existe aucune contrainte qui puisse venir limiter la manière dont il entend vivre sa vie. L'individu sait ce qu'il désire et il convoite ce qui est bon pour lui. Son existence n'a pas à être déterminée par la société; l'individu est le seul maître d'œuvre de sa vie.", Ibid. p. 54-55

${ }^{174}$ We translate from : “Au nom de l'idéal d'égalité, la famille libérale réfute le principe de diversité sur lequel se fondent les sociétés holistiques. Toute société holistique tire toujours sa cohérence et son harmonie de l'agencement interne des différentes parties qui la composent, soit des différents sous-groupes (états, ordres, classes, castes, etc.) qu'elle porte en elle. Concrètement, cet agencement, qui repose sur la hiérarchie dite naturelle des êtres humains, prend la forme d'un système de privilèges et de droits différents pour chacun des sous-groupes, mais aussi de l'attribution de rôles distincts pour ceux-ci. Or, l'idéal d'égalité qui est au fondement du libéralisme se veut le renversement de ce principe, affirmant plutôt la non différence de tous les êtres humains
} 
From the point of view of human security, as a law of nature, it is clear that the individual is the fundamental reference. Understanding the necessary tendency of human nature as a permanent confirmation of the intrinsic state of security, it accounts for the atomistic conception of society. Indeed, if individual life is motivated only by its own conservation, then it becomes the foundation and the finality of human life. In this sense, society has only an instrumental function and then falls within the framework of the order of natural means for the confirmation of the human security intrinsic state of affairs. It exists only for this purpose. Society therefore has as its foundation and finality (the conservation of) each individual coexisting with others. Thus a holistic conception of society, which would go beyond this instrumental sense, is false because it would aim at giving it a sense of finality that it would certainly remove from the individual. We understand that such a conception could only have negative consequences for individual conservation and it is why it had caused revolutions, because it was illogically turned towards the conservation of society. But in reality, it must be recognized that, being nothing in itself than the fact of individuals, (because without individuals, there is no society), society could not therefore constitute a finality in itself and a holistic society, through this false conception would necessarily benefit to some people who would pull the strings. In the Ancient Western Society, these people were monarchs and other privileged classes at the expense of the lower class. The atomic society of liberals is a consequence of individual sovereignty which refers to liberty and implies equality. In the logic of individual preservation, society cannot have any other foundation. Thus and again, liberalism returns in the forecasts of human security.

The other premise of liberalism is mistrust towards political authority. This mistrust originates from the atomistic conception of society which is specific to this ideology. Indeed, in this perspective, where individuals are considered to be the foundation of society and where, by extension, it is perceived as something external coming to be grafted on to them, all political power, or all authority dedicated to the governance of society is looked with suspicion, or as a potential impediment to the full enjoyment of individual liberty. ${ }^{175}$

This mistrust of any political authority originates in the first political battles led by classical liberalism, which may have contributed to making this new thought, this new political force, a real ideological whole. Indeed, one of the main unifying elements of the political forces and ideas which gave birth to liberal ideologies is a radical rejection of "absolutist" political

sur la base de leur égalité naturelle. En ce sens, d'un point de vue traditionnel, l'idéal d'égalité défendu par le libéralisme porte bien en lui une certaine visée "uniformisante», dynamique qui est contraire à l'esprit de distinction et de hiérarchie sociale sur lequel reposent les sociétés holistiques.” Ibid. p. 54

${ }^{175}$ Ibid. p. 55 
regimes, such as those which were in force in Europe before the modern era. These rested on a hierarchical and holistic conception of society at the head of which was sitting a monarch who, believing that he had his authority from God and his title from a hereditary descent, exercised his political power without limits on society and its members. Consequently there was no power sharing and no possible opposition. ${ }^{176}$

Although liberalism condemns absolutism, it does not simply reject the principle of authority by opposing any form of political authority. Thus Liberal is not to be thought as sharing or enshrining some anarchist postulates, since this ideology does have a positive conception of power, that is to say a particular way of conceiving it, notably with regard to its origins, its methods of application and its ends. The mistrust of Liberalism towards political authority targets first and foremost at a tendency inherent in all power, to which precisely European absolutism, which is to become abusive, has largely succumbed. According to Liberalism, this tendency seems to be in some way part of the very nature of all political power. As Montesquieu opined "it is an eternal experience that any man who has power is prone to abuse it". All power inevitably tends to overflow from its place of origin to exercise itself, with excess, beyond its original destiny. This tendency is revealed by two of the main features of European absolutist regimes: their authoritarianism and their arbitrary nature. ${ }^{177}$

What analysis should be made of the liberal mistrust towards political authority within the framework of human security, as a law of nature? The mistrust to political authority relates to human security, as a law of nature, in the sense of the final order of means by which it can adequately be confirmed. Indeed, according to the aspects of human security, as a law of nature, it is the foundation and finality of political society. A political authority which instead of serving each individual conservation, but only that of some on a discriminatory basis, turns out to be a germ of insecurity. Political authority, which generally impacts on individual life, can undermine individual conservation if it is exercised improperly and favour it when it is exercised well. Since the natural tendency is conservation and in view of the negative consequences that it generally suffers under the influence of absolute regimes, liberal mistrust is legitimate and can only arouse firm attention on the structuration of political power. The liberal mistrust is reflected, within the framework of the historical process of experimentation, by the progressive education of the human being on the order of natural means which adequately confirm the human security, as order of human nature. The painful experience through the

\footnotetext{
${ }^{176}$ Ibid. p. 56; See also A. HEYWOOD, op. cit.

177 Ibid.
} 
negative consequences on the conservation of certain configurations of political power teaches, by these consequences, that they are false configurations which must be improved or changed. Since liberals are aware of the negative consequences of absolute power, they are suspicious of it and will make sure that they no longer adopt all the political configurations likely to lead to it. Thus this mistrust of liberalism still falls within the theoretical framework of human security. The last postulate of liberalism relates to property. For liberalism, liberty enjoyed by individuals is not limited simply to that of control of their bodies, but also to the possession of the things that surround them and which they use to satisfy their needs and their interests, meaning their properties ${ }^{178}$

Importance of this question of property is due to the fact that, from the liberal perspective, property is conceived as a simple extension of oneself, as an extension of the individual freedom of which all human beings are owners. This right to property is therefore part of liberalism, alongside other rights available to all individuals, by virtue of their nature. The right of property is rightly found in all major charters or liberal declarations of rights. Article 17 of the Declaration of the Rights of Man and of the Citizen of 1789 is an example: "Property being an inviolable and sacred right, no one can be deprived of it, except when public necessity, legally established, obviously requires it, and subject to just and prior compensation" ${ }^{179}$.

The rise of the bourgeoisie, if it is certainly explained in large part by the emergence of capitalism, is nevertheless also largely attributable to the spread of the liberal worldview and to political action carried out in the name of this ideology. Among the characteristic ideas of liberalism, the question of property is undoubtedly one of the most decisive for the bourgeoisie. It should be remembered that this question constitutes one of the main workhorses of this social class in the early days of modernity. In the Ancient Regime property rights were a privilege granted only to higher-ranked social classes, with the great liberal modern revolutions there will be an extension of this natural right to all. ${ }^{180}$

From the perspective of human security, as a law of nature, due to his/her physical and rational nature, the human being necessarily conserves him/herself on the basis of natural resources. In this logic, these can only lead to an appropriation of individuals who would use them. In the event that nature's resources are sufficient for everyone, everyone should ensure their conservation. But in the opposite hypothesis, property becomes a necessity because it responds

\footnotetext{
${ }^{178}$ Ibid. p. 60

${ }^{179}$ Ibid. p. 61

${ }^{180}$ Ibid.
} 
to the logic of permanence of conservation. In this case, it must be protected since it is part of the person of the individual who uses it. Each individual being free and equal to others to secure the means of its conservation, as long as an individual has legitimately appropriated his means of conservation, that is to say, does not harm anyone, then s/he is entitled to undergo no kind of interference without his/her consent. Property is therefore a consequence of liberty and equality, but it also implies a common starting point which is nature. Availability for all and enjoyment by all of these resources is the cause of all political organization. Since these are coveted by all, it is possible that selfishness leads them to conflicts whose consequence is ultimately the conservation of no one. So the resolution of each individual with others on an organization for the management of these resources for the benefit of each, resolution that fundamentally represents political society, is the only way for each to conserve itself. Such an agreement cannot fail to govern the question of ownership. Whatever its source, no one can consent to a political organization which does not guarantee the necessary minimum for its conservation. So the Ancient Western Society that did not provide means of conservation for everyone finally aroused revolutionary demands. Liberals' emphasis on property thus fits with the theoretical framework of human security.

It must therefore be said that the postulates of liberalism well match with those of human security. The resulting political program can have as its purpose but working so that these postulates become concrete. Let's find it out.

\subsubsection{The Political Program of Liberalism}

Liberalism provides a political program adapted to its various postulates of freedom of equality, atomic society and mistrust towards political authority. We will analyze dwell on each of them. Based on the principle of liberty, liberalism agrees with a political program which more directly arises from the distinction between natural right-political rights. "Concretely, this idea that liberty is a matter of natural law is articulated in the political program of liberalism through the recognition of rights and inalienable liberties for all individuals. Since liberty is somehow "sacred", no government or leader, no matter what the context, should be allowed to infringe this inviolable right. So we could hear during the troubles of July 1789 the French revolutionaries chanting "Liberty or death!" Individuals enjoy natural rights and all the political action of liberalism is an effort to impose these rights where they are not recognized, to strengthen them where they remain fragile and to preserve them where they are threatened. It is this idea of existence of such natural liberty that will give birth to the great declarations and charters of human rights and liberties, as we find them formulated during most of the great 
political revolutions of Modernity, whether the Bill of Rights enacted in England in 1689 following the Glorious Revolution, the Declaration of Independence of the United States of America of 1776 (which includes in its first part an important declaration on the rights of citizens) formalizing the secession of the British colony of America from its mother country and the Declaration of the rights of the Man and the Citizen of 1789 at the time of the French Revolution. We can thus read, for example, in article 1 of this last declaration that "men are born and remain free and equal in rights"181

From the perspective of human security, as a law of nature, the political program which befits liberty is that protecting liberty. In this sense, liberty is political and that is what translates the idea of political rights. Since freedom is both an ontological attribute and a means of confirming the human security intrinsic state of affairs, political society is not only the necessary result of them, but also an instrument which aims at guaranteeing them. Thus a political program which is not centered on human rights cannot be an effective instrument for the conservation of individuals. The well-known case of that is the premodern western society, which was not a society of rights and the negative consequences in terms of individual conservation it had led to provoked revolutionary reactions resulting in the Modern State. Thus, a political program which is not based on individual liberties and which does not have for purpose, to protect them is doomed to be known not falling within the framework of the natural means for confirming human security. The process of historical experimentation enables to know that in the long run. The political program of liberalism with regard to liberty is thus in conformity with the theoretical framework of human security.

With regard to equality, "The political action of liberalism is based on the acceptance that equality among human beings is a natural right which must be protected and that any fundamental questioning of this equality cannot be accepted - and this, according to varying

\footnotetext{
${ }^{181}$ We translate from "Concrètement, cette idée que la liberté relève du droit naturel s'articule dans le programme politique du libéralisme par le biais de la reconnaissance de droits et de libertés inaliénables pour tous les individus. La liberté étant en quelque sorte "sacrée », aucun gouvernement ni aucun dirigeant, et cela, peu importe le contexte, ne devraient être autorisés à enfreindre ce droit inviolable. Aussi pouvait-on entendre durant les troubles de juillet 1789 les révolutionnaires français scander « La liberté ou la mort! » Les individus jouissent de droits naturels et toute l'action politique du libéralisme se veut un effort afin d'imposer ces droits là où ils ne sont pas reconnus, de les renforcer là où ils demeurent fragiles et de les préserver là où ils sont menacés. C'est cette idée de l'existence d'une telle liberté naturelle qui va donner naissance aux grandes déclarations et chartes de droits et libertés de la personne, telles qu'on les trouve formulées à l'occasion de la plupart des grandes révolutions politiques de la modernité, que ce soit le Bill of Rights déclaration des droits) édicté en Angleterre en 1689 à la suite de la Glorieuse Révolution, la Déclaration d'indépendance des États-Unis d'Amérique de 1776 (qui comporte dans sa première partie une importante déclaration quant aux droits des citoyens) officialisant la sécession de la colonie britannique d'Amérique de sa mère patrie et la Déclaration des droits de l'homme et du citoyen de 1789 au moment de la Révolution française. On peut ainsi lire, par exemple, à l'article premier de cette dernière déclaration que "les hommes naissent et demeurent libres et égaux en droits", Ibid. p. 44
} 
levels of tolerance for inequality found within this vast ideological family. It is this idea which is enshrined for example in the second paragraph of the Declaration of Independence of the United States of America written by Thomas Jefferson: "We take these truths for obvious by themselves: that all men are born equal, that the Creator has endowed them with certain inalienable rights, including life, freedom and the pursuit of happiness". Admission of this natural equality among human beings will bring about three major political reforms in societies where liberalism will succeed in imposing itself following the great political revolutions which will shake up modernity: abolition of privileges, birth of democracy and adoption of the rule of the majority" 182

From the point of view of human security, as a law of nature, the political program which confirms natural equality is certainly one which still guarantees the rights and freedoms of everyone on an egalitarian basis. Based on the theoretical framework of human security, political society is essentially the product of a consent of each individual to be part of it. Consequently, no consenter could admit that such an organization would lead to unequal treatment against him/her. Political society, as it returns to the order of means to confirming the human security intrinsic state of affairs, can be understood as a synallagmatic contract between each individual and all the others, taken individually. Yet any synallagmatic contract basically means equality of rights and obligations. No political society whose formulation would lead to an inequality in the enjoyment of conservation resources is doomed only to the fate of being known unreal because it will necessarily imply rejection and the formulation of another supposed to guarantee equality will be privileged. For example, the premodern western society was a society of unequal classes and all did not enjoy the same privileges. We can therefore understand why liberalism favours a political program banishing them and why the revolutions towards the modern state have been successful. Within the framework of human security, it is not a question of saying that they have succeeded, it is a question of knowing that the order of natural means for the confirmation of human security is discovered or is known by experience. Individual sovereignty therefore implies inviolable political equality. Thus democracy which

\footnotetext{
${ }^{182}$ We translate from "L'action politique du libéralisme se fonde sur l'acceptation que l'égalité parmi les êtres humains relève d'un droit naturel qui doit être protégé et que toute remise en cause fondamentale de cette égalité ne peut être acceptée - et cela, en fonction de divers niveaux de tolérance aux inégalités que l'on trouve au sein de cette vaste famille idéologique. C'est cette idée qui se trouve enchâssée par exemple dans le second paragraphe de la Déclaration d'indépendance des États-Unis d'Amérique rédigée par Thomas Jefferson : «Nous tenons ces vérités pour évidentes par elles-mêmes: que tous les hommes naissent égaux, que le Créateur les a dotés de certains droits inaliénables, parmi lesquels la vie, la liberté et la recherche du bonheur.» L'admission de cette égalité naturelle parmi les êtres humains va entraîner trois réformes politiques majeures dans les sociétés où le libéralisme va parvenir à s'imposer à la suite des grandes révolutions politiques qui secoueront la modernité : l'abolition des privilèges, la naissance de la démocratie et l'adoption de la règle de la majorité ", Ibid. p. 49
} 
advocates the sovereignty of the people can only be the adequate regime which confirms human security. Thus again the political program of liberalism with regard to equality is in conformity with human security, as a law of nature.

Regarding the principle of atomistic society, "Empowerment of individuals vis-à-vis society leads to the birth of a previously unknown division of traditional societies, but which will play a central role in liberalism, between what must now be called the "private sphere" and the "public sphere". Thus freed from this existential determination with regard to society, individuals can now claim an exclusive or private sphere of action over which society will be prohibited from having control, as an area cut off from the whole and from its influence. In this private sphere, a place of personal development withdrawn from society, the individual can therefore reign as master, as sovereign, live his life as he wishes. In contrast, what we call the public sphere designates all the remaining space, that which remains shared among individuals and which results from their coexistence within the same society. This sphere is the privileged place of politics, like the place of power struggles over society". ${ }^{183}$

From the perspective of human security, as a law of nature, the political program relating to the atomic society implies the one in which individual liberty is confirmed. Since the individual is free to seek conservation in a way that does not improperly infringe on the freedom of others, political society should guarantee a sphere of expression. Let us remember that, in the democratic context, popular sovereignty means less collective sovereignty than the sum of individual sovereignties. Precision is necessary in view of the natural tendency to confirm human security. Everyone consents to political society because it aims for its own conservation. Any holistic political society which dissolves the individual in the whole and whose interests would become superior to individual conservation certainly does not fall within the order of natural means necessary for the confirmation of human security. The separation of the public

\footnotetext{
183 “'Au nom de l'idéal d'égalité, la famille libérale réfute le principe de diversité sur lequel se fondent les sociétés holistiques. Toute société holistique tire toujours sa cohérence et son harmonie de l'agencement interne des différentes parties qui la composent, soit des différents sous-groupes (états, ordres, classes, castes, etc.) qu'elle porte en elle. Concrètement, cet agencement, qui repose sur la hiérarchie dite naturelle des êtres humains, prend la forme d'un système de privilèges et de droits différents pour chacun des sous-groupes, mais aussi de l'attribution de rôles distincts pour ceux-ci. Or, l'idéal d'égalité qui est au fondement du libéralisme se veut le renversement de ce principe, affirmant plutôt la non différence de tous les êtres humains sur la base de leur égalité naturelle. En ce sens, d'un point de vue traditionnel, l'idéal d'égalité défendu par le libéralisme porte bien en lui une certaine visée " uniformisante», dynamique qui est contraire à l'esprit de distinction et de hiérarchie sociale sur lequel reposent les sociétés holistiques", Ibid. p. 55
} 
and private spheres within political society that liberalism provides therefore certainly corresponds to the theoretical framework of human security.

With regard to the mistrust towards the political authority, "in order to counter the authoritarian and arbitrary tendency of power, liberalism will adhere to a political principle that is now widely used, that of the primacy of law (or the "rule of law" in the tradition of customary law). This principle states that all power, whatever it is, must be subject to the rule of law, which is supreme; no power, or even any of its representatives, including the head of state, is above the law. Concretely, it is this legal principle which is behind all the political constitutions of liberal countries. In this constitutional document, it is a question of laying the foundations of law, on which all subsequent laws will be based and to which all power deriving from it must comply. The purpose of this basic law is to frame power, that is, to define it, to set its limits and to circumscribe it according to the main principles on which society is based. This framing of power by law finds its illustration for example in the now classic division of power into three distinct branches, such as it exists in most Western countries of our time, namely a legislative power (power to make laws, amend or repeal them), an executive power (power to apply laws or govern) and a judicial power (power to have the law enforced by the courts)"184.

From the perspective of Human Security, as a law of nature, the political program implied by the mistrust towards political authority is certainly that which involves the sum of individual sovereignties or popular sovereignty. In this sense, the democratic regime is the one that can guarantee the most against the arbitrariness of power. Each individual essentially grounded to be the original constituent, s/he is the depositary of power. This power cannot therefore be the object of absolutism. But since all individuals cannot directly participate in governance, representation, through voting, becomes a necessity. If the vote leads to the victory of the majority for practical reasons, it should not however been understood that the minority is not legitimate in requiring satisfaction of conservation. In fact, the choice of representatives

\footnotetext{
184 "Afin de contrer cette tendance autoritaire et arbitraire du pouvoir, le libéralisme va adhérer à un principe politique aujourd'hui largement répandu, celui de la primauté du droit (ou de la «rule of law» dans la tradition $d u$ droit coutumier). Ce principe stipule que tout pouvoir, quel qu'il soit, doit être soumis à l'autorité de la loi, laquelle est suprême; aucun pouvoir, ni même aucun de ses représentants quel qu'il soit, y compris même le chef d'État, n'est au-dessus de la loi. Concrètement, c'est ce principe juridique qui se trouve derrière toutes les constitutions politiques des pays libéraux. Dans ce document constitutionnel, il s'agit de poser les fondements de la loi, sur lesquels vont reposer toutes les lois subséquentes et auxquels doit se soumettre tout pouvoir en découlant. L'objet de cette loi fondamentale est bien d'encadrer le pouvoir, c'est-à-dire de le définir, de fixer ses limites et de le circonscrire suivant les grands principes sur lesquels repose la société. Cet encadrement du pouvoir par la loi trouve son illustration par exemple dans la division désormais classique du pouvoir en trois branches distinctes, telle qu'elle existe dans la plupart des pays occidentaux de notre époque, à savoir un pouvoir législatif (pouvoir de faire les lois, de les amender ou de les abroger), un pouvoir exécutif (pouvoir d'appliquer les lois ou de gouverner) et un pouvoir judiciaire (pouvoir de faire respecter la loi par les tribunaux)", Ibid. p. 58
} 
ultimately means that ideas of government are popularly approved and therefore endowed with the rule of law. Representatives therefore have the task of working for the conservation of each member in accordance with the constitutional provisions. Ensuring that this finality is achieved without a majority dictatorship can only go through the separation of powers. This is a necessary safeguard against the arbitrariness that would imply either the concentration of the different areas of public service in the hands of a single authority, or the rigid separation of these for the benefit of their respective owners. The flexible separation of powers in the sense of control operated by each power over others becomes a necessity. Democratic society formulated that way, certainly falls within the framework of the means necessary for the confirmation of human security, as a law of nature. The liberal political program which translates mistrust towards political authority still matches with the theoretical framework of human security.

With regard to property, in addition to the fundamental mission of any State, importance of this natural right requires the protection of individual properties It is this mission that John Locke eloquently announces by writing in the Second Treaty of Civil Government: "The great and chief end, therefore, of men uniting into commonwealths, and putting themselves under government, is the preservation of their property; to which in the state of Nature there are many things wanting". ${ }^{185}$ For the State, working for the individuals on which it is founded consists in investing itself to preserving their life and their properties, against all those who are tempted to steal them.

From the perspective of human security, as a law of nature, the liberal political agenda on property is certainly one that protects the property of individuals; it is necessary to add that it ensures to each one a property for the purposes of conservation. It is not possible that individuals consent to a political society which would not secure their ownership because what would then be the basis of their conservation? The protection of property is quite simply an implication of the previous principles of freedom and equality. So on this point liberalism still corresponds to the theoretical framework of human security.

Ultimately, these observations on liberalism in relation to human security, as a law of nature, allow us to detect a certain correspondence between both. Except that the liberal conception of reality in relation to the one implied in the theoretical framework of human security must be clarified. The reality for liberalism is not fixed for all because based on and according to individual liberty, it is changeable. Liberty in itself is a matter of principle, therefore including

185 J. LOCKE, Two Treatises of Government, op. cit. p. 159 
in a framework of a law of nature. So it can be seen as a fixed reality. The individual is naturally free once and for all. In this sense, any other reality is subject to the will of freedom. According to the theoretical framework of human security, it is also a question of noting that freedom is an ontological attribute of human nature and the fundamental means of confirming the order of this nature knowable in terms of security. Since this already accounts for human nature and therefore already real, it is no longer to be created or realized but rather to be confirmed in what it is, due to the inherent tendency to this same nature to permanence or continuity, the way it is. This is what we called conservation. This is still done adequately based on a natural order of means that the human being does not always know and which s/he realizes through experience. That way, s/he succeeds in learning or discovering the order of natural means suitable for its conservation by changing initiatives of the experience leading to negative consequences on its conservation. If, therefore, according to liberalism, human liberty enables to change reality as it pleases, the reality it creates can end up being known as unreal in the light of negative consequences on conservation, and real in the light of positive consequences on it. At the end, it is more a question of confirming the human natural reality that is already embodied by the state of security. On the hypothesis that the change of reality by way of liberal liberty can lead human nature to extinction, it must then be concluded that the real reality is that which confirms this liberty or the one by which this liberty is confirmed or conserved. Liberty being preserved only on a certain reality, it therefore implies an order, and can thus never mean license which implies disorder. Therefore, it is ultimately a question of discovering the most adequate reality which enables to confirm human security of which freedom is part. This state of affairs is not contradicted by the facts in which liberalism was the leading actor before, during and after the advent of the modern state. Since liberalism cannot therefore admit free actions whose finality is its own extinction, it surreptitiously admits that liberty of action is only admitted in the sense that it confirms liberty. Understood that way, liberalism, by changing reality, admits or therefore signifies a process of education on the best reality which allows to better confirm liberty. This reality is understood within the theoretical framework of human security as the order of natural means necessary to its confirmation. However, this order does no longer get to be created, but discovered since it is already real, but unknown by the human being. Liberalism thus falls within the framework of human of security. It understands that human security is the foundation and the finality of politics. It still enables us to know that with regard to its ideological flexibility. 


\subsection{The ideological flexibility of liberalism}

The ideological flexibility of liberalism means that, in the debate between the various political ideologies, liberalism has recognized itself as accepting at the fundamental level the postulates of other ideologies, in particular socialism. So we come to talk about social liberalism. This denomination which may seem an ideological mixture allows, in our opinion, and from the point of view of the theoretical framework of human of security, to bring out the real meaning of liberalism. We will consider this reasserted sense of liberalism (1.2.1) and its implications (1.2.2).

\subsubsection{Social liberalism: Reassertion of the real meaning of liberalism}

The real sense of liberalism reasserted by social liberalism was made in relation to classical liberalism which was built on the postulates of autonomy and rationality of individuals seeking the maximization of their interests, what was considered to be the political theory of possessive individualism. ${ }^{186}$

The protection of property is at the heart of classical liberalism. John Locke had stressed that the ultimate end to which men seek union with political societies under the leadership of governments is the protection of their property. ${ }^{187}$ Ludwig von Mises in turn expressed that the program of liberalism could be summed up in one word: property, that is to say, the possession of the means of production, and all the other requirements of classical liberalism result from this fundamental requirement. ${ }^{188}$ The protection of property ensures that the means of production remain in the most productive hands when people enjoy the fruit of their labor, their productive activities grow. A completely free market maximizes abundance by ensuring the production and exchange of goods and services at the right amount and at the right price to match their greatest values. In this sense, liberalism and capitalism constitute one and the same understanding, or else a society in which liberal principles are embodied is a capitalist society. ${ }^{189}$

Principles proper to classical liberalism contemplate a narrow and strictly limited role for government. "As the liberal sees it, the task of the state consists solely and exclusively in guaranteeing the protection of life, health, liberty and private property against violent attacks.

\footnotetext{
${ }^{186}$ C.B. MACPHERSON, The Political Theory of Possessive Individualism, 1962, quoted by B. Z. TAMANAHA, in "The Dark Side of the Relationship between the Rule of Law and Liberalism", New York Journal of Law and Liberty, Vol. 3, n516, 2008, p. 519

${ }^{187}$ J. LOCKE, Two Treatises of Government, op. cit, p. 159

${ }^{188}$ L. von MISES, Liberalism: The Classical Tradition 2, 1927, Bettina Bien Greaves, Ed., Liberty Fund, Inc. 2005

${ }^{189}$ Ibid. p. Xxv
} 
Everything that goes beyond this is an evil "190. The government can impose taxes only when it is necessary for its functions. Mises identified the benefits of joblessness and viewed them as encouraging indolence, like most conventional liberals. He was opposed to the state mission of popular education and argued that abundance and income inevitably develop under liberalism. He was also opposed to the minimum wage as an artificial interference in the labor market that lowers output and increases unemployment, and opposed workers' unions for the same reason. ${ }^{191}$ Mises recognized that these various positions impose agonizing consequences on the unemployed or earn low wages but insisted on the fact that in the long run, the material wellbeing of all increases by the implementation of these ideas.

Apotheosis of classical liberalism in the middle of the 19th century in England and America, known as the laissez-faire era, ${ }^{192}$ led to serious social upheavals, appalling working conditions and widespread poverty. Intense pressure for reform was generated when the working class was given the right to vote, further exacerbated by the overthrow of liberal capitalism in favour of socialism. Critics have accused liberalism of applying the coercive power of law in favour of owners at the expense of workers. ${ }^{193}$ Faced with these visible harmful consequences of classical liberalism, thinkers campaigned for change if nothing was done, and began to advocate the modification of liberal doctrines to improve its most painful consequences. This movement gave birth to a new "social liberalism".

Unlike abstractions of classical liberalism, notably freedom of contract and formal equality, the new liberals or social liberals are turning to reality. Hobhouse noted the constant concern, "We are perpetually confronted with the masses whom the machine of wealth grinds down in its onward sweep or tosses aside into the rubbish heap."194 "The new liberal has to look deeper into the meaning of liberty and to take account of the bearing of actual conditions on the meaning of equality"195. Les nouveaux libéraux observèrent que la liberté véritable est menacée par des conditions sociales et économiques indépendantes de la volonté de personnes. "There may be a tyranny of custom, a tyranny of opinion, even a tyranny of circumstance, as real as any tyranny of government and more pervasive". 196

\footnotetext{
190 Ibid. p. 30

${ }^{191}$ Ibid. pp. 12-14, 57, 85

192 P.W.J. BARTRIP, “State Intervention in Mid-Nineteenth Century Britain: Fact or Fiction?", in Journal of. British Studies. 23, n63, 1983

${ }^{193}$ H. J. LASKI, The Rise of European Liberalism, 1936, Transaction Press 1997

${ }^{194}$ L.T. HOBHOUSE, "The New Spirit in America”, in Contemporary Review, Vol. 100, n 1, 3, 1911, p. 522

195 Ibid. pp. 115

${ }^{196}$ Ibid. p. 63
} 
Once the prevailing social and economic conditions were taken into account, social liberalism had a series of consequences. It recognizes that there can be no clear separation between the individual and society, because individuals are deeply formed and limited by social forces; individuals are born in communities, perpetually live there and from them take their language, their identity and their values; everything an individual does affects others; and each owes its successes (and its failures) significantly to the others and to the surrounding circumstances. ${ }^{197}$ Individuals and societies are therefore closely linked in many ways. Property rights are the product of government and are granted by government for they exist and are preserved by coercion by the State. ${ }^{198}$ From the above, it appears that rich people have not amassed their fortune by their own efforts alone, but also by the labor of the poor who are not satisfied in their needs. Therefore, the government has a positive obligation to regulate the circumstances that impede the exercise of liberty. It must ensure that able-bodied workers can earn a "living wage", that education is provided so that this opportunity is real and that a basic minimum is available to help those in extreme need. ${ }^{199}$ As Hobhouse described, "We said above that it was the function of the State to secure the conditions upon which mind and character may develop themselves. Similarly we may say now that the function of the State is to secure conditions upon which its citizens are able to win by their own efforts all that is necessary to a full civic efficiency."200 To provide these services, the government can tax the wealthy, particularly through inheritance taxes and taxes on high earners. ${ }^{201}$ The wealthy have little reason to oppose to the situation, given that the social situation and the legal regimes imposed by the government contribute to and create the conditions that favours acquisition of their wealth.

New liberalism or social liberalism therefore justified the welfare state. It moved away from socialism by not advocating state or collective ownership of the means of production and by leaving a large field for the market to function. But still social liberalism has moved away from classical liberalism. To mark the difference, Hobhouse noted about property rights: "to carry through the real principles of Liberalism, to achieve social liberty and living equality of rights, we shall have to probe still deeper. We must not assume any rights of property as axiomatic. We must look at their actual working and consider how they affect the life of society" 202 This is a departure from classical liberalism, which regarded property rights as sacrosanct. A notable

\footnotetext{
${ }^{197}$ Ibid. pp. 63-73

198 Ibid. p. 98

${ }^{199}$ Ibid. pp. 74-87

${ }^{200}$ Ibid. p. 83

${ }^{201}$ Ibid. p. 97

${ }^{202}$ Ibid. p. 27
} 
difference between these competing variants of liberalism is also relevant: classic liberals showed constant fear and contempt for democratic legislation, while social liberals welcomed it as a means of implementing reforms.

Ultimately, according to Hobhouse, social liberalism is supposed to meet two conditions: "In the first place, it must be democratic. It must come from below, not from above. Or rather, it must emerge from the efforts of society as a whole to secure a fuller measure of justice, and a better organization of mutual aid. It must engage the efforts and respond to the genuine desires not of a handful of superior beings, but of great masses of men. And, secondly, and for that very reason, it must make its account with the human individual. It must give the average man free play in the personal life for which he really cares. It must be founded on liberty, and must make not for the suppression but for the development of personality"203.

From the perspective of human security, as a law of nature, social liberalism clearly reasserts the real meaning of liberalism. By distinguishing itself from "classic" liberalism, it manages to make the quintessence of this ideology understood as being at the benefit of human security. Social liberalism no longer insists solely on the protection of the natural liberty of individuals, but it also integrates the protection of their natural equality by ensuring for all basic social conditions for conservation. We see here that social liberalism is trying to integrate freedom from fear and freedom from need into its substance. Thus it takes care to protect civil and political rights and economic and social rights. The purpose of the liberal social political order is therefore to create adequate conditions to ensure that everyone has the basic and sufficient minimum for their preservation and expression of the liberty of individuals in a manner that is consistent and respectful of equality before law. Social liberalism enables to know that human security is at the center of all social life and, above all, that it is a necessity to confirm it. Since political society is essentially an agreement between its different members, no one can consent to a form of it which does not ensure its preservation in this intrinsic state. Classical liberalism had recognized, in its own way, the ontological attributes of the human person, but the way of confirming them did not lead to satisfaction, rather creating a system of injustice. What social liberalism would correct. In that, social liberalism insists a little more on the order of natural means necessary for the confirmation of human security, as the human intrinsic state of affairs. It proposes a formulation of political society which would allow a conservation of each of its members. This is therefore part of the historical process of experimentation for education on or

\footnotetext{
${ }^{203}$ L. T. HOBHOUSE, Liberalism, Williams and Norgate, n.d London, 1911, pp. 172-73
} 
the discovery of the order of natural means necessary to the confirmation of human security. The role of the State thus depart from a passive arbitrator giving free rein to the actors themselves according to their potentialities to ensure their own conservation in compliance with minimum rules, to an interventionist arbitrator whose mission is insuring to all members of the social body a basic minimum of resources necessary for conservation while creating conditions for the expression of creativity or individual liberty. This was concretely theorized under the concept of "managerial State".

\subsubsection{The managerial State, configuration of the liberal political order}

The managerial State continuously monitors, organizes, controls and regulates the social, economic and political activities carried out there. Unlike anti-liberal states, the managerial State maintains the liberal distinction between the state and civil society. It does not seek to directly and completely absorb the national economy and culture into the bureaucratic apparatus of the State. ${ }^{204}$ But the distinction between state and civil society in managerial States is tenuous and fragile, as the state diffuses its power in civil society. In the words of a scholar, the managerial State "bears responsibility for all of the conditions of contemporary society: the conditions of air, food and water; the relationship in which its citizens must be involved; the habits they develop; their education; their health; and their ability to earn their living"205

States have started to develop mechanisms and strategies to better control the hazards of industrialization. One way to do this was to develop a knowledge of industrialization and its consequences; such knowledge facilitates direction and control. New social sciences economics, sociology, political science - have been developed based on the idea that industrialization and societies in general include systems or structures; that is, they were more numerous than the sum of their parts. The different parts could be understood and made somewhat predictable by understanding the laws of the whole. The systems ended up being perceived as coordinated by an instrumental rationality; that is, the reason has come to be seen as the effective application of means, or the invention of new ones, for a given purpose. The nature of the system gave the end: war-victory, economy-prosperity; political-social order. To regard what constituted a complex set of unforeseen events as integral, plannable sets gave those in power a new feeling that the effects of industrialization could be mitigated and their

\footnotetext{
${ }^{204}$ G. MAJONE, "The Rise of the Regulatory State in Europe," in Wolfgang C. Müller and Vincent Wright, Eds., The State in Western Europe: Retreat or Redefinition, Frank Cass, Newbury Park, CA, and Great Britain: 1994, 77-101

${ }^{205}$ H. JACOBY, The Bureaucratization of the World (Berkeley and Los Angeles, CA: University of California Press, 1973, pp. 147-149
} 
results controlled. In short, the rationalization of knowledge about politics and society has helped make the managerial State possible. What this meant for politics was that the state was now seen as the coordinator of all the complex systems supposed to make up society, such as economics, politics, class structure and the value system. Intervention in each subsystem was limited to coordinating them with the others in the management of the whole state. ${ }^{206}$

In the managerial State, the political consciousness of the citizen becomes that of the rational consumer, who looks at the State through the prism of a utilitarian calculation of costs and benefits. Taxes, for example, become less seen as necessary contributions to the public good and more than the price of government services. The managerial State becomes the producer of public goods (a slippery good of meaning between a normative good - what should be done and a good in the sense of a commodity) which are sold to citizens through the industrialized mass media. ${ }^{207}$ Perhaps the most significant change that has undermined the social conditions of the liberal state and favoured the formation of managerial States has been the reorganization of capitalist society, which has brought about a change in the form of capitalist individualism. Before the second half of the 19th century, the dominant form of capital organization was the sole proprietorship, the enterprise belonging to an individual, a family or a small partnership. In most cases, business owners have been directly involved. ${ }^{208}$

In certain circumstances, the managerial State would intervene directly in the industrial capitalist economy by nationalizing industries that fail as private enterprises but supply public goods with the system as a whole (for example, railways and public services); by subjecting private companies to environmental regulations; providing social services; and boosting the economy by investing in the military. In some cases, the State would manage the economy indirectly by adding incentives and disincentives to the tax code or by passing tariffs or subsidies to favour certain industries or forms of investment over others. The specific strategies used depended on factors related to the situation in specific States, such as the history of bureaucratization within them; the roles of war and the military in the development of State institutions; the strength, ideology and character of political parties and unions; and the relative position of the national economy in the world economy. ${ }^{209}$

\footnotetext{
${ }^{206}$ W.C. OPELLO, op. cit. pp. 90-91

${ }^{207}$ Ibid. p. 92

${ }^{208}$ Ibid. p. 94

209 D. M. JONES, "Democratization, Civil Society, and Illiberal Middle Class Culture in Pacific Asia," Comparative Politics, n³0, January, 1998, pp. 147-169
} 
Even States which maintained a strong ideology of economic liberalism and professed allegiance to the non-intervention of the state in the markets developed into managerial States. In France and Germany, some of the institutions created to manage the mercantilist economies have provided fertile ground for the growth of management. In both cases, the state took responsibility for infrastructure development and developed national education systems, in part to prepare well-trained officials with managerial and engineering skills.

One of the most important areas of state management of industrial capitalism is social welfare. Social protection programs such as health insurance, social security, unemployment insurance and assistance to the poor are important tools used by the State to manage prosperity and maintain public order. These programs are often used to channel money to consumers to secure sufficient aggregate demand for mass-produced products by industrial companies and to redirect labor to the new jobs the economy requires. They are also important elements in the management of the general social order by disciplining aid recipients, by stipulating program requirements and by mitigating the worst effects of upheavals of the capitalist market. ${ }^{210} \mathrm{In}$ practice, the management of social services for the poor, the elderly and the unemployed involves the state in a profound regulation of people's daily lives. Furthermore, despite efforts to maintain the universality and equality of rights programs, wealthy and privileged groups have been able to avoid the more intrusive forms of intervention they entail. Feminists have most clearly recognized the disciplinary aspects of social services. Women and men are subject to the management of social services by the State in different ways and to different degrees. ${ }^{211}$

In terms of political participation, the managerial State distributes citizens according to an "interior-exterior" logic, to better recognize sovereign unity and indivisibility in the nation. This political distribution is managed by the formalization and routine of procedural democracy. The main way for citizens to participate in political life in the administering State is to hold regular elections, which avoid any unpredictable, disruptive and spontaneous participation, such as demonstrations, riots and bombs. Elections domesticate and pacify participation and transform it into a routine and peaceful public activity. Through rules that govern the composition of the electorate and transform voters' choices into election results, the managerial State controls when, where, how and who will participate. In the managerial State, elections are increasingly understood as electoral systems. Elections make sense and are explained by the press and the

\footnotetext{
${ }^{210}$ Ibid. p. 99

${ }^{211}$ I. M. YOUNG, Justice and the Politics of Difference, Princeton University Press, Princeton, NJ: 1990; S. KOVEN, S. MICHEL, (Eds.), Mothers of a New World: Maternalistic Politics and the Origins of Welfare States, Routledge, London, 1993
} 
academic discipline of political science, as part of a rational system of rules and regulations aimed at producing predictable results. Manipulating the election results by determining how individual votes will be translated into seats in a representative body is crucial to regulating this system. Two sets of regulations are essential to the management of this system: those which establish the criteria of victory and those which define the electoral districts. ${ }^{212}$

From the perspective of human security, as a law of nature, we see that the managerial State embodying the liberal social political order has as its main concern in the achievement of the conservation of individuals. It provides public service in all areas of interest for this conservation. It is concerned with satisfying needs implied by the rational and physical components of human nature. Certainly it must be noted that it corresponds to the order of natural means of confirming the human security intrinsic state of affairs. We can therefore observe an increasingly asserted insistence towards the managerial side of public service, less than on the principles of the latter as it is considered to gain ideological support. Thus, quite simply, the order of government is effective if it results in the conservation of each member of political society, based on the theoretical framework of human security. That said even if this "historic time" seems to entail a kind of halt in the disclosure of the principles of human security, it continues to operate in a process of discovery of the best formulation of the management of public service. It should however be observed that it is perhaps the complete lack of understanding of human security, as a law of nature, which grounds a defective formulation of the public management, leading to negative consequences on the individual conservation. Thus, it must be agreed that the finite order and the final order that human security are inescapably inclusive, in a natural and necessary context of the coexistence of individual,. So, the governmental political order in the form of the managerial State should enable to be aware of the union between the principle and the practice and to know in the end, that security being a perfect existent of human nature, does no longer need to be created or realized but to be confirmed the way it is. The historical process of experimentation or education on this reality should then continue until it is fully understood. We can know this in the light of the not always positive consequences of the managerial State on the conservation of individuals. That said, it can be noted that social liberalism proposing the managerial State has allowed us to know that: "The social services were not to be regarded as regrettable necessities to be retained only until

${ }^{212}$ W. C. OPELLO, op. cit. p. 103 
the capitalist system has been reformed or socialized; they were a permanent and even a glorious part of the social system itself". ${ }^{213}$

After relating liberalism and human security, we will now study the relationship between it and the ideologies of the right and the left.

\section{RIGHT AND LEFT IDEOLOGIES}

Liberalism sparked the development of other political ideologies in reaction to its assumptions. These occupied its right and left poles and were thus classified as right and left political ideologies. In this context, it is a matter of dwelling on these ideologies, in particular their conception of the world and their political program and confronting them with the law of human security as the foundation and finality of political society.

\subsection{Right-wing ideologies}

After presenting the conception of the world and the related political program proper to Rightwing ideologies, we will envisage it related to the law of human security.

\subsubsection{The Conception of the World proper to Rights-Wing ideologies}

"The conception of the world to which the Right subscribes is based on an observation, that the order of the world is legitimate. (...). The feeling of satisfaction that feeds all right thinking is not primarily directed towards the established order, that is, the system in place, the social, economic or political institutions as they exist here and now in society, because the ideologies that claim to belong to this camp know how to show themselves in certain contexts as critical towards these institutions as the ideologies of the left. At the foundation of all right-wing ideology lies the idea that there exists, beyond institutions in place, an order of the world, that is to say a structure which ensures reality its harmonious organization and gives it its stability. And this order of the world deserves our respect, because it conforms to the order of things, in other words, this order is just as it should be. It is therefore towards this order of the world that

${ }^{213}$ E. D. HUTTMAN, Introduction to Social Policy, McGraw-Hill, 1981, New York, p. 94; See P. LYONS, "Ideology in Social Welfare Policy Instruction: An Examination of Required Readings", in The Journal of Sociology \& Social Welfare, Vol. 10, Issue 3, Stockton State College, 1983 
the feeling of satisfaction driving right-wing ideologies is destined and possibly, by extension, towards the system in place, if it proves being in accordance with this order" ${ }^{214}$.

According to right-wing ideologies in general, there is a world order which must be respected and based on which society should function. However that is understood in various ways.

The first classic explanatory feature of the right which is most widely shared by all the political forces of this camp, as well in the center-right, on the right as on the extreme right, is conservatism which is based on the weight of tradition. According to this scheme, if the world order can appear legitimate, it is because it is the result of a long process: reality is always only the fruit of a slow work accomplished by eras and generations earlier. The order of the world carries with it the weight of tradition and, if it deserves our respect, is that it has stood the test of time. It has made its evidence. The fact that this order has so far succeeded in being in force is, according to the Right, a testimony to the strength of its arrangement and legitimacy. With regard to this explanatory scheme, right-wing ideologies may experience more or less satisfaction, depending on the different tendencies which animate this ideological camp. ${ }^{215}$

Secondly, for a part of the right, which is called the religious right, to this general conception is added an explanation of the origin of this order. For this right, which is showed as much on the extreme right (fundamentalism) as in the center right, passing through the right in short, religion and its dogmas occupy a large place in this order. From this faith-based perspective, if the order of the world can be seen as legitimate, it is because it is due to its divine origin, that is, it is the work of God. Behind reality is a divine order; God being perfect, his creation could not therefore be otherwise than perfect, and therefore legitimate - although one can find in the world "sin", "evil" and many other "vices". Everything that shows itself in the world is legitimate and conforms to the order of things, since it is the work of the God creator. ${ }^{216}$

\footnotetext{
${ }^{214}$ We translate from : "La conception du monde à laquelle souscrit la droite se fonde sur un constat, celui que l'ordre du monde est légitime. (...). Le sentiment de satisfaction qui alimente toute pensée de droite n'est pas en premier lieu dirigé vers l'ordre établi, c'est-à-dire le système en place, les institutions sociales, économiques ou politiques telles qu'elles existent ici et maintenant dans la société, car les idéologies qui se réclament de ce camp savent se montrer dans certains contextes aussi critiques à l'égard de ces institutions que les idéologies de gauche. Au fondement de toute idéologie de droite repose l'idée qu'il existe, par-delà les institutions en place, un ordre du monde, c'est-à-dire une structure qui assure à la réalité son organisation harmonieuse et lui procure sa stabilité. Et cet ordre du monde mérite notre respect, car il est conforme à l'ordre des choses, autrement dit, cet ordre est bien tel qu'il devrait être. C'est donc à l'endroit de cet ordre du monde qu'est destiné le sentiment de satisfaction qui anime les idéologies de droite et éventuellement, par extension, à l'endroit du système en place, s'il s'avère que celui-ci est conforme à cet ordre", D. PARENTEAU, I. PARENTEAU, op. cit.

${ }^{215}$ D. PARENTEAU, I. PARENTEAU, ibid. pp. 28-29 ; A. HEYWOOD, op. cit. pp. 59-60 ; R. ECCLESHALL, Alii, Political Ideologies, An introduction, $3^{\text {rd }}$ Ed. Routledge, Taylor and Francis Group, New York, 2003, pp. 4955
}

${ }^{216}$ D. PARENTEAU, I. PARENTEAU, Ibid. pp. 29-30 ; A. HEYWOOD, op. cit. Chap. 10, pp. 241-242 
The third explanatory scheme of the right is that of the "economic" right, in the foreground the one expressing itself as libertarianism. If we can be satisfied with the way the world order is presented, this is due to the fact that at its foundation there are self-structuring "spontaneous" mechanisms. These mechanisms or these material forces operate in a way, in the shadow, autonomously, and ensure reality its internal cohesion by giving it its harmonious and stable organization. Reality works by itself and knows better than anyone how it should do it, as it knows how to achieve optimal performance itself. If the order of the world is legitimate, it is due to its capacity to ensure itself its own harmonious organization. ${ }^{217}$

The fourth and final explanatory scheme on the right hand is what is called "social-Darwinist". This scheme, which draws its inspiration from a simplistic interpretation of the thought of the well-known English biologist Charles Darwin (1809-1882), is the one on which the reactionary right (Extreme fascist right) is exclusively based. This last scheme takes up, while radicalizing it, the first scheme exposed above by instilling in it a biologizing meaning. According to this scheme, if the order of the world can appear satisfactory to us, it is due to the fact that it is the result of a long process of natural selection. This selection consists of a process by which the strongest people, social classes or nations, as well as the greatest civilizations, have succeeded in asserting themselves, at the expense of the weakest elements of humanity. The history of the world is one of inevitable competition between the different elements that make up humanity, where only the best can hope to survive. It is a constant struggle in which all are continuously subjected to the harsh law of the strongest, which enables to select the most suitable elements for the elimination of the weakest, naturally doomed to perish ("survival of the fittest"). If the world order can be considered legitimate, it is due to the fact that it can recognize and give first place to the best elements. $^{218}$

Following this presentation of the conception of the world proper to the right-wing ideological family, how can it be viewed in relation to human security, as a law of nature?

One of the first observations of the Right ideological family is the anchoring on a wellestablished order which must be respected and preserved. In this sense, reality is understood as not being able or not needing to be the object of change. In a way, it is immutable. At first glance, this assumption corresponds well to human security, as a law of nature because it means that the intrinsic state of human security is already a real order which can no longer be created

\footnotetext{
${ }^{217}$ D. PARENTEAU, I. PARENTEAU, Ibid. p. 30; R. SCRUTON, « Libertarianism », op. cit. pp. 390-391 ; ; A. HEYWOOD, op. cit. pp. 73-74; M. FREEDEN, op. cit. pp. 276-279

${ }^{218}$ D. PARENTEAU, I. PARENTEAU, Ibid. pp. 30-31
} 
but which must be confirmed. However, it is necessary to make sure of this with regard to the different features under which the Right-wing ideologies appear. Indeed, the different features mentioned above correspond each to a particular ideology. The first feature actually refers to conservatism. This ideology characterized itself as the keeper of traditions and the social organization according to them. Traditions are well characterized by a certain fixity in time, but they are not looked as being free from evolution or change over time. This raises certain considerations. Either the order that needs to be kept is immutable, or it is changeable. If it is not immutable, then it is necessarily changing and so, by the process of time, it is called to show itself different in the future from what it was in the past. Consequently, one can simply ask oneself: what tradition or what order do we keep? Since it is possible that through the historical process, the order or tradition of the past has evolved or due to circumstances, be forced to change and has resulted in the today's order, which in turn does not guarantee any continuity in the future, in favour of a new one, conservatism no longer has any particular order or tradition to preserve. For example, the Ancient Western world was characterized by the belief that the king received his power from God and that human beings were fundamentally unequal. The culmination of revolutions towards a new order nourished by liberal principles signified the decadence of the ancient. This new order has also undergone subsequent changes or adjustments. So if conservatism is concerned with keeping order, which one would it keep? Either it would keep an order which changes over time and which may be a liberal order, or it would display a tenacity towards an order whose negative consequences have nevertheless been proven and which would have justified the change or evolution that it would have experimented. In both cases, the logic of this political ideology is no longer understandable. However, from the perspective of the theoretical framework of human security, one must think that if conservatism protects an order which asserts the principles of a law of nature then it is in conformity with human security. Otherwise, one must think that its postulates would not fall within the framework of the order of natural means necessary to confirm human security.

With regard to the second aspect, it should be noted that religion postulates an order which is essentially immutable: the divine order. The law of God does not imply any change or evolution and thus stands the test of time. In principle, religion is therefore more conservative than conservatism.

Regarding the third aspect, it characterizes libertarianism. The approach to this political ideology is more methodological than substantial. It postulates that order defines itself through an internal process. That way it may appear to correspond to the theoretical framework of 
human security. This ideology already admits, and even in a constructivist logic, that order is a reality. It would therefore be distinguished from conservatism and religion in that reality is not fixed, although it is not changed by Man but itself. Human security, as a law of nature postulates, however, that this order already exists except that it is not known by Men who discover it through the historical process of experimentation. Thus, unlike libertarianism which postulates an internal dynamic specific to order, human security, as a law of nature postulates a static to which Man is gradually educated by the results of the initiatives he implements for the conservation of his/her intrinsic state of affairs. It is not a reality that regulates or changes by itself, but it is man who is gradually aware of the best way to preserve him/herself according to the natural necessity of coexistence with his fellows. This testifies the fact that human security is the foundation and finality of human action. Libertarianism therefore involves a process which is understood in another way within the theoretical framework of human security but which necessarily involves the same consequence of knowledge or disclosure of the natural social reality.

The fourth aspect of the right-wing ideological family corresponding to fascism is manifestly not in conformity with human security, as a law of nature. These ideas of inequality between races, of combat for survival, of the right of the strongest are postulates which cannot constitute adequate means of preserving individuals in a natural context of coexistence. Its consequences are necessarily negative, both for the victims and for the perpetrators, because this kind of ideology involves the use of violence for conservation purposes and perfectly implies the state of nature as developed by Thomas Hobbes. It is the ideological legitimation of Man as a wolf for another. However, the consequences of such a state are inevitably known, namely that the strongest is never the strongest and that several weak can combine their strength and defeat the strong. So insecurity is perpetual for all. From the perspective of the human security, as a law of nature, the natural tendency of human beings is to keep themselves in the state of security which is consubstantial with their nature. If all are called to preserve themselves in coexistence, it is difficult to understand how nature would force them to a kind of natural selection. Since based on this, nobody can truly ensure permanence in and of the intrinsic state of security, this ideology is essentially false, for its results is extinction, instead of conservation required by nature. Such an ideology just ends up being known unreal, because revolutionary reactions will certainly come to abolish it and to establish an order which at least would no longer be based on these postulates. 


\subsubsection{The Political Program of Right-wing political ideologies}

Political ideologies of the right-wing family conceive a political program which is certainly the consequence of the way they apprehend the world. "From these four explanatory schemes follows a simple political program which consists essentially in preserving the order of the world, that which, without distinction of the four schemes, ensures reality its legitimacy, as well as its harmonious organization and its stability. It is this particular trait that explains the [general] name of "conservatism" by which we also designate this ideological camp, the name that the conservatives themselves most often give themselves - let us add on this question that unlike the left, which more willingly accepts the name "left", the right more generally refuses the right label". 219

The political program generally proposed by the right-wing ideological family centers on the idea that there is a threat to the world. Such a threat is variously appreciated by the different currents of this ideological family: moral decay for religious rights, cultural decay for traditionalist rights. ${ }^{220}$ "This recognition of a threat and the idea of decadence by which it manifests itself play a fundamental role in all right-wing ideologies. The feeling of satisfaction shown by this ideological group with regard to the order of the world is always mixed with a feeling offear, that of seeing precisely this legitimate order lose its strength, wither away, even disappear. This feeling of satisfaction / fear takes the place of elementary conjuncture for all right thinking, conjuncture on which comes to be grafted a political program"221.

The political program envisaged by right-wing ideologies, namely the maintenance of world order, the preservation of tradition against any threat that any change would represent, is very understandable. If the order of things does not depend on the human being who in this apprehension is considered to be undergoing it, any enterprise which would aim to change it

\footnotetext{
${ }^{219}$ We translate from : "Il découle de ces quatre schémas explicatifs un programme politique simple qui consiste essentiellement à préserver l'ordre du monde, celui qui, indistinctement des quatre schémas, assure à la réalité son caractère légitime, de même que son organisation harmonieuse et sa stabilité. C'est ce trait particulier qui explique le nom [général] de «conservatisme» par lequel on désigne également ce camp idéologique, nom que se donnent le plus souvent les conservateurs eux-mêmes - ajoutons sur cette question que contrairement à la gauche, qui accepte plus volontiers l'appellation de "gauche», la droite refuse plus généralement l'étiquette de droite", Ibid. p. 31

${ }^{220}$ Ibid.

221 "Ce constat d'une menace et l'idée de décadence par laquelle celle-ci se manifeste jouent effectivement un rôle fondamental dans toutes les idéologies de droite. Au sentiment de satisfaction manifesté par ce camp idéologique à l'égard de l'ordre du monde se mêle toujours immanquablement un sentiment de crainte, celui de voir précisément cet ordre légitime perdre de sa force, dépérir, voire disparaître. Ce sentiment de satisfaction/crainte tient lieu de conjoncture élémentaire pour toute pensée de droite, conjoncture sur laquelle vient se greffer un programme politique." Ibid.
} 
can only be perceived as bringing disorder and insecurity for all. From the perspective of human security, as a law of nature, it must be recognized that the order of natural means aimed at the preservation of the state of intrinsic security it implies corresponds to the political program of the ideological right, at least in theory. Indeed, since the logic is to ensure the permanence of the natural human order, it is for individuals subject to the natural necessity of coexistence to agree on an organization that achieves this objective for each of them. Thus, the best formulation of this political society is one that will ultimately confirm or allow to ensure the permanence of order, because it is only in this that resolves everyone. Human security, as a law of nature necessarily includes an order of means or an adequate formulation of political society that Men do not always know and which they discover through the historical process of experimentation of the consequences of initiatives they implement for their conservation. Thus they recognize that those which end with a happy consequences on the conservation of each member of the political society are part of this order of natural means and those which have an unfortunate consequence, even just on some, are not part of it and they must then change them or to improve them. Thus it must be said that the order of the world from the perspective of human security is a natural human order which, by virtue of its individual meaning, acquires a collective meaning. This natural order is, like any natural order, unchangeable and even inviolable. Thus, it could not be said that it weighs on the human beings as a threat, but that due to their ignorance, these cannot adequately confirm themselves according to the means required by that order. The political program of right-wing ideologies would therefore be in conformity with the theoretical framework of human security if the latter intends to guarantee each individual conservation. If this is not the case, it would be necessary to know or at least think that this ideological family ends up carrying negative consequences which would thus account for its nullity. Fascism is an example. Its negative consequences for human security led to the knowledge that its assumptions were false and thus that they were inadmissible as an adequate formulation of a political society. A political program for the preservation of a tradition encouraging the unequal or inequitable treatment of individuals, members of political society is inevitably doomed to be overtaken.

The political ideology of the right therefore enshrines the existence of an order in the world that it is more or less static on which the political program must rest and which it must preserve. It should be noted that if the fascist ideology is the most radical of all in terms of consequences for human security, it must be recognized that libertarianism, conservatism and religion, to varying degrees, only mean human security. It must then be checked for leftist ideologies. 


\subsection{The Left ideological family}

After presenting the conception of the world and the related political program proper to Leftwing ideologies, we will envisage it related to human security.

\subsubsection{The conception of the world proper to left-wing political ideologies}

"Ideologies of the left share all a conception of the world based on an observation, that of the inequality of the established order. All left thinking, since it is the expression of an ideology, is fundamentally normative. It is based on a judgment of value relating to the social, economic or political system in place which is fueled by dissatisfaction. To conceive the world therefore always consists, for the left, in drawing a portrait of the configuration of power, that is to say, the way in which it is inequitably distributed between the different spheres of society (or more generally in the world)" 222

In the Left-wing political ideological family we generally find socialism, communism ${ }^{223}$ and anarchism. ${ }^{224}$

First, the left ideological family develops on the basis of a recognition of social inequality, favouring a small number, the dominant class, at the expense of a large number: the dominated class. "The inequitable character of the established order stems from such an imbalance between these two main groups, that is to say, between the different resources available in society, be they financial, cultural, symbolic, etc., which belong to each. It is such a pattern that we find, for example, in the Marxist communist tradition, for which modern history boils down to a struggle between the proletarian class (the class of the great number) and the bourgeois class (the small number). This scheme characterizes the traditional way that the left has to grasp the world. The more or less serious recognition of the extent of this inequity will mark the degree of radicalism of each of the ideologies that make up this camp". ${ }^{225}$

\footnotetext{
${ }^{222}$ We translate from: "Les idéologies de gauche partagent toutes une conception du monde qui repose sur un constat, celui du caractère inéquitable de l'ordre établi. Toute pensée de gauche, puisqu'elle est l'expression d'une idéologie, est foncièrement normative. Elle est fondée sur un jugement de valeur portant sur le système social, économique ou politique en place qui se nourrit d'une insatisfaction. Concevoir le monde consiste donc toujours, pour la gauche, à dresser le portrait de la configuration du pouvoir, c'est-à-dire la manière dont il est inéquitablement réparti entre les différentes sphères de la société (ou d'une manière plus générale dans le monde)." Ibid. p. 23

${ }^{223}$ V. GEOGHEGAN “Socialism”, in R. ECCLESHALL, Alii, op. cit. p. 73 et s; M. FREEDEN, op. cit. p. 415 A. VINCENT, Modern Political Ideologies, $3^{\text {rd }}$ Ed. Blackwell Publishing Ltd, 2010, pp. 83-110; D. PARENTEAU, I. PARENTEAU, ibid. p. 83; R. SCRUTON, “Socialism", op. cit. pp. 646-648

${ }^{224}$ D. PARENTEAU, I. PARENTEAU, ibid. p. 103 et s. ; A. VINCENT, ibid. p. 111 et s.

${ }^{225}$ We translate from: "Le caractère inéquitable de l'ordre établi provient d'un tel déséquilibre entre ces deux principaux groupes, soit entre les différentes ressources disponibles dans la société, qu'elles soient financières, culturelles, symboliques, etc., qui reviennent à chacun. C'est un tel schéma que l'on trouve, par exemple, dans la tradition communiste marxiste, pour qui l'histoire moderne se résume à une lutte entre la classe prolétarienne (la
} 
Then, the left develops a scheme that gives an account of the causes of the observed social imbalance. "It is therefore in this conception of the world to draw attention to the injustices in all their forms of which these minority groups are victims in society. This second scheme is concerned with the "exclusions" suffered by minorities. Again, depending on the different degrees of dissatisfaction that mark the left, this situation leads to different findings of inequity". 226

How do we envisage the ideological family of the left from the perspective of the human security, as a law of nature?

The ideological family of the left sees the world as being or being able to be unequal, what necessitates or justifies an intervention on it in order to make it equal. At first glance, reality, under the prism of leftists, is not frozen but moldable or modifiable so that it can be egalitarian and for the benefit of all. It is mainly at this level that the main opposition between this family and that of the right is situated, which sees reality as having an autonomous logic imposing itself on Man. However, it should be noted, on closer examination, that the leftist family cannot in its ideology exclude the postulate of an established order. Indeed, if the current order is considered unfair or unequal, it is in reference to an irrefutable principle of reality which is equality between individuals. This principle in itself embodies a natural state of affairs or functioning or reality and it is for the preservation of the latter that the leftists are at work. So for them an order is legitimate if and only if it is egalitarian. Based on this consideration, they are no longer very different from the rightists who recognize a present order and who seek to preserve it. The ultimate difference can only be found in the conception that each has of reality. For the left, since reality or order can only be understood in terms of inter-individual equality, the one that does not configure itself that way is automatically perceived as a reality or an order against which intervention is necessary and justified in order to establish an order or a reality which has as its foundation and finality this natural equality. Regardless of individual details, the social order should, on the left, ensure fair treatment for all. So we have to truly understand the order or the reality according to the left ideological family. It appears as having two dimensions: a fundamental or natural or of-principle dimension which does not change and a

classe du grand nombre) et la classe bourgeoise (le petit nombre). Ce schéma caractérise la manière traditionnelle qu'a la gauche de saisir le monde. La reconnaissance plus ou moins grave de l'ampleur de cette iniquité marquera le degré de radicalité de chacune des idéologies qui composent ce camp", D. PARENTEAU, I. PARENTEAU, ibid. p. 24

226 "Il s'agit alors dans cette conception du monde de dresser le constat des injustices sous toutes ses formes dont sont victimes ces groupes minoritaires dans la société. Ce second schéma est préoccupé par les "exclusions» dont sont victimes les minorités. Là encore, suivant les différents degrés d'insatisfaction qui marquent la gauche, cette situation conduit à différents constats d'iniquité ", D. PARENTEAU, I. PARENTEAU, Ibid. p. 25 
positive dimension which is contextual and which must reflect or is worthy of respect only when it best reflects the fundamental dimension. In this sense, changeability is intrinsically linked to the positive order, in cases where this does not translate or materialize into the principle order. So the leftists feel obliged to intervene to modify or improve it so that it conforms to the higher order of equality.

Thus, the predicates of the left ideological family with regard to the conception of the world match with the postulates of the theoretical framework of human security in the sense that they enshrine at least equality as part of the natural human order. According to human security, as a law of nature, security is the state consubstantial with human nature so that it accounts for its order. This necessitates confirmation, given the tendency of this nature to permanence. In view of that, a conception of the world enshrining inequality between naturally equal individuals is certainly not part of the order of natural means that it includes.

\subsubsection{The Political Program proper to left-wing ideologies}

As far as the political program of the Left ideological family is concerned, it can only relate to the establishment of a political order which promotes an egalitarian public service. "The first principle of the political program to which the left invites, regardless of the explanatory scheme on which it is based, is that of changing the world. All leftist ideologies subscribe to the idea that another world is possible. On the basis of the unfairness of the structures in place, the left challenges the legitimacy of the established order, that is to say, the social, economic and political institutions of society. Its main political objective thus consists in rebalancing the relations of power that exists between those who are favoured by the system in place and those who are precisely disadvantaged by it. And, of all the changes it calls for, in order to achieve this goal, the question of the distribution of power in society appears as the most important issue. (...) Power here refers to a general concept, that is, the capacity for initiative and action of a given group in society in view of its interests. In any program of the left, distributing power consists in restoring power to those who are disadvantaged by the system in its present configuration and, on the contrary, in restricting the power enjoyed by those who benefit from the system in place" ${ }^{227}$.

\footnotetext{
${ }^{227}$ We translate from : "Le premier principe du programme politique auquel invite la gauche, et ce, indistinctement du schéma explicatif sur lequel il se fonde, est celui de changer le monde. Toutes les idéologies de gauche souscrivent à l'idée qu'un autre monde est possible. Sur la base du caractère inéquitable des structures en place, la gauche conteste la légitimité de l'ordre établi, c'est-à-dire des institutions sociales, économiques et politiques de la société. Son principal objectif politique consiste ainsi à rééquilibrer le rapport de force qui existe entre ceux qui sont favorisés par le système en place et ceux qui précisément sont désavantagés par ce dernier. Et, de tous les changements qu'elle réclame en vue de parvenir à cet objectif, la question de la répartition du pouvoir dans la
} 
The measures envisaged for this purpose depend on each particular ideology within the family. Thus, this rebalancing can call on several means, the degree of radicalism which is very variable, a degree which corresponds to the level of dissatisfaction that ideologies harbor with regard to the established order. The deeper this level of dissatisfaction with the existing system, the more radical and urgent the measures to change the world will appear. Depending on the various ideologies that constitute this camp, three main trends can be distinguished. In the center left, this situation, considered problematic, will generally call for the implementation of simple changes within the political order without any real questioning of the structures in place, while on the left, in response to this situation deemed unacceptable, it will more commonly opted for reforms affecting the foundations of this order. Finally, the far left sees revolution as the only solution to deal with this revolting situation" 228 .

Thus, through its action aimed at changing the world, the left offers itself as a "progressive" ideology, hence the other name by which this ideological camp is also designated. Its work or its victories are perceived by its supporters as contributing, in the long run, to the advancement of mankind, of society in general or of the world order as a whole, and this, compared to previous societies or previous configurations of the international system. For the left, if history can be the scene of progress for the human race, this is due to the work accomplished by those who, carried by progressive ideals, have preceded or will follow us. All left-wing thought is always explicitly or implicitly dependent on a certain historical and progressive conception of the world, the importance and place of which in the various left-wing ideologies can vary greatly $(. .$.$) For this ideological tradition, the entire history of the world comes down to a slow,$ but inevitable, progress of the human race. Even in a more moderate form, this idea of progress to be made, or already partly accomplished, occupies a fundamental place in all world conceptions and political programs of this ideological camp. ${ }^{229}$

société s'affiche comme l'enjeu le plus important. (...) Le pouvoir renvoie ici à un concept général, soit la capacité d'initiative et d'action d'un groupe donné dans la société en vue de ses intérêts. Dans tout programme de la gauche, répartir le pouvoir consiste à redonner du pouvoir à ceux que le système désavantage dans sa configuration présente et, au contraire, à restreindre le pouvoir dont jouissent ceux à qui profite le système en place." Ibid. p. 25

228 "Ce rééquilibrage peut faire appel à plusieurs moyens dont le degré de radicalité est très variable, degré qui correspond au niveau d'insatisfaction que nourrissent les idéologies à l'égard de l'ordre établi. Plus ce niveau d'insatisfaction à l'égard du système en place sera marqué, plus les mesures en vue de changer le monde s'avéreront radicales et apparaîtront urgentes. En fonction des diverses idéologies qui composent ce camp, on distinguera trois grandes tendances. Au centre gauche, cette situation, jugée problématique, en appellera en général à la mise en ouvre de simples changements au sein de l'ordre politique sans véritable remise en cause des structures en place, alors qu'à gauche, en réponse à cette situation jugée inacceptable, on optera plus communément pour des réformes affectant les fondements de cet ordre. Enfin, l'extrême gauche voit dans la révolution la seule solution en vue de faire face à cette situation révoltante.", Ibid. p. 26

${ }^{229}$ Ibid. 
Following this presentation of the political program of the left ideological family, it should be appreciated in relation to human security, as a law of nature. Indeed, since the political action of the left consists in a rebalancing of social relations, it militates for a social organization which ensures for all equal enjoyment of the services which it offers. The change of the world is therefore so evident in this ideology which does not support an uneven political society. Thus it will continue to campaign for this type of society whenever elements are introduced which could lead to unfair treatment. It should be thought that the different measures used depend on the depth of socio-political inequality. Thus the American and French revolutions resulting in the modern State were justified in the light of the inequality which was established since the foundation of the Ancient Western order. The leftist political action admits some philosophy of history in that it believes in the progress of humanity which ultimately means that national political society is gradually becoming egalitarian with time. The left therefore takes the fruits of its struggles for granted and can only conceive them in the sense of sustainability. In this the left is no longer very different from the right because it is conservative of elements of the positive egalitarian order in project which it is trying to achieve in accordance with the principle or higher egalitarian order. It must therefore be noted that this both philosophical and methodological aspect of the Left corresponds in a certain way to political society as it is envisaged within the framework of human security, as a law of nature. Indeed, Man has not come to know the best formulation of the political society such as it is the order of the natural means of confirmation of the human security intrinsic sate of affairs and s/he is inevitably doomed to discover this last by the experiment. This involves testing several formulations of political society and learning by their positive or negative consequences on individual conservation. Thus, initiatives which would have positive consequences would be capitalized and those which would have negative consequences should be changed or improved. The process is expected to continue until the order of means for confirming human security is fully discovered. In this understanding, the establishment of an egalitarian socio-political order by the left already corresponds, at least in this substance, to the theoretical framework of human security. Because it is necessary to first clarify the whole substance of this principle order which is also the principal means by which it is confirmed.

At the end of this presentation of the ideological families of left and right and the analysis of their correspondence to human security, as a law of nature and as a prelude to check it the latter as the foundation and finality of national political order, it must be recognized that they basically share more similarities than it seems. The left and the right both postulate in their 
various conceptions of the world, an established upper world order which is a question of giving concrete form or preserving according to the circumstances. The difference would situate in the substance of this order. In varying degrees, they correspond to assumptions of human security, which allow us to know what to expect when particular ideologies of these families assume the authority of positive law through popular assent and enactment. Liberalism at the center of these ideologies is certainly the one that has succeeded, theoretically, in the synthesis of all and which certainly falls within the framework of the order of natural means of confirming the human natural order that human security accounts for. We will check that by examining the national law of the modern state in practice. 


\section{CONCLUSION OF CHAPTER III}

Throughout this chapter we started to check the application of the theoretical framework of human security into the national political order. We first dwelled on political order in idea. This was a necessary prerequisite because national law as it stands or as it constitutes a set of positive rules serves above all a set of ideas and conceptions relating to the meaning of social life and its confirmation. This set of political ideas or ideologies, which are concurrent to the modern State, therefore constitutes national law or national political order in idea. Linking it with human security, as a law of nature was an opportunity to check that the latter one stands as the foundation and finality of national of the former. We undertook this verification with liberalism and the right-left ideological families. Liberalism has been considered as the ideology which is at the heart of the advent of the modern state and which holds a central position within political ideologies in that it includes all the elements of the ideological families of right and left and it still stands as the dominant ideology in the contemporary world. The conception of the world and the political program of liberalism has proved to be based on and founded on human security. This meaning was gradually understood during the development process of this ideology, from its classic version to its social version. In reality, the social precision associated with liberalism and which so marks the moderation of this ideology and implying intervention of the State to ensure to all members of society availability of resources necessary for conservation, revealed the real meaning of this ideology and the logical implication of its postulates, from the point of view of the theoretical framework of human security. Then considering the right-wing ideological family, we noted that to varying degrees, it also had human security as its foundation and finality. This enabled both to understand the general tendency of this ideological family, conservative of the social order and to bring out and understand the real meaning of its ambiguous postulates. This was also the case for the leftist ideological family whose creed is equality. At the end, from this relationship between political ideologies and human security, we can know that all of them have human security as their foundation and finality. Their differences are understood and surpassed in reference to the final order that human security implies. Thus the process of historical experimentation ends or will end up revealing the common sense they refer all implicitly. So national political order or national law in idea having human security, as foundation and finality, that should be known in this political order in practice within the framework of the modern State. 


\section{CHAPTER IV: HUMAN SECURITY AND THE NATIONAL POLITICAL ORDER IN PRACTICE}

National political order or national law in practice in this framework will be understood in two senses: a set of rules pursuing a certain purpose and enacted within the social body and the implementation of these rules. After previously checking that the idea of this order has human security, as foundation and purpose, we will afterward check the same for positive law. It will be a question precisely of reading national political order in these two directions and in major trends of the modern State. The idea of major trends is justified in that based on the historical process of experimentation, it is not possible in this work to evoke the legal history or the historical evolution of the national political orders of all states in the era of modern State. Thus we will dwell on before, during and after the advent of the modern State to better emphasize that positivation through national law, of political ideologies remains in all its trajectory governed by the postulates of human security. National political order will indiscriminately include its constitutional and governmental variants in order to show that constitutional changes are necessary in view of the negative consequences which legal initiatives lead to in giving concrete form to constitutional dispositions. Thus we will study the advent of the modern state national political order (1) and the democratic national political order (2), in relation to human security, as a law of nature. This partition immediately highlights, from a historical perspective, that national political order with reference to the modern state has undergone a progressive evolution towards an increasingly consistent affirmation of democracy.

\section{THE LAW OF HUMAN SECURITY AND THE ADVENT OF MODERN POLITICAL ORDER}

The idea of a modern political order to signify the modern state implies, like the latter, that there existed a premodern state and therefore also a premodern political order. In this context we will characterize them with the aim of clearly identifying the reasons which supported such an evolution. Here it is a question of presenting the situation which prevailed or which preceded the modern state. Such a situation will be discussed in parallel with of human security, in order to check whether the former falls within the theoretical premises of the latter. Thus, we will begin by studying the popular revolutions which are characterized respectively by an affirmation of the people as the source of power (1.1) and the periods which immediately 
followed them which served to clarify the meaning of the concept of "people" as source of power (1.2).

\subsection{Popular revolutions}

Two popular socio-political revolutions are generally recognized as marking the advent of the modern state. These are the American Revolution of 1776, its suites included, and the French Revolution of 1789 as well as its suites. ${ }^{230}$ "Such events, of course, are not rare in history. But these two differed from previous overthrows in that their proponents were not merely concerned with a change in rulers, but had previously conceived of a structure of conditions of legitimate rule and realized this structure in the form of legally binding norms. Individuals were appointed to rule only on the basis of these normative conditions, and were authorized to exercise their rule on this basis alone". 231

These events mark the establishment of a new political order over an ancient one which should be characterized (1.1.1), and whose consequence is the affirmation of the people as the origin of power (1.1.2). These situations will be interpreted as one of the aspects of the law of human security.

\subsubsection{The situation prevailing in popular revolutions}

The American and French political revolutions are products of an arbitrary political management that reached a saturation point. It is first necessary to understand the general context in which these revolutions took place.

The Westphalian Peace Treaties ended the Thirty Years War ${ }^{232}$, opposing Catholics against Protestants in every European monarchy, particularly in the North of Europe. These Treaties which are generally recognized as marking the Peace of Westphalia, because of the two cities Munster and Osnabrïck where they were signed, sanctioned the division of Europe into distinct political territorial units or States. Thus, the peace of Westphalia enshrined the principle of territorial sovereignty and established the principle of fixed borders and universally recognized in law. On this basis, these treaties naturally include the principle of non-intervention in the space of other States. The Treaty also encouraged the further development of the use of diplomacy, which is the art and practice of conducting interstate relations through embassies

\footnotetext{
${ }^{230}$ D. GRIMM, Constitutionalism, Past, Present, and Future, Oxford University Press, 2016, p. 41 ${ }^{231}$ Ibid. p. 41-42

232 L. KILSDONK, The Thirty Years War(s), Lawrence University Honors Projects, 120. 2018, https://lux.lawrence.edu/luhp/120
} 
and ambassadors which had already started in the 16 th century. ${ }^{233}$ The Peace of Westphalia is arguably the most important historical benchmark for the formation of the modern territorial state. Through it, the principle of state sovereignty normalized in the new political imaginary in the sense that within the State, sovereignty meant a legitimate and controlling authority, while outside, the sovereignty meant a right of reciprocal self-determination against dynastic or other claims and of all extreme religious interference. ${ }^{234}$ In addition, "Territoriality arose, then, in good part as a historically contingent resolution of a spiritual crisis in Christendom. By sanctioning the division of the Christian commonwealth into territorially bounded states, the Peace of Westphalia also consolidated and gave a new political form to Europe. Europe as a political identity began to take hold; that is, the term "Europe" increasingly was used to refer to an imagined political space defined by its own rules. Within Europe there obtained a system of states and an international society with an international law to regulate conflict and trade. The peoples outside Europe came to be understood not only as non-Christian others but as extralegal peoples who were not governed by the same rules of the international society of Europe; this had enormous consequences for colonial and imperial policies (...). Estrangement of European peoples from themselves becomes a double estrangement, simultaneously religious and political. A third estrangement, through colonialism, was also in the making. European states will come to be seen as more economically and culturally advanced than the nonEuropean peoples they conquered and colonized."235

Regarding England, even if it was not involved in the Thirty Years War since having operated a schism in 1534 by the Act of Supremacy ${ }^{236}$, canceling all papal jurisdiction and making King Henry VIII, the holder of the Supreme ecclesiastical authority in England, it was also involved in the enterprise of enlarging its territorial space by the conquest of new territories outside Europe. One of them is North America. It established colonies there and these were managed by English settlers, under the authority of the metropolis. The independence movement thus presented itself as an insurrection of the settlers against the central power of the metropolis. The independence movement originated from a set of metropolitan taxes imposed on the

\footnotetext{
${ }^{233}$ G. MATTINGLY, Renaissance Diplomacy, Houghton Mifflin, Boston, 1955

${ }^{234}$ J. H. HINSLEY, Sovereignty, $2^{\text {nd }}$ Ed. Cambridge University Press, Cambridge, 1986; R. B. J. WALKER, Inside/Outside: International Relations as Political Theory, Cambridge University Press, Cambridge, 1993

${ }^{235}$ R. B. J. WALKER, op. cit.; W. C. OPELLO Jr., S. J. ROSOW, The Nation-State and Global Order. A Historical Introduction to Contemporary Politics, Lynne Rienner Publishers, 1999, p. 48

${ }^{236}$ K. GIBBONS, "When did the Schism begin, and why? Views on the English Reformation amongst Catholic polemicists", in Études Épistémè [En ligne], n³2, 2017, consulted on 19 November 2019, URL: http://journals.openedition.org/episteme/1809; See also J. B. CONACHER, "The Reformation in England: A Reconsideration of Henry VIII's Break from Rome", Reform, $\mathrm{n}^{\circ} 22$, Canadian Catholic Historical Association, 1955, pp. 39-57
} 
colonies and by the latter to be abusive. These taxes had far-reaching negative consequences on the economic rights of colonial societies established in America. ${ }^{237}$ Using the slogan "No taxation, no representation" these two major interest groups formed an alliance with traders, artisans, and small farmers to protest the new taxes and boycott British products. In reaction, the metropolis imposed new taxes which seemed to satisfy the two large interest groups which sought to calm the situation that had nevertheless exposed and to their detriment the most radical groups of colonial society constituted of traders, craftsmen and small farmers. They accused the British government of maintaining an unjust colonial economic and social structure and began to fight for independence. A series of continual, provocative and damaging reactions and counter reactions from both parties resulted in the organization of the First Continental Congress in 1774, bringing together the Delegates of all the Colonies. ${ }^{238}$ Congress did not seek a break with the United Kingdom, but tried to define the rights of the colonies of America, to fix the limits of the power of the Parliament, and to agree on the tactics to be followed to resist the laws of coercion. In October 1774, delegates adopted a Declaration of Rights and Grievances, which rejected the right of Parliament to tax or legislate on colonies, and stated that only colonial assemblies had this power. They reluctantly conceded to Parliament the right to regulate trade. The Congress wrote the continental association, an agreement asking the colonies to cease all commercial relations with the metropolis until the repeal of the laws of coercion by the Parliament. Congress adjourned, planning a second rally, in May 1775. By that date, however, hostilities had already started between the United Kingdom and its colonies. ${ }^{239}$ As far as France is concerned, the eras following the Westphalian Treaties were marked by a political absolutism embodied by kings whose legitimacy was dynastic and divine. The revolution took place following the arbitrariness of the "Ancien Régime", and particularly under Louis XVI. The Ancient Regime was based on the idea of social tripartition: the Clergy or those who pray, the nobility or those who fight, and the Third Estate or those who work. This division was also a hierarchy: those who pray are the first, those who work the last. The existence of privileges attached to the first two orders is the hallmark of this hierarchy. Belonging to the first two orders guaranteed numerous privileges: tax exemptions, in particular for the clergy, authorization to levy taxes, seigneurial rights, on secular or religious fiefs, possibility of accessing different political or military functions, as well as many honorary

${ }^{237}$ C.J.H. HAYES, A Political and Social History of Modern Europe, Vol. 1, Afton, New York, May, 1916, pp. 277-281; For additional Bibliography, see pp. 284-285

${ }^{238}$ Th. J. LOWI, B. GINSBERG, American Government: Freedom and Power, $3^{\text {rd }}$ Ed. W. W. Norton, New York and London, 1994, pp. 27-31,quoted by W. C. OPELLO Jr., S. J. ROSOW, ibid. p. 69; C.J.H. HAYES, ibid.

${ }^{239}$ C.J.H. HAYES, ibid. 
privileges, including the carrying of the sword, theoretically reserved for the nobility. With regard to the Third Estate, the mass of peasants as a whole was crushed by the burden of taxes, while the bourgeoisie bore less and less all the taxes which burdened its activity. The practice of monarchical power by Louis XVI tended to evolve towards an "enlightened despotism", calling on competent and pragmatic ministers, favourable to reforms. But the foundations of the king's authority remain of an absolute and authoritarian nature. ${ }^{240}$

Since 1776, France has been experiencing a slowed growth cycle. The increase in state spending, especially military, with the participation in the American Revolution (1775-1783), had increased the public debt to the point that the monarchy barely managed to pay interests. The solutions proposed by enlightened and resolute ministers of Louis XVI (Jacques Turgot, Jacques Necker, Calonne) all implied the end of fiscal privileges and therefore a strong contribution from the exempt classes. All were met with resistance from the aristocracy, strongly attached to its privileges. The economic and financial difficulties were compounded by an agricultural crisis caused by a series of poor harvests. After the rigors of winter 1788, the country experienced a shortage of wheat. In addition, the industrial crisis caused by the cessation of Spanish imports of wool and cloth, as well as by the opening of the French market to English products, in 1786, led to the closure of many factories. Popular misery increased, while the growing number of vagrants generated a climate of insecurity in the countryside known as "fears". 241

“In 1789, Louis XVI (r. 1774-1792) summoned the Estates General, its first meeting since 1628, to gain support and consent for new taxes to pay debts associated with France's recent war with Britain in North America. The nobility and the clergy refused the king's request and challenged his authority by demanding a say in the governance of the realm in exchange for the relinquishment of their immunity from taxation. This challenge to the king's authority encouraged the Third Estate, that is, the bourgeoisie, which was already very heavily taxed, to make their own demands. The Third Estate declared itself the only true representative of the French people. Rioting and protests broke out in Paris and on July 14, 1789, a mob stormed the Bastille prison". 242

\footnotetext{
${ }^{240}$ See E. HOBSBAWM, L'Ère des révolutions, Editions Complexe, 2000 ; G. LEFEBVRE, La Révolution française, PUF (2 tomes, 1951 et 1957) ; A. SOBOUL, La Révolution française, Gallimard, 1981 ; J. NICOLAS, La Rébellion française, Mouvements populaires et conscience sociale 1661-1789, Gallimard, Folio, 2008 ; C.J.H. HAYES, ibid, Chap. XV, "The French Revolution Introductory", p. 383

241 "Révolution française", Encyclopédie Microsoft $®$ Encarta® 2009 [DVD]. Microsoft Corporation, 2008

${ }^{242}$ W. C. OPELLO Jr., S. J. ROSOW, op. cit. p. 70
} 
After this brief presentation of the facts prevalent in the American and French revolutions, we will try to examine them in relation to the aspects of human security, as a law of nature.

As we have seen, human security is the real dispositional state of human nature. It is the state consubstantial with this nature so that it accounts for its order. In other words, human nature is only itself but in security. It is not enough to be a human being, it is sufficient to be in security. Human security thus pertaining to the essence of human nature, that is to say the most real state of this nature, it characterizes it as its order whose implication is that it has no longer to be created or realized, since real already, but has to be confirmed as it is. For the human animate nature, this means that the natural and then unavoidable tendency of the human being is the conservation of and in this intrinsic state, to ensure its permanence. Thus human security being the foundation and finality of human nature, it embodies its law. Since this implies a confirmation and no longer a realization, it necessarily includes an order of means of confirmation just as natural which, too, has no longer to be realized, but to be discovered. The order of means arises both on the individual level, as regards the human being in relation to himself, and on the collective level, as regards the human being in relation to his fellows. The order of natural means on a collective level is justified by two requirements Men have to deal with in the search for conservation: cohabitation of other human beings and dependence on the resources of nature. On the basis of these requirements, political society already represents in itself this order of means, though its exact formulation is knowable, at least by experience.

Regarding the situation prevailing before the American and French revolutions, we will examine them in turn.

The United Kingdom is a political society, that is to say, a group of people constituted that way to ensure individual conservation. The main reason which motivates the United Kingdom in the enterprise of conquering territory outside its own, in this case, in North America, is undoubtedly for the advantage of an availability, for its benefit, of additional resources, lying in these territories or produced as a result of their control, and ensuring or allowing the conservation of its people. So it should be thought that the main reason is the benefit of resources from nature (soil, subsoil and even human beings) and because of nature (economic opportunities for and of the metropolis and the settlers in these territories). ${ }^{243}$ As for the metropolis, the territories of North America represented markets for products coming from homeland and a source of financing through the various taxes imposed on the businesses of the colonists. For the settlers,

${ }^{243}$ C.J.H. HAYES, op. cit. pp. 269-270 
these territories provided them with business advantages and certainly authority over both property and people (natives). The colonists and the holders of power in the United Kingdom, being part of the same political society (Great Britain), the question of the formulation of this one, governing their relations for a common interest becomes here the determining factor for the continuation of these ones. Relations between the two groups of actors related to goods, in particular their accumulation to the advantage of each, for the satisfaction of personal or collective needs. The search by each party for an advantage is certainly the source of the conflict, and the outcome of this situation in a conflict gives to understand the great value of the resources at stake, whose the need for control justified it. In other words, if parties manage to kill each other for resources, then one must understand how important these latter are. This is the logic of the Hobbesian natural state where man is a wolf for man in the goal of satisfaction of his own security, or conservation. From the point of view of the colonists who considered themselves to suffer an injustice from the power in place in the metropolis, it was either a question of rising up against it, or of separating or getting rid of it in the sense that the thencurrent formulation of the political society no longer guaranteed their interests, according to the idea or up to the level they might hope. Thus the colonists opposed against the metropolitan measures considered arbitrary, whose persistence had to be replied by a struggle for separation.

The case of France reveals a purely internal situation, in which the organization of politics does not benefit everyone but some. The different social orders were distinguished by the nature and extent of the privileges they could enjoy. These were less and less important depending to whether one descended in the hierarchy. The King had so enough to the point his stature was absolutist, the clergy, a little more than the Nobility and the latter a little more than the Third Estate. Now this last social order is indeed the one whose labor is used for the production of social goods and in the service of other orders and of itself. In such a context, one must understand the value of privileges. These are means allowing the conservation of their holder, in a logic of human security, basically understood as well-being. It is with this in mind that they are prized and coveted by all orders and whose unequal enjoyment pushes the disadvantaged to dissatisfaction. Thus, one can understand the reaction of the targeted ones of the additional taxation of King Louis XVI, for the repayment of the debts involved during the American Revolution, the support brought to the American troops by the French forces. For the king it was a question of getting rid of a certain insecurity that represented the debt, and for the targeted orders by taxes, it was a question of resources and certainly against a harmful reduction. The advantageous disposition of goods or resources is thus also crucial in the French case. This is 
one of the issues lying at the center of political society, taken as an adequate means of individual conservation in a natural necessity of coexistence, hence the importance of its current formulation. It is clear that the one which does not lead to the conservation of each one is doomed to be challenged. Thus, it must be thought that the Third Estate which found itself as the main victim or the most disadvantaged had reached a level where it could no longer bear such a situation. So it revolted. ${ }^{244}$

Human security was therefore at the heart of the situations prevailing in the American and French Revolutions. It was posed precisely on a collective level in terms of the order of means necessary for individual conservation. If the political societies at these times were already recognized as the prerequisite for the order of natural means, its exact formulation, understood as that which should benefit each member part of it, was certainly not yet understood because the one apparently in force did not achieve the expected essential finality. Since human security is the foundation and the finality of political society, it was surely the foundation, but it was not yet the finality. It therefore had to be challenged in its then-formulation in order to establish another which was intended to achieve this finality. We must now look the response brought by these revolutions.

\subsubsection{The response brought by popular political revolutions: the people at the Origin of Power}

The popular American and French political revolutions marked the affirmation of people in the direct participation in public affairs. For this reason they are constitutional revolutions erecting or claiming people as origin of the decision and the shaping of the public organization for the general interest corresponding to the conservation of each individual who is part of it. It goes without saying that before these revolutions, the people, although they found themselves within the limits of a territory, consequences of the Peace Treaties of Westphalia, were not the holders of sovereignty, since it generally fell to the king, claiming himself as the guarantor of order within the territory. In this framework, it is a question of taking it into account as part of the response brought by the American and French revolutions and putting it in parallel with the aspects of the law of human security.

With regard to the American Revolution, the Declaration of Independence of 4 July 1776, adopted at the Second Continental Congress, mentioned the attachment of the constituents to

${ }^{244}$ C.J.H. HAYES, Ibid. pp. 385-386 
natural law, the social contract, inalienable rights, popular sovereignty, and limited government. ${ }^{245}$ These were followed by a series of grievances from the colonial elite against the British rule. The following year the colonists declared independence and adopted a written constitution entitled "Articles of Confederation and Perpetual Union" that was in force until 1789. This Constitution created a confederal State, that is, one in which a federal government enjoys powers devolved to it by the constituent member States. This constitution did not include a national-level executive body, and laws passed by the Continental Congress had to be enforced by member States. Although the Continental Congress could declare, make peace, ratify treaties, lend money and regulate trade with Native Americans, it could not levy direct taxes or regulate trade among member States. The army was not included and each State took care of its militia. ${ }^{246}$

"The Articles of Confederation, did not, then, create a state strong enough to promote the economic interests of New England merchants and southern planters. The newly independent states competed with one another for foreign commerce, and European states treated each state of the Confederation as a sovereign state. At the same time, the influence of radicals in the Continental Congress and the legislatures of certain states, such as Pennsylvania and Rhode Island, increased, threatening dominant economic interests. Faced with these threats, the Virginia state legislature called a conference of state leaders, which met in 1786 in Annapolis, Maryland, in order to organize a subsequent conference to revise the Articles of Confederation. In the meantime, Daniel Shays, a former Revolutionary War army captain, led a rebellion of debt-ridden farmers against the state of Massachusetts to prevent foreclosures on their land. Although Shays's Rebellion (1786), as this event is known, ended peacefully when fourteen of the captured rebels were eventually pardoned and the state legislature met some of their demands, it demonstrated the weakness of state militias and the growing influence of the radicals" 247 .

Following to this a conference was convened in May 1789 in Philadelphia for the purpose of revising the Constitution. The 55 Delegates agreed on the ideological principles on which the new State should be based. Indeed, they specifically wanted a State capable of promoting trade and protecting the property from radical state laws. ${ }^{248}$ So they got there and adopted a new

\footnotetext{
245 . A. ROGOFF, “A Comparison of Constitutionalism in France and The United States", in Maine Law Review, Vol. 49, n²1, p. 30

246 Th. J. LOWI, B. GINSBERG, op. cit. pp. 32-33

${ }^{247}$ W. C. OPELLO Jr., S. J. ROSOW, op. cit. p. 69

248 C. A. BEARD, An Economic Interpretation of the Constitution of the United States, Macmillan, New York, 1913
} 
Constitution at the Philadelphia Convention. To embody power and ensure protection, the central government was divided into three separate and equal bodies: the legislature, the executive and the judiciary. The legislative body was subdivided into a senate, whose members were appointed from among the member states and an assembly directly elected for two years.

"Power and protection were also accomplished by dividing governmental responsibilities between the central government and the constituent state governments. A strong, but not too strong, national state was imposed upon the preexisting states, which had been autonomous from one another under the Articles of Confederation and as colonies of Britain. The Constitution rescinded the right of states to maintain armies in peacetime, and gave the central state the power to conduct foreign policy and command the national army as well as the state militias (if called into national service). To Congress the Constitution granted the right to declare war, to call the state militias into national service, and to appropriate money to support the armed forces. In addition, Congress was given the responsibility of assisting commerce by making "internal improvements," such as building roads, bridges, and canals, creating a national currency, controlling patents, collecting tariffs, and providing subsidies. To the states were given the power to make law in a host of areas, including property, banking, business, family, public health, education, crime, elections, local government, occupation, and land-use. To ratify the new Constitution, it was necessary that a bargain be struck with those who believed that, despite separation of powers and federalism, the state was still too strong and might still threaten economic interests and individual rights. A Bill of Rights was adopted in 1791 in the form of amendments to the original document. In spite of the guarantee of individual rights to all persons, the Constitution maintained the Three-fifths Compromise, which stipulated that five slaves would be counted as three persons for purposes of apportioning seats in the House of Representatives" 249 .

Following these facts, from the perspective of human security, it must be noted that the main reason that grounded the initial American constitution is the securitization of the general situation of resources of an economic nature. The main protagonists who represented the constituent people consisted of the main economic interest groups and who were settlers. This is still enough to confirm the economic foundation of this revolution. The revision of the very first formulation of this constitution was justified by the damaging consequences on the economic interests of its implementation. Before this revision, some settlers started an insurrection against the new order because this one was damaging their economic interests and

${ }^{249}$ W. C. OPELLO Jr., S. J. ROSOW, op. cit. pp. 69-70 
that insurrection stopped when a solution was found. The second agreement on the organization of the Federation included consequently a formulation which was to guarantee the satisfaction the situation of these resources for each protagonist. This still demonstrates the great value of resources for human conservation. The response of the American Revolution therefore signified the use politics at the service of economics. The wording of the new organization was different from that of the British Homeland. A system of separation of powers supported by a Bill of Rights instituted a political environment which was to secure private property and all the Territory of the federation, these two elements corresponding to the security of goods and territory, at the benefit of people. It should then be noted that not all human components of American society were represented in these constitutional negotiations and were the founders of the new state. This is how we have to agree with the opinion that "American political writers used the terms "democracy" and "republic" to describe their polity. The states were certainly republics, if that term is meant to denote that their heads of state were not selected by hereditary succession. But if the criterion of "democracy" is that all adult citizens have the right to vote and to stand for election to office, then America was not a democracy, and did not become so, even in law, for two centuries thereafter. Slaves and women were excluded, as were white males who could not meet the prescribed requirements" ${ }^{" 250}$. The people in question in the creation of the new State were therefore just only a well distinguished layer of the population among the whole established in the American territory, an elitist group united by strong economic interests, sufficiently strong whose satisfaction justified the separation with the homeland and a precise organization of public powers.

With regard to France, being aware of embodying the immense majority of the nation, the Third Estate had so highly claimed its desire to obtain profound reforms that the speech of the Minister of the King immediately excluded the Estates General. On 6 May 1789, the deputies of the Third Estate called themselves the "communes" with reference to the United Kingdom and demanded to participate in the verification of credentials. On 17 June, facing the growing resistance from the nobility and the upper clergy, and while part of the lower clergy joined in with the demands of the communes, the latter proclaimed themselves "National Assembly". On 20 June, finding their usual meeting room closed by order of the king, the members of the "National Assembly" met in the "Jeu de Paume" room where they took the famous oath not to separate before giving a constitution to France. Joined by the majority of clergy and some

${ }^{250}$ S. GORDON, Controlling the State, Constitutionalism from Ancient Athens to Today, Harvard University Press, 2002, p. 296 
nobles, the National Assembly declared itself constituent on 9 July. The activity of the Constituent Assembly was of exceptional intensity. The abolition of feudal privileges and rights (night of 4 August 1789), the Declaration of the Rights of Man and of the Citizen (26 August 1789) and many other laws. ${ }^{251}$ The Constituent Assembly knew how to promote its action through organizing an immediate celebration of its regenerative actions, as shown by the enhancement of the night of 4 August or the feast of the Federation on 14 July 1790.

The completion of the Constitution was difficult: the Constitutional Act adopted on 3 September 1791 was sanctioned by the King of France on 14 October when the Legislative Assembly had met on October 1 . The regime so formed lasted barely nine months, three times less than the Constituent Assembly. The Constitution thus drawn up (the first in the history of France) defined a constitutional monarchy, based on a census suffrage. The Declaration of Human Rights, recognized in the preamble of the constitutional text, enshrined fundamental rights, freedom, equality, security of property and resistance to oppression. The legislative power belonged to an Assembly which controls a government of six ministers. The king, on whom the sanction of laws depended (suspensive veto for two legislatures, that is to say, four years), still had real power. The election of judges and mayors by "active citizens" ensured the separation of powers; finally, freedom of the press was attested, unless a state of emergency be established by "martial law"252.

The direct result of the French Revolution was the abolition of the absolute monarchy as well as the disappearance of a society of orders and feudal privileges of the nobility. The last remnants of serfdom were abolished, feudal taxes and tithes were suppressed, the great manorial domains were parceled out, and the principle of equality before taxes was adopted.

The Elaboration of the French constitution therefore looked a little more popular than that of the United States of America. The people, who did no longer include only the majority Third Estate, but also the clergy and the nobility, asserted themselves as the original constituent in order to establish a social order which would have allowed the conservation of all its members. However, it should also be noted that not all categories of the population had taken part in the negotiations, like women. Even if the social representation was stronger, one would also have to come to the conclusion that it was much more of a Republic but not of a true democracy.

${ }^{251}$ C.J.H. HAYES, Ibid. p. 386

252 Ibid. pp. 399-400 
After these historical and renewal elements of the national political order, it is necessary to make the distinctive point between the ancient constitutionalism and the new one that led to the American and French revolutions. "The term "constitution" was originally used to denote a family of laws that did not necessarily have to relate to the exercise of rule, while "constitution" generally meant the condition or situation of a state-initially broadly, as it was shaped by historical development, natural features, and legal order; later more narrowly focused on the status accorded it by conventions, fundamental laws, and governmental contracts. Even in this narrower focus, the constitution remained a condition determined by law. It did not designate the legal form itself. Consequently, every state was in a certain "constitution" and where no constitution could be identified, no state existed. The older concept of constitution was thus an empirical concept. By contrast, the modern constitution prescribed how state power should be established and exercised in the form of a systematic and exhaustive claim embodied in a legal document. In this way, the constitution became synonymous with the law that regulated the establishment and exercise of state power. It no longer designated the situation of a state as formed by its laws, but the law that formed the situation. "Constitution" thus emerged as a normative concept. Certainly not all countries had a constitution in this new sense. Rather, the existence of a constitutional document that provided for basic rights and popular representation became a distinguishing feature of the categorization of the world of nations, and the question as to whether only the constitutional state in this sense could claim legitimacy was a dominant theme throughout the nineteenth century." 253

We can therefore conclude that the modern political order was born out from the claiming of people or one of its general representative or components as the original holder of the power to define a much fairer social organization that allows the conservation of everyone. The modern State thus displaced the conception of State from a private domain of some to a Republic in the sense that governance had to be done in the name and for the general interest. From the point of view of human security, as a law of nature, these facts can be considered to fall within its theoretical framework. The advent of the modern constitution only happened with human security as its foundation and finality. It was notably a stage of the historical experimentation for the discovery of the order of natural means that implies human security for purposes of conservation. The rest of events at the national level should confirm this state of affairs.

\footnotetext{
${ }^{253}$ D. GRIMM, op. cit. p. 43-44
} 


\subsection{A later stammering confirmation of the People as an original constituent}

The American and French political revolutions were ultimately movements to impose the Republic by a group of people who presented themselves as the people. However, their results were just the beginning of history because the new written constitutions were quickly amended, without all the components of the people being involved. Thus, the aftermath of these revolutions continued to mark the preponderance of certain privileged groups (1.2.1) and strong leaders (1.2.2) in the national political order. From the perspective of human security, these facts are to be understood in the framework of the historical process of experimentation and discovery of the good formulation of the political society by which the conservation of each is guaranteed.

\subsubsection{The preponderance of privileged groups in the definition of the national political order}

In this context, we will raise the legal facts successive to the French revolution and of other revolutions which followed it.

The 1791 Constitution was only applied for a year due to the war and the fall of royalty. The new Assembly, the Convention, received the mission to design a new Constitution. This is the Condorcet project which was adopted in 1793 by the Assembly. ${ }^{254}$ Preceded by a declaration stating that common happiness is the goal of society, this Constitution, rich with 124 articles, established in particular universal suffrage, however reserved for men. It provides for executive power, including seven ministers and a secretary chosen from outside the Assembly. The Assembly was given a very important power. Then, wartime justified a Constitution providing for a strong executive. The 1795 Constitution included 377 articles. It abandoned the principle of universal suffrage, affirmed the unity and indivisibility of the Republic. The executive power was entrusted to a Directory composed of five members elected by the legislative body. After the "coup" of 18 Brumaire, a new Constitution of 95 articles, containing no significant declaration of rights, was drawn up by Sieyès and Napoléon Bonaparte. It gave power to a head of state, the First Consul. In fact, it was tailor-made for the future Napoleon I, who was sure to use it to establish a military dictatorship. ${ }^{255}$ Logically, after the restoration of peace inside and

\footnotetext{
${ }^{254}$ N. de CONDORCET, Plan de Constitution présenté la Convention Nationale, Imprimerie Nationale, Paris, 1793, Bibliothèque Nationale de France, https://gallica.bnf.fr/; M. BIARD, La Constitution de 1793, http://www.la-bibliotheque-resistante.org/mes textes/la_constitution_de_1793 biard.pdf

${ }^{255}$ See P. GUENIFFEY, Le Dix-huit Brumaire. L'épilogue de la Révolution française, Coll. "Les journées qui ont fait la France", Gallimard, 2008, A. JOURDAN, "Le Dix-huit Brumaire de Napoléon Bonaparte : Retour sur un coup d'État", in La Vie des Idées, le 28 mai 2008, http://laviedesidees.fr ; A. CREPIN, "Le 18 Brumaire, une
} 
outside, Bonaparte had the Constitution of the year X drawn up: rich with 86 articles, it considerably strengthened his powers, in particular by appointing him consul for life and giving him the opportunity to choose his successor. ${ }^{256}$ The resumption of war has as first consequence the transformation of the Consulate into an Empire governed by the Constitution of the year XII. It contained 142 articles. The most important of them was that which conferred on Bonaparte the title of Emperor (art. 1). The Empire was hereditary. This Constitution established in France a dictatorial and military regime. ${ }^{257}$ After this phase of authoritarian constitutionalism, it was the turn of the constitutional monarchies.

The Constitutional Charter of 4 June 1814 was ultimately inspired by Louis XVIII himself. It includes a preamble and 76 articles. The Charter is a compromise between principles of the Ancient Regime and certain principles inherited from the Revolution. Thus, it guarantees equality before the law, before tax and for admission to public office, freedom of worship, of the press, as well as the sustainability of the transfers of national property carried out during the revolutionary period. Executive power was entrusted to the king, whose responsibility could not be questioned. The legislative power was entrusted to two Chambers, that of the peers and that of the members of parliament, elected for five years at the "suffrage censitaire". ${ }^{258}$ After Napoleon's return on 20 March 1815, a new Constitution, the Additional Act to the Constitutions of the Empire, was promulgated on 22 April. Written in part by Benjamin Constant, it constituted an amended version of the Charter of $1814 .{ }^{259}$ At his return, Louis XVIII reinstated the Charter. After the promulgation by Charles $\mathrm{X}$ of four ordinances in flagrant contradiction with the Charter of $1814,{ }^{260}$ the July Revolution brought a change of dynasty, in favour of the house of Orleans. The Charter of 1830 contains some important modifications compared to that of 1814, inspired by the desire to copy the British model: abolition of the right

\footnotetext{
étape dans la constitution d'une armée nouvelle", Annales historiques de la Révolution française, $\mathrm{n}^{\circ} 318,1999$, pp. 663-676

${ }^{256}$ Le Sénat Conservateur, La Constitution de l'An X, https://www.senat.fr/

${ }^{257}$ C. ZACHARIE, "Napoléon et les Règles de Dévolution de la Couronne, Contribution à l'étude du droit constitutionnel impérial", in Revue française de droit constitutionnel, Presses Universitaires de France, Vol. 4, n ${ }^{\circ}$ 76, 2008, pp. 703-731

${ }^{258}$ A. le DIVELLEC, "La Charte de 1814 dans l'histoire des Constitutions politiques libérales", Jus Politicum, $\mathrm{n}^{\circ} 13, \quad 2015, \quad$ http://juspoliticum.com/article/La-Charte-de-1814-dans-1-histoire-des-constitutions-politiquesliberales-948.html

${ }^{259}$ J. BLOQUET, "L'acte Additionnel Aux Constitutions de L'empire du 22 Avril 1815 : Une Bataille Perdue d'avance?" in Napoleonica. La Revue, Vol. 1, n 13, La Fondation Napoléon, 2012, pp. 3-39 ; Article available on line at : https://www.cairn.info/revue-napoleonica-la-revue-2012-1-page-3.htm ; A. LAQUIEZE, "Benjamin Constant et l'Acte Additionnel aux Constitutions de l'Empire du 22 Avril 1815", in Historia Constitucional (revista electrónica), $\mathrm{n}^{\circ}$ 4, 2003, http://hc.rediris.es/04/index.html

${ }^{260}$ Ordonnances du 25 juillet 1830, https://data.bnf.fr/fr/15102923/france_ordonnances_de_juillet_1830/
} 
to legislate by ordinance when the "security of the State" was in question, adoption of the tricolor flag, division of the initiative of the laws between the Chamber and the king. ${ }^{261}$

After the constitutional monarchies, it was another republican attempt. After the Revolution of 1848 and the abdication of Louis-Philippe I, a Constituent Assembly was elected on 23 April 1848. The Constitution of 4 November 1848 included a preamble and 116 articles, and attempted to combine the system of monocamerism, imitated by the Constitutions from 1791 and 1793, with the presidential system inspired by the example of the United States (creation of a vice-president of the Republic). The President of the Republic is elected by universal suffrage (art. 46). After this stage, there was a return to the Empire. ${ }^{262}$

The coup of 2 December 1851 was ratified by the plebiscite of 21 and 22 December by the following motion: "Le peuple français veut le maintien de l'autorité de Louis Napoléon Bonaparte et lui délègue les pouvoirs nécessaires pour établir une Constitution", ("The French people want to maintain the authority of Louis Napoleon Bonaparte and delegate to him the powers required to establish a Constitution"). Drafted in twenty-four hours, the Constitution of 1852 (45 articles) closely resembled the one of Year VIII. Executive power was entrusted to Louis Napoléon Bonaparte for ten years (art. 2). The head of the executive commands the armies, declared war, signed peace, alliance and trade treaties, appointed all jobs, had the right to pardon, had the initiative of laws (title III). The legislative body, made up of deputies had to be elected for six years by uninominal ballot and had no right of initiative. ${ }^{263}$ This authoritarian regime gave birth to the Second Empire, after a slight amendment to the existing Constitution. It was modified by several texts, notably between 1866 and 1869, in order to perpetuate the more liberal orientation that the regime took: this is how parliamentarians are granted the rights of inquiry, initiative and amendment. ${ }^{264}$

\footnotetext{
${ }^{261}$ A. LAQUIEZE, Les origines du régime parlementaire en France, 1814-1848, Chapitre II. Constitutionnalisme libéral et régime de balance des pouvoirs à exécutif monarchique : la Charte de 1830, 2002, pp. 77-124, https://www.cairn.info/les-origines-du-regime-parlementaire-en-france--9782130524878-page-77.html; J-B. NOE, La Restauration ou l'impossible réconciliation, https://www.jbnoe.fr/IMG/pdf/la_restauration_-_cours5.pdf

${ }^{262}$ R. MONNIER, "La Constitution du 4 novembre 1848 : l'ambition d'une république démocratique", Textes réunis par Jean Bart, Jean-Jacques CLÈRE, Claude COURVOISIER et Michel VERPEAUX, in Annales historiques de la Révolution française, $\mathrm{n}^{\circ} 326$, octobre- décembre 2001, mis en ligne le 10 mars 2008, consulté le 19 avril 2019. URL : http://journals.openedition.org/ahrf/1184

263 J. BOUVERESSE, Histoire des Institutions de la Vie Politique et de la Société Françaises de 1789 à 1945, Publications de l'Université de Rouen et du Havre, Coll. Cours, Histoire du droit, 2012 ; A. DIGNAT, 14 janvier 1852, "Constitution sur mesure pour Louis-Napoléon", Publié ou mis à jour le : 2019-04-29, https://www.herodote.net/14 janvier_1852-evenement-18520114.php ; R. CAZALS, Les proscrits de 1852, MIREHC Mémoires Identités Représentations Histoire comparative de l'Europe, Toulouse: FRAMESPA, 3, 1999, pp.24-32. ffhalshs-00139516f

264 J. BOUVERESSE, ibid.
} 
With regard to the United States, let us recall that the founding fathers of the Nation who stood as the original Constituent People, were elites whose main objective was the protection of their economic interests and who framed the constitution with the purpose of satisfying this goal. In this sense, it should be remembered that the slave trade which was to follow in this New State pursued this proven economic goal. From this point of view, slaves could not be considered as part of the People at the same rank as their masters. At that time it was hardly imaginable when we know that the (free) woman was not already considered as part of the People to enjoy the right to vote. Thus the ages subsequent to the formation of the new State were marked by a progressive struggle for the recognition of civil rights to all members of the American people. ${ }^{265}$ It must therefore be admitted that "Assertions of the peoples' sovereignty over time contained an unintended dynamic of raising popular expectations for a greater degree of popular participation and that the peoples' will be satisfied"266.

In 1846, with the development of the slavery conflict in the United States following the American-Mexican war, popular sovereignty became the foundation for a proposed resolution on slavery in the country. At the end of the war, the United States acquired land formerly owned by Mexico. The effort to incorporate this land into the United States has brought to light immense disputes over the extension of slavery, whether authorized, protected, abolished or perpetuated in newly acquired areas. Attempts to resolve the problem in Congress have reached an impasse. Several leaders of Congress, seeking to resolve the impasse on slavery as a condition of admission or administration of the territories, had sought common ground. ${ }^{267}$ For some moderates, slavery in the territories was not an issue for Congress to resolve; they had argued that the peoples of each territory, like those of each American state, were sovereigns and should determine the status of slavery. Popular sovereignty had become part of the rhetoric to leave to the inhabitants of the new American territories the decision to accept or reject slavery; this was to resolve the expansion of slavery in the United States. This was common ground between proponents of limiting the spread of slavery in the territories and those opposed, thereby limiting the widespread American assumption that the people were sovereign. The settlers' struggle for equality with the King of Great Britain was written into the Declaration of American Independence and was common knowledge in the United States after the American

\footnotetext{
265 J. BOUVERESSE, ibid.

${ }^{266}$ R. P. FORMISANO, For the People: American Populist Movements from the Revolution to the 1850s, University of North Carolina Press, p. 43

${ }^{267}$ M. A. MORRISON, Slavery and the American West: The Eclipse of Manifest Destiny and the Coming of the Civil War, University of North Carolina Press, 1997, p. 78
} 
Revolution. Chief Justice John Jay, in his Inaugural Speech in Chisholm v. Georgia (1793) illustrated the sense of popular sovereignty: "It will be sufficient to observe briefly that the sovereignties in Europe, and particularly in England, exist on feudal principles. That system considers the Prince as the sovereign, and the people as his subjects; it regards his person as the object of allegiance, and excludes the idea of his being on an equal footing with a subject, either in a court of justice or elsewhere ... No such ideas obtain here; at the Revolution, the sovereignty devolved on the people, and they are truly the sovereigns of the country, but they are sovereigns without subjects, and have none to govern but themselves (...)From the differences existing between feudal sovereignties and governments founded on compacts, it necessarily follows that their respective prerogatives must differ. Sovereignty is the right to govern; a nation or State sovereign is the person or persons in whom that resides. In Europe, the sovereignty is generally ascribed to the Prince; here, it rests with the people; there, the sovereign actually administers the government; here, never in a single instance; our Governors are the agents of the people, and, at most, stand in the same relation to their sovereign in which regents in Europe stand to their sovereigns" ${ }^{268}$.

In 1886, 93 years after the decision of the Supreme Court in Chisholm v. Georgia, judge Thomas Stanley Matthews expressed it in Yick Wo v. Hopkins: "When we consider the nature and the theory of our institutions of government, the principles upon which they are supposed to rest, and review the history of their development, we are constrained to conclude that they do not mean to leave room for the play and action of purely personal and arbitrary power. Sovereignty itself is, of course, not subject to law, for it is the author and source of law; but, in our system, while sovereign powers are delegated to the agencies of government, sovereignty itself remains with the people, by whom and for whom all government exists and acts. And the law is the definition and limitation of power. It is, indeed, quite true that there must always be lodged somewhere, and in some person or body, the authority of final decision, and in many cases of mere administration, the responsibility is purely political, no appeal lying except to the ultimate tribunal of the public judgment, exercised either in the pressure of opinion or by means of the suffrage. But the fundamental rights to life, liberty, and the pursuit of happiness, considered as individual possessions, are secured by those maxims of constitutional law which are the monuments showing the victorious progress of the race in securing to men the blessings of civilization under the reign of just and equal laws, so that, in the famous language of the Massachusetts Bill of Rights, the government of the commonwealth "may be a government of

2682 U.S. 419 Chisholm v. Georgia, JAY Opinion - in part 
laws, and not of men." For the very idea that one man may be compelled to hold his life, or the means of living, or any material right essential to the enjoyment of life at the mere will of another seems to be intolerable in any country where freedom prevails, as being the essence of slavery itself ${ }^{\prime 269}$.

According to one author, before and after the revolution, the Americans believed that the people of a republic, like a king in a monarchy, ruled as sovereign. This interpretation persisted from the revolutionary period until the Civil War. ${ }^{270}$ Despite this widespread belief, the term "popular sovereignty" was little used by early Americans. In expressing the basic concept of government by the people, they described an ideal of how the people would exercise their sovereignty in the United States and where state agents and employees were just public servants.

From 1865 to 1870 , in the aftermath of the constitutional crisis of the civil war, three critical amendments were approved. The Thirteenth, Fourteenth and Fifteenth Amendments abolished slavery, enshrined the civil rights of freed slaves and prohibited the denial of the right to vote based on race. ${ }^{271}$ In 1920, the nineteenth amendment enshrined suffrage for women in state and federal elections. This amendment is associated with the victory of the progressive national policy movement. ${ }^{272}$

These historical elements depict the journey that France and the United States have undertaken in the search for the political order capable of satisfying the general interest. This notion have been effectively cemented through the respective political revolutions. The formulation of the manner by which it was to be confirmed at the constitutional level was left either to the hands of the National Assembly, charged with representing the people, in that it was more or less considered as the prerogative of a group of privileged people, or the charismatic leader who sometimes found himself to be the king (case of France). Whatever content it took, its application deemed inappropriate or inadequate to satisfy the general interest, and the constitution was immediately revised. This is the reality of the postulates of the Human Security, as a law of nature. Indeed, political society is an instrument by which a human group is organized for the conservation of each member. If its current formulation does not lead, in concrete form, to this result, it shows its inadequacy and inevitably calls for a change or a

\footnotetext{
269118 U.S. 356 Yick Wo v. Hopkins, 1886 - in part

${ }^{270}$ Ch. G. FRITZ, American Sovereigns: The People and America's Constitutional Tradition Before the Civil War Cambridge University Press, 2008, p. 7

271. R VILE, Encyclopedia of Constitutional Amendments, Proposed Amendments, and Amending Issues, 1789$2015,4^{\text {th }}$ Ed. 2015, pp. 193, 206, 463

${ }^{272}$ R. S. KAY, "Formal and Informal Amendment of the United States Constitution", in The American Journal of Comparative Law, Vol. 66, Oxford University Press, 2018, p. 250
} 
revision, until individuals end to the one which leads to this result. The constitution is significant in this endeavor because it embodies political order at its most basic level and it is on this basis that the government is deployed. The notion of general interest proper to the modern political order or to the modern State is an unavoidable historical outcome, based on the fact that political society is instrumental in confirming each individual human security. Thus, it is the participation of all individuals in the formulation of its content which shows that it is necessarily of general interest and not of the privileged ones. If in this constitutional journey which France has carried out we can observe that at times, the people demanded an authoritarian power that could embody a certain charismatic leader, the result of this formulation had to be known in practice and in the fate this fundamental political instrument had to experience. The fact that the authoritarianism of this leader generally ended in failure, either by a revolution in the internal level, or by a defeat on the international level as for inclinations of imperialist subjugation of other territories, a change of constitution finally proves again that dictatorship as a government order does not fit into the order of natural means for the confirmation of human security intrinsic state of affairs. This also applies in a certain way to the United States, whose results of the social uprisings gradually confirmed the constitutional consecration of popular sovereignty.

While the American and French revolutions marked the advent of the modern political order, under the influence of liberal ideas, their aftermath did not mean complete popular sovereignty. This was to have a triple effect in other states that aligned themselves in the model of modern political order.

\subsubsection{The preponderance of Strong Leaders in the definition of the modern political order}

The movement of American and French revolutions spread the affirmation of the Republic and the necessity to understand people as the foundation of political society. This idea spread throughout Europe and grounded many demands for reform of the modern political order. However, the notion of the Republic was much more quickly integrated than that of popular sovereignty or of the people as the original constituent. Indeed, in history, we have been able to note strong leaders, pursuing objectives of general or republican interest, being at the origin of the constitution, in the behalf of the people. These cases also fall within the framework of the modern State and they are rather variants of it which deserve in this framework to be studied in relation to the theoretical framework of human security. We will look at the communist and Nazi cases. 
The Soviet Union officially started in December 1922 under the treaty of union signed by Russia and three other federated republics: Belarus, Ukraine and the Soviet Socialist Federal Republic of Transcaucasia (an entity including Armenia, Azerbaijan and Georgia). Under the treaty, Russia became officially known as the Soviet Federal Socialist Republic. The Treaty of Union was incorporated into the first Soviet constitution, promulgated in 1924. The Bolshevik revolution of 1905 paved the way for the emergence of the first parliament of imperial Russia: the Duma. The first Duma met for the first time on 10 May 1906 and was only a tool in the hands of the Tsar. Those who held the reins of power no longer wanted it to be a simple debate room. The Duma had no power of its own. It could only make laws after the Tsar was initiated. ${ }^{273}$ The right of veto belonged to the Tsar. If the Duma did not adopt the budget, the last budget should prevail. The Duma could not make laws regarding loans. The ministers were responsible only to the tsar and not to the Duma. It operated that way until 1917. The outbreak of the First World War exposed the weaknesses of the autocratic regime of the tsar. On 23 February 1917, riots broke out. About 70 to 80,000 semi-hungry workers and people from Petrograd marched through the streets of the capital. The government did not resist the upsurge of the revolution. A provincial committee made up of members of the Duma constituted a provincial government. ${ }^{274}$

At the request of Dumas, the tsar had to abdicate. Shortly after their return from exile, the Bolshevik leaders, including Lenin, began to agitate against the provincial government. Lenin published his famous document - April thesis - which demanded immediate peace. He coined the slogan "All Powers to the Soviets". 275 The Bolsheviks (signifying the majority), one of the workers' parties led by Vladimir Ilyich Ulyanov (later known by his revolutionary pseudonym Lenin, 1870-1924), took power on 6 November 1917 on the grounds that the intermediate democratic regime to which they expected, like all other revolutionaries, had proven ineffective. Their support came in part from working class radicals in important cities such as Moscow and Petrograd. But they obtained more general support from other sectors of the population by promising and establishing a separate peace with Germany, thereby ending Russia's engagement in the First World War. The Bolsheviks called for a social and political revolution which was to create a society based on equality through collective and national appropriation and the management of the economy. All citizens had to get a job. The nobility was to be abolished and the land given to those who worked it; the private property of industry had to be

\footnotetext{
${ }^{273}$ B. VISHNOO, R. SHIRUR, B. VIDYA, World Constitutions, Sterling Publishers Pvt. Ltd., 1997, pp. 1-2

${ }^{274} \mathrm{Ibid}$

${ }^{275}$ Ibid. p. 4
} 
eliminated as well as the vast inequalities of wealth, status and influence which it had engendered. ${ }^{276}$

The Constitution of 1918 was adopted by the Fifth Congress of the Russian Soviet Union on 10 July 1918. The Constitution created a federation. Russia made up three-quarters of the Tsarist Empire. The Soviet Republic was organized on the basis of a union of free nations, as a federation of Soviet national republics (Article I, Chapter I and Clause 2). The founders of the Constitution aimed to replace the capitalist superstructure of society with a world federation made up of various nationalities and territories. This constitution was based on the Marxist ideology and on Lenin's dream of founding a communist democracy. The dictatorship of the proletariat and democracy tried to exist at the same time as Lenin. When Lenin realized this, he opted for the dictatorship of the proletariat instead of mass democracy. ${ }^{277}$ The Bolsheviks established a political structure which consolidated power under the leadership of the party. The strategy was to penetrate the state apparatus, one of the hallmarks of the absolutist state, with loyal party members. The party was built on soviets (committees), ad hoc groups that were created in 1917 to coordinate strikes by workers, soldiers and peasants. The Soviets elected representatives to the national councils, which had to elect Party leaders who were to define and oversee state policy. Thus, the founders of the Constitution aimed to replace the capitalist superstructure of society with a world federation made up of various nationalities and territories. $^{278}$

The entire Soviet economy, with the exception of individual households, was headed and administered by the National Planning Commission for the USSR (GOSPLAN). GOSPLAN determined production targets, wages and prices. It determined which consumer goods (refrigerators, cars, clothes, etc.) would be produced and where they would be produced. The goods produced were sold in state-run stores at prices set by the plan. These stores were often out of stock because GOSPLAN emphasized heavy industrial and military production at the expense of consumer goods for each Soviet citizen. The State also provided a wide range of social and medical services. Beginning in the 1920s, Soviet citizens were guaranteed unemployment insurance, free medical care in State-run clinics and hospitals, old age pensions, and disability benefits. Housing, although often scarce and poorly constructed, was provided at

\footnotetext{
${ }^{276}$ W. C. OPELLO Jr., S. J. ROSOW, op. cit. p. 81

277 Introduction: Russian Democracy. A Historical Background, p. 9

${ }^{278}$ J. P. BRUNET, M. LAUNAY, “La Russie des Soviets de 1917 à 1921”, in D'une Guerre Mondiale à l'Autre (1914-1945), Coll. HU, Hachette Education, pp. 97-105
} 
low rents. ${ }^{279}$ The political structure of the State as well as modernist ideology enabled the secretary general of the Communist Party to adopt an extraordinary power. Iosif Vissarionovich Dzhugashvili (later known by his revolutionary pseudonym Joseph Stalin), who became secretary general in a power struggle after Lenin's death in 1924 and held this post until his own death in 1952, ruled the Soviet State ruthlessly. His regime characterized a despotism reminiscent of that of the tsars. In 1934, after the assassination of his then-future successor, he released a reign of terror over the Soviet Union which lasted until 1938, during which he purged the Communist Party and the army of elements and arrested ordinary citizens accused of "antistate" activities. The State secret police became omnipresent. Millions of people lost their lives during the execution or overwork in labor camps in Siberia. ${ }^{280}$

It may be noted, following these facts, that history of Russia in the paradigmatic framework of the modern State has human security as its foundation and finality. Indeed, it must be recognized that the Bolshevicks embodied the demand for a Republic, that is to say, a political structure or organization serving the general interest. However, the other variant of the modern State, which is the participation of the people as original constituent, was not affirmed in the immediate period following the American and French revolutions. It should even be said that the Russian case is an example of the adoption of a system of satisfaction of the general interest by limiting the participation of the people as much as possible. As in the previous cases, it should be remembered that the institution of the republic is an important and decisive step in the discovery of the order of natural means necessary for the confirmation of human security. Political society thus has as instrumental nature in the service of the conservation of each of the people who are its member. This was the plan of the Bolsheviks by defining a constitution on the main structure of the Communist Party which succeeded in satisfying the economic needs of people. The usefulness of these is no longer to be demonstrated for the benefit of human security. We can then characterize Communist Russia of that time to a Republic without popular sovereignty. However the terror to which the population was subject to in the satisfaction of the general interest from the leaders is the testimony that popular sovereignty is essential with despotism. It is clear that this form of political organization must ultimately be known as not falling within the natural order of means necessary implied by human security because its formulation, although aimed at it, did not lead to it. Subsequent events necessarily had to evolve towards a more harmonious formulation of the general interest to a much less precarious

\footnotetext{
${ }^{279}$ W. C. OPELLO Jr., S. J. ROSOW, op. cit. p. 81

${ }^{280}$ Ibid. p. 82
} 
popular sovereignty. ${ }^{281}$ Thus the process of historical experimentation implied by human security is also verified in the Russian case.

As for Germany, the German empire created by Bismarck was defeated in the First World War, which led to the transformation of Germany into a liberal constitutional State called the Weimar Republic (1919-1936). The Weimar Republic was imposed by the Allies on a Germany deeply divided between liberals and socialists, who supported it, and conservatives, who preferred the ancient imperial State. This division prevented the Weimar Republic from governing effectively and prevented it from facing the serious economic problems that Germany faced in the 1920s: rising inflation and massive unemployment due to the excessive reparations imposed on Germany by the war by allies and the global economic depression. ${ }^{282}$ Struggling with a foreign State, the Germans began to be attracted in large numbers by parties seeking to destroy the Weimar Republic. One of these parties was the German Communist Party, formed in 1919 by radical members of the Social Democratic Party (SPD) who supported the Russian revolution and favoured a dictatorship of the proletariat. The other was the National Socialist German Workers Party (NSDAP) or Nazi Party, led by Adolf Hitler (1889-1945), a fiercely racist and anti-Semitic fascist party. In the 1932 elections, the Nazis became the largest party in the Reichstag. The Nazis and the Communists, who came in third rank, formed an anti-Weimar majority, which prevented the pro-Republican parties from forming a stable government. As the economic crisis in Germany continued, riots and street clashes between the Nazis and the Communists became widespread. Encouraged by the conservative parties and many agrarian and industrial leaders, the president of the Republic, Paul von Hindenburg (1925-1934), appointed Adolf Hitler chancellor on 30 January $1933 .^{283}$

Once in power, Hitler overthrew the Weimar Republic from within and erected in its place an anti-liberal and anti-socialist State (the Third Reich) led by a "master race" of the Aryans, united by its love for the Fatherland, which promised to protect Germany from the machinations of the "small" races (in particular the Jews), the "decadent" Western democracies and the "subhuman" Marxists. The Nazi party had recognized neither the constitution nor any law, except for the will of the Führer. The Nazis destroyed the federal structure of the Weimar Republic and centralized all political and administrative powers in Berlin, the capital of the

\footnotetext{
${ }^{281}$ Introduction: Russian Democracy. A Historical Background, p. 26

282282 E. KOLB, The Weimar Republic, Transl. P. S. FALLA, London, Unwin Hyman, 1988; R. B. MYERSON, "Political Economics and the Weimar Disaster", in Journal of Institutional and Theoretical Economics, 2004, pp. 187-209

${ }^{283}$ W. C. OPELLO Jr., S. J. ROSOW, op. cit. p. 86
} 
Third Reich. Jews were excluded from the civil service and members of the Nazi party were placed in key administrative positions. The Reichstag was abolished and the land governments were merged with the national ministries. The governors of the Länder, who were now administrative units of the central State, were Nazi governors (party leaders) appointed by Hitler. The judiciary was purged of "non-Aryan" judges and centralized under the Reich's ministry of justice. Special people's courts, dominated by members of the Nazi party, have been established to try those accused of political crimes. A vast network of secret police including the Geheimestaatspolizei (GESTAPO) and the Schutzstaffel (SS) was created. ${ }^{284}$

Under the Nazis, the State intervened massively in civil society. Hitler had developed many public works projects to create jobs and achieve full employment; married couples with children received family allowances; free vacations were given to low-paid workers at state stations; and the factories were under the direction of the State, if not property, as well as agriculture. While fascist economy was at the service of the state, workers and employers had to join one and the same company, the National Labor Front, controlled by the Nazi party, which regulated working conditions and salaries. Independent unions were abolished and strikes were banned. Professionals, such as lawyers and doctors, had to join guild-like organizations under the control of the Nazi party. ${ }^{285}$ In order to create the "master race", the Nazis instituted a policy of sterilization and extermination of what they considered as undesirable elements of the German population: the incurable sick, the weak-minded, homosexuals, gypsies and especially the Jews. Jews and others have been systematically rounded up and placed in labor or extermination camps, where millions of people have died, subjected to scientifically sophisticated techniques of mass murder and genocide. The roundups and exterminations were so common and bureaucratic that they appeared "normal" to the participants. In her famous accounts of the trial of Adolph Eichmann, a former camp commander who had escaped justice until 1963, Hannah Arendt described the process as the "banality of evil". ${ }^{286}$

Hitler's belief that Germany needed a "Lebensraum" (living space), which it sought to obtain from the "racially inferior" Slavic peoples at the east, had proven to be the cause of the decline of the Nazi State. In 1939 Hitler invaded Poland, an act of aggression that triggered World War II. The Allied forces defeated Germany in 1945 ending so the Nazi fascist State. After the war,

\footnotetext{
${ }^{284}$ S. ROTHMAN, European Society and Politics, Bobbs-Merrill, Indianapolis, IN, 1970, p. 695

285 A. J. HEIDENHEIMER, D. P. KOMMERS. The Governments of Germany. $4^{\text {th }}$ Ed. Thomas Crowell, 1975 , New York, p. 23

${ }^{286}$ H. ARENDT, Eichmann in Jerusalem: Report on the Banality of Evil, Penguin Books, New York, 1963
} 
the victors occupied and divided Germany in areas controlled by the United States, France, Great Britain and the Soviet Union. The Soviet Union received land from Polish territory in the east for which Poland had been compensated by assigning it German territory and from which the Germans were expelled. Berlin, which was well within the Soviet zone, was itself divided into American, French, British and Soviet occupation zones. In 1949, the British, French and American occupiers merged their areas to form a new liberal democratic State, the Federal Republic of Germany (West Germany), whose capital was Bonn. In response, the Soviets transformed their area of occupation into a new communist State called the German Democratic Republic (East Germany), whose capital is East Berlin. Thus, two rival German States existed until 1990, when the German Federal Republic absorbed the German Democratic Republic and only one German State was created. ${ }^{287}$

Nazi Germany is another example of a break in the historic trend of popular sovereignty. From a human security perspective, it embodies the formulation of a political society that seeks the conservation of some of its members through the persecution of others. After the establishment of the Weimar Republic, the Nazi regime marked a return to submission to a charismatic authority charged with overseeing the constitutional formulation of state governance. Hitler centralized power like a Kaiser for the sake of the general interest, but the abuses he engaged in testified that this regime could not correspond to the order of natural means necessary for the confirmation of the human security natural state of affairs. Finally, the Nazi Germany advocated to be a Republic, but was not ruled at the benefit of each of its members, what can only lead to consequences damaging human security. The foundation and the finality of the Nazi State were therefore neither more nor less human security except that the order of adequate means to confirm it was undoubtedly false. This could only lead to a subsequent dissolution of this formulation because its results were unnatural.

Through all these facts relating to the advent of the modern State and its consequences in the subsequent period, we were able to check that the modern national political order had human security as its foundation and finality, because all the initiatives that have been tried were pursuing the satisfaction of the general interest but in a logic whose consequences did not lead to the conservation of all the members of the political society. The process of historical experimentation revealed that the formulations of the political order which did not lead to human security, were to be changed or improved. The advent of democracy, including popular

\footnotetext{
${ }^{287}$ W. C. OPELLO Jr., S. J. ROSOW, op. cit. p. 87
} 
sovereignty, is generally the constitutional formulation subsequent to the period immediately following the revolutions marking the start of the modern State.

\section{HUMAN SECURITY, AS A LAW OF NATURE AND NATIONAL DEMOCRATIC POLITICAL ORDER}

The negative impact of the concretization of constitutional formulations on individual conservation was bound to lead to their change or their evolution towards a formulation that can lead to positive results of conservation for each member of political society. For this purpose, democracy, in the broad sense of "government of the people by the people and for the people", has proven to be the most adequate formulation. Indeed, democracy makes or recognize the people, as the original constituent, that is to say, the ones who are the origin and the end of political society. In the perspective of human security, it will be necessary to know that each individual member of political society is its foundation and its finality. In this framework we will check the application of the postulates of human security, as a law of nature, in the relationship between democracy and the modern political order in theory (2.1) and in practice (2.2).

\subsection{Democracy and modern political order in theory}

Modern political order has led to the phase of democracy, which must be described as "modern", if one takes into account that it was already in force in ancient Greece. ${ }^{288}$ However, unlike ancient democracy, modern democracy subsequent to the American and French revolutions differs from modern democracy in that it implies at least in theory that the people are the source of power. Unlike in the previous formulations of political society, the notions of "Republic" and popular "sovereignty" find at least their enshrinement in the modern political order. Thus, they openly assert human rights (2.1.1) and specific institutions (2.1.2).

\subsubsection{The affirmation of human rights in the modern political order}

The American and French revolutionaries adopted human rights instruments, respectively the Bill of Rights and the Universal Declaration of Human and Citizen Rights which were to be part of their political order. They understood that human rights were at the heart of popular sovereignty, ant that without them the people could not really claim to be the origin of power. ${ }^{289}$

\footnotetext{
${ }^{288}$ A. BLACK, A World History of Ancient Political Thought, Its significance and consequence, Revised and Expanded Ed. Oxford University Press, 2016

289 D. GRIMM, Constitutionalism, Past, Present, and Future, op. cit. pp. 65-67
} 
The fact that the subsequent concretization within the political orders immediately subsequent to these instruments of rights did not confirm the sovereignty of the people, understood in the sense of all its components, is revealing that their drafters had not yet really understood the meaning of their provisions. They gradually discovered it through subsequent social demands. Human rights, in this historic trajectory of the modern State, proved necessary for the assertion of the people or better, of all the people as the sovereign.

Democratic political order presupposes the sovereignty of the people, as the origin of power. The people can then define the democratic constitution only if its members enjoy a certain number of rights. Since these preexist to the constitution which is therefore their product, it must be recognized that, even if they come to be "positived", they are above all, natural. The existence of natural rights has been postulated by theorists of the myths of the state of nature. These can be seen as summarizing the general human right to security whose the general means of satisfaction is freedom: "[t] he Right of Nature ... is the Liberty each man hath, to use his own power, as he will himself, for the preservation of his own Nature; that is to say, of his own Life; and consequently, of doing anything, which in his own Judgement, and Reason, he shall conceive to be the aptest means thereunto" 290

Indeed, it is in search of security that individuals believe they are free to do everything in their power to achieve this end. Ultimately it would be the misuse of this freedom that creates insecurity for everyone. The solution to this problem is then for all human beings who are part of the State to agree to a civil status or political society according to a formulation capable of guaranteeing everyone the satisfaction of this general right to security. In this regard, the theories of Hobbes and Locke, although predicting a different fate for the status of these rights vis-à-vis the holder of power, all testify that the people are the original constituent. ${ }^{291}$ Hobbes' theory leaves the fate of this right to the will of the agent who can easily become an absolutist. ${ }^{292}$ The French post-revolutionary State can thus enter into this scheme of ideas since the holder of power proved to be an absolutist for a long time after the Revolution. ${ }^{293}$ On the other hand, Locke's theory is however much more democratic in that after having delegated their power to a holder, the people constituent remain free to rebel against him/her, when the latter comes no longer to guarantee everyone's right to Security. This testifies that each individual part of the

\footnotetext{
${ }^{290}$ R. TUCK, (Ed.), Thomas Hobbes: Leviathan, Cambridge University Press, Cambridge, 1996, p. 91; B. RUSSELL, CHAPTER XIV Locke's Political Philosophy, pp. 623-627

${ }^{291}$ Ibid.

${ }^{292}$ B. RUSSELL, ibid. Chapter VIII “Hobbes's Leviathan” pp. 545-557

${ }^{293}$ C. ZACHARIE, op. cit.
} 
people, for the guarantee of their natural right to security is the foundation and finality of the political order. The constitution that recognizes or accounts for that at the fundamental level is necessarily democratic, because it is only in such a formulation that popular sovereignty takes on its full positive meaning.

Supporting popular sovereignty, human rights fit well in the perspective of human security, as a law of nature. Human security is indeed the foundation and finality of all human action. In the necessity of a coexistence of many individuals bound to conservation through the resources of nature, political society is discovered as included within the order of natural means to confirming the intrinsic state of security. The discovery of the best formulation of political society is subject to the process of historical experimentation through which formulations leading to negative results for conservation of each member are called to be changed or improved. Since each human being has security as the law of his/her nature, it is therefore clear that the general right to security corresponds to the natural tendency to its confirmation or conservation. According to the requirements of coexistence of the multitude, this general right can only include in its package and necessarily, the right of everyone to political participation, because political society is conceived at the fundamental level as an agreement or an understanding between each of the individuals on a collective organization for the conservation of each. Thus we see, at the foundational or constitutional level, the natural identity or synonymy of political society with democracy. Popular sovereignty democracy highlights is in reality the sum of individual sovereignties of each of the members participating in the agreement. Thus the democratic political order has finally been discovered, already at least in theory, as entering the order of natural means to confirming human security, with regard to the consequences of the previous formulations of this order, both constitutional and governmental. While promoting or implementing the Republic or the general interest, did not ultimately lead to it because they excluded certain members. Then we understand that the general interest has meaning only in the guarantee of the conservation of each member of the social group.

The democratic political order which highlights the people as constituent, for it is as sovereign, that citizens can take part in the political decision-making, directly or indirectly, and that they can control those who take these decisions on their behalf. In a democracy each citizen expresses his/her will by voting, according to the principle "one man, one voice". By virtue of this principle, if the right to vote can be considered as the main theoretical foundation of democracy, other rights are not negligible: "If the starting point of democracy is the right of citizens to be part of decision making affecting their lives, a right that is the same for everyone, 
a set of other rights is needed to make this fundamental political right a reality. These are the rights and freedoms of expression, association and assembly, which we know well. The right to freely express one's opinion presupposes the existence of independent media and of laws which prevent excessive media concentrations in the hands of a single owner. Freedom of association includes the right to form associations for economic, social and cultural purposes, including political parties. The right to peaceful assembly requires free movement within and between countries. None of these rights can be truly exercised in the absence of freedom, security and legality. Democracy is therefore inseparable from the fundamental rights and freedoms of the person and the duty to respect these same rights and freedoms for others". ${ }^{294}$

The rights in question here are political rights or rights which allow the individual to decide on all questions relating to the political organization of society. These rights are at the fundamental level of society in that it is on their basis that the management of public affairs for the satisfaction of the general interest would be ensured. Following human rights in general and political rights in particular, the necessary institutions for the democratic political order must still be identified.

\subsubsection{Institutions of democratic political order}

The democratic constitution generally includes the separation of powers. This can be seen as consubstantial with modern democracy. In the panoply of principles regulating constitutional government, the separation of powers occupies a position of great ambivalence. On the one hand, all constitutional democracies rest on a certain division between three distinct branches of government: the legislative, the executive and the judiciary. On the other hand, the separation of powers is invoked as an ideal or a standard, even a set of standards with which the constitutional provisions of the modern state must comply. The separation of powers is like an ideal to which it is precious to conform.

\footnotetext{
${ }^{294}$ We translate from : "Si le point de départ de la démocratie est le droit des citoyens d'être partie prenante des décisions qui ont une incidence sur leur vie, droit qui est le même pour tous, il faut un ensemble d'autres droits pour que ce droit politique fondamental soit une réalité. Ce sont les droits et libertés d'expression, d'association et de réunion, que l'on connaît bien. Le droit d'exprimer librement son opinion suppose l'existence de médias indépendants et de lois qui préviennent les concentrations abusives de médias entre les mains d'un seul propriétaire. La liberté d'association inclut le droit de créer des associations à des fins économiques, sociales et culturelles, y compris des partis politiques. Le droit de réunion pacifique suppose la libre circulation à l'intérieur des pays et entre eux. Aucun de ces droits ne saurait être véritablement exercé en l'absence de liberté, de sécurité et de légalité. La démocratie est donc inséparable des droits et libertés fondamentaux de la personne et du devoir de respecter ces mêmes droits et libertés pour les autres", in BEETHAM, "La Démocratie: Principes Essentiels, Institutions et Problèmes”, in Ch. BASSIOUNI (Rapp. Gén.), La Démocratie: Principes et Réalisation, Union Interparlementaire, Genève, 1998, p. 24
} 
This principle has a long history in constitutional theory. In the 18th Century, the separation of powers was seen as a shield against the abuse of state power and the threat of tyranny. The French Declaration of the Rights of Man and the Citizen mentioned that "any society in which the protection of rights is not ensured and the separation of powers is not established has no constitution". Nowadays theorists maintain that the separation of powers is the true essence of constitutionalism $^{295}$ and a universal criterion of constitutional government. ${ }^{296}$ This principle means that specific functions, duties and responsibilities are assigned to separate institutions with defined competences and means. In the constitutional framework, the meaning of the terms legislative, executive and judicial powers is of importance:

- Legislative power: power to create, modify and repeal laws

- Executive power: power to execute and enforce laws

- Judicial power: power to interpret the law and resolve disputes

The doctrine of the separation of powers generally means that if one of the three spheres of government is responsible for making laws, this body will not also be responsible for their execution or a court decision on them. The same will be said of the executive, it is not supposed to make the law or administer justice and the judiciary should not make or execute the laws. Lord Mustill in R. v. Home Secretary, Ex p Fine Brigades Union defined the doctrine of the separation of powers in England as follows: "It is a feature of the peculiary British conception of the Separation of powers that Parliament, the executive and the courts have each their distinct and largely exclusive domain. Parliament has a legally unchallengeable right to make whatever laws it thinks right. The executive carries on the administration of the country in accordance with the powers conferred on it by law. The courts interpret the laws, and see that they are obeyed" 297 .

The meaning of the separation of powers shows a variety of meanings. The concept can mean at least three different things: the same person should not be in more than one of the three organs of government, for example, that ministers should not seat in parliament; one body of government should not interfere in the jurisdiction of another, for example, that the executive should not interfere in judicial decisions; one government body should not exercise the

\footnotetext{
${ }^{295}$ E. BARENDT, "Separation of Powers and Constitutional Government", Public Law, 1995, n 599

${ }^{296}$ M. J. C. VILE, Constitutionalism and the Separation of Powers, Oxford: Oxford University Press, 1967, p. 97; E. CAROLAN, The New Separation of Powers: A Theory of the Modern State, Oxford: Oxford University Press, 2009, p. 18

${ }^{297}$ Cité par Ph. M. MOJAPELO, "The doctrine of separation of powers (a South African perspective)", in Forum Advocate, April 2013, p. 37
} 
functions of another, for example that ministers should not have legislative powers. It should be noted, however, that a complete separation of powers is not possible, either in theory or in practice. Some overlap is inevitable.

The modern conception of the principle of the separation of powers is found in the constitutional theory of John Locke. He wrote that "It may be too great a temptation for the humane frailty, apt to grasp at powers, for the same persons who have power of making laws, to have also in their hands the power to execute them, whereby they may exempt themselves from the law, both in its making and execution to their own private advantage" 298 . It is clear that he advocated the division of governmental functions into legislative, executive and judicial. However, it is Montesquieu who is generally at the origin of the first formulation of the doctrine of the separation of powers. He based his talk on the British constitution. In De L'Esprit des lois, Montesquieu recognized the three fundamental pillars of state authority, namely the executive, the legislature and the judiciary; and he added that these functions should be devolved to three separate government bodies, with, in each case, different officials. He supported his argument by saying, "Everything would be lost if the same man, or the same body of principals, or nobles, or the people, exercised these three powers: that of making laws, that of executing resolutions and to try crimes and disputes of individuals"299

His idea ends up becoming a standard made up of four basic principles:

- The principle of trias politica, which simply requires making a formal distinction between the legislative, executive and judicial components of state authority; ${ }^{300}$

- The principle of the separation of personnel, which requires that the power of legislation, administration and judgment rests with three separate organs of state authority and that each of these organs is staffed by different officials and employees, that is, a person seating in one of the organs of state power should be prevented from serving in another.

- The principle of the separation of functions which requires that each organ of the authority of the State is only endowed with its appropriate functions, that is to say that

\footnotetext{
${ }^{298}$ Cité par M. J. C. VILE, op. cit. p. 62

299 "Tout serait perdu, si le même homme, ou le même corps des principaux, ou des nobles, ou du peuple, exerçaient ces trois pouvoirs: celui de faire des lois, celui d'exécuter les résolutions publiques, et celui de juger les crimes ou les différends des particuliers", in Ch. de SECONDAT, de Montesquieu, De l'esprit des lois, Une Edition électronique réalisée à partir du livre Montesquieu, De l'esprit des lois, 1758, L. VERSINI (Ed.), Paris, Éditions Gallimard, 1995, p. 113

${ }^{300}$ M. J. C. VILE, op. cit. p. 13
} 
the legislator should legislate, the executive power is limited to the State administration and the judiciary are limited to the function of judgment.

- The principle of checks and balances, which represents the special contribution of the United States, to the concept of separation of powers, and which requires that each organ of state authority be given special powers intended to control the exercise of other powers so that the balance between powers can be maintained. Complete independence of each of the powers is likely to block the functioning of the public service. It is then necessary that power stops power. Thus the separation of powers implies a necessary flexibility.

The main purpose of the doctrine is to prevent the abuse of power in different spheres of government. In the democratic constitution, public power is subject to constitutional control. The different spheres of government should act within their limits. The courts are the ultimate guarantor of the constitution, they have a duty to protect it in the event of a violation. In the context of the doctrine of the separation of powers, the duty to ensure that the exercise of power by other branches of government takes place in the constitutional context. Courts must also respect the limit of their own power. Different scholars also echo their views on the purpose of the doctrine. Montesquieu said in this regard: "When, in the same person or in the same body of the judiciary, the legislative power is united with the executing power, there is no freedom; because it is feared that the same monarch or the same senate would make tyrannical laws to execute them tyrannically. There is still no freedom if the power to judge is not separated from the legislative and the executive. If it were joined to the legislative power, the power on the life and the freedom of the citizens would be arbitrary: because the judge would be legislator. If joined to the executing power, the judge could have the force of an oppressor." ${ }^{301}$ Sir William Blackstone confirmed this opinion: "In all tyrannical government the supreme magistry, or the right both of making and enforcing the laws, is vested in one and the same man, or one and the same body of men; and whenever these two powers are united together, there can be no public liberty. The magistrate may enact tyrannical laws, and execute them in a tyrannical manner, since he is possessed in quality of dispenser of justice, with all the quality of dispenser of justice, with all the power which he as legislator thinks proper to give himself. But, where the

\footnotetext{
${ }^{301}$ We translate from "Lorsque, dans la même personne ou dans le même corps de magistrature, la puissance législative est réunie à la puissance exécutrice, il n'y a point de liberté; parce qu'on peut craindre que le même monarque ou le même sénat ne fasse des lois tyranniques pour les exécuter tyranniquement. Il n'y a point encore de liberté si la puissance de juger n'est pas séparée de la puissance législative et de l'exécutrice. Si elle était jointe à la puissance législative, le pouvoir sur la vie et la liberté des citoyens serait arbitraire: car le juge serait législateur. Si elle était jointe à la puissance exécutrice, le juge pourrait avoir la force d'un oppresseur", Ch. de SECONDAT, de Montesquieu, op. cit. pp.112-113
} 
legislature and executive authority are in distinct hands, the former will take care not to entrust the later with so large a power, as may tend to the subversion of its own independence, and therewith of the liberty of the subject $»^{302}$. He continued saying that «In this distinct and separate existence of the judicial power, in a particular body of men, nominated indeed, but not removable at pleasure, by the crown, consists one main preservative of the public liberty, which cannot subsist long in any state, unless the administration of common justice be in some degree separated from both the legislative and also from the executive power. Were it joined with the legislative, the life, liberty and property, of the subject would be in the hands of arbitrary judges, whose decisions would be then regulated only in their own opinions, and not by any fundamental principles of law, which, though legislatures may depart from, yet the judges are bound to observe. Were it joined with executive, this union might soon be an over balance for the legislative"303.

From the perspective of human security, the principle of the separation of powers, a fundamental element of the democratic constitutional order, is a logical consequence of popular sovereignty. Indeed, the people, for practical reasons, not being able to directly exercise the management of public affairs, can only delegate it to representants who will be responsible for ensuring the general interest on their behalf. Experience in the management of public affairs has inevitably led to the knowledge that the concentration of different areas of public affairs in the hands of a single individual or a single assembly results in absolutism, the result of which is arbitrary, and human insecurity. Thus subjecting the management of the general interest to the goodwill of a person or a group, although this or that one may be virtuous, does not guarantee that $\mathrm{s} / \mathrm{he}$ would remain so forever, because it is also possible that $\mathrm{s} / \mathrm{he}$ no longer be virtuous. Thus, it is risky to ground the Republic on the personality of the rulers. It is therefore necessary to rest it on an objective element that is Law, which is identified in the institution or organ of power. Having as origin, all the individuals who identify themselves as the people, Law can only achieve its goal because it comes in fact from all and no longer from a subjective good will. However, if representation is in itself of practical utility, it does not completely guarantee against the arbitrariness, because it is possible that representatives turn away from their mandate of satisfying the general interest to satisfy their personal interests. So we must associate with Law, which materializes itself the organ of power, another lever which would limit as much as possible the possibilities of arbitrariness. This lever is still Law or organ of

\footnotetext{
${ }^{302}$ Cité par Ph. M. MOJAPELO, op. cit. p. 38

303 Ibid.
} 
power. It is therefore a question of dividing the general power into several specific parts devolved to different agents, so the separation of powers. The rigidity of such a separation can lead to a damaging consequence for the satisfaction of the general interest. Each of the agents being able to become a despot in the management of his sphere of competence, it is necessary that separation of powers be flexible, that is to say, each power has to be endowed with a competence of collaboration with and control of the other power. That way it is possible that the arbitrary is avoided as much as possible.

It must therefore be noted that the separation of powers is part of the correct formulation of political society. Thus it is certainly part of the natural order system which necessarily involves confirmation of human security. The premises of human security, as a law of nature have thus been checked in the democratic political order in theory, through human rights and the separation of powers. We have still have to know it in practice.

\subsection{Modern democratic order in practice}

The modern democratic political order is developing, generally since the 1990s with the fall of the Berlin Wall, which marked the reunification of Germany. "The era created its own transcendental justification or principle of legitimacy in the form of an enhanced rule of law, which observers have variously characterized as constitutional democracy" ${ }^{304}$. In this context, we will undertake to check the theoretical framework of human security on facts relating to the modern African democratic order. The majority of African States underwent colonial rule and, by gaining independence, they were tied to constitutionalism. We will discuss the two aspects of this order, namely, human rights (2.2.1) and the separation of powers (2.2.2).

\subsubsection{Human rights in modern political order in practice}

At the end of the 20th Century, at least 59 of the 91 independent constitutions were significantly changed or replaced by the promulgation of new ones. In Africa, constitutional change was the rule of postcolonial politics, generally beginning in the few years immediately following independence. ${ }^{305}$ Across the postcolonial world, constitutional reconstruction has also advanced rapidly. From the 1990s, constitutional reconstruction was felt everywhere. ${ }^{306}$

\footnotetext{
${ }^{304}$ ARJORMAND, p. 9

305 T. V. Le VINE, "The Fall and Rise of Constitutionalism in West Africa", in The Journal of Modern African Studies $n^{\circ} 35,1997$, pp. 181-206, p. 108

306 J. GO, “A Globalizing Constitutionalism? Views from The Postcolony, 1945-2000”, Chapter Four, in S. A. ARJOMAND, (Ed.), Constitutionalism and Political Reconstruction, Brill, Leiden, 2007, p. 98
} 
The timing of these new or changed constitutions provides an opportunity to envision broader events and processes in world society and their relationship to the constitutional order. These events and processes are numerous and occur at different levels. For example, since the culmination of decolonization in the mid-twentieth century, there has been a massive wave of democratization, a wave that probably began in the early 1970s and continued after 1989 with the decline of the Soviet Union. ${ }^{307}$ Global attention to human rights and self-determination (both individual and national) has also increased concomitantly; popular skepticism towards dictatorships and the concentration of political power; the delegitimization of communism. Political reconstruction through rational control, as evidenced through constitutional reconstruction, is an integral part of these major world trends, not only in the former colonies of Europe or the Soviet Union, but throughout the world. ${ }^{308}$

There are clear tendencies indexing a constitutional convergence not evident in the constitutions of independence. For example, many of these once-socialist constitutions have abandoned single-party regimes. The proportions are small but suggestive. Among the independence constitutions that were later changed or replaced, $20 \%$ called for the one-party rule, while only $10 \%$ among the new or amended constitutions required it. ${ }^{309}$ The Algerian Constitution of 1963 for example described the National Liberation Front as a "Parti d'avant-garde unique" ("Unique avant-garde party.") which would ensure stability, would serve as the only powerful impetus organ and control the National Assembly (Preamble, art. 23 and 27). However, the existing Algerian constitution, last amended in 1996, makes no such a reference. Rather, it contains a new article which guarantees and recognizes the right of citizens to create political parties (Article 42). Likewise, the 1975 Constitution on Cape Verde Independence (promulgated in 1980) established an official single party regime called the African Party for the Independence of Cape Verde (Parti africain pour l'indépendance du Cap-Vert, PAICV). On the other hand, the 1992 Constitution (last amended in 1995) dismantled the single party regime and explicitly provided for the creation of multiple political parties, each having the right to broadcast airtime on public radio and television. In fact, it frankly declares that the new regime must be a "pluralist democracy" (Preamble, arts. 47, 56). The socialist constitutional model seems to have

\footnotetext{
${ }^{307}$ S. HUNTINGTON, The Third Wave: Democratization in the Late Twentieth Century, Norman: University of Oklahoma Press, 1991

${ }^{308}$ H. KLUG, Constituting Democracy: Law, Globalism and South Africa's Political Reconstruction, Cambridge University Press, Cambridge and New York, 2000, pp. 8-11; D. LUTZ, "Thinking about Constitutionalism at the Start of the Twenty-First Century”, in Publius: The Journal of Federalism, n³0: pp. 115-35, 2000

${ }^{309}$ J. GO, op. cit. p. 99
} 
lost the influence it once had on earlier postcolonial constitutions, perhaps reflecting a new post-communist constitutional order. ${ }^{310}$

Attention was paid to human rights and had an impact on postcolonial constitutional reconstruction. Of course, the influence of human rights awareness on the first constitutions of independence was already strong. In addition to the Universal Declaration of Human Rights adopted by the United Nations in 1948, almost all of the independent constitutions included some sort of human rights provision. This is true even for the constitutions of independence from the former British Empire, a notable development given that, in British legal tradition, it was not urgent for fundamental rights to enjoy special constitutional and legal protection against any parliamentary interference. ${ }^{311}$

However, the provisions related to rights in these constitutions of independence were not exactly the same. The details certainly differed, but more strikingly, the form in which they were codified. Slightly more than $20 \%$ of the constitutions relating to independence (19 of 89) did not include sections devoted to rights under a separate title. The rights in these constitutions, when enumerated, were enumerated in the preamble or in other articles. ${ }^{312}$ French legal tradition has had a partial influence on these constitutions. In the constitutions of the fourth and fifth Francophone Republics, the rights are listed in the preamble rather than guaranteed in the substantive provisions of the constitution. ${ }^{313}$ Thus, following an intra-imperial isomorphism, a little more than half of the ex-French colonies adopted this mode in their constitution of independence, while only $15 \%$ of the ex-British colonies adopted it. ${ }^{314}$

Whatever the source of the difference between the constitutions relating to independence, this difference was significantly overcome thanks to the constitutional reconstruction of the latter part of the 20th century. Of all the existing postcolonial constitutions, only $10 \%$ do not include rights provisions under a separate title. Among independent constitutions, this figure was $20 \% .{ }^{315}$ This change is part of a larger global trend: rights have become an important part of constitutionalism. ${ }^{316}$

\footnotetext{
310 ibid

${ }^{311}$ Fr. MODERNE, "Human Rights and Postcolonial Constitutions in Sub-Saharan, Africa", in L. HENKIN, A J. ROSENTHAL (Eds.) Constitutionalism and Rights: The Influence of the United States Constitution Abroad, pp. 315-48. New York: Columbia, University Press, 1990, pp. 324-325; S. de SMITH, The New Commonwealth and its Constitutions, Stevens and Sons, London, 1964, Ch. 5

312 J. GO, op. cit. p. 99

${ }^{313}$ B. O. NWABUEZE, Constitutionalism in the Emergent States, London: C. Hurst and Company, 1973, p. 43

${ }^{314}$ J. GO, op. cit. p. 100

315 B. O. NWABUEZE, op. cit, p. 43

${ }^{316}$ J. GO, op. cit. p. 100
} 
From the perspective of the human security, as a law of nature, we must begin by recognizing the importance of the historical aspect which it implies and which is clearly apparent in the facts relating to the African democratic constitutional order taken as an example. Indeed, the constitutions of independence, precisely African, must be placed in the framework of a progressive evolution towards the understanding of the meaning of popular sovereignty. The wind of democratization in the 1990s was the occasion to testify to an awareness of the citizens, through the various socio-political demands, of the need for a political society which is centered on the people, in particular whose formulation has as foundation and end the satisfaction of individual rights. This is the general right to security. The consecration of human rights in contemporary African democratic constitutions is revealing that human security is above all the foundation of political society which turns out to be the means by which individuals naturally subject to cohabitation must preserve themselves. The fundamental agreement which it represents can then only have, as final aim, the conservation of each member. When the terms of this agreement do not lead to this result, claims will be made for their change or improvement until they lead to it. This process should continue until they come to the understanding of the perfect formulation. The constitution basically translating political society, the democratic constitution is precisely that which highlights human rights at their most essential level which is individual and the sum of which constitutes popular sovereignty. The trajectory of African democratic constitutionalism, in itself, is inevitably proof that it confirms the aspects of the theoretical framework of human security. We will verify it again with regard to the separation of powers.

\subsubsection{The separation of powers and democratic constitutionalism in practice}

The principle of the separation of powers is a characteristic of modern African constitutions and not simply an abstract theoretical and philosophical construction developed centuries ago. Its main objective, the prevention of tyranny, is as powerful today as it was centuries ago when Lord Acton made his famous warning that "power tends to corrupt and absolute power corrupts absolutely". ${ }^{317}$ Whether enshrined in the American, British or French models, the principle of the separation of powers did not envisage a rigid separation of the different branches of power into tight compartments, but rather envisaged such a separation as well as preventing the dangers inherent in the concentration of powers.

${ }^{317}$ Ch. M. FOMBAD, (Ed.), Separation of Powers in African Constitutionalism, Oxford University Press, 2016, p. 89 
As a principle aimed at promoting good governance and respect for the rule of law, the enshrinement of constitutionalism in the modern democratic African order shows not only that it remains one of the central elements of modern constitutionalism, but also that its continuous application cannot ignore the dramatic changes brought to the structuring of modernity, societies and the need to devise new and more effective means to face the challenges they pose. What has become clear is that despite the separation of powers, the executive has become dominant. This is a phenomenon which is much more serious in the countries which have inherited and maintained the civil legal tradition, that is, the French tradition, than in those of the common law of Anglo-Saxon tradition. ${ }^{318}$ It is, however, a problem that limited the practical effectiveness of entrenching the separation of powers in modern African political orders. Emergence of hybrid institutions of accountability such as the Ombudsman, anti-corruption agencies and human rights commissions show that the traditional checks and balances associated with the three powers are no longer sufficient. These hybrid institutions not only complement traditional accountability measures, but also reflect the political, social and constitutional changes underway. They underscore the ability of doctrine to adapt to modern realities and to reflect specific needs, as well as governance deficits and risks. ${ }^{319}$ It can be argued that the traditional triad encouraged false complacency about the existence of adequate checks and balances within the different branches, which is clearly false. The gradual constitutionalization of hybrid institutions of accountability is particularly important because of the capture and control of the three branches of government by powerful leaders whose power is strengthened by the ruling parties, which increases the risk of democratic overthrow in the emerging democratic transitions of Africa. What makes these institutions distinct and potentially essential to the democratic project of Africa is their independence from other branches, their ability to be both reactive and proactive and their accessibility to the most vulnerable in society. ${ }^{320}$

In many ways, they will act as intermediary institutions between ordinary citizens and the three branches of government and give them an opportunity to directly seek solutions to their problems. The growing popularity of these institutions does not testify the failure of the doctrine of the separation of powers, but to solid proof of its durability, viability and adaptability. As

\footnotetext{
318 M. A. CABANIS, L. MARTIN, Le Constitutionnalisme de la Troisième Vague en Afrique Francophone, Bruylant-Academia SA 2010, pp. 59-90

${ }^{319}$ Ch. M. FOMBAD, (Ed.), ibid.

${ }^{320}$ Ibid.
} 
Bruce Ackerman rightly points out, "the separation of powers is a good idea" and "there is no reason to assume that the classic writers have exhausted his goodness". ${ }^{321}$

From the perspective of human security, as a law of nature, the principle of the separation of powers enshrined in the African democratic political order is revealing that it was understood as necessarily part of the good formulation of political society. However, the only principle not being sufficient, its implementation in the practice of public authorities revealed that according to the context, the development of other hybrid institutions in support of these powers is necessary. That said, it should still be made clear that no matter which path the historic process of seeking the right formulation of political society takes, depending on the context, this process is inevitable. As long as the formulation adopted does not succeed in satisfying the conservation of each of the members who make up political society, the need for its improvement or its change ends up being an inescapable imperative.

${ }^{321}$ B. ACKERMAN, “The New Separation of Powers" Harvard Law Review, n 113 2000, p. 633 


\section{CONCLUSION OF CHAPTER IV}

In this chapter, we have completed the relationship between human security, as a law of nature and national political order. It was precisely question to check the postulates of human security law within the national political order in practice. This one was considered to represent and characterize political society at the most basic level. The verification of the aspects of human security as theorized had to be done in an empirical logic. So we focused on the modern constitutionalism that characterized the modern State. In this sense, the facts relating to the American and French revolutions, in particular their advent, the responses they were carrying, as well as their consequences, the facts relating to the constitutionalism of Communist Russia and to Nazi Germany, constitutional democracy, in theory and practice have shown us that popular sovereignty is at the heart of political society as an instrument for the conservation of each individual. Each stage of political society or the formulation of it is always the result of a previous one whose negative consequences for the conservation of each must inevitably lead to its change or improvement. Thus if political society is recognized, because of the fundamental or foundational understanding or agreement that it supposes, as part of the order of natural means necessary for the confirmation of human security, the historical process of discovery of its best formulation as necessarily provided by nature is a constant. As far as the constitutional democratic political order is concerned, the historical trajectory observed in all the facts noted and concerning the African case taken as an example suggests that this educational enterprise will last until it can lead to a formulation confirming the sovereignty of the people, sum of the consents of each individual to be constituted that way with others for the purposes of guaranteeing their general right to security, as the foundation and the purpose of political society. 


\section{CONCLUSION OF PART I}

In the first part of this thesis, we studied human security as foundation and finality of national law. This was the necessary prerequisite of human security as foundation and finality of international law. Thus, we began by establishing the theoretical framework of human security, considering it as the law of human nature. Thus, according to a reconsideration of the modern essentialist approaches of Brian Ellis, in particular of the intrinsic and traditional properties of Aristotle, in particular of the final cause, we have been able to know that human security is the intrinsic or essential dispositional state of human nature, understood as a perfect existing which is no longer to be created or realized, since it is already real, but which is subject to perpetual confirmation or conservation due to the animate nature of Man. Human security was that way understood as the finite and final order of human nature, satisfying all the characteristics of a perfect law of nature. Then, and as a consequence of the natural imperative of the conservation of man in cohabitation with his fellows and in dependence on the resources of nature, it was necessary to verify that human security is the law of nature of political society, that is to say, its foundation and finality. This was done and at the same time allowed us to know that political society is part of the ultimate order of human security and thus it is part of human nature. Depending on the level of human understanding, political animality is a natural nature, that is to say, when nature and experience are in phase, and a cultural nature, that is to say, man does not always understand the best formulation of political society and so s/he is educated to it or discover it through experience. The verification of human security as the law of nature of political society was ultimately the application to a high dimension of human security as the law of human nature. It was then necessary to undertake the verification of the elements of the theoretical framework of human security in practice, in national law, with reference and example to the modern state. Thus this practice consisted of two things: the national political order in idea, made up of political ideologies and the national political order, including its constitutional and governmental components. We have been able to verify that human security is the foundation and finality of all political ideologies, which often, the subject of social consensus, become the positive law as means of conservation initiatives. Thus we were able to verify in general that human security is the foundation and finality of national law. Having emptied this prerequisite, we can undertake accordingly the verification that human security is the foundation and finality of international law. 


\section{PART II: HUMAN SECURITY: FOUNDATION AND FINALITY OF INTERNATIONAL LAW}

Human security as foundation and finality of national political order or of internal law, should entail that human security is the foundation and finality of international law. This is the subject of verification of this part. The instrumental nature of domestic political society and therefore of internal law makes international political society and international law just as much an instrument at the service of the purpose for which relations between different political societies or States are sustained. Being non self-sufficient, National political societies sustain between them relations of diverse nature. This creates an interconnection of people and goods whose regulation is necessary in the interest of States. All of this will be checked under the account of human security. Like national law, international law is based on a set of ideas more or less shared by different political societies. These are ideologies which are intended to reflect the meaning of interstate relations, to orient the way in which they will be conducted and to receive concrete expression through positive international law. It will be a question of checking the application of the theoretical framework of human security in its elements through all these theoretical deployments or international law in idea and through its presentation or its configuration or practical international law.

Starting with international law in idea, ideology has basically been defined as a worldview and a political agenda. Political ideology on national and international plans is different at least at the level of the political program. Indeed, the conceptions of the world and of the human person can be similar between the two kinds of ideology but the political programs which they advance, are in accordance to specific contexts of international society. International political society is configured in sovereign States without a form of authority which can impose itself on them without their consent. This is different from national political society represented by a centralized power which is imposed on the governed. So the political program which can mean foreign policy here will behave differently from an internal political program. The ideology of international law will be considered as the set of concepts to which international law may be subject to, its foundations, its aims and the strategies for achieving it. It will be a question of international law in idea. In this context, it is for us to check that human security, in its theoretical framework, is at the heart of these sets of ideas which can be known, as the theory of international relations (Chap. V) and synthesizes all of them in the meaning it implies for international society (Chap. VI). Defined as the law of international relations, positive international law, and stands therefore as the product of these ideas and the framework in which 
they are receive concrete form. The study of the theory of international relations thus proves to be an essential prerequisite in a study of the sense of international law. 


\section{CHAPTER V: HUMAN SECURITY AND THE IDEOLOGY OF INTERNATIONAL LAW OR INTERNATIONAL LAW IN IDEA}

From time immemorial, international relations have been the subject of abundant reflection. History has therefore had an intense debate full of twists and turns. Schools of thought were born in reaction to some, others have revised their postulates because of the consequences they have given rise to in practice. One of the oldest traces of the theory of international relations is to be found in the writings of Thucydides who recounted the debate between idealists and realists. These two schools have centralized the debate on the meaning of international relations. The schools born after them were in reaction to their postulates. We will therefore study in turn the rational approaches (1) and the reflective approaches (2) of international relations. When asked what is the foundation and finality of these theories, we will check that it is human security. Despite a different methodology they however use to achieve it, the fact remains that human security is found in their hearts. Human security, as a law of nature will allow us to harmoniously reconstruct the general logic that drives this debate.

\section{HUMAN SECURITY, AS A LAW OF NATURE AND RATIONALIST THEORIES OF INTERNATIONAL RELATIONS}

According to $\mathrm{Smith}^{322}$, rationalism is a foundational approach to the philosophy of science. Influenced by Auguste Comte's positivist emphasis on the unity of scientific methodologies, rationalism refers to the idea that nature is governed by regular laws. It advances the notion of "reason" to explain these regularities by developing causal mechanisms. ${ }^{323}$ The positivist epistemology adopted by rationalism refers to the idea that nature is governed by instances of observable regularities. ${ }^{324}$ These regularities are considered independent of time, of the human observer and approached according to the human understanding of causation. The goal of the positivist approach is to discover conditions for results and occurrences. Rationalism views individuals as rational actors and ignores some others of their characteristics, not simply by what they believe in this assumption, but for reasons of parsimony and the genesis of

\footnotetext{
${ }^{322}$ S. SMITH, "Positivism and Beyond", in S. SMITH, K. BOOTH, M. ZALEXSKI (Eds.) International Theory: Positivism and Beyond, Cambridge University Press. Cambridge 1996, pp. 11-44

${ }^{323}$ Ibid. p. 21

324 M. A. NEUFELD, The restructuring of International Relations Theory, Cambridge, University Press, New York, 1995, p. 28
} 
predictions. This approach for Keohane is useful for the production of knowledge. ${ }^{325}$ The sources of this deductive approach are in observation and measurement. This approach has had an influence in the theory of international relations. Widely understood in International Relations, rational approaches include realism (1.1) and liberalism (1.2).

\subsection{Human security and realism in international relations}

Realism is one of the oldest schools of thought in the field of international relations. The consequences of the implementation of its postulates have drawn criticism which in turn has led to their revising. After presenting these postulates (1.1.1) and the conception of security they imply (1.1.2.) we will be consider them related to human security, as a law of nature.

\subsubsection{Postulates of realism and law of human security}

Realism is generally considered as a prescriptive theory or a "problem-solving theory" to mean that it is concerned with taking and reporting on the world as it is "in reality". This reality includes individuals, their constitution, the meaning of their existence and the nature of the relationships they can sustain. Realism then presupposes a certain fixity of this reality which must be respected and in accordance with which existence must be conducted. This feature of the realist theory is well illustrated by Hans Morgenthau, one of the eminent theoreticians of this approach: "realism is a theory which tries to understand international politics as it actually is and as it ought to be in view of its intrinsic nature". ${ }^{326}$ Ainsi selon cet auteur, la politique est gouvernée par une loi objective dont on peut se permettre de voir l'origine dans la nature réelle de l'homme qui la conduit ou l'entreprend, laquelle n'a jamais changé et ne changera sans doute jamais: "Political realism believes that politics, like society in general, is governed by objective laws that have their roots in human nature. (...) The operation of these laws being impervious to our preferences, men will challenge them only at the risk of failure. (...) Human nature, in which the laws of politics have their roots, has not changed since the classical philosophies of China, India, and Greece endeavored to discover" ${ }^{327}$.

Since reality is a perfect existent, realism refuses any questioning of its ontological elements and considers them rather as natural, immutable, ahistorical and empirically observable.

\footnotetext{
${ }^{325}$ M. KURKI, C. WIGHT, "International Relations and Social Science", in T. DUNNE, M. KURKI, S. SMITH (Eds.) International Relations Theories, Oxford University Press, Oxford, 2013, p. 24

${ }^{326}$ H. MORGENTHAU, Politics Among Nations, Knopf, New York, 1967, p. 14

${ }^{327}$ Ibid. p. 4
} 
However, this attitude is not arbitrary because it conforms to the positivist epistemology of realism. In other words, "ontological units of realism are part of a philosophical system which sees in the observation of positive facts, in experience, the sole foundation of knowledge. Through this epistemology, which stems from the tradition of the natural sciences, where the theorist stands as an outside observer seeking to explain the functioning of circumscribed nature in a particular framework by placing the human sphere in the same way as the other spheres of nature, realism is one of the so-called explanatory theories" ${ }^{\prime 28}$. This explanatory tradition, specific to natural sciences, applied to international relations, involves an undertaking of discovery of scientific, universal and ahistorical laws enabling to understand these ones and to ground foreign policy of States. Realists can therefore claim the relevance of their content. "Realists legitimize their authority status by arguing that their analysis of international relations is based on reliable and valid principles of natural sciences which offer and objectively explain reality, unlike alternative approaches which, according to them, are only a reflection of the vicissitudes of public opinion and of subjective representation" ${ }^{329}$; "[Realism] entail(s) not simply a claim about nature of international relations but a claim to know : specifically, a scientific claim to know objectively the reality of international relations" $" 330$.

Realist theorists therefore seek to base international relations on certain ontological elements that they care about or are concerned about finding beforehand. These are declined in the configuration of the international society in sovereign States without any constraint being imposed on them without their consent, situation qualified as anarchy.

The state of anarchy in international society is mainly the work of Thomas Hobbes. International anarchy is however an indirect consequence of human nature.

One of the most well-known Hobbesian concepts is that of the state of nature, perceived as anarchic and leading to a state of war - and "such a war opposing every man to every man (...) $)^{331}$. He draws his notion of the state of war from his conceptions of human nature and the

\footnotetext{
${ }^{328}$ We translate from: "Les unités ontologiques du réalisme relèvent d'un système philosophique qui voit dans l'observation des faits positifs, dans l'expérience, l'unique fondement de la connaissance. Par cette épistémologie, qui découle de la tradition des sciences naturelles, où le théoricien se pose en observateur extérieur cherchant à expliquer le fonctionnement de la nature circonscrite dans un cadre particulier en plaçant la sphère humaine au même titre que les autres sphères de la nature, le réalisme fait partie des théories dites explicatives", H. VIAU, op. cit. p. 20

329 We translate from : “Les réalistes légitiment leur statut d'autorité en plaidant que leur analyse des relations internationales est fondée sur les principes sûrs et valides des sciences naturelles qui offrent et expliquent objectivement la réalité, contrairement aux approches alternatives qui ne sont, d'après eux, que le reflet des vicissitudes de l'opinion publique et de la représentation subjective”, Ibid.

${ }^{330}$ Ibid.

${ }^{331}$ Th. HOBBES, Leviathan or the Matter, Form, op. cit. p. 77
} 
condition in which individuals exist. In the state of nature, there is no government and everyone enjoys equal status, each individual has the right to everything; that is, there is no constraint on an individual's behavior. Anyone can use force at any time, and everyone must be constantly ready to counter that force with force. As a result, motivated by acquisition of resources in a spirit of competition, individuals are likely to use violence against each other. Mistrustful of each other and motivated by fear, they are also likely to take preventive measures to ensure their own security. Whether for profit, security or reputation, individuals seeking power will therefore strive to destroy or submit to each other. ${ }^{332}$ In such uncertain conditions where everyone is a potential aggressor, waging war on others is a more advantageous strategy than peaceful behavior, and it must be learned that domination over others is necessary for the continuous survival of people.

Hobbes is mainly interested in the relations between individuals and the State and his comments on interstate relations are rare. However, what he says about the lives of individuals in the state of nature can also be interpreted as a description of how States can behave towards each other. Once States are established, individual will for power becomes the basis for state behavior, which often manifests itself in their efforts to dominate other States and peoples. According to Hobbes, States, for their own security, widen their domains under all pretexts of danger and fear an invasion or assistance that can be brought to the invaders and try as much as possible to control and weaken their neighbors. ${ }^{333}$ Consequently, the quest and the struggle for power are at the heart of Hobbes's vision of relations between States. The same will apply to the model of international relations developed by Hans Morgenthau, deeply influenced by Hobbes and adopting the same vision of human nature.

By subjecting themselves to a sovereign, individuals escape the war of all against everything that Hobbes associates with the state of nature; however, this war continues to dominate relations between states. This does not mean that states are always fighting, but rather that they are willing to fight ${ }^{334}$. Each country decides for itself whether or not to use force, and war can break out at any time. The achievement of internal security by the creation of a State is then accompanied by a condition of insecurity between States. Arguably, if Hobbes were fully consistent, he would agree that, to escape this condition, States should also enter into a contract and submit to a world sovereign. If the idea of a world State can be thinkable, this position is

\footnotetext{
332 Ibid.

${ }^{333}$ Ibid. p. 104

${ }^{334}$ Ibid. Chap. XIII
} 
not that of Hobbes himself. He does not propose that a social contract between nations be put in place to end international anarchy. Indeed, the condition of insecurity in which States are placed does not necessarily lead to the insecurity of their citizens. Until an armed conflict or other type of interstate hostility occurs, individuals within a State may feel relatively secure. In a word, from the perspective of the interpretation that contemporary authors have made of the works of Hobbes, where the nature of Man is fundamentally vicious, and institution of the State creates the domestic order, but initiates international anarchy. This representation of the international order constructed, by Hobbes intrinsically generated, in the analysis of international relations, a personification of the State and a fragmentation of the spheres where the internal sphere of the State is cut off from the external sphere of interstate relations (insideoutside). ${ }^{335}$

We therefore see that the ontology of realism is materialist in the sense that reality is, through observation, made up of identifiable, tangible elements. These elements are considered to have their own existence and cannot therefore be changed. It is a reification which is declined in two ways: that of the relations between the personified States and that of the fragmentation of the various spheres of the State. ${ }^{336}$ As far as relations between states are concerned, "the representation of the anarchic international environment has created a radical and impermeable separation between states. In this respect the international system can be considered as a billiard game where the balls are independent of each other hitting each other in a defined space. Therefore, the central ontological entity of the rationalist meta-paradigm turns out to be the rational and autonomous state. The state is then personified." 337 The state of nature characterizing the international system becomes a framework of competition for States $^{338}$ in the pursuit of their national interests, the most important of which is survival. For this purpose, in a utilitarian and rational logic, all means are used by governments. "But only once the survival of the state is ensured, the national interest can be of another order, such as the increase of power, the pursuit of glory or the defense of certain ideas" ${ }^{339}$. And according to

\footnotetext{
${ }^{335}$ H. VIAU, op. cit. p. 24

${ }^{336}$ Ibid. p. 31

${ }^{337}$ We translate from : "La représentation de l'environnement international anarchique a engendré une séparation radicale et imperméable entre les États. À cet égard le système international peut être considéré comme un jeu de billard où les boules sont indépendantes les unes des autres s'entrechoquant dans un espace défini. Par conséquent, l'entité ontologique centrale du méta paradigme rationaliste s'avère l'État rationnel et autonome. L'État est alors personnifié", Ibid. p. 31

${ }^{338}$ R. ARON, Paix et guerre entre les Nations, Coll. "Liberté de l'esprit", Calmann-Lévy, $8^{\mathrm{e}}$ Ed. Paris, 1984, p. 103

339 Ibid. p. 81-102
} 
the process of reification of the State, the identification of these national interests can only be done by the personified State, or in other words than by "reason of State" 340 .

The second process of reification of realism is that of the fragmentation of the State into different spheres. "The logic of the social pact, which underlies the representation of the international system, has created a fragmentation of the different spheres that make up the state. The most important separation is that which has been established between foreign policy and internal policy. The inner sphere includes a civil order, while the outer sphere corresponds to the state of nature, namely anarchy. In other words, the state of nature (or of potential wars) between states differs in essence from civil status within states" ${ }^{341}$. In this sense, Raymond Aron specifies that "Politics as far as it concerns the internal organization of communities has as its immanent, the subjection of men to the rule of law. Politics insofar as it concerns relations between states, seems to have for meaning - ideal and purpose at the same time - the simple survival of states in the face of the threats that the existence of other states creates"342.

This was a sign that international relations were the prerogative of other actors. Hence the need for a reformulation of realism. Kenneth $\mathrm{N}$. Waltz, reformulated the realist theory of international relations in a new and distinct way. In his book Theory of International Politics, he attempted to remedy the shortcomings of Hans Morgenthau's classic realism with a more scientific approach, known as structural realism or neorealism. While Morgenthau rooted his theory in the struggle of power, which he related to human nature, Waltz strove to avoid any philosophical discussion about human nature and set out to construct a theory of international politics analogous to microeconomics. He argues that States in the international system are like businesses in a national economy and have the same basic interest: to survive. At the international level, the environment for the actions of States, or the structure of their system, is defined by the fact that certain States prefer survival to other objectives which can be achieved in the short term and act with relative efficiency to achieve this goal. ${ }^{343}$

\footnotetext{
${ }^{340}$ VIAU, op. cit. p. 31

${ }^{341}$ We translate from : "La logique du pacte social, qui sous-tend la représentation du système international, a engendré une fragmentation des différentes sphères qui composent l'État. La séparation la plus importante est celle qui a été établie entre la politique extérieure et la politique intérieure. La sphère intérieure comprend un ordre civil, tandis que la sphère extérieure correspond à l'état de nature, soit l'anarchie. En d'autres termes, l'état de nature (ou de guerres potentielles) entre les États diffère en essence de l'état civil à l'intérieur des États", Ibid. p. 32

${ }^{342}$ We translate from :"La politique tant qu'elle concerne l'organisation intérieure des collectivités a pour immanente la soumission des hommes à l'empire de la loi. La politique dans la mesure où elle concerne les relations entre États, semble avoir pour signification - idéal et objectif à la fois - la simple survie des États face à la menace virtuelle que crée l'existence des autres États.", R. ARON, op. cit. p. 19

${ }^{343}$ K. WALTZ, Theory of International Politics, Boston, McGraw-Hill, MA, 1979
} 
Waltz argues that by paying attention to each state and to ideological, moral and economic issues, the classic realists make the same mistake. They fail to develop a serious account of the international system - one that can be extracted from the broader socio-political realm. Waltz recognizes that such an abstraction distorts reality and omits many of the factors important to classical realism. According to Waltz, the uniform behavior of states over the centuries can be explained by the constraints imposed by the structure of the international system. The structure of a system is first defined by its organizational principle, then by the differentiation of its units and finally by the distribution of capacities (power) between the units. Anarchy, or the absence of central authority, is for Waltz the principle of control of the international system. The units of the international system are states. Waltz recognizes the existence of non-state actors, but rejects them as relatively unimportant. Since all states want to survive and anarchy presupposes a system of mutual aid in which each state must take care of itself, there is no division of labor or functional differentiation between them. Although functionally similar, they are nevertheless distinguished by their relative capacities (the power they represent) to perform the same function. ${ }^{344}$

As a result, Waltz sees the power and behavior of the State differently from conventional realists. For Morgenthau, power was both a means and an end, and the rational behavior of the State was simply understood as the means by which to accumulate the most power. Neo-realists assume that security is the fundamental interest of each State and therefore focus on the distribution of power. What also distinguishes neorealism from classical realism are methodological rigor and scientific self-conception. Waltz insists on the empirical testability of knowledge and on falsificationism as a methodological ideal which, as he himself admits, can only have a limited application in international relations. ${ }^{345}$

The distribution of capacity between States may vary. However, anarchy, the guiding principle of international relations, remains unchanged. This has a lasting effect on the behavior of States which socialize in the logic of mutual assistance. Trying to refute neoliberal ideas about the effects of interdependence, Waltz identifies two reasons why the anarchic international system limits cooperation: insecurity and unequal gains. In the context of anarchy, each State is uncertain of the intentions of others and fears that the possible gains from cooperation will favour others more than itself and thus lead it to depend on others. States do not voluntarily

\footnotetext{
344 Ibid

${ }^{345}$ S. GUZINNI, Realism in International Relations and International Political Economy: The continuing Story of a death Foretold, Routledge, The New International Relations Series, Taylor and Francis, London, New York, 1998, pp. 127-128
} 
place themselves in situations of increased dependence. In a mutual system of aid, security considerations subordinate economic gain to political interest. ${ }^{346}$

From the perspective of human security, as a law of nature, we will consider the epistemological and ontological postulates of the realist theory of international relations. On the epistemological level, realism as initially formulated wants to be a positivist school of thought which aims to account for reality after observation of it, as it is posed or exists and to propose behaviour that conforms or is adapted to it. Such a methodology, in our opinion, should receive merit because the reality of a thing, of a phenomenon can be better accounted only if that or this one reveals itself in its substance or what it is to the observer. This methodology corresponds to that of the theoretical framework of human security which, based on modern or scientific and traditional essentialism, accounts for the essence of human nature. The essence representing the most basic or intrinsic disposition of a thing, it accounts for it at the most fundamental level and therefore is useful to characterize it in what it is. Human security, as a law of nature is screened by metaphysical necessity and is quite simply knowable by experience, in the form of an observation or a simple feeling. Human nature being an existent, it is only this which can reveal the reality which it constitutes and security is precisely the one which is consubstantial with it and which accounts for its order. Its animate component therefore makes it a reality that calls for, less a creation or realization, since it is already real, but a confirmation, that is to say, an assurance of permanence in what it is. So like realism the epistemology of human security is just as scientific. The issue that arises afterward is that of the best way to observe reality and it is only from the confrontation of the observed ontological elements that the best form of observation can emerge.

Realism starts with human nature to detect the real meaning of international relations. So the meaning these ones will carry is that of this very nature. Realism discovers that human nature is selfish, so its ontological units that are states and the international anarchic system can only characterize international relations of satisfaction of States interests, the most important of which is survival. We must therefore examine the relevance of its elements.

Is human nature really selfish? This observation is often considered to start from Hobbes in his myth of the state of nature. Indeed, it is presumed that subject to their personal conservation, individuals, in a state of nature or outside any organized society, resort to all the means they deem necessary for this purpose. Thus, not being subject to any other law than that which they

\footnotetext{
${ }^{346}$ K. WALTZ, Theory of International Politics, op. cit. p. 107
} 
dictate to themselves, individuals find themselves in a state of general license which results in the war of all against all. Realists would have concluded from this situation that man is inherently selfish. It should be noted, however, that the ultimate goal in this presumed state of nature is individual conservation or individual security. Selfishness can be seen as an attitude or a means adopted to ensure the acquisition of the resources necessary for conservation. To better know whether this attitude is intrinsic to Man, it is necessary to consider the hypothesis of an abundance of conservation resources for all the individuals experiencing the state of nature. In such a situation since the behavioral logic is conservation, that of all would be ensured so what would then be the worth of selfishness? If such individuals remain selfish, then they are so by nature, but if they do not display this attitude, then this is justified by certain circumstances. Since in such a case, everyone would have enough resources at his disposal to satisfy its conservation, it must be thought that selfishness would not even be displayed by anyone and therefore this attitude is only possible in a context of resources shortage. Thus, everyone looking for ensuring the acquisition for its own use, the conflict becomes possible. However, Hobbes' solution of civil state or peaceful or cooperative solution is grounded on that the adoption of a selfish attitude for the purposes of conservation leads to general insecurity which would not benefit anyone. Thus the social contract would be the solution to ensure the security of all. If individuals then adopt such an attitude it means enough that they are less selfish than they are looking for a better way to preserve themselves. So we have to think that conservation in the (intrinsic) state of security characterizes Man more than selfishness. The realist observation of the natural selfishness of man cannot therefore be completely satisfactory, because it would tend to confuse finality and means. Using a means is not enough to fully account for human nature. Still, it is necessary to discover the means which can better lead to or satisfy the finality required by this same nature. Having discovered that selfishness does not lead to conservation, individuals would try to adopt another means which ensures this conservation and which is cooperation. Since the rational calculation here is done based on the finality pursued, it is then a question of knowing that the means which does not lead to this finality does not enter in the frame of those the human being really adopts to satisfy it. So selfishness would characterize human nature less than cooperation for the purpose of security of each member. The selfishness of human nature as an ontological element according to the realist theory of international relations cannot therefore be proven.

As for Human security, as a law of nature, security is the foundation and finality of all human action. Being a perfect existent which requires permanence due to the animate nature of Man, 
security is the essential and real state of this nature. So the best means, just as natural, for this confirmation is that which the human being seeks to discover, still taken in a natural context of coexistence with others and in dependence on the resources of nature. The only important tendency, because necessary, is that which concerns conservation in this intrinsic state, that is security. In this sense, the legitimate means towards which Man is carried in a utilitarian logic, are those which are naturally necessary and which s/he must therefore discover. Political society is the natural means for this purpose and its best formulation is discovered as part of the historical process of expérienciation or learning on the consequences of the formulations it embodies.

Realists also noted that the survival of the State is the main reason for international relations. From the perspective of human security, as a law of nature, internal political society is the means available to a group of individuals to ensure everyone's preservation. Now it should be noted that national political societies cannot be sufficient enough to mobilize all the resources necessary to meet the conservation requirements, resources which can be found in other political societies. We must remember that nature is naturally one, and it has gradually come to be considered as compartmentalized through the territorial spatial configuration of national political societies. Consequently, these became the owners of the natural resources forming part of their territory. We then observe an unequal distribution of natural resources for the benefit of different political societies; however, such a distribution, in no way, means that these resources are available to all national conservation requirements. Relations between national political societies therefore become necessary and thus it is clear that the aim of such relations is the conservation or the security of each of them.

What would be the nature of such relationships? They can be conflictual or peaceful. They can be conflictual through the use of force either to violently appropriate the resources available to a national society reluctant to cooperate or share with the aggressor, or to protect their interests, whether they be of spatial (borders) or economic order wherever they are threatened. Relationships can also be peaceful in the sense that they can be based on agreements between different national societies. So we have to think that the defense of national interests is the foundation and the finality of international relations. The question that arises after this is that of the nature of the international system considered by the realists to be anarchic and whether that nature influences the meaning of these relationships.

The anarchy of international system is an ontological element of realism arising from Hobbes's conclusions. According to him, the constitution of civil society through the social contract 
between all the individuals present in the state of nature allows them to escape the war of all against all, but shifts the sphere of anarchy to an inter- social or international level. As individuals are preoccupied with their internal survival before all, the organization for its insurance takes the form of a multitude of sovereign political societies whose relations are not intended ipso facto to be governed by law. Each one being an autonomous entity to satisfy the needs of conservation of the people who constitute themselves into, it is therefore the main means they use to provide the necessary resources, which can be located in other political societies. We would therefore find ourselves in the presence of a collection of sovereign political societies and thus not subject to an authority which would impose themselves on them without their consent. Consequently, the absence of such an authority having a power of constraint on the States, following the example of what happens inside societies, makes this inter-social or international space anarchic, for nothing guarantees that one State will not be attacked by another, even if such an attack does not currently exist. It is therefore a state of an international nature or of potential wars. ${ }^{347}$

Is such a reasoning the conclusion of an irrefutable epistemological process? "It is important to insist on the constructed nature of Hobbes' propositions (...) as well as on the construction of the theoretical framework by the various contemporary authors. Hobbes (...) does not report an event that he observed. And even if the social pact had been a specific event in history, it would not have deserved more to be approached as the one and only absolute reality. (...) The theorists of the rationalist meta-paradigm seem to have been victims of an intellectual shift. It is important to remember that the state of nature of Hobbes and Rousseau does not come from an "empirical historical anthropology", but from a philosophical attempt to think the political" ${ }^{348}$. The anarchy of international system resulting from Hobbes' theoretical constructions cannot therefore be positivist because it does not follow from an observation of reality. But does this mean that the international system is not anarchic? The conclusion about international anarchy generally follows from the attempt to apply to international society, the order as it is configured internally or in the domestic sphere. So, Hobbes concluding the state

\footnotetext{
${ }^{347}$ R. ARON, op. cit. p. 19

${ }^{348}$ We translate from "Il est important d'insister sur la nature construite des propositions de Hobbes (...) de même que sur la construction du cadre théorique par les différents auteurs contemporains. Hobbes (...) ne rapporte pas un événement qu'ils auraient observé. Et même si le pacte social avait été un événement précis dans l'histoire, celui-ci n'aurait pas plus mérité d'être abordé en tant que seule et unique réalité absolue. (...) Les théoriciens du méta-paradigme rationaliste semblent avoir été victimes d'un glissement intellectuel. Il est important de se rappeler que l'État de nature de Hobbes et de Rousseau ne relève pas d'une "anthropologie historique empirique", mais bien d'une tentative philosophique de penser le politique", H. VIAU, op. cit. pp. 25-26. M. C. WILLIAMS, "Hobbes and International Relations: a Reconsideration", in International Organization, vol. 50, no. 2, Printemps, 1996
} 
of (internal) nature by the (internal) political society did not however consider a transposition of the same solution at the international level. If the state of internal nature results in an internal social contract then why would this not be possible on the international level? The displacement of the state of nature from a micro to a macro level due to the resolution of the situation at the micro level should also entail the displacement of the solution at the macro level. If we know that the state of nature results in the insecurity of all and the lack of conservation of each, only the political society resulting from the understanding or the agreement between individuals can guarantee, according to the adequate formulation however, this conservation. By transposing to the international level, the state of international nature in turn becomes a state where the state is a wolf for another, what leads to insecurity for all. The solution can therefore also only reside in the international social contract, which is an understanding, an agreement and represents international political society guaranteeing to all States, according to the appropriate formula, however, the satisfaction of the conservation of each. A bit like one would remain confined to the state of internal nature, the realists would therefore have remained confined to international anarchy and propose ways to respond to it. However, the state of internal nature is a licentious state, that is to say individuals, in search of their conservation, would decide to use all means that are likely to satisfy it, including at the price or the suffering of others. The licentious behaviour which therefore means the state of nature is a means of preserving individuals and it is because of the consequences of this means for the unavoidable purpose of conservation that these same individuals would decide to consent, to agree, to organize themselves, to conclude a partnership contract or to constitute themselves as a political corporation. Likewise, we must think that international anarchy is a means available to national political societies to preserve themselves and less an ontological reality. Just as individuals would adopt licentious conduct to ensure their security in the state of nature, it is States which, in fact, adopt anarchic conduct in search of satisfaction for their security. According to an objective realism it is therefore not international society which is in itself anarchic it is the States which adopt anarchic behaviour and since this is a means that has or is likely to have harmful consequences for the conservation of all, it can be replaced by a means which would have a happy consequence for the security of each States.

Realism presupposes a methodology enabling to detect or observe or account for unchanging or ahistorical ontological elements. No ontological element likely to change, or modification can therefore enter the realist account. Such is the case for international anarchy. It can be observed as the behavior of States, but it can equally not be adopted by them. On the 
epistemological level, one can by observation account for it in the present, and in the future, by the same observation, no longer account for it. Similarly, States as they are currently configured have not always been so. What we can be sure of, however, is that political society or simply social order is observable at all times and it is the formulation of it that changes over time. Thus realism in its methodology of giving an account of reality should raise this state of affairs, otherwise it may appear as integrating or encouraging a kind of subjectivism which aims to promote a bias. Realism is therefore much more reliable epistemologically than ontologically. That said, from a human security perspective we realize that realism is a theoretical approach which aims to guide efforts aiming at ensuring conservation or security of a human group located within specific borders, according to the demands of international life.

\subsubsection{The realist conception of security and human security}

"It is important to remember that the modern vision of the world and, therefore, of modern knowledge, emerged from the Thirty Years War, that is to say from a context of violence, fears and conflicts, the result of religious disagreements. These theological disagreements on the truth, which turned into struggles, were extremely violent and long, since, on the one hand, these disagreements were immeasurable and, on the other hand, the question of damnation and eternal, intrinsic salvation to their respective truth, animated the faith and the courage of the combatants". 349

Thus the political context of Europe favoured the option for empirical materialism which guaranteed objective knowledge. ${ }^{350}$ "Indeed, this recourse to positivism can be seen as a means of countering any new war waged and fueled by non-material (theological) proposals for the proclamation of the truth. It is an intellectual response to the Thirty Years War, in order to change practices so that no other war so long and bloody can be repeated. The aim of this new paradigm was therefore to separate the propositions of faith from the propositions of knowledge. By limiting discourse to the world of positive phenomena, societies and politicians would, according to this rationalist logic, be freed from the conflicts engendered by non-

\footnotetext{
${ }^{349} \mathrm{We}$ translate from : "Il est important de se rappeler que la vision moderne du monde et, donc, de la connaissance moderne, a émergé de la guerre de Trente Ans, c'est-à-dire d'un contexte de violence, de peurs et de conflits, résultat de désaccords religieux. Ces désaccords théologiques sur la vérité, qui se transformèrent en luttes, furent extrêmement violents et longues, puisque que, d'une part, ces désaccords étaient incommensurables et que, d'autre part, la question de la damnation et du salut éternel, intrinsèque à leur vérité respective, animait la foi et le courage des combattants", VIAU, op. cit. p. 36-37

${ }^{350}$ VIAU, Ibid. S. TOULMIN, Cosmopolis: the Hidden Agenda of Modernity, Free Press, New York, 1990
} 
material propositions coming from conscience and individual convictions" ${ }^{\prime 351}$. Therefore, a public discussion of the truth, contained within the limits of the propositions of material knowledge, could be protected.

This revolution resulted in the progressive contestation and abolition of privileges and social identities based on divine power in favour of a liberal vision of universal equality, justice and citizenship.

"In accordance with this vision, the role of the state was no longer to proclaim a specific identity, as much individuals of this State had to be separated, in principle, from their religious, ethnic or class identities to be understood, in the public sphere, only as a citizen. The intangible proposals were deliberately concealed in favour of a principle of universality". ${ }^{352}$

Citizens became in principle equal and private physical violence was delegitimized from one individual to another or from one class to another. The structure of violence was also based on the principle of universality where private violence should be eliminated from the public sphere. Violence therefore became institutionalized, centralized and regulated by law. The State obtained a legitimate monopoly on violence, both in its internal sphere and in its external sphere $^{353}$ In the internal sphere, the State, or the Supreme Authority vis-à-vis its citizens, is invested with the capacity to maintain the civil order and to use the force against any individual who would threaten by physical acts violent state power. In the external sphere, the State faces the absence of a common power, or an Authority, to ensure order between States. It is then States which find themselves in an anarchic environment where they have to ensure their survival or security against the virtual threat that other represent. ${ }^{354}$ Threats were also defined in terms of material action or capacity for action, as opposed to non-material threats, in this case religious threats, which had already led to so much civil violence. This empirical and material definition of the threat placed military capabilities at the heart of international relations. Modern military strategy therefore became a new political practice.

\footnotetext{
${ }^{351}$ We translate from : "En effet, ce recours au positivisme peut être vu comme un moyen de contrer toute nouvelle guerre conduite et alimentée par des propositions non-matérielles (théologiques) de la proclamation de la vérité. C'est une réponse intellectuelle à la guerre de Trente Ans, afin de modifier les pratiques pour qu'aucune autre guerre aussi longue et sanglante ne puisse se répéter. Le but de ce nouveau paradigme fut donc de séparer les propositions de la foi des propositions de la connaissance. En limitant le discours au monde des phénomènes positifs, les sociétés et les politiques seraient, selon cette logique rationaliste, libérées des conflits engendrés par des propositions non-matérielles provenant de le conscience et des convictions individuelles", VIAU, ibid. M. Williams, "Identity and the Politics of Security", loc. cit. p. 210-216

352 VIAU, ibid. p. 38

${ }^{353}$ Ibid. p. 39

${ }^{354}$ Ibid. pp. 39-38
} 
Military capabilities proved to be the barometer of state power. But military capabilities also include demographic, technological, economic, territorial or diplomatic capabilities, all of which are essential dimensions of a State's ability to defend itself from the threat of another State. The power of a State therefore becomes a threat to the security and survival of any other, while being a means of protecting the first. The threat being defined by power, a struggle of power between States implicitly engages on the international stage. This power struggle is also called the "security dilemma". This is the first paradox that modern representation of the world engenders. ${ }^{355}$

The increase for each State of its level of security leads to the feeling from the others of decrease in theirs. This results in an escalation of state capabilities or, in other words, an escalation of forces. The concept of power is therefore at the heart of national security. Aron explains: "If we assume that security is the final end of state policy, the effective means will be to establish a new balance of power or to modify the old so that potential enemies, because of their inferiority don't be tempted to take the initiative for an assault". 356 This was what was called the security dilemma.

For Waltz, although the security dilemma is a permanent condition of the international system, it can be mitigated through the balance of power. A more or less equal distribution of capacities between the great powers helps to reduce the perception of threat that each may have in relation to the other. The objective of the great powers is then to maintain this balance which ensures the status quo of the international system and, consequently, the security of each and their respective position in the structure of the system. ${ }^{357}$ Indeed, the position of each State in the structure of the international system is determined by the distribution of capacities which has naturally been established between them. ${ }^{358}$

Security from a realist point of view is supposed to refer to state security. Realists ensure themselves, as a super individual, that States are secure, that is to say they are able to resist all kinds of threats that would undermine their survival. It is also about their conservation, whether military, economic or otherwise. But whatever the territorial or economic object of state

\footnotetext{
355 Ibid. p. 40

${ }^{356}$ We translate from "Si l'on suppose que la sécurité est la fin dernière de la politique des États, le moyen efficace sera d'établir un nouveau rapport de force ou de modifier l'ancien afin que les ennemis potentiels, en raison de leur infériorité ne soient pas tentés de prendre l'initiative d'une agression n", R. ARON, op. cit. p. 82, VIAU, ibid. p. 40

${ }^{357}$ WALTZ, "structure and of interacting units. [...] Structure is defined by the arrangement of its parts", See Theory of International Politics, Addison-Wesley Publishing Co., 1979, p.79-80; See also H. VIAU, ibid. p. 42 ${ }^{358}$ H. VIAU, Ibid.
} 
security, this security can only be envisaged as a means for the ultimate security of the individuals who constitute themselves into political society. The protection of territorial borders against violation from other States is understandable only to the extent that the territorial space is the anchorage point for the conservation of citizens. They are housed there, they depend on its resources. The security dilemma that poses a permanent threat to States is only conceivable in terms of fear of the nuisances than can possible come from another State security forces. States then seek to maximize their power to ensure conservation for their members. War or aggression in general, for example, has negative consequences only with regard to the individual, either in consideration of persons, or in consideration of goods which are for their use. State insecurity from a realist perspective ultimately means insecurity or lack of means of conservation for each of individual member of the State. Thus, based on supposedly intangible realities, mainly including selfishness of human nature or more generally the tendency of individuals to satisfy their own interests and possibly to the detriment of others, realism tries to ensure a set of individuals who constituted themselves that way or have agreed in political society, the conservation of each of them, possibly to the detriment of others sets of individuals in their relations with them. Thus they confirm that political society has human security as its foundation and finality. This was later confirmed by the review of the conception of security within the realist approach.

The reconceptualization of security in the realist paradigm should lead to the addition of security referents. "It is important first to recall the context in which this theoretical debate took shape and evolved. It was part of the backdrop of the detente and the end of the Cold War in the 1980s. At the same time as this diplomatic relaxation, this debate took place in a context where social movements for peace and public opinion wishing to democratize policies (search for transparency and legitimacy) relating to questions of strategy and foreign policy acquired increasing media visibility. Also, still in this context, began to take more and more place in the media, in collective consciousnesses, as well as in the security agendas of different governmental and non-governmental actors, various threats such as ethnic, religious or the economic and ecological crises that had been hidden during the Cold War". 359

\footnotetext{
${ }^{359}$ We translate from : "Il est important d'abord de rappeler le contexte dans lequel ce débat théorique a pris forme et a évolué. Il s'est inscrit en toile de fond de la détente et de la fin de la Guerre froide dans les années quatre-vingt. Parallèlement à cette détente diplomatique, ce débat s'est inscrit dans un contexte où les mouvements sociaux pour la paix et l'opinion publique souhaitant une démocratisation des politiques (recherche de transparence et de légitimité) relevant des questions de stratégie et de politique étrangère acquirent une visibilité médiatique croissante. Aussi, toujours dans ce contexte, commencèrent à prendre de plus en plus de place dans les médias, dans les consciences collectives, ainsi que dans les agendas de sécurité des différents acteurs
} 
The sense of realist security has thus been broadened. It was no longer just a matter of referring to the threat posed by one State to the security of the other, but of taking into account all situations which would have had a negative consequence for the integrity of the State. So it was clear that state security could be undermined by a variety of internal or external causes. We can note economic crises that can more or less lead to socio-political crises. These crises directly affect individuals and threaten the stability, not only of the States where they prevail, but also that of third States which may suffer the consequences. The phenomenon of civil wars is well known from this perspective. The sense of expanded security is therefore one of awareness that the threat to state security is no longer just a military one. Realist epistemology therefore made it possible to be known and to acknowledge the existence of other ontological elements of security which may be economy, individuals, civil society, classes, etc. ${ }^{360}$ It should therefore be noted that the expansion of the concept of security still has the State as a reference. It is a matter, although including in sphere of security, other elements, of ultimately securing the State. This is then the ultimate cause of all security initiatives.

From a human security perspective, what should we think of this broadening of the sense of security? On the epistemological level, it must be said that the positivist method, through observation, has come to be aware of the extension or the additional character of threats to the security of the State. It should be thought that either these threats did not exist at the time of conventional realist security, or they were simply ignored. Human security, as a law of nature allows us to know that the order of means to confirming this human intrinsic state of affairs is discovered throughout the historical process of experimentation. This is to be compared to the realist methodology which accounts for or should account for reality as it arises in all and regardless of contexts. But such logic is different from the point of view of the theoretical framework of human security, for which it is about discovering the order of natural means as it has always existed for the confirmation of this essential order of human nature. In the realist account, objectively, it should mean that, but rather it is ultimately about conforming to a reality that postulates to be objective and observed once and for all, however subjective. This is

\footnotetext{
gouvernementaux et non gouvernementaux, diverses menaces telles que les conflits ethniques, religieux ou les crises économiques et écologiques qui avaient été occultées pendant la Guerre froide", H. VIAU, op. cit. p.104 ${ }^{360}$ E. A. KOLODZIEJ, "Renaissance in Security Studies? Caveat Lector!", in International Studies Quarterly, Vol. 36, 1992, p. 421-43 ; B. BUZAN, O. WAEVER, J. de WILDE, Security A New Framework For Analysis, Lynne Rienner Publishers, London, 1998; B. BUZAN, "Rethinking Security after the Cold War", in Cooperation and Conflict; Nordic Journal of International Studies, Vol. 32, n 1, March 1997, pp. 5-28
} 
justified by a certain reluctance, within this approach, of a conceptual revision of security ${ }^{361}$ and of reaching a conclusion of enlarged security, constructed as to conform to the supposedly rigorous requirements of the scientific character of realism. This could be understandable in the presence of objective elements enabling to note the fixity of the ontological elements observed. Now, we realize that the new ontological elements of security are proven because insecurity of the individual, for example, from the economic and social point of views is a threat to the security of the State. It is then about a categorization of the ontological elements into main and secondary. The State remains the main one and the others which come under or not its jurisdiction become secondary. This solution that satisfies realism does not pay enough attention to the fact that the security of the State is in reality only the security of a group of individuals who have constituted themselves that way. The new threats observed against the security of States at the end are only threats to the conservation of the individuals who are part of them. So working within the framework of international relations for the security of these new ontological elements has only one consequence for each of the States: the security of each the individuals who agreed on them.

\subsection{Liberalism and Human Security}

Liberalism is the second theory of the rational meta-paradigm. As with realism, we will consider its postulates (1.2.1) and its conception of security (1.2.2) in relation to human security.

\subsubsection{Postulates of Liberalism and Human Security}

Liberalism is one of the oldest theories of international relations which deals with the best way to create a peaceful international order. The epistemology of liberalism is rational in that only reason enables to discover the meaning of reality. Like realists, liberals start from a certain conception of human nature which they apply to international relations. Reason as a source of knowledge was promoted during the Age of Enlightenment.

The Era of Enlightenment was marked by philosophical rationalism and the exaltation of the sciences, as well as by criticism of the social order and the religious hierarchy, the main elements of the political ideology at work during the French Revolution. ${ }^{362}$

${ }^{361}$ H. DORFF, “A Commentary on Security Studies for the 1990s as a Model Core Curriculum”, International Studies Notes, Vol. 19, 1994, p. 23-31; J. MEARSHEIMER, "The False Promise of International Institutions", in International Security, Vol. 19, n 3, 1994/1995, pp. 5-49

${ }^{362}$ W. BRISTOL, "Enlightenment", in The Stanford Encyclopedia of Philosophy, E. N. ZALTA (Ed.), Fall, 2017 
The expression "Era of Enlightenment", appeared in the $18^{\text {th }}$ Century, is frequently used by writers of the time, convinced that they have just emerged from a long period of darkness and ignorance and have entered a new age illuminated by reason, science and respect of humanity. Already in the $17^{\text {th }}$ Century, René Descartes advocated thinking of "only natural light", and no longer according to divine or supernatural patterns. ${ }^{363}$

$17^{\text {th }}$ Century rationalist philosophers, such as René Descartes and Baruch Spinoza, political philosophers Thomas Hobbes and John Locke, and some skeptical thinkers in France, such as Pierre Bayle, can be considered the forerunners of the Era of Enlightenment, although some elements of their doctrines oppose the empiricist and anti-authoritarian conceptions of $18^{\text {th }}$ Century thinkers. Scientific discoveries and cultural relativism linked to the study of nonEuropean civilizations also contributed to the birth of the "spirit of the Enlightenment". 364

The most important of the assumptions and hopes common to the philosophers and intellectuals of the Enlightenment is undoubtedly the unshakable faith in the power of human reason. The discovery of universal gravitation by Isaac Newton (at the end of the $17^{\text {th }}$ Century) notably benefited from a considerable echo in the $18^{\text {th }}$ Century; indeed, if humanity was able to reveal the laws of the Universe, it could hope to discover the laws proper to nature and to human society; through the judicious use of reason the prospect of perpetual progress in the field of knowledge, technical achievements and moral values opens up. ${ }^{365}$

In the wake of John Locke's philosophy, $18^{\text {th }}$ Century thinkers, unlike René Descartes, consider that knowledge, far from being innate, comes only from experience and observation guided by reason. They claim that education has the power to make people better and even to improve human nature. From now on, the search for the truth must continue by the observation of nature rather than by the study of authorized sources such as Aristotle and the Bible. ${ }^{366}$

While they saw in the Church the main force that held the human spirit in slavery in the past, most Enlightenment thinkers did not completely renounce religion. Rather, they adopted a form of deism, accepting the existence of God and a hereafter, but rejecting the mysteries of Christian theology. According to them, human aspirations should not relate to the distant future, but to the means of improving the present life. So happiness on earth is placed above religious

\footnotetext{
${ }^{363}$ Ibid.

364 Ibid.

365 Ibid.

366 Ibid.
} 
salvation. Enlightenment thinkers attacked nothing with as much violence and ferocity as the Church, its wealth, its political power and its will to hinder the free exercise of reason. ${ }^{367}$

Thus, more than a set of determined ideas, the Enlightenment was an attitude, a method of thinking. According to Emmanuel Kant, the watchword of the century had to be "dare to know": the desire to reexamine and question all the ideas and values received, to explore new ideas in different directions, must be permanent. Thus based on reason, the principles of natural law were discovered as essential prerogatives of human nature, among which freedom occupies pole position and from which the others derive. ${ }^{368}$

Epistemologically, the scientific rationalism of liberalism matches with human security, as a law of nature. If based on essentialism, security is considered to be the state consubstantial with human nature, it is therefore discovered by experience, as being the ultimate cause of human action. The order of means in confirmation of this state compelled to permanence is known or discovered by reason driven more or less by experience. Through positive and negative consequences on individual conservation of the initiatives implemented for this purpose, they come to know what to keep and what to modify or improve. Thus scientific rationalism integrates both reason and experience, which lead to knowledge necessary for human conservation. So liberalism falls within the framework of the knowledge of the order of natural means which enables to confirm the intrinsic state of security. Liberal epistemology in theory of international relations is thus consistent with the theoretical framework of human security. The natural rights discovered by this approach are in accordance with the postulates on human security. We will then try to see their results with regard to international relations.

Until the middle of the $18^{\text {th }}$ Century, liberals stressed that the goal of freedom would be compromised by actions and interference of the government. Liberals deal with political issues on the basis that every enlightened human being is able to recognize his best interests and defend them so as not to infringe the rights of others. Liberals believe that any outside interference in the harmonious pursuit of actors creates conflict and problems. They argued that this principle applies to both politics (freedom of expression, association, religion) and the economy. And they think it applies both at the state level and the international system level. Liberal political theorists believe that justice would be done if freedom could be maximized and the elements of government kept in balance. Thus, the governmental structures put in place

\footnotetext{
367 Ibid.

368 Ibid.
} 
in the $18^{\text {th }}$ Century emphasized the separation of powers. The US constitution is a remarkable example, using precisely this mechanism to create tranquility and harmony within the State. ${ }^{369}$ "The liberal view in International Relations was similar. In the late seventeenth and most of the eighteenth century the world was often seen as one of balance. There were roughly a half dozen great powers that aligned and realigned over time, as conditions changed. States would seek their own self-interest rather than the overall good of the system as they aligned to create the smallest coalition that could protect their national security. But the result would be that the system would stay in balance. This parallels to the way in which individual economic producers, in seeking to maximize their own profit interests, end up keeping the overall economic system stable. Once states' full sovereignty was recognized in 1648 the Peace of Westphalia, ending the Thirty Years' War, it appeared that large-scale war in Europe would be prevented. Relative peace will prevail if outside forces like the Catholic Church are banished from world politics (which was largely accomplished by the Peace of Westphalia) and states simply do what they ordinarily do, that is, form alliances and reform alliances when conditions change". 370

At the end of the $18^{\text {th }}$ Century, liberals had to reconsider both their national and international theories, in a sense that led to harmony and cooperation. External intervention also came to be considered necessary for the equilibrium of the system. Within the States, the industrial revolution made it more difficult for producers to switch from one product to another and for individuals to compete with big business. Most government regulation was seen as necessary to maintain a competitive balance. Internationally, the balance of power ended, not because of the Church intervening from the outside but through the conquest of a large part of Europe by a great power: France under Napoleon. So the liberals came to prefer more regulation in the national level and institutions intervening in the international level. ${ }^{371}$

Liberal scientific rationalism in international relations places relations between society and the State at the center of world politics. It is based on the premise that a causal factor determining the behaviour of a State is the relationship between the State and the national and transnational society in which it is anchored. This basic idea can be reformulated according to the three

\footnotetext{
${ }^{369}$ F. CHERNOFF, Theory and Metatheory in International Relations. Concepts and Contending Accounts, Palgrave Macmillan, 2007, p. 60

${ }^{370}$ Ibid. p. 61

${ }^{371}$ Ibid.
} 
ontological elements shared by all liberal theories, which specify the nature of society actors, of the state and of the international system. ${ }^{372}$

The first assumption is that fundamental players in international politics are rational individuals and private groups, who organize and exchange ideas to promote their interests. ${ }^{373}$ Liberal theory is based on a "bottom-up" view of politics, in which the demands of individuals and groups in society are treated as exogenous causes of the interests underlying the behaviour of the state. Socially differentiated individuals define underlying material and ideal tastes and preferences for future "states of the world" and promote them through political exchange and collective bargaining. The central intuition is that we cannot understand the exercise of power between states or the promotion of collective action between states without first understanding the fundamental social objectives that each state seeks. ${ }^{374}$

Liberal theory thus rejects the idea of an automatic harmony of interests between individuals and groups in society. On the contrary, scarcity and differentiation make certain competition inevitable. Models of political order and conflict result from variations in the underlying model of interaction in pursuit of these preferences for material and ideal well-being. Empirically, social demands are so conflicting that social actors are likely to regard coercion as an acceptable means of promoting them and are generally associated with three factors: diverging fundamental beliefs, scarcity of material goods and inequalities of political power. These three potential motivations define three strands of liberalism - "ideational", "commercial" and "republican" liberalism. ${ }^{375}$

The second assumption of liberal theory is that States or other political institutions represent a subset of national society, whose weighted preferences are the underlying goals (state preferences) pursued by representatives of the Rational State via foreign policy. ${ }^{376}$

\footnotetext{
${ }^{372}$ A. MORAVCSIK, "Taking Preferences Seriously: A Liberal Theory of International Politics", in International Organization, Vol. 51, $\mathrm{n}^{\circ}$. 4, 1997, pp. 513-553; A. MORAVCSIK, "Liberalism and International Relations Theory", in Center for International Affairs Working Paper Series, Vol. 92, n 6, Harvard University, Cambridge, Mass. 1992-93

373 . MORAVCSIK, "Liberal International Relations Theory: A Social Scientific Assessment", Paper $\mathrm{n}^{\circ}$ 01-02, Published by the Weatherhead Center for International Affairs, Harvard University April 2001, p. 5

374 J. W. LEGRO, "Culture and Preferences in the International Cooperation Two-Step", in American Political Science Review, Vol. 90, $\mathrm{n}^{\circ}$. 1, March 1996, pp. 118-137; M. FINNEMORE, K. SIKKINK, "International Norm Dynamics and Political Change", in International Organization, Vol. 52, n'. 4, 1998 pp. 887-917; T. RISSEKAPPEN, "Collective Identity in a Democratic Community: The Case of NATO," in P. J. KATZENSTEIN, (Ed.), The Culture of National Security: Norms and Identity in World Politics, Columbia University Press, New York, 1996, pp. 357-399

${ }^{375}$ A. MORAVCSIK, op. cit. p. 5

${ }^{376}$ Ibid.
} 
Representative institutions therefore constitute a critical belt of transmission through which the preferences and social power of individuals and groups in civil society enter the political domain and are subsequently reflected in state policy. ${ }^{377}$ In the liberal conception of internal policy, the State is not an actor but a representative institution, constantly subject to capture and recovery, construction and reconstruction, by coalitions of social actors. This pluralistic premise neither assumes that all individuals and groups exert equal influence on state policy, nor that the structure of State institutions is irrelevant. On the contrary, each government represents certain individuals and groups more fully than others - from the ideal type of a tyrannical individual to broad democratic participation - and thus, political institutions can be of decisive importance. ${ }^{378}$ The variation in representative institutions and practices help define which group influences national policy.

Regarding the nature of international system, the third assumption of liberal theory, configuration of the State, preferences shape the behavior of the State in the international system. States need a "goal", an underlying issue which is sufficient to provoke conflict, establish cooperation or take any other significant action of foreign policy. It is the precise nature of the policy issue. ${ }^{379}$ In a purely liberal explanation, the distribution of capacities essential to realism and the dissemination of information are therefore treated either as fixed constraints, or as endogenous to indicate preferences, or both. ${ }^{380}$ This does not mean, of course, that each State simply pursues its ideal policy, oblivious to the others. Instead, each State seeks to satisfy its distinct preferences under the constraints imposed by the preferences of other States. The difference is only that the liberals see the distribution of preferences, rather than capabilities (realism) or information (institutionalism), as a system that decisively shapes these strategies. For example, where inter-state interaction generates a result such as trade protection, liberals explain it to compensate for social and unresolved preferences of internal and transnational distribution conflicts, while realists explain it to compensate for considerations arising from the need to manage security competition in the prevailing configuration of political power. ${ }^{381}$

Assuming that state preferences vary exogenously, liberal theory thus sets aside the realist assumption that state preferences should be treated as if they were naturally conflicting. In their

\footnotetext{
${ }^{377}$ Ibid. p. 66

378 Ibid.

${ }^{379}$ Ibid. p. 164

380 Ibid.

${ }^{381}$ Ibid. p. 165
} 
place, liberals assume that criticism, a theoretical link between different state preferences, on the one hand, and variable behaviour from one State to another, is provided by the notion of political interdependence. Policy interdependence can be described as the set of costs and benefits for dominant social groups, societies that arise when the dominant social groups in a given society seek to achieve their own preferences internationally. Liberal theory assumes that this model of interdependence between state preferences - "asymmetric interdependence" imposes a constraint on state behaviour. ${ }^{382}$ Following conventional analyzes of international strategic behaviour, the basic patterns of policy interdependence can be divided into, at least, three broad categories, corresponding to the strategic situation (the structure of political externalities) that results from unilateral action. ${ }^{383}$

In short, liberalism focuses on the best way to create a fairer and more peaceful international order. Liberalism is theorized around the principle of interdependence, that is to say, a condition in which two or more international actors trust each other to ensure each other's availability of essential goods and resources. According to liberals, this principle discourages war or conflict by promoting the harmony of interests, that is, common or shared goals that can be achieved through cooperation. Liberals see regimes as the most important sources of order in international society considered anarchic. The most effective regimes are supported by international organizations which ensure absolute gains for all their members. Liberals believe that national political systems determine the international conduct of States. For example, they think that democracies do not wage war on each other, what they call the theory of democratic peace. So working for the expansion of democracy is a way to widen the area of international peace populated by the democratic states of the world. ${ }^{384}$ Liberals have successfully built a wide variety of international regimes to coordinate state efforts in areas as diverse as security, economic and social development, decolonization, international law. Most of these regimes operate under the aegis of the United Nations, which represents the greatest instrument of global governance in the contemporary world.

\footnotetext{
${ }^{382}$ R. KEOHANE, J. NYE, Power and Interdependence: World Politics in Transition Little, Brown, Boston, 1977; A. MORAVCSIK, ibid. p. 165

${ }^{383}$ L. MARTIN, “Interests, Power, and Multilateralism”, in International Organization, Vol. 46, n. 4, 1992, pp. 765-792; A. HASENCLEVER, P. MAYER, V. RITTBERGER, Theories of International Regimes, Cambridge University Press, Cambridge, UK, 1997, A. MORAVCSIK, ibid. p. 166

384 J. M. OWEN, "How Liberalism produces Democratic Peace”, in International Security, Vol. 19, n 19, 1994, pp. 87-125; K. GRAYSON, "Democratic Peace Theory as Practice: Reading the Significance of Liberal Representations of War and Peace", YCISS Working Paper, $\mathrm{n}^{\circ}$ 22, March 2003; M. DOYLE, "Liberalism and World Politics", in American Political Science Review, Vol. 80, n. 4, 1986, pp 1151- 1169
} 
What should we think of liberalism in relation to human security, as a law of nature? Liberalism in theory of international relations conforms to the postulates of human security. Liberalism emphasizes the instrumental nature of political society, as postulated by the theoretical framework of human security. The function of the State according to this theory is to ensure that the interests of individuals or social groups are met. Since all political societies have this vocation, they can seek to satisfy it, either by conflict or war, or by cooperation. Liberals opt for cooperation because from experience, we have seen the negative consequences of conflicts in the quest for the satisfaction of States interests. Only cooperation allows a harmonious satisfaction of all national preferences. This cooperation is based on the consent of States, as recognized in the theoretical framework of human security with regard to national political society. In reality, it is this agreement that is worth political society and it is in the sense of the transposition of this one at the international level by liberals that regimes are worth all their meaning. Indeed, these are agreements by which States agree in order to satisfy their respective preferences together. International anarchy, which signifies the absence of authority imposed on States and dictates their conduct, therefore does not ultimately mean the absence of order. This one exists or is the result of the agreement represented by regimes. Although the political authority in force within a State cannot be accurately translated at the international level, it should still be recognized that all of them are only possible on the basis of an agreement between the members. This is what postulates human security, as a law of nature. If States have consented to the establishment of an international organization responsible for centralizing cooperation for the individual satisfaction of preferences, it must be assumed that the form of this will evolve until it actually succeeds in ensuring satisfaction preferences of each of the States that have consented. On a general level, liberalism in international relations is the theory which corresponds to the postulates of human security because it makes the satisfaction of the interests of individuals or groups of individuals located within national borders, the final goal of international relations. It is still necessary to know that specifically with regard to its way of liberalism conception of security.

\subsubsection{The liberal concept of security and human security}

The liberal concept also applies to the liberal aspect of security which is also optimistic based on political solutions whose aim is to establish and preserve peace. The liberal solution is based 
on the use of four instruments: international law, international organizations, political integration and democratization. ${ }^{385}$

In terms of global security, it should be mentioned that the application of liberalism does not mean that wars do not exist, but that liberal States will only intervene to protect and consolidate their status or to defend their allies. For this reason, many scholars argue that liberal States seek only to protect their interests and not international justice and peace.

Liberals believe that international organizations will play a greater role in solving global security problems. The existence and functionality of these organizations rests on the following points: the participation of States as contracting parties, the existence of multilateral treaties as constituent parties, the existence of certain common objectives or means, the implementation place of its own constitutional structure. There are two main categories of organizations: intergovernmental and non-governmental. Intergovernmental organizations are made of States, they have specific procedures concerning the decision-making process as well as the seat. They deal with solving global problems which concern different fields, such as: economic exchanges, education, crime, humanitarian assistance, etc. ${ }^{386}$

According to liberalism, peace and security in the world could only be maintained and developed through the cooperation of States. Furthermore, world peace should be maintained not only through military intervention, but also through the implementation of measures such as the protection and promotion of human rights. ${ }^{387}$ For example, liberals believe that the fight against terrorism could also be waged through legislation, not just military activity. It is important to mention two concepts that form the trend of liberalism in security: collective security and arms control. Collective security is fundamentally the concept used during the creation of the North Atlantic Treaty Organization (NATO). It is therefore a protective measure adopted by several Allied States. When one of these States is threatened, its allies intervene and annihilate the aggressor. This concept is based on participation and obligation, which means that all the States that form a community must intervene in order to destroy any threat to the alliance. Obviously, this is not the case with NATO, because some countries refused to participate in the military intervention in Iraq or in Afghanistan or in Iceland, which is unable to participate in such an intervention. We can say that the objective of these countries is to

\footnotetext{
385 J. W. MEISER, “Liberalism”, in S. MCGLINCHEY, R. WALTERS, C. SCHEINPFLUG (Eds.), International Relations Theory, E-International Relations Publishing, Bristol, 2017, pp. 22-27

${ }^{386}$ R. O. KEOHANE, J. S. NYE, Power and Interdependence. Longman, New York, 2001

387 J. W. MEISER, op. cit. p. 24
} 
annihilate all risks and consolidate world security or to neutralize an enemy before it can act. One could say that the concept has the following characteristics:

- prevent: wars cannot be stopped, but international organizations can prevent an aggressor from launching operations);

- block: international organizations must recognize the aggressors and arrest them;

- annihilate: the allies have the legitimate power to put out of harm's way, potential aggressors when these constitute a threat to international security;

- discourage: the international community must inform the aggressor of its opposition to its actions and give it the last warning so that this one ceases its actions.

In terms of global security, arms control translates into fewer weapons, which means having less insecurity for States. As a result, officials are trying to reduce the number of weapons and intensify the disarmament processes and curb illegal arms trafficking. It should be noted that the application of liberalism does not mean that wars do not exist, but that liberal States will only intervene to protect and consolidate their status or to defend their allies. For this reason, many scholars argue that liberal States seek only to protect their interests and not international justice. $^{388}$

In conclusion "a core argument of liberalism is that concentrations of unaccountable violent power are the fundamental threat to individual liberty and must be restrained. The primary means of restraining power are institutions and norms at both domestic and international level. At the international level institutions and organisations limit the power of states by fostering cooperation and providing a means for imposing costs on states that violate international agreements. Economic institutions are particularly effective at fostering cooperation because of the substantial benefits that can be derived from economic interdependence. Finally, liberal norms add a further limitation on the use of power by shaping our understanding of what types of behaviour are appropriate" 389 .

From the perspective of human security, the liberal conception of security in international relations includes a strict and a broad meaning. The strict meaning relates to the defense or military aspect. So international regimes represented by international law and international organizations enable to organize collective defense. Thus the anarchic conduct one State would adopt while attacking another can be controlled and mitigated. In a broad sense, security

\footnotetext{
388 J.H. OWEN, How Liberalism Produces Democratic Peace, in International Security, Vol. 19, n . 2, MIT, Press, Paris, 2004, pp. 95-96

${ }^{389}$ J. W. MEISER, op. cit. p. 27
} 
encompasses the interests of all kinds of States. It therefore concerns politics in the strict sense. International regimes then create a framework which enables to satisfy the preferences of States. Human security conceives a concept of integral security, that which preserves this state that is consubstantial with human nature. It cannot then be frozen in the military aspect because groups of individuals can be sheltered from all external attacks, but face internal difficulties which undermine the satisfaction of basic needs. Such a situation certainly falls within the framework of security since if it is not resolved the conservation of individuals does not follow. Security means absence of pain or suffering, but the military threat is not the only cause of suffering, the lack of housing, food, health are causes that ultimately lead to the extinction of human nature. The liberal conception of security is then in accordance with the postulates of human security. The fact remains that if international regimes do not ultimately lead to the retention of nationals, their formulations should experience an improvement for the benefit of all. Liberalism in theory of international relations therefore pursues the end to satisfy the security interests of individuals who constituted themselves into political societies through cooperation, materialized in the agreement based on the principle of freedom.

This first section allowed us to study rationalist theories including realism and liberalism, in relation to the theoretical framework of human security. So we can note that the epistemological positivism of these schools of international relations leads to the knowledge of ontological elements different from these approaches. However, realism and liberalism, whatever their evolution may be, have as their final goal the satisfaction of the human security interests of a group of individuals who have constituted themselves into political society. According to realism, it is a question of pursuing this objective by opting for any means capable of achieving it, including those at the cost of other political societies. According to liberalism, it is a question of achieving it in cooperation with other political societies pursuing the same objective. The liberal method has proven to be the most adequate because it is the one that favours the absence of or a very careful recourse to conflict. Now we will study reflexive theories.

\section{HUMAN SECURITY AS A LAW OF NATURE AND REFLEXIVISM IN THEORY OF INTERNATIONAL RELATIONS}

Reflexivism brings together a set of theoretical approaches of international relations that oppose rationalist theories of the social phenomenon and generally against positivism. The term "reflexivism" was popularized by Keohane who distinguished this meta theory of international 
relations by that of rationalism. Reflexive theorists tend to emphasize the reflexivity inherent both in the theory and in the social world they study. Unlike the term "reflexivism", the concept of "reflexivity" is widely used outside of international relations and became popular in social theory at the end of the $20^{\text {th }}$ Century. ${ }^{390}$ Reflexivity refers to the way in which the elements and phenomena of social life have the capacity to reflect on themselves. ${ }^{391}$ In other words, they can have effects on their characteristics, dynamics and existence, or have implications for their own characteristics. An example is the "self-fulfilling prophecy" (or self-confirming prophecy) ${ }^{392}$, a situation in which the simple act of describing, predicting, imagining or believing in something can possibly make it happen. ${ }^{393}$ More generally, reflexivists emphasize the meaning of human self-awareness: the way people observe, imagine, describe, predict and theorize about themselves and the social reality around them, and the recursive effect of this knowledge of oneself or of these reflections on this social reality itself.

Reflexivists also often assert that the study and theorization of international relations can or should be and are necessarily reflective. On one hand, they argue that theories about social reality can affect or could change social reality itself. ${ }^{394}$ Familiar methodological examples of observing and theorizing abilities to affect the object and the phenomena in study include the observer's hope effect and the long-standing concerns of anthropologists and ethnographers regarding possible effect of participant observation on the people and behaviors studied. Furthermore, reflexivists argue that these theories invariably, reflect significantly the social context in which they were produced; in a sense, the social world shapes the theories that account for it. ${ }^{395}$ Emphasis on reflexivity often has a normative or ethical aspect. ${ }^{396}$ Reflexivists often argue that theorists should be as aware as possible to reflect as much as possible on the influences (assumptions, prejudices, normative commitments, etc.) that fuel and shape the theories they produce. ${ }^{397}$ In addition, they should be able to apply their own theories to the

\footnotetext{
${ }^{390}$ P. BOURDIEU, L. WACQUANT, An Invitation to Reflexive Sociology, University of Chicago Press, 1992

${ }^{391}$ M. EAGLETON-PIERCE, "Examining the Case for Reflexivity in International Relations: Insights from Bourdieu", in Journal of Critical Globalisation Studies, $\mathrm{n}^{\circ}$ 1, 2009, pp. 111-12

${ }^{392}$ I. OREN, "Can Political Science Emulate the Natural Sciences? The Problem of Self-Disconfirming Analysis", in Polity, Vol. 38, $\mathrm{n}^{\circ} 1,2006$

${ }^{393}$ D. P. HOUGHTON, "The Role of Self-Fulfilling and Self Negating Prophecies in International Relations", in International Studies Review, Vol. 11, n 3, 2009; R. JERVIS, System Effects: Complexity in Political and Social Life, Princeton University Press, 1997, pp. 60, 148-50

${ }^{394}$ B.J. STEELE, Ontological Security in International Relations: Self-Identity and the IR State, Routledge, 2008, pp. 150, 160-64

395 I. OREN, "Is Culture Independent of National Security? How America's National Security Concerns Shaped 'Political Culture' Research", European Journal of International Relations, Vol. 6, n 4, 2000

396 B. ACKERLY, J. TRUE, "Reflexivity in Practice: Power and Ethics in Feminist Research on International Relations", in International Studies Review, Vol. 10, $\mathrm{n}^{\circ}$ 4, 2008

${ }^{397}$ M. NEUFELD, "Reflexivity and International Relations Theory”, in Millennium Vol. 22, n¹, 1993, p. 55
} 
standards and arguments set out in those same theories. ${ }^{398}$ Finally, they should think about the likely and possible effects of their theorizing undertaking. Reflexivist theories of international relations generally include constructivism (2.1) and the Critical School (2.2). We will expose and examine them in relation to human security, as a law of nature.

\subsection{Constructivism and human security}

We will consider the postulates (2.1.1) and the conception of security (2.1.2) of constructivism, in relation to human security.

\subsubsection{Constructivist postulates and human security}

Constructivism is a theory of international relations questioning the foundations of international society. It highlights the role of ideas in international relations. After all, two States facing the same international environment can act very differently. This is clearly illustrated by the conflict between realists and liberals. Realism and liberalism agree that international society is defined by a structural anarchy which is characterized by the absence of a final judge to settle disputes and impose binding laws. In addition, both theories use rational choice to conclude that States will respond to this anarchy in a specific way. Realists claim that anarchy leads to security dilemmas, forcing States to fend for themselves to survive in a fundamentally hostile international system. Liberals say rational States will recognize the futility of competition, preferring to create strong regimes to solve their common problems.

Constructivism seeks to provide an answer to the question why these two theories lead to such opposite conclusions on the behavior of States, given that they start from the same principle: international anarchy. If States are rational actors with well-defined interests, constructivists argue that they should always act in a predictable way, either as realist self-help, or as builder of the liberal regime. Historically, however, States have responded to the world in very different ways. Some, like Sweden, spent much of the $20^{\text {th }}$ Century behaving as liberals. Others, like Russia, reacted in the same international environment as realists. Constructivism examines this situation and concludes that one cannot understand the world as a set of clearly defined cause and effect relationships. A cause can have many different effects, depending on how it is

\footnotetext{
398 I. HAMATI-ATAYA, "The 'Problem of Values' and International Relations Scholarship: From Applied Reflexivity to Reflexivism", in International Studies Review, Vol. 13, n 2, 2011
} 
perceived. Like a riot that occurs in a residential area. Some may decide to lock themselves in their house while others may decide to regroup with their neighbors. It can also be the case of a strategy whose anarchic structure gives rise to different responses depending on the State. Some opt for arming against potential threats. Others join collective security regimes in the hope of gaining greater strength and stability. States, like people, react to their context in different ways, depending on how they perceive their situation. Some do so with an individualist logic and others with a logic of cooperation. Alexander Wendt, one of the most important thinkers of social constructivism, sums up this idea in a simple statement: "Anarchy is what states make of it". 399

Constructivism maintains that theories based on rational choice are wrong. Constructivism maintains that the international society in which we live is not fixed objectively. Instead, international society is seen as a product of the social construction of reality. This means that aspects of international society such as anarchy, sovereignty, regimes and the security dilemma are products of the human action. Unlike rocks or oceans, these social facts depend on human interactions to make them real. If human beings were to disappear from the face of the earth, so would the social facts. As a result, social constructivists claim that humans are more than rational computers that react to the world around them, as a rational choice would like. We create and reproduce the societies in which we live, and we can choose to change them if our perception of reality changes. From a social-constructivist point of view, realists are wrong to assert that States have no alternative but mutual suspicion, selfishness and the security dilemma. There are other alternatives, but realists choose not to accept them. Likewise, liberals are wrong if they claim that international anarchy generates an objective need to build a liberal order based on interdependence, regimes and liberal democracy. These are only likely results because liberals choose them. Thus, according to social constructivism, international anarchy can manifest itself as a realist world of States in conflict, as a liberal world of cooperating States or in some other forms of society. The way States define their national interests in an anarchic society is not dictated by the structures in which they live. It is socially constructed by their perceptions of the world in which they live. ${ }^{400}$

Social constructivism makes several claims about the world we live in. First, there is a link between identity and national interest. Constructivists believe that interests of States flow from

\footnotetext{
${ }^{399}$ A. WENDT, “Anarchy is What States Make of It: The Social Construction of Power Politics”, in International Organization, Vol. 46, n 2 , 1992, pp. 391-425

${ }^{400}$ Ibid.
} 
the way they perceive themselves and those around them. A constructivist analysis of the national interest of a State therefore requires an understanding of its fundamental values. These values define what the State considers important and affect the way it perceives other actors in international society. If a State perceives its neighbor as sharing values similar to its own, it is more likely to seek a peaceful and cooperative relationship. If a State considers its neighbor to be radically different, their relations risk being competitive or conflicting. Thus, States with radically different identities may behave like realists, while those with similar identities are likely to behave like liberals. "(...) Constructivists argue that states can have multiple identities that are socially constructed through interaction with other actors. Identities are representations of an actor's understanding of who they are, which in turn signals their interests. They are important to constructivists as they argue that identities constitute interests and actions. For example, the identity of a small state implies a set of interests that are different from those implied by the identity of a large state. The small state is arguably more focused on its survival, whereas the large state is concerned with dominating global political, economic and military affairs. It should be noted, though, that the actions of a state should be aligned with its identity. A state can thus not act contrary to its identity because this will call into question the validity of the identity, including its preferences. This issue might explain why Germany, despite being a great power with a leading global economy, did not become a military power in the second half of the twentieth century. Following the atrocities of Adolf Hitler's Nazi regime during the Second World War, German political identity shifted from one of militarism to pacifsm due to unique historical circumstances"

Constructivists argue that the agency and the structure are mutually constituted, which implies that the structures influence the agency and that this agency influences the structures. The agency can be understood as the capacity of a person to act, while the structure refers to the international system made up of material and ideal elements. Alexander Wendt provides an excellent example of the social construction of reality when he explains that 500 British nuclear weapons are less threatening to the United States than five North Korean nuclear weapons. ${ }^{402}$ These identifications are not caused by nuclear weapons (the material structure), but rather by the meaning given to the material structure (the ideal structure). It is important to understand that the social relationship between the United States and Great Britain and the United States and North Korea is perceived in a similar way by these States, because this shared

\footnotetext{
${ }^{401}$ S. THEYS, “Constructivism”, in S. MCGLINCHEY, R. WALTERS, C. SCHEINPFLUG (Eds.), op. cit. p. 37 ${ }^{402}$ A. WENDT, "Constructing International Politics”, International Security, Vol. 20, n 1,1995, pp 71-81
} 
understanding (or intersubjectivity) forms the basis of their interactions. In this example, this means that the social enmity relationship between the United States and North Korea represents the intersubjective structure, (that is, ideas and beliefs shared between the two States), while the States -United States and North Korea are the actors who have the capacity, (that is to say, an agency) to change or strengthen the existing structure or the social bond of enmity. This change or strengthening ultimately depends on the beliefs and ideas of the two States. If these beliefs and ideas change, the social relationship can become a friendship. This position differs considerably from that of realists, who maintain that the anarchic structure of the international system determines the behavior of States. Constructivists, on the other hand, argue that "anarchy is what states make of it". This means that anarchy can be interpreted in different ways depending on the meaning that the actors attribute to it. ${ }^{403}$ The example also shows that nuclear weapons in themselves have no meaning unless we understand the social context. It further demonstrates that constructivists go beyond material reality by including the effect of ideas and beliefs on world politics. It also implies that reality is still under construction, which opens up the prospect of change. In other words, the meanings are not fixed but can change over time depending on the ideas and beliefs of actors. ${ }^{404}$

Social norms are also essential to constructivism. These are generally defined as a standard of behaviour appropriate for actors with a given identity ${ }^{405}$. States that conform to a certain identity are expected to conform to the standards associated with that identity. This idea comes with the hope that certain types of behavior and action are more acceptable than others. This process is also called "the logic of relevance", where the actors behave in a certain way because they feel that this behavior is appropriate. ${ }^{406}$ To better understand the standards, we can identify three types: regulatory standards, constituent norms and prescriptive norms. Regulatory standards order or constrain certain behavior; constitutive standards create new actors, interests or categories of action; and prescriptive standards prescribe certain standards, which means that there are no bad standards from the point of view of those who promote them. ${ }^{407}$ It is also important to note that standards go through a "standards life cycle" before being accepted. A standard only becomes expected behavior when a critical mass of relevant State actors adopt it

\footnotetext{
${ }^{403}$ S. THEYS, op. cit.

${ }^{404}$ Ibid.

405 P. J. KATZENSTEIN, The Culture of National Security: Norms and Identity in World Politics, Columbia University Press, New York, 1996, p. 5

406 J. MARCH, J. OLSEN, "The Institutional Dynamics of International Political Orders", in International Organization, Vol. 52, n 4, 1998, pp. 943-969

${ }^{407}$ M. FINNEMORE, K. SIKKINK, "International Norm Dynamics and Political Change", in International Organization, Vol. 52, $\mathrm{n}^{\circ}$ 4, 1998, pp. 887-917
} 
and internalize it in their own practices. For example, constructivists would argue that the majority of States have come together to develop policies to mitigate climate change, as it is a necessity for the survival of humanity. After decades of diplomacy and advocacy, this behavior has become appropriate behavior which the majority of citizens expect their leaders to adhere to. Liberals, on the other hand, could reject the notion of climate change policy in favour of continued economic growth and the search for innovative scientific solutions, while realists could reject it because of the damage that climate policies could cause to national interests in the shorter term. ${ }^{408}$

Constructivism sees the world and what we can know of it as socially constructed. This point of view refers to the nature of reality and the nature of knowledge. From the perspective of human security, as a law of nature, how can constructivism be considered in the theory of international relations?

Constructivism turns out to be a much more pronounced theory on the epistemological level than the ontological one. Indeed, the whole constructivist logic rests on the non-fixity of the nature of international relations. Indeed, the main actors in these relationships, which are States, find themselves involved in a permanent social process of defining their identities and their interests. This reality, which claims to be objective, is therefore of a procedural or methodological order since the ontological reality is constantly doomed to change. The ontological elements at the conclusion of which constructivist theorists would reach cannot be considered as fixed themselves because of the process of change which they are subject to. So the whole objectivity of constructivist theory is to account for this dynamic of international relations. If we consider the ontological element of rationalism shared by constructivism, which is the anarchic international society, we can then know that the nature of this element is also subject to change, or at least is likely to it. A simple look in history indeed gives us to know that interstate society was not always a reality and that the degree of anarchism was not always the same in the period between the two world wars world and in the period following the Second World War. Thus, the anarchy of international system is not a definitive reality, because if we can see that anarchy has evolved from a more acute level to a moderate level, it is just as possible to consider its disappearance in the interstate system. At least, this possibility is part of the constructivist epistemological objectivism.

${ }^{408}$ S. THEYS, op. cit. p. 38 
In this methodological sense, constructivism in the theory of international relations corresponds to the theoretical framework of human security. Constructivism highlights the process of permanent construction at two levels: identities and interests, whether those of the States or those of the social groups that constitute them. At first glance, that seems to contradict the postulates of human security, as a law of nature. This one postulates that identity is fixed in that human nature is an identity reflected by the intrinsic state of security which is consubstantial with human nature. Thus this identity or this state of security is a perfect existent which is no longer to be realized or created, for it is already real, but which is to be confirmed or preserved as it is. The absence of confirmation gradually leads to a definitive extinction, which ultimately means that human nature cannot really be what it is not, or cannot be in anything else than in this state of security. So this identity does not change, because if that were the case, there would be no more human nature, because such a complete change would entail that nature no longer be. Human nature cannot therefore find itself in a situation of total insecurity and continue to be. So the constructivist process of change of identity which can only be envisaged from the point of view of ontological elements, cannot therefore be proven, at least as far as the most ontological of these is concerned, which is the individual. Regarding the other ontological elements that are the State and international society, these have a secondary or accessory status in the ontological rank because they cannot exist without individuals who happen to be the primary ontological elements. Just as the accessory follows the principal, so the State cannot exist without the individual, so international society cannot exist without individuals who have constituted themselves into States. From the point of view of human security, as a law of nature, political society, whatever its size or scale, has an instrumental nature, that is to say, it is part of the order of natural means necessary for the conservation of individuals, subject by this same nature to dependence, for this purpose, to the resources it harbors and to coexistence. Having to be formulated in a way which results in the conservation of all the individuals who make it up or who essentially are considered consenting to it, political society itself is called to go through a historical experiential process for the discovery of the adequate formulation. The constructivist process of identity change in the theory of international relations can therefore only be envisaged with regard to political societies in their reciprocal relationships, because it is only in an international dimension that it can be considered as an ontological element. It is certain that the State, or even international society as configured in the postmodern era, have not always been so. Thus until the discovery of the adequate formulation which would allow the satisfaction of the interests of all the groups of individuals who constitute themselves into political societies, the formulation of the international social organization is bound to evolve. 
As for the constructivist process of changing interests, it is intimately linked to identity and properly belongs to the order of means necessary for the confirmation of human security. This change of interests is justified by the consequences of their satisfaction for the various human groups constituting national political societies.

It must therefore be said that constructivism in the theory of international relations accounts for the necessary historical process of experimentation or learning from the positive and negative consequences of the formulations of international society. These consequences should serve to provide information on the elements of the natural international order necessary for the conservation of all individuals who constituted themselves into national political societies.

\subsubsection{The constructivist conception of security and law of human security}

Ideas, as the basis of interests and identities are said to be conceived in an intersubjective way. ${ }^{409}$ Intersubjective structures are very important for constructivists because they think that they constitute the dominant principles of the international system. They believe anarchy is what States create based on their ideas and assumptions, while the security dilemma and wars are the result of predictions made by States. They also asserts that policies of mutual trust can create the structure of common knowledge in which States will be led towards peaceful security and will ensure security for each one. One example is the end of the Cold War. When the superpowers came to the idea of an end of the Cold War, it ended. ${ }^{410}$ They argue that international politics is not only a safe haven in the sense that realism believes or gains wealth as liberalism believes, but a sphere of understanding. In this way, States can follow foreign policies that do not correspond to realism or liberalism.

On the constructivist basis, security takes on meaning under conditions that States understand it, from their environment in which they act and form the meaning they give to anarchy. ${ }^{411}$ According to Wendt, there are three cultures of anarchy, namely Hobbesian, Lockean and Kantian. States create specific types of security for each. The Hobbesian culture which had dominated world affairs until the seventeenth century led States to see each other as enemies; States took each other as threatening adversaries who used violence against each other on every occasion. Therefore, violence has been used as a basic tool for survival in the Hobbesian culture. On the contrary, in the Lockean culture, the violence that has dominated the system of modern States since the Treaty of Westphalia in 1648 has not been used as a basic means of survival.

\footnotetext{
${ }^{409}$ K. WALTZ, Theory of International Politics, op. cit. p.79, A. WENDT, “Anarchy is What States Make of It: Social Construction of Power Politics", op. cit. A. WENDT, Social Theory of International Politics, op. cit. ${ }^{410}$ A. WENDT, Social Theory of International Politics, ibid.

${ }^{411}$ A. WENDT, "Anarchy is What States Make of It: Social Construction of Power Politics", op. cit
} 
Rivalry is the main feature of the Lockean culture, in which States saw themselves as rivals who could use violence to defend their interests. However, the elimination of each other or the use of violence, without any limitation against rival States, was avoided. Friendship and trust are elements that have characterized the Kantian culture. In the Kantian culture, which has only recently appeared in relations between democracies, not only do States not consider themselves as rivals, but friends, and the use of force to settle conflicts is seen as unnecessary. In the Kantian culture, States trusted each other and worked as a team to combat security threats. This is why, based on Wendt's argument, three types of security accounts can be distinguished in the history of world politics. The latter is the culture in which the security dilemma is at its lowest level. ${ }^{412}$

Constructivism emphasizes that not all institutions such as identities, interests and anarchy are given. Their relationships are based on and can be interpreted and reproduced during the practice process. Agents define and interpret concepts such as security and insecurity based on their knowledge, which is not intrinsic to the situation. Agents just have to guess what their security is and what it is not. So all of these institutions are changing. Agents interpret their security based on threats that are not naturally constructed. ${ }^{413}$ Social constructions are variable and not timeless and changes can be negative or positive. This particular reflection on social constructions can produce new practices and interactions. The end of the Cold War is proof that thinking about social constructions had changed the nature of practices and interactions. For example, when Gorbachev wanted to end the Cold War and cooperate with the West, he rejected the Leninist belief in world politics and, more importantly, he understood that the role and practice of the Soviet Union were in conflict with those of the capitalist world. Therefore, agents can change the world by changing their ideas about the world. All standards and identities are constructed and modifiable by the practice of actors or agents. Concepts like security and insecurity follow the same path, that is, they are changed if their practices change the intersubjective meaning of current conditions for agents. ${ }^{414}$

In substance, the famous assertion that "anarchy is what States make of it" simply means that it is a permissive condition and thus lacks inherent logic. Whether anarchy compels States to distrust the safety of others or whether it allows States to be cooperative and friendly depends on the social interactions they sustain.

\footnotetext{
${ }^{412}$ A. WENDT, Social Theory of International Politics, op. cit.

${ }^{413}$ A. WENDT, "Anarchy is What States Make of It: Social Construction of Power Politics, op. cit

414 Ibid.
} 
Anarchy does not mean chaos. There are numerous rules and ideas that determine what anarchy means and neither does competition. Instead, an anarchic system is filled with rules and ideas from actions and interactions of States in the international system. If States regard others as potential enemies, anarchy would lead to insecurity. If, on the contrary, States act as if others were friends, then anarchy can lead to cooperation and trust. Constructivists claim that this is exactly what has happened in Western Europe since the Second World War. In fact, one observer contends that the fear of anarchy and its consequences has encouraged key international actors to change their behavior in order to change this structure. ${ }^{415}$ Of course, the European Union was not seen as an attempt to change the logic of anarchy. At the end of the World War II, the victorious allies had two objectives in mind: to defend Western Europe from Soviet Union and communism, and to contain or control Germany.

Many initiatives have been designed to achieve these two objectives, including the Marshall Fund, the International Bank for Reconstruction and Development (which will later become the World Bank), NATO and the European Coal and Steel Commission. The latter, and apparently the least relevant of them, was to grow and become the European Community, then the European Union, an organization that changed the map and destiny of Europe as well as the understanding of international relations. However, all these measures were put in place for reasons that realists find very familiar: Western Europe was vulnerable, distrusted the Soviet Union and feared that Germany would again become an aggressive power. Thus, the actions undertaken by the Western European States (assisted, supported and encouraged by the United States, appeared to be very realistic in nature. These States were faced with an uncertain international context and took steps to enhance their security However, the increase in security was not the only result of the activities undertaken at the end of the Second World War. ${ }^{416}$

The Western European powers began to change their behavior in favour of more cooperative relations. It was not so simple for France and Great Britain, which had been allies in the two world wars, but which also had cooperative relations with their enemies of war, Germany and Italy. Economic, political and military cooperation, spurred on by the common Soviet threat, created a climate of confidence. Starting with the Coal and Steel Commission, European States have expanded their cooperation in many areas of politics and economics, forming the European

\footnotetext{
${ }^{415}$ R. N. LEBOW, "The Long Peace, the End of the Cold War, and the Failure of Realism", in International rganization, Vol. 48, $\mathrm{n}^{\circ} 2,1994$, p. 251

${ }^{416}$ Ibid. p. 270; See also J. ACKERMAN, B. CARLSON, H. YOUNG, "Constructivism and Security", Air Command and Staff College (ACSC) Distance Learning Program, Maxwell AFB, AL: ACSC, 2010, p. 5
} 
Court of Justice, the European Commission of Human Rights, the Organization for Security Cooperation in Europe and the Monetary Union, among others. Sustained cooperative interaction over time has led to habits of cooperation, consultation and community. Western European States used to treat each other as friends. This changed the nature of anarchy. Western European States have transformed anarchy into a cooperative structure to the point of eliminating the borders between them. ${ }^{417}$

This has never been more evident than after the end of the Cold War. In 1989, when the Berlin Wall fell and in the early 1990s, when the Soviet Union dissolved and Germany reunited, Western Europe was faced with two realities. First, the common threat of the past 40 years has disappeared. Second, Germany, the feared aggressor in world wars, was unified. What was the reaction? Have European States returned to suspicious and competitive relations and individual security-enhancing efforts, as the realist logic of anarchy would predict? ${ }^{418}$ No. On the contrary, integration of States into the European Union has deepened. Through their interactions, the States of Western Europe have changed their own context. By cooperating, they established a climate of trust and modified the range of possible actions and the rules governing their relations. As Emanuel Adler said, Europe has become a security community, which means that it is not just a group of States which, through increased communication, have abandoned war as a means of social contact; it is also a community Region in which people master the practice of peaceful change. ${ }^{419}$ Indeed, as Lebow says, in Europe these supposedly inevitable consequences of anarchy have been largely overcome by a complex network of institutions that govern relations between States and provide dispute resolution mechanisms. ${ }^{420}$ Where States had fought to death, no member of the Union was planning any more military plans against another. ${ }^{421}$ Indeed, a common security policy and even a security community are possible today, when they were previously impossible. ${ }^{422}$ Western European States have built their own cooperative context through their actions and interactions. They escaped the realist logic of anarchy and made Europe a zone of peace. ${ }^{423}$

\footnotetext{
${ }^{417}$ Ibid. p.6

${ }^{418}$ J. MEARSHEIMER, "Back to the Future: Instability in Europe After the Cold War", in International Security, $\mathrm{n}^{\circ} 15,1990$, pp. $5-56$

${ }^{419}$ E. ADLER, "Imagined (Security) Communities: Cognitive Regions in International Relations", in Millennium: Journal of International Studies, Vol. 26, n² 2, 1997, pp. 276

${ }^{420}$ R. N. LEBOW, op. cit. p. 269

${ }^{421}$ Ibid. p. 269

${ }^{422}$ R. N. LEBOW, Ibid. E. ADLER, op. cit.

${ }^{423}$ A. BA, M. J. HOFFMAN, "Making and Remaking the World for IR 101: A Resource for Teaching Social Constructivism in Introductory Classes”, in International Studies Perspectives, Vol. 4, 2003, pp. 22-24
} 
Apprehension of security by constructivism largely accounts for the changing character of State mentalities. Security in international relations is a function of State values. Constructivism will account for security by considering the historical evolution of the ideas that actors have about it according to their identities and their interests. We cannot then say that constructivism has a particular postulate relating to security in international relations. It will simply report on the current sense of security, based on its epistemology. It will be a question of state or human security, on a liberal point of view, realist according to real parameters of international life. This confirms its nature as a methodology for understanding international relations. We must think, in a perspective of human security that the international social reality or the order of natural means necessary for the conservation of the groups of individuals who constitute themselves into political societies will remain involved in a constant process of discovery.

All these developments allow us to know that the constructivist theory of international relations has as its logic human security, as a law of nature, in reference to the final order which it implies. Constructivism will therefore account in general for the historical process of experimentation for the discovery of the best formulation of international society for the conservation of the individuals constituting the various national political societies. Afterward we will dwell on the Critical School of International Relations.

\subsection{The Critical School and human security}

In this framework, we will study the postulates (2.2.1) and the conception of security (2.2.2) of the Critical School of International Relations, in relation to the postulates of human security.

\subsubsection{The postulates of the Critical School and human security}

The critical school was developed in Germany between the two world wars and preceded the major works of poststructuralism. Theodor Adorno and Max Horkheimer were the main thinkers of this movement. Herbert Marcuse, Otto Kirchheimer and Walter Benjamin also played an important role. They were Marxists and very critical of both modern European society and traditional social theories that sought to explain it. During the Second World War, they dispersed, but some returned later to Frankfurt. They were inspired by Freud's notions of "self" and "consciousness", and in particular Marx's analysis of class conflicts, the exploitation of 
workers and the dynamics of capitalist economic systems. But in some ways, they took these ideas even further. Critical theorists in Germany, as well as other Marxists like Gramsci, attach the highest value to the goal of human emancipation. ${ }^{424}$

According to critical theory, whatever theory is advanced, it must be aimed at the goal of human emancipation. In the $18^{\text {th }}$ Century, Kant argued for human emancipation, but conceived this one as a set of circumstances in which individuals would be free to pursue their own interests, and in particular their own rationality and moral perfection. Certain conditions are necessary for that to be fully possible; in particular, just laws found in a Republic are best suited to create them. But war can always stop them. Kant advocated for the creation of an international system in which peace would prevail. The notion of human emancipation in Marxism and critical theory was very different. ${ }^{425}$

Critical theorists criticize certain elements of modernity. They usually try to revise or push many of the Enlightenment's views on how society can be studied and changed. Critical theorists reject as too simplistic the idea that the proper use of instrumental rationality could solve all problems related to society and human affairs. Critical theorists argue that Enlightenment thinkers accepted the idea of instrumental rationality without considering the moral consequences. They agree that the use of instrumental rationality in recent centuries has produced two major results: modern science and the modern economic system. Both have been used to undermine human emancipation. Science had been largely a tool of the State and the modern economy was capitalist. They criticize instrumental rationality for justifying the various economic and political forms by which the ruling class dominated the governed. ${ }^{426}$

As stated earlier, The Critical Theory aimed to criticize society and traditional theories about society. According to critical theory, traditional theories contain no self-criticism and, whether they like it or not, they legitimize the unjust social and political orders in which they are developed. For example, a sociological theory that each social institution is born and exists simply because it has a function that it fulfills in that particular society justifies and legitimizes all of these institutions. Instead, the theory should blame society for banning an institution, if it is unjust, such as slavery. The problem for critical theorists is that instrumental rationality is presented as a purely neutral tool that can be used by neutral social science to solve problems the way its users want. We could then probably use it for moral purposes. Critical theorists have

\footnotetext{
${ }^{424}$ F. CHERNOFF, op. cit. p. 171

${ }^{425}$ Ibid.

${ }^{426}$ Ibid.
} 
a double objection to this conception of instrumental rationality. The first is that any theory is formulated for a specific purpose, as Robert Cox said. ${ }^{427}$ Critical theorists argue that instrumental rationality is not axiologically neutral, but that it itself carries value considerations to the extent that traditional social scientists place high value on instrumental rationality. Traditionalists might admit that they like it, but could then say that it is not a moral value, but rather an intellectual value, and therefore morally neutral, like the value of valid proof in geometry. Rationalists therefore take subjective considerations for objective truths. ${ }^{428}$

According to rationalists, valid proof is better than invalid proof. But accepting this kind of value has no moral or political impact. These values are sometimes called "epistemic values" to indicate clearly that these are values we support in the quest for knowledge. Critical theorists do not share this view. Critical theorists believe that the modern world has created a capitalist economic order and a liberal free trade system that provides benefits to certain groups and exploits others by using and adopting instrumental rationality. They argue that the assertion that instrumental rationality is neutral in terms of value to society is a mistake. Critical theorists hold as example the many forces that oppose the emancipation of individuals in modern society. Horkheimer, and in particular Adorno, believed that the creative forces were powerful and that they could, if properly guided, bring about transformation. However, after about ten years or so, they came to see modern society as so tightly controlled that even the creative and progressive forces were probably not causing enough change. ${ }^{429}$ Adorno, who attached great importance to the power of artistic and cultural leaders, first thought that culture and the arts had the creativity and the capacity to transform society gradually. But later he gave up hope. He came to believe that culture had been transformed into another consumer good and that the production of art had been transformed into another industry and became part of the world of modern capitalism. In doing so, the creative core of cultural forces has been evaporated. ${ }^{430}$

Critical theorists emphasize language and discourse. Critical theory accepts this analysis, at least up to a point. Foucault followed Wittgenstein by conceiving of the social world as being fundamentally composed of discourse. The views of the Italian Marxist Antonio Gramsci were closely aligned with those of critical theorists. Gramsci combined the importance of discourse with the Marxist idea that there is conflict and class domination. Gramsci used the term

\footnotetext{
${ }^{427}$ R. COX, "Social Forces, States, and World Orders: Beyond International Relations Theory”. In R. COX, T. J. SINCLAIR, (Dir.), Approaches to World Order, p. 85-123. CSIR. Cambridge University Press, Grande-Bretagne 1981

${ }^{428}$ F. CHERNOFF, op. cit. p. 172

${ }^{429}$ Ibid.

${ }^{430} \mathrm{Ibid}$
} 
"hegemony", popular among Marxists to refer to the winners of the social class struggle and who was able to influence the discourse of society. Hegemonic discourse influences people's ideas and perceptions and has always done so in a way that reaffirms the privileged position of hegemonic forces in society. ${ }^{431}$

According to Gramsci, the framework that emerges from the dominant discourse of a society melts into the "daily consciousness" of masses. It is useful to note how Gramsci emphasized discourse in a more practical way, since he wanted not only to develop a solid theory, but also to bring about social change. Gramsci, argued that a Marxist society was to be created but intended to work in it as envisioned by Marx. Until then, the political successes of socialism had not resulted in popular uprisings in the most advanced industrial societies, as Marx had predicted. One was the result of a coup in Russia and the other was the result of a 20-year-long civil war in agrarian and poor China. The two socialist regimes had maintained power largely by force. Why did socialism appear differently from what Marx predicted and why did it need strength to maintain it? Gramsci considered loyalty and affection from masses of individuals as a key factor. It is this loyalty that should be the basis of the rise of socialism. But this did not happen under the present circumstances of the mid-twentieth century. It was therefore necessary to change the circumstances, and in particular the main loyalties of masses, with regard to the scientific approach. The loyalty of people goes mainly to their families and their countries. Marxists then had to learn to transfer these loyalties to the objectives of human equality and social progress. People had to change their mindset. How could this be accomplished? Gramsci's response was that it would require a change in the dominant discourse of society. Therefore, a fight against this discourse is a necessity. When the appropriate discourse prevails, people will accept the benefits of a more egalitarian social and economic order. Choosing a way of seeing the world is political in nature. ${ }^{432}$

One of the main objectives of theorizing was to bring about human emancipation. Most critical theorists formulate this assertion in one way or another. Gramsci insisted a lot on this. The identification of the postulates of a society is the essential precondition to free oneself from their unjustified or non-critical acceptance. Such an attitude is a form of human emancipation in the sense that it frees individuals from the need to base their actions on reluctant acceptance of these views.

${ }^{431}$ Ibid. p. 173
${ }^{432}$ Ibid. p. 174 
Contemporary critical theory in International Relations specifies the objectives of a social theory and maintains that any principle must receive the consent of all the individuals to whom it claims to apply. ${ }^{433}$ When one standard loses its legitimacy, another must replace it. Critics say this step is resolved by applying Habermas' notion of "ethics of speech", which, is universal and has moral content because it embodies democratic values. The ethics of discourse, in turn, depend on Habermas' theory of communication action. ${ }^{434}$ Critical theory in international relations theory then has the obligation to work for a more democratic world in which individuals participate in the authority of the institutions which concern them. One of the most important contemporary critical theorists in International Relations is Andrew Linklater. According to him, the important thing in the application of critical theory to International Relations is that it tells us that knowledge always reflects pre-existing social conditions and interests; greater freedom in the world is possible because it is a mistake to believe that the rules which govern international politics are immutable; some of the weaknesses of Marxism can be overcome by applying critical learning ideas that help create an emancipatory historical sociology and critical theory appreciates social arrangements based on their ability to engage in open dialogue between those with different interests. It envisages new forms of political community. ${ }^{435}$

According to critical theorists, the changes to promote human emancipation include the transcendence of the whole modern international system. Linklater maintains that this is the only way to achieve human emancipation. There have been various claims that, because of globalization, the state system, which is at the center of realistic analysis of world politics, is in decline. States, say observers, lose importance in world affairs because borders have made democracy worldwide insignificant with the development of technology and expansion, and the world capitalist system ends up dominating the international economy because it makes trade freer than ever; he introduced into this system States which had been separated from it for a long time, such as the former communist States of the eastern bloc; it even made it possible to integrate the current communist States, like China and Vietnam. Cultural dominance of Western styles and popular American culture are blurring the differences between societies around the

\footnotetext{
${ }^{433}$ R. DEVETAK, “Postmodernism”, in S. BURCHILL, A. LINKLATER (Ed.), Theories of International Relations, Macmillan, 1996, p. 71

${ }^{434}$ N. RENGGER, "The Boudaries of Conversation. A response to Dallmayr", in Millenium: Journal of International Studies, Vol. 30, ${ }^{\circ}$ 2, pp. 357-364, 2001, p. 98

435 A. LINKLATER, "Citizenship and Sovereignty in the Post-Westphalian State", in European Journal of International Relations $\mathrm{n}^{\circ} 2$, 1996, pp. 77-103; R. COX, Power production, power and world order, New York: Columbia University Press, 1987, M. HOFFMAN, "Critical theory and the inter-paradigm debate", in Millennium Journal of International Studies $\mathrm{n}^{\circ} 16,1987$, pp. 231-49
} 
world. The major role that banks, non-governmental organizations and even terrorist organizations would play would have the effect of making borders less important. ${ }^{436}$

Let us consider these postulates of the critical school of international relations in relation to human security, as a law of nature. Critical theorists of international relations on the epistemological level try to account for the "meaning" of a theory of international relations by questioning the alleged objectivity of rationalist theory. They do not take this objective reality or this established order that realists and liberals account for as truth; they undertake to know it effectively by questioning the data of their observations. They come to the conclusion that the postulates of the rationalist theory of international relations are not proven and rather that they are constructs pursuing well defined goals. Theories are therefore a set of ideal constructions claiming logic purposely to legitimize in so doing, the pursuit of certain specific goals which justify such intellectual endeavors from the start. They therefore come to the conclusion that theories are strategies aimed at precise ends. On this basis, they question the aims of realistic and liberal theories and realize that they have had a negative impact on the human person. Thus they in turn undertake to seek a strategy which will have a happy ending advantageous for the human person, understood in term of emancipation. In doing so, they would tend to focus on the finality without knowing that they are focusing on a final cause in the end. Indeed, how can we work for the emancipation of the human person, instead of any other purpose like enslavement for example, if this end does not correspond or is not in conformity with human nature? It must be thought that it is precisely because emancipation comes from human nature that critical theories seek to find the best means or the best strategy to confirm it. Thus, whether consciously or not, critical theorists admit an objective reality or an ontology of the human person, which therefore becomes the ultimate cause of their intellectual undertaking. Therefore there is no contradiction with the theoretical perspective of human security because this is precisely what it accounts for.

Thus, from the perspective of human security, the interpretative epistemology of critical theory is only possible within the framework of the final order it constitutes, that is to say, in the discovery of the order of natural means for the confirmation of human security. This latter stands, in an essentialist basis, as an objective human nature. Security is therefore the foundation and finality of the human action. Critical theorists do not disagree with this because their normative positioning aims at the emancipation of the human person. Thus the purpose of their reflexive undertaking is aimed at satisfying the interests of the human person. If it is really

\footnotetext{
${ }^{436}$ F. CHERNOFF, op. cit. p. 174
} 
necessary to ensure the emancipation of the human person, it is because this is a reaction to the consequences arising from the ontological elements of rationalism, namely the State and anarchic international society. The focus on these elements can have the consequence that the individual, who represents, for the critical approach, the ontological element par excellence in inter-state relations, can see his concerns taking a secondary place. Only the individual is the objective element of all human endeavor, and thus critical theory is consistent with human security. It must therefore be understood that the interpretive approach can only be a methodology for understanding the best way to achieve this end. However the meaning of this approach which aims here to create or establish itself is different from the postulates of the human security which rather admits a process of discovery of the order of adequate means to ensure the conservation of the individual, ignored by the latter. History becomes a framework for experimentation allowing to test initiatives and learn from their consequences on individual conservation. Thus, since the result should be the same, we must think that the interpretative method for the creation of an international order allowing the emancipation of the human person corresponds to the process of historical experimentation to discovering the order of means necessarily adequate for the preservation of the human person.

\subsubsection{Critical Security studies and law of Human Security}

Critical security studies began to emerge in the 1990s. The Copenhagen School, capitalizing on other critical security studies, noted the need for security studies to diversify their fields (political, economic, social ecological). An essential component of the Copenhagen analysis is that the social production of security is stable enough to be treated objectively. ${ }^{437}$ Buzan and others clearly explained their divergence with much of the field, stating that: "an emerging school of 'critical security studies (CSS) wants to challenge conventional security studies by applying post positivist perspectives, such as critical theory and poststructuralism. Much of its work ... deals with the social construction of security, but CSS mostly has the intent ... of showing that change is possible because things are socially constituted. ... [But the Copenhagen School maintain that],even the socially constituted is often sedimented as structure and becomes so relatively stable as practice that one must do analysis also on the basis that it continues ... in our purposes we are closer to traditional security studies, which at

${ }^{437}$ D. MUTIMER, "Critical Security Studies: A Schismatic History", in A. COLLINS (Ed.), Contemporary Security Studies, Oxford University Press, Oxford: 2007, p. 62, quoted by D. ROBINSON, "Critical Security Studies and the Deconstruction of Realist Hegemony", in Journal of Alternative Perspectives in the Social Sciences, Vol. 2, $\mathrm{n}^{\circ} 2,2010$, p. 850 
its best attempted to grasp security constellations and thereby steer them into benign interactions. This stands in contrast to the "critical" purposes of CSS, which point toward a more wholesale refutation of current power wielders" ${ }^{\prime 438}$.

Another fundamental element of the Copenhagen school, created in particular by Ole Waever, is the idea of "securitization" of political issues. Analysis of the concept of "securitization" from the Copenhagen School emphasizes that national security is often invoked by States to legitimize the use of force or other extraordinary actions, to then mobilize resources and exercise special powers. It would otherwise be unacceptable to national and international audiences. A problem is "securitized" when it is "presented as an existential threat, requiring emergency measures and justifying actions outside the normal bounds of political procedure. ... the actor [claims] a right to handle the issue through extraordinary means, to break the normal political rules of the game e.g., in the form of secrecy, levying taxes or conscription, placing limitations on otherwise inviolable rights, or focusing society's energy and resources on a specific task). (...) it is in this practice that the issue becomes a security issue - not necessarily because a real existential threat exists but because the issue is presented as such a threat." 439

A successful securitization process therefore constitutes first an existential threat, then an emergency intervention, then actions freed from normal social and political rules. Usually, the process of securitization conforms to the particular rhetorical structure in which the problem or challenge is assimilated to the survival of the State, then to the priority of action, because if the problem is not treated at the time it is diagnosed, it could be too late. ${ }^{440}$ Securitization is therefore an "act of speech" in which the realization of the rhetorical process of securitization creates rights, commitments or obligations; and the process is also intersubjective in that the public must accept or tolerate.

The Copenhagen school raises various criticisms within critical security studies, generally focused on the assumptions shared by the realist school. ${ }^{441}$ Wendt points out that the Copenhagen school follows neo-realists by accepting that anarchies have a particular logic without succeeding in deconstructing the interactions within these systems. ${ }^{442} \mathrm{McSweeney}$

\footnotetext{
${ }^{438}$ B. BUZAN, O. WAEVER, J. de WILDE, "Security Analysis", in Security: A New Framework for Analysis, Lynne Rienner, Boulder, 1998, pp34-35; D. ROBINSON, ibid.

${ }^{439}$ Ibid. p. 24

${ }^{440}$ Ibid. p. 26

441 M.C. WILLIAMS, "Words, Images, Enemies: Securitization and International Politics", in International Studies Quarterly, n 47, 2003, p. 512

${ }^{442}$ A. WENDT, Social Theory of International Politics, op. cit. p. 21
} 
criticizes them for portraying identity as an objective social reality to be discovered, rather than as a continually negotiated process shaped by social forces. ${ }^{443}$ While Johan Eriksson argues that security itself is a social construct and points out that by calling for an enlargement of the areas to be considered as security, the Copenhagen School could in fact widen the scope of the problems that can be secured. ${ }^{444}$

Another consistent approach to Critical Security Studies has been recognized in what is called the "Welsh School". Ken Booth and his colleagues built their approach around elements of Marxism, Gramscism and post-Marxist critical theory, with a particular fondness for the Frankfurt School of Thought and theorist Jurgen Habermas. ${ }^{445}$ At the heart of the Welsh school thinking is the concept of "emancipation". According to these authors, research is a form of political practice with normative elements, emancipation should be the primary objective of studies on security. The father of this concept is Max Horkheimer. According to him, the goal of critical theory is the happiness of all individuals. ${ }^{446}$ And this happiness is possible through the concept of emancipation which would correspond to a social state without exploitation or oppression, in which there really exists a subject larger than the individual, that is to say humanity conscious of itself" 447 .

Critical theorists demonstrate that even if they agreed with rationalist theoretical premises, they could not take the State as the reference object of security. The State, which according to the social pact should be the means of ensuring the security of the individual, has become the end. Indeed, the end of the social contract, which was to correspond to the common conservation or defense of the contractors, seems to have been replaced by the security of the State to the detriment of the security of the citizens, used as a means to ensure that of the 'State. Positing the State as the benchmark of security is, according to Ken Booth, completely "illogical", since it amounts to privileging the security of the means rather than that of the end. ${ }^{448}$ Thus, the Welsh School's research aims to denaturalize the dominant discourse on security and to study the possibilities of social transformation. ${ }^{449}$ In this context, "emancipation" means liberating

\footnotetext{
${ }^{443}$ S. SMITH, "The Contested Concept of Security", in K. BOOTH (Ed.), Critical Security Studies and World Politics, Lynne Rienner, Boulder, 2005, p. 35

${ }^{444}$ S. SMITH, "The Contested Concept of Security", ibid. p. 36

${ }^{445}$ D. MUTIMER, "op. cit.

${ }^{446}$ L. FERRY, A. RENAUT dans Max Horkeimer: Théorie Critique (Essais), Horkheimer, Coll. "Critique de la politique", Paris, Éd. Payot, 1978, p. 19

${ }^{447}$ Ibid. p. 20

${ }^{448}$ K. BOOTH, "Security and Emancipation", in Review of International Studies, Vol. 17, n 4, 1991, p. 320

${ }^{449}$ E. STAMNES, "Critical Security Studies and the United Nations Preventive Deployment in Macedonia", in International Peacekeeping, Vol. 11, $\mathrm{n}^{\circ}$ 1, Spring 2004, pp. 162-164
} 
individuals from war and the threat of war, poverty, low education, political oppression, etc. ${ }^{450}$ For Booth, the concept of emancipation should be given priority over power and order, which are the responsibility of others, and true stable security can only be achieved by individuals and groups if it is not to deprive others. ${ }^{451}$

Steve Smith notes that the normative element of the Welsh School draws criticism from those who advocate "objectivity", but affirms that in reality, there is no neutral place to pronounce on the meaning of the concept of security, all definitions being theoretical. All definitions reflect normative commitments. ${ }^{452}$

Finally, it is questionable whether the framework of critical security studies can really be applied to real events. While this field is still in its infancy, analyzes are starting to be produced on the basis of these ideas. Eli Stamnes shows how critical security studies can shed light on United Nations operations. ${ }^{453}$ Paul Williams who argues that critical security studies help reveal the real beneficiaries of South African economic policies and stresses the need for a constructive transformation of South African society. ${ }^{454}$

Thus, from Buzan's call to broaden the definition of security in the 1980s, critical security studies have become a diverse field that challenges all aspects of thinking about security and the functioning of the international system. Within these studies, Copenhagen and Welsh School of thought have so far succeeded in developing coherent and influential approaches, although diversity and the self-critical nature of the field as a whole constitute its strength. The idea of expanding "security" seems to be gaining acceptance in International Relations and the concepts of security and emancipation are starting to be used in real-world analyzes. Although connected to critical Security studies, the emerging field of human security is considered superfluous, because these studies can already state their ideas and some researchers remain "wary of human security as hegemonic discourse co-opted by the State"455. In general, the influence of critical security studies in international relations remains limited today, but the growing awareness and popularity of the paradigm augurs well for the future of critical thinking and hopefully of humanity.

\footnotetext{
450 K. BOOTH, op. cit. p. 319

${ }^{451}$ Ibid.

${ }^{452}$ S. SMITH, op cit. 28

${ }^{453}$ E. TAMNES, op cit. p. 177

${ }^{454}$ M.C. WILLIAMS, op cit. p.82

${ }^{455}$ E. NEWMAN, "Critical Human Security Studies”, in Review of International Studies, n 36, 2010, p.77
} 
Thus, the concept of security in the context of the critical approach to international relations is diverse. From a human security perspective, we will consider these approaches. As far as the Copenhagen School is concerned, security can only come within the framework of the historical process of experimentation for the discovery of natural means aiming at confirming the state of human security. Indeed, to conceive security as a construction and as a process of communication allows the governing authorities to draw attention to the threats which undermine society and to gain support to manage them. Such an identification of threats can be permanent or changing depending on the management teams, in particular their visions, their social projects, their strategies, etc. Normally, this enterprise can only have as purpose the conservation of human beings members of political society. Thus, security normally comes under the governmental order and this one will have consequences which will account for whether it belongs or not to the order of natural means necessary for the conservation.

As far as the Welsh School is concerned, it makes the individual the main point of reference for security and thus vows to its emancipation. The State is seen in this perspective as a philosophical abstraction. Based on this, human security finds its meaning in the sense of the Critical School. According to the postulates of human security, as a law of nature, the human being is the element without which one cannot speak of a political society and therefore security only has meaning in reference to it. Emancipation of the human being is certainly the general concept which one can be another or include in the meaning of "human security" in the critical approach of international relations. Emancipation is understood simply as "the happiness of individuals". This fits well with the simple understanding of security that is freedom of pain or well-being. However, the essentialist conception of human security that we develop in this context is not shared by critical researchers, who think that no theory is objective and that there can be no laws governing human behavior. This is perhaps the missing element in this theory, which is slow to receive enough attention in international relations so as to underclass rationalism, which postulates the existence of such objective laws. Yet the ontological element is an infallible and unmistakable objective starting point. By constantly looking for the best way to achieve emancipation of the human being, they are in fact trying to discover the best way to achieve the final cause that they admit implicitly. That need to be clarified again. For, why looking for realizing emancipation of the human being without considering it as a certain necessity, that is, it corresponds to the real state of the human person? Necessity is about objectivity and therefore is an element to account for a natural law. If in reality it is necessary to work for the happiness of the individual, it is because actually, this one is a being of 
happiness, he is itself only being happy, and this state is precisely what we call "security" or a non-ill-being state or simply a state of well-being corresponding to the intrinsic nature of the human being. Critical theorists would therefore not be far from liberals, who postulate that there is a natural law characterizing the human person and at the service of which political organization, whether internal or international, is responsible for conforming. Although critical theorists believe that there is no immutable law or state of affairs applying to human conduct, they cannot accept a state of permanent human suffering, but given their assertive normative position of the emancipation of human being, they would rejoice if international society manages to experience a state of international human security. So will they try to make it go away? One has to answer no, because their only task would be to try to maintain this state of affairs or situation. It must therefore be concluded that if one state of affairs is preferable to another in a logic of nonexistence of an objective law characterizing the behaviour of individuals, that one is supposed corresponding to the normal state of things. Now what is normal refers to a conformity to a norm, to an order, to a law. Critical theorists thus admit an objective meta-law which they too seek to confirm: the security of the human being.

Admitting this is then to think that the process for achieving the security of the human being, which in the critical perspective, is "emancipation", also falls within the framework of the historical process of experimentation for the discovery of the order of natural means necessary aiming at the conservation of individuals. When critical theorists question themselves to understand the international social reality, they are in fact trying to restore order in the thought or reasoning to reach objective conclusions. Thus they would capitalize on the knowledge which leads to or is likely to lead to a positive consequence for the finality of human emancipation. It is in this logic that their criticism of rationalism is accentuated by the fact that the results of its materialization in international affairs are often negative for the human being. Thus, ultimately, critical theories, like constructivism in the family of reflexive theories, also conform, at varying degrees, to human security, as a law of nature. 


\section{CONCLUSION OF CHAPTER V}

In this chapter, we have studied human security, as a law of nature, at the heart of the theory of international relations, which is understood as belonging to a set of ideas or ideologies of international law. The purpose was to verify that each of them has human security as foundation and finality. So we started with the rationalist approaches, postulating the existence of objective laws governing international relations. With regard to realism, we noted that its aim is the satisfaction of the human security interests of a group of people who have constituted themselves into political society or State, by any means, including those who would harm other groups of individuals constituted also into political societies. It is a question of unilateralism in the satisfaction of human security. Even if realists can be brought to cooperate, the main concern is unilateral satisfaction. Such an option would not be chosen if it should not lead to results. Liberals also see international relations as aiming at satisfying the human security interests of individuals who are constitute themselves into political societies, but in a way that does not harm the security interests of other political societies. Liberals then promote cooperation developed through regimes which undertake to unite States around common values, allowing them to conduct peaceful relations. So the difference between realism and liberalism is in the means used to achieve human security. They both remain subject to the historical process of experimentation for the discovery of the natural order necessary for the conservation of each individual constituting the political societies which in turn constitute international society. We then turned to reflexive theories which admit no existence of law or objective reality which would govern State behaviour or to which States are imperatively bound. According to the constructivists, international relations are in permanent construction because they are the product of a constant interaction between the various actors of international society. State values and preferences are in perpetual definition, so that an unchanging reality cannot be possible. On this basis constructivism corresponded to the historical process of experimentation for the discovery of the order of natural means necessary for the confirmation of human security. The step-by-step results of identities, values and initiatives put in place by international actors are only significant in that they allow us to progressively understand the meaning and the adequate means for the satisfaction of human security. As far as critical theories are concerned, it has been noted that their critical nature with regard to rationalist theories and their proven normative positioning was, under the understanding of the emancipation of the human being, only aiming at satisfying international human security. This theory, despite its postulates which may seem very distant from those of human security, is nevertheless the one which seems to come closest 
to it. It basically admits, albeit unacknowledged, many elements of human security. So based on the postulates of the theoretical framework of human security, we can conclude that it is at the heart of all the theories of international relations. The fate of these theories can also be read on the basis of the historical methodology which allows us to know that they are on the way to finally recognize each other around this common denominator. This analysis was very important in this context since it allowed us to consider at the same time the theories of international relations as the set of postulates and ideas grounding international law. This one being both the instrument and the product of international relations, we can know that it is doomed to materialize these theories. So it already appears at this stage as the (positive) law of human security. Before knowing it in depth, a necessary clarification is prior: the way through which human security, as it emerges from the theoretical framework discovered, stands as the foundation and finality of international relations or of international society, by unifying the juststudied theories. 


\section{CHAPTER VI: HUMAN SECURITY AS LAW OF NATURE OF INTERNATIONAL SOCIETY}

Human security as law of nature of international society is the direct consequence of human security as law of nature of national political society. In this framework we will set out to check it. International society can be understood as the space made up of national political societies characterized by the relationships they maintain with one another, in pursuit of a set of interests defined either individually or collectively. Bull and Watson apprehend international society as "a group of states (or, more generally, a group of independent political communities) which not merely form a system, in the sense that the behaviour of each is a necessary factor in the calculations of the others, but also have established by dialogue and consent common rules and institutions for the conduct of their relations, and recognize their common interest in maintaining these arrangements" 456 The concept of "international society" highlights "the social" in the international: States behave under the influence of the rules and institutions which guide their behaviors, at the same time, these States exert an influence on the way in which these rules and institutions are shaped, following the example of individuals in society. ${ }^{457}$ "Thus, the international is socialized, in the sense that states should not be seen simply as blackboxes, rationally seeking survival; rather, the socialization - which refers to the relationship between states - is what guides behavior" ${ }^{\prime 45}$ Based on these definitions, it appears that international society is the product of States sustaining a more or less interested interaction. Based on the theoretical perspective of human security, we will check that this one stands as the foundation and the purpose of international society. This is the meaning to which human security refers as the law of nature of international society. Thus we will check it by considering in turn human security as the finite (1) and final (2) order of international society.

\footnotetext{
${ }^{456}$ H. BULL, A. WATSON, The expansion of international society, Clarendon Press, Oxford, 1984, p. 1

${ }^{457}$ B. BUZAN, An introduction to the English school of international relations: the societal approach, John Wiley \& Sons, Cambridge, 2014, p. 13

${ }^{458}$ A. F. MIQUELASI, "International Relations and the Concept of "International Society": Understanding the Relevance of the English School", RICRI, Vol. 4, n 8, p. 106
} 


\section{HUMAN SECURITY: FINITE ORDER OF INTERNATIONAL SOCIETY}

Human security as the finite order of international society is its first constant, as foundation and finality of international society. As a law of nature, the finite order refers to the fact that it is no longer a matter of this order to be created or to be made, since already real. The verification of this is based on the simple and consistent observation that the individual (1.1) and national political societies (1.2) are respectively the primary and secondary ontological units of international society.

\subsection{The individual: primary ontological unit of the International Society}

Human security stands as the finite order of international society in that international society being basically a society of individuals (1.1.1.), the law of nature of the human consequently becomes the law of nature of international society (1.1.2.).

\subsubsection{International society: a society of individuals}

An essentialist conception of international society reveals us that its most basic unit is the individual. Indeed, let us remember that according to the scientific essentialism of Brian Ellis, only dispositional or intrinsic properties account for the reality of a thing. It is a set of informational quotients without which such a thing could not be what it is or behave the way it does. The methodology of essentialism is positivist and generally consists of observation. On this basis, observation of what is called "international society" gives us to see that individuals are the ontological element. This is so true that without individuals there can be no such a society. It should even be said that the individual is the only central thing that is observable, because in fact, if we always recognize that international society is made up of national political societies, we cannot in reality see these ones. Only individuals are observable. Thus it is the individuals who make or constitute themselves into a political society, which in essentialist perspective, has the sense of a contract. Thus, national political society is only an intangible entity, having existence only in the minds of individuals, hence its qualification of "legal person". Consequently, international society can be considered as an entity made up of intangible entities and therefore as an intangible meta entity which exist, not in States, since an idea cannot maintain and sustain ideas, but in the individuals who maintain and sustain the idea of national political society. In a word, international society is just an idea that cannot make 
sense outside of the individuals who maintain and sustain it. Thus it is the individuals who constitute themselves into States, constitute themselves into international society. This confirms the essentialist postulate that without essence there is nothing. So it is the essence that is or does or constitutes the thing. Thus international society primarily exists only by being a society of individuals.

A simple hypothesis allows us to realize this evidence. Let us imagine that no individual exists anymore! The consequence would be that no State would anymore exist, since no individual would exist to consent to constitute himself into it with others. No individual would have and sustain an idea of the State, or show agreement about it. Since there would then be no agreement called "State", there can be no super agreement called "international society". National society is therefore an idea framework for inter-individual relations and, consequently, international society is an idea framework for inter-inter- individual relations.

These developments should not be considered as evading the entire structural, organizational system formalized by state or interstate activity, it is just a matter of making the system transparent in all its elements to detect the most fundamental or essential, its impulse center, the element that does or constitutes it and without which it would not exist. By so doing, we can see that the individual is the essential element both of the national and the international system.

In the field of social ontology, many theories undertake to unveil the mystery of the social world by characterizing a non-social "basis of determination": that is to say a domain of non-social entities which determines exhaustively the social. Some have argued that the relationship between the social and the non-social is strong: for example, it is asserted that social entities are reducible to a particular set of non-social entities. Others make weaker assertions, such as the set of social properties that arise globally on a set of non-social properties. ${ }^{459}$

One of these theories, psychologism, is the view that social facts are made up exclusively of the psychological states of individuals. This is the opinion advanced by Mill ${ }^{460}$ and endorsed by future theorists of "social mentality" such as Tarde. ${ }^{461}$ Most historical versions of psychologism are "internists" in the sense that they view the content of mental states as dependent only on what is in a person's head. Psychologism is a postulate relating to ontology.

${ }^{459}$ B. EPSTEIN, "Social Ontology", in Stanford Encyclopedia of Philosophy, (Summer 2018, Edition), E. N. ZALTA (Ed.), 21 march 2018, https://plato.stanford.edu/archives/sum2018/entry/social-ontology/

${ }^{460}$ J. STUART MILL, A System of Logic, Ratiocinative and Inductive, John W. Parker, London, 1843

${ }^{461}$ G. TARDE, Les Lois Sociales: Esquisse d'une sociologie, F. Alcan, Paris, 1898 ; G. TARDE, L'opinion de la foule, F. Alcan, Paris, 1901 
It is consistent with the idea that psychological states are caused by non-psychological factors. An individual's belief that the wind is blowing is caused in part by the wind. But his psychological state, according to internists, is in his brain or other internal states, and does not understand the wind. According to psychologism, the social world is determined exclusively by these internal psychological states. ${ }^{462}$ Versions of psychologism differ in terms of the psychological states on which a given social entity or fact is determined or depends. Many theories of group attitudes assert that beliefs, intentions and other attitudes of a given group depend only on the attitudes of the members of that group. ${ }^{463}$

Psychological theories also differ with regard to the psychological states which determine social entities or facts. Theories of group attitudes argue that group attitudes are determined not only by psychological states in general, but also by the particular attitudes of members. Finally, psychological theories differ as to the social entities determined by psychological states. Theories of group attitudes, for example, limit their claims to group attitudes only. Other points of view, such as those of Mill and Popper, ${ }^{464}$ propose that psychological states exhaustively determine social facts in general. ${ }^{465}$

Psychologism can be used to check that international society is a society of individuals in that only the psychological state of individuals predisposes them to form a society. The rational component of human nature makes him a thinking being and it is generally on reason he determines his action. Only individuals can consent to an agreement or maintain an idea of national society and international society only based on their experiences or for a very specific purpose. Therefore they do so only by psychic states dictated by logic or utility.

Another aspect of social ontology is atomism. Social atomism (or atomistic individualism) assert that the social world is built from individuals understood as isolated "atoms". As Taylor ${ }^{466}$ points out, the term "atomism" is mainly used by his critics. Therefore, its characterization often depends on its usefulness. But, typically, atomism is a combination of two claims: the vision that society is built exclusively from individuals and that individuals are somehow isolated from each other, instead of being interdependent. ${ }^{467}$ The atomism is taken

\footnotetext{
462 B. EPSTEIN, op. cit.

${ }^{463}$ R. TUOMELA, K. MILLER, “We-Intentions”, in Philosophical Studies, Vol. 53, n³, 1988, pp. 367-389; M. E. BRATMAN, "Shared Intention”, in Ethics, Vol. 104, n¹, 1993, pp. 97-113

464 J. S. MILL, op. cit. ; K. POPPER, The Open Society and its Enemies, Routledge and Kegan Paul, London, 1945

${ }^{465}$ B. EPSTEIN, op. cit.

466 Ch. TAYLOR, “Atomism”, in Philosophy and the Human Sciences: Philosophical Papers, Cambridge University Press, Cambridge, 1985, pp. 187-210,

${ }^{467}$ B. EPSTEIN, op. cit.
} 
literally by the theories which apply the methods of statistical physics to society. The idea is to model societies as large aggregates, just as liquids and gases are aggregates of molecules or colonies of ants. Historical examples are Quetelet ${ }^{468}$ and Spencer ${ }^{469}$. The simplest of these models assumes that individual interactions are governed by deterministic rules and that a society or a market is an aggregate of these interacting individuals. Certain theories are accused of being atomistic in the sense that they treat individuals as isolated beings and not in interaction. Neoclassical economic theory is sometimes challenged on this basis; others point out that even in basic neoclassical models, relationships between individuals are integrated into markets, prices and other characteristics ${ }^{470}$

Although atomism can be the subject of a negative appreciation, the fact remains that with regard to international society, the individual can be considered as the atom, since it turns out to be the most basic element of it. Although atomism is generally used to account for atom in isolation, the reality is that no atom works separately without interacting with others. A single individual cannot be incorporated on his own, since at least two or three people are needed if we take the example of the primordial society or family. It is several individuals who agree to constitute themselves in and sustain the idea of a national political society and international society. Thus, if the interaction between atoms cannot deny atomistic ontologism, the interindividual social or national interaction and the inter-inter-individual social or international interaction cannot deny the individual as the ontological unit both of national society and international society.

Theorists in several fields have turned away from mentalist analysis of the building blocks of the social. Psychologism presupposes that the social sciences are sciences of the "spirit" or the "psyche" of society. However, social sciences study not only social thoughts, but also actions. This suggests a different and broader basis of determination for the social, that is, a larger set of blocks from which the social world is built. After all, actions are not the same as thoughts or behaviors, but involve the world. ${ }^{471}$ Even behaviorism ${ }^{472}$ rejects the idea that the social is constructed from internal psychological states. Instead, it argues that only human behavior observable from the outside can form the basis of a scientific inquiry into the psychological and

\footnotetext{
${ }^{468}$ A. QUETELET, Du système social et des lois qui le régissent, Guillaumin, Paris, 1848

${ }^{469}$ H. SPENCER, The Principles of Sociology, Appleton, New York, 1895

${ }^{470}$ P. A. SAMUELSON, "Modern Economic Realities and Individualism", in J. E. STIGLITZ (Ed.), The Collected Scientific Papers of Paul A. Samuelson, Vol. 2, MIT Press, Cambridge, MA, 1966, pp. 1407-1418; K.J. ARROW, "Methodological Individualism and Social Knowledge", in The American Economic Review, Vol. 84, n², 1994, pp. 1-9

${ }^{471}$ B. EPSTEIN, op. cit.

472 B.F. SKINNER, Science and Human Behavior, Macmillan, New York, 1953
} 
social sciences. Behaviorism, however, is more like psychologism than it leaves it: it replaces internal states of mind with outflows of the mind in behavior and takes the social as determined exhaustively by these outflows or behaviors. ${ }^{473}$

It should be noted that no action can arise from or be directed outside without coming from inside the individual. But no matter what object we focus on, the inside or the outside of individuals, it should be noted that it is always a matter of individuals. As far as international society is concerned, individuals are the ones who think and who take action to materialize a national political society and consequently an international political society.

All these elements therefore allow us to know that international society is basically a society of individuals. This basically entails that the law of nature of the human becomes consequently the law of nature of international society.

\subsubsection{Law of human nature: Law of nature of international society:}

As individuals consent to constitute themselves and sustain political and international society, it goes without saying that the law of nature of the human becomes that which governs these legal entities. Human security precisely standing as that law of nature, it becomes the law of nature of international society.

Human security as a finite order of human nature has been accounted for as the real state of this nature, one which accounts for its harmonious functioning. Based on an essentialist approach, we have noted that this state arises from an intrinsic property of this nature, so that without it, this nature would no longer be itself. So human nature is itself only in security. It is about a perfect existent which does not realize itself any more but is called to be confirmed in what it already is in reality. As international society is essentially a society of individuals, the law governing the nature of the latter becomes consequently the law of nature essentially governing the legal entities they constitute. What is particularly important to note in this context is that human security embodies the order of human nature shared by all individuals. There is only one human nature whose security characterizes the harmony in its double dimension of physical and rational, in spite of all the peculiarities that human beings can present, in particular race, age level, gender, culture, etc. Seeing therefore individuals to see human nature, a national or an international political society into which they constitute themselves is then a society of

${ }^{473}$ G. GRAHAM, «Behaviorism », The Stanford Encyclopedia of Philosophy (Spring 2019 Edition), E. N. ZALTA, https://plato.stanford.edu/archives/spr2019/entries/behaviorism/ 
(human) nature. Now if the latter has security as its law of nature, then international society as far as it is concerned has human security as its law of nature, that is, its foundation and finality. Any conception of international society as an entity independent of individuals and the law of nature governing human nature is fundamentally lacking. Seeing it as an interstate space made up of standards and institutions is certainly a reality that cannot be denied, but it is necessary to remain focused on its essence. Since these institutions do not exist outside the human nature encompassing all individuals, the law governing human nature is necessarily that which essentially governs them. Since this is a true law of nature, it assumes all the characteristics of metaphysical necessity, ideality, structure and scientific objectivity.

A metaphysical proposition is a unique form of proposition. It should be distinguished from empirical or factual statements, which if true, are contingent. Metaphysical propositions, if they are true, are not contingent but necessary. The fact is that metaphysical truth does not show as a fact but as a principle, that which applies to all real or possible facts. Such a principle is a universal correlation of the fact. ${ }^{474}$ In this sense, "The metaphysical necessity, being a feature common to all factual possibilities, is categorical or non-hypothetical. This means it is illustrated by any and every fact. For though facts may each have incompatible alternatives, and in this sense be restrictive (that is, selective) of possibilities, facts are in no way restrictive of the universal correlates of fact. Hence, no matter which facts they are, the facts will exhibit those correlates. It follows that metaphysical principles are essentially positive, that they identify features, meanings, or characters which, while present in every actuality, yet exclude no conceivable entity or state of affairs. Hartshorne states: "Metaphysical truths may be described as such that no experience can contradict them, but also such that any experience must illustrate them" ${ }^{\prime 47}$

Human security as the law of nature of international society obeys metaphysical necessity in the simple sense that without an individual, international society cannot exist as a legal entity, or even possibly continue to be otherwise. Since security necessarily accounts for the order of human nature, in that it is consubstantial with it and that based on that, this nature cannot be or continue to be what it is without its essential state of security, this consequently becomes the law of nature of the legal entity into which several individuals agree to constitute themselves. If it happens that international society is considered to be governed otherwise than by the law

\footnotetext{
${ }^{474}$ J. B. Cobb, Jr., F. I. GAMWELL (Eds.), Existence and Actuality: Conversations with Charles Hartshorne, University of Chicago Press, Chicago and London, 1984, Material prepared for Religion Online by Ted and Winnie Brock, http://www.religion-online.org/cgi-bin/relsearchd.dll/showchapter?chapter_id=1895 475 Ibid.
} 
of human nature which is its fundamental ontology, it would then be devoid of ontology and if it is so devoid, it would simply no longer exist, since the individuals who is this very ontology would no longer be. But if it exists, it necessarily exists governed by the law of its ontology which is accounted for by human security.

With regard to the second requirement of idealization, the authentic laws of nature seem only to describe the behavior of ideal kinds of things or things in their ideal circumstances. The new essentialism makes proposals of this kind possible. Indeed, "it enables us to give a good account of the abstractness, or ideality, of many laws of nature, because the essential properties of things are necessarily to be found among their intrinsic properties, and the intrinsic properties of things are just those of its properties that it has independently of its causal relations to other things. Therefore, in order to describe the essential properties of anything, it is necessary to abstract from any external forces that may be acting upon it to say how it would be or behave in the absence of such forces" ${ }^{\prime 46}$. Considering human security as law of nature of international society, we realize that the idealization requirement is met there. Human security as a law of nature of international society accounts for the most ideal state of affairs in relation to this entity. In recognizing individuals as the ontological units of international society, its fundamental reality or its ideal state of affairs cannot be other than that which governs these ontological units. Human nature has as its law of nature human security which is the most ideal state of the ontological unity represented by individuals who constitute themselves into international society. Thus international society being ideally a society of human nature, human security which governs this nature is then ideally the law of international society.

With regard to the requirement of objectivity of a law of nature, let us recall that it means that the laws of nature should be discover and therefore be or describe a reality which exists independently. ${ }^{477}$ Human security as the law of nature of international society, effectively describes a reality that exists independently. First of all, individuals are the primary subjects of international society. Without them, no international society is even thinkable because it is in fact individual who essentially sustain this thought or this agreement. Secondly, security is the state consubstantial with human nature, it is the law of this nature so that it is in itself only in this state. Human security is therefore a perfect existent because it is the intrinsic reality of human nature, which exists objectively and transcends all individual particularities. These all

\footnotetext{
${ }^{476}$ B. ELLIS, op. cit. 101

477 Ibid.
} 
sum up to the intrinsic common denominator of the state of security. Thus human security is the objective law of nature of international society, and accounts for the identity of this entity. With regard to the requirement of structure, an adequate theory of the laws of nature should be able to explain the different categories of laws of nature and the hierarchy within each category. ${ }^{478}$ As far as international society is concerned, human nature occupies the most superior ontological structure. So human security accounting for the law of this nature consequently accounts at the highest level for the law of nature of international society. Before all other laws that could possibly govern international society, human security holds the pole position and therefore, as in any hierarchy, governs all other laws which can come at the lower level. No other possible and secondary law of international society can therefore be valid only in accordance with human security.

Human security is therefore checked as the law of nature of international society. Because it is primarily a society of individuals, and thus the law of nature governing them and which is the objective law of human nature encompasses them all, this law consequently becomes the law of the entity they constitute themselves into and they sustain which is international society. That said, there is no matter to deny the significant participation of national political societies or States.

\subsection{National Political Society as the secondary ontological unit of international society}

The adjective "international" reflects that international society is a society or an entity of nations or States. Thus international society becomes a society of societies or an entity of entities (1.2.1) and consequently, the law which governs them, governs the international society (1.2.2).

\subsubsection{International society: a society of states}

International society has States as a secondary ontological unit. States have been identified as groups of individuals located within the boundaries of a specific territory under the rule of a government. Individuals, on the basis of a natural need for cohabitation, agree to constitute themselves into States. States are secondary ontological units of international society in that they are organized groups of individuals. They are legal persons in that they are ideally

\footnotetext{
${ }^{478}$ Ibid. p. 100
} 
sustained by individuals for organizational purposes. The nature of the State as a legal person accounts for the secondary rank of the ontological unit that it constitutes for international society. National political society is then a precise political organization. It is the set of organizations of this nature that constitute what can be considered to be the "international organization" called "international" society".

An observation of international practice shows us that States are the major players in international policy and therefore the major components of it. International society is an interstate society. This fact is most abundantly demonstrated by intergovernmental activities or relations, which in many ways has contributed to spreading the idea of a pre-eminence of States over individuals in international affairs. States, through their representatives, are therefore considered to be at the center of international relations. All the individuals having constituted themselves into States and being unable to sustain direct relations between them can only act through their representatives or governments.

Government, broadly defined, means the organization, structure, system, political system and forms of exercise of power of a State; in the narrow sense, the body that holds executive power. The term government therefore has two distinct but overlapping meanings. In its organic sense, the government is one of the institutions provided for by the constitution of the State, the one to which executive power is vested. In a broader functional approach, government can be understood as the exercise of political power, the regime of a country, its foundation and the functioning of its institutions. It is then a question of characterizing and classifying the forms of political power, that is to say of normative power, of command and constraint, over society taken collectively and over the governed taken individually. The concept of government includes the fact of governing and the institutional and personal modalities of this activity. Government as organ has a fraction of political power, it exercises a state function among others, and is placed at the top of the State alongside other institutions such as Parliament."To govern" means "to handle the rudder".

Groups of individuals who have thus made up for the purpose of organizing their relationships, or States, and act through their representatives in relationships with other groups of individuals. International society can thus be considered as this space made up of organized groups of individuals, sustaining relationships through their representatives or governments. According to Bull, "the starting point of international relations is the existence of states, or independent political communities, each of which possesses a government and asserts sovereignty in relation to a particular portion of the earth's surface and a particular segment of the human 
population". ${ }^{479}$ Similarly, according to Robert Gilpin, "the state is the principal actor in that the nature of the state and the pattern of relations among states are the most important determinants of the character of international relations at any given moment" ${ }^{\prime 80}$. International practice still justifies this reality in that diplomats and political leaders embody in their negotiations and decisions, the States they represent.

International society is then made up of State subjects. They are secondary ontological units of international society. These political human groupings formed by individuals, for the purpose of normalizing their relationships, maintain relationships with each other through their representatives. The space constituting these groupings is indeed international society. The relationships that governments can maintain with each other suffices to account for the fact that without them no international society could exist. It is in reality, this plurality of political societies which accounts for this entity, because a single political human grouping would not be enough to create an international society; there would indeed be no interstate or other States with which relations could be sustained. Thus, the law of nature of (domestic) political society is that which governs international society.

\subsubsection{Law of international society: law of the national political society or State}

Political society has been recognized as made up and sustained by individuals whose law of nature is human security. Thus the law of nature of national political society or State, that is its foundation and finality, was discovered and verified as being human security. Consequently, the law of nature of international political society, which integrates all national political societies so as to constitute a super entity, is itself human security.

At a micro level, national political society, as part of the theoretical framework of human security, has an instrumental nature. At a macro level, becoming the ontological unit of a larger entity which is international political society, the law of nature which governs it seems fundamental with regard to this super entity. So we can still understand that international society is often seen as obeying the state logic. As the State takes the appearance of a finite order at this level, international society is in turn apprehended as obeying this finite order. If the understanding of it, however, is not distinct from the finite order in which it participates, namely human security, it would then be necessary to start by knowing that national society has human

\footnotetext{
${ }^{479}$ H. BULL, The Anarchical Society, Macmillan, London: 1977, p. 8

${ }^{480}$ R. GILPIN, War and Change in World Politics, Cambridge University Press, Cambridge, 1981, p. 18
} 
security as its foundation and as its finality. All actions undertaken on behalf of the State are dictated by (human) security. If the denominator or the common factor of all States is therefore (human) security, this one is consequently the foundation and the finality of the general entity which includes them all. We can then easily draw it as follows:

IS being International Society and $\mathrm{S}$ being State,

$\mathbf{I S}=\mathrm{Sa}+\mathrm{Sb}+\mathrm{Sc}+\mathrm{Sn}$

Since Human Security (HS) is the law of nature of each State:

$\mathrm{IS}=(\mathrm{HS}) \mathrm{Sa}+(\mathbf{H S}) \mathrm{Sb}+(\mathbf{H S}) \mathrm{Sc}+(\mathrm{HS}) \mathrm{Sn}$

Putting HS into factor, then human security is the law of nature of the international society:

IS $=$ HS $(S(a+b+c+n)$

The State being a group or an association of individuals who have agreed to constitute themselves in this way to assure everyone's security, the security of the State understood as the security of this group or association of individuals could seem confusing. Indeed, if we conceive this as the security of the association or the group, it no longer refers exactly to the security of individuals since the emphasis would be on association. This is generally how security is understood in relation to the State in international relations, when it is emphasized that the State is the major or main actor of international relations. Now if the security of the association or group of individuals is directly understood as the security of individuals or of each individual, this becomes truer because security only has meaning for each individual who accepts or consents to constitute or to associate with others to confirm the law of its nature. So state security has it sense only in the security of every individual who is essentially considered as part of that agreement it embodies.

Consequently, international society is an association of associations of individuals whose purpose is to satisfy the security of each of them. The law of nature of political society then extends internationally and becomes the law of nature of international society. The most important in this context is to perceive these consequences or these extensions by scale. Indeed, starting from the individual, we have an increasingly higher scale and when we start from international society, the scale is more and more reduced. However, it is always the same configuration, like a geometric figure whose scale is more or less reduced depending on the practical needs of representation or understanding. Thus the scale of representation, 
understanding and confirmation of the law of human nature that is human security is individual, national and international.

That said, in the second place, as secondary and necessary ontological unit of international society, the fundamental necessity for State to be secure as a means at the service of human security then becomes a fundamental necessity of international society, as a meta-means.

Indeed, we have noted that individuals, in an essentialist perspective, can be considered as consenting to constitute themselves into a political society to confirm their intrinsic law. This entity which they maintain and sustain in idea is materialized by a set of objective and subjective elements which serve to achieve the purpose for which they are thus made up. Perhaps the most objective element is the territory of the State which is the space in which individuals live. Among the subjective elements we can note public institutions which symbolize the order by and in which individuals conserve themselves. These institutions are subjective in that they are not the same for all national political societies. If the State, as a means, serves a goal of confirming an existential tendency of individuals, it is clear that this means can effectively fulfill it only if it is secure, that is to say, in its objective and subjective elements, it is free from vices or disturbances likely to negatively affect its ability to fulfill the mission for which it is basically instituted. At the international level, one of the major objectives of the State that has always been recognized is the security of the State. This is understandable with regard to the major instrument that it constitutes for individuals. Ensuring the security of borders means ensuring the security of the place where people live, where they are housed, from which they are withdrawing the resources necessary for their conservation in general. In the case of an event or a danger threatening the State or damaging its performance, it is clear that the immediate consequence would no longer be the conservation of individuals. Thus, we can say that security is inscribed in this entity which individuals have consented for and which they maintain with regard to the obvious utility it provides to them. With the example of a house which assures one of the most crucial utility for an individual, the need for its security is very proven in that if it happens to be damaged, the consequence is harmful for the an individual whose conservation could become difficult from that. Thus ensuring the security of the means assures the security of the individual and thus enables him conservation. Therefore we can see in what sense the security of the means is necessary for the security of the finality. The security of the means could not exist for itself or for its own purpose because that would no longer make sense since its vocation is essentially utilitarian. Its security only makes sense for the purpose it serves to satisfy. So, the law of nature of the international society's primary ontological unit 
being human security, and the necessity of State security, as a means, entails consequently the necessity of international society security, as a means at the service of human security

From the dual point of view of the primary (individual) and secondary (State) ontological units, the law of nature of international society is indeed human security. This law is human security since the primary final cause of international society is the security of the human nature shared by each individual who, for this purpose, agrees and sustain with others a national political society or State and afterward this latter sustain with other, through representatives, international society. The necessity of state security, due to its instrumental nature must itself be secure in order to adequately serve the end for which it is sustained by individuals. The secondary final cause of international society is then the security of the state means, which in turn makes it assume an instrumental nature which itself requires that it be secure in order to adequately serve the objective for which it is consented and maintained by States, through their representatives. This is indeed the prelude to the final order of international society that human security stands for.

\section{HUMAN SECURITY: FINAL ORDER OF INTERNATIONAL SOCIETY}

Human security as the final order of international society is the second component of human security, as law of nature of international society. Indeed, we were able to note that human security as a finite order no longer implied realization this intrinsic state is not anymore to be created or be made, since already real. Now because of the animate nature of Man this intrinsic state of affairs need to be confirmed as it is in view of its vocation to permanence. This is the sense of the final order embodied by human security. So it's not enough to just be a human being, it's enough to be in security. The final order implies an order of means of confirmation of the finite order. International society does indeed belong to the order of means in that it arises from a natural necessity (2.1), the proper confirmation of which necessarily involves the historical process of experimentation (2.2).

\subsection{Human security and instrumental necessity of international society}

International society happens to be a necessity in the natural equation for confirming human security, as a law of nature. It should be clarified here that international society only has meaning in the relationships that exist between States. If these one were living in autarky, then, there would be no society whose meaning well indicates an agreement between the actors who 
agree to associate. However, the association still has a goal for which it is made. In this case we say that the ultimate reason for which States would collaborate is the confirmation of the human intrinsic state of security. Their agreement can only have the meaning of being an instrument at the service of individual conservation. To this end, globalization is a phenomenon characteristic of international society (2.1.1.) because it allows the appropriation of the resources necessary for this conservation (2.1.2.).

\subsubsection{Globalization: a characteristic phenomenon of international society with the objective of human security}

Globalization can be understood through the following definitions: "Globalization can thus be defined as the intensification of worldwide social relations which link distant localities in such a way that local happenings are shaped by events occurring many miles away and vice versa." 481 "The concept of globalization reflects the sense of an immense enlargement of world communication, as well as of the horizon of a world market, both of which seem far more tangible and immediate than in earlier stages of modernity" 482 . "Globalization may be thought of as a process (or set of processes) which embodies a transformation in the spatial organization of social relations and transactions - assessed in terms of their extensity, intensity, velocity and impact - generating transcontinental or interregional flows and networks of activity, interaction, and the exercise of power." 483 "Globalization as a concept refers both to the compression of the world and the intensification of consciousness of the world as a whole ${ }^{\text {"484 }}$. Globalization has also basically been understood as compressing the time and space aspects of social relations. ${ }^{485}$

Based on these definitions, the phenomenon of globalization can be considered to be distinguished by four distinct qualities. ${ }^{486}$ First, globalization involves the creation of new and the multiplication of existing social networks and activities which increasingly overcome traditional, political, cultural and geographic boundaries. ${ }^{487}$ Second, globalization is reflected

\footnotetext{
${ }^{481}$ A. GIDDENS, The Consequences of Modernity, Polity Press, 1990, p. 64

${ }^{482}$ F. JAMESON, M. MIYOSHI (Eds.), The Cultures of Globalization, Duke University Press, 1998, p. xi

483 D. HELD, A. MCGREW, D. GOLDBLATT, J. PERRATON (Eds.), Global Transformations, Stanford University Press, 1999, p. 16

${ }^{484}$ R. ROBERTSON, Globalization: Social Theory and Global Culture, Sage Publications, London, 1992, p. 8

485 J. H. MITTELMAN (Ed.), Globalization, Critical Reflections, Lynne Rienner, 1996

${ }^{486}$ M. B. STEGER, Globalization. A Very Short Introduction, Oxford University Press, p. 9

${ }^{487}$ Ibid. p. 11
} 
in the expansion and extension of social relationships, activities and interdependencies. Third, globalization implies intensification and acceleration of social exchanges and activities, which means that local events are caused by events occurring far away and vice versa. In other words, the antagonistic processes of globalization and localization imply each other in fact: the local and the global form the ends of a spatial continuum whose central portion is marked by the national and the regional. ${ }^{488}$ Fourth, the creation and expansion of interconnections and interdependencies does not only happen at an objective material level. Indeed, the processes of globalization also involve the subjective plane of human consciousness. Thus, it should be noted that globalization also refers to people becoming more and more aware of the growing manifestations of social interdependence and the enormous acceleration of social interactions. Their awareness of the large retreat of geographic boundaries and distances encourages a strong sense of being part of a whole. Maintained on a daily basis, these persistent experiences of global interdependence gradually change peoples' individuals and collective identities and thus dramatically impact the way in which they act in the world. ${ }^{489}$ Based on all of these definitions, "Globalization refers to a multidimensional set of social processes that create, multiply, stretch, and intensify worldwide social interdependencies and exchanges while at the same time fostering in people a growing awareness of deepening connections between the local and the distant ${ }^{490}$.

We can therefore say that emergence of the discourse on globalization marked in itself an intensification of globalization as a social, economic, political and cultural process. ${ }^{491}$ Globalization refers to both the compression of the world and the intensification of the world as a unit. ${ }^{492}$ This apprehension takes into account both the empirical aspect, that is to say, the compression of the whole world into a single and global system, as well as the conceptual ideas about the ways by which the world as a unit should be represented in broad sociological terms. ${ }^{493}$ Globalization is then a process of compression of space and time rooted in the flexibility of the new forms of capitalism. ${ }^{494}$ In addition, globalization is also understood as complex connectivity in that it refers to a rapidly developing and constantly densifying network

\footnotetext{
${ }^{488}$ Ibid. pp. 11-12

${ }^{489}$ Ibid. p. 12

${ }^{490}$ Ibid. p. 13

${ }^{491}$ TURNER, KHONDKER, Globalization, East and West, Chapter 2: Conceptualizing Globalization, December 2009, p. 21

${ }^{492}$ ROBERTSON, op. cit. quoted by TURNER, KHONDKER, ibid.

${ }^{493}$ TURNER, KHONDKER, Ibid. p. 22

${ }^{494}$ Ibid.
} 
of interconnections and interdependencies that characterizes modern social life. ${ }^{495}$ Without being exhaustive, globalization still means a growing attention from the world because it informs about a social process in which the constraints of geography on cultural and social arrangements decrease and in which people become more and more aware that these are decreasing. ${ }^{496}$

The phenomenon of globalization accelerated when culture itself was considered an industry. ${ }^{497}$ In fact, cultures have always been in contact and in exchange with one another. But a completely new historical situation appeared from the moment when the successive industrial revolutions endowed the so-called developed countries with machines to manufacture cultural products and cultural means of great power, allowing them then to spread all over the world, the elements of their own culture. 498 "So globalization is not in itself a novelty. And like its predecessors, the one we live in today has a profound impact on human beings by modifying their identity, their work, their community, their family, their values, their life and consumption styles, their culture, etc. Like its predecessors, today's globalization is based on a technological revolution: yesterday the industrial revolution, the steam engine, today information technology. But precisely, because of the specificity of these new tools for processing information and communication, the globalization that we are experiencing is distinguished by four characteristics: its extent, its progression, its speed, sometimes even the simultaneity of exchanges and finally the aspiration of civil society to be listened to and heard"499

Globalization therefore suffices to witness international society as a space allowing multidimensional interaction for the satisfaction of the security of the individual groups constituting themselves into national political societies. Interaction is only justified for the confirmation of human security, because it is fundamentally instrumental. This is the goal that individuals aim at when they interact with others either personally or through their

\footnotetext{
495 Ibid.

496 Ibid.

${ }^{497}$ J.P. WARNIER, La mondialisation de la culture, La Découverte, Paris, 1999, p. 15

498 Ibid.

499 “Donc, la mondialisation n'est pas en elle-même une nouveauté. Et comme ses devancières, celle que nous vivons aujourd'hui impacte profondément les êtres humains en modifiant leur identité, leur travail, leur communauté, leur famille, leurs valeurs, leurs modes de vie et de consommation, leur culture, etc. Comme ses devancières, la mondialisation d'aujourd'hui s'appuie sur une révolution technologique : hier la révolution industrielle, la machine à vapeur, aujourd'hui les technologies de l'information. Mais précisément, à cause de la spécificité de ces nouveaux outils de traitement de l'information et de la communication, la mondialisation que nous vivons se distingue par quatre caractères : son étendue, sa progression, sa rapidité, parfois même la simultanéité des échanges et enfin l'aspiration de la société civile à être écoutée et entendue", in Ch. BOUTIN, De la mondialisation à l'universalisation: une ambition sociale, Rapport intermédiaire au Président de la République, decembre 2010, p. 14
} 
representatives. Globalization, as a characteristic phenomenon of international society, is of the order of a natural necessity that exists far beyond the divisionist logic of the world that Men sustain. Meeting the needs of groups of individuals depending on other groups of individuals reflects the unity of nature whose resources are necessary for the conservation of human nature.

\subsubsection{Globalization: A phenomenon of acquisition of the resources necessary for individual conservation}

Nature has subjected individuals to conservation based on its resources. However, an important fact is that Men have divided this nature into territorial areas "belonging" to different human groups that settle there and from which they withdraw the resources necessary for their survival. However, another fact is also essential: insufficiency, inexistence, depending on the case, of the resources necessary for the conservation of groups of individuals who have constituted themselves into political societies and the location of these ones within boundaries of another group of individuals. The natural tendency of the human person being the perpetuation or the permanence in its intrinsic state of security and not in its extinction, the necessary attitude is that which consists for these groups of individuals, through their representatives, to try to appropriate the resources they need. International society then becomes this space for interaction sustained by national political societies for individual conservation.

The resource necessary for a State can therefore be located within the borders of another State. This resource, due to its conservation purpose, then becomes very important for external actors who would do everything in their power to acquire it or secure its acquisition. This resource, as we know, can be of diverse nature due to cultural elements and depending on national priorities. Thus, it can be a resource of a political, economic, religious, personal nature, which can itself serve as a means for satisfying or securing other resources or values ultimately intended to conservation. One of the fundamental reasons of international society is the answer to this logic according to which the good of each one is in the hands of the other. International relations are then the means that allows each organized group of individuals to ensure that this good is available to them. These translates as we have seen the phenomenon of "globalization".

Globalization is therefore a phenomenon which accounts for the process of defining and acquiring the resources-means necessary for individual conservation. It allows the connection of places, which in turn promotes the circulation of things and people and finally the discovery of growing interests in things and people. We therefore find ourselves in a situation where the circulation of resources allows the discovery or renewal or updating of the resource package of 
values. Globalization therefore accounts for a phenomenon of necessary relations between human societies for the acquisition of resources for the ultimate purpose of confirming human security. In reality, these relationships stems from a purely utilitarian attitude of governments and individuals.

The resource of economic nature is undoubtedly one of the most important which grounds international relations in a utilitarian logic. The economic resource is undoubtedly that which allows the acquisition of material means capable of satisfying the needs corresponding to the physical nature of Men. First, the lack of full availability of resources in the national territorial space obliges national societies to sustain relations with others. One author confirms this about natural resources: "Oil, gas and minerals are vital natural resources that meet crucial human needs. Whether for transportation, for heating, or for everyday goods and services, these resources constitute essential raw material inputs. Modern civilization would struggle to survive without readily available access to these resources at reasonable and affordable prices. It is for this reason that oil, gas and a large number of other minerals are considered to be "strategic" resources, critical for national and global well-being and prosperity. The fact that, generally speaking, there are well-functioning and sophisticated markets for these resources, and that they are usually available at prices which are affordable (at least for the developed world), reflects the fact that cooperation exists between a variety of actors - states, companies and communities - and at local, national, regional and international levels". 500

The cultural resource is also of great importance in the phenomenon of globalization. Its acquisition or simply its contact for the purpose of conservation of human nature justifies an increasingly growing interaction with time. The cultural resource generally refers to knowledge that includes education, languages, arts of all kinds. Their proven need for the physical and spiritual well-being of the human person is a truism. Thus individuals, whether personally or through their representatives, travel the globe from one place to another, either for their acquisition or for their sale. This makes this resource deeply linked to the economic resource. Indeed, Western cultural industries for example are both products and means of the capitalist system dominating the international scene. It must even be said that it is the engine of globalization. Capitalism is a system as much economic as political and social in which economic agents (entrepreneurs), holders of the means of production allow this production to

\footnotetext{
${ }^{500}$ R. DANNREUTHER, "Introduction: The Dynamics of Conflict and Cooperation", in R. DANNREUTHER, W. OSTROWSKI, (Eds.) Global Resources Conflict and Cooperation, Palgrave Macmillan, Hampshire 2013, p. 1
} 
be exchanged on a market, where the transactions are monetary in nature. In fact, beyond its identity, and its activity which consists in producing goods and services, it is the finality of its action which seems to constitute the mark of the capitalist entrepreneur. The market exchange associated with the monetary gain that results from it would explain the production logic of this system. ${ }^{501}$ The market therefore becomes a very important element for the capitalist system because it is necessary to sell goods and services. The national territory alone then proves to be insufficient for this objective and the international market then becomes a necessity. Governments are therefore confronted with the need to find outside means of selling their goods and services, either produced by them or by companies to which they respond, in order to secure the benefits which in the long term allow them to have a greater possibility of satisfying both personal needs, for individual entrepreneurs, and overall national needs for States, through taxes on the activity of individual entrepreneurs. The external market can therefore be considered as a resource-value which makes it possible to acquire the possibilities intended to satisfy the ultimate value of security. In the logic of the capitalist system of profit, that is to say, obtaining profits higher than the costs of investments, the acquisition of the means of production is an obvious imperative. Indeed, the outside can house such means which can be more attractive in terms of abundance, quality and affordable cost possibilities. Then such resources wherever they are located in an international economic system will be targeted. This is the example of natural resources which hold one of the most important places in international relations. No doubt is possible about the sensitive and even critical nature of minerals (oil, gas, gold, diamonds, coltan, etc.) and forestry resources for example in international relations. States are ready to invest all kinds of means to acquire them because the satisfaction of the needs they allow is quite simply undeniable.

The political resource, too, is of obvious importance in international relations to the point that the political system in force abroad can pose a threat to another State. The cold war between liberal and communist political values is a clear example of the importance of this resource. Indeed, political value is that which is found to be essential for the satisfaction of the final value of security. It represents the meta-means which would confirm human nature in its intrinsical state of affairs of human security. The political systems in force within States in an anarchic international environment therefore have a proven content in relation to state security. It is therefore necessary to control it well.

\footnotetext{
${ }^{501}$ Encyclopedia Encarta, Microsoft @ Encarta ® 2009. ㄷ 1993-2008 Microsoft Corporation.
} 


\subsection{Human security and the formulation of international society}

Human security as the final order of international society requires a certain formulation or configuration of this one, which is a good illustration of the order of means which it constitutes. In this context, it is a matter of dwelling on this order of means that international society embodies for the conservation of each individual who has agreed to constitute with others a national political society. We will consider it taking into account the two elements required by the final order of human security, namely liberty or freedom (2.2.1.) and the historical process of experimentation (2.2.2.).

\subsubsection{The formulation of international society and the principle of liberty}

Liberty occupies a crucial place within the theoretical framework of human security. It has been noted both as an ontological attribute of human nature and as a means of confirming it in its general state of affairs. Its aspect of means interests us in this context.

Liberty is a principle of action without external constraint. Individual conservation has been noted to be supported by liberty, itself reflecting human diversity. Conservation cannot therefore be uniform because it is a function of a set of conceptions that men have of their lives and of the adequate way they undertake to live it. Liberty is of the natural human order in that, unlike license (behavior) which refers to disorder and whose ultimate consequence is extinction, it basically admits a regulation whose respect can only confirm the vocation to the permanence of human nature. Since freedom is the intrinsic property of each individual, it can never imply that an individual flout that of the other. If this appears to be the case, it should be credited to the license whose consequences are obvious: they ultimately result in a lack of conservation for its actor. Thus, the attitude included by the order of confirmation is that everyone acts freely without infringing on the freedom of others and bears for him/herself the consequences of his actions to that end.

The recall of this quintessence of the principle of liberty in the conservation of the individual or in the confirmation of the intrinsic state of human security is important in that it is worth on the larger scale of interstate relations, or of international society. From inter-individual relationships of conservation, we move to inter-group of individuals relationships of conservation or inter-inter-individual relationships of conservation. On this scale, the emphasis 
is on the freedom of groups of individuals acting as a single individual, what is called national political society or State.

The freedom of State is understood as the principle of State action for the achievement of its purpose which is the conservation of each individual who is part of it. The characteristic reality of States being their diversity in conceptions of the world, of individual life and in conception of how to preserve the latter, the normal attitude included in the order of their relations is quite simply freedom. The licentious behavior displayed by a State or the representatives of a group of individuals so constituted towards another in the goal of its preservation can only ultimately result in the failure of satisfying it. In this context, the debate described by Thucydides in his History of the Peloponnesian wars ${ }^{502}$ between Athenians and Spartans is revealing.

Indeed, Thucydides (460-411 BC), like other theorists of classical politics, considered politics to involve moral questions. Most importantly, he asked whether relations between States where power is crucial can also be guided by the standards of justice. During the debate in Sparta, Athenians asserted the priority of self-interest over morality. They said that considerations of good and bad never diverted men from the possibilities of enlargement offered by a superior force $^{503}$ The "Melian Dialogue" presents the classic debate between idealist and realist conceptions: can international politics be based on a moral order derived from the principles of justice, or will it always remain the arena of conflicts of national interests and power?

The Melian dialogue clearly illustrates both the rejection of and inclusion of ethical standards in relations between States. This dialogue relates to the events of 416 BC. AD when Athens invades the island of Melos. The Athenian envoys offered the Melians a choice, a destruction or a surrender, and immediately asked them not to go to court, but to think only of their survival. In the words of the envoys, "We both know that the decisions about justice are made in human discussions only when both sides are under equal compulsion, but when one side is stronger, it gets as much as it can, and the weak must accept that. (...) To be under equal compulsion means to be under the force of law, and thus to be subjected to a common law giving authority" ${ }^{\text {504 }}$. As such an authority does not exist over States, Athenians maintained that in the situation of international anarchy, the only right is the right of the strong to dominate the weak.

\footnotetext{
502 G. CAWKWELL, Thucydides and the Peloponnesian War, Routledge, London: 1997

503 THUCYDIDES, History of the Peloponnesian War, trans. Rex Warner, Penguin Books, Harmondsworth, 1972 , Chap. I, p. 76. See also THUCYDIDES, On Justice, Power, and Human Nature: The Essence of Thucydides' History of the Peloponnesian War, Paul Woodruff (Ed. and Trans.), Hackett, Indianapolis, 1993

${ }^{504}$ W. J.KORAB-KARPOWICZ, "How International Relations Theorists Can Benefit by Reading Thucydides," The Monist, Vol. 89, n², 2006, p. 234
} 
They explicitly combine law and force and exclude considerations of justice in foreign affairs. In history, Thucydides shows that power, if not restrained by moderation and a sense of justice, generates the uncontrolled desire for more power. There is no logical limit to the size of an empire. Intoxicated with the prospect of glory and gain, after the conquest of Melos, Athenians waged war against Sicily. They paid no attention to the Melian argument that considerations of justice are useful to everyone in the long run. And, while Athenians overestimated their strength and ended up losing the war, their logic of self-interest turned out to be of very short-range. ${ }^{505}$ The Athenian-Spartan dialogue described by Thucydides interests us in that it highlights the principle of liberty in interstate politics. We can see that Athenians and Spartans were pursuing the goal of security, which however was defined differently according to the liberty of each. For the Athenians, it is a question of enlarging their empire, if necessary by the Spartan territory, which obviously implies many more resources at their disposal, not only for the security of the meta means which is their empire but also in the long term to meet the confirmation requirements of the individuals who make them up. For the Spartans, it is a question of conserving the territorial resource on which they have agreed to make up as a political society, because this certainly is useful to satisfy the conservation needs of each of them. Athenian ambitions pretended to extend beyond their sphere of liberty to encroach on the Spartan sphere. The question of morality that Thucydides raises, refers, from the point of view of the law of human security, to liberty which is part of the ontology of the State by extension or enlargement of the human scale. Since the Athenian behavior aims to encroach on the liberty of the Spartans which includes the sovereign decision of the use of the resource at their disposal, it is thus licentious because abusive. This abuse is evident in the use of force without regard to the rights of others. In the long term, the consequence is that the Athenian Empire ends up falling and therefore no longer satisfying the purpose for which it was maintained and sustained by Athenians, namely their security.

In reality, one must consider the licentious behavior of the State, as a means of its conservation, in relation to the consequences which it implies. It is probable that the natural reaction to an unjust assault be the victim's revenge. If the harmful conduct against others consequently results in the perpetrator's suffering in reaction to the suffering s/he has inflicted, it is doubtful that it will be unpleasant for him. For if such an act entail as a consequence such a reaction, it

\footnotetext{
${ }^{505}$ W. J.KORAB-KARPOWICZ, "How International Relations Theorists Can Benefit by Reading Thucydides," in The Monist, Vol. 89, n², 2006, p. 234
} 
is because the pain suffered is not pleasant and it is necessary to return it to its perpetrator so that $\mathrm{s} /$ he experiences it too, either as a lesson from his/her doing, or for the satisfaction that the victim obtains from revenge. The case of the bombing of Pearl Harbor against the United States by Japan during the Second World War, which gave rise to reprisals for the atomic bombing of Hiroshima and Nagasaki, is obvious. If Japanese had planned such reprisals, it is likely they would have banished the idea of launching the attack Pearl Harbor. Thus since no State desires a licentious behavior against it, none therefore really opposes it on any other. Thus, license does not fall within the natural means that international society constitutes for the confirmation of human security. In this context the myth of the state of nature of Thomas Hobbes is still relevant.

Thomas Hobbes in the Leviathan develops the state of nature on two scales, national and international. At the international level, the state of nature is an extension of the state of nature after is solving at the national level. Indeed, the solution to the state of nature is the social contract by which individuals agree to create civil or political society. The creation of sovereign States has the effect of displacing the state of nature to international society. Since there is no authority imposed on States, anarchy becomes characteristic of international society. In this context of anarchy, States, like at the national level, have the choice between conflict or cooperation for the satisfaction of their conservation purpose. Let us consider this options.

International society has been seen in a simple sense as the interaction between States for the satisfaction of the conservation purposes of the people who make them up. These relations may take place between two or more States or between all States. In either case, the use of conflict cannot fall within the order of means for the conservation of the groups of individuals constituting the States respectively. The conflict has an unintended consequence to the detriment of parties. Just as in a State where Man is a wolf for another, no Man can claim to be secure in the long term. If the State becomes a wolf for another State, the consequence is necessarily the same, no State can really claim to be more powerful than the others, conflict can only lead sooner or later to harmful consequences for the parties. A quick glance through history tells us what havoc conflicts have wreaked on individuals. The two world wars bear evidence of the fact that conflict in interstate interactions does not enter into the order confirming human security on this scale. It should be remembered that cohabitation of individuals is a fact of nature. This one has subjected individuals to cohabit and to draw from it the resources necessary for their conservation. Thus nature being an order in itself the satisfaction of these requirements is governed by an order just as natural whatever the level of human interaction. Now men have divided nature into territorial spaces of sovereignty or States. If the latter naturally fall under 
the order of natural means to confirming human security, international society cannot fall under an order of natural means for this purpose implying the conflict. The purpose of this one is destruction, which is contrary to the purpose of conservation which naturally requires human nature.

On the other hand, cooperation confirms the idea underlying international society. The concept of society refers to agreement, understanding, consensus which must necessarily be given by each party, signifying acceptance for itself of the consequences of this manifestation of their will and freedom. Cooperation makes it possible to achieve peace, to the satisfaction of each party's interests, as long as each wishes to engage in it. Thus the formulation of international society which responds to the final order of human security implies cooperation between the various actors. That said, the proper formulation of this cooperation is subject to the historic process of experimentation which makes it possible to discover the order of natural means necessary for the confirmation of the human security intrinsic state on this scale.

\subsubsection{The discovery of the adequate formulation of international society through the historical process of experimentation}

The final order of human security is not always known and it is often necessary for individuals to go through a process of historical experience which is a process of learning. Indeed, from the consequences of initiatives they implement for their conservation, individuals educate themselves on what is or not accounting for the order of natural means necessary for the confirmation of human security.

The discovery of the proper formulation of international society for the benefit of groups of individuals who constitute themselves into States is a constant in international society. Having seen that human security, as law of nature of international society is no longer to be made or created since it is a finite order, but is to be confirmed, there is indeed an order of means which is the exact formulation of international society. This one, if is not known by States, is discovered or is called to be discovered through experience. In this way, they capitalize on the results of positive initiatives and decide to improve or changes initiatives leading to negative consequences. States are called to work continuously towards the discovery of the best form which structures their relations. The best form of international society, as we know, is that which is cooperative and which leads to beneficial consequences for all States in terms of meeting the conservation needs of each of the individuals making them up. 
This process can be noted in the recent history of international society, in particular the two world wars and their aftermaths. In fact, following the heavy toll of the First World War, the League of Nations was created as a collective security organization in order to ensure international peace. But not really receiving state support, it was unable to prevent the Second World War whose serious consequences led to the creation of the United Nations. From the perspective of human security, as a law of nature it can be noted that the cause of the two world wars was undoubtedly the search for the satisfaction of security needs both state and human. The aim was to secure the state as meta-means, either by strengthening it through an additional territorial acquisition, including that of another State, or by defending it from any external interference. The security of the state means was aiming at the end security of individuals who have decided to gather as a State. The means used were force. The First World War was damaging for States and individuals. States had felt the need to create an international organization with the aim of ensuring the collective security of all States in order to refrain the ways to licentious behaviour of States which had hitherto been so current in inter-State relations. ${ }^{506}$ But States had not deeply shared the idea of the League of Nations, which manifested itself in a reluctance to participate in that organization and to give it all the necessary support. Consequently, States reserved the right to conduct their unilateral actions, preferring trusting the balance of powers. This was not enough, however, to prevent the outbreak of the Second World War which in its turn damaged both individuals and States. These had to resolve to create the United Nations. The main role of this Organization is to ensure collective security based on free adherence of all States. Clearly the United Nations had the same mission as that of the League of Nations, but unlike the latter, States deeply shared its idea and are still supporting it in action. Thus it was not the League of Nations which failed to prevent the Second World War, but States or the groups of individuals so made up, through their representants which, then, had not yet understood that international anarchy did not mean or did not imply a licentious conduct, but necessarily cooperation based on the respect of the principle of freedom of each of them. Their understanding started to manifest through the international organization of the United Nations which they recognized as necessary in view of the natural requirements of coexistence and the use of nature's resources for conservation purposes. This verifies the

\footnotetext{
${ }^{506}$ It is the case of Poland Occupation by Germany which intended to make of it a « lebensraum », event considered as the triggerer of the World War II. Indeed Hitler pretended to the enlargement of the German territory or the German life space. "Lebensraum, in its crudest sense, meant a demand for empty space where Germans could settle. Germany was not over-populated in comparison with most European countries (...) When Hitler lamented: "If only we had a Ukraine (...)," he seemed to suppose that there were no Ukrainians." in TAYLOR, The Origins Of The Second World War, 1961, p. 40
} 
process of historical experimentation necessary for the confirmation of human security, as a law of nature.

States or groups of individuals thus constituted are caught up in a process of education or discovery of the order of means necessary for the confirmation of their intrinsic order through the consequences of initiatives they undertake to this end. Generally those which have had negative consequences are either rejected or called to be improved or changed in expectation of happy consequences, while those which have positive consequences are called to be capitalized or renewed. Thus as the experimentation goes on, the order of natural means necessary for the confirmation of human security ends up being revealed. That which applies on an individual scale, applies on a national scale and still applies on an international scale.

This principle still allows us to note that the United Nations, which embodies international society, although part of the final order of human security, is still subject to the necessary requirement of discovery of its exact formulation for a purpose beneficial to all States and each individual who constitutes each of them. One can therefore immediately note that what is not confirming the law of nature is called to be known unreal and what is confirming it is called to be known real by discovery. Time ultimately reveals all the quintessence of the order of natural means necessary for the confirmation of human security on an international scale. In comparison with the national scale, the human political animality on the international scale has a more cultural than a natural nature, because the groups of individuals who constitute themselves into States do not naturally cooperate with others as in the frame of family which is naturally made up of man, woman and child. They come to know it by the constraints or natural limits of the resources of the only national territory in and for the conservation purpose. Immanuel Kant in his Perpetual Peace Project already envisaged this form of international society which would manage to guarantee peace for all its actors, both States and individuals. The perpetuity mentioned there serves to testify to the reality and the need for a permanence of peace which is well-being or security for everyone. Being for everyone, security is therefore for each individual. The theoretical framework of human security amplified on an international scale allow us to know that States or, better, individuals who made them up will gradually come to discover the quintessence of the best formulation of the international society. 


\section{CONCLUSION OF CHAPTER VI}

Throughout this chapter, we have studied the relationship between human security, as a law of nature and international society. The international society shows as very relevant to human security, as a law of nature, given the rank of its scale in the human political organization. Above all, international society has been viewed as the framework for state interaction for the satisfaction of diverse national and individual interests. Like the State, it is a legal entity, which has meaning or existence only constituted by the States or better by the various groups of individuals constituting and nurturing these ones. It is very much an agreement, an understanding or a consensus. Human security has been checked as the law of nature international society, that is to say, its foundation and finality, in that it constitutes its finite and final order. As a finite order of international society, human security represents its final cause, that is to say, it constitutes its foundation and end. This is true at two levels: the individual and the State. At the individual level, the individual has been viewed as the primary ontological unit of international society. This can be seen in the fact that without individuals to organize or consent to or maintain the State, there would be no representatives through whom the idea of international society would be possible. Looking at international society, only individuals appear to be the reality without which nothing would exist. In an essentialist conception, kind of things being identical, international society having sense only sustained on a slightly larger scale by individuals, who themselves sum up into human nature whose security accounts for the order, human security automatically becomes the law of nature of international society. At the state level, international society has been recognized as having the State as a secondary ontological unit. Although it is immediately instrumental in its international nature, it is often considered to be the major actor in international relations conducted by its representatives. Then the necessity of international society was considered identifiable with that of the State. Since the State exists only maintained by individuals, the law of nature governing them automatically becomes that which governs international society. Thus each State having human security as its final cause, this automatically becomes that of international society. Then we verified that human security constitutes the final order of international society, through the phenomenon of globalization which manifests a multidimensional interaction, connecting both people and goods with the aim of satisfying state and individual interests, the only national territory being largely limited. Thus the acquisition, sale or mobilization of resources of an economic, cultural, political nature for the purposes of human security characterize international society. The question of its formulation then becomes necessary for the unavoidable purpose it pursues. The 
natural order of means necessary for the conservation of each individual constituting each of the States excludes recourse to license and to conflict because their negative consequences are certain, but includes freedom of each State and the cooperation of all. The generality of these means makes the historical process of experimentation necessary for the discovery of their best form. Thus the positive and negative consequences of the initiatives of an international organization gradually specify the quintessence of this order of means until its total discovery. Thus completing the verification of human security, as a law of nature, that is to say, the foundation and finality of international law in idea has prepared us to pursue the same verification for international positive law. 


\section{CHAPTER VII: HUMAN SECURITY AS FOUNDATION AND FINALITY OF INTERNATIONAL CONSTITUTIONAL LAW}

Human security, governing the ideology of international law, implies therefore that it constitutes the foundation and finality of international law, that is to say, the positive rules organizing interstate relations. Thus international law is this body of rules which formalize the ideological choices of States with regard to the conception of their relationships and the best way to satisfy their interests, summing up in human security. That essentially makes international law, the law of human security. Whatever their sources and substance, the ultimate ground and purpose of the positive rules ruling relations between States is essentially to satisfy the conservation interests of the groups of individuals who make them up. The instrumental vocation of international law is then indisputable because it is a means serving a precise purpose, which therefore stands as its ultimate cause. International law with human security as foundation and finality implies that the theoretical framework of this applies to it. This theoretical framework rules the individual, and by scale extension national and international levels. The last two, having a more assertive instrumental vocation, are conditioned by the individual scale. Thus individuals involved in a natural necessity of conservation by means of resources of nature and in coexistence with similar ones are, at increasingly large scales, aware of the naturalness of national society and international society. The consideration of things from the perspective of human security then influences the way of knowing politics and law in general. Just as the national scale implies, in the general sense of politics, a bipartite and hierarchical conception of law in constitution and in government, the international scale consequently implies in the general sense of international politics, a bipartite and hierarchical conception of international law in international constitution and international government. Not being able to study international law in all its different branches and in its different compartments corresponding to all levels of internationality, we will limit ourselves only to what it is worth at the universal level including in a certain unit, all political national societies or States, in its two fundamental constitutive and governmental components.

Human security as foundation and finality of international constitutional law means that human security is the final cause of the positive rules standing as the constitution of international political society. This one cannot exist at the fundamental level, without agreement between its members. And it is precisely this agreement that is worth constitution or international constitutional law. "Politics" signifying "organization", "order", which refer to the concept of 
law, and "society" essentially implying an agreement between parties who make it up, the concepts of "international politics", "international society" and international law can only be synonymous in the sense of an agreement of the parties relating to the organization, the order of their relationships. The substance of this agreement applies within international constitutional law. Having human security as its foundation and finality, it is a set of fundamental rules whose reality is inscribed in and is governed by the theoretical framework of human security. To speak of an international constitution in the national sense might seem somewhat absurd because national society and international society, upon simple observation, are not constituted, or even organized in the same way. Generally, international society is considered anarchic because it is made up of independent and equal sovereign States, and is therefore not subject to any authority imposed on them, as is the case at the national level where a central power has authority over the governed. In a word, at the international level, there are no governors and governed in the domestic sense and then it is difficult to conceive an international constitution in the sense or in the logic of the national society. We will provide elements of response understood as an implication on an international scale of the elements accounting for human security, as a law of nature. So we will start by presenting the current reality of an international constitution in relation to human security, as a law of nature (1), which will allow us to get to the evidence of its trajectory (2).

\section{HUMAN SECURITY AND THE REALITY OF AN INTERNATIONAL CONSTITUTION}

Human security, as a law of nature makes real an international constitution. Despite the current difference in the configuration of national society and international society, it is indeed possible, based on the theoretical framework of human security, to know that international society has a constitution in the meaning of the national constitution (1.1). This constitution through its principle provisions founds the confirmation of human security (1.2).

\subsection{The international constitution from the theoretical framework of human security}

The theoretical framework of human security allows us to know that the international constitution is a reality (1.1.1.), what is further evidenced by the international constitutional theory (1.1.2.). 


\subsubsection{The international constitution from the perspective of the theoretical framework of human security}

Human security, as noted, accounts for the order of human nature as an intrinsic disposition of this one. Security is the state consubstantial with human nature, that which signifies that nature. Human nature being itself only in the state of security, which is thus its law. Since human nature is a reality, and is only reality of this intrinsic dispositional state which is security, it is therefore a question of a perfect existent which is no longer to be made or created, what is known as "finite order", but to be confirmed or conserved according to the very fact of the animate character of this nature, through a set of equally natural means. This is known as "final order". Human security, as the human's law of nature has fulfilled the requirements of a law of nature, which quite simply means a state of affairs, the functioning of a thing, a reality.

That said, the natural, and then unavoidable tendency of human beings is the conservation of their nature in its essential state. They are naturally compelled based on resources of the physical nature and in cohabitation with fellow humans. Thus the confirmation of human security could not be done without nature provided for an order of adequate means, which also no longer is to be created, but to be discovered. In this process, the negative consequences of licentious attitudes teaches that the use of liberty is the starting point of the order of natural means adequate for conservation. The licentious attitude implies the use of all means for individual preservation, including those harming others. Since it does not ultimately result in the conservation of anyone, this means is known unreal. Individuals then recognize the need to use their liberty which implies the use of means which lead to the desired end, those which imply that each one undergoes on his/her behalf the consequences of initiatives s/he has undertaken to preserve himself without interfering in any way with the liberty of others. But since all are called to live together and benefit from the resources of nature, they come to understand that the best use of freedom implies an organization of their relationships, which should lead to the conservation of each. Thus the use of liberty manifests itself in the consent of each one to associate with others to assure each one the resources necessary for conservation. This agreement is precisely worth the political society.

Politics is therefore natural for human beings, its fundamental meaning is that of "organization", to which individuals freely consent for the confirmation of their law of nature, and without which they would all get lost. The organization implying the order, the fundamental agreement it manifests is the very one which constitutes political society. Since it is an organization, the agreement does not only refer to a "yes", but it implies a substance, terms of the organization, 
conditions of order, to which we consent. These refer specifically to the constitution. The very idea of a constitution presupposes, in a realistic context of a high number of participants in the agreement, a fundamental law which would establish bodies responsible for implementing its principles in action for the conservation of everyone. Thus the constitution is the set of basic rules organizing or governing subsequent collective efforts or initiatives for the conservation, essentially considered as agreed by the individuals belonging to a multitude. The fundamental agreement manifested by political society and embodied by constitution therefore necessarily falls within the theoretical framework of human security.

Politics is therefore natural for human beings, its fundamental meaning is that of "organization", to which individuals freely consent for the confirmation of their law of nature, and without which they would all get in trouble. Organization implying order, the fundamental agreement which embodies it is the very one which stands as political society. Since it is an organization, the agreement on it does not only refer to a "yes", but it implies a substance, terms of the organization, conditions of order, to which the consent is given. These ones refer specifically to "Constitution". The very idea of Constitution presupposes, in a realistic context of a high number of participants in the agreement, a fundamental law which would establish bodies or organs which are responsible for implementing its principles and materialize them for individual conservation. Thus the Constitution is the set of basic rules to which each of the individuals belonging to a multitude consents, organizing or governing subsequent collective efforts or initiatives for the conservation of each one. The fundamental agreement as materialized through political society and as embodied through the Constitution therefore necessarily falls within the theoretical framework of human security.

It goes without saying that in the hypothesis that several groups of individuals constitute themselves into several political societies, the configured space is a space made up of national political societies. The national society made up of individuals at the internal scale becomes a super individual or a legal person in presence of others of the same kind. We can know that the territorial concentration of individuals does not always guarantee them the availability of all the resources necessary for their conservation, including both people and goods, which may be located inside the territory of another political society. Acquisition of these resources becomes a necessity because of the necessity of conservation. Nature being one, the fact for political societies compartmentalizing this nature necessarily has a setback that individuals must manage. At this level also arises at the international scale the same behavioral logic that arose 
at the internal one. The constructions of the state of nature from Hobbes and Rousseau are edifying in this framework.

Indeed, the essential solution to the state of nature, where man is a wolf for man, is the social contract or institution of political society. For Hobbes and Rousseau, this event displaces the state of nature from the inter-individual scale, to the political inter-society or inter-state scale, for, in the lack of authority that would impose itself on independent different political societies, anarchy would characterize the space or the behavioral model in force within the interstate space. According to Viau, "According to Hobbes, the nature of Man is wicked and selfish, hence this unrestrained desire among men to appropriate ever more wealth and to expand ever more their power. Consequently, in the absence of Leviathan, at the international level, it would be, according to the realist interpretation, the state of nature which would reign. For Rousseau, the nature of Man is peaceful and fearful. However, he believes that once Man has made society with few Men, he (as a soldier and not as a citizen) decides to attack another. Rousseau believes that the independence that is taken from men, in accordance to the social contract, takes refuge in societies, and these large bodies, working on the basis of their own impulses, produce more terrible shocks to proportions that their masses outweigh those of individuals" ${ }^{\circ 07}$. Unlike man, on whom nature imposes limits of many kinds, the artificial nature of the State makes its expansion possible. According to Rousseau, "[...] it (the State) feels weak as long as there is stronger than it. Its security, its conservation, requires that it be made more powerful than all its neighbors" 508 . So "In summary, whether it is from the perspective of interpretation that contemporary authors have made of the works of Hobbes, where the nature of Man is fundamentally wicked, or whether it is that of Rousseau, according to which the nature of the personified State is essentially insatiable of power and selfish, institution of the State creates the domestic order, but initiates international anarchy"509

\footnotetext{
507 "Pour Hobbes, la nature de l'Homme est méchante et égoïste, d'où ce désir effréné chez les Hommes de s'approprier toujours plus de richesses et d'étendre toujours plus leur pouvoir. Par conséquent, en l'absence de Léviathan, au plan international, ce serait, selon l'interprétation réaliste, l'état de nature qui règnerait. Pour Rousseau, la nature de l'Homme est pacifique et craintive. Cependant, il estime qu'une fois l'Homme ait fait société avec quelques Hommes, il (en tant que soldat et non citoyen) se décide à en attaquer un autre. Rousseau croit que l'indépendance qui est enlevé aux Hommes, conformément au contrat social, se réfugie dans les sociétés, et ces grands corps, livrés à leurs propres impulsions, produisent des chocs plus terribles à proportions que leurs masses l'emportent sur celles des individus", H. VIAU, op. cit. p. 23

508 “[...] il (l'État) se sent faible tant qu'il en est de plus forts que lui. Sa sûreté, sa conservation, demandent qu'il se rende plus puissant que tous ses voisins" in J.-J. ROUSSEAU, "Du contrat social ou principes du droit politique", in Euvre complètes : Du contrat social, écrits politiques, B. GAGNEBIN, M. RAYMOND (Dir.), Éditions Gallimard, Bibliothèque de la Pléiade, Dijon, 1964, p. 604

509 "En résumé, que ce soit dans la perspective de l'interprétation que les auteurs contemporains ont fait des travaux de Hobbes, où la nature de l'Homme est fondamentalement méchante, ou que ce soit celle de Rousseau, selon laquelle la nature de l'État personnifié est essentiellement insatiable de puissance et égoïste, l'institution de
} 
Anarchy remains considered as characterizing contemporary international society. Hobbes and Rousseau represented an inter-state interaction marked by license, that is to say a frame in which States use all the means allowing them to ensure for themselves the acquisition of the resources necessary for their conservation to the detriment of others. Such an attitude, as in the internal scale, ultimately leads to insecurity for everyone because license is a mess that does not guarantee permanent conservation. That is the same regarding the use of violence in interstate relations, as observed in the Melian conflict between Sparta and Athens as described by Thucydides. Thus, from a human security perspective, States end up realizing that the use of state license as a means for conservation of the groups of individuals who make them up does not come under the order of natural means for the confirmation of the law of human security. Since this implies permanence, the means which do not lead to it are sanctioned as inadequate or unreal. Thus, States are educated on the fact that respect for the freedom of other States, which is equivalent to their independence and sovereignty, is a principle which founds conservation in a context of coexistence of States and on the basis of interdependence on human and material resources located in the different territories of each. This state liberty is the basis for international cooperation and each State therefore consents to organize relations with others. It is precisely this interstate agreement that constitutes an international Constitution. Again it is not just a "yes" but the terms of an interstate order or the quintessence of an international organization defined by the different actors and by which they seek to satisfy the conservation interests of groups of individuals who make them up.

From the point of view of human security, as a law pf nature, an international Constitution is in line with the natural means necessary for its confirmation. It is this Constitution that is worth international society or international politics in the universal sense in which we understand it in this context. It includes a set of fundamental principles or rules which are intended to govern and found initiatives to achieve human security for the benefit of all parties. It is imperative to note that this Constitution, although generally a good starting point within this order of means, its adequate formulation remains to be discovered. It is all the more true that this Constitution would exist even if the present international society was not experiencing any organization because the final order of human security is as real as its finite order. It is no longer to be created but to be discovered.

l'État crée l'ordre domestique civil, mais initie l'anarchie internationale", in R. ARON, Paix et Guerre entre les Nations, 8e Ed. Coll. "Liberté de l'esprit", Calman Levy, Paris, 1984, p. 182, cité par H. VIAU, op. cit. p. 25 
An international Constitution, in the sense of the national constitution is therefore a reality from the perspective of human security. This is supported by international constitutional theory.

\subsubsection{An International constitution from the point of view of the international constitutional theory}

The International constitutional theory is understood in this context as analyzes which find that there is an international Constitution. These analyzes relate specifically to the Charter of the United Nations which is considered to presently standing as the international Constitution. Many arguments support this view and after more than sixty years of the United Nations history, the Constitutional predisposition of the Charter has been confirmed and strengthened in such a way that it is legitimate to recognize it as a constitution.

The United Nations Charter was formally established based on an international treaty. ${ }^{510}$ Already at the last plenary session of the San Francisco Conference, the American President Harry Truman compared the Charter to a Constitution and insisted on its character as a living instrument: "The Constitution of my own country came from a Convention which - like this one - was made up of delegates with many different views. Like this Charter, our Constitution came from a free and sometimes bitter exchange of conflicting opinions. When it was adopted, no one regarded it as a perfect document. But it grew and developed and expanded. And upon it there was built a bigger, a better, and a more perfect union. This Charter, like our own Constitution, will be expanded and improved as time goes on. No one claims that it is now a final or a perfect instrument. It has not been poured into a fixed mold. Changing world conditions will require readjustments - but they will be the readjustments of peace and not of war. ${ }^{511}$ In the same vein, the Australian Delegate to the last Assembly of the League of Nations noted that "from the upheavals caused by two world wars has arisen one of the most characteristic creations of the XXth Century: the organization of an international community governed by a written Constitution" ${ }^{\text {"512. }}$. Professor Brierly sees the Charter of the United Nations as the beginning of the international constitutional law. ${ }^{513}$ The First General Councilor and Director of the Legal

\footnotetext{
510 The United Charter was signed on 26 June 1945 at San Francisco and according to its article 110 came into force on 24 October 1945 after the required number of ratification reached. See L. M. GOODRICH, E. HAMBRO, Charter of the United Nations: Commentary and Documents 385, 1946

511 Speech of the President, on 26 June 1945, Documents of the United Nations Conference on International Organization, 1945, United Nations Information Organizations (Eds.), 1945, p. 680

512 Speech of Professor K.H. Bailey, April 1946, in Secrétariat de la Société des Nations (Ed.), L'Héritage de la Société des Nations, Vol. 53, 1946

513 J.L. BRIERLY, The Law of Nations: An Introduction to the International Law of Peace, 6 ${ }^{\text {th }}$ Ed. 1963, (Sir Humphrey Waldock Ed.). p. 95
} 
Department of the United Nations A. Feller named the Charter as the constitutional instrument which governs the organizational structure of the world community: "The Charter is not just a legal text intended to describe with precision the rights and duties of parties like a conveyance or a contract of sale; it is a political document designed to embody statements of ideals, of principles, and of moral sentiment. ... [S] uch is the nature of constitutions, at least of those constitutions which live in the minds of people and are adaptable to growth along with the societies they are intended to govern." 514

More systematically, the doctrinal School lead by Verdross is that of which analyzes have sufficiently reached the conclusion that the Charter of the United Nations stands as an international Constitution. According to Verdross and Simma, the Constitution of the modern community of States resulted from the formation of sovereign territorial States that recognized each other as equal subjects of international law. It was a system of original standards whose validity was assumed by the States themselves as the basis for international law created by them by mutual consent. ${ }^{515}$ According to these authors, "The UN (...) has been founded by a multilateral treaty on the basis of general international law being in force at the time. It redesigned the classical international law of the non-organized community of States, which had returned to life after the breakdown of the League, as the order of the newly organized international community. However, in the beginning the UN Charter was just the constitution of a partial structure (Teilordnung) within the universal system of international law because the UN originally included only fifty-one States. But since almost all States have become members of that organization and the remaining States have recognized its fundamental principles, the UN Charter has gained the rank of the fundamental order of present universal international law (...) General international law as it had hitherto been in force was incorporated into the new universal order". 516

Verdross and Simma used the term "constitution" in a normative sense. The Constitution refers to a set of rules of international law which prevail over other standards as long as their existence is a precondition for the validity of the latter from a logical and legal point of view. ${ }^{517}$ At the same time, the Constitution was defined as a result of history or in other words the result of an agreement between States at a particular time rather than a theoretical construct. In the

\footnotetext{
${ }^{514}$ A. H. FELLER, "Book Review of Hans Kelsen, The Law of the United Nations", Colum. L. Rev. Vol. 51, 1951, pp.537- 538

${ }_{515}$ B. FASSBENDER, The United Nations Charter as the Constitution of the International Community, Legal Aspects of International Organization, Vol. 51, Martinus Nijhoff Publishers, Leiden, Boston 2009, p. 32

${ }^{516}$ Ibid. pp. 32-33

${ }^{517}$ Ibid. p. 33
} 
development of modern international law, this Constitution has become more comprehensive with regard to its geographic sphere of operation and the complexity of its rules. Introduced by limited principles, mainly concerning the creation of international law, this Constitution includes the substantive rules which all States must comply with. When the universality of the United Nations was achieved by the accession of all States, its founding document replaced the substantive Constitution of the unorganized community of States, and for the first time a written text became the Constitution of the world community. ${ }^{518}$ According to Simma, "On the formal side, a constitution enjoys priority over "ordinary" rules; with regard to substance, it lays down the basic rules governing the life of a community. ... If we apply these concepts to the United Nations Charter, it meets most of the criteria just mentioned. ... I have no problems at all with viewing the basic norms of the Charter as the constitutional law of the universal international community, and the Charter organs, at least in practical terms, as organs of the international community of States as a whole". 519

Fassbender reaches the conclusion that the concept of Constitution of the universal community developed by Verdross and Simma oscillates between the general principles of law common to all States allowing them to establish legal relations and to build a legal community and a more great system of primary rules which may be formal or substantive. While, therefore, the theoretical concept is not quite as precise, the eventual result is quite clear: the United Nations Charter is supposed to be the written Constitution of the international community. This opinion was widely shared and Simma confirmed by saying: "in the last few years the view that the UN Charter is a true constitutional instrument of the community of states has gained wide acceptance, 520 .

One of the key elements of the constitutional nature of the United Nations Charter is that it involves a constitutional program. Indeed, a constitution establishes a program that legitimizes the new order that it carries or embodies. "Reading the Charter, in particular its Preamble and Chapter I, in light of this observation, one clearly recognizes the will of its drafters firmly to establish a new world order in which international peace and security would be safeguarded, and friendly relations among Nations be promoted"521. He so confirms the validity of Dieter Grimm's remark about the Constitution of the United States of America for the Charter of the

\footnotetext{
518 Ibid.

519 B. SIMMA, "From Bilateralism to Community Interest in International Law", in Collected Courses of the Hague Academy of International law, Vol. 250, 1994 pp. 217, 260-62

${ }^{520}$ B. SIMMA, Human Rights, in Ch. TOMUSCHAT (Ed.) The United Nations at Age Fifty: A Legal Perspective 263, 270, 1995, cite par FASSBENDER, ibid. p. 34

${ }^{521}$ FASSBENDER, ibid. p. 88
} 
United Nations. "The Declaration of Independence and, therefore, the American Revolution were legitimized by values which would subsequently form the basic principles of a new order expressed in the Constitution. Only through the Constitution as a normative text did the new order assume permanence and acquire a legally valid form" ${ }^{22}$. During the Second World War, in 1941, Roosevelt and Churchill chose the title of "Charter" to characterize the after-war international order. ${ }^{523}$ By the Charter of Atlantic, they intended to highlight common principles on which they would base their hopes for a better future for the world. "The charter proclaimed, in phrases reminding of constitutional instruments, a number of international rights and principles, among them the rule that no territorial changes shall take place 'that do not accord with the freely expressed wishes of the peoples concerned', and 'the right of all peoples to choose the form of government under which they will live'. the two statesmen also declared that they hoped 'to see established a peace which will afford to all nations the means of dwelling in safety within their own boundaries, and which will afford assurance that all the men in all the lands may live out their lives in freedom from fear and want ${ }^{\prime \prime 524}$. These constitutional purposes of the United Nations Charter are confirmed in its Preamble by these introductory words "We Peoples of the United Nations" which are modeled on the preamble to the Constitution of the United States of America. The Charter of the United Nations was established by the peoples of the United Nations through their governments. The Chairman of Commission number 1 of the San Francisco Conference, Mr. Henri Rolin of Belgium alleged that the Charter was "drafted in the name of the peoples of the United Nations and in the name of mankind (au nom des peuples des Nations Unies, au nom de la collectivité humaine)—which is already an indication that we are considering not so much the official states and governments as the human collectivities of the peoples which are forming the bulk of the states" ${ }^{\prime 25}$. So similarly to the national level where individuals are involved in drafting a Constitution, so internationally, States represented by their governments have acceded to the Charter of the United Nations.

All these elements allow us to see that the United Nations Charter is worth international Constitution, exactly as at the national level. The international constitutional theory therefore concludes in the same sense of the theoretical framework of human security. Thus the Charter of United Nations, is at the service of human security.

\footnotetext{
${ }^{522}$ D. GRIMM, “Integration by Constitution”, in International Journal of Constitutional Law, n 3, 2005, pp. 193, 200 et seq. Cité par FASSBENDER, ibid.

${ }^{523}$ L. M. GOODRICH, E. HAMBRO, op. cit. p. 305; R. B. RUSSELL, J. E. MUTHER, A History of the United Nations Charter: The Role of the United States 1940-1945, 1958, p. 975

${ }^{524}$ FASSBENDER, op. cit. p. 89

525 Ibid. p. 93
} 


\subsection{The United Nations Charter at the service of Human Security}

The Charter of the United Nations governs the satisfaction of human security in two specific ways: indirect and direct. It does this indirectly by taking an interest in the States, in which the main role of conservation of individuals is recognized (1.2.1). It does this directly by clearly governing the fate of the individual (1.2.2.).

\subsubsection{The United Nations Charter indirectly at the service of human security}

The United Nations Charter is indirectly at the service of human security through its provisions which protect the State or which highlight its central role in international cooperation. The idea here is to know that human security is guaranteed to be satisfy when the State is protected. It is a question here of dwelling on the security of the State mainly regarded as pledge of the security of the individuals who make it up. If individuals, for the purposes of conservation, have agreed to organize their relationships through the legal entity they materialize by institutions, this must be protected in its stability to be able to achieve its permanent goal. The Union Nations Charter recognizes this need already in its preamble.

The rights of States are condensed in the principles of the United Nations Charter. We distinguish those which enshrines a society of sovereign States and those which founds a peaceful international society. ${ }^{526}$

Among the principles which enshrines a society of sovereign States, we can note the sovereign equality of States, the fulfillment of obligations in good faith, non-interference or nonintervention in the internal affairs of another State.

According to Article 2 (1) of the Charter, "The Organization is based on the principle of the sovereign equality of all its Members". One of the central elements of international law is the principle of the sovereign equality of all members of the United Nations. It asserts that States have equal rights and duties regardless of their factual disparities. This principle implies that States have attributes of external sovereignty. They all have essential characteristics of the State, named a territory, people and an effective government. The principle of sovereign equality finds expression in the fact that each Member State, despite its size, has the right to vote in the General Assembly. The system of organized international relations based on international law would be quickly broken if one of the structural elements of the equality of

\footnotetext{
${ }^{526}$ L. A. ALEDO, Le Droit International Public, Coll. Connaissances du Droit, Dalloz, 2005, p. 50
} 
Article 2 (1) were to be flouted. The principle of sovereign equality is severely tested by the disparities in size and power between different States. ${ }^{527}$ However "this equality necessary for the construction of international law, as the legal spirit can identify it, also appears thanks to its inclusion in the charter, as a principle effectively wanted and accepted by States, which obliges them. This assertion of the legal equality of States does not, however, prevent them from agreeing, in a rather paradoxical way, to confer on some of them a particular legal power. Thus, five States, the United States, the United Kingdom, France, Russia and China, have in their capacity as permanent members of a veto right." $" 528$

How does the principle of sovereign equality of States serve human security? From the point of the theoretical framework of human security, the sovereign equality of States refers to the principle of liberty. Indeed, liberty, the ontological attribute of human nature is also the necessary basis for the confirmation of human security. From this perspective, what is true for an individual is true for a political society. So likewise each individual is free to determine $\mathrm{him} / \mathrm{h}$ erself in the way s/he sees fit him/her and to bear the consequences of this for him/herself without encroaching on the space of freedom of another, what includes equality of this fact between individuals, in the same way, each State is free to determine itself and to pursue its conservation and that of the individuals who make it up without encroaching on the space of the other. The principle of the sovereign equality of States is certainly the pledge of a peaceful international coexistence because freedom implies order and not disorder, the license which signifies the latter and which necessarily entails unfortunate consequences for conservation sought by all is a sign of international insecurity.

There is also the principle of good faith. Article 2 (2) states that: "All Members, in order to ensure to all of them the rights and benefits resulting from membership, shall fulfil in good faith the obligations assumed by them in accordance with the present Charter". The principle of good faith refers to an obligation of behavior on the behalf of States to respect the commitments they make in their relations with other States. "Member States are bound to meet their obligations not only in a legalistic fashion. The spirit of trust and seriousness, which should prevail in the implementation of international commitments together with the principle of

\footnotetext{
${ }^{527}$ F. CEDE, L. SUCHARIPA-BEHRMANN, The United Nations, Law and Practice, Kluwer Law International, pp. $19-20$

528 “ (...) cette égalité nécessaire à la construction du droit international, tel que l'esprit juridique peut l'identifier, apparait aussi grâce à son inclusion dans la charte, comme un principe effectivement voulu et accepté par les Etats, qui les oblige. Cette affirmation d'égalité juridique des Etats n'empêche toutefois pas ces derniers de s'entendre, d'une façon assez paradoxale, pour conférer, à certains d'entre eux, une puissance juridique particulière. Ainsi, cinq Etats, les Etats Unis, le Royaume Uni, la France, la Russie et la Chine, disposent en leur qualité de membre permanent d'un droit de véto". L. A. ALEDO, op. cit. p. 50
} 
justice included in the Charter, constitutes an element of natural law. ${ }^{" 529}$ The Principle of good faith, from the perspective of human security is an implication of the principle of liberty. Indeed, consenting to an obligation is a matter of individual liberty. Liability is only valid if it is based on the subject's freedom. No liability if it results from a constraint. Thus, compliance with freely agreed obligations is a guarantee of security for all. Failure to comply with freely agreed commitments has the effect of violating the right of the party attached to compliance with that commitment. This is precisely the characteristic of the state of nature in the Hobbesian sense that the actor of such a failure triggers in inter-individual relations. Similarly, the failure of good faith on the international level is an international license, which causes or is very likely to cause a licentious reaction from other States; what would characterize the state of international nature. The principle of good faith is therefore essential for human security. It is the corollary of the principle of sovereign equality. Based on the latter, the free consent of a State to fulfill a certain obligation in return of the performance from another of its obligation, for the purposes of conservation; is the pledge of conservation for all. In the end, it is always a question of all States enjoying their freedom in a way that does no harm others. Since the principle of liberty is a principle of order, it is a question of not allowing its liberty to turn into licentious behaviors, what always result in negative consequences. One would understand the importance of this principle by simple hypothesis. Two States A and B decide to conclude a contract whose performance of the various obligations on the behalf of each of them is expected to have positive consequence either for the final conservation of the individuals making each of the States up or for the security of the state institution in itself. The goal of interstate relations is therefore ultimately human security. If this objective is the foundation and the end of state action, then the non-observance of the principle of good faith by one of the States is harmful to the other.

Finally, in the group of principles which enshrine a society of sovereign States, we note the principle of non-interference or non-intervention. Article 2 (7) provides that "Nothing contained in the present Charter shall authorizes the United Nations to intervene in matters which are essentially within the domestic jurisdiction of any State or shall require the Members to submit such matters to settlement under the present Charter; but this principle shall prejudice the application of enforcement measures under Chapter VII'. This principle of non-interference in the internal affairs of a State is addressed to the United Nations itself. However, the principle is generally understood as not only opposing the organs of the United Nations, but also States in their mutual relations. The principle of non-intervention which determines the outer limits of

${ }^{529}$ F. CEDE, L. SUCHARIPA-BEHRMANN, op. cit. pp. 20-21 
the exclusive sphere of national jurisdiction, generally regarded as free from interference by the United Nations, makes it explicitly clear that members are not obliged to submit cases essentially falling within their jurisdiction to the authority of the United Nations. However, according to the last part of this article, the rule of non-intervention cannot restrict collective security initiatives taken under Chapter VII of the Charter of the United Nations. ${ }^{530}$

The principle of non-interference in the domestic affairs of a State is another affirmation or expression of the principle of liberty and is thus the corollary of the sovereign equality of States. Each State being free and independent, none can pretend interfering in the affairs of the other without its consent since none can allow it on itself. It is easy to understand why this principle is at the service of human security. Individuals having freely constituted themselves into a State, for the conservation of each member, they are determined according to their will or by the form in which they freely conceive this structure. Interference with this organization without its consent necessarily creates a disturbance which has harmful consequences for conservation of individuals. It is clear that interference may be positive, but even then it should be consented to by the State facing it. Exception to this principle is still understandable to guarantee peace and human security. In all situations where the management team of a State uses the authority entrusted to it by the individuals who make it up, the Charter of the United Nations recognizes the specific responsibility of the Security Council to act for the benefit of individuals. This exception is a true mark of international solidarity in favor of human security and therefore makes it possible to fully understand the meaning of State sovereignty as having the sole function of satisfying the conservation requirements of individuals. Such an exception could not therefore oppose the sovereign equality of States. From the perspective of human security, of course, it should be seen as a guarantee of the principle of liberty which reasserts that if necessary through collective action when it tends to turn into license, which alone implies disorder and can only result in negatives consequences to the detriment of conservation. It must therefore be said that the interventionist exception of the international community in the domestic affairs of a State certainly falls within the order of natural means adequate for the confirmation of human security.

Among the principles on which a peaceful international society is based, we must begin by noting the peaceful settlement of disputes. According to Article 2 (3), “All Members shall settle their international disputes by peaceful means in such a manner that international peace, security and justice are not endangered". This principle obliges States to resolve disputes in

${ }^{530}$ Ibid. p. 24 
which there is a conflict between legal positions and political interests, exclusively by peaceful means. "The Charter does not prescribe a specific instrument to be used by the parties but let them the choice of means. Peaceful settlement of disputes is not an obligation of results but of behavior. It obliges States to seek in good faith the settlement of their disputes by the means they deem appropriate, without requiring them to actually reach such a settlement." 531 The principle of peaceful settlement of dispute certainly falls within the order of natural means for the confirmation of human security. It involves cooperation, not the use of violence which is certainly harmful to parties. The tragic human toll of the two world wars gives absolutely reason to this principle.

The following principle goes straight towards peaceful settlement of disputes: the non-use of force. Article 2 (4) states that: "All Members shall refrain in their international relations from the threat or use of force against the territorial integrity or political independence of any State, or in any other manner incompatible with the purposes of the United Nations". The prohibition of the use of force can be considered the heart of the Charter. This principle marks the culmination of the efforts which began in the $20^{\text {th }}$ Century to banish war as a means of national policy. "In order to understand the scope and contents of Art. 2 (4) it is advisable to put this principle in the wider context of the UN as a peace organization for a new era of international politics after WWII. The founding fathers of the UN were deeply convinced that after the two world wars international relations had to be reorganized in a radically new way to prevent once and for all similar catastrophes. They conceived the general prohibition to use force as the foremost rule to be observed in interstate relations. As the only exception to this rule, selfdefense is permitted in case of armed attacks (Art. 51). The right to self-defense should be exercised only as long as the system of collective security does not come into effective operation. Respect for the prohibition of the threat or use of force thus constitutes the cornerstone of the UN security system. The collective security system under the main responsibility of the permanent members of the SC can be activated only when this basic rule was breached. In that case the collective security system of the UN is called upon to stop the aggressor and to restore international peace" 532 The two world wars were expressions of the use of force in international relations and the main reason for the creation of the United Nations. From the perspective of human security, we have seen that licentious force certainly does not fall within the order of natural means for the confirmation of human security. So it had to be experienced twice in

\footnotetext{
${ }^{531}$ L. A. ALEDO, op. cit. p. 51

${ }^{532}$ F. CEDE, L. SUCHARIPA-BEHRMANN, op. cit. p. 21
} 
abundance to realize its damaging nature for all and the need to ground international relations on more peaceful principles, what confirms human security. This principle also has as a corollary the sovereign equality of States, which refers to the principle of liberty, in accordance with the theoretical framework of human security. In strict compliance with this ontological attribute, no State can truly use force against another, because none of them can appreciate such a behavior towards it.

The other important principle in this context is the principle of assistance. According to Article 2 (5), "All Members shall give the United Nations every assistance in any action it takes in accordance with the provisions of the present Charter and shall refrain from giving assistance to any State against which the United Nations is taking preventive or enforcement action". This article focuses on assistance in support of measures decided by the Security Council under Chapter VII of the Charter concerning preventive or coercive actions within the framework of the collective security system. "This needs to be stressed since a cursory reading of the first part of Art. 2 (5) may lead to the conclusion that the obligation is so general in nature that it covers each and every action decided by any organ in conformity with the Charter. Secondly, it has to be clarified that the obligation to assist the organization under this article requires the conclusion of agreements in accordance with Art. 43 of the Charter whenever such measures decided by the Security Council comprise military action and the contribution of troops. Since to date such agreements have not been concluded the obligation stated in Art. 2 (5) concerning military action has remained theoretical". ${ }^{53}$ The principle of assistance ensures the proper functioning of the collective security system and effectiveness of the decisions of the Security Council.

Through these principles, the United Nations Charter is at the service of human security, in an indirect way because it governs the rights of the State and inter-State action so that it can satisfy in the end, the conservation requirements of each individual who constitutes each State. That said, it also directly serves human security.

\footnotetext{
${ }^{533}$ Ibid. p. 22
} 


\subsubsection{The United Nations Charter, at the direct service of Human Security}

The United Nations Charter confirms its commitment in favor of human security since its preamble. Let's start by quoting it:

6

\section{WE THE PEOPLES OF THE UNITED NATIONS}

\section{DETERMINED}

to save succeeding generations from the scourge of war, which twice in our lifetime has brought untold sorrow to mankind, and

to reaffirm faith in fundamental human rights, in the dignity and worth of the human person, in the equal rights of men and women and of nations large and small, and

to establish conditions under which justice and respect for the obligations arising from treaties and other sources of international law can be maintained, and

to promote social progress and better standards of life in larger freedom,

\section{AND FOR THESE ENDS}

to practice tolerance and live together in peace with one another as good neighbors, and to unite our strength to maintain international peace and security, and

to ensure, by the acceptance of principles and the institution of methods, that armed force shall not be used, save in the common interest, and

to employ international machinery for the promotion of the economic and social advancement of all peoples,

\section{HAVE RESOLVED TO COMBINE OUR EFFORTS TO ACCOMPLISH THESE AIMS}

Accordingly, our respective Governments, through representatives assembled in the city of San Francisco, who have exhibited their full powers found to be in good and due form, have agreed to the present Charter of the United Nations and do hereby establish an international organization to be known as the United Nations.

We will understand each part of this preamble.

The "peoples of the United Nations" are first of all resolved to "to save succeeding generations from the scourge of war, which twice in our lifetime has brought untold sorrow to mankind". Emphasis here is straightly on the human person and not on the State. Evocation made to succeeding generations for a document which has a universal vocation makes all individuals and therefore each of them, the beneficiary of any action in preservation against the scourge of war. Then mention is made of the human consequences of war. Reference to mankind translates 
human identity or simply human nature. We know that human security is an essential reality of the human being. It gives an account of this nature, objectively and thus independently of all the peculiarities that it may show. Human nature being summed up and signified only in the state of intrinsic security, this first paragraph of the preamble is undoubtedly the testimony of that human security is at the foundation of the United Nations Charter. According to this paragraph, it is humanity which has suffered untold suffering. The sense in which we should apprehend humanity is both individual and collective. Only individuals suffered untold suffering from the two world wars. Although different States suffered damages, individuals found themselves the ultimate recipient of all the suffering since it is them who make political societies up and materialize it by institutions for the conservation of each one. Collective suffering of the human race is conceivable in the sense that this suffering affects the identical essence of individuals. Human security involving permanent confirmation or perpetuity of this nature in this intrinsic state for each individual, a negative result is a common concern. Thus it is to human nature that the two world wars have been prejudicial because of their nonconfirmation of individuals in this intrinsic state which characterizes them all and which is security. It is then obvious that the Charter of United Nations starts by affirming the resolution of this community of individuals to work so that this does not happen again in the future: "At its beginning the preamble recalls the determination of "the peoples of the United Nations" to save succeeding generations from the scourge of war. This reaffirmation couched in pathetic language contains the very essence of the UN peace concept. The words chosen proceed from the proposition that there is a community of peoples congregating under the aegis of the UN. They foreshadow the modern concept of the UN as the organized community of States. Thereby the UN is endowed with a superior degree of legitimacy giving it a unique status in the international community" ${ }^{\prime 534}$.

The Peoples of the United Nations "[then] reaffirm faith in fundamental human rights, in the dignity and worth of the human person, in the equal rights of men and women and of nations large and small'. In this affirmation, two types of actors are highlighted, the human person and political society. It is very clear that the basic human rights, the dignity and the worth of the human person are in accordance with human security. Without doubt, evoking them in this way would at least suggest that if they are in accordance, they cannot be synonymous. The idea of "fundamental human rights" refers to the rights that are at the foundation of Man. Now what is "at the foundation" is of essence, or of the most basic or intrinsic properties or of the most basic

\footnotetext{
${ }^{534}$ F. CEDE, L. SUCHARIPA-BEHRMANN, op. cit. p. 12
} 
constituent of a thing. This is how human security makes sense. The idea of "fundamental human rights" therefore implies two things: the recognition of a (essential) natural reality encompassing all men and the requirement that this be respected, generally by outside agents. Thus, in no way is it allowed harmful interference in this natural reality, but rather a confirmation of it in what it is, and generally in consideration of its natural vocation to permanence. Thus affirming a faith in fundamental human rights in the charter of the United Nations, which is the result of a tragic historical experience, is sufficient evidence of its commitment to human security. "The explicit reference to human rights among the objectives of the United Nations certainly constitutes an important innovative element. It is grounded on the founding fathers' firm belief that the new world order established after WWII ought to be committed to the protection of human rights since the painful experience of the recent past had shown that international peace and security were truly dependent on the respect for the fundamental right of the individual in each and every State. In the meantime this commitment to the protection of the fundamental rights of man has become a legitimate concern of the entire international community" 535 . The concepts of "dignity" and "worth" can be considered as synonymous for they refer to the quality of a thing, which itself refers to the identity of that thing. Thus one can understand the dignity and the worth of a thing only in reference to its identity or its nature. The dignity and worth of the human person can only have meaning in human identity, which is quite simply that nature. The expression of the Charter is in the singular to further translate that there exists beyond all the particularities of the human race, a human identity that includes them all. It is this identity that makes their common denominator which is precisely related to the essence. By studying the characteristics of a law of nature, we noted that it applies uniformly to all members of the kind. As far as human nature is concerned, it sums up at the intrinsic state of security. The dignity and worth of the human person, in the sense of the charter, can only have meaning in human security. The human person is only worthy in this state which accounts for his/her nature. This faith is therefore not blind but naturally and then objectively enlightened.

Reference to equality of men and women is the consequence of liberty, as an ontological attribute of the human being. Its objectivity and identity with regard to men and women necessarily leads to equality. So basically men and women have equal rights. Recognition of this principle is at the service of human security, in that it devotes equal treatment to all objective situations and equitable treatment in consideration of the particularities of each

535 Ibid. p. 12 
gender. This persists at the higher scale of political society. Equality between large and small nations is the corollary of the principle of sovereign equality of States. Basically the State is an organization consented by the individuals who make it up. It is a legal person or an entity which has no existence independently of these ones. By constituting themselves into a political society, individuals can be considered as becoming a single person, which is well implied by the concept of "nation". Individual liberty is then translated on this scale into sovereign liberty or independence of the State. Since all States find themselves in an identical situation as with regard to the ontological attribute of identical liberty for all individuals regardless of their particularities, they therefore all become equal in sovereignty, whatever their size, large or small.

Then, the Charter affirms the resolution of the peoples of the United Nations "to establish conditions under which justice and respect for the obligations arising from treaties and other sources of international law can be maintained". This resolution is full of meaning with regard to human security. A fair international society is only beneficial for all its actors. Justice in this context should be understood in relation to compliance with treaty obligations. Justice basically means giving each one what it is his/hers. Thus a just society is a society where guarantees of conservation are assured for everyone. Based on that freely agreed agreements must be executed in good faith. This is an indicator of order. Because an actor who does not respect freely agreed commitments towards others creates a state of nature or disorder which inevitably has damaging consequences. Thus compliance with obligations arising from treaties and other sources of international law is part of justice in that the performance of the debtor is a right for the other party. Giving each member what it is his/hers then means respecting the freedom of other without any unauthorized interference and respecting the terms of the agreement in case of consent. The consequence of this respect is that it creates a favorable environment for the conservation of the groups of individuals who constitute themselves into States, which would not be achieved in a licentious climate. The two world wars are a clear proof of this. Another complementary interpretation was provided: "According to this paragraph the UN and the international community are to carry out all activities within the framework of international law: Not only the obligations explicitly mentioned must be obeyed but also all other norms of international law referred to in general terms (customary law, general principles of law). In addition to the norms of international law contained in the Dumbarton Oaks proposals the principle of justice, an element derived from natural law, was introduced in the Charter (cf. Preamble, Art. 1(1), Art. 2(3)). The inclusion of the principle of justice into the scope of legal 
obligations may be explained by the founding fathers' vision of the UN to be first and foremost a community of values to be obeyed not only formally in a purely juridical sense"536.

The last resolution in the preamble of the Charter is "to promote social progress and better standards of life in larger freedom". This resolution is very edifying in the sense of the order of means for the confirmation of human security. To work for social progress and the best living conditions is to work for the conservation of all the individuals who constitute each of the States. The idea of progress reflects a social dynamic characterized by a constant effort to evolve or improve the way of meeting conservation requirements. This testifies that men are not always aware of the order of adequate means to preserve themselves either individually or collectively. So the spirit of progress gives meaning to a logic of constant learning or discovery and more beneficial of the best means for this conservation. The idea of "larger freedom" means a greater appropriation or confirmation of this ontological attribute for each one. Complementary and edifying is Alain Pellet's comment on this paragraph: "Paragraph 4 of the preamble, through which the peoples of the United Nations declare their resolve to "promote social progress and better standards of life in larger freedom", does not say anything else: the fundamental rights of man, his freedom, are inseparable from economic and social progress. The search for prosperity and well-being has only one valid finality: man; and reciprocally, poverty, the fear of tomorrow, misery and hunger render the development of the human person illusory. As the right to peace represents the junction of the objectives of preserving peace and international security and the faith proclaimed by the peoples of the UN in the fundamental human rights, the right to development, recognized by the General Assembly as an "inalienable human right", determines the meeting point of this faith and the quest for material well-being"537. Undoubtedly this paragraph further confirms that the United Nations Charter is at the service of human security.

After the resolution on these ends, the Peoples of the Nations are resolved on the means to achieve them.

The first resolution is "to practice tolerance and live together in peace with one another as good neighbors". This resolution confirms that peaceful relations are the only ones which can allow better conservation of individuals constituting themselves into States. Thus they are included in the order of natural means necessary for the confirmation of human security and in

\footnotetext{
${ }^{536}$ Ibid. p. 13

537 J-P. COT, A. PELLET, "What they had in mind, The Preamble to the Charter", in Development: Seeds of Change Village Through Global Order, Journal Of The Society For International Development, Special double issue, vol. $1, \mathrm{n}^{\circ} 2,1986$, p. 25
} 
another way emphasize that conflicting relationships are not included there, because of their harmful consequences for this security and therefore undesirable. The two world wars are blatant evidence of that. "This return to the initial inspiration does not exclude other preoccupations and the search for other ways in which the goals of the UN can be served. After all, the implementation of a collective security, however necessary its eventuality, would be the recognition of a failure: it only works a posteriori, it has only curative virtues, whereas the fundamental philosophy of the Charter is preventive: one must, as it is defined in the first paragraph of the preamble, prevent war, maintain peace. Beyond collective security, the principle of which is outlined in paragraphs 6 and 7, the tolerance and the respect of a spirit of good neighborhood as called for by paragraph 5, carry this promise". 538

The second solution resolved, "to unite (their) strength to maintain international peace and security" highlights the participation of all for the conservation of all. It is a necessary contribution from all members of international society and not a charge for each one alone in its side. This still confirms the consensual nature of international society for the purposes of human security. As we have seen at the national scale, political society is the product of an inter-individual agreement. Each individual, on the basis of a natural condition for cohabitation consents with others in the same way to the organization of their relationships for the conservation of each one. So the cooperation expressed by the union of forces confirms that it is part of the final order of human security.

The other resolution of means is accepting principles and instituting methods guaranteeing that the force will not be used, except for the common interest. "In this sense the Charter does not distinguish itself from the Covenant of 1919. Drawing the lessons from the failure of the Genovese Organization, there is no doubt that the writers of the 1945 text conceived mechanisms which they wanted more precise and realistic, but the basic idea is the same: promote collective security, which finds a terse and precise definition in the seventh paragraph of the preamble. One must ensure the full" acceptance of principles and the institution of methods, that armed force shall not be used, save in the common interest..." The principle of an armed and vigilant peace is thus reproposed; the efficiency of the system depends in fact on the common response to an aggression. The States are not only free to maintain an army, but it is furthermore essential that they accumulate the necessary military means to intervene in case of an aggression or a breach of peace, either by a member State - which should not take place: these powers are, by definition "peace-loving" - or by a non-member State. The parties which

\footnotetext{
${ }^{538}$ Ibid. p. 23
} 
renounce the use of force in their international relations in order to satisfy their egotistic interests, are thus the "secular arm" of the Organization, which is neither a State nor even less a "super-state", but the framework for their cooperation, as it is outlined in particular in chapters VII and VIII of the Charter" ${ }^{\prime 3}$. This resolution enshrines the use of force as a last resort and for the common good. This makes perfect sense in the presence of a deviant State, which, despite the peaceful means which the international community would take, would resort to licentious behavior to the detriment of one or more other States. International society in this hypothesis is supposed to have no other choice than to compel the State whose pretension, from his actions is to restore the state of nature, by which we remember world wars whose consequences are well known.

The latest resolution is to "to employ international machinery for the promotion of the economic and social advancement of all peoples". This resolution emphasizes international cooperation to ensure the well-being of all human groups constituting international society. We can clearly detect at this level a repetition of a resolution of ends. The comment made in favor of human security is therefore valid here.

The preamble of the United Nations Charter is very instructive in that it allows us to see that it has human security as its law, that is to say, its foundation and its end. It distinguishes both the ends and the means which generally corresponds to the finite and final order which is human security. Thus the preamble of the United Nations Charter introduces the charter as having human security as its final cause, that is to say, the subsequent provisions only make sense to serve the purpose for which they are actually enacted: human security. In this sense, the binding legal force of the preamble of the United Nations Charter is therefore obvious. The preamble gives meaning to all the provisions which can appear as the body of the Charter and in which it presents itself as the head. The preamble is the spirit of the text whose body is intended to allow its implementation. Thus it is a beacon which gives meaning to the provisions and which guides their interpretation. We cannot therefore on this basis conceive the preamble as having a simple ornamental worth. Its normative nature is that of governing the provisions of the text. ${ }^{540}$ If it is

\footnotetext{
${ }^{539}$ Ibid.

${ }^{540}$ See other elements of discussion in Z. HAJNAL, "Written and Unwritten Values in the Preamble of the United Nations, Charter - The Axioms of Human Coexistence and Progress", independent paper, 2018, p. 35; O. SPIJKERS, The United Nations, the Evolution of Global Values and International Law, Intersentia Ltd, Cambridge, United Kingdom, 2011; L. ORGAD, “The Preamble in Constitutional Interpretation”, International Journal of Constitutional Law, October, 2010; http://papers.ssrn.com/sol3/papers.cfm?abstract_id=1686745

M. MAKANE MBENGUE, "Preamble", Max Planck Encyclopedia of Public International Law, September 2006, http://opil.ouplaw.com/view/10.1093/law:epil/9780199231690/law-9780199231690e1456?rskey=b9QT73\&result $=29 \& \mathrm{q}=$ contract $\% 20$ interpretation \&prd=EPIl
} 
the preamble which establishes the agreement of the United Nations Charter and which raises the establishment of the United Nations while specifying the ends and means for the latter which are summed up in human security, then the provisions are only in the service of human security. This allows us to see that human security marks a harmony between the spirit (preamble) and the body (provisions) of the United Nations Charter. This one therefore has human security as its foundation and finality.

\section{INTERNATIONAL CONSTITUTIONAL LAW AND THE HISTORICAL PROCESS OF EXPERIMENTATION}

Human security as the foundation and finality of international constitutional law implies that it governs its trajectory. Thus, international constitutional law is involved in the final order of human security, that is to say, it comes within the framework of the natural order of means necessary for its confirmation. The discovery of this one on a larger scale including for their conservation, all the individuals constituting each of the national political societies or States gives an account of the realities of this trajectory. The process of historical experimentation through which such a discovery is possible informs about the real formulation of this body of rules by its positive or negative results. Thus we will verify this by dwelling on the history of two major successive events that have marked international constitutional law, namely the advent of the League of Nations and the United Nations (2.1) and at the experience history of the United Nations (2.2).

\subsection{From the Covenant of the League of Nations to the United Nations Charter}

The history of the consecutive advent of the League of Nations and the United Nations will testify to the fact that human security governs the trajectory of international constitutional law. To do this we will subdivide it into two moments, namely the advent of the League of Nations (2.1.1.) and the advent of the United Nations (2.1.2.).

\subsubsection{The advent of the League of Nations}

The advent of the League of Nations is linked to the First World War. Its death toll was 16 millions of dead. The death rate was amplified by the technological and industrial power of the belligerents. It was one of the deadliest conflicts in history, paving the way for major political changes, including revolutions within several nations involved. ${ }^{541}$ On 11 November 1918, the

\footnotetext{
${ }^{541}$ H.P. WILLMOTT, World War I, Dorling Kindersley, New York, 2003, p. 307
} 
armistice marked the victory of the Allies and a complete defeat of Germany. Although the armistice ended the war, it took 6 months of negotiations at the Paris Peace Conference to reach a peace treaty, namely the Treaty of Versailles.

The Treaty of Versailles itself was based on Wilson's 14 points. ${ }^{542}$ The war had raised serious historical questions as to its causes and why the Allied powers had emerged victorious after the social and economic impact of the war. The most important question, however, was how a similar war could be avoided in the future. Wilson's 14 points were seen as the foundation for world peace and it was hoped that they would establish peace after the war. Wilson's idealism of respect for national borders, freedom and neutrality of the sea and commerce, recognition of micro-nationalities, abolition of secret covenants and treaties and mutual disarmament were greatly appreciated and founded the hope of the international postwar order. France, for its part, had drawn up a draft in which it proposed that annual meetings of the council for the resolution of conflicts, for it would be an international force to ensure the application of decisions. ${ }^{543}$ The final draft from the United States proposed an end to unethical behavior, including forms of espionage and dishonesty, coercive methods towards recalcitrant States were to include measures such as blockade and closing of borders to trade or relations with all or part of the world and the use of force when necessary. ${ }^{544}$ At the Paris Peace Conference in 1919, the final Pact of the League of Nations was drawn up by a special commission and that organization was established by the Part I of the Treaty of Versailles. On 28 June 1919, 44 States signed the convention, 31 of which had taken part in the war alongside the Triple Entente or had joined it during the conflict. ${ }^{545}$

This laconic history of the creation of the League of Nations is very revealing of the fact that the League of Nations was the consequence or the deliberate result of a phenomenon which had negative consequences for human life. Indeed, as a reminder, the world war caused enormous losses in human life and it was the result of certain licentious behaviors of States in their reciprocal relationships. The war was certainly the means by which States pretended or hoped or planned to satisfy the requirements of conservation (in the way they define it) of the human groups which made them up or particular interests of their leaders. Both sides were driven by

542 R.H., FERRELL, Woodrow Wilson and World War I, 1917-1921, Harper \& Row, New York 1985; J-P. MAURY, "Woodrow Wilson, Les 14 points", Dijithèque MJP, 2008, http://mjp.univperp.fr/m/maury.htm

${ }^{543}$ K. J. SCHMIDT. "The League of Nations”, American History, http://www.let.rug.nl/usa/essays/1901-/theleague-of-nations-karl-j-schmidt.php

544 http://www.let.rug.nl/usa/essays/1901-/the-league-of-nations-karl-j-schmidt.php

544 Ibid.

${ }^{545}$ F. GRIMAL, Threats of Force: International Law and Strategy, Routledge, 2013. p 21 
this goal. This means having proved unsuccessful for all the protagonists, they decided to organize their relations with a view to achieving the desired end in a way that can benefit to all. In other words, they decided to change the means. This scenario matches in some way with contractualist philosophies. The state of nature can be considered as the international situation prevailing before and during the war, because it was characterized by licentious behavior for the purpose of conservation. According to the Hobbes situation where Man is a wolf for Man" and which is only regulated by the social contract or the social agreement consented by all individuals, the State before and during the First World War can be regarded as a wolf for another, behavior whose negative consequences led to an international social contract or agreement of international society, through the form of the League of Nations. Human security as a law of nature is therefore in force in this case. The advent of the League of Nations corresponds to the historical process of experimentation or discovery of the order of natural means adequate for the confirmation of the intrinsic state of human security. This is an educational process following the consequences of conservation initiatives. Initiatives with negative consequences are understood as not falling within this order of means, so they must be rejected or improved and those with positive consequences are understood to be part of this order, again according to their level of satisfaction with conservation requirements. The consequences of the First World War certainly made it clear that State license certainly does not fall within the range of natural means necessary for the confirmation of human security on an international scale.

Edifying is the preamble of the League of Nations Pact or what can so be considered:

The high contracting parties,

In order to promote international co-operation and to achieve international peace and security by the acceptance of obligations not to resort to war,

by the prescription of open, just and honourable relations between nations, by the firm establishment of the understandings of international law as the actual rule of conduct among Governments, and

by the maintenance of justice and a scrupulous respect for all treaty obligations in the dealings of organised peoples with one another, Agree to this Covenant of the League of Nations. 
Based on its formulation, the preamble of the League of Nations is strongly emphasized on the State and not expressly on the individual. Nevertheless we can detect a commitment to human security. The second and third paragraphs point this out. The second paragraph, however, is ordered somewhat arbitrarily, perceivable in formulating the means which is normally cooperation, and the end which is normally peace and security, to conclude in the third paragraph that another means (not to use war) is important for this. So for a means (cooperation) and an end (peace and security), a means is necessary (not resorting to war). For more coherence, it should have been reformulated and understood as follows:

In order to achieve international peace and security (end) and [to this end] to promote international co-operation, (means of first order)

[It requires] by the acceptance of obligations, not to resort to war (means of second order),

Thus between the means, there is a hierarchy, between those (secondary) which are at the service of others (primary) for the achievement of the ultimate end. In the spirit of the preamble of the League of Nations Covenant, not to resorting to war is a means enabling to develop cooperation between States, which allows in turn to achieve peace and security of Nations. Human security, being understood primarily as the security of each individual who is part of a nation and secondarily as the security of the elements which materialize the state means, certainly through these paragraphs of the preamble, is the ultimate foundation and finality or the final cause of the League of Nations Covenant.

That said, the historical process of experimentation is not limited to the mere agreement of each individual to form a political society with others. It continues in the proper formulation of it. Indeed, as long as the best formulation of political society is not found individuals are called to try other formulations. So the League was not spared from that.

One of the often-cited causes of the outbreak of the Second World War is the failure of the League of Nations as an instrument at the service of international peace and security. The League of Nations experienced difficulties from the start of its existence. One of the most important difficulties that faced the League was that of representation. Because of its politics of isolationism, and regardless of the overall influence and commitment of President Wilson in the creation of the League of Nations, the absence of the United States of America influenced without no doubt the performance of this organization. ${ }^{546}$ German participation was not allowed

${ }^{546}$ T. J. KNOCK, To End All Wars: Woodrow Wilson and the Quest for a New World Order, Princeton, University Press, 1995, p. 263 
from the start because it was considered as aggressor in the First World War. Russia suffered the same fate because communist regimes were not welcome. The League was later weakened when the dominant powers left it in the 1930s. Japan was, from the start, a permanent member of the Council but withdrew in 1933 following the manifest opposition of the organization to its invasion of the Manchuria. ${ }^{547}$ Italy also began as a permanent member of the Council but withdrew in 1937. The League of Nations finally accepted Germany as a permanent member of the Council in 1926, but Hitler withdrew it when he accessed to power in $1933 .{ }^{548}$

A second reason for the failure of the League was its lack of neutrality. This was characterized by its indecision. This can be justified by the fact that from the outset the League of Nations had presented itself as an organization created by the Allied powers as a component for the restoration of peace and thus was considered an organization of victors. ${ }^{549}$ Voting on a resolution required 9 and later 15 votes from Council members. Therefore resolute and effective action was, in extreme, difficult if not impossible. The decision-making process within the League of Nations was sluggish because some decisions required the unanimous consent of all members of the Assembly. This problem resulted from the fact that certain members of the organization were reluctant to see their fates decided by other countries and consequently, they had a real right of veto, for, by a single negative vote no decision of this kind could not be to be enforced. ${ }^{550}$

The League also displayed a remarkable weakness regarding the collective security which was at the heart of its mandate. The members were supposed to put their military capacities at the service of the League of Nations in the event of a breach of peace on the international scene. This then involved States to act against friendly States in a way that could ruin their interests and to support States with which they had no affinity. This weakness was evident in the crisis in Abyssinia (now Ethiopia) when the British and French governments had to strike a balance between maintaining the security they had tried to build for themselves in Europe to defend themselves against enemies of the domestic order, ${ }^{551}$ to which Italy provided major support, and their obligations towards Abyssinia as a member of the League of Nations. ${ }^{552}$ In the end, France and Britain ended up abandoning the concept of collective security, preferring rather to

\footnotetext{
${ }^{547}$ F. MCDONOUGH, The Origins of the First and Second World Wars, Cambridge University Press, 1997, p. 62 ${ }^{548}$ Ibid.

${ }^{549}$ G. GORODETSKY, Soviet Foreign Policy, 1917-1991: A Retrospective, Routledge, 1994. p. 26; P. RAFFO, The League of Nations, The Historical Association, 1974. p. 1

550 D. S. BIRN, The League of Nations Union, Clarendon Press, 1981. pp 226-227; F.S. NORTHEDGE, The League of Nations: Its Life and Times, 1920-1946, Holmes and Meier, 1986, pp. 279-282, 288-292

${ }^{551}$ Ibid. p. 254

${ }^{552}$ Ibid. pp. 253-254
} 
appease in the face of growing German militarism. The League of Nations also lacked its own armed force and depended on the big powers for the execution of its resolutions, for which they did not show any will. ${ }^{553}$ The most important, namely France and Great Britain, were reluctant to use the means of sanction and more reluctant to resort to military action on the part of the League of Nations. They opted more for pacifism after the First World War. Furthermore, the League of Nations 'plea for the disarmament of its members, while seeking to realize its collective security mandate, meant that the League was depriving itself of the only force by which it could impose its authority. ${ }^{554}$

These problems manifested themselves in several conflicts in which mediation by the League of Nations was expected. Of course the League of Nations had successfully intervened in certain international conflicts such as the Petrich incident in 1925 between Greece and Bulgaria and the Albanian border conflict. ${ }^{555}$ However, such successes were few in number and these were situations in which the small powers were involved and it must be recognized that if a large power were involved, a resolution would have tended to favor the latter. The convincing case is the Italian bombing of the city of Corfu where, despite any evidence of Greek involvement, it was forced to pay compensation to Italy. In addition, the most complex international conflicts which completely discredited the League were conflicts in which the aggressor was a great power and the League failed to be decisive. We can note the Manchurian Case which involved $\mathrm{Japan}^{556}$ and Abyssinia involving Italy, ${ }^{557}$ the two great powers acting in an abusive manner. The League was also unable to stop the growing rearmament in Europe ${ }^{558}$ and the aggressive German expansion ${ }^{559}$ which culminated in the Second World War.

This laconic history of the functioning of the League of Nations is evidence that the sole contract of society is not enough because its formulation or its substance is very crucial for the purpose sought by its members, whatever the scale of force of human security. The League of Nations was indeed a major historical outcome which the various States had come to be aware

\footnotetext{
${ }^{553}$ F. MCDONOUGH, op. cit. pp. 54-55

${ }^{554}$ F.S. NORTHEDGE, op. cit. p. 139

${ }^{555}$ History of the League of Nations (1919-1946), UNOG Library, Registry, Records and Archives Unit, pp. 6 et s.

556 A. IRIYE, The Origins of the Second World War in Asia and the Pacific, Longman Group UK Limited, 1987; G. SCOTT, The Rise and Fall of the League of Nations, Macmillan, 1974; I. HILL NISH, Japanese foreign policy 1869-1942, Kasumigaseki to Miyakezaka, Routledge and Kegan Paul, 1977, pp 176-178

${ }^{557}$ F.S. NORTHEDGE, op. cit. pp. 222-225; G. W. BAER, Test Case: Italy, Ethiopia, and the League of Nations, Hoover Institution Press, 1976

558 J. GOLDBLAT, Arms control: the new guide to negotiations and agreements, SAGE Publications Ltd, 2002

${ }^{559}$ E. J. OSMAŃCZYK, A. MANGO, Encyclopedia of the United Nations and International Agreements: G to M. Taylor \& Francis, 2003. pp 809-810
} 
of. However, everything suggests that the formulation of this agreement and its deployment demonstrated the level of consideration or worth they had for it. In reality, if the League of Nations had experienced such a failure, it was because of its members. It is therefore not ultimately the failure of the League of Nations but that of its members through it. For without the latter the League of Nations would never have existed and would never have deployed in any way. It was States which came up with the idea "League of Nations", which formulated it and which sustained it. The entire history of the League of Nations was therefore only that of States without which it would have been nothing. This history testified to the level of maturity or understanding of the signification of the idea of international society in that precise era. It is therefore States which have failed through the League of Nations and the main reason is that they had not yet come to be sufficiently educated on the best way for them to meet their conservation requirements, even after the ravages of the First World War they had painfully experienced. They had understood that the unjust war was not part of the order of natural means for the confirmation of the human security at the international scale, for the benefit of cooperation, but apparently they had not yet understood that the formulation of that cooperation necessarily implied the principle of liberty and equality of all the contracting parties. The League of Nations pact concluded by States aimed at abolishing the state of nature on the international scene, without States being able to get rid of their licentious tendencies. The pact of the League of Nations which represented international constitutional law at that time had inevitably to experience the fate which was its, necessarily subject to the historical and natural process of experimentation for the discovery of the order of natural means necessary for the confirmation of human security, it had to manifest the state or the level of education of the States on that one. Thus consequences of this level of education conditioned the trajectory of the League of Nations and had necessarily to be a prelude to the advent of the Charter of the United Nations, in accordance with the theoretical framework of human security.

\subsubsection{Advent of the Charter of the United Nations}

At the final session of the League of Nations in 1946, one of its founders and ardent defenders Lord Robert Cecil said a memorable word: "The League of Nations is dead; long live the United Nations". It is striking to note the number of ideas to discredit the League of Nations that have been taken up. ${ }^{560}$ A member of the American delegation explained: "Quite clearly there was a

\footnotetext{
${ }^{560}$ M. P. COTTRELL, "Lost in transition? The League of Nations and the United Nations", in I. SHAPIRO, J. LAMPERT, (Eds.), Charter of the United Nations,: Yale University Press, New Haven, CT, 2014, pp. 91-106
} 
hesitancy in many quarters to call attention to the continuity of the old League and the new United Nations for fear of arousing latent hostilities or creating doubts which might seriously jeopardize the birth and early success of the new organization" 561.

The Charter of the United Nations was then called to present itself as the improved Covenant of the League of Nations. The first United Nations Declaration dates back on 1 January 1942, when representatives of 26 nations decided to join their forces to defeat the Axis Powers and achieve a just peace. Thus, unlike the League of Nations, the United Nations began in the form of an alliance born shortly after the entry into war of the United States of America, following the Japanese attack on Pearl Harbor and the declaration of war by Germany on the United States in December 1941. A truly global conflict between the Grand Alliance (United States, Great Britain and the Soviet Union) and the Axis Powers (Germany, Italy and Japan) was sustained. ${ }^{562}$ The Second World War was, quite simply, deadly. Civilian and military deaths have been estimated at 72 million. The impact of the war on global and national economies, as well as on political structures around the world, had been deep. European empires collapsed during or as a result of the war. The United States and the Soviet Union became the most powerful nations in the world. Germany and Japan were occupied and militarily emasculated. In short, the world was transformed. ${ }^{563}$

The United Nations was created, in part, to manage this transformation. As in the case of the League of Nations, it was an initiative of the American president Franklin D. Roosevelt, whose administration had advocated the creation of the United Nations in the last years of the war. In August 1944, delegates from China, the Soviet Union, the United Kingdom, and the United States met at Dumbarton Oaks to develop the basic plan for the new international organization. By October, the outline of the Charter of the United Nations was ready. After the capitulation of Germany, the Charter was signed in San Francisco on 26 June 1945. On 24 October 1945, the War of the Pacific also ended before the United Nations officially start to work. ${ }^{564}$

The fundamental question the drafters of the United Nations Charter had to deal with was essentially the same as the one which Wilson and his European counterparts had encountered in 1918-1919. They wanted to create an organization that would be a guarantee of flawless peace. There was a lot of skepticism, what was understandable, given the fate of the noble goals

\footnotetext{
${ }^{561}$ L. M. GOODRICH, "From League of Nations to United Nations", International Organization, Vol. 1, n 1 , 1947, p. 3.

562 J.M. HANHIMAKI, The United Nations. A Very Short Introduction, Oxford University Press, 2008, p. 13

${ }^{563}$ Ibid. p. 13

${ }^{564}$ Ibid. p. 13-14
} 
of the League of Nations. As before, the basic dilemmas and enigmas had not changed: how to reconcile national sovereignty and international idealism? How to reconcile imbalances between countries in terms of power and influence, resources and commitments? How, in other words, could be drafted a charter effectively recognizing and regulating the structural inequality of states? How was it possible to prevent certain countries from simply withdrawing from the organization, like Japan in the 1930s, by dissatisfaction with its decisions? ${ }^{565}$

Drafters of the United Nations Charter fixed that issue with a simple mechanism: the right of veto. In other words, the Charter conferred powers superior to five of the founding members of the UN, namely China, France, Great Britain, the United States and the Soviet Union, what enabled them to prevent any decision they judged against their interests. They became the five permanent members of the United Nations Security Council, countries that were to have a seat in the most important organ of the new organization, as long as it existed. It was thought this strategy, would encourage key countries to stay in the United Nations. It also provided them with the means to neutralize the world organization. ${ }^{566}$

Although its founders were deeply aware of the failures of the League of Nations, most of its ideals and many structural elements were at the heart of the Charter of the United Nations. Most clearly, the United Nations Charter and the League of Nations Covenant cited the promotion of international security and the peaceful settlement of disputes as key objectives. But the Charter was different in two important respects.

The Charter of the United Nations differed from the Covenant of the League of Nations in particular by emphasizing the promotion of social and economic progress as a central objective. The latter was also part of the League of Nations Covenant, but it appeared briefly in article 23. On the other hand, the preamble of the United Nations Charter reads as follows: "to employ international machinery for the promotion of the economic and social advancement of all peoples". The importance of economic and social development took root in the interwar period. For many, the global economic depression of the late 1920s and 1930s was the source of the political upheavals in ultranationalism and the acts of aggression that sparked the Second World War. The promotion of economic and social equality was thus seen as a means of guaranteeing international security. ${ }^{567}$

\footnotetext{
565 Ibid. p. 15

566 Ibid. p. 15

${ }^{567}$ Ibid. p. 17
} 
The founders of the United Nations wanted to create an organization capable of preventing the "scourge of war" from damaging humanity again. To this end, they defined the question of international security in broader terms than those who erected the League of Nations. They also aimed to create a structure enabling the United Nations to participate actively in world affairs in its key areas: military security, economic and social development, as well as respect for human rights and international justice. In a sense, there was something for everyone but also a recipe for future puzzles. ${ }^{568}$

The advent of the United Nations Charter as we see it therefore is the product of negative consequences which themselves result from a certain formulation of the Covenant of the League of Nations. This body of rules by which human security was sought turned out to be either poorly formulated or misunderstood by its own designers, due to the practice that followed. Their level of understanding of the order of natural means necessary for human conservation was reflected both in that text and in its practice. Its consequences, in terms of damages, were unpleasant and even more unpleasant than those of the First World War. So they became aware of the need to organize themselves differently or to improve the previous organization, that is, the League of Nations Covenant: hence the charter of the United Nations. This one is therefore a reflection of the League of Nations Covenant, more aware of its importance by its designers. It shows their level of understanding more aware of the possible consequences of badly formulated and poorly understood initiatives for the confirmation of human security, as a law of nature. Legal rules being fundamentally means through which those who elaborate them pursue a precise purpose more or less understood by themselves, the consequences of their materialization are an important indicator of their adequacy to or of their real level of understanding. The advent of the Charter of the United Nations is a perfect illustration of this level of understanding. Human security, as the human nature' intrinsic order, as a real existent, also governs conduct for the purpose of its confirmation at all scales or at all levels of human interaction.

The Charter of the United Nations, too, is not to be outdone as regards the internal dynamics of discovery of its adequate formulation for the materialization of its spirit or quite simply of discovery of this spirit. So it is obvious that international constitutional law is subject to the historical process of experimentation for the confirmation of human security.

${ }^{568}$ Ibid. p. 17 


\subsection{International Constitutional Law and the historical process of experimentation}

Studying international constitutional law in relation to the historical process of experimentation is in fact trying to understand this dynamic within the Charter of the United Nations. As far as it is concerned, this can be seen in the United Nations reform project (2.2.1) which is evidence of the evolution of its trajectory towards its adequate formulation (2.2.2).

\subsubsection{The United Nations Reform Project}

The United Nations Reform Project is part of the historical process of experimentation for the discovery of the order of means adequate for the confirmation of human security. This reform project is posed in the light of an ever-changing international context and to which it is necessary to adapt or provide an adapted response. "Ever since the early 1990s, there has been talk about the need to reform the UN Security Council in order to make it more democratic and representative. Nor was it an accident that the last decade of the twentieth century saw a massive litany of initiatives-or "agendas"-that addressed the key functions of the UN system: peace, democracy (and human rights), and development. In the twenty-first century hardly a day has gone by without complaints and arguments over the way development aid is administered, human rights are not effectively promoted, peace operations are not producing sustained results (...)" 569 . These reforms have either a constitutional aspect because they imply a modification of the Charter of the United Nations, or a simply managerial aspect which implies a change or a new orientation of the working of its different bodies in the fulfillment of their mandates. In this context, we will focus on aspects of the reform project relating to the Charter of the United Nations.

The constitutional aspects of the reform project are very much concerned with the function of maintaining international peace and security and therefore target the organ which assures it, namely the Security Council. "How could the Security Council be made more effective as an instrument of solving international disputes? How could it be made more representative of the global community? The question of reforming the UNSC tends to focus on two intertwined issues: veto and membership." 570

\footnotetext{
${ }^{569}$ Ibid. p. 135

${ }^{570}$ Ibid. p. 136
} 
Regarding participation, the Security Council that emerged from the San Francisco Summit was made up of eleven members, five permanent members including the United States, France, China, Russia and the United States. And for the selection of non-permanent members, the Charter of the United Nations set out two criteria: first, the contribution of the Member State to the maintenance of international peace and security and an equitable geographical distribution. ${ }^{571}$ The criteria were set aside and the second criterion was further implemented according to a "gentlemen's agreement", the very nature of which is controversial. In the first two decades, that is, the period before the first amendment to the Charter of the United Nations, which resulted in an increase in the number of non-permanent seats from six to ten, the geographical distribution was the following: two seats for Latin America, two for Western Europe and the British Commonwealth, one for the African and Asian States and one for the Eastern European States, considered as the group of States of communist tendency. ${ }^{572}$

Over time, however, members of the United Nations have become increasingly unhappy with the situation. The sudden increase in the number of members, mainly from Asia and Africa, due to the independence of a large number of decolonizing countries, has given member States the feeling of not being represented on the Security Council. As a result, member States began to press for the enlargement of the Security Council. The question of the enlargement of the Security Council was raised for the first time at the eleventh General Assembly following the admission of 16 new member States to the United Nations in 1955. Sixteen Latin American States plus Spain had presented a draft resolution relating to the increase in the number of members of the Security Council, specifically demanding that the number of non-permanent members of the Council be increased from six to eight. However, the question of the enlargement of the Security Council proved to be closely associated with international politics and became hostage to the question of China in the Security Council and remained so for the next seven years. ${ }^{573}$

The question was finally brought to the eighteenth session of the General Assembly. In 1963, two groups of States, one from Latin America and Asia and Africa presented two separate draft resolutions to the Special Political Committee of the General Assembly requesting an amendment to the Charter aimed at increasing the number of members of the Security Council.

\footnotetext{
${ }^{571}$ Y. Z. BLUM, "Proposals for UN Security Council Reform", in The American Journal of International Law, Vol. 99, n. 3, July 2005, p. 636

572 Ibid.

${ }^{573}$ D. BOURANTONIS, The History and Politics of UN Security Council Reform, Routledge, New York, 2005, pp. $13-15$
} 
Twenty-one Latin American States had submitted their draft resolutions on 10 December 1963, and called for an increase in the category of non-permanent members of the Security Council from six to eight. In fact, it was the reiteration of the Latin American proposal submitted in 1955. Two days later, on the 13 of December 1963, 37 African and Asian states submitted a draft resolution requesting an increase from 11 to 15 members of the Council of security by adding four additional seats to the category of non-permanent members. After a series of consultations, the two groups of States agreed to jointly present their demands to the General Assembly, primarily to put more pressure on the United Nations to expand the Security Council. $^{574}$

Members had huge differences of opinion on the resolution, especially among the permanent members of the Security Council, and at the end of the session, only China among the permanent members had voted in favor of the resolution. The General Assembly adopted Resolution 1991 on 17 December 1963, Part A of which increased the number of members of the Security Council from 11 to 15 . The resolution was adopted by 97 votes to 11, with four abstentions. France and the Soviet Union were among the opponents of the resolution, and the United States and the United Kingdom chose to abstain. Although the majority of the permanent members were not in favor of the resolution at the General Assembly, they had all ratified it within 19 months. Edward C. Luck explained this attitude in terms of Cold War policy, lack of coordination among permanent members and the financial problems facing the United Nations. 575

After the successful adoption of the resolution increasing the number of non-permanent members of the Council, the question of enlargement remained unresolved until 1979. This time, the initiative was taken by India and 12 States not aligned. Co-sponsored by Japan, the resolution recommended increasing from 10 to 14 non-permanent seats. The geographical distribution was to be as follows: one for the Eastern European States, two for the Western European States, three for the Latin American States, three for the Asian States and five for the African States. ${ }^{576}$ However, the resolution did not achieve sufficient support. In the same spirit, the Latin American States have submitted a draft resolution requesting an increase in the number of members of the Security Council from 15 to 21 thanks to the increase in the number of non-permanent members to 16 members. However, this resolution also failed. All permanent

\footnotetext{
${ }^{574}$ Ibid. p. 19

${ }^{575}$ E. C. LUCK, "Reforming the United Nations: Lessons from a History in Progress", in International Relations Studies and the United Nations, Occasional Papers, ${ }^{\circ} 1,2003$, pp. 7-10

${ }^{576}$ Draft Resolution Doc. A/34/L.57 and Add.1, at
} 
members except China denounced the resolution, which did not entail any substantive deliberation after the resolutions, and the issue remained deferred until the early $1990 \mathrm{~s} .{ }^{577}$

In the context of the changes brought about by the end of the Cold War, India and 35 other nonaligned States presented to the General Assembly a resolution calling for reform of the Security Council. Co-sponsored by Japan, the resolution required the inclusion of Security Council reform on the provisional agenda of the $48^{\text {th }}$ session of the General Assembly. The unanimous adoption of resolution 47/62 of 11 December, 1992 officially placed the issue of Council reform on the agenda of the General Assembly. ${ }^{578}$

Regarding the veto, this right remains one of the most contentious issues in the debate on the reform of the United Nations, and the debate as a whole is very similar to that of 1945 . The majority of the members of the United Nations oppose the existence of the right of veto insofar as it inherently conflicts with the principle of the sovereign equality of States. In addition, the veto is seen as making the United Nations anti-democratic. The only States that support the veto in the contemporary context are those that have power or aspire to it. ${ }^{579}$ However, despite the unpopularity attached to the right of veto, the beginning of the euphoria, which became clear when discussions on Security Council reform began in the post-Cold War era, about the limitation or elimination of this advantage conferred on the Security Council diminished considerably and attention shifted to the enlargement of the Security Council. The reason is the firm opposition of the permanent members to give up their right of veto. Only the United Kingdom and France showed some complacency with the right of veto. ${ }^{580}$ Examination of the reform proposals supported by the main States shows that it is obvious that, on one side of the spectrum, lies the prospect of the G-4 (Japan, Germany, India and Brazil) which aspires to become permanent members of the Security Council and therefore have no difficulty with the veto. In contrast, we find the group "United for Consensus", which systematically opposes the maintenance of the right of veto in the event of reform. The intermediary perspective is that of the African Group which claimed permanent seats for certain African States, with all the rights of existing permanent members; However, they specify that even if Africa opposes in principle

\footnotetext{
577 B. FASSBENDER, "All Illusions Shattered: Looking Back on a Decade of Failed Attempts to Reform the United Nations Security Council”, in Max Planck Yearbook of United Nations Law, Vol. 7, 2003, p. 187

578 The Resolution required from Member States to submit by summer 1993, to the Secretary their propositions regarding the Reform of the Security Council. United Nations Publications A / 48/264 Add. 1-10. See also J.V. FRIESELEBEN, "Reform of the Security Council", in Managing Change at the United Nations, Center for UN Reform Education, New York, 2008, pp. 3-4

${ }^{579}$ B. FASSBENDER, “All Illusions Shattered”, op. cit. pp. 211-212

580 GASIMOVA, “The Security Council's Endless Enlargement Debate”, in Central European Journal of International and Security Studies, Vol. 6, $\mathrm{n}^{\circ} 3-4,2012$, p. 272
} 
the veto, it is of the opinion that, as long as it exists and for reasons of common justice, it should be made available to all permanent members of the Security Council. ${ }^{581}$

This sketch of the debate on the reform of the United Nations is an indicator of that the historic process of experimentation is in force, for the discovery of its adequate formulation allowing the satisfaction of all the requirements regarding the conservation of all the human groups that constitute its members. When it came into force, the question of its reform did not arise directly. It was during its implementation, the evolution of the configuration of international society that the need for reform was considered. Even if the debate does not arise in the same terms for all parties according to their interests, it is a clear indicator that the initial agreement no longer satisfies the whole. If the reform of the Security Council is still at the project stage today, we must however be confident as to the dynamic of experimentation to which the Charter of the United Nations is subject under the theoretical framework of human security.

\subsubsection{The essential purpose of international constitutional law: Resulting to the best formulation for the confirmation of human security}

The Charter of the United Nations which currently accounts for international constitutional law is subject to a constant process of discovery of its best formulation for the confirmation of human security. By virtue of this, it should be known that it implies a natural order of means by which it is confirmed whether it is at the individual level or at the collective level. Without pretending to predict exactly this best formulation, it is however possible to somehow read it, or to consider trends from which one can be quite certain, based on the principles of human security, as a law of nature.

Human security as a law of nature is confirmed based on the principle of liberty. Liberty, being an ontological attribute of the human person, it is consequently and by extension or by enlargement of scale, an ontological attribute of the legal person that is political society or State. Thus each State basically has the right to preserve itself according to its liberty, and bearing the consequences without having to encroach on the liberty of another State. Thus, since no one can naturally be forced into the undertaking of satisfying its conservation, inter-individual cooperation for this purpose, understood as the only possibility for individuals to keep themselves subject to the natural need for cohabitation and the dependence on nature, is still based on the freedom of each one which materializes here by his consent. This is exactly what

\footnotetext{
${ }^{581}$ African Union, The Common African Position on the Reform of the United Nations, pp. 9-10
} 
holds true on a larger scale for political societies or States. In the same way, the principle of liberty, identical for all individuals, involves a natural equality between them in spite of their characteristics and their particularities, in the same way, by enlargement of scale, the principle of liberty, identical for all States involves a natural equality between them, whatever their characteristics or particularities. This principle has come to be recognized as essential in the history of international constitutional law, in particular the Charter of the United Nations. This is how it is based on the principle of the sovereign equality of States. The creation of the United Nations and the membership within it were intentionally made on the basis of state liberty. However, what about the consecration of an organic structure in which the equality of States is not fully enshrined?

Indeed, According to Article 7 of the Charter of the United Nations, its principal organs are: a General Assembly, a Security Council, an Economic and Social Council, a Trusteeship Council, an International Court of Justice, and a Secretariat. The first two deserve special attention as they could be considered as the main decision-making centers, and therefore the United Nations directories.

The order in which these organs are mentioned implies an order of importance which, however, badly hides the reality. Indeed, the General Assembly is the body made up of all the member States of the United Nations in an egalitarian principle on a democratic basis. Each State thus has a voice equal to each of the others. The resolutions adopted by the General Assembly are not binding. The Security Council is made up of permanent and non-permanent States. Permanent States, having the distinction of being superpowers, enjoy an individual veto against which nothing can resist. Security Council resolutions are binding. ${ }^{582}$

As can be seen, the Security Council has greater authority than that of the General Assembly. This clearly shows that the most powerful have more authority in decision-making, even if they enjoy sovereignty in the same way. In reality, this directing structure of the United Nations

\footnotetext{
582 We translate from: "En toute hypothèse, l'organe est bien singulier, sans équivalent dans aucune autre organisation internationale, universelle ou régionale. Non pas tant parce qu'il est un organe restreint, ne comprenant qu'une partie des membres, et une très faible partie (15 sur plus de 180, soit environ $8 \%$ des membres), mais bien davantage en raison de l'inégalité profonde entre ses membres eux-mêmes, 5 membres permanents d'un côté, 10 non permanents, élus pour deux ans par l'Assemblée générale, de l'autre. Ces membres permanents (...) sont nominativement désignés dans la Charte, c'est-à-dire sinon intangibles du moins fortement protégés contre tout changement. Ils disposent enfin du privilège, unique pour l'ONU, du droit de veto, c'est-àdire qu'ils peuvent bloquer individuellement toute résolution qui ne leur convient pas, y compris si elle les concerne. Autant dire que, d'une part, ils sont au-dessus de la Charte - on ne peut pas non plus les exclure sans leur consentement - et que, d'autre part, la Charte ne peut fonctionner sans leur accord" in S. SUR, "Le conseil de sécurité : blocage, renouveau et avenir", Pouvoirs, Vol. 2, n 109, 2004, p. 61-74, http: www.cairn.info/revuepouvoirs-2004-2-page-61.htm
} 
responds to a combination of the solutions of the myths of the state of nature of Hobbes and Locke. Indeed, the logic of the Security Council tends to respond to the Hobbesian logic while the General Assembly tends to respond to the Lockean one.

Hobbes defends the solution which consists in transferring all natural powers to one or to an Assembly which will be responsible for ensuring collective security. This individual or this Assembly thus acquires unlimited power, having the capacity to impose its force on all. He is responsible only for himself. The United Nations Security Council stands as the guarantor of peace and international security, and the decisions it takes at this level command unfailing respect. It is in fact an Assembly, from Hobbes' point of view, whose composition, however, would tend to betray identification with the latter's theoretical model. Indeed, under Article 23 (1) of the Charter of the United Nations, "The Security Council shall consist of eleven Members of the United Nations. The Republic of China, France, the Union of Soviet Socialist Republics, the United Kingdom of Great Britain and Northern Ireland, and the United States of America shall be permanent members of the Security Council. The General Assembly shall select six other Members of the United Nations to be non-permanent members of the Security Council, due regard being specially paid, in the first instance to the contribution of Members of the United Nations to the maintenance of international peace and security and to the other purposes of the Organization, and also to equitable geographical distribution.".

As we have seen, the members of the Security Council do not all have the same status because there are some who are permanent and others who are not. In addition, those who are permanent have an additional right of veto with obvious consequences. The use of the latter renders ineffective all decisions which would be taken even by the majority of members of the Council. Thus within the Security Council, we observe a predominance of the Hobbesian model of governance and a semblance of the Lockean model: it is a democratic assembly where some make the law. ${ }^{583}$

\footnotetext{
${ }^{583}$ We translate from : "Le droit de veto parait critiquable, que l'on se place sur le terrain de l'efficacité ou sur celui de la représentativité. Sur le premier, il est clair qu'il constitue une entrave à la capacité de décision du Conseil, qui se trouve hors d'état d'intervenir dès lors que son action ne conviendrait pas à un membre permanent, quelles que soient par ailleurs les menaces ou atteintes à la sécurité internationale. Quant à la représentativité, comment accepter cette prérogative exorbitante reconnue aux seuls membres permanents, qui fait du Conseil leur otage tout en les plaçant au-dessus de la Charte? Le procès est classique, et il n'est guère besoin d'y insister. Il se conclut par un jugement négatif sur l'organisation onusienne de la solidarité collective. Elle suppose que tous soient solidaires de la sécurité de chacun, que les États membres subordonnent, à tout le moins accommodent leurs intérêts nationaux aux objectifs de la Charte. Or le droit de veto affirme la suprématie de quelques intérêts nationaux sur l'ensemble", in S. SUR, ibid.
} 
In reality, it must be thought that the presence of other States in the Security Council on a nonpermanent basis, on a rotating basis, would have been very flagrant of the predominance of certain States on the most crucial questions of human societies that are international peace and security. This would have been quickly perceived and equally blatantly as discriminatory. It was therefore necessary to organize the situation in a democratic and egalitarian appearance by giving all States the opportunity to participate with the right to vote. This formula, which does not reduce the reality of the inequality ratio, certainly helps to mitigate the force of possible uprisings. Other States have the opportunity to participate in this prestigious Council even if a single veto of a permanent member has the power to block everything.

The legitimacy of the Security Council in its composition and functioning rests mainly on the accession of States to the United Nations. Joining the United Nations means adhering to its constituent Charter, which states in Article 24 (1) that "In order to ensure prompt and effective action by the United Nations, its Members confer on the Security Council primary responsibility for the maintenance of international peace and security, and agree that in carrying out its duties under this responsibility the Security Council acts on their behalf." The wording of this article confirms the Hobbesian mode of transition from the state of nature to the state of society. The Second World War is undoubtedly one of the historical events which translate into reality and by comparison the myth of the state of nature developed by Hobbes. Indeed, at that time, there was almost no order in international society if one took into account the failure of the League of Nations. However, behaviors of the parties to this conflict reflects to the two models of Hobbes and Locke. Indeed, for the Axis camp, this is an assertion of excessive international imperialist inclinations carried out by Nazi Germany. For this camp it is a matter of maximizing power with the ultimate effect of conserving the human groups they make up. It shows an identification with the attitude of the Hobbesian state of nature. For the Allied camp, it is a question of defending against the enemy which is nothing other than an actor who had decided not to behave rationally according to the principles of the natural law which makes of all, equal actors between whom no form of subordination can exist. It was therefore a question of defending oneself against those who came to break the natural order which allows everyone to keep themselves in their freedom. This attitude generally corresponds to that of the state of nature developed by Locke.

The war marking the victory of the Allies, according to Locke, insecurity of the state of nature could only be resolved through the constitution of an international political society which was to ensure the collective defense of all its members or States, even if the latter could not exactly 
assume the exact form of national political society. Indeed, the allies have drawn up an international social constitution including both the requirement of respect for the principle of sovereignty and the need for collective cooperation in order to achieve the security of all its members and therefore the conservation of all human groups making them up. However, the logic of this society which takes the form of the United Nations, will no longer obey exclusively the Lockean formula, but will be a mixture of it with the Hobbesian formula with predominance of the latter, at least in its management structure.

After drawing up the Charter of the United Nations with a Security Council, a little more powerful of the power of 5 permanent members the victors left it to the free adhesion of other States. This meant for the latter that they had, by their sovereignty, the freedom to choose to belong to such a society resolute of noble ideals or else, to remain outside it, in this unorganized state where the risk of aggression and insecurity is permanent, in a word in the state of nature. The choice became very clear. And it should be added that the image of the drafters of this Charter had certainly contributed. Because they positioned themselves as powerful actors who had used their power for a legitimate and just purpose to protect their liberties and those of others threatened by aggressors pursuing unjust, illegitimate and irrational goals. They then proposed to constitute for the benefit of all Nations a political framework of cooperation in which the liberty and therefore the sovereignty of each member would be respected against any unjust aggression, by also proposing to continue to be its guarantors with all the others, despite the fact that they had a little more prerogatives for this task. Considering the context, such a proposal was hardly unacceptable both for the independent States of the time and for those who were to be thereafter.

Implementing and based on their sovereignty, States freely decide to submit under the authority of the decisions of the Security Council for the maintenance of international peace and security. Although these ones are influenced by the right of veto of the permanent five, each of them is likely to participate in its decisions when based on the rotation procedure, its turn comes. Unlike the Lockean social model where individuals can remove the rulers, this is a predominantly Hobbesian mixed model.

The General Assembly of the United Nations is undoubtedly the most democratic organ of the United Nations because indeed States have an equal right to vote. Basically States can only be bound by General Assembly Resolutions on their own. And these one do not even have binding force. This testifies here to the inscription on the Lockean model of the social state. 
It should be noted that because of the obvious deep changes on the international scene to which it finds difficulties to respond or conform, this current structure of the United Nations of 70 years old, is called into question because it is considered as no longer really reflecting the political and economic configuration of contemporary international society. This is what has raised voices for reform of the United Nations, which has so much to do with the Security Council. In reality, the idea of a reform of this body is obvious in view of the theoretical aspect of human security, applicable by enlargement of scale, at the international level. With historical experimentation, States end up becoming aware of the reality imposed on them by such a formulation of international society to which they have freely consented. If the historical context was favorable to such an agreement, they start questioning it through the evolution of time and national and international situations.

It must, however, be recognized that the lack of such a structure of the League Council precipitated the world into the Second World War because the veto was a general right and thus no real intervention by this organization was possible when one of the States was the aggressor. The legitimating unanimity of an action could be vetoed, even by the aggressor State. The structuration of the Security Council, by endowing five permanent members was understood as a solution to this failure leading to negative consequences.

That said, what precisely facilitates such a questioning of the structure of the Security Council is the practice that results from it. Indeed, only five States have the most important power to decide the fate of the international community in matters of international peace and security and they can do so based on non-objective considerations. As situations are dealt with on an unequal basis and according to the interests of the permanent members, others State realize the inequality that exists within an organization supposed to establish equal treatment. Hobbes's solution to the state of nature is the constitution of a political society led indefinitely by a guarantor (Leviathan or assembly) charged with ensuring the general order. The solution proposed by Locke, on the other hand, is a political society led by a guarantor who would be legitimized to this task as long as it acts for the interests of the governed, the latter retaining their natural rights to depose him/her if necessary. The Leviathan being able to turn, if not to the arbitrary, but to the discretionary, subjective attitude for the satisfaction of its own interests, Locke's solution is undoubtedly the most in conformity with the principles of liberty and equality between the contracting parties. In the obvious possible case that the guarantor no longer respect the terms of the contract, a resort is necessary either to put him back on the right way or to depose him/her. Thus impression that States can have, which they certainly started to 
have and which will certainly become more and more important is that of having tied their fate in the hands of five States which are free like them and which are equal to them indefinitely. And the question "why not us too" will inevitably come out louder and louder until it is no longer possible to ignore it. Because according to the theoretical framework human security, valid at all scales, no unequal system is really part of the order of natural means necessary which it implies for its confirmation. The consequences of the application of the Hobbesian social contract have sufficiently demonstrated this, if we refer only to the political experience of Great Britain. In our view, the most important question which will be gradually resolved in this sense and with regard to international constitutional law is the reconciliation of an equal participation, endowed with authority, of all actors in international peace and security. This would truly respect the principle of sovereign equality of States. Such a formulation of international constitutional law would be a considerable step for the discovery of the order of natural means for the confirmation of human security for each individual making up each of the States members of international society. 


\section{CONCLUSION OF CHAPTER VII}

At the end of this chapter, we recall that we began the study of human security, as the foundation and finality of international law in its constitutive aspect. It was then a matter of dwelling on international constitutional law.

First, we began to present the reality of an international Constitution from the standpoint of the theoretical framework of human security. Thus, it was noted that the international Constitution, just like the national Constitution was based on and aimed at human security by enlargement of scale. The international Constitution is inscribed in the order of natural means necessary for the confirmation of the finite order which is human security. That is part of the finite order of human security on a larger scale. The only way for groups of individuals making up national Political Societies or States to meet the requirements for their conservation, based on natural imperatives of coexistence and dependence on the resources of nature, is simply to cooperate. Thus interstate or inter-national cooperation agreement is basically worth international Constitution, just like the inter-individual cooperation agreement is worth, at the basic level, national constitution. The reality of an international Constitution from the standpoint of the theoretical framework of human security has been supplemented by analyzes of the international constitutional theory. Based on objective elements characteristic of national constitutions, valid on an international level, in particular with regard to the Charter of the United Nations, this theory confirms the reality of international constitutional law embodied by the United Nations Charter. This stands as the fundamental agreement which is worth international society or the set of rules which govern international life in its universal dimension. After emptying the reality of an international Constitution, we turned to the Charter of the United Nations as being at the service of human security. This service was noted as indirect in that it ensures the security of the state legal person, which is the agreed means and made up by a group of individuals for the conservation of each. Thus by governing for the security of this super-means, the Charter of the United Nations rules for human security. It does so specifically through the principles relating to a Society of Sovereign States and those grounding a peaceful international society. Afterward the Charter of the United Nations was verified as being directly at the service of human security through its preamble. An analysis of his letter led us to the conclusion that human security was the foundation and the purpose of the Charter of the United Nations. To completely know it, it was still necessary to empty the question of the legal value of its preamble; what was done by the right apprehension of the latter as being the beacon of all the subsequent provisions, thus allowing to understand them, and 
pave the way by which these are called to receive a concrete form. Thus in the charter of the United Nations, the preamble is the spirit and the provisions are the body so as to know this international Constitution as complete and one in its double aspect.

Second, we dwelled on the trajectory of international constitutional law from the point of view of the theoretical framework of human security. This was necessary in the sense of the final order which it implies and which relates to the natural order of means necessary for its confirmation. Since the international Constitution was seen as part of this means, it was therefore less than its exact formulation in the service of its end, which is human security. The trajectory of international constitutional law, which is therefore only the trajectory of its formulation, has been taken into account by the successive advances of the League of Nations Covenant and the Charter of the United Nations. The League of Nations Covenant was the result recognized as necessary by the States after the First World War, and itself the result of excessive licentious state behaviour in search for conservation. The consequence of the war to the detriment of all was to resolve them to turn to the cooperative means for the benefit of all and for the purpose of conservation sought by each represented by the League of Nations Covenant. This first international constitutional agreement translated through its implementation, the level of understanding of States about cooperation, as means necessary for the conservation of all. This level turned out to be very low as they persisted with the licentious logic, which resulted in the Second World War. The consequences of the latter, which were heavier and more damaging than the first, were a more significant lesson for the actors who had to resolve to consent to an international cooperation agreement, the solidity and respect of which were evidence of their awareness of its importance and the adverse consequences of licentious conduct in the pursuit of conservation. Hence the advent of the Charter of the United Nations, one of the founding principles of which is the sovereign equality of States, is the basis of cooperation for the satisfaction of the requirements necessary for the conservation of each and all. The Charter of the United Nations therefore presented itself as the League of Nations Covenant more aware of its importance from its own founders. This already highlighted the historical process of experimentation for the discovery of the order of natural means necessary on this international scale for the confirmation of human security. This dynamic is therefore in force within international constitutional law. We can know that first and objectively from the United Nations reform project which concerns, of course, its constitutional aspect, the United Nations Security Council. This reform project relates to participation within it, in particular its enlargement to a greater participation of States or to a greater representativeness and to the right 
of veto, as regards the matter of international peace and security, recognized to permanent members. Although this reform is still in the exploration stage, the manifestation of a will for it can be an indicator that the current formulation of the Charter of the United Nations can no longer be able to respond to the changes in international society which arise individual State or collectively. Thus and then, this allows us to envisage a persistence of the dynamic of discovering the best formulation of international constitutional law based on human security, as a law of nature. Given the principle of freedom and its corollary of equality, the reform of the Security Council is likely to be an outcome. In the appropriate constitutional formulation to which we would reach, international governmental law would also participate as having human security as foundation and finality. 


\section{CHAPTER VIII: HUMAN SECURITY: FOUNDTION AND FINALITY OF INTERNATIONAL GOVERNMENTAL LAW}

Human security as the foundation and finality of international governmental law is a direct consequence of the fact that human security stands as the foundation and finality of international constitutional law. By international governmental law we mean the resolutory practice from the constitutional bodies materializing the international Constitution. In this case, it is a question of the work or the normative production of the organs of the United Nations giving concrete form to the Charter. In this framework, it is a question of verifying that the practice has human security as foundation and finality. Since its nature is legal this practice is a governmental law, taking the forms of resolutions of the General Assembly and the Security Council, which are often based on reports from the Secretary General. These elements of international governmental law are also the basis for unveiling or interpreting the meaning of human security from the Charter of the United Nations. Governmental law being very abundant and including practically all the United Nations practice, we will mainly refer to that which is directly or indirectly relating to the question of security. This delimitation is necessary in that within the United Nations, although security can be considered as a cross-cutting or encompassing issue, it is not yet understood in the sense that we understand it in relation to human security. The historical approach of the United Nations practice will show us the union of these two approaches or that the resolutory practice of the United Nations is an enterprise of progressive awareness that human security is its foundation and finality. Law, as a set of positive rules, is a means for a precise purpose, and therefore according to the theoretical framework of human security, falls in the order of natural means adequate for its confirmation. Knowledge of it only resulting in a historic process of experimentation, it is logically that international governmental law, is verified under such an approach. This will reveal the trajectory and therefore the meaning of that law. Based on that, we can know that human security is the foundation and finality of the resolutory practice of the United Nations in that, under the label (2) or not (1) of "human security", it does human security. 
1. HUMAN SECURITY: FOUNDATION AND FINALITY OF THE UNITED NATIONS RESOLUTORY PRACTICE WITHOUT THE LABEL "HUMAN SECURITY"

In this framework, we will check international governmental law or the resolutory practice of the United Nations as having human security as its foundation and finality even though, according to its conception and what it looks, it does not seem so. In fact, the action of the United Nations is in line with the understanding it currently has of international peace and security, and this does not refer to human security because the United Nations has a completely different meaning about it. This is why we speak of a "label" of human security. However, in doing so, it makes human security because its action has sense according to the theoretical framework of human security. We can know that based on the resolutory practice of the United Nations at the service of state security (1.1) and the security of individuals (1.2).

\subsection{Human Security and the United Nations Resolving Practice at the Service of State Security}

International peace and security has, from the earliest days of the United Nations, been viewed as focusing solely on interstate security. So international peace was seen as a climate of excessive use of force at the expense of a State. More generally, international peace and security have enable to protect the interests of the aggressed State (1.1.1.) and often those of the intervening States (1.1.2.). However these interests fall into the scope of human security.

\subsubsection{Human security and international peace and security in the service of the aggressed State}

International peace and security was seen as the main goal of international order after the Second World War. However, this international peace and security was understood only for the benefit of States. In this sense, edifying are the first two purposes of the Nations: article 1 (1) "To maintain international peace and security, and to that end: to take effective collective measures for the prevention and removal of threats to the peace, and for the suppression of acts of aggression or other breaches of the peace, and to bring about by peaceful means, and in conformity with the principles of justice and international law, adjustment or settlement of international disputes or situations which might lead to a breach of the peace" 
(2) "To develop friendly relations among nations based on respect for the principle of equal rights and self-determination of peoples, and to take other appropriate measures to strengthen universal peace".

So it is not at random that international peace and security was originally designed and applied in the sense of interstate relations. It was historically a question of protecting States against external attacks. As noted by the Commission on Global Governance, "Since the seventeenth Century, international security has been defined almost entirely in terms of national survival needs. Security has meant the protection of the State (...) from external attack" ${ }^{584}$. This traditional view of collective security considered it as an agreement among states that they would see external aggression against one of their number as an act against them all, and that they would respond with a collective use of force against the perpetrators of such aggression" ${ }^{\prime 55}$. The Charter of the United Nations established a system of collective security.

Collective security could be defined as an agreement by which States act collectively to provide security for another. ${ }^{586}$ This strict economy of the concept of international peace and security is a direct consequence of the causes of the Second World War. The principle of State sovereignty was fragile in interstate relations, which were still governed by the stronger principle of national interest, even after the consequences of the First World War and its most significant aftermath than the creation of the League of Nations. Collective security was then understood in relation to the affirmation of the principles of the sovereign equality of States, of non-interference in the internal affairs of States, of the non-use of force in international relations and of the collaboration of all States to decisions taken under Chapter VII of the Charter of the United Nations. By design, the international society represented by the United Nations was created to strengthen the meaning of these principles and ensure their irresistible guarantee by the sum of the state forces or collective force.

How did the resolutory practice of the United Nations, serving from its earliest days, State security serve human security? The answer to this question can only be understood with reference to the theoretical framework of human security. According to it, we can know that

\footnotetext{
${ }^{584}$ Commission on Global Governance, Our Global Neighbourood, Oxford University Press, Oxford/New York, 1995 , p.78

${ }^{585}$ Definition proposed by H. C. JOHNSON, G. NIEMEYER, "Collective security: The validity of an ideal”, in International Organization, Vol.8, pp.19-35, 1954, p.20; C.A. KUPCHAN, "Concerts, collective security and the future of Europe", in International Security, Vol. 16, $\mathrm{n}^{\circ}$ 1, 1991, pp. 114-161, p.118; and noted by G. WILSON, The United Nations and Collective Security, Routledge, Taylor and.Francis Croup, London/New York, 2014, p. 6 586 A. ROBERTS, D. ZAUM, Selective Security: War and the United Nations Security Council since 1945, London: Routledge, 2008, p. 11
} 
individuals are subject to conservation in coexistence with fellows and in dependence on the resources of nature, and for that they come to constitute themselves into a political society. The formulation of this one should therefore have the role of guaranteeing each individual conservation of and in its nature's intrinsic state of affairs accounted for by human security. What works nationally, works internationally. Thus by agreeing to be members of the United Nations, States resolved to pursue their collective conservation. While this is state security, it should be understood as being intimate to human security. Indeed, since the State is only a means at the service of the end that is individual conservation, state security can therefore only be a means at the service of human security. Collective security is therefore an international mechanism for guaranteeing security for each of the groups of individuals who have constituted themselves into States, either directly by protecting them from harm to their persons, or indirectly by protecting their common goods, which may be the territory or government or others. Whether directly or not, collective security serves human security.

That said, it must still be recognized that the benefit of the assaulted State of international collective support is seen as being in the interest of international society as a whole. Indeed, any situation of aggression is considered or intend to consider itself a threat to international peace and security. Thus States affirm that when an aggression is directed against one of them, it is carried out against all. The intervention must therefore be understood as being for the benefit of all. Then the same reasoning which is advanced for the State which benefits from collective support is also advanced for each of the States participating in the collective effort. This is not a purely idealistic but realistic reasoning in that in view of the interdependence of States, a critical situation in one State may affect the others and the absence of an adequate response would be dangerous because it may encourage other States to take licentious action against others, as we have noticed that in the causes of the Second World War.

Within the United Nations, the decision-making power with regard to international peace and security rests primarily with the Security Council under Chapter VII of the Charter and subsidiary to the General Assembly. The Security Council repeatedly used to rule on this matter. Determination of threats to international peace and security and intervention in favor of the assaulted State was not abundant immediately after the creation of the United Nations. Before 1990, the Security Council voted only three times before 1990, and this was the case in open situations of invasion and inter-state conflicts. ${ }^{587}$ In 1950, in its Resolution $82^{588}$, the Security

\footnotetext{
${ }^{587}$ North Korea, 1950, Maldives, 1982, Iran-Irak, 1987

${ }^{588}$ UN Doc. S/RES/54, 25 June 1950
} 
Council judged the invasion of South Korea by North Korea as a breach of peace and international security and noted the grave concern of the armed attack on the Republic of Korea by the forces of North Korea. The Council thus evoked self-defense under Article 51 of the Charter. In 1982 the Security Council in Resolution 502 ${ }^{589}$ clearly condemned Argentina's invasion of the British Falkland Islands and considered it as a breach of international peace and security. However, no act of aggression had been observed, although Argentina's guilt was unequivocal. The breach of the peace was noted despite short-lived hostilities. The postinvasion occupation was part of the breach of the peace, and England's defensive action was widely expected. ${ }^{590}$ The Security Council also noted a breach of peace and international security in its Resolution $598^{591}$ in the conflict between Iran and Iraq. He did so without determining responsibility and preferring to call for a cease-fire. ${ }^{592}$

All these cases had in common a clear determination of responsibility for the border attacks, appointing and condemning the guilty States. To that effect, the aggression appeared to differ from the breach of the peace. ${ }^{593}$ A breach of the peace is seen as a more neutral term that does not attribute blame or responsibility to the conflict in order to facilitate a political solution to the crisis for a return to its original State. ${ }^{594}$

Finally, there is the conflict between Iraq and Kuwait. In 1990, Iraq invaded Kuwait while both were negotiating ${ }^{595}$ for the resolution of their border conflict. This invasion was ardently condemned by the Security Council. The open military invasion using extreme force was recognized as such in the Security Council debates following the second attack. Kuwait qualified the situation as an armed military invasion by the overflowing of Iraqi forces within the internationally recognized borders of an independent sovereign State ${ }^{596}$, in short, unjustified brutal aggression. ${ }^{597}$ Despite the widespread condemnation of the invasion by some members of the Security Council as an indisputable act of aggression ${ }^{598}$, Resolution 660 characterized

\footnotetext{
${ }^{589}$ K. MANUSAMA, The United Nations Security Council in the Post-Cold War Era Applying the Principle of Legality, Martinus Nijhoff Publishers Koninklijke Brill NV, Leiden, Boston, 2006, p. 60

${ }^{590}$ Ibid. p. 35

${ }^{591}$ UN Doc. S/RES/598, 20 July 1987

${ }^{592}$ UN Doc. S/23373, 9 December 1991

${ }^{593}$ N.D. WHITE, Keeping the peace: The United Nations and the maintenance of international peace and security, Manchester University Press: Manchester, $2^{\text {nd }}$ Ed. 1997, pp. 48-50, quoted by K. MANUSAMA, Ibid, p. 60

${ }^{594}$ K. MANUSAMA, Ibid,

${ }^{595}$ Ibid. note 98 , p. 63

${ }^{596}$ UN Doc. S/PV.2932, 2 August 1990, pp. 4-6

${ }^{597}$ UN Doc. S/PV.2933, 6 August 1990, pp. 4-5

${ }^{598}$ K. MANUSAMA, ibid. p. 64
} 
the invasion as a breach of international peace and security and not as an act of aggression. ${ }^{599}$ In Resolution 661, the Security Council, reaffirming Resolution 660, expressed its determination to end the invasion and occupation of Kuwait by Iraq and thus, acting under Chapter VII, imposed economic sanctions to Iraq. Iraq did not only invade the territory of Kuwait because it also targeted nationals of third States in the conflict, in violation of international law. The Security Council took into account the plight of diplomats and foreigners in Iraq and Kuwait after Iraq announced that it was holding foreign nationals near its military and strategic installations. These actions were unequivocally condemned by the Security Council. ${ }^{600}$ Its consequent resolution 664 expressed concern for the security and well-being of third-country nationals in Iraq and Kuwait and recalled Kuwait's obligations in this regard. ${ }^{601}$ Iraq's non-compliance with these resolutions led the Security Council to adopt Resolution 687 in 1991 which authorized a military coalition to expel Iraqi forces from Kuwait. These ones were massively bombed from 16 January 1991, and on 27 February, Iraq notified the Security Council and the Secretary General of its acceptance of all the United Nations resolutions against it; which led to the suspension of hostilities. Two days later, the Council adopted Resolution $686^{602}$ in which the conditions for a cease-fire were established.

"Based on the twelve resolutions since the invasion of Kuwait, it demanded from Iraq, inter alia, that it rescind all its actions with respect to Kuwait; accept all-round liability for any loss, damage or injury as a result of its invasion; return Kuwaiti property; repatriate Kuwaiti and third-state nationals; and return all prisoners-of-war. Furthermore, the resolution required Iraq to provide information and assistance in identifying explosives, including chemical and biological weapons, in Kuwait and in Iraq where coalition members were operating. Iraq accepted the resolution, but no formal cease-fire came into effect. As operative paragraph one of resolution 686 (1991) declared, the previous resolutions continued to have full force and effect. Not until the next resolution did a formal and permanent cease-fire come into effect,

\footnotetext{
${ }^{599}$ UN Doc. S/RES/660, 2 August 1990, "Thus, the choice of category, while forcefully and explicitly stated, appears to be a compromise between those that viewed the Iraqi actions as acts of aggression and other speakers in the debate. Both views, however, employ principles of international law, such as non-interference and the prohibition on the threat or use of force, as the foundation for their respective opinions. It can be argued, therefore, that, based on the Council debate and the subsequent resolution, the breach of the peace found by the Security Council is firmly based on and described as a clear violation of international law." in K. MANUSAMA, ibid. p. 64 
although it would become contentious later whether the authorization of resolution 678 (1990) to use force was thereby ended or merely suspended"603.

All these cases marked a resolute practice of the United Nations Security Council in favor of international peace and security. The direct beneficiary of these resolutions was undoubtedly the State victim of aggression at its borders. Third States have also benefited, if we note the case of the conflict between Iraq and Kuwait where nationals of third States were targeted. An act of aggression or an invasion is therefore quite simply a threat to international peace and security. Undoubtedly interventionist resolutions were made for the benefit of State security, however it was just as undoubtedly and inevitably the protection of human security through them. When it comes to situations of concern for international peace and security, these are situations concerning human security, however indirect they may be, they have an ultimate impact on individuals who constitute themselves into different States. We therefore know that international governmental law which appears to serve state security in accordance with the Charter of the United Nations has human security as its foundation and finality. This is further verified when the intervention serves the particular needs of States.

\subsubsection{Human security and international peace and security at the service of the security of intervening States}

International governmental law is also at the service of human security, when it is an instrument for the satisfaction of the national interest. The sense of national interest here is much more ambiguous because it implies a certain instrumentation of the international collective security mechanism for an end which is really not international peace and security, but an advantage specific to the State which diverts it for this purpose. While this is a realistic reading of international law, in particular the resolutory practice of the United Nations in the service of state security, it is nevertheless a means of the ultimate satisfaction of the requirements for the conservation of groups of individuals whose or for whom the rulers act in this way.

Thus, the resolutory practice of the United Nations in matters of international peace and security has often served the security interests of intervening States. They have been particularly edified in history for having embodied the logic of double standards in understanding international security issues. Since such a logic only manifests the prevalence of the principle of national interest at the highest level of international administration in a way that cannot be at service of

${ }^{603}$ J. LOBEL, M. RATNER, "Bypassing the Security Council: Ambiguous authorizations to use force, cease-fires and the Iraq inspection regime", in American Journal of International Law, n 93, 1999, pp. 148-149, quoted by K. MANUSAMA, op. cit. p. 67 
all members of international society, it translates all the continuity of force of initiatives aiming at confirming human security unilaterally. Based on the theoretical framework of human security, the consequences of such an attitude carry a certain significance within the framework of the order of natural means necessary for the confirmation of the finite order. Before we dwell on it, we will begin by noting these situations. These seem to be a constant in terms of international peace and security in all the different conceptions it has received.

The early days of the United Nations were dominated by the Cold War between the two great powers, the United States of America and the Soviet Union. This confrontation had an impact on the United Nations commitment to international peace and security. The discretionary nature of the collective security system established by the Charter of the United Nations meant that each superpower would have its veto power to block any attempt from other members to govern a situation that involved its interests in a way that did not affect them negatively. This has been observed in situations where each of them intended to use the collective security mechanism in areas of influence of others. ${ }^{604}$ On the Soviet side, one can note its military interventions in Hungary and Czechoslovakia, respectively in 1956 and 1968, with the aim of ensuring the maintenance of these States within its area of influence at a time when it feared that they only put in place liberal policies beyond what it could tolerate. ${ }^{605}$ However, such acts could have been qualified as a violation of Articles 2 (4) of the Charter of the United Nations and as threats to or breaches of the peace, in accordance with Article 39, the Soviet veto prevented any response by the Council from Security. ${ }^{606}$ Likewise, the Soviet intervention in 1979 was followed by no response from the Security Council, and attempts at condemnation met with the Soviet veto. ${ }^{607}$ With regard to the United States, their interventions inside the American continent were also followed by no intervention by the Security Council. The United States used its veto in the Security Council to guard against any criticism of its military incursions in Grenada ${ }^{608}$ and in Panama ${ }^{609}$. "Thus, on both sides of the superpower divide, Security Council responses to events which could justifiably have been brought within the remit of its primary responsibility for the maintenance of international peace and security were thwarted by the

\footnotetext{
${ }^{604}$ N.D. WHITE, op. cit. pp. 11-20

${ }^{605}$ T.E., VADNEY, The World Since 1945, $2^{\text {nd }}$ Ed., Penguin, London, 1992, pp.198-201; G. LUNDESTAD, East, West, North, South: Major Developments in International Politics 1945-1996, $2^{\text {nd }}$ Ed, Scandinavian University Press, Oslo, 1997, pp.230-232, 250-252; quoted by G. WILSON, op. cit. p. 44

${ }^{606}$ UN Docs S/3730/Rev.1; S/PV.754 (Hungry), S/8761; S/PV.1443 (Czechoslovakia), quoted by G. WILSON, Ibid. p. 44

${ }^{607}$ UN Docs S/13729; S/PV.2190 quoted by G. WILSON, Ibid. p. 44

${ }^{608}$ S. DAVIDSON, Grenada: A Study in Politics and the Limits of International Law, Avebury, Aldershot, 1987; 14 UN Docs S/16077/Rev.1; S/PV.2491; G. WILSON, Ibid. p. 45

${ }^{609}$ UN Docs S/21048; S/PV.2902; G. WILSON, Ibid. p. 45
} 
veto power. The statistics on the use of the veto power within the Security Council demonstrate succinctly the extent to which its collective security capacity was stalled." ${ }_{610}$

The Cold War was therefore an opportunity to understand that the implementation of the United Nations Charter, with regard to international peace and security, undoubtedly the area of matters considered the most important, would be dictated by the particularistic and not collective logic of national interest. These examples were striking because they were the fact of two superpowers invested of all the ideological and military authority from their positioning against the international arbitrariness carried by the Axis camp during the Second World War and against which they decided to fight, and from their central role in the instigation and the shaping of the international order of the United Nations. Immediately after the consent of such an order, they embarked on a completely contrary conduct because they continued to behave exactly as formerly the powers of the axis had done, by displaying inclinations of appropriation, even softly, of other sovereign States, what confirms the paternalistic posture which they assumed and which undoubtedly had the purpose of guaranteeing them the satisfaction of human security under the cover of the satisfaction of "state security".

South Korea's aggression by North Korea is a case in point. The two superpowers had special interests in this matter. North Korea was a communist, and a successful aggression on South Korea meant an expansion of communism, to the advantage of the Soviet Union and to the detriment of the United States. ${ }^{611}$ Taking advantage of the absence of the Soviet Union from the Security Council during this period The United States quickly set to work on a resolution noting the breach of peace in South Korea ${ }^{612}$ thus laying the necessary precondition for taking measures authoritarian under Chapter VII. This was soon followed by a recommendation to members to provide assistance to South Korea to restore international peace and security. ${ }^{613}$ Finally, the Security Council recommended that States provide forces or assistance according to Resolution 83 to the service of the unified command under the authority of the United States. The use of the Flag of the United Nations was also authorized. ${ }^{614}$ At its return, Russia set out to impose its veto power on other subsequent Security Council resolutions. "This six-week

\footnotetext{
${ }^{610}$ G. WILSON, Ibid. p. 45

${ }^{611}$ A., WOLFERS, "Collective security and the war in Korea”, Yale Review, 1954, Vol. 43, pp.481-502, pp.489492; W. STUECK, "The United Nations, the Security Council, and the Korean War", in R., LOWE, A. ROBERTS, J. WELSH, D. ZAUM, The United Nations Security Council and War, The Evolution of Thought And Practice Since 1945, Oxford University Press, New York, 2008, pp.265-279; D. G. ACHESON, Present at the Creation: My Years in the State Department, W.W. Norton, New York, 1969, pp. 448-51

${ }^{612}$ CS Resolution 82, 1950

${ }^{613}$ CS Resolution 83, 1950

${ }^{614}$ CS Resolution 83, 1950

${ }^{614}$ CS Resolution 84, 1950
} 
period of successful US initiatives on Korea in the Security Council came to an abrupt end on 1 August, when Soviet delegate Jacob A. Malik returned to the body as its president, a monthlong rotating position. The Security Council quickly became a debating society in which the United States and its allies battled the Soviet Union for world opinion rather than seeking solutions to the problems of war and peace. When on 19 September the General Assembly convened its annual session in New York, it largely replaced the Security Council as the focal point at the United Nations for diplomatic manoeuvring on Korea. After November the Security Council became merely the recipient of periodic reports from the UN command and of occasional Soviet and North Korean reports of alleged US misdeeds in the war.6 Indeed, the United States used the occasion of the Korean crisis and the Soviet stymieing of Security Council action to persuade allies in the General Assembly to pass the 'Uniting for Peace Resolution', which sought to strengthen the larger body's capacity to respond effectively in crisis situations" $" 615$.

The international peace and security that were at stake in the Korean crisis was just as much a strong cover for American and Soviet interests. These cases further confirm our comments that international governmental law is at the service of human security by intervening at the service of the state security of the interveners, in the understanding we had above (1.1.1). Subsequently the problem will no longer become that this law has human security as its final cause, but the fate of its formulation thus within the framework of the order of adequate natural means for a harmonious conservation of all the individuals constituting the different member States of the United Nations. Before we get there we will see that international government law is at the service of human security without however doing so under this label, when it is concerned with the safety of individuals.

\subsection{Human Security and the United Nations resolutory practice at the service of the security of individuals}

The resolutory practice of the United Nations with regard to international peace and security has evolved over time, incorporating the fate of human beings. Thus in the collective security agenda was added the concern to serve civilian populations. It was still mainly intervention. In this sense, it has successively come to bear two names with more or less different conceptual implications but having an equal impact for the benefit of populations. These are humanitarian intervention (1.2.1) and the Responsibility to protect (1.2.2).

${ }^{615}$ W. STUECK, op. cit. pp. 265-266. Yearbook of the United Nations, 1951, Columbia University Press, New York, 1952, pp. 229-30. 


\subsubsection{The resolutory practice of the United Nations and humanitarian intervention}

International peace and security for the benefit of individuals was very early signified in terms of humanitarian intervention. Conflicts have proven to have negative consequences not only for States, but also for civilian populations. International conflicts between States were faced with internal conflicts between the government of the day and rebel armed groups in the vicinity of which civilians are found and who become direct or indirect targets. ${ }^{616}$ In such situations, the United Nations have come to note an international concern and a question of collective security. This resolute practice of the United Nations in favor of humanitarian intervention is indeed evidence that it is at the service of human security.

Security Council resolution 688 is often cited as the start of the United Nations humanitarian intervention in the name of international peace and security. It regarded as a breach of international peace and security the repression of the Kurdish populations in northern Iraq under the authority of President Saddam Hussein which resulted in the displacement of millions of civilians to neighboring Turkey. ${ }^{617}$ Before the Security Council, France and Turkey raised concerns about the suffering of the refugees, arguing respectively that the risk of damage to the political and moral authority of the Security Council in the event of failure to protect the Kurds and that the movement of the latter affected regional security. The resolution was adopted, and immediately afterward the United States, in cooperation with the United Kingdom and France, sent troops to secure displaced populations and facilitate humanitarian assistance. The mission was called "Provide Comfort". 618

Although this resolution intervened for the benefit of individuals, it was clear from its wording that it aimed at another end which was regional security, and referred much more to the security of the States bordering Iraq, in pole position, Turkey. The threat to international peace in this case was therefore related to the cross-border effect of the conflict in Iraq or the flow of refugees across international borders, rather than the repression of the Kurds in Iraq ${ }^{619}$ It was then a question of ensuring the protection of the Kurds to protect the border, in other words the security of individuals was the means for the ultimate goal of state security. In the event that the Kurds were moved inside Iraq to other cities without having to worry about the borders of neighboring States, one would wonder if the Security Council would have adopted at that time, Resolution

\footnotetext{
${ }^{616}$ E. CARISCH, L. RICKARD-MARTIN S. R. MEISTER, The Evolution of UN Sanctions From a Tool of Warfare to a Tool of Peace, Security and Human Rights, Springer, 2017, p. 51

${ }^{617}$ UN doc. S/22435, 2 April 1991

${ }^{618}$ J. WELSH, “The Security Council and Humanitarian Intervention”, in R., LOWE, A. ROBERTS, J. WELSH, D. ZAUM, ,op. cit. p. 238

${ }^{619}$ J. WELSH, Ibid.
} 
688. In any case, according to the explanations of this resolution, it can be concluded that the protection of the Kurdish populations from repression by their leaders was not the final goal of the action: "It is not the role or the intention of the Security Council to interfere in the internal affairs of any country. However, it is the Council's legitimate responsibility to respond to the concerns of Turkey and the Islamic republic of Iran . . . about the massive numbers of people fleeing, or disposed to flee, from Iraq across international frontiers because of the repression and brutality of Saddam Hussein. The transboundary impact of Iraq's treatment of its civilian population threatens regional stability. That is what the Council has addressed today". ${ }^{20}$

Having said that, one should not forget the argument of the representative of France that the lack of protection in favor of the Kurds had risked tainting the moral and not only the political authority of the Security Council. It is clear that the protection of the international borders by Resolution 688 aimed at calling much more into the political authority of the Council, while the protection of the Kurdish populations called much more into the moral authority of this Council. So although aware of the politico-temporal context of that era of full interest in state security strictly understood in the sense of territorial integrity, we can still note a beginning of attention to and concern of the United Nations in critical situations to the detriment of civilian populations in the name of international peace and security. So it was indeed a resolution with an asserted political formulation, yet, in background, aiming at a clear but non-asserted humanitarian objective. Deciding that way managed the risk of damaging the moral and political authority of the Council. This conclusion is relevant if we try to question the preferential considerations of the members of the Security Council. Indeed, they would have privileged the integrity of international borders over the integrity of the Kurdish populations. Objectively and in fact, the gravity was much more on the side of the repression of the civilian populations than that of the insecurity at the borders of the countries bordering Iraq due to the massive influx of populations fleeing the repression. Furthermore, at that time, in 1991, the principle of non-refoulement, which is a strong principle of international law, was then 30 years old. This principle prohibits any State from driving back to its borders, populations fleeing a danger. Non-refoulement is therefore a right of civilians. Thus if international law had already recognized three decades earlier the nonexistence of a violation of the territorial integrity of a border of State by populations in distress, then one could not think that the Security Council had granted more importance, in this case, of regional territorial insecurity. Although worrying, it was less, compared to the repression of Kurds populations who enjoyed and already had at

${ }^{620}$ UN doc. S/PV.2982, 5 April 1991. 
their benefit an international law which diminished the importance of border security in such a context. The Security Council had done concomitantly, by Resolution 688, the politically (in the wording) and the humanely (in the background) correct. In order to be in harmony with the political context of the time, it was therefore a question of carrying out, under the guise of protecting international borders, a humanitarian intervention.

Somalia is the case that marks the unequivocal positioning of the Security Council in favor of humanitarian intervention. On that occasion, a multitude of resolutions were adopted on the decline of order and the humanitarian crisis in this country. ${ }^{621}$ For the first time in the history of the United Nations, the Council of the United Nations authorized military action under Chapter VII without the consent of a sovereign government and only on humanitarian grounds. ${ }^{622}$ During the discussions on the Resolution 746, reference was made to the flow of refugees across borders and a clear indication that member States saw the suffering of civilians as the justification for the Security Council's response. ${ }^{623}$ The preamble of this resolution noted the deep concern of the Security Council at the magnitude of the human suffering caused by the conflict and considered that the situation constituted a threat to international peace and security.

The Security Council in the 1990s will still have to intervene in the context of international peace and security in situations of humanitarian distress, which have arisen in Haiti, Rwanda, the former Yugoslavia and Kosovo. ${ }^{624}$

All these cases reflect the resolutory practice of the United Nations in favor of humanitarian intervention, on the ground of international peace and security. In the logic of the United Nations, this was indeed an evolution in the interpretation of the meaning to be given to the concept of international peace and security, in that this no longer included only the security of States understood in the sense of territorial integrity or the inviolability of borders, but also the security of individuals endangered directly or indirectly in situations of intra-state violence. In so doing, and even if it was not a question within the United Nations, of labeling these interventions as human security intervention, but as "humanitarian intervention", it is nonetheless true that the purpose was actually human security. We can find it out based on the elements of human security.

\footnotetext{
${ }^{621}$ MONUSOM I, CS Resolution 751 of 24 April 1992, UNITAF, CS Resolution, 794 of 3 December 1992, and MONUSOM II, CS, Resolution 814 of 26 March 1993

${ }^{622}$ J. WELSH, op. cit. 539

${ }^{623}$ UN doc. S/PV.3060 of 17 March 1992

${ }^{624}$ J. WELSH, op. cit. pp. 541-556
} 
Indeed, this evolution of the sense of international peace and security fits naturally into the historical process of experimentation for the discovery of the order of natural means necessary for the confirmation of human security. The conception of international society in the United Nations framework as an interstate or State-made system quickly became known to show limits because individual concerns had an influence on what was considered state security. Not only can the human distress experienced within the territorial limits of one State be prolonged within another, but also it is even shocking in itself with regard to the indispensable mirror effect that can experience the members of the international community with regard to these situations and the negative precedents that they may present in the absence of answer. By creating the United Nations, its creators understood that everyone's security was everyone's worry and that in reality there can be no lasting security if members of a society are insecure. It can become contaminated or can spread. However, the primary members of this society are the individuals for whom States through their governments would claim to overhang on the international level, without really succeeding because it is them who constitute themselves into political societies. If individuals are the primary and final actors in politics, whether national or international, international society which symbolizes the latter and which the United Nations represents has as its final cause only in the conservation of individuals, as noted by the preamble of the Charter of the United Nations. Human insecurity is therefore a fundamental concern for international peace and security and the United Nations has rightly and progressively come to understand that. By making state security, it makes human security indirectly and by making the security of individuals, it makes human security directly, whether it labels it or not that way. Humanitarian intervention which was considered to be the first exception to the principle of non-interference in the internal affairs of a State, with a lot of precaution, did not really have any difficulty in justifying itself in the name of peace and international security. This will also be the case in the following decade with the concept of the responsibility to protect.

\subsubsection{The resolutory practice of the United Nations and the responsibility to protect}

The responsibility to protect is a concept that has interested the United Nations resolutory practice in the context of a growing assertion of the need for international intervention for the benefit of human beings. The cases of serious international crimes suffered by civilian populations throughout the 1990s have sparked debate on the theory and practice of humanitarian intervention. After the failure of the United Nations to be able to respond adequately to these human tragedies, notably in Rwanda, Bosnia, Kosovo, for the most cited, 
States began to demand a right of intervention to stop or prevent massive violations of human rights. Their central concern was whether the then-resolutory practice of the United Nations regarding the use of force responded to the challenges of the post-Cold War era, particularly those relating to humanitarian emergencies. Thus, States tended to admit that it was no longer possible to tolerate abuses against civilians as necessary for the formation of the State, or to remain inactive in such situations. If, however, the rights of the State remained the central tenets of international order, it was necessary to know how populations affected by massive human rights violations could be protected. ${ }^{625}$

At the $54^{\text {th }}$ session of the United Nations General Assembly, Secretary General Kofi Annan called on States to prevent a new Rwanda and to reach consensus on the issue of humanitarian intervention. This was the starting point for research into the definition of a normative framework for humanitarian intervention by the United Nations. This response was the creation of the "Responsibility to protect" developed by the International Commission on Intervention and State Sovereignty ${ }^{626}$ set up by the Canadian Government. In December 2001, this Commission issued its Report entitled: Responsibility to Protect. ${ }^{627}$ This concept was supported in the 2004 Report of the United Nations High Level Panel on Threats, Challenges and Change entitled: A More Secure World: Our Shared Responsibility ${ }^{628}$ and in the Report of the Former Secretary General entitled: In Larger Freedom: Towards Development, Security and Human Rights for $\mathrm{All}^{629}$, recognition of the Responsibility to protect as a United Nations standard was confirmed by the adoption of the Final Document of the 2005 World Summit ${ }^{630}$ bringing together the heads of States and Governments, devoting in particular paragraphs 138 and 139, the responsibility to protect. The United Nations Security Council subsequently adopted Resolutions under this label.

As regards the substance of the responsibility to protect, it is necessary, above all, to point out the Commission's preliminary clarification: "This report is about the so-called "right of humanitarian intervention": the question of when, if ever, it is appropriate for states to take

${ }^{625}$ C. G. BADESCU, Humanitarian Intervention and the Responsibility to Protect Security and human rights, Routledge, London, New York, 2011, p. 2

${ }^{626}$ ICISS

${ }^{627}$ International Commission on Intervention and State Sovereignty, The Responsibility To Protect, National Library of Canada cataloguing in publication data, Ottawa, December 2001

${ }^{628}$ High-level Panel on Threats, Challenges and Change, A More Secure World: Our Shared Responsibility, United Nations, New York, 2004

${ }^{629}$ United Nations, General Assembly, In Larger Freedom: Towards Development, Security and Human Rights for All, Report of the Secretary-General, A/59/2005, 21 March 2005

${ }^{630}$ United Nations, General Assembly, 2005 World Summit Outcome, Resolution A/RES/60/1, 24 October 2005 , paras. 138-14 
coercive - and in particular military - action, against another state for the purpose of protecting people at risk in that other state. At least until the horrifying events of 11 September 2001 brought to center stage the international response to terrorism, the issue of intervention for human protection purposes has been seen as one of the most controversial and difficult of all international relations questions. With the end of the Cold War, it became a live issue as never before. Many calls for intervention have been made over the last decade-some of them answered and some of them ignored. But there continues to be disagreement as to whether, if there is a right of intervention, how and when it should be exercised, and under whose authority" $" 631$.

The Responsibility to protect then came to clarify the meaning to be given to humanitarian intervention in international affairs. However, for the purpose of protecting people, another terminology was used which mentioned "intervention", in particular military intervention. Faced with the reluctance of humanitarian workers in any association of "military" and humanitarian action, the term "responsibility to protect" ${ }^{632}$ was preferred. This compromise is understandable given the context of considerations relating to humanitarian intervention. Indeed, since military intervention is highly political, it can then serve political interests, which can cast doubt on its neutrality. Now, neutrality is one of the cardinal principles of humanitarian assistance which has often proved crucial for access to victims. Humanitarian assistance through military intervention can therefore lead to a great deal of suspicion from parties to the conflict, which can consequently limit humanitarian access to the detriment of victims. Since, in all cases, it is a question of humanitarian intervention, the conceptual positioning of the responsibility to protect makes it possible to distinguish the humanitarian response through politics it signifies, from the humanitarian response through the "humanitarian assistants" or "humanitarian relievers".

According to the Commission, the Responsibility to Protect refers to "the idea that sovereign states have a responsibility to protect their own citizens from avoidable catastrophe - from mass murder and rape, from starvation - but that when they are unwilling or unable to do so, that responsibility must be borne by the broader community of states" ${ }^{\$ 3}$. The Responsibility to Protect according to this commission is based on two principles: ${ }^{634}$

\footnotetext{
${ }^{631}$ ICIIS Report, op. cit. p. vii

${ }^{632}$ Ibid. p. 9

${ }^{633}$ Ibid. p. viii

${ }^{634}$ Ibid. p. xi
} 
- State sovereignty implies responsibility, and it is the State which has the primary responsibility to protect its populations;

- Wherever a population suffers from serious distress, as a result of a civil war, a rebellion or a State decline and the State in question does not want or cannot stop or prevent them, the principle of non-intervention converts to the responsibility to protect.

According to the Commission, the Responsibility to Protect is based on ${ }^{635}$

- Obligations inherent in the concept of sovereignty;

- The responsibility of the Security Council under Chapter VII of the Charter of the United Nations relating to international peace and security;

- Specific legal obligations in the field of human rights and human protection declarations, conventions and treaties, international humanitarian law and national law,

- The constantly evolving practice of States, regional organizations and the Security Council itself.

Regarding its elements, the substance of responsibility includes three responsibilities: ${ }^{636}$

- The responsibility to prevent, consisting in acting on the root and direct causes of internal conflicts and all anthropogenic crises creating a risk for populations;

- Responsibility to react consisting in responding to critical situations with appropriate measures which may include coercive measures, such as international sanctions and prosecutions and in extreme cases, military intervention;

- The responsibility to rebuild, which consists of providing, after a military intervention, the necessary assistance for recovery, reconstruction and reconciliation, addressing the causes of the harm that the intervention aimed to contain.

With regard to the principles for military intervention, the Commission's Report mentions that humanitarian intervention for human protection is an exceptional and extraordinary measure. For it to be legitimized, it must be a danger to human life or a serious risk thereof, which corresponds:

- situations of large-scale human loss with or without genocidal intent and which is the product of either deliberate state action or state negligence or its inability to act or a state decline situation;

${ }^{635}$ Ibid.

636 Ibid. 
- Large-scale ethnic cleansing, whether perpetrated by murder, forced eviction, acts of terror or rape

Military intervention is based on the precautionary principles:

- of the just intention of stopping or preventing human suffering manifested in multilateral operations;

- of last resort, that is to say, the use of force is only legitimized after all other preventive measures or peaceful resolution of the crisis have failed;

- proportional means, that is to say, humanitarian intervention must be the minimum necessary to protect populations;

- of reasonable expectations, that is to say, one should normally expect intervention to stop or prevent human suffering, without creating a worse situation than that justified by its intervention.

This substance of the Responsibility to protect was adopted in other words within the United Nations, during the World Summit of 2005 and noted in its final Outcome in the paragraphs 138 and 139 under the title "Duty to protect of populations against genocide, war crimes, ethnic cleansing and crimes against humanity "637:

Paragraph 138 "Each individual State has the responsibility to protect its populations from genocide, war crimes, ethnic cleansing and crimes against humanity. This responsibility entails the prevention of such crimes, including their incitement, through appropriate and necessary means. We accept that responsibility and will act in accordance with it. The international community should, as appropriate, encourage and help States to exercise this responsibility and support the United Nations in establishing an early warning capability".

Paragraph 139: "The international community, through the United Nations, also has the responsibility to use appropriate diplomatic, humanitarian and other peaceful means, in accordance with Chapters VI and VIII of the Charter, to help to protect populations from genocide, war crimes, ethnic cleansing and crimes against humanity. In this context, we are prepared to take collective action, in a timely and decisive manner, through the Security Council, in accordance with the Charter, including Chapter VII, on a case-by-case basis and in cooperation with relevant regional organizations as appropriate, should peaceful means be inadequate and national authorities are manifestly failing to protect their populations from genocide, war crimes, ethnic cleansing and crimes against humanity. We stress the need for the

${ }^{637} 2005$ World Summit Outcome, op. cit. p. 33 
General Assembly to continue consideration of the responsibility to protect populations from genocide, war crimes, ethnic cleansing and crimes against humanity and its implications, bearing in mind the principles of the Charter and international law. We also intend to commit ourselves, as necessary and appropriate, to helping States build capacity to protect their populations from genocide, war crimes, ethnic cleansing and crimes against humanity and to assisting those which are under stress before crises and conflicts break out."

This substance of the Responsibility to protect was later to be clarified, and the responsibility for drawing up a report to this effect was left to the Secretary General of the United Nations. In 2009, this latter issued a Report ${ }^{638}$ which included the majority of elements present in the ICISS Report. Thus we can know that the responsibility to protect individuals against mass atrocities and ethnic cleansing is the primary responsibility of the State and the secondary responsibility of international community represented by the United Nations in case of failure of the State. This report then outlines three pillars on the basis of which States can implement the Responsibility to Protect: The protection responsibilities of the State, International assistance and capacity-building, Timely and decisive response.

The Note by the General Assembly President on the responsibility to protect populations from genocide, war crimes, ethnic cleansing and crimes against humanity ${ }^{639}$ sheds light on the legal scope and value of this concept in international affairs. Its entry is unequivocal: "The five main documents in which responsibility to protect has been articulated are the High Level Panel's "Report on Threats, Challenges and Change"; the Secretary-General's report "In Larger Freedom "; the Outcome Document of the World Summit 2005; United Nations Security Council Resolution 1674; Secretary General's report on "Implementing the Responsibility to Protect". None of these documents can be considered as a source of binding international law in terms of Article 38 of the Statute of the International Court of Justice which lists the classic sources of international law" ${ }^{\prime 640}$. This point of view immediately enables to understand that the legal worth of the Responsibility to protect, at least as it emerges from the meaning that it is assumed within the General Assembly, is that of soft law, and if one dares not simply to speak of a "common intention" of States. Edifying and rightly is the continuity of this note from the General Assembly: "At the negotiations on the World Summit Outcome Document, the then

\footnotetext{
${ }^{638}$ United Nations, General Assembly, Follow-up to the outcome of the Millennium Summit, Implementing the responsibility to protect, Report of the Secretary-General, A/63/677, 12 January 2009

${ }^{639}$ United Nations, General Assembly, Follow-up to the outcome of the Millennium Summit, Concept note on the responsibility to protect populations from genocide, war crimes, ethnic cleansing and crimes against humanity, Note by the President of the General Assembly, A/63/958, 9 September 2009

${ }^{640}$ Ibid. Annex, p. 3
} 
United States Permanent Representative John Bolton stated accurately that the commitment made in the Document was "not of a legal character". The Document is carefully nuanced to convey the intentions of the member States. Paragraph 138 when it deals with the individual State's responsibility to its own people is clear in its commitment. When it comes to the international community helping States, the phrase used is a general appeal — "should as appropriate”. Paragraph 139 continues this nuanced approach. The language is clear and unconditional when it speaks of the "international community through the UN" having the "responsibility to use appropriate diplomatic, humanitarian and other peaceful means in accordance with Chapters VI and VIII of the Charter". The Document is very cautious when it comes to responsibility to take action through the United Nations Security Council under Chapter VII. Paragraph 139 uses at least four qualifiers. Firstly, the Heads of State merely reaffirm that they "are prepared" to take action, implying a voluntary, rather than mandatory, engagement. Secondly, they are prepared to do this only "on a case by case basis", which precludes a systematic responsibility. Thirdly, even this has to be "in cooperation with regional organizations as appropriate". Fourthly, this should be "in accordance with the Charter" (which covers only immediate threats to international peace and security). Finally, the Heads of State emphasize "the need for the General Assembly to continue consideration of the responsibility to protect populations from genocide, war crimes, ethnic cleansing and crimes against humanity and its implications, bearing in mind the principles of the Charter and international law (emphases ours). It is therefore, amply clear, that there is no legally binding commitment and the General Assembly is charged, in terms of its responsibility under the Charter to develop and elaborate a legal basis. $" 641$

This view correctly points out that the Responsibility to protect only has a legal worth within the framework of the powers recognized to the Security Council under Chapter VII of the United Nations Charter. If this eminent institution qualifies, in accordance with article 39 of this Charter, existence of a threat to the peace, of a breach of the peace or of an act of aggression, situations of massive violations of rights human rights, including serious crimes against civilian, it can then intervene, if it so decides. The nature of the intervention may or may not be military, in accordance with article 39 . Thus, the Responsibility to protect only comes under international governmental law when the Security Council decides to intervene, at its discretion, to protect civilian populations from massive violations of their rights, presenting themselves as serious international crimes. In other words, if, in its discretion, the Security Council does not

${ }^{641}$ Ibid. Annex, p.3 
qualify all situations of large-scale human distress as a threat or a breach of international peace and security, then there can be no substantial actions taken in this respect, engaging the entire international community.

In line with these considerations, the Security Council has had to deal with several situations of human distress. We can cite in particular the Resolutions 1962 regarding Côte d'Ivoire and $1973^{642}$ and 1973 regarding Libya ${ }^{643}$ which noted the State responsibility to protect its populations from serious international crimes, the threat to international peace and security that constituted situations of human distress in these countries and the responsibility of the United Nations to intervene.

The fact remains, however, that the Responsibility to protect in its national and international components (apart from any action under Chapter VII of the Charter of the United Nations) has full effect.

The Responsibility to Protect as a norm of international governmental law formally demonstrates the political humanitarian intervention of the United Nations, that is to say, the United Nations decides to intervene in a sovereign State, for the benefit of civilian populations in distress. Although in so doing, the Responsibility to protect is not conducted within the United Nations framework under the label of "human security", the fact remains that according to the theoretical framework of human security, it is well and true a question of human security. Since it is still a matter of humanitarian intervention, under the name of the Responsibility to protect, the arguments developed above accounting for the humanitarian intervention in the morning of the 1990s also apply in this context. The Responsibility to protect enables to understand the real meaning of sovereignty as being at the service of individuals and thus national government authorities have legitimacy only in the protection of individuals. In case of failure, it is up to the international community to intervene and restore the State so that it can start again on the just meaning of political power. According to the limited substance that it has within the United Nations, however, it is at least a matter of securing individuals for crimes of genocide, war, against humanity. From "humanitarian intervention" to "the responsibility to protect", we observe the ongoing process of education on the order of natural means adequate to confirm human security that members of international society are subject to. It is less a conceptual evolution than a step-by-step awareness of that the real meaning of international

\footnotetext{
${ }^{642}$ United Nations, Resolution, 1962, S/RES/1962, 20 December 2010

${ }^{643}$ United Nations, Resolution 1973, S/RES/197, 17 March 2011
} 
peace and security is human security. International governmental law is thus defined as being at the service of human security, by still including in its content the label "human security".

\section{HUMAN SECURITY: FOUNDATION AND FINALITY OF THE UNITED NATIONS RESOLUTORY PRACTICE UNDER THE LABEL "HUMAN SECURITY"}

International governmental law, through the resolutory practice of the United Nations, also has human security as foundation and finality when it is at its service, clearly under this label. It will be a question of verifying it in this context by considering the substance of this label within the United Nations (2.1) and that in perspective in its trajectory (2.2).

\subsection{The Substance of the label "human security" in the United Nations resolutory Practice}

The substance of the label "human security" in the resolutory practice of the United Nations is inseparable from its advent and from the debate that it was subject to within the United Nations (2.1.1.) and from the final consensus on its definition (2.1.2).

\subsubsection{The advent and debate of human security within the United Nations}

The advent of human security within the United Nations was marked with the 1994 Report of the United Nations Development Program (UNDP). ${ }^{644}$ It begins by noting that "The concept of security has for too long been interpreted narrowly: as security of territory from external aggression, or as protection of national interests in foreign policy or as global security from the threat of a nuclear holocaust. It has been related more to nation-states than to people. The superpowers were locked in an ideological struggle-fighting a cold war all over the world. The developing nations, having won their independence only recently, were sensitive to any real or perceived threats to their fragile national identities. Forgotten were the legitimate concerns of ordinary people who sought security in their daily lives. For many of them, security symbolized protection from the threat of disease, hunger, unemployment, crime, social conflict, political repression and environmental hazards. With the dark shadows of the cold war receding, one can now see that many conflicts are within nations rather than between nations". 645 This

\footnotetext{
${ }^{644}$ United Nations Development Programme, Human Development Report 1994, New York, Oxford, Oxford University Press, 1994, Chap. 2

${ }^{645}$ Ibid. p. 22
} 
paragraph is a kind of reminder of the context in which emergency of human security is felt. It made it clear that security was not only a matter of concerns about the State, including territorial integrity, but also a matter of concerns of individuals. What this report confirms is that "Human security is not a concern with weapons - it is a concern with human life and dignity" ${ }^{\prime 646}$.

This report identified four essential characteristics of human security: Human security is a universal concern, the components of human security are interdependent, Human security is easier to ensure through early prevention, Human security is people-centred. ${ }^{647}$ In addition, two main aspects can be noted: “"It means, first, safety from such chronic threats as hunger, disease and repression. And second, it means protection from sudden and hurtful disruptions in the patterns of daily life-whether in homes, in jobs or in communities. Such threats can exist at all levels of national income and development ${ }^{\prime 648}$. These aspects are summarized in a general definition: "There have always been two major components of human security: freedom from fear and freedom from want". ${ }^{649}$ The immediate clarification of the United Nations position in relation to this definition is highly significant: "This was recognized right from the beginning of the United Nations. But later the concept was tilted in favor of the first component rather than the second. The founders of the United Nations, when considering security, always gave equal weight to territories and to people". ${ }^{650}$

In this definition of the UNDP, human security is linked to seven dimensions to which correspond specific types of threats: $:^{651}$

- Economic security, covering access to employment and resources, is threatened by poverty;

- Food security, meaning material and economic access to food for everyone, at all times, faces the threat of hunger and famine;

- Health security and access to medical care and better health conditions has to deal with injuries and illnesses;

- Environmental security faces the threats of pollution, degradation of the environment endangering human survival and the exhaustion of resources;

\footnotetext{
${ }^{646}$ Ibid.

${ }^{647}$ Ibid. pp. 22-23

${ }^{648}$ Ibid. p. 23

649 Ibid. p. 24

${ }^{650}$ Ibid.

651 R. A. RAVELONA, Sécurité humaine : Clarification du concept et approches par les organisations internationales Quelques repères, Document d'information, Organisation Internationale de la Francophonie, Janvier 2006, p. 7
} 
- Personal security is thwarted by threats which can take several forms: threats from the State, foreign States, other groups of people (ethnic tensions), threats against women or children because of their vulnerability and dependence;

- Community security meaning that most people who get their security of belonging to a social group (family, community, organization, political grouping, ethnic group, etc.), may be threatened by tensions often occurring between these groups due to competition for limited access opportunities and resources;

- Political security, which must guarantee respect for fundamental rights and freedoms, is threatened by arbitrariness and repression.

This conception of the UNDP is generally considered by doctrine as the broad ${ }^{652}$ conception of human security.

In 2005, in his report In Larger freedom: Development, Security and Respect for Human Rights for All, former United Nations Secretary Kofi Annan, although not specifically referring to the concept of human security, echoed the summary definition of this concept in the 1994 UNDP Report: "Larger freedom implies that men and women everywhere have the right to be governed by their own consent, under law, in a society where all individuals can, without discrimination or retribution, speak, worship and associate freely. They must also be free from want - so that the death sentences of extreme poverty and infectious disease are lifted from their lives - and free from fear - so that their lives and livelihoods are not ripped apart by violence and war. Indeed, all people have the right to security and to development" ${ }^{\prime \prime 53}$.

In the 2005 World Summit Outcome, which also enshrines the responsibility to protect, human security is enshrined in these terms in paragraph 143: "We stress the right of people to live in freedom and dignity, free from poverty and despair. We recognize that all individuals, in particular vulnerable people, are entitled to freedom from fear and freedom from want, with an equal opportunity to enjoy all their rights and fully develop their human potential. To this end, we commit ourselves to discussing and defining the notion of human security in the General Assembly"654

\footnotetext{
${ }^{652}$ S. FUKUDA-PARR, C. MESSINEO, op. cit.

${ }^{653}$ In Larger Freedom: Towards Development, Security and Human Rights for All, Report of the SecretaryGeneral, op. cit. p. 5

${ }^{654} 2005$ World Summit Outcome, op. cit. p. 31
} 
Until 2005, human security was therefore fundamentally understood as freedom from fear and freedom from want, the former referring to freedom from all situations of violence and the latter, the capacity to meet one's needs, at least the most essential.

The Report of the Secretary General, issued in $2010,{ }^{655}$ took stock of the progress made in the promotion of this concept since the 2005 World Summit. It took stock of the debates devoted to human security, of the various definitions which were given and of the link existing with the sovereignty of States and the duty to protect and presented the principles and approach aimed at promoting human security, as well as the application of this concept to the current priorities of the United Nations. Thus, recalling several definitional contributions from different groups and international organizations, that report detects their common denominator on three constituent elements of human security: "First, human security is in response to current and emerging threats - threats that are multiple, complex and interrelated and can acquire transnational dimensions. Second, human security calls for an expanded understanding of security where the protection and empowerment of people form the basis and the purpose of security. Third, human security does not entail the use offorce against the sovereignty of States and aims to integrate the goals of freedom from fear, freedom from want and freedom to live in dignity through people-centered, comprehensive, context-specific and preventive strategies" ${ }^{256}$. In this clarification undertaking of the concept of human security, this Report is concerned with reporting on the difference that would exist between human security and the responsibility to protect: "As agreed in paragraph 143 of the World Summit Outcome, the purpose of human security is to enable all individuals to be free from fear and want, and to enjoy all their rights and fully develop their human potential. The use of force is not envisaged in the application of the human security concept. The focus of human security is on fostering Government and local capacities and strengthening the resilience of both to emerging challenges in ways that are mutually reinforcing, preventive and comprehensive". ${ }^{657}$ This paragraph suggests that the fundamental difference between human security and the responsibility to protect is in the use of force.

With regard to the principles and approach of human security, the same Report is instructive: "Moreover, human security underscores the universality and primacy of a set of freedoms that are fundamental to human life, and as such it makes no distinction between civil, political,

\footnotetext{
${ }^{655}$ United Nations, General Assembly, Follow-up to the outcome of the Millennium Summit, Human security, Report of the Secretary-General, A/64/701, 8 March 2010

${ }^{656}$ Ibid. Parag. 19, p. 6

${ }^{657}$ Ibid.
} 
economic, social and cultural rights, thereby addressing security threats in a multidimensional and comprehensive manner. (...). ${ }^{658}$ Contained in scope, human security informs policies that, while comprehensive, are nevertheless targeted, and capture the most critical and pervasive threats that are relevant to a particular situation. For example, some human security challenges are specific to the internal dynamics of a particular community, such as lack of access to resources and opportunities, while others are transnational, such as pandemics, climate change and financial and economic crises. The consideration of the scope of human security is important in formulating policy and operational recommendations and calibrating them to particular contexts". ${ }^{659}$

In these paragraphs, the universal, global and multidimensional nature of concerns relating to human security is clearly highlighted, what confirms the synthesis of the various definitional contributions of human security developed so far. Very important is the precision which is brought with regard to the bearer of the responsibility of human security. "Human security is based on a fundamental understanding that Governments retain the primary role for ensuring the survival, livelihood and dignity of their citizens. It is an invaluable tool for assisting Governments in identifying critical and pervasive threats to the welfare of their people and the stability of their sovereignty." 660 To international community has been devolved a complementary or supporting role to States.

This substance of human security on the international scale will be reflected in the SecretaryGeneral's second Report ${ }^{661}$, which will propose a United Nations consensus on human security. This proposal will inspire or will be the official position of the United Nations on the meaning of human security. This one stands as international governmental law under the label "human security".

\subsubsection{The United Nations Consensus on Human Security}

The United Nations Consensus on the meaning Human Security is noted in the General Assembly's Resolution adopted on 10 September $2012 .{ }^{662}$ This resolution appears in a preamble and in a body that we will understand. The study of this resolution is necessary in view of its importance for international community: it stands as the official instrument of the United Nations on human security, the only one of its kind which provides information on the meaning

\footnotetext{
${ }^{658}$ Ibid. Parag. 26, p. 7

${ }^{659}$ Ibid. Parag. 27, p. 7

${ }^{660}$ Ibid. p. 1 (Summary)

${ }^{661}$ Report of the Secretary-General, A/66/763, op. cit.

${ }^{662}$ A/RES/66/290 66/290, op. cit.
} 
of human security within the United Nations, as an interpretation of the Charter of the United Nations.

First of all, the General Assembly begins by reaffirming its attachment to the purposes and principles set out in the United Nations Charter and to international law. This already shows that an understanding of human security cannot be independent of these legal bases. That is reinforced by the consideration of the interdependence and mutual reinforcement of the three pillars of the United Nations, named, development, human rights, peace and security.

The essence of the United Nations consensus on human security is contained in paragraph 3. The General Assembly “agrees that human security is an approach to assist Member States in identifying and addressing widespread and cross-cutting challenges to the survival livelihood and dignity of their people". Consequently, a common definition of the concept of human security includes the following:

(a) The right of people to live in freedom and dignity, free from poverty and despair. All individuals, in particular vulnerable people, are entitled to freedom from fear and freedom from want, with an equal opportunity to enjoy all their rights and fully develop their human potential;

This paragraph already enshrines the general synthesis of the meaning of human security which has been given so far, namely freedom from fear and the freedom from want. Although "life in freedom and in dignity, free from poverty and despair" precedes in this formulation the mention of "freedom from fear and want", the latter perfectly summarizes the former. A life of dignity in the sense of the theoretical framework of human security is a life that respects and confirms the human being in that essential order of his/her nature. Thus dignity refers only to the intrinsic value of this nature, which is accounted for by the state of security consubstantial to it. Since this is a state of well-being or of freedom from pain, poverty, fear, unmet needs (at least basic) and all causes of despair cannot confirm it. On the contrary, they help to precipitate the human being's extinction. Thus only the enjoyment of rights and the possibility for individuals to fully develop their capacities are guarantees of their permanent preservation. Since they are the ones who make up political societies or States, within precise territorial limits, we understand that they can only join together for the security of everyone. The task of the rulers could not aim at something else. 
(b) Human security calls for people-centred, comprehensive, context-specific and prevention-oriented responses that strengthen the protection and empowerment of all people and all communities;

This paragraph is right to point out the centrality of the human being in the responses to human security. From the point of view of the theoretical framework of human security, the human being is the primary ontological unit. A political society cannot exist without human beings, summing up in "human nature" and whose essential tendency is only the confirmation of the intrinsic finite order nature which has a vocation to permanence in what it is. For this purpose, it is therefore quite natural that political society, which is nothing else than the organization to which individuals essentially agree, be centered on the human being. Since it is a question of conservation in what Man is, the answers which are the product of social organization cannot be limited to certain aspects of human life, they necessarily include them all, hence their wholeness. Although global, they cannot however elude the context. We should not forget the contextual diversity that characterizes coexistence in society. It can be a cultural, gender, territorial, political, or economic, etc. context in which some members of society are involved and which may be different from others. Since humans are conserved in these different contexts that on the basis also of the principle of liberty, then the answers for conservation must just as much be contextual. Emphasis on prevention is proven to provide early protection. It enables to act on the causes of crises in order to prevent their occurrence, which can have more harmful effects on individuals, and to reinforce the resilience of populations, in case prevention efforts prove unable to prevent the occurrence of the crisis. Resilience, indeed, empowers both collective and individual capacities for action.

(c) Human security recognizes the interlinkages between peace, development and human rights, and equally considers civil, political, economic, social and cultural rights;

Peace, development and human rights are the three pillars of the United Nations, and these can only be understood or measured by their benefit to human beings. The fact that human security places equal importance on civil, political, economic, social and cultural rights reflects the link between human security and human rights. Indeed, from the perspective of human security, as a law of nature, human rights can be considered as titles or prerogatives which allow its confirmation. Their civil, political, economic, social and cultural natures characterize the multiple, albeit unitary, substance of human nature. This one, being itself only in all these dimensions, it is on purpose that the substantial state "security" accounting for it cannot ignore 
one of them in its conservation undertaking. Human rights in all their diversity are therefore necessarily interdependent. They all contribute to the conservation of the individual.

(d) The notion of human security is distinct from the responsibility to protect and its implementation;

Based on the 2005 World Summit Outcome, we realize that within the United Nations, the responsibility to protect is distinct from human security. The first concerns only a certain type of threat, serious international crimes (war crimes, crimes against humanity, ethnic cleansing, etc.) while the rest of the threat package is in the account of human security. Report of the Secretary-General explains this distinction as follows: "the notion of human security is distinct from the responsibility to protect and its implementation. While human security is in response to multidimensional insecurities facing people, the responsibility to protect focuses on protecting populations from specific cases of genocide, war crimes, ethnic cleansing and crimes against humanity. As such, human security has broader application, bringing together the three pillars of the United Nations system, whereas the responsibility to protect centres on the aforementioned situations". ${ }^{663}$ Clearly the United Nations wanted to distinguish the subjects with regard to their potential implications.

(e) Human security does not entail the threat or the use of force or coercive measures. Human security does not replace State security;

This paragraph is a continuity of the distinction between human security and the responsibility to protect with regard to the use of force, but here the expression is general. Within the United Nations one cannot talk about human security when we talk about the threat or use of force. We thus realize that a distinction is made between human security and the security that the State must ensure and which is undoubtedly linked to the maintenance of order and necessarily involves the use of force. Such a distinction further demonstrates that this is a desire to separate matters.

${ }^{663}$ Follow-up to General Assembly resolution 64/291 on human security, Report of the Secretary-General, A/66/763, op. cit. Parag. 23, p. 6 
(f) Human security is based on national ownership. Since the political, economic, social and cultural conditions for human security vary significantly across and within countries, and at different points in time, human security strengthens national solutions which are compatible with local realities;

This paragraph reflects that human security is mainly ensured or preserved at the national level. With national society configured as a State, it is therefore logical that human security should be primarily of national appropriation. Based on the theoretical framework of human security, individuals constitute themselves in political society to guarantee to each one the confirmation of their intrinsic state of security. The State is essentially an agreement of human beings for the purpose of their conservation. This resolution rightly acknowledges that. If the association of individuals agrees with other associations for an international society, it is in reality always only for the sake of conservation. The various conditions mentioned blatantly correspond to all types of rights and still emphasize the need to take into account the context for the satisfaction of human security.

(g) Governments retain the primary role and responsibility for ensuring the survival, livelihood and dignity of their citizens. The role of the international community is to complement and provide the necessary support to Governments, upon their request, so as to strengthen their capacity to respond to current and emerging threats. Human security requires greater collaboration and partnership among Governments, international and regional organizations and civil society;

This paragraph emphasizes that the primary responsibility for ensuring security rests with the State. This is an obvious consequence of the previous paragraph. The role of international society then becomes subsidiary or complementary. International society being an interstate society, the United Nations which embodies it represents that society aiming at approaching common or global concerns in a logic that does not give it primacy over the State. States are the main actors in international relations and international organizations are secondary actors, established by States for the collective management of common concerns. Thus national appropriation of human security means that States are better placed to know the needs it demands, how they can meet them and what support they can require from international community. That said, when it comes to common concerns, it is normal for international cooperation to be strengthened. The phenomenon of climate change is a topical example because it involves all states, which can only manage it through cooperation. 
(h) Human security must be implemented with full respect for the purposes and principles enshrined in the Charter of the United Nations, including full respect for the sovereignty of States, territorial integrity and non-interference in matters that are essentially within the domestic jurisdiction of States. Human security does not entail additional legal obligations on the part of States;

This paragraph is in line with the previous ones since it reiterates that human security is mainly a national matter. To support that, it notes the principles set out in the United Nations Charter on national sovereignty. Since care is taken to distinguish it from the responsibility to protect, which may give rise to military intervention from the United Nations, under Chapter VII of the Charter, and from the maintenance of order assured by the State, human security would then be a matter of a national appropriation that international society could not compete with.

This substance of human security within the United Nations which is valid under international government law under the label "human security" is undoubtedly full of safeguards. It is a narrow view of human security compared to what it means from the point of view of its theoretical framework, which is grounded on its identity of a law of nature. That said, the United Nations officially does "human security" through this resolution. This then helps to verify that governmental law is at the service of human security. But this way of doing things, from the perspective of human security necessarily implies an appreciation of the perspectives of its trajectory based on the implications of its current conception.

\subsection{The resolutory practice of the United Nations at the service of human security under the label "human security" in perspective}

The resolutory practice of the United Nations at the service of human security, under this exact label will end up being done completely in the light of the credible consequences of the current practice which one can expect through the yardstick of human security, as a law of nature. Thus, this framework will be an opportunity to verify that international governmental law ends up being known that at the service of human security under this label, with regard to its trajectory. We will undertake to decline this by noting a certain lack of logic in the resolutory practice of the United Nations for the benefit of the human person, which grounds actions that ultimately do not always have a happy impact on individual conservation. Then it is a matter of the final order of human security regarding the positive law aiming at giving concrete form to the Charter of the United Nations. Its current formulation at the service of human security contains some ambiguity (2.2.1) whose correction would be known necessary (2.2.2). 


\subsubsection{The resolutory practice of the United Nations at the service of human security: A certain ambiguity}

The United Nations resolutory practice at the service of human security noted above, whether it is without or under the label "human security", is mainly equivocal in the separation of matters under international peace and security. We will focus on the different substances of the responsibility to protect and human security receive within the United Nations.

\section{Ambiguity of the substance of the responsibility to protect within the United Nations and the theoretical framework of human security}

The official position of the United Nations on the responsibility to protect was enshrined in the 2005 World Summit Outcome, notably in paragraphs 138 and 139, under the designation "Responsibility to protect populations from genocide, war crimes, ethnic cleansing and crimes against humanity". The responsibility to protect within the United Nations only concerns serious international crimes and in view of the United Nations resolutory practice, we can see that it is implemented by the Security Council under the Chapter VII. From the point of view of the theoretical framework of human security, this is a narrow conception of human security which necessarily has repercussions in terms of its confirmation.

The responsibility to protect is the term given to the United Nations political humanitarian intervention to distinguish it from the apolitical one of humanitarian assistance. A question then arises as to what justifies the choice of putting in the account of the responsibility to protect only the most serious crimes that the international community can face. Furthermore, in so doing, is it not doing human security?

The United Nations Secretary General's Report ${ }^{664}$ on the Responsibility to protect: timely and decisive response noted that "The need for a collective response to protect populations from genocide, war crimes, ethnic cleansing and crimes against humanity was founded on the brutal legacy of the twentieth century, marred as it was by the Holocaust, the killing fields of Cambodia, the genocide in Rwanda, the mass killings in Srebrenica and other events. These and other tragic events, which underlined the profound failure of individual States to live up to their responsibilities and obligations under international law, as well as the collective inadequacies of international institutions, led my predecessor, Secretary-General Kofi Annan, to take a series of steps that resulted in the development of the concept of the responsibility to

\footnotetext{
${ }^{664}$ United Nations, General Assembly, Follow-up to the outcome of the Millennium Summit, Responsibility to protect: timely and decisive response, Report of the Secretary-General, A/66/874-S/2012/578, 25 July 2012
} 
protect ${ }^{665}$. The first question undoubtedly finds its answer in this aforementioned passage. The development of the Responsibility to protect was necessary in view of the serious consequences of violent conflicts on civilian population. In view of the examples cited, the fact that people are often subject to abuses due to their direct targeting or that they are collateral victims during violent conflicts necessitated measures for their protection. From the start, violent conflicts have always been linked to serious international crimes through massive human rights violations. It was precisely these that led the United Nations to recognize their responsibility to intervene for the protection of civilian populations within the borders of sovereign States.

The main international characteristic of international core crimes including genocide, war crimes, ethnic cleansing, crimes against humanity, concerning the responsibility to protect, is that they are against the essence of humanity. This is how it is often said they flout the conscience of humanity. That justifies the universal nature of these crimes and clarifies that they are crimes against human nature. Since this is an identity grouping together all its members or individuals who belong to it, it is therefore a question of crimes against the very essence of man or crimes against mankind. These considerations are part of the theoretical framework of human security. According to this one, security is the state consubstantial with human nature, that which accounts for it or which intrinsically characterizes this nature. Human security being the most basic property of human nature, it is therefore essential to it, so that it is not enough to be a human being, but to be in security. Human security embodying thus the natural human order, serious international crimes flouting this nature in its very essence and justifying based on that the common concern of the whole international community, can only be crimes against human security. Just as we speak of a human nature in the case of serious international crimes, so we speak of a human nature with regard to human security. We can simplify as following:

$>$ Human nature $=$ Serious international crimes $=$ Responsibility to protect

$>$ Human nature $=$ Human security

$>$ Human security $=$ Serious international crimes $=$ Responsibility to protect

So we realize that if the United Nations conceive serious international crimes, as a concern that is managed under the responsibility to protect and not of human security, there is an ambiguity. Obviously this is a definitional decree.

The most basic definition of human security that comes out of all thinking is "freedom from fear and freedom from want". Serious international crimes undoubtedly concern the freedom

${ }^{665}$ Ibid. Parag. 4, p. 2 
from fear. This implies the protection of all violent events having harmful consequences on the physical and moral integrity of human beings. The level of fear that serious international crimes can inflict on individuals is unimaginable. The responsibility of States and of international society consists precisely in guaranteeing individuals this freedom from fear. With regard to the responsibility to protect and human security as they are enshrined within the United Nations, this responsibility mainly rests on the State and subsidiary on the United Nations, except that the regime of the intervention of the United Nations is different in the two cases: the sovereign decision of the United Nations Security Council regarding the responsibility to protect and a state request for support to international community regarding human security. In either case, how could we think that implementation of this responsibility for the protection of populations from international core crimes cannot help guarantee them freedom from fear? Since it cannot be said, it is still clear that the responsibility to protect is a matter of human security.

According to the report of the ICISS Report, the responsibility to prevent consists in eliminating both the root causes and the direct causes of internal conflicts and other man-made crises which endangered populations. The Secretary General's Report entitled: Responsibility to Protect: State Responsibility and Prevention, 666 "Since economic deprivation or real or perceived disparities constitute risk factors for atrocity crimes, a range of political, economic and social measures can be taken to increase actual or perceived equity in the distribution of resources, assets, income and opportunities among groups and to promote overall economic development and prosperity. Relevant measures to promote horizontal equality could include employment and safety net programmes for marginalized populations, including young people, as well as fiscal reforms to enhance transparency and equity. Anti-discriminatory initiatives and policies aimed at reducing corruption, including corruption or favoritism linked to identity, can complement these reforms. Since corruption and inequity undermine the legitimacy of State, such reforms can contribute to mitigating grievances that create instability" ${ }^{\prime 67}$ This paragraph is part of the preventive component of the responsibility to protect from serious international crimes, multidimensional measures which may be political, economic or social. This range of measures is well suited to the global and contextual nature of government responses to the benefit of human security, which also emphasizes prevention. ${ }^{668}$ How then can one do the

\footnotetext{
${ }^{666}$ United Nations, General Assembly, Follow-up to the outcome of the Millennium Summit, Responsibility to protect: State responsibility and prevention, Report of the Secretary-General, A/67/929-S/2013/399, 9 July 2013 ${ }^{667}$ Ibid. Parag 45, p. 12

${ }^{668}$ Paragraph 3b of the United Nations Consensus on Human Security, A/RES/66/290 66/290, op. cit.
} 
responsibility to protect without doing human security? This is only possible from and through a definitional decree.

The reactive component is after highlighted within the responsibility to protect. When prevention efforts have failed to prevent the occurrence of a crisis, then duty bearers must react. This reaction effectively consists in protecting populations from mass violence. Protection is also the other component of human security. According to the Report of the Secretary-General Follow-up to General Assembly resolution 64/291 on human security, it is noted that "human security aims at ensuring the survival, livelihood and dignity of people in response to current and emerging threats - threats that are widespread and cross cutting. Such threats are not limited to those living in absolute poverty or conflict. As evidenced by the recent earthquake and tsunami in east Japan and the financial and economic challenges in Europe and the United States of America, today, people throughout the world, in developing and developed countries alike, live under varied conditions of insecurity. These threats seriously challenge both Governments and people, and call for a rethinking of security where the protection and empowerment of individuals form the basis for achieving stability, development and human progress". 669 Protecting populations from mass violence is effectively working for their survival. When such crises do occur, they are in fact existing threats because they involve a serious risk of acute distress on civilian population and that is why their protection is crucial. The Consensus on Human Security also mentions in paragraph $3 b$ that "Human security calls for people-centred, comprehensive, context-specific and prevention-oriented responses that strengthen the protection and empowerment of all people and all communities". We can still see the responsibility to protect and human security in an equal way. Concluding then in a difference between the two can only come from a definitional decree. Let us note it again in the aforementioned Report of the Secretary General Follow-up to General Assembly resolution 64/291 on human security.

Indeed: "the notion of human security is distinct from the responsibility to protect and its implementation. While human security is in response to multidimensional insecurities facing people, the responsibility to protect focuses on protecting populations from specific cases of genocide, war crimes, ethnic cleansing and crimes against humanity. As such, human security has broader application, bringing together the three pillars of the United Nations system,

${ }^{669}$ Follow-up to General Assembly resolution 64/291 on human security, Report of the Secretary-General, A/66/763, op. cit. 
whereas the responsibility to protect centres on the aforementioned situations". ${ }^{670}$ The word "difference" means that there is no general similarity between two things. If the concerns for human security are among the multidimensional situations that individuals face on a daily basis, then when they are subject to mass violence, as was a certain daily in Rwanda in 1994 or in Libya in 2011, these are human security concerns. What this report says is that the responsibility to protect deals specifically with serious international crimes. So, since these are facts that also come under human security, then the responsibility to protect becomes a specific element or a component of human security. This analysis is confirmed in the Report's own words, particularly, the broad scope of human security and the specificity of the responsibility to protect. Human security is therefore the general and the responsibility to protect the special. But there can be no question of seeing a difference, but rather the wholeness of human security and a part of it which is the responsibility to protect. At this level, one can still certainly say that doing the responsibility to protect is doing human security. So there is no difference.

Another indication is important in this explanatory passage: the interests in the three pillars of the United Nations, namely peace, human rights and development, are put in the account of human security, without this being specified for the Responsibility to protect. So one would ask whether the Responsibility to protect does not also include these three pillars. Referring to the point of view of the ICISS, we can note this link between the responsibility to protect and these pillars:

1.12 "The current debate on intervention for human protection purposes is itself both a product and a reflection of how much has changed since the UN was established. The current debate takes place in the context of a broadly expanded range of state, non-state, and institutional actors, and increasingly evident interaction and interdependence among them. It is a debate that reflects new sets of issues and new types of concerns. It is a debate that is being conducted within the framework of new standards of conduct for states and individuals, and in a context of greatly increased expectations for action. And it is a debate that takes place within an institutional framework that since the end of the Cold War has held out the prospect of effective joint international action to address issues of peace, security, human rights and sustainable development on a global scale. ${ }^{.671}$

2.22 "This Commission certainly accepts that issues of sovereignty and intervention are not just matters affecting the rights or prerogatives of states, but that they deeply affect and involve

\footnotetext{
${ }^{670}$ Ibid. p. 6

${ }^{671}$ ICISS Report, p. 3
} 
individual human beings in fundamental ways. One of the virtues of expressing the key issue in this debate as "the responsibility to protect" is that it focuses attention where it should be most concentrated, on the human needs of those seeking protection or assistance. The emphasis in the security debate shifts, with this focus, from territorial security, and security through armaments, to security through human development with access to food and employment, and to environmental security", 672

3.2 "Prevention of deadly conflict and other forms of man-made catastrophe is, as with all other aspects of the responsibility to protect, first and foremost the responsibility of sovereign states, and the communities and institutions within them. A firm national commitment to ensuring fair treatment and fair opportunities for all citizens provides a solid basis for conflict prevention. Efforts to ensure accountability and good governance, protect human rights, promote social and economic development and ensure a fair distribution of resources point toward the necessary means" ${ }^{\prime 673}$

These three paragraphs highlight that peace, human rights and development are of interest under the responsibility to protect. The preventive component of it necessarily includes these pillars. If human rights are fully guaranteed in all their interdependence, it is almost plausible that a society would not turn against itself. If there is peace in a society, then this is evidence of the absence of internal conflicts. Development, which is generally defined as the extension of individuals' capacities for choice, allows in conformity with principles of human rights, the satisfaction of these and social peace. Thus, with regard to the pillars of the United Nations, the explanation of the Report of the Secretary-General would have focused only on the "reaction" component of the responsibility to protect, which as such would imply certain measures that would not include human security. That would be ambiguous when we know that the reaction is not the only measure signifying the Responsibility to protect. If this one includes in its specific character, the three pillars of the United Nations, precisely in its preventive component, in the same way as human security in its general character and if the reaction to protect populations from mass violence serves to providing them with freedom from fear, an essential component of human security, then and again the responsibility to protect and human security mean each other. Thus if the difference can only exist based on a definitional decree which is related to the interventions that each implies, it does not succeed in convincing of the absence of a conceptual identity of the responsibility to protect and human security.

\footnotetext{
672 Ibid. p. 15

${ }^{673}$ Ibid. p. 19
} 
Ambiguity of the substance of human security within the United Nations and the natural law of human security

With regard to human security mainly, the only reference to its synthetic definition of freedom from fear and freedom from want enables us know that the international consensus on human security is ambiguous. Indeed, let us recall paragraph 3 (e) which provides that "Human security does not entail the threat or the use of force or coercive measures. Human security does not replace State security". This provision is very surprising because it inscribes the use of force outside human security. It is clearly contradictory to its component that is freedom from fear. If measures are taken for the protection of public order, for the safety of populations, as well as preventive measures, then would not human security be done? It is clear from the formulation of the international Consensus that human security cannot be done in this way. This is a blatant contradiction of the freedom of fear-component of human security. How can people be protected from fear, by measures to protect and prevent attacks on their safety without doing human security? The 1994 UNDP Report already notes that human security can be explicitly defined as "first, safety from such chronic threats as hunger, disease and repression. And second, it means protection from sudden and hurtful disruptions in the patterns of daily lifewhether in homes, in jobs or in communities". ${ }^{674}$ What therefore is the sense of the protection implied by human security? If such a protection exists without the use of force then would it be a question of guaranteeing freedom from fear only through preventive measures? It cannot be said. Human security, as recognized in the International Consensus in paragraph $3 b$, calls for global responses, adapted to the context which reinforce protection. Furthermore, the Secretary General's Report: Follow-up to General Assembly resolution 64/291 on human security, notes that "human security makes no distinction between civil, political, economic, social and cultural rights and as a result addresses threats to the survival, livelihood and dignity of people in a multidimensional and comprehensive manner". ${ }^{675}$ How then would such comprehensive, multidimensional and integrated responses preclude the use of force for the purpose of human security? One could not really think so.

In reality, paragraph $3 \mathrm{e}$ reflects the reluctance of the United Nations to fully assert that human security includes everything related to the conservation of individuals. So a separation of matters is privileged, as in paragraph $3 \mathrm{e}$ human security where is distinguished from the security

\footnotetext{
6741994 UNDP Report, op. cit. p. 23

${ }^{675}$ Follow-up to General Assembly resolution 64/291 on human security, Report of the Secretary-General, A/66/763, op. cit. p. 6
} 
that the State must guarantee. In the understanding of the United Nations, there are several conceptions of security: human security, security through force or more generally security of the territory or national security. It is difficult to think, according the United Nations conception, that a matter of human security be a matter of national security and vice versa. Besides, from the start, the concept of human security has always been considered to be different from the traditional concept of state security, which includes military, territorial security ${ }^{676}$. But the words used to signify human security are so inclusive that the distinctive apprehension the United Nations maintains in relation to traditional security is betrayed : "human security underscores the universality and interdependence of a set of freedoms that are fundamental to human life: freedom from fear, freedom from want and freedom to live in dignity. As a result, human security emphasizes the interlinkages between security, development and human rights and considers these to be the building blocks of human and, therefore, national security". 677

As soon as we agree to signify human security as freedom from fear and freedom from want, everything is included, the military, the non-military the territorial, the non-territorial, the use and non-use of force, prevention, reaction, economic, political, social, cultural, etc. This is what global, multidimensional, integrated, universal responses refer to. That is precisely the understanding implied by the theoretical framework of human security.

Indeed, human security, as a law of nature, allows us to know that the natural tendency of the human being is the confirmation of this state which is consubstantial with its nature. Since it is an existent, it can no longer be created or realized, since it is already real, but rather confirmed in what it is. In other words, the human being is devoted to its conservation or its continuity permanently in this state which accounts for its nature. This logic implies that everything regarding individual conservation is a matter of human security.

The definitional decree at work relating to the concepts of the responsibility to protect and human security from the United Nations means that in their current states, a meaning has been decided to them, that the meaning of these concepts has been agreed by the different members of the United Nations. It is therefore a political consensus on the meaning of the responsibility to protect and human security, instead of the objective meaning that these concepts carry or simply are in themselves. The United Nations understanding is certainly ambiguous and it is

\footnotetext{
6761994 UNDP Report, op. cit. p. 24

${ }^{677}$ Follow-up to General Assembly resolution 64/291 on human security, Report of the Secretary-General, A/66/763, op. cit. Parag. 18, p. 5
} 
necessary to note it because that implies practical consequences which do not always result in the conservation of the sets of individuals who constituted themselves into political societies or (politically) organized themselves for this purpose.

\subsubsection{The ambiguous intervention under the responsibility to protect and human security}

The responsibility to protect and human security do not entail the same interventions or at least the same type of responsibilities. Having unveiled the ambiguity existing in the current United Nations understanding of these concepts, and having concluded in a substantial identity between them, we have come to know that the distinction was certainly decreed based on a certain choice of the consequences they had to respectively lead to in terms of intervention. It goes without saying that this one in turn could only contain ambiguity.

Let's start by recalling the responsibilities under the responsibility to protect and human security.

With regard to the responsibility to protect, the 2005 World Summit Outcome specifies in paragraph 138 that "Each individual State has the responsibility to protect its populations from genocide, war crimes, ethnic cleansing and crimes against humanity. This responsibility entails the prevention of such crimes, including their incitement, through appropriate and necessary means. We accept that responsibility and will act in accordance with it." ${ }^{278}$ Then paragraph 139 mentions that: "The international community, through the United Nations, also has the responsibility to use appropriate diplomatic, humanitarian and other peaceful means, in accordance with Chapters VI and VIII of the Charter, to help to protect populations from genocide, war crimes, ethnic cleansing and crimes against humanity. In this context, we are prepared to take collective action, in a timely and decisive manner, through the Security Council, in accordance with the Charter, including Chapter VII, on a case-by-case basis and in cooperation with relevant regional organizations as appropriate, should peaceful means be inadequate and national authorities are manifestly failing to protect their populations from genocide, war crimes, ethnic cleansing and crimes against humanity. We stress the need for the General Assembly to continue consideration of the responsibility to protect populations from genocide, war crimes, ethnic cleansing and crimes against humanity and its implications, bearing in mind the principles of the Charter and international law. We also intend to commit

\footnotetext{
6782005 World Summit Outcome, op. cit. p. 30
} 
ourselves, as necessary and appropriate, to helping States build capacity to protect their populations from genocide, war crimes, ethnic cleansing and crimes against humanity". 679

The responsibility to protect therefore rests primarily on the State and secondarily on international community. Only the latter's responsibility, particularly within the framework of the United Nations, will interest us since we are dwelling on international governmental law which stands here as the resolutory practice of the United Nations. So far, the United Nations intervention to protect civilians from serious international crimes has been part of international peace and security. In this context, it is much more the reactive component of the responsibility to protect; the resolutory practice consequently entailing all the authority devolved to the decisions taken in this matter.

The United Nations decisions related to international peace and security bind the entire international community. In this matter, the United Nations can be considered as ruling over all States. These are required to assist in the execution of the decisions taken. The Security Council, through the United Nations, can be considered in turn as the government of international society, much like the executive branch represents the government within states. The responsibility to protect from serious international crimes has been recognized as falling within the framework of international peace and security and thus these situations of violence against civilians are considered as threats to or breaches of international peace and security. The situations which have given rise to this qualification at the international level have entailed a binding intervention of the United Nations whether or not it were armed. At the same time, the preventive component of the responsibility to protect does not have the same authority. It is generally left to the full authority of the State, and the United Nations only intervenes in complementarity. However, this way of doing has a consequence on the occurrence of crises. The Secretary General of the United Nations, in his Report: Mobilizing collective action: the next decade of the responsibility to protect, ${ }^{60}$ notes that "Despite this progress, the international community has fallen woefully short of its aspiration to prevent and respond to atrocity crimes. As noted in my report for the World Humanitarian Summit, brutal and intractable conflicts are devastating the lives of millions of people in almost every region, threatening the futures of entire generations. Today we face a more challenging context, in which some States and non-State actors routinely threaten populations and make calculated

\footnotetext{
${ }^{679}$ Ibid.

${ }^{680}$ United Nations, Follow-up to the outcome of the Millennium Summit, Mobilizing collective action: the next decade of the responsibility to protect, Report of the Secretary-General, A/70/999-S/2016/620, 22 July 2016
} 
decisions to disregard their legal obligations and protection responsibilities. Some of these situations, such as in Iraq and the Syrian Arab Republic, have been the focus of sustained international attention, while others, such as the Democratic People's Republic of Korea, Eritrea and South Kordofan in the Sudan, have been kept from our view. At a moment when so many of the international norms and standards related to protection are being flouted, it is crucial that Member States remain true to the commitments they made in 2005".681

The United Nations resolutory practice from the Security Council then becomes ambiguous. Indeed, in the implementation of the Responsibility to protect, a stronger focus on the reaction or a stronger authority recognized to it to the detriment of prevention would let understand that the latter is less important than the former. In reality, prevention is far more important than reaction because the occurrence or "realization" of the crisis is an indicator that prevention has failed, because its purpose is precisely to prevent "realization" of the crisis. Crisis prevention is used to act on the immediate and immediate causes of crisis so that they do not reach the saturation point of the crisis. In other words crisis prevention aims at acting on the various causes of the crisis so that this does not materialize. As the increased violence against civilians is generally anthropogenic, its prevention is much more realistic than the prevention of crisis of natural origin, given the great hazard weighing on them. The prevention of these crimes then consists in diagnosing and working to contain all the causes which could lead to serious international crimes. Successful preventive action cannot therefore result in a crisis. The United Nations resolutory practice would therefore suggest that a greater authority of action on the effect of the cause would be more important than a greater authority of action on the cause of the effect. When in reality it is quite the opposite. International peace and security are much more threatened by the causes of serious international crimes than by their effects because without cause, no effect. It is the failure of action on the cause that enables the occurrence of their effects. Addressing the causes of these crimes would result in lasting international peace and security, without mentioning the low cost involved. It is therefore the preventive component of the responsibility to protect which should benefit from a much more substantial authority or at least the same as that which benefits reaction in the United Nations resolutory practice. Since these crimes against civilian populations are a concern for international peace and security, suggesting that all States are equally offended, and thus justifying all the authority of the consequent resolutory practice, then the causes of these crimes which make them possible or materialize them, are therefore as much a concern for international peace and security and,

${ }^{681}$ Ibid. Parag. 4, p. 2 
consequently, the measures to manage them should be invested with the same authority as the reactive measures managing the effects they produce. The ambiguity is precisely at this level: measures to manage the effects of causes have more authority than measures to manage the causes of these effects. The consequence is clear, crises are constant in the international scene. That said, for the little it is interested in, the intervention of the Security Council under the responsibility to protect populations against serious international crimes is disparate and still testifies to all the concern of this resolutory practice for the same peace and international security. Identical situations in terms of amplified violence against civilians, however, receive a difference of considerations or a different interest in intervention. Paragraphs 15 and 16 of the previous report of the Secretary-General ${ }^{682}$ are instructive to this effect:

15. "Political divisions, particularly within the Security Council, are exacerbating the move away from decisive action - whether for prevention or for response. In some contexts where atrocity crimes have been committed, or are at risk, major global Powers support opposing factions and put these allegiances ahead of their protection responsibilities. The founders of the United Nations recognized the importance of harnessing the power of key States to an effective collective security system, but they also expected members of the Security Council to use their power responsibly and in the interests of greater security for all. Today, however, Security Council deliberations frequently fail to generate common solutions and at times serve to deepen discord among Member States. The Security Council may "remain seized" of a matter, but this is of little relevance to suffering populations unless concrete steps forward are taken"

16. "Security Council disunity is particularly damaging in the early stages of a crisis, when space for dialogue is wider and when strong and united messages from the international community have greater potential to dissuade local actors from following a deadly path. In other instances, vetoes by permanent members, whether used or threatened, preclude the identification and pursuit of a common purpose. The pattern of violence during the Syrian crisis tragically illustrates the impact of this deadlock on the behaviour of the warring parties, who can feel emboldened by the lack of strong international engagement. Fighting in the Syrian Arab Republic escalated and conflict-related deaths increased dramatically following the failure of the Security Council to adopt a resolution in February 2012, particularly as a result of the intensified aerial bombardment of populated areas by government forces".

${ }^{682}$ Ibid. p. 5 
Thus, after acknowledging that the widespread violence suffered by the civilian population is a concern for international security, these situations receive a different intervention, depending on political considerations in force within the Security Council. As we can see in these lines, this is clearly not in compliance with the spirit of the United Nations Charter as it was drafted by the founding fathers of the United Nations. The fundamental reason for this disparate trend in the United Nations resolutory practice may be the one advanced by the President of the General Assembly in his thinking about the responsibility to protect: "The Security Council's powers are not directed even against violations of international legal obligations but against an immediate threat to international peace and security. Collective security is a specialized instrument for dealing with threats to international peace and security and not an enforcement mechanism for international human rights law and international humanitarian law. The discretion given to the Security Council to decide a threat to international peace and security implies a variable commitment totally different from the consistent alleviation of suffering embodied in the responsibility to protect. (...) [Furthermore] In case a responsibility to protect type of situation becomes a threat to international peace and security, the question of the veto will arise. The veto ensures that any breach committed by a permanent member or by a member state under its protection would escape action. Member states, therefore, need to decide whether "a mutual understanding" among permanent members "to refrain from employing or threatening to employ the veto" in responsibility to protect situations is adequate or whether an amendment of the Charter is necessary. A "mutual understanding" implies no enduring obligation and therefore has no legal force. The problem is that if a veto has been cast, the General Assembly cannot overturn it; even without it, the General Assembly cannot take up a matter that is on the agenda of the Security Council." 683

This thinking reveals a very reductive understanding of the concept of the Responsibility to protect and all the realism that surrounds the United Nations resolutory practice with regard to international peace and security. Obviously this conception is not that which the States adopted at the end of the World Summit of 2005. Although the Security Council is not the only organ of the United Nations charged of the Responsibility to protect, between these organs, there is officially a distribution of matters with regard to this responsibility. It is not because the Security Council acting in favor of international peace and Security would manage to include in this matter, amplified violence on civilian populations, that it would not imply consequently

${ }^{683}$ Concept note on the responsibility to protect populations from genocide, war crimes, ethnic cleansing and crimes against humanity, Note by the President of the General Assembly, A/63/958, op. cit. pp. 4-5 
for this organ to reinterpret what it would be supposed to consider of its mandate regarding human security in the sense of an international consensus on what it should be. Likewise, is there a valid basis for the lack to include the prevention of serious international crimes as a concern for international peace and security? If such a basis does not exist, it should also be thought that the veto power of the United Nations permanent members could stand itself as an obstacle in terms of prevention. Let us be realist! If the crisis has materialized into intensified violence against civilian population and the veto can be applied to block the reaction of international society, the veto can also block all preventive measures addressing the root and immediate causes of the crisis. For, the veto against the reaction to a crisis, which is nothing more than the effect of a cause, is a simple indicator that the genuine main subject is not the fate of the civilian victims. In these cases one would be talking about something else, that is to say, the interest of intervention would be quite different or elsewhere. So the root or immediate causes of these crises would surely be of some interest that the veto would also protect in case of reaction against them. From which it emerges that the prevention of serious international crimes against civilian populations can itself create a problem. So we can understand the ambiguity: there may be more important interests than the fate of the civilian population.

Having found that the responsibility to protect is included within human security, which fundamentally involves freedom from fear and want, the current ambiguous meaning of the United Nations resolutory practice relating to the responsibility to protect is a concern for human security. The preventive component of the responsibility to protect helps to manage the root and immediate causes of serious international crimes. This concept is therefore undoubtedly interested in the management of all these causes in their diverse nature, be they political, economic, cultural, etc. Such measures are therefore global, multidimensional, adapted to the context; what comes out of the substance of human security. According to paragraph $3 \mathrm{~g}$ "Governments retain the primary role and responsibility for ensuring the survival, livelihood and dignity of their citizens. The role of the international community is to complement and provide the necessary support to Governments, upon their request, so as to strengthen their capacity to respond to current and emerging threats. Human security requires greater collaboration and partnership among Governments, international and regional organizations and civil society"; and 3h "Human security must be implemented with full respect for the purposes and principles enshrined in the Charter of the United Nations, including full respect for the sovereignty of States, territorial integrity and non-interference in matters that are essentially within the domestic jurisdiction of States. Human security does not entail 
additional legal obligations on the part of States". ${ }^{644}$ The United Nations consensus on human security is clear on the responsibility entailed by human security. It is a state matter. International society is limited only to support such that its responsibility, which can be assumed in one way or another, turns out to be very small or without any significant authority. It cannot therefore be compared to the responsibility of the United Nations with regard to the responsibility to protect, in the United Nations ambiguous understanding, of course, which can lead to reactive measures based on Chapter VII of the United Nations Charter ruling international peace and security. States can well cooperate in areas of common interest, but that does not prevent it to be a matter of national appropriation or, in other words, a domestic matter, and it is very clearly stated that there is not additional obligations towards States than those within their jurisdiction. So human security is not a matter of international peace and security entailing an intervention of authority from the United Nations.

The United Nations consensus on the responsibility for human security can therefore be equivocal in the sense that it lets it be known that freedom from fear and freedom from want is not a concern of international peace and security involving an intervention of authority from the United Nations. This consensus is ambiguous in that it notes that human security is a problem of a universal, multidimensional, global character. It was human distress resulting from the internal conflicts in Rwanda, Former Yugoslavia and Somalia of the 1990s that inspired the 1994 UNDP report on Human Security. How can we think of human security as being general including almost everything regarding the conservation of individuals as implying a minimal intervention of the international community with regard to the interdependence to which States are subject to willy-nilly? Human security also implies a very strong emphasis on prevention, which encompasses all possible dimensions or areas of human conservation, which are characterized by their cross-border dimensions. Thus questions of international economics, for example, certainly have global repercussions which influence the satisfaction of human security. In this case would an international intervention of authority be abusive? The current migration phenomenon is an example of a global, multidimensional, universal problem concerning human security at the highest point. Mass immigration has deep economic, sociocultural causes that are mismanaged and lead to human insecurity.

More generally, the responsibility to protect falls within the framework of human security, the prevention of serious international crimes not receiving consistent international authority,

${ }^{684}$ United Nations Consensus on Human Security, A/RES/66/290, op. cit. 
prevention of human insecurity therefore do not receive consistent international authority. This is confirmed in cases of human insecurity still prevalent all over the world and not only in countries characterized by poor or developing. It is a reality of the concern for human security. So we have to think that as long as the root causes of human insecurity are not frankly addressed, human insecurity will persist and in a globalized world, its threat would weigh on all States. We must therefore believe that the United Nations resolutory practice which currently represents international governmental law shows that the definitional or political decree of human security which supports it is far from having the positive consequences that its objective quintessence would imply. There is no question of denying the leading role of the State, it is rather to highlight the ambiguity that arouses the United Nations resolutory practice with regard to human security and to stimulate thinking relating thereto on the basis of the natural law of human security.

Based on the final order of human security, one can know that there is an order of natural means necessary for the confirmation of the finite order which it includes concomitantly. Not always being aware of it, the human being discovers it through experience. It is what we have called the historic process of experimentation, allowin humans to learn the best way to conserve themselves in their intrinsic state following the consequences of the initiatives they implement. Through those which have a positive consequence on its conservation, they learn that they are part of the final order of human security, and through those which have an unfortunate consequence, they learn that they must be either rejected or improved. As for what then applies on an individual level, based on the principle of liberty, this also applies to a political society. Individuals who constitute themselves into political societies discover or are called to discover through this historical experiential process the adequate formulation of their organization for the conservation of each of them. This also applies to international society. The groups of individuals who constitute themselves or organize themselves that way discover through experience their natural formulation necessary for the conservation of each of the individuals who constitute them. Thus the formulations or conceptions which grounds practices giving rise to negative consequences for some are called to be revised, modified, improved or be rejected because, in reality, these negative consequences are not only negative for those who experience them but for all contractors. Indeed, since the natural logic is the confirmation of the intrinsic state of security by a permanent conservation, it is necessary to know that the dissatisfied members will seek other means, including disorder, so as to undermine security of the satisfied of the current system. Exactly as we have seen in the national level, insecurity or non- 
conservation of a single one is a concern for everyone because it is not a matter of a majority of members but of each one. Such a result does not have its cause in the dissatisfied member but in the current formulation of the organization or its conception grounding practices which do not have happy consequences on each contracting parties. The history of international society is punctuated by this evidence; anarchy for example is in a process of progressive solving because the members of international society always find themselves at a stage where they learn that they have to change the conception they have about their relationships, their common organization, this, and most importantly, based on the negative consequences on themselves of initiatives arising from their own conceptions of the ways they undertake their conservation. We can note the First World War which was the result of a certain way of approaching interstate relations and which had such negative consequences on the States that these set up the League of Nations. The conception of the interstate relations which the States still maintained, however having understood the necessity of that organization was to result to the Second World War. From the atrocious consequences of this war, States had to resolve themselves to understand, at least that their conception of interstate relations for the conservation of the individuals who make them up, had to be rejected or improved. Thus the major resolution at the end of this war was the creation of the United Nations on strong principles. Within the framework of this organization, the conception that States had of international peace and security, in turn, experienced a progressive evolution. They gradually understand, as a result of negative experiences faced mainly by individuals targeted at the hearts of crises, that these inevitably have repercussions beyond their borders. They understand that threats to security of human beings are a concern for international peace and security. Based on of this extension of the understanding of international security, States take measures in response which also have their positive or negative consequences and which still reflect in these facts the adequacy or not of that conception with human security. International society is at this stage with the issues of the responsibility to protect and human security. The conception they are currently subject to within the United Nations, is too called to be improved based on the negative consequences it can lead to, and which is moreover nothing else than a definitional decree or a political conception in the place of their objective conceptions understood in the sense of human security, as a law of nature. Based on its theoretical framework, it is possible to read the trajectory of international governmental law taking the form of the United Nations resolutory practice. The unavoidable necessity implied by this theoretical framework allows us to envisage the inevitable subsequent consequences of the ambiguity currently in force within the United Nations about the real status of the human person in international affairs. The human 
person who is actually at the center of international affairs is not yet fully understood as such. If this is about a law of nature, that is a state of affairs, of functioning or reality, which is no longer to be realized since it is already real, it is therefore an existent, and based on that we can know that the United Nations resolutory practice ends up being known at the service of human security in materialization of this real spirit of the charter of the United Nations. 


\section{CONCLUSION OF CHAPTER VIII}

In this chapter, we verified international governmental law as having human security as foundation and finality. This verification was done mainly based on the component of the final order that constitutes human security, as a law of nature, and which involves the process of historical experimentation necessary for the confirmation of the confirmation of the finite order it constitutes concomitantly. We have been able to know that international governmental law which is embodied in the United Nations resolutory practice is at the service of human security without and under this label. Without the "human security" label, the United Nations resolutory practice is at the service of state security and the security of individuals. In the service of state security, the United Nations resolutions in fact guarantee the security of individuals who constitute themselves into States from any attack on their integrity which can be brought to them directly or on the resources, in particular territorial or institutional they use for conservation. In doing so, and from a realist perspective it was noted that the United Nations intervention for the benefit of state security can also serve other States' security. At the service of individual security the United Nations resolutory practice is the product of an evolution in the conception of international peace and security. Situations of violence against civilian has come to be considered as threats to or a ruptures of international peace and security, what justified humanitarian intervention. The need for conceptual precision in this intervention for the protection of populations targeted by attacks inside the State has led to the emergence of the responsibility to protect, which made it possible to distinguish the political humanitarian intervention from the United Nations apolitical humanitarian intervention from "relievers" or providers of humanitarian aid. The international intervention for the benefit of individuals has undoubtedly been identified as an intervention for human security. Under the label "human security", the United Nations resolutory practice was the end of a long process of thinking within the United Nations after the advent of human security in the 1994 UNDP Report. The basic meaning of human security is freedom from fear and freedom from want. In addition to the characteristics noted which reflect its generality including almost everything concerning the well-being of the human person, human security was thus enshrined in the 2005 World Summit Outcome and thus noted in the successive reports of the Secretary General. The Resolution of the General Assembly being worth the United Nations Consensus on the meaning of human security, sums up human security in "freedom from fear and freedom from want". If the United Nations resolutory practice in this substance and under this general label is at the service of human security, we have envisaged the trajectory of this resolutory practice, as lasting to be 
known at the service of human security, totally under this label. Analyzing the ambiguity it contains, one could know, from the yardstick of the historical process of experimentation of learning of the order of natural means for the confirmation of human security, that the negative consequences which would ensue for the conservation of individuals making up the United Nations member States, would gradually lead to knowing that international peace and security really means "human security". 


\section{CONCLUSION OF PART II}

At the end of this part we recall that we have verified human security as the foundation and finality of international law. We have considered international law based on a conception of law as a normalized reality and as a normalized idea. As a normalized reality, it corresponds to a state of affairs, a reality that is positive or to which the authority is recognized to impose respect or to oblige. As a normalized idea, law corresponds to an idea invested of authority to impose respect or to oblige. In the first case, it is the "positivation" of a law of nature that must be confirmed and in the second, the "positivation" of a means for the achievement of a specific goal. Human security as the foundation and finality of international law then meant that the idea accounting for the meaning of international relations positively conformed to the "positived" natural reality. International law being the law of international relations, it materializes the ideas put forward to signify them which often have sense as the theory of international relations. Therefore before approaching human security, as a law of nature, in relation to the rules of international law, it was then necessary to consider the relationship between human security and the ideology of international law. We approached it in an integral logic first consisting in checking that human security is at the heart in all the theories of international relations and how it integrated them in a harmonious way in itself according to the meaning it makes of international society. The ideology of international law thus verified as having human security at its foundation and finality, this could therefore only be the same of the positive rule of international law or law of international society, in this case, the Charter of the United Nations, in its two constituent and governmental dimensions. 


\section{GENERAL CONCLUSION}

In this thesis, we have undertaken to study the real relationship between human security and international law. Starting from a very rich literature review on human security in general and in relation to international law specifically, we realized that the real link between human security and international law was still lacking of completeness, the fundamental reason being that human security, was not so far the subject of a clear theoretical framework. The contribution, undoubtedly the most important on this topic, is the one of Barbara von Tigerstrom who, after bringing elements to understanding the substance of human security, envisaged how several branches of international law ensured it, noting in each case, the limits within that operation, for the resolution of which, she proposed relevant recommendations. The simple fact that this effort of analysis was not taken into account in the international scene characterized by abundant human insecurity was a clear evidence that the link between human security and international law depends, less on this latter in itself, but on the actors which develop and implement it. Thus they use it at the service of human security according to the simple understanding they have of it, which is confirmed in fact. Thus it was noted that the relevant recommendations of our scholar could not be welcomed as they deserve, if national and international actors lacked a sufficient understanding of the real meaning of human security, which is a consequence of a lack of theoretical framework of it. We therefore enrolled in this study as a continuation of this significant contribution from our predecessor and our questioning of the real link of human security with international law marked an attempt to explore and propose a theoretical framework of human security that would account as much as possible of its meaning, expectations and implications for international society, and therefore for international law. Thus, it would further strengthen or support the valuable recommendations in the expectation of a higher level of effectiveness in ensuring human security through international law.

A theoretical framework of human security, in connection with international law, was therefore only possible by subscribing to a level of thinking that transcends or to a slightly higher dimension than the positive rule of international law. Advancing that human security postulates being at the heart of international affairs, we formulated the hypothesis according to which the link between human security and international law is ontological, in other words, that human security postulates to be the foundation and finality of international law, as a consequence of its postulate of being the foundation and finality of national law. International law only existing 
as a consequence of the existence of national laws governing national political societies or States, if human security postulates to be the foundation and finality of international law, it then postulates beforehand to be the same for national law. This ontological requirement of human security therefore implied to have a broader or encompassing understanding of law. Since it postulates itself as the foundation and finality of positive law, it thus stand as a law of nature, that is to say, a state of affairs or functioning, or a reality, and consequently inspires a suitable understanding of law, or this latter in all its states, from its natural expression to its implementation, or in other words, law before law, law in law and law after law. This therefore led to inscribing our study in an interdisciplinary approach centralized on law. Thus general and political philosophy, history, sociology, the theory of law and international relations were very useful in verifying our hypothesis because they assured this "full law". Thus we undertook to use documentary content, searching for a logic or a meaning, whose force was afterward checked into facts

We structured the plan of verification of our hypothesis in two parts corresponding to its two declensions: The necessary Prerequisite of Human Security as the foundation and finality of International Law: Human Security the foundation and finality of Internal Law and Human Security, as the foundation and finality of International Law.

In the first Part, we set out to explore the ontological relationship between human security and national or domestic law. It was a matter of discovering the theoretical framework of human security by verifying it as the law of human nature and therefore that of political society. Based on an essentialist perspective, as the law of human nature, human security is a matter of the intrinsic state which accounts for it, and is concomitantly identified as the finite and final order of this nature. The finite order found as a perfect existent can therefore no longer be realized or created or made, but is only subject to confirmation as it is, by means of a final order which accounts for a set of means just as natural. In other words, human nature being itself only in the state of security which is of its essence, that is to say, a real existent that does not need to be realized again, is subjected to confirmation, due to its animate nature necessitating a permanence in that state. It is what we have called conservation. This is called to be achieved under an order of natural means that Men do not always know, and thus they are devoted to learn it through the historical process of experiencing the consequences of the initiatives they undertake for conservation. For this result, the positive consequences had to be retained or capitalized and the negative consequences rejected or improved, until the complete discovery of the order. Thus human security has been verified as the law of human nature or the law of 
nature of the human. The human person, being subjected to its conservation in coexistence with its fellows and depending on the resources of nature, political society was understood as pertaining to the final order of human security. However although the human political animality is revealed as a natural nature, that is to say, human security, as a law of nature and the human experience are in adequacy, it is not complete and must end with the historical process of experimentation which educates on the best formulation of the political society for the conservation of each of its members; what is understood as the cultural nature of the human political animality. Thus we were able to verify that human security is the law of nature of political society, that is to say, its foundation and its finality.

All of these elements that fall within the theoretical framework of human security were then to be verified in national or domestic law or national political order, especially in its ideological and positive manifestations in the case of the modern State. Thus the study of political ideologies, whose development is concomitant with the modern State in that they are a set of ideas on the politics called, in case of consensus, to be invested of the authority of (positive) law was, beforehand, conducted in relation to human security. If this latter stands as the foundation and finality of national law in its positive expression, then it governs in the same way, the idea thereof. Then we examined it in relation to liberalism considered as the central ideology of all and in relation to those of the right and the left. Thus, to varying degrees, and liberalism a little more, all ideologies have been known to have human security as their foundation and finality. The difference was no longer in their foundation and finality, but in the means they propose to confirm it. The full reality of it had to be known based on the experience process. Human security being thus verified as the foundation and finality of national law in idea, that presaged a truism for the positive or practical national law. We then considered it in the context of the facts relating to the modern State, in particular its advent through the American and French revolutions and their suites, in particular those of these of the United States and France and those they have entailed in other States of the World. Thus the national constitutional and governmental national orders could be observed as enshrining the pre-studied ideologies and subjected to the process of historical experimentation for the discovery of the best formulation of the State. Most of the contemporary political orders are structured and implemented centered on human rights and the separation of powers. Thus again we have been able to verify that the practical national political order has human security as foundation and finality. 
Having emptied the necessary prerequisite, we could then moving forward in checking human security as foundation and finality of international law. We have also undertaken it in its idea and positive components. The ideology of international law or international law in idea was presented as the set of ideas which reflects the meaning of international society or international relations, which are generally endorsed or embodied in the rule of positive international law. If human security stands as the foundation and finality in its positivity, then it stands the same way and beforehand for the idea of it. The theory of international relations manifesting this international law in idea has been examined, in its rationalist and critical schools of thought, in relation to the theoretical framework of human security. We have been able to note that all these theories, to varying degrees, pursue or try to account for the process of confirming human security. Its theoretical framework enable to well understand these theories, to identify inconsistencies and to envisage their perspectives, through the historical process of experimentation to which they are necessarily subject to. So, we have been able to verify that international law in idea has human security as foundation and finality, it was then necessary to dwell on the way it harmoniously unifies all these ideas by studying the implication of its theoretical framework for international society. Thus, by noting the ontological elements of international society which are the human beings, at the primary level and the State at the secondary level it was easy to conclude that since human security is the law of human nature and therefore the law of nature of national society, it is necessarily the foundation and finality of international society. International relations have only human security as foundation and finality and are therefore subject to the historical process of experimentation for the discovery of their best formulation for the benefit of each member constituting each of the different national political societies making international society up. Thus we were able to verify that human security is the foundation and finality of international society, thereby finalizing the verification that human security is the foundation and finality of international law in idea.

Finally, we set out to verify human security, as the foundation and finality of positive international law in its two constitutional and governmental variants. We started with the constitutional variant by verifying that it was part of the finite and final orders of human security. In the sense of the finite order, we approached, above all, the reality of an international constitution. This was noted as obvious based on the human security, as a law of nature and on the international constitution theory. The Charter of the United Nations which is currently worth Constitution of international society was then examined in relation with the theoretical framework of human security. The interpretation of its preamble in particular leaves no doubt 
that this instrument is based on and intended for human security. A little detour has been made with regard to the legal value of the preamble of the Charter and we have argued in favor of its binding character, noting that it stands as the spirit of the subsequent provisions which constitute the body of the Charter and from which they cannot be dissociated without continuing to have their value or signification. In the sense of the final order, we have noted and described its trajectory as part of the historic process of experimentation to which the Charter of the United Nations is subject to. This led us to approach its advent, which inevitably included the League of Nations, whose ontological relationship of its Constitutive Covenant to human security has been established. The lack of understanding of its full worth for the benefit of all its members after a devastating war was to result in the Second World War that led to the United Nations, when State understood the importance and significance of an international society Constitution. The follow-up to the Charter of the United Nations, in this same historic process of experimentation, is characterized by a complete adhesion of all States and an inquiry on its reform, considered by certain members as no longer reflecting the realities of international society. Altogether, the irrefutable historical process should inform us about the subsequent practical consequences of this Charter. International constitutional law was therefore also verified as having human security as its law. It remained to verify this ontological relation of human security with international governmental law, which was understood as the legal practice in giving concrete form to the Charter of the United Nations. It was precisely the normative production of the United Nations. We were then able to observe that it was in the service of human security by doing it or not under the label "human security". The study of the evolution of the United Nations normative practice informed us that, without the label "human security", the United Nations indirectly is doing it by working in favor of state security and directly in favor of intervention for the benefit of individuals; what turn from humanitarian intervention to the responsibility to protect. Under the label "human security", the United Nations resolutory practice was marked by the United Nations consensus on human security. The commentary on the content of this resolution informed that although conforming to the theoretical framework of human security, was flagrantly noted as a definitional (political) decree and thus accused inconsistencies in the way it distinguishes the concepts of human security and of the responsibility to protect. That understanding has consequences for the types of response both entail within the United Nations. The relation between the United Nations normative practice and the theoretical framework of human security allowed us to reach such a conclusion and to objectively raise an identity of human security and the responsibility to protect, to note the current limits of intervention in favor of international peace and security and to conclude the 
United Nations normative production in favor of human security as remaining subject to the historical process of experimentation for the discovery of its best formulation for the benefit of human security. So, we have verified that human security is the foundation and the finality of international governmental law.

Ultimately, we have verified that human security, as a law of human nature, is consequently and in a broader sense, the foundation and finality of both national law and international society. The prior awareness of international actors on such an evidence should enable people to reflect deeply on the most adequate formulation of international law, starting with the recommendations of Barbara von Tigrestrom, so that this law concretizes its real final cause of human security and in prevention of harmful consequences to the latter to the detriment of the international individual community. 


\section{GENERAL BIBLIOGRAPHY}

\section{I- DICTIONARIES AND ARTICLES IN ENCYCLOPEDIES}

- ATKINS, (Ph.) «Essential vs. Accidental Properties », Stanford Encyclopedia of Philosophy First published Tuesday April 29, 2008; substantive revision Monday April 18, 2016, https://plato.stanford.edu/entries/essential-accidental;

- ARNAUD (A. J), (Dir.), Dictionnaire Encyclopédique de Théorie et de Sociologie du Droit, Paris, LGDJ, 1993

- AUROUX (S), (Dir.), Encyclopédie philosophique universelle, les Notions philosophiques, Dictionnaire, Tome II, PUF, 1990 ;

- BAUER, (S.) GERBIER (L.), «Famille», in CNRS (éd.), Grand Dictionnaire de la Philosophie, Larousse, Paris, 2003, pp. 1236-1237 ;

- BRISTOL, (W.), «Enlightenment », The Stanford Encyclopedia of Philosophy, E. N. ZALTA (ed.), Fall, 2017

- CHARRAK, (A.) «Culture», Grand Dictionnaire de la Philosophie, in CNRS (éd.), Grand Dictionnaire de la Philosophie, Larousse, Paris, 2003, pp. 691-692 ;

- Centre Interdisciplinaire de formation à la Psychothérapie Relationnelle, CIFPR Glossaire de la Psychothérapie, Paris/Aix Marseille, http://cifpr.fr

- CRANSTON, (M.) «Liberalism », in, EDWARDS (P.), (ed.), The Encyclopedia of Philosophy, Macmillan and the Free Press, New York, 1967, pp. 458-461;

- Dictionnaire Encarta, Microsoft ${ }^{\circledR}$ Encarta ${ }^{\circledR}$ 2009. @ $\odot$ 1993-2008 Microsoft Corporation ;

- Dictionnaire sur PC Ortolang du CNRTL (Centre National de la Recherche Scientifique), comprenant les dictionnaires de l'Académie française jusqu'à la 9ème édition. http://www.cnrtl.fr;

- EPSTEIN, (B.), « Social Ontology », in ZALTA (N.), (ed.), Stanford Encyclopedia of Philosophy, 2018; https://plato.stanford.edu/archives/sum2018/entry/social-ontology/;

- GRAHAM, (G.), «Behaviorism », The Stanford Encyclopedia of Philosophy ZALTA, (E. N.), (ed.), Spring 2019, https://plato.stanford.edu/archives/spr2019/entries/behaviorism/

- MARTIN, (D.) Dictionnaire des idées de Kant Vocabulaire de la Critique de la raison pure, des Prolégomènes, du cours Logique et de la Fondation de la métaphysique des møeurs, Mise à jour : 30/01/2018, http://www.danielmartin.eu/Philo/Vocabulaire.pdf;

- OSMAŃCZYK, (E. J.), MANGO, (A.), Encyclopedia of the United Nations and International Agreements: G to M. Taylor \& Francis, 2003; 
- RIMBOUX, (E.), «Politique», Grand Dictionnaire de la Philosophie, Edition numérique, Larousse, Bibliothèque Nationale de France, pour la bibliothèque numérique Gallica, 2003

- ROBERTSON, (D.) The Routledge Dictionary of Politics, 3rd Ed. Taylor \& Francis Group , Routledge USA and Canada, New Fetter Lane, London, New York, 2004;

- SCRUTON, (R.) The Palgrave Macmillan Dictionary of Political Thought, 3rd edition, Palgrave Macmillan, New York, 2007;

- VILE, (J. R.), Encyclopedia of Constitutional Amendments, Proposed Amendments, and Amending Issues, 1789-2015, $4^{\text {th }}$ Ed. 2015

- WALDRON, (J.) «Liberalism», in CRAIG, (E.), (Ed.), The Shorter Routledge Encyclopedia of Philosophy, 2005 Routledge, New York, pp. 570-576

\section{II- BOOKS}

- ACHESON, (D. G.), Present at the Creation: My Years in the State Department, W.W. Norton, New York: 1969;

- ALEDO, (L. A.), Le Droit International Public, Coll. Connaissances du Droit, Dalloz, 2005;

- ALFORD, (C. F.) Narrative, Nature, and the Natural Law. From Aquinas to International Human Rights, Palgrave Macmillan, New York, 2010;

- ARENDT, (H.), Eichmann in Jerusalem: Report on the Banality of Evil, Penguin Books, New York: 1963;

- ARON, (R.), Paix et Guerre entre les Nations, Paris, Calman Levy, 8e Ed. Coll. « Liberté de l'esprit », 1984 ;

- BAER, (G. W.), Test Case: Italy, Ethiopia, and the League of Nations, Hoover Institution Press, 1976;

- BADESCU, (C. G.), Humanitarian Intervention and the Responsibility to Protect Security and human rights, Routledge, London and New York, 2011;

- BARNES, (J.) Early Greek Philosophy, Harmondsworth, Penguin Books, 1987;

- BARTH, (H.), The Idea of Order, Contributions to a Philosophy of Politics, D. Reidel Publishing Company, Dordrecht-Holland, 1960;

- BECK, (U.) Qu'est -ce que le cosmopolitisme? Paris : Aubier, 2006. (Alto). Trad. De : « Der Kosmopolitische Blick oder Krieg ist Frieden»

- BECK, (U.) « Nationalisme méthodologique - cosmopolitisme méthodologique : un changement de paradigme dans les sciences sociales ». Raisons politiques, 2014. n ${ }^{\circ} 54$;

- BEETHAM, (D.) «La Démocratie: Principes Essentiels, Institutions et Problèmes », in Ch. BASSIOUNI (Rapp. Gén.), La Démocratie: Principes et Réalisation, Union Interparlementaire, Genève, 1998, pp. 23-32 ; 
- BEITZ (C.), Political Theory and International Relations, Princeton, Princeton University Press, 1979, réed. augm. 1999 ;

- BENN, (S. I.) A Theory of Freedom, Cambridge University Press, Cambridge, 1988

- BERGES (M.), (Dir.), Penser les relations internationales, Paris, L'Harmattan, Collection Pouvoirs comparés, 2008,

- BIRD (A.), Nature's Metaphysics, Laws and Properties, Oxford University, Press, Oxford, 2007; BLACK, (A.), A World History of Ancient Political Thought, Its Significance and Consequences, revised and expanded edition, Oxford University Press, 2009;

- BIRN, (D. S.), The League of Nations Union, Clarendon Press, 1981;

- BOUCHER (D.), The Limits of Ethics in International Relations, Natural Law, Natural Rights, and Human Rights in Transition, Oxford University Presss, 2009

- BOSANQUET, (B.), Philosophical Theory of the State in Philosophical Theory of the State and Related Essays, 1923, GAUS, (G. F.), SWEET (W.) (eds.), St. Augustine Press, Indianapolis, 2001;

- BOURANTONIS, (D.), The History and Politics of UN Security Council Reform, New York, Routledge, 2005;

- BOURDIEU, (P.) WACQUANT, (L.), An Invitation to Reflexive Sociology, University of Chicago Press, 1992;

- BOUTIN, (Ch.), De la mondialisation à l'universalisation: une ambition sociale, Rapport intermédiaire au Président de la République, decembre 2010 ;

- BOUVERESSE, (J.), Histoire des Institutions de la Vie Politique et de la Société Françaises de 1789 à 1945, Publications de l'Université de Rouen et du Havre, Coll. Cours, Histoire du droit, 2012 ;

- BRIERLY, (J.L.), The Law of Nations: An Introduction to the International Law of Peace, 6th Ed. Sir Humphrey Waldock Ed. 1963;

- BRISSON (L.) (dir.), Platon : Euvres complètes, Éditions Flammarion, 2008 ;

- BRUNET (J. P.), LAUNAY, (M.) «La Russie des Soviets de 1917 à 1921 », in D’une Guerre Mondiale à l'Autre (1914-1945), Coll. HU, Hachette Education, pp. 97-105 ;

- BULL, (H.), The Anarchical Society, Macmillan, London, 1977;

- BULL, (H.) WATSON, (A.), The expansion of international society. Oxford, Clarendon Press, 1984;

- BUZAN, (B.), WAEVER, (O.), de WILDE, (J.), Security A New Framework For Analysis, Londres, Lynne Rienner Publishers, 1998;

- BUZAN, (B.), An introduction to the English school of international relations: the societal approach, John Wiley \& Sons, Cambridge, 2014

- CABANIS, (M. A.) MARTIN (L.), Le Constitutionnalisme de la Troisième Vague en Afrique Francophone, Bruylant-Academia SA 2010, pp. 59-90 ; 
- CARISCH, (E.), RICKARD-MARTIN (L.), MEISTER, (S. R.), The Evolution of UN Sanctions From a Tool of Warfare to a Tool of Peace, Security and Human Rights, Springer, 2017;

- CAROLAN, (E.), The New Separation of Powers: A Theory of the Modern State, Oxford: Oxford University Press, 2009;

- CAWKWELL, (G.), Thucydides and the Peloponnesian War, London: Routledge, 1997;

- CEDE, (F.), SUCHARIPA-BEHRMANN, (L.), The United Nations, Law and Practice, Kluwer Law International, The Hague, Boston, 2001;

- CHERNOFF, (F.), Theory and Metatheory in International Relations. Concepts and Contending Accounts, Palgrave Macmillan, 2007;

- CHRISTMAN, (J.) ANDERSON, (J.) (eds.), Autonomy and Challenges to Liberalism, Cambridge, University Press, Cambridge, 2005

- CHUNG (R.) \& NOOTENS (G.) (dir.), Le Cosmopolitisme. Enjeux et débats contemporains, Montréal, Presses universitaires de Montréal, 2010 ;

- CLAPHAM, (A.), Brierly's Law of Nations, An Introduction to the Role of International Law in International Relations, Oxford University Press, 7th Ed. 2012

- COBB Jr., (J. B.), GAMWELL (F. I.) (eds.), Existence and Actuality: Conversations with Charles Hartshorne, University of Chicago Press, Chicago and London, 1984, Material prepared for Religion Online by Ted and Winnie Brock, http://www.religion-online.org/cgibin/relsearchd.dll/showchapter?chapter_id=1895

- CORTEN (O.), Le discours du droit international, Présentation d'Emmanuelle JOUANNET Collection Doctrine(s), Editions Pedone, Paris, 2009 ;

- COX, (R.) Power production, power and world order, New York: Columbia University Press, 1987;

- DAVIDSON, (S.), Grenada: A Study in Politics and the Limits of International Law, Aldershot: Avebury, 1987;

- DEBIEL (T.), WERTHES (S.) (Eds.), Human Security on Foreign Policy Agendas: Changes, Concepts and Cases, INEF Report 80/2006, Duisburg: Institute for Development and Peace, University of Duisburg-Essen, INEF Report, 80, 2006

- De GUTTRY (A.) et al. (eds.), International Disaster Response Law, T.M.C. ASSER PRESS, Springer, The Hague, 2012;

- de la BOETIE, (E.), Discours de la servitude volontaire, 1548

- de Vattel, (E.) Le droit des gens, ou Principes de la loi naturelle appliqués à la conduite et aux affaires des nations et des souverains (Nouvelle édition...augmentée de quelques remarques nouvelles et d'une bibliographie choisie et systématique du droit de la nature et des gens) par Vattel ; par de Hoffmanns (M.), 1835 ;

- de SECONDAT, (Ch.), de Montesquieu, De l'esprit des lois, Une édition électronique réalisée à partir du livre Montesquieu, De l'esprit des lois (1758), VERSINI (L.) (ed.), Paris, Éditions Gallimard, 1995 ; 
- de SMITH, (S.) The New Commonwealth and its Constitutions, Stevens and Sons, London, 1964;

- DEBIEL, (T.), WERTHES, (S.) (eds.), Human Security on Foreign Policy Agendas: changes, concepts, cases, INEF Report 80, Duisburg: University of Duisburg-Essen, 2006

- DELEUZE, (G.) GUATTARI, (F.), L'anti-CEdipe, Minuit, Paris, 1972 ;

- DOAK (K. M.), Tanaka Kōtarō and World Law, Rethinking the Natural Law Outside the West, Palgrave Macmillan, 2019

- DWORKIN, (G.), The Theory and Practice of Autonomy, Cambridge: Cambridge University Press, 1988;

- ECCLESHALL, (R.), Alii, Political Ideologies, An introduction, $3^{\text {rd }}$ Ed. Routledge, Taylor and Francis Group, New York, 2003;

- ELLIS, (B), The Philosophy of Nature, A Guide to the New Essentialism, Acumen Publishing Limited, Chesham, 2002;

- FASSBENDER, (B.), The United Nations Charter as the Constitution of the International Community, Legal Aspects of International Organization, Vol. 51, Martinus Nijhoff Publishers, Leiden, Boston 2009;

- FERRELL, (R.H.), Woodrow Wilson and World War I, 1917-1921, New York: Harper \& Row, 1985;

- FIERKE, (K. M.), Critical Approaches to International Security, Cambridge, Polity, 2007

- FRANKOVITS (A.), L'approche fondée sur les droits de l'homme et le système des Nations Unies, UNESCO, 2006 ;

- FREEDEN, (M.), Ideologies and Political Theory: A Conceptual, Approach, Clarendon Press, Oxford, 1996;

- FRIEDRICH (C. J.) (ed.), The Philosophy of Kant: Moral and Political Writings, New York: The Modem Library, 1949;

- FRITZ,(Ch. G.), American Sovereigns: The People and America's Constitutional Tradition Before the Civil War Cambridge University Press, 2008;

- FOMBAD, (Ch. M.) (ed.), Separation of Powers in African Constitutionalism, Oxford University Press, 2016;

- FORMISANO, (R. P.), For the People: American Populist Movements from the Revolution to the 1850s, University of North Carolina Press, 2008;

- GIDDENS, (A.), The Consequences of Modernity, Polity Press, 1990;

- GILPIN, (R.), War and Change in World Politics, Cambridge University Press, Cambridge, 1981 ;

- GOODRICH, (L. M.), HAMBRO, (E.), Charter of the United Nations: Commentary and Documents 385, 1946;

- GOLDBLAT, (J.), Arms control: the new guide to negotiations and agreements, SAGE Publications Ltd, 2002; 
- GORDON, (S.), Controlling the State, Constitutionalism from Ancient Athens to Today, Harvard University Press, 2002;

- GORODETSKY, (G.), Soviet Foreign Policy, 1917-1991: A Retrospective, Routledge, 1994;

- GREEN, (Th. H.)1895, Lectures on the Principles of Political Obligation and Other Essays, HARRIS (P.), MORROW (J.) (eds.), Cambridge University Press, Cambridge, 1986, pp. 228-229;

- GUENIFFEY, (P). Le Dix-huit Brumaire. L'épilogue de la Révolution française, Coll. « Les journées qui ont fait la France », Gallimard, 2008 ;

- GRIMAL, (F.), Threats of Force: International Law and Strategy, Routledge, 2013

- GRIMM, (D.), Constitutionalism, Past, Present, and Future, Oxford University Press, 2016;

- GUZINNI, (S.), Realism in Interational and International Political Economy: The continuing Story of a death Foretold, Routledge, The New International Relations Series, Taylor and Francis, London, New York, 1998

- HAAKONSSEN (K.) (Ed.), Grotius, Pufendorf and Modern Natural Law, Ashgate, Dartmouth, Aldershot, Brookfield, 1999

- HABERMAS J., Après l'Etat - nation, trad. Rochlitz (R.), Paris, Fayard, 2003 ;

- HANHIMAKI, (J.M.), The United Nations. A Very Short Introduction, Oxford University Press, 2008;

- HAYES, (C.J.H.), A Political and Social History of Modern Europe, Vol. 1, Afton, New York, May, 1916;

- HASENCLEVER, (A.), MAYER, (P.), RITTBERGER, (V.), Theories of International Regimes, Cambridge University Press, Cambridge, UK, 1997

- HEIDENHEIMER, (A. J), KOMMERS (D. P.), The Governments of Germany. 4th Ed. New York, Thomas Crowell, 1975;

- HELD (D.), Un nouveau contrat mondial, trad. Bouyssou (R.), Paris, Les Presses de Sciences - Po, 2005 ;

- HELd, (D.), (A.), MCGREW, (D.), GOLDblatT, PERRATON (J.), (eds.), Global Transformations, Stanford University Press, 1999;

- HEYWOOD, (A.), Political Ideologies. An Introduction, 3rd Ed. Palgrave MacMillan, 2003 ;

- HENCKAERT (J.-M.), DOSWALD-BECK (S. L.), Droit international, humanitaire coutumier. Volume 1 : Règles, Traduit de l'anglais par Dominique LEVEILLÉ, Bruylant, Bruxelles, 2006 ;

- HILL NISH, (I.), Japanese foreign policy 1869-1942, Kasumigaseki to Miyakezaka, Routledge \& Kegan Paul, 1977;

- HINSLEY, (J. H.), Sovereignty, 2nd Ed. Cambridge University Press, Cambridge, 1986;

- History of the League of Nations (1919-1946), UNOG Library, Registry, Records and Archives Unit; 
- HOBBES (Th.), Léviathan, Traité de la matière, de la forme et du pouvoir de la république ecclésiastique et civile, 1651, Traduction originale de M. P. FOLLIOT, Coll. Les classiques des sciences sociales ;

- HOBBES, (Th.) Leviathan, 1651, R. TUCK (ed.), Cambridge: Cambridge University Press, 1991;

- HOBHOUSE, (L. T.) Liberalism, Williams and Norgate, n.d, London, 1911;

- HOBSBAWM, (E.), L'Ère des révolutions, Editions Complexe, 2000 ;

- HOFFMAN, (M.), "Critical theory and the inter-paradigm debate », Millennium Journal of International Studies, $\mathrm{n}^{\circ} 16,1987$, pp. 231-49;

- HOLTON (R.), Cosmopolitanisms. New Thinkings and New Directions, London, Palgrave Macmillan, 2009;

- HORKHEIMER, (M.), Théorie Critique, Paris, Payot, 1978 ;

- HUNTINGTON, (S.) The Third Wave: Democratization in the Late Twentieth Century, University of Oklahoma Press, Norman, 1991;

- HUTTMAN, (E.D.) Introduction to Social Policy, New York: McGraw-Hill, 1981;

- IRIYE, (A.), The Origins of the Second World War in Asia and the Pacific, Longman Group UK Limited, 1987;

- KANT, (I.), The Doctrine of Virtue, transl. of M. J. GREGOR New York: Harper Torchbooks, 1964;

- KOLB, (E.), The Weimar Republic, Transl. FALLA, (P. S.), London, Unwin Hyman, 1988;

- LOCKE (J.), Traité du gouvernement civil, 1690, Traduction française de D. MAZEL en 1795, à partir de la 5e édition de Londres en 1725, Coll. Les classiques des sciences sociales

- LOCKE, (J.), Two Treatises of Government, 1698, P. LASLETT (ed.), Cambridge: Cambridge University Press, 1988;

- LOWI, (Th. J.), GINSBERG, (B.), American Government: Freedom and Power, $3^{\text {rd }}$ Ed. New York and London: W. W. Norton, 1994

- JACOBY, (H.) The Bureaucratization of the World, University of California Press, Berkeley and Los Angeles, 1973;

- JAMESON, (F.), MIYOSHI (M.), (eds.), The Cultures of Globalization, Duke University Press, 1998;

- JERVIS, (R.), System Effects: Complexity in Political and Social Life, Princeton University Press, 1997;

- JONES (C.), Global Justice: Defending Cosmopolitanism, Oxford, Oxford University Press, 1999;

- JONSSON (U.), Human Rights Approach to Development Programming, UNICEF, April 2003

- KANT (E), Critique de la raison pratique, précédée des fondements de la Métaphysique et des moeurs, traduit par F. PICAVET, 1ere Ed, Paris, PUF, 1943

- KANT (E.), Idée d'une histoire universelle au point de vue cosmopolitique, 1784, Traduction faite à partir de l'Edition des Euvres complètes de Kant de l'Académie de Berlin 
(Tome VIII). Traduction de Ph. FOLLIOT, A. de DIEPPE, Juin 2002 http://classiques.uqac.ca

- KANT (E.), Projet de Paix perpétuelle, Essai Philosophique, 1880, http://gallica.bnf.fr;

- KATZENSTEIN, (P. J.), The Culture of National Security: Norms and Identity in World Politics, Columbia University Press, New York, 1996;

- KEOHANE, (R. O.), NYE, (J. S.), Power and Interdependence. New York: Longman, 2001

- KOEHLER (G.) et al., Human Security and the Next Generation of Comprehensive Human Development Goals, Institute of Development Studies, April 2012;

- KNOCK, (T. J.), To End All Wars: Woodrow Wilson and the Quest for a New World Order. Princeton, University Press, 1995;

- KORAB-KARPOWICZ, (W. J.), On History of Political Philosophy: Great Political Thinkers from Thucydides to Locke, New York: Routledge, 2012;

- LASKI, (H. J.), The Rise of European Liberalism, Transaction Press 1997, 1936;

- le VINE, (T. V.) « The Fall and Rise of Constitutionalism in West Africa », The Journal of Modern African Studies $n^{\circ} 35,1997$, pp. 181-206;

- LEBOW, (R. N.) « The Long Peace, the End of the Cold War, and the Failure of Realism », International Organization, Vol. 48, n² 2, 1994, pp. 249-278;

- LEFEBVRE, (G.), La Révolution française, Presses Universitaires de France, 2 tomes, 1951 et 1957 ;

- LEGRO, (J. W.) « Culture and Preferences in the International Cooperation Two-Step », American Political Science Review, Vol. 90, n¹, march 1996, pp. 118-137;

- LEVI-STRAUSS, (Cl.) Les structures élémentaires de la parenté, PUF, Paris, 1949 ;

- LIST, (Ch.), PETTIT (Ph.), « Aggregating Sets of Judgments: An impossibility result», Economics and Philosophy, Vol. 18, 2002, pp. 89-110;

- LUNDESTAD, (G.), East, West, North, South: Major Developments in International Politics 1945-1996, $2^{\text {nd }}$ Ed, Oslo: Scandinavian University Press, 1997;

- MCDONOUGH, (F.) The Origins of the First and Second World Wars, Cambridge University Press, 1997;

- MACFARLANE (S.N.), KHONG (Y. F.), Human security and the UN; a critical history, Indianapolis: Indiana University Press, 2006;

- MANN, (M.), The Sources of Social Power, A history of power from the beginning to A.D. 1760, Vol. I, Cambridge University Press, New York, 1986;

- MANUSAMA, (K.), The United Nations Security Council in the Post-Cold War Era Applying the Principle of Legality, Martinus Nijhoff Publishers Koninklijke Brill NV, Leiden, Boston, 2006;

- MARCH, (J.) OLSEN, (J.), «The Institutional Dynamics of International Political Orders », International Organization, Vol. 52 n4, 1998, pp. 943-969; 
- MAURY (J-P.), «Woodrow Wilson, Les 14 points », Dijithèque MJP, 2008, http://mjp.univ-perp.fr/m/maury.htm

- MATTINGLY, (G.), Renaissance Diplomacy, Houghton Mifflin, Boston, 1955;

- MILL, (J. S), A System of Logic, Ratiocinative and Inductive, John W. Parker, London, 1843

- MILL, (J. S.), On Liberty, London, 1910;

- MIQUELASI, (A. F.), «International Relations and the Concept of International Society: Understanding the Relevance of the English School », RICRI, Vol.4, n8, pp. 103-115;

- MITTELMAN (J. H.), (ed.), Globalization, Lynne Rienner, 1996;

- MORGENTHAU, (H.), Politics Among Nations, New York, Knopf, 1967;

- MORRISON, (M. A.) Slavery and the American West: The Eclipse of Manifest Destiny and the Coming of the Civil War, University of North Carolina Press, 1997;

- NASH, (G.B.), Unknown American Revolution: The Unruly Birth of Democracy and the Struggle to Create America, Viking, 2005

- NEF (J.), Human Security and Mutual Vulnerability, The Global Political Economy of Development and Underdevelopment 2e Ed.), Ottawa, IDRC Books, 2003;

- NEUFELD, (M. A), The restructuring of International Relations Theory, New York: Cambridge, University Press, 1995;

- NICOLAS, (J.) La Rébellion française, Mouvements populaires et conscience sociale 16611789, Gallimard, Folio, 2008 ;

- NISARD (M.), (dir.), Cicéron (0106-0043 av. J.-C.). Oeuvres complètes, 1869, http://www.gallica.bnf.fr;

- NORTHEDGE, (F.S.), The League of Nations: Its Life and Times, 1920-1946, Holmes \& Meier, 1986;

- NWABUEZE, (B. O.), Constitutionalism in the Emergent States, London: C. Hurst and Company, 1973;

- PARENTEAU, (D.), (I), Les Idéologies Politiques, Le Clivage Gauche-Droite, Presses de l’Université du Québec, 2008 ;

- PELleT (A.), (Dir.), La Charte des Nations Unies. Commentaire article par article, Economica, $2^{\mathrm{e}}$ Ed. 1991

- PELLEGRIN (P.) (dir.), Aristote : Euvres complètes, Éditions Flammarion, 2014 ;

- OPELLO Jr. (W.C.) ROSOW, (S.J.), The Nation-State and Global Order. A Historical Introduction to Contemporary Politics, Lynne Rienner Publishers, 1999;

- OREN, (I.) «Is Culture Independent of National Security? How America's National Security Concerns Shaped Political Culture' Research », European Journal of International Relations vol. $6, \mathrm{n}^{\circ} 4,2000$, pp.543-573

- OURLIAC, (P.) GAZZANIGA, (J.-L.), Histoire du droit privé français, II, 4, Albin Michel, Paris, 1985 ; 
- POPPER, (K.), The Open Society and its Enemies, Routledge \& Kegan Paul, London, 1945;

- QUETELET, (A.), Du système social et des lois qui le régissent, Paris: Guillaumin, 1848 ;

- RAFFO, (P.), The League of Nations, The Historical Association, 1974;

- $\quad$ RAWLS (J.), The Law of Peoples, Cambridge (Mass.), Harvard University Press, 1999;

- RAZ, (J.), The Morality of Freedom, Clarendon Press, Oxford, 1986;

- ROBERTS, (A.) ZAUM, (D.), Selective Security: War and the United Nations Security Council since 1945, London: Routledge, 2008;

- ROBERTSON, (R.), Globalization: Social Theory and Global Culture, London, Sage Publications, 1992

- ROMMEN, (H. A.), Natural Law: A Study in Legal and Social History and Philosophy, trans. HANLEY (Th. R.), Introduction and Bibliography by HITTINGER (R.)

- ROTHMAN, (S.), European Society and Politics, IN: Bobbs-Merrill, Indianapolis, 1970;

- ROUSSEAU (J.-J.), Du contrat social ou Principes du droit politique, 1762, Un document produit en version numérique par Jean-Marie Tremblay, 24 février 2002 à partir du texte publié en 1762, Union Générale d’Éditions, Paris, 1963 ;

- ROUSSEAU, (J.-J), Du contrat social ou principes du droit politique, in Euvre complètes : Du contrat social, écrits politiques, GAGNEBIN, (B.), RAYMOND (M.), (dir.), Dijon, Éditions Gallimard, Bibliothèque de la Pléiade, 1964 ;

- RUSSELL, (B.), A History of Western Philosophy and its Connection with Political and Social Circumstances from the Earliest Times to the Present Day, Simon and Schuster, New York, 1945;

- RUSSELL, R. B.), MUTHER, (J. E.), A History of the United Nations Charter: The Role of the United States 1940-1945, Brooking Institution, $1^{\text {st }}$ Ed. 1958;

- SAINT-HILAIRE, (J. B.), La Politique d'Aristote, Traduit en Français d'après le Texte Collationné sur les Manuscrits et les Éditions Principales, 3ème Éd. revue et corrigée, Paris, Librairie Philosophique de Ladrange, 1874 ;

- SCOTT, (G.), The Rise and Fall of the League of Nations, Macmillan, 1974

- SEN, (A.), Inequality Reexamined, Harvard University Press, 1992;

- SINGER (P.), One World. The Ethics of Globalization, New Haven, Yale University Press, 2002;

- SKINNER, (B.F.), Science and Human Behavior, New York: Macmillan, 1953

- SOBOUL, (A.), La Révolution française, Gallimard, 1981 ;

- SPENCER, (H.), The Principles of Sociology, New York: Appleton, 1895;

- SPIJKERS, (O.), The United Nations, the Evolution of Global Values and International Law, Intersentia Ltd, Cambridge, United Kingdom, 2011;

- STEGER, (M. B.), Globalization. A Very Short Introduction, Oxford University Press, 2003; 
- STEELE, (B.J.), Ontological Security in International Relations: Self-Identity and the IR State, Routledge, 2008

- STOETT (P.), Human and Global Security: An Exploration of Terms, Toronto: University of Toronto Press, 1999

- TADJBAKHSH (S.), A. CHENOY, Human Security: Concepts and Implications. London, Routledge; 2007;

- TARDE, (G.), L'opinion de la foule, F. Alcan, Paris,1901;

- TARDE, (G.), Les Lois Sociales: Esquisse d'une sociologie, F. Alcan, Paris, 1898;

- TAYLOR, (A.J.P.) The Origins of The Second World War, Simon and Schuster Publishers, 1961;

- TEHRANIAN (M.), (ed.), Worlds Apart: Human Security and Global Governance, London: I.B. Tauris, 1999

- THOMAS (C.), WILKIN (P.), (eds.), Globalization, Human Security, and the African Experience, Boulder, Colo.: Lynne Rienner, 1999;

- THUCYDIDES, History of the Peloponnesian War, trans. WARNER (R.), Penguin Books, Harmondsworth, 1972;

- THUCYDIDES, On Justice, Power, and Human Nature: The Essence of Thucydides' History of the Peloponnesian War, WOODRUFF, (P.), (ed. and trans.), Hackett, Indianapolis, 1993;

- TOULMIN, (S.), Cosmopolis: the Hidden Agenda of Modernity, Free Press, New York, 1990;

- TUCK, (R.), (Ed.), Thomas Hobbes: Leviathan, Cambridge University Press, Cambridge, 1996;

- TURNER, (B.S.), KHONDKER (H. H.), Globalization, East and West, Sage Publications Ltd, 2010;

- $\quad$ von Pufendorf (S.) : Les Devoirs de l'homme et du citoyen, tels qu'ils lui sont prescrits par la loi naturelle, trad. BARBEYRAC (J), 1707. Réédition : Presses universitaires de Caen, Caen, 2002 ;

- $\quad$ von Pufendorf (S.) : Le Droit de la nature et des gens, ou Système général des principes les plus importans de la morale, de la jurisprudence et de la politique, trad. BARBEYRAC, (J.) (2 volumes) 1706 ;

- VADNEY, (T.E.), The World Since 1945, $2^{\text {nd }}$ Ed., Penguin, London, 1992;

- VILE, (M. J. C.), Constitutionalism and the Separation of Powers, Oxford University Press, Oxford, 1967;

- VILLEY (M.), Leçons d'histoire de la philosophie du droit, Paris, Dalloz, PUF, 1962 ;

- VINCENT, (A.), Modern Political Ideologies, $3^{\text {rd }}$ Ed. Blackwell Publishing Ltd, 2010;

- Von MISES, (L.), Liberalism: The Classical Tradition 2, 1927, B.B. GREAVES, (ed.), Liberty Fund, Inc. 2005;

- WALKER, (R.B.J.) Inside/Outside: International Relations as Political Theory, Cambridge University Press, Cambridge, 1993; 
- WALT, (S.), «The Renaissance of Security Studies», International Studies Quarterly, Vol. 35, 2, pp. 211-239, 1991;

- WALTZ, (K.), Theory of International Politics, Boston, MA: McGraw-Hill, 1979;

- WARNIER, (J.P.), La mondialisation de la culture, La Découverte, Paris, 1999 ;

- WILLMOTT, (H.P.) World War I, Dorling Kindersley, New York, 2003;

- WILSON, (G.), The United Nations and Collective Security, Routledge, Taylor \&.Francis Croup, London/New York, 2014;

- WYN JONES (R.), Security, Strategy, and Critical Theory, Boulder, Lynne Rienner Publishers, 1999;

- YOUNG, (I. M.), Justice and the Politics of Difference, Princeton University Press, 1990;

\section{III- ARTICLES}

- ACKERLY, (B.) TRUE, (J.), "Reflexivity in Practice: Power and Ethics in Feminist Research on International Relations », International Studies Review Vol. 10, n4, 2008, pp. 693-707;

- ACKERMAN, (B.), « The New Separation of Powers », Harvard Law Review, $\mathrm{n}^{\circ} 113, \mathrm{n}^{\circ} 3$, 2000, pp. 633-729;

- ACKERMAN, (J.) CARLSON, (B.) YOUNG, (H.) «Constructivism and Security », Air Command and Staff College (ACSC) Distance Learning Program, Maxwell AFB, AL: ACSC, 2010, pp. 1-16;

- ADLER, (E.) «Imagined (Security) Communities: Cognitive Regions in International Relations », Millennium: Journal of International Studies, vo. 26, n² 2, 1997, pp. 249-277;

- ALBERTH (J.), CARLSSON (H.), «Critical Security Studies, Human Security and Peace », D-level paper, Political Science, Linköping University, spring 2009;

- ANDERSON, (E.S), «What Is the Point of Equality? », in Ethics, n 109, 1999, pp. 287337;

- ARAUJO, (R. J.), «International Law Clients: The Wisdom of Natural Law », in Fordham Urban Law Journal, Vol. 28, $\mathrm{n}^{\circ}$ 6, 2001, pp. 1751-177;

- ARROW, (K.J.) « Methodological Individualism and Social Knowledge », The American Economic Review, Vol. 84, n², 1994, pp. 1-9;

- ATHANASIOU (E.), "Human Security at Test: The United Nations Peacekeeping Operation, in the Democratic Republic of Congo», Human Security Journal, Vol. 5, Winter, 2007, pp. 72-80;

- AXWORTHY (L.), «Human Security and Global Governance: Putting People First », Global Governance, vol. 22, 1, 2001;

- BA, (A.) HOFFMAN, (M. J.), « Making and Remaking the World for IR 101: A Resource for Teaching Social Constructivism in Introductory Classes », International Studies Perspectives, Vol. 4, 2003, pp. 15-33; 
- BAJPAI (K.), « Human Security: Concept and Measurement», Kroc Institute Occasional Paper 19, August 2000;

- BARENDT, (E.), «Separation of Powers and Constitutional Government », Public Law, 1995, pp. 599-616;

- BEGBY (E.), BURGESS (J. P.), «Human Security and Liberal Peace », Public Reason, 1 (1), 2009, pp. 91-104;

- BARTRIP, (P.W.J.), « State Intervention in Mid-Nineteenth Century Britain: Fact or Fiction? », Journal of. British Studies, Vol. 23, n 1, 1983, pp. 63-83;

- BERLIN, (I.), Four Essays on Liberty, Oxford University Press, Oxford, 1969;

- BIRKIN, (F.) STAPLETON, (P.) LARRINAGA, (C.) «New Essentialism and the Foundations of Accounting Realism », Paper presented at the Administrative Sciences Association of Canada Conference, Halifax 2003 and at the Interdisciplinary Perspectives on Accounting conference, Madrid, 2003;

- BLUM, (Y. Z.), «Proposals for UN Security Council Reform », The American Journal of International Law, Vol. 99, $\mathrm{n}^{\circ}$. 3, July 2005, p. 632-649;

- BOSOLD, (D.), WERTHES, (S.), «Human Security in Practice: Canadian and Japanese Experiences », Internationale Politik und Gesellschaft/International Politics and Society, 1, 2005, pp. 84-101;

- BILGIN, (P.), «Individual and Societal Dimensions of Security ». International Studies Review, 5, 2003, pp. 203-222;

- BLOQUET, (J.) «L'acte Additionnel Aux Constitutions De L'empire Du 22 Avril 1815 : Une Bataille Perdue d'avance ? » Napoleonica. La Revue, Vol. 1, $\mathrm{n}^{\circ} 13$, La Fondation Napoléon, 2012, pp. 3-39 https://www.cairn.info/revue-napoleonica-la-revue-2012-1-page3.htm;

- BRYSK (A.), «Human Rights and National Insecurity», in BRYSK (A.), SHAFIR (G.) (eds.) National Insecurity and Human Rights. Democracies debate counterterrorism, University of California Press, London, England, pp. 1-13;

- BOOTH, (K.), « Security and Emancipation », Review of International Studies, Vol. 17, n 4 , 1991, pp. 313-326

- BOYLE (K.), SIMONSEN (S.), «La sécurité humaine, les droits de l'homme et le désarmement », Forum du Désarmement, op.cit. pp. 5-16 ;

- BRATMAN, (M. E.), «Shared Intention », Ethics, Vol. 104, n²1, 1993, pp. 97-113;

- BURNS (T.) “Aristotle and Natural Law”, in History of Political Thought, Vol. 19, n. 2, Summer 1998, pp. 142-166;

- BUZAN, (B.), "Rethinking Security after the Cold War », in Cooperation and Conflict; Nordic Journal of International Studies, Vol. 32, n¹, mars 1997, pp. 5-28

- CAZALS, (R.), «Les proscrits de $1852 »$ Mémoires Identités Représentations Histoire comparative de l'Europe, FRAMESPA, 1999, 3, Toulouse, pp. 24-32. ffhalshs-00139516f ;

- CHANDLER (D.), " Human Security: the dog that didn't bark» Security Dialogue 39:4, 2008, pp. 427-438; 
- CONACHER, (J.B.), « The Reformation in England: A Reconsideration of Henry VIII's Break from Rome », Reform, ${ }^{\circ}$ 22, Canadian Catholic Historical Association, 1955, pp. 3957 ;

- COLLIER (J.), "On the Necessity of Natural Kinds", in P. RIGGS, ed. Natural Kinds, Laws of Nature and Scientific Reasoning », Dordrecht: Kluwer, 1996;

- COT, (J-P), PELLET, (A.), "What they had in mind, The Preamble to the Charter », Development: Seeds of Change Village Through Global Order, Journal Of The Society For International Development, Special double issue, Vol. 1, n², 1986, pp. 22-27;

- COTTRELL, (M. P.), « Lost in transition? The League of Nations and the United Nations », in SHAPIRO (I.), LAMPERT, (J.), (eds), Charter of the United Nations, CT: Yale University Press, New Haven, 2014;

- COUDENHOVE-KALERGI, (R. N.) 《1939 La paix de demain », Politique étrangère, 4, 2006, pp. 763-770 ;

- COX, (R.) « Social Forces, States, and World Orders: Beyond International Relations Theory », in COX, (R.). SINCLAIR, (T. J.) (dir.), Approaches to World Order, CSIR, Cambridge University Press, 1981, pp. 85-123;

- CREPIN, (A.), «Le 18 Brumaire, une étape dans la constitution d'une armée nouvelle », Annales historiques de la Révolution française, ${ }^{\circ} 318$, 1999, pp. 663-676 ;

- DELSOL (C.), « Mythologies de l'international », Politique étrangère, 4, 2006, pp. 10751083 ;

- de SILVA. TAROUCA, (A.), «L'idée d'ordre dans la philosophie de saint Thomas d'Aquin ». In: Revue néo-scolastique de philosophie, 40e année, Deuxième série, n555, 1937, pp. 341-384 ;

- DEVETAK, (R.), « Postmodernism », in BURCHILL, (S.) LINKLATER, (A.). (ed.) Theories of International Relations, Macmillan, 1996, pp.179-209;

- DANNREUTHER, (R.), «Introduction: The Dynamics of Conflict and Cooperation », in DANNREUTHER, (R.) OSTROWSKI, (W.), (eds.) Global Resources Conflict and Cooperation, Palgrave Macmillan, Hampshire 2013;

- DIGNAT, (A.), « 14 janvier 1852, Constitution sur mesure pour Louis-Napoléon », 29 avril 2019 11:06:45, https://www.herodote.net/14_janvier_1852-evenement-18520114.php;

- DORFF, (R. H.), " A Commentary on Security Studies for the 1990s as a Model Core Curriculum », International Studies Notes, Vol. 19, 1994, p. 23-31;

- DOYLE, (M.) «Liberalism and World Politics », American Political Science Review, Vol. 80, n 4,1986 , pp. 151-169;

- EAgLETON-PIERCE, (M.), «Examining the Case for Reflexivity in International Relations: Insights from Bourdieu », Journal of Critical Globalisation Studies, n²1, 2009, pp. 111-12;

- ELLIS, (B.), «Causal Laws and Singular Causation », Philosophy and Phenomenological Research, Vol. 41, n², September 2000, pp. 329-351;

- ESTRADA-TANCK (E.D.), Human Security and Human Rights under International Law: Crossroads and Possibilities, European University Institute, 2010 
- FARER (T.), «Human Security: Defining the Elephant and Imagining its Tasks», Asian Journal of International Law 1:1 2011, pp. 43-55;

- FASSBENDER, (B.), « All Illusions Shattered: Looking Back on a Decade of Failed Attempts to Reform the UN Security Council », Max Planck Yearbook of United Nations Law, Vol. 7, 2003;

- FELLER, (A. H.), "Book Review of Hans Kelsen, The Law of the United Nations », Columbia Law Review. Vol. 51, 1951, pp.537- 539;

- FINNEMORE, (M.), SIKKINK, (K.), «International Norm Dynamics and Political Change », International Organization, Vol. 52, n4, 1998, pp. 887-917;

- FREISELEBEN, (J.V.), "Reform of the Security Council», in Managing Change at the United Nations, New York, Center for UN Reform Education, 2008, pp. 1-20;

- GASIMOVA, (S), "The Security Council's Endless Enlargement Debate ", Central European Journal of International \& Security Studies, Vol. 6, n 3-4, 2012;

- GASPER, (D.), « Human Rights, Human Needs, Human Development, Human Security Relationships between four international human “ discourses», Forum for Development Studies, 1, 2007, pp. 9-43

- GASPER, (D.), « Securing Humanity: Situating Human Security as Concept and Discourse», J. of Human Development, 6(2), 2005, pp. 221-245

- GAUTIER-AUDEBERT (A.), «La responsabilité de protéger », Revue Ubuntou, no 1, 2013, pp. 49-65 ;

- GIBBONS, (K.), «When did the Schism begin, and why? Views on the English Reformation amongst Catholic polemicists », Études Épistémè, n³2, 2017, http://journals.openedition.org/episteme/1809;

- GLASIUS, (M.), KALDOR (M.), «Individuals First: A Human Security Strategy for the European Union», Internationale Politik und Gesellschaft, 1, 2005, pp. 62-82;

- GO, (J.), «A Globalizing Constitutionalism? Views from The Postcolony, 1945-2000 », Chapter Four, in ARJOMAND, (S. A.) (ed.), Constitutionalism and Political Reconstruction, Brill, Leiden, 2007, pp. 89-114;

- GOODRICH, (L. M.), «From League of Nations to United Nations », International Organization, Vol. 1, n ${ }^{\circ}, 1947$, pp. 3-21;

- GORDON (G. M), « Natural Law in International Legal Theory: Linear and Dialectical Presentations », in HOFFMANN (F.), ORFORD (A.), (Eds.), The Oxford Handbook of the Theory of International Law, Oxford University Press, 2016, Chapter 5, pp. 279-305

- GRIMM, (D.), «Integration by Constitution », in International Journal of Constitutional Law, Vol, n², 2005, pp. 193-208;

- HAAKONSSEN (K.), «Hugo Grotius and the History of Political Thought », in Political Theory, vol.13:239-265, 1985; 
- HAJNAL, (Z.), «Written and Unwritten Values in the Preamble of the United Nations, Charter - The Axioms of Human Coexistence and Progress » Independent paper, 2018, pp. $1-35$;

- HALL, (S.), « The persistent Spectre: Natural Law, International Order and the Limits of Legal Positivism », in EJIL, Vol. 12, n 2, 2001, pp. 269-307;

- HAMATI-ATAYA, (I.) « The Problem of Values and International Relations Scholarship: From Applied Reflexivity to Reflexivism », International Studies Review, Vol. 13, n², 2011, pp. 362-398;

- HOBHOUSE, (L.T.) «The New Spirit in America », Contemporary Review, Vol. 100, n¹, 1911, pp. 1-11

- HOLMES, (S.), B. CONSTANT et la genèse du libéralisme moderne, traduit de l'anglais par CHAMPEAU, (O.) Paris, P.U.F., coll. Léviathan, 1994 ; HOUGHTON, (D. P.), «The Role of Self-Fulfilling and Self Negating Prophecies in International Relations », International Studies Review, Vol. 11, n³, 2009; pp. 552-584;

- HOUGH, (P.), «Who's Securing Whom? The Need for International Relations to Embrace Human Security», St Antony's International Review 1 (2), 2005, pp. 72-87;

- JACOBY (T.), «Hegemony, Modernisation and Post-War Reconstruction», Global Society 21 (4), 2007, pp. 521-537;

- JOHNSON, (H. C.) NIEMEYER, (G.), «Collective security: The validity of an ideal », International Organization, 1954, Vol.8, pp. 19-35;

- JOLLY, (R.), BASURAY (D.), , « Human Security - national perspectives and global agendas», Journal of International Development, 19(4), 2007, pp. 457-472;

- JONES, (D.M.) « Democratization, Civil Society, and Illiberal Middle Class Culture in Pacific Asia », Comparative Politics, n³0, January 1998, pp. 147-169;

- JOURDAN, (A.) «Le Dix-huit Brumaire de Napoléon Bonaparte : Retour sur un coup d'État », in La Vie des Idées, le 28 mai 2008, http://laviedesidees.fr/ ;

- KALDOR (M.), al. " Human Security: A New Strategic Narrative for Europe», International Affairs, Vol. 83, 2, 2007, pp. 279-288

- KALDOR (M.), MARCOUX (S.), «La sécurité humaine : un concept pertinent ? », Politique étrangère, 4, 2006, pp. 901-914 ;

- KAY, (R. S.) «Formal and Informal Amendment of the United States Constitution », The American Journal of Comparative Law, Vol. 66, ${ }^{\circ}$ 1, Oxford University Press, 2018, pp. 243-268;

- KHONG (Y.F.), «Human Security: A Shotgun Approach to Alleviating Human Misery?» Global Governance, Vol. 7, 3 July-September 2001LIOTTA (P.H.), OWEN (T.). « Why Human Security?» in The Whitehead Journal of Diplomacy and International Relations. Vol 7, 1, Winter/Spring 2006, 37-54

- KING (G.), MURRAY (J.L.), «Rethinking Human Security», Political Science Quarterly, Vol. 116, 4, 2002, pp. 585-610

- KINGSBURY (B.), Roberts (A.), «Introduction: Grotian Thought in International Relations », in Bull et al., 1990; 
- KLABBERS (J.) «Constitutionalism and the making of international law: Fuller's procedural natural law », in NoFo, Vol. 5, 2008, pp. 84-112;

- KLUG, (H.), Constituting Democracy: Law, Globalism and South Africa's Political Reconstruction, Cambridge University Press, Cambridge and New York, 2000;

- KOUDRIAVTSEV (Y. N.), «Droit international et problèmes globaux de l'époque actuelle », RBDI, 2, 1988, pp. 417-428;

- KOLODZIEJ, (E. A.) «Renaissance in Security Studies? Caveat Lector! », International Studies Quartely, Vol. 36, 1992, p. 421-38;

- KORAB-KARPOWICZ, (W. J.), « How International Relations Theorists Can Benefit by Reading Thucydides », The Monist, Vol. 89, n², 2006, pp. 231-43

- KOVEN, (S.) MICHEL, (S.) (eds.), Mothers of a New World: Maternalistic Politics and the Origins of Welfare States, London: Routledge, 1993;

- KUHN, (H.), «Le concept de l'ordre », in Gregorianum, vol. 43, No. 2, Pub. GB PressGregorian Biblical Press, 1962, p. 5, Stable URL: http://www.jstor.org/stable/23572398;

- KUPCHAN, (C.A.), «Concerts, collective security and the future of Europe », International Security, 1991, Vol,16, n. pp.114-161;

- KURKI, (M.) WIGHT, (C.), «International Relations and Social Science », In DUNNE, (T.), KURKI, (M.), SMITH, (S.), (eds.) International Relations Theories, Oxford: Oxford University Press. 2013, pp.14-35;

- LAKHDAR (B.), MARCOUX (S.), «L'ONU survivra-t-elle en 2034 ? », Politique

- étrangère, 4, 2006, pp. 771-783

- LAQUIEZE, (A.), « Benjamin Constant et l'Acte Additionnel aux Constitutions de l'Empire du 22 Avril 1815 », Historia Constitucional (revista electrónica), n. 4, 2003, pp. 197-234 ; http://hc.rediris.es/04/index.html;

- LAQUIEZE,_(A.), « Les origines du régime parlementaire en France, 1814-1848, Chapitre II, Constitutionnalisme libéral et régime de balance des pouvoirs à exécutif monarchique : la Charte de 1830, 2002, pp. 77-124, https://www.cairn.info/les-origines-du-regimeparlementaire-en-france--9782130524878-page-77.htm;

- le DIVELLEC, (A.). «La Charte de 1814 dans 1'histoire des Constitutions politiques libérales », Jus Politicum, n¹3, 2015, http://juspoliticum.com/article/La-Charte-de-1814dans-1-histoire-des-constitutions-politiques-liberales-948.html ;

- LINKLATER, (A.) "Citizenship and Sovereignty in the Post-Westphalian State », European Journal of International Relations, $\mathrm{n}^{\circ} 2$, 1996, pp. 77-103;

- LOBEL, (J.), RATNER, (M.), « Bypassing the Security Council: Ambiguous authorizations to use force, cease-fires and the Iraq inspection regime », American Journal of International Law, Vol. 93, n¹, 1999, pp. 124-154;

- LUCK, (E. C.), «Reforming the United Nations: Lessons from a History in Progress », International Relations Studies and the United Nations, Occasional Papers, n 1 , 2003, pp. 7-10;

- LUTZ, (D.), «Thinking about Constitutionalism at the Start of the Twenty-First Century », Publius: The Journal of Federalism, n³0, 2000, pp. 115-35; 
- LYONS, (P.) «Ideology in Social Welfare Policy Instruction: An Examination of Required Readings », in The Journal of Sociology \& Social Welfare, Vol. 10, n³, Stockton State College, September 1983, pp. 376-389;

- MAKANE MBENGUE, (M.), « Preamble », Max Planck Encyclopedia of Public International Law, September 2006,

- http://opil.ouplaw.com/view/10.1093/law:epil/9780199231690/law-9780199231690e1456?rskey=b9QT73\&result $=29 \& \mathrm{q}=$ contract\%20interpretation \&prd=EPIL

- MACFARLANE (N.), KHONG (Y.F.), Human Security and the UN. A Critical History, Bloomington, IN: University of Indiana Press, 2006;

- MAJONE, (G.) « The Rise of the Regulatory State in Europe » in MÜLLER, (W.C.), WRIGHT, (V.) (eds.), The State in Western Europe: Retreat or Redefinition, Newbury Park, CA, and Great Britain: Frank Cass, 1994, pp. 77-101;

- MARTIN, (L.) «Interests, Power, and Multilateralism, », International Organization, Vol. $46, n^{\circ} .4,1992$, pp. 765-792;

- MARTIN, OWEN (T.), « The second generation of human security: lessons from the UN and EU experience», International Affairs, 86, (1), 2010 pp. 211-224

- MATSUMAE (T.) CHEN (L.C.), (eds.), Common Security, Tokyo: Tokai University Press, 1995 in Asia: New Concept of Human Security, Tokyo: Tokai University Press, 1995;

- MCCORMACK (T.), «Power and agency in the human security framework», Cambridge Review of International Affairs, Volume 21, 1, March 2008, pp. 113-128;

- MEARSHEIMER, (J.) «Back to the Future: Instability in Europe After the Cold War », International Security, ${ }^{\circ} 15,1990$, pp. 5-56

- MEARSHEIMER, (J.) « The False Promise of International Institutions » in International Security, Vol. 19, n³, 1994-1995, pp. 5-49;

- MEISER, (J. W.), « Liberalism », in MCGLINCHEY, (S.), WALTERS, (R.), SCHEINPFLUG (C.), (Eds.), International Relations Theory, E-International Relations Publishing, Bristol, 2017, pp. 22-27;

- MIRABELLA (D.) «The Death and Resurrection of Natural Law », The Western Australian Jurist, Vol. 9, n², pp. 254-260;

- MODERNE (Fr), « Human Rights and Postcolonial Constitutions in Sub-Saharan, Africa », in HENKIN (L.), (A.J.), ROSENTHAL, (Eds.) Constitutionalism and Rights: The Influence of the United States Constitution Abroad, pp. 315-48, Columbia, University Press, New York, 1990, pp. 315-348;

- MOJAPELO, (Ph. M.), «The doctrine of separation of powers (a South African perspective) », Forum Advocate, April 2013, pp. 37-40;

- MONTBRIAL (T.), «Le « système international » : approches et dynamiques », Politique étrangère, 4, 2006, pp 735-746 ;

- MORAIS, (M.), « La vocation pédagogique de l'histoire chez Kant et son horizon cosmopolitique », Archives de Philosophie, Tome 66, 2003-4, pp. 603-633, http://www.cairn.info.fr;

- MORAVCSIK, (A.) « Liberal International Relations Theory: A Social Scientific Assessment », Paper $n^{\circ}$ 01-02, Published by the Weatherhead Center for International Affairs, Harvard University April 2001, pp. 1-51; 
- MORAVCSIK, (A.) "Liberalism and International Relations Theory », in Center for International Affairs Working Paper Series, Vol. 92, $\mathrm{n}^{\circ}$ 6, Harvard University, Cambridge, Massachusetts, 1992-93, pp. 92-96;

- MORAVCSIK, (A.) « Taking Preferences Seriously: A Liberal Theory of International Politics », International Organization, Vol. 51, n 4, 1997, pp. 513-553;

- MORRIS (K.), «The arab spring: the rise of human security and the fall of dictatorship», Internet Journal of Criminology, 2012, pp. 1-33;

- MUGLIONI, (J.-M.), « Le principe téléologique de la philosophie kantienne de l'histoire », Revue germanique internationale, $\mathrm{n}^{\circ} 61,1996$, pp. 113-127 ; http://rgi.revues.org/585; -

- MUTIMER, (D.), « Critical Security Studies: A Schismatic History », in A. COLLINS, (Ed.), Contemporary Security Studies, Oxford: Oxford University Press, 2007, pp. 53-74

- MYERSON, (R. B), "Political Economics and the Weimar Disaster », Journal of Institutional and Theoretical Economics, 2004, pp. 187-209;

- NEUFELD, (M.), «Reflexivity and International Relations Theory », Millennium, Vol. 22, $\mathrm{n}^{\circ} 1,1993$, pp. 53-76;

- NEWMAN, (E.), «Critical Human Security Studies », Review of International Studies, ${ }^{\circ}$ 36, 2010, pp.77-94

- NEWMAN (E.), « Human Security and Constructivism », International Studies Perspectives, 2, 2001, pp. 239-251

- NUSSBAUM (M.), «Patriotism and Cosmopolitanism» in Joshua Cohen (Ed.), For Love of Country, Boston, Beacon Press, 1996;

- O'CONNELL, (M. E.), DAY, (C.) « Sources in Natural Law Theories: Natural Law as Source of Extra-Positive Norms », in D'ASPREMONT (J.), BESSON (S.) (Eds.), Oxford Handbook of The Sources Of International Law, Oxford University Press, pp. 1-24

- OREN, (I.) «Can Political Science Emulate the Natural Sciences? The Problem of SelfDisconfirming Analysis », Polity, Vol. 38, n¹, 2006, pp. 72-100;

- ORGAD, (L.), « The Preamble in Constitutional Interpretation », International Journal of Constitutional Law, October 2010;

- ONUF, (N.) «Henry Wheaton and "The Golden Age of International Law », in International Legal Theory, American Society of International Law, (Interest Group on the Theory of International Law), Vol. 6, n 1, 2000, pp. 2-9;

- OWEN, (J. M.) «How Liberalism produces Democratic Peace », International Security, Vol. 19, n 19, 1994, pp. 87-125;

- OWEN (T.), «Des Difficultés et de l'intérêt de définir et d'évaluer la sécurité humaine », Forum du Désarmement, Nations Unies, Genève, Juillet 2004, pp. 17-28 ;

- OWEN (T.), « Human Security - Conflict, Critique and Consensus: Colloquium Remarks and a Proposal for a Threshold-Based Definition», in Security Dialogue, Vol. 35, 3, International Peace Research Institute, Oslo, Norway, Sage Publications, 2004, pp. 373-387

- OWENS (H.), ARNEIL (B.), « The Human Security Paradigm Shift: A New Lens on Canadian Foreign Policy? Report of the University of British Columbia Symposium on Human Security,» in Worlds Apart: Human Security and Global Governance, pp. 1-12 
- PARIS (R.), « Human Security. Paradigm Shift or Hot Air», International Security, Vol. 26, 2, 2001, pp. 87-102

- PELLET (A.), «La formation du droit international dans le cadre des Nations Unies», Journal européen de Droit international, 1995, pp. 401-425

- POGGE (T.), «Cosmopolitanism and Sovereignty », in Ethics, n $^{\circ} 103,1992$, pp. 48-75. World Poverty and Human Rights, Oxford, Blackwell, 2002

- REMOND (C.), «La Sécurité Humaine et le Rapport entre Humanitaires et Militaires: Perspective Historique depuis 1990 », Human Security Journal, Volume 7, Summer 2008, pp.16-31;

- RENGGER, (N.) «The Boundaries of Conversation. A response to Dallmayr », Millenium: Journal of International Studies, Vol. 30, n², 2001, pp. 357-364

- ROGOFF, (M. A.) «A Comparison of Constitutionalism in France and The United States », Maine Law Review, Vol. 49, n²1, pp. 21-83;

- PREZELJ (I.) «Challenges in Conceptualizing and Providing Human Security» HUMSEC Journal, Issue 2, pp. 1-22

- RICHMOND (O.), «Human Security, the Rule of Law, and NGOs: Potentials and Problems for Humanitarian Intervention,»Human Rights Review, Vol. 2, No. 4, July-September 2001;

- RIOUX (J.-F.) al. "Le néo-réalisme ou la formulation du paradigme hégémonique en relations internationales », Études internationales, vol. 19, 1, 1988, pp. 57-80 ;

- RISSE-KAPPEN, (T.), "Collective Identity in a Democratic Community: The Case of NATO », in P. J. KATZENSTEIN, (ed.), The Culture of National Security: Norms and Identity in World Politics, New York: Columbia University Press: 1996), pp. 357-399;

- ROBINSON, (D.), «Critical Security Studies and the Deconstruction of Realist Hegemony », Journal of Alternative Perspectives in the Social Sciences, Vol. 2, n 2, 2010, pp.846-853;

- ROGOFF, (M. A.) «A Comparison of Constitutionalism in France and The United States », Maine Law Review, Vol. 49, n²1, pp. 21-83;

- ROMULO (C.P.), " Natural Law and International Law », in Natural Law Institute Proceedings, Vol. 3, Notre Dame Law School, 1950, pp. 119-128;

- ROTHSCHILD (E.), «What is Security? » Daedalus, Vol.124, 3, 1995, pp. 53-98

- RUIZ FABRI (H.), «Le droit dans les relations internationales », Politique étrangère 3-4, 2000, pp. 659-672;

- SAMUELSON, (P. A.), « Modern Economic Realities and Individualism », in STIGLITZ, (J. E.), (ed.), The Collected Scientific Papers of Paul A. Samuelson, MIT Press, Vol. 2, Cambridge, 1966, pp. 1407-1418;

- SENARCLENS (P.), « Théories et pratiques des relations internationales depuis la fin de la guerre froide », Politique étrangère, 4, 2006, pp. 747-759 ;

- SIMMA, (B.), «Human Rights », in TOMUSCHAT (Ch.), (ed.) The United Nations at Age Fifty: A Legal Perspective, The Hague et al., Kluwer, 1995, pp. 263-280;

- SIRA (I. H.) GRÄNS (J.), « The promotion of human security in EU security policies», INEX, Policy Brief, $\mathrm{n}^{\circ}$ 7, March 2009, pp. 1-8;

- SHANI (G.), «From National to Human Security? Reflections on Post 3.11 Japan », The Journal of Social Science, 76, 2013, pp. 5-24; 
- SCHALL, (J.V. S.J.), " Natural Law and the Law of Nations: Some Theoretical Considerations », in Fordham International Law Journal, Vol. 15, Iss. 4 1991, pp. 997-1030

- SHINODA (H.), " The Concept of Human Security: Historical and Theoretical Implications» (chap I), in Conflict and Human Security: A Search for New Approaches of Peace-building, IPSHU English Research Report Series, 19 2004, pp 5-22;

- SCHNEEWIND (J.B.), « Kant and natural law ethics », in Ethics, Vol.104, n53-74, 1993;

- SCHMIDT, (K. J.), «The League of Nations », American History, http://www.let.rug.nl/usa/essays/1901-/the-league-of-nations-karl-j-schmidt.php

- SHOEMAKER, (S.), «Causal and Metaphysical Necessity », Pacific Philosophical Quarterly, n79, Blackwell Publishers 1998, pp. 59-77;

- SMITH, (S.), " Positivism and Beyond », In SMITH, (S.) BOOTH, (K.), ZALEXSKI, (M.), (eds.) International Theory: Positivism and Beyond, Cambridge University Press Cambridge, 1996, pp. 11-44;

- SMITH, (S.), «The Contested Concept of Security », in K. BOOTH (Ed.), Critical Security Studies and World Politics, Boulder: Lynne Rienner, 2005, pp. 27-62;

- STAMNES, (E.), «Critical Security Studies and the United Nations Preventive Deployment in Macedonia », International Peacekeeping, Vol. 11, n 1,Spring 2004, pp. 162-164;

- SUR, (S.), «Le Conseil de Sécurité, Blocage, Renouveau et Avenir », Pouvoirs 2/2004, n 109, p. 61-74, http: www.cairn.info/revue-pouvoirs-2004-2-page-61.htm

- SUR (S.), «Le droit international au cœur des relations internationales », Questions internationales, 49 - mai-juin 2011, pp. 4-11

- SUHRKE (A.), «Human Security and the Interests of States» Security Dialogue 30:3, 1999, pp. $265-276$

- STANLEY (H.), « Raymond Aron et la théorie des relations internationales », Politique étrangère, 4, 2006p. 723-734THAKUR (R.), « The United Nations and Human Security,» in Worlds Apart: Human Security and Global Governance, pp. 51-60;

- STUECK, (W.), "The United Nations, the Security Council, and the Korean War » in, LOWE (R.), ROBERTS, (A.), WELSH, (J.), ZAUM, (D.), The United Nations Security Council and War, The Evolution of Thought And Practice Since 1945, Oxford University Press, New York, 2008, pp.265-279;

- TAMANAHA, (B. Z.) "The Dark Side of the Relationship between the Rule of Law and Liberalism", New York Journal of Law and Liberty, Vol. 3, n516, 2008, p. 513-547;

- TANZELLA-NITTI (G.), "The Aristotelian-Thomistic Concept of Nature and the Contemporary Debate on the Meaning of Natural Laws », Acta Philosophica, n6, 1997;

- TAYLOR, (Ch.), «Atomism », Philosophy and the Human Sciences: Philosophical Papers, Vol. 2, Cambridge University Press, Cambridge, 1985, pp. 187-210

- TAYLOR (P.), CURTIS (D.), « The United Nations», in BAYLIS (J.), SMITH (S.), (eds.),The Globalization of World Politics, Oxford University Press; New York; $3^{\text {rd }}$ Ed. 2005 ;

- THEYS, (S.), « Constructivism », S. MCGLINCHEY, R. WALTERS, C. SCHEINPFLUG (Eds), MCGLINCHEY，(S.)，WALTERS，(R.)，SCHEINPFLUG (C.)，(Eds.), 
International Relations Theory, E-International Relations Publishing, Bristol, 2017, pp. 3641;

- TRICAUD, (F.) «Hobbes et Locke : convergences et divergences », in: XVII-XVIII. Bulletin de la société d'études angloaméricaines, des XVIIe et XVIIIe siècle, $\mathrm{n}^{\circ} 25,1987$, pp. 77-87, http://www.persee.fr/doc/xvii_0291-3798_1987_num_25_1_1120;

- TRUONG, (T-D.), «Human Security and Human Rights», in SMITH (R.), van den ANKER (C.) (eds.), The Essentials of Human Rights, London: Hodder Arnold, 2005, pp. 172-175;

- TUOMELA, (R.), MILLER, (K.), «We-Intentions », Philosophical Studies, Vol. 53, n³, 1988, pp. 367- 389;

- VISHNOO, (B.) SHIRUR, (R.) VIDYA, (B.), World Constitutions, Sterling Publishers Pvt. Ltd., 1997;

- VLIETINCK, (E.), «La philosophie de l'histoire», in Revue néo-scolastique de philosophie, 25e année, $\mathrm{n}^{\circ} 97,1923$, p. 85-95 ; https://www.persee.fr/doc/phlou_0776555x_1923_num_25_97_2334;

- WELSH, (J.), « The Security Council and Humanitarian Intervention », in LOWE (R.), ROBERTS, (A.), WELSH, (J.), ZAUM, (D.), The United Nations Security Council and War, The Evolution of Thought And Practice Since 1945, Oxford University Press, New York, 2008, pp. 535-562;

- WENDT, (A.), «Anarchy is What States Make of It: The Social Construction of Power Politics », International Organization, Vol. 46, n², 1992, pp. 391-425;

- WENDT, (A.), «Constructing International Politics », International Security, Vol. 20, ${ }^{\circ}{ }^{1}$, 1995, pp 71-81;

- WILLIAMS, (M. C.), « Hobbes and International Relations: a Reconsideration », in International Organization, Vol. 50, n², Printemps, 1996;

- WILLIAMS, (M.C.), «Words, Images, Enemies: Securitization and International Politics », International Studies Quarterly, n 47, 2003, pp. 511-531;

- WHITE, (N.D.), Keeping the peace: The United Nations and the maintenance of international peace and security, Manchester University Press: Manchester, $2^{\text {nd }}$ Ed. 1997;

- WOLFERS, (A.), «Collective security and the war in Korea », Yale Review, 1954, Vol. 43, pp.481-502, pp. 489-492;

- ZACHARIE, (C.), « Napoléon et les Règles de Dévolution de la Couronne, Contribution à l'étude du droit constitutionnel impérial », Revue française de droit constitutionnel, Presses Universitaires de France, Vol. 4, n 76, 2008, pp. 703-731;

\section{V- THESES}

- MILLS, (S.), Gilbert Simondon, Causality, Ontogenesis \& Technology, PhD Thesis, University of the West of England, Bristol, February 2014; 
- VIAU, (H) La (re) conceptualisation de la sécurité dans les théories réaliste et critique : quelques pistes de réflexion sur les concepts de sécurité humaine et de sécurité globale, Series Memoires, 1 août 2000

- SEARL (M.), A Normative Theory of International Law Based on New Natural Law Theory, A thesis submitted to the Department of Law of the London School of Economics for the Degree of Doctor of Philosophy London, September 2014

\section{VI- DOCUMENTS}

\section{1- Reports and communications}

- High-level Panel on Threats, Challenges and Change, A More Secure World: Our Shared Responsibility, New York: United Nations, 2004;

- International Commission on Intervention and State Sovereignty, The Responsibility To Protect, National Library of Canada cataloguing in publication data, Ottawa, December 2001;

- United Nations Development Programme, Human Development Report 1994, Published for the, New York, Oxford, Oxford University Press, 1994;

- United Nations, General Assembly, Follow-up to the outcome of the Millennium Summit, Note by the Secretary-General, A/59/565, 2 December 2004;

- United Nations, General Assembly, In Larger Freedom: Towards Development, Security and Human Rights for All, Report of the Secretary-General, A/59/2005, 21 march 2005;

- United Nations, General Assembly, 2005 World Summit Outcome, Resolution A/RES/60/1, 24 October 2005:

- United Nations, General Assembly, Integrated and coordinated implementation of and follow-up to the outcomes of the major United Nations conferences and summits in the economic, social and related fields, Follow-up to the outcome of the Millennium Summit, Implementing the responsibility to protect, Report of the Secretary-General, A/63/677, 12 January 2009;

- United Nations, General Assembly, Integrated and coordinated implementation of and follow-up to the outcomes of the major United Nations conferences and summits in the economic, social and related fields, Follow-up to the outcome of the Millennium Summit, Concept note on the responsibility to protect populations from genocide, war crimes, ethnic cleansing and crimes against humanity, Note by the President of the General Assembly, A/63/958, 9 September 2009;

- United Nations, General Assembly, Integrated and coordinated implementation of and follow-up to the outcomes of the major United Nations conferences and summits in the economic, social and related fields, Follow-up to the outcome of the Millennium Summit, Human security, Report of the Secretary-General, A/64/701, 8 march 2010;

- United Nations, General Assembly, Integrated and coordinated implementation of and follow-up to the outcomes of the major United Nations conferences and summits in the economic, social and related fields, Follow-up to the outcome of the Millennium Summit, 
Follow-up to General Assembly resolution 64/291 on human security, Report of the Secretary-General, A/66/763, 5 April 2012;

- United Nations, General Assembly, Integrated and coordinated implementation of and follow-up to the outcomes of the major United Nations conferences and summits in the economic, social and related fields, Follow-up to the outcome of the Millennium Summit, Responsibility to protect: State responsibility and prevention, Report of the SecretaryGeneral, A/67/929-S/2013/399, 9 july 2013;

- United Nations, General Assembly, Integrated and coordinated implementation of and follow-up to the outcomes of the major United Nations conferences and summits in the economic, social and related fields, Follow-up to the outcome of the Millennium Summit, Responsibility to protect: timely and decisive response, Report of the Secretary-General, A/66/874-S/2012/578, 25 july 2012;

- United Nations, General Assembly, Resolution adopted by the General Assembly on 10 September 2012 [without reference to a Main Committee (A/66/L.55/Rev.1 and Add.1)], Follow-up to paragraph 143 on human security of the 2005 World Summit Outcome, A/RES/66/290 66/290, 25 October 2012;

- United Nations, General Assembly, Integrated and coordinated implementation of and follow-up to the outcomes of the major United Nations conferences and summits in the economic, social and related fields, Follow-up to the outcome of the Millennium Summit, Mobilizing collective action: the next decade of the responsibility to protect, Report of the Secretary-General, A/70/999-S/2016/620, 22 july 2016;

- TADJBAKHSH (S.) «Human Security»: Looking back before Looking forward», Paper for the ICHSWA Conference Birjand, Iran November 26th 2009;

- The Responsibility To Protect, Report of the International Commission on Intervention and State Sovereignty, National Library of Canada cataloguing in publication data, Ottawa, December 2001,

- Un Monde plus Sûr : Notre Affaire à Tous, Rapport du Groupe de personnalités de haut niveau sur les menaces, les défis et le changement, Nations Unies, 2004 ;

- Yearbook of the United Nations, 1951, Columbia University Press, New York, 1952;

\section{2- $\underline{\text { Other }}$}

- ALKIRE (S.), A Conceptual Framework for Human Security, Working Paper 2, Centre for Research on Inequality, Human Security and Ethnicity, CRISE, Queen Elizabeth House, University of Oxford, 2003;

- BIARD, (M.), La Constitution de 1793, http://www.la-bibliothequeresistante.org/mes_textes/la_constitution_de_1793_biard.pdf

- Commission on Human Security, Human Security Now, New York, Commission on Human Security, 2003;

- de CONDORCET, (N.), Plan de Constitution présenté la Convention Nationale, Imprimerie Nationale, Paris, 1793, Bibliothèque Nationale de France, https://gallica.bnf.fr/; 
- Discours du Président prononcé le 26 juin 1945, Documents of the United Nations Conference on International Organization, 1945, United Nations Information Organizations eds., 1945 ;

- Discours du Professeur K.H. Bailey, Avril 1946, in L'Héritage de la Société des Nations, $\mathrm{n}^{\circ}$ 53, Secrétariat de la Société des Nations, 1946 ;

- FERRIS (E.), How can international human rights law protect us from disasters, Paper prepared for the American Society of International Law, Annual Meeting, 10 April 2014

- FUKUDA-PARR (S.), MESSINEO (C.), Human Security: A critical review of the literature, Working Paper, No. 11, Center for Research on Peace and Development, January 2012;

- GRAYSON, (K.), «Democratic Peace Theory as Practice: Reading the Significance of Liberal Representations of War and Peace», YCISS Working Paper, $\mathrm{n}^{\circ} 22$, March 2003;

- HENLEY SHEPARD (S.), Cultivating a human rights conscience: moving beyond reducing risk to build community resilience to disasters and climate change, Course Paper within the framework of the PhD Block course 2012 in Bonn, Germany «From Vulnerability to Resilience in Disaster Risk Management, December 2013

- HOWARD-HASSMANN (R. E.), Human Security: Undermining Human Rights? » Human Rights and Human Welfare, Working Paper, 63, January 2011

- GASPER (D.), The Idea of Human Security, Institute for Social Studies, The Hague

GARNET Working Paper, 28, January 2008;

- LEANING (J.), ARIE (S.), Human Security: A Framework for Assessment in Conflict and Transition. Prepared for US AID, Tulane Complex Emergency Response and Transition Initiative (CERTI), Tulane University. December 2000;

- Le Sénat Conservateur, La Constitution de l'An X, https://www.senat.fr/

- KERKKÄNEN (A.), The Failure of the Security Paradigm in Syria. The human security perspective, Working Paper 79, The Finnish Institute of International Affairs, January 20;

- KILSDONK, (L.), The Thirty Years War(s), Lawrence University Honors Projects, 120. 2018, https://lux.lawrence.edu/luhp/1201

- LEANING (J.) and al., Human Security: A Framework for Assessment In Conflict and Transition, CERTI Crisis and Transition Tool Kit, December 2000

- MCFETRIDGE (D.), The Voluntary Principles on Security and Human Rights, An implementation toolkit for major project sites, Working Paper, World Bank Group, July 2008

- MACARTHUR (J.), «A Responsibility to Rethink? Challenging Paradigms in Human Security ». Paper to Symposium on Resolving Threats to Global Security, Dalhousie University, Halifax, N.S. Canada. 2007

- MACK (A.), A Report on the Feasibility of Creating an Annual Human Security Report, Program on Humanitarian Policy and Conflict Research, Harvard University, février 2002; 
- MONNIER, (R.) «La Constitution du 4 novembre 1848 : l'ambition d'une république démocratique,Textes réunis par Jean Bart, Jean-Jacques CLÈRE, Claude COURVOISIER et Michel VERPEAUX », Annales historiques de la Révolution française, $\mathrm{n}^{\circ} 326$, octobredécembre 2001, http://journals.openedition.org/ahrf/1184

- NOE, (J-B.), La Restauration ou l'impossible réconciliation, https://www.jbnoe.fr/IMG/pdf/la restauration-cours-5.pdf

- RAVELONA (R. A.), Sécurité humaine : Clarification du concept et approches par les organisations internationales. Quelques repères, Document d'information, Organisation Internationale de la Francophonie, Janvier 2006

- WOODWARD (S.), « Post-Cold War Debates on International Security» mimeo, 2010. Presentation to the New School GPIA Workshop: The Practices of Human Rights - Human Security, October 8, 2010

\section{3- Texts and Jurisprudence}

$\begin{array}{llcl}\text { - Ordonnances } & \mathrm{du} & 25 & \text { juillet } \\ \text { https://data.bnf.fr/fr/15102923/france_ordonnances_de_juillet_1830/ }\end{array}$

- U.S. 419 Chisholm v. Georgia, JAY Opinion - in part

- U.S. 356 Yick Wo v. Hopkins, 1886 - in part

- Draft Resolution Doc. A/34/L.57 and Add.1, at http://www.globalpolicy.org/images/pdfs/Security_Council/Razali_Reform_Paper.pdf

- African Union, Executive Council, The Common African Position on the Proposed Reform of the United Nations, The Ezulwini Consensus, $7^{\text {th }}$ Extraordinary Session, 7-8 mars 2005

- $\quad$ CS Resolution 82, 1950

- $\quad$ CS Resolution 83, 1950

- CS Resolution 84, 1950

- UN Doc. S/RES/54, 25 June 1950

- $\quad$ UN Doc. S/RES/598, 20 July 1987

- $\quad$ UN Doc. S/23373, 9 December 1991

- UN Doc. S/PV.2932, 2 August 1990

- UN Doc. S/PV.2933, 6 August 1990

- UN Doc. S/RES/660, 2 August 1990,

- $\quad$ UN Doc. S/PV.2937, 18 August 1990

- UN Doc. S/RES/664, 18 August 1990

- $\quad$ UN Doc. S/RES/686, 2 March 1991

- UN doc. S/22435 du 2 Avril 1991

- UN Doc. S/3730/Rev.1; S/PV.754 (Hongry), 
- $\quad$ UN Doc. S/8761; S/PV.1443 (Tchecoslovaquia)

- $\quad$ UN Doc. S/13729; S/PV.2190;

- $\quad$ UN Doc. S/16077/Rev.1; S/PV.2491

- $\quad$ UN Doc. S/21048; S/PV.2902;

- $\quad$ UN doc. S/PV.2982 du 5 April 1991

- $\quad$ MONUSOM I, CS Resolution 751, 24 April, 1992

- $\quad$ UNITAF, CS Résolution, 794, 3 December 1992

- $\quad$ MONUSOM II, CS, Resolution 814 du 26 March 1993

- $\quad$ UN doc. S/PV.3060, 17 March 1992

- UN, Resolution 1962, S/RES/1962, 20 December 2010

- $\quad$ UN, Resolution 1973, S/RES/197, 17 March 2011 